U.S. Geological Survey National Water-Quality Assessment Program

\title{
Hydrogeology, Chemical Characteristics, and Water Sources and Pathways in the Zone of Contribution of a Public-Supply Well in San Antonio, Texas
}

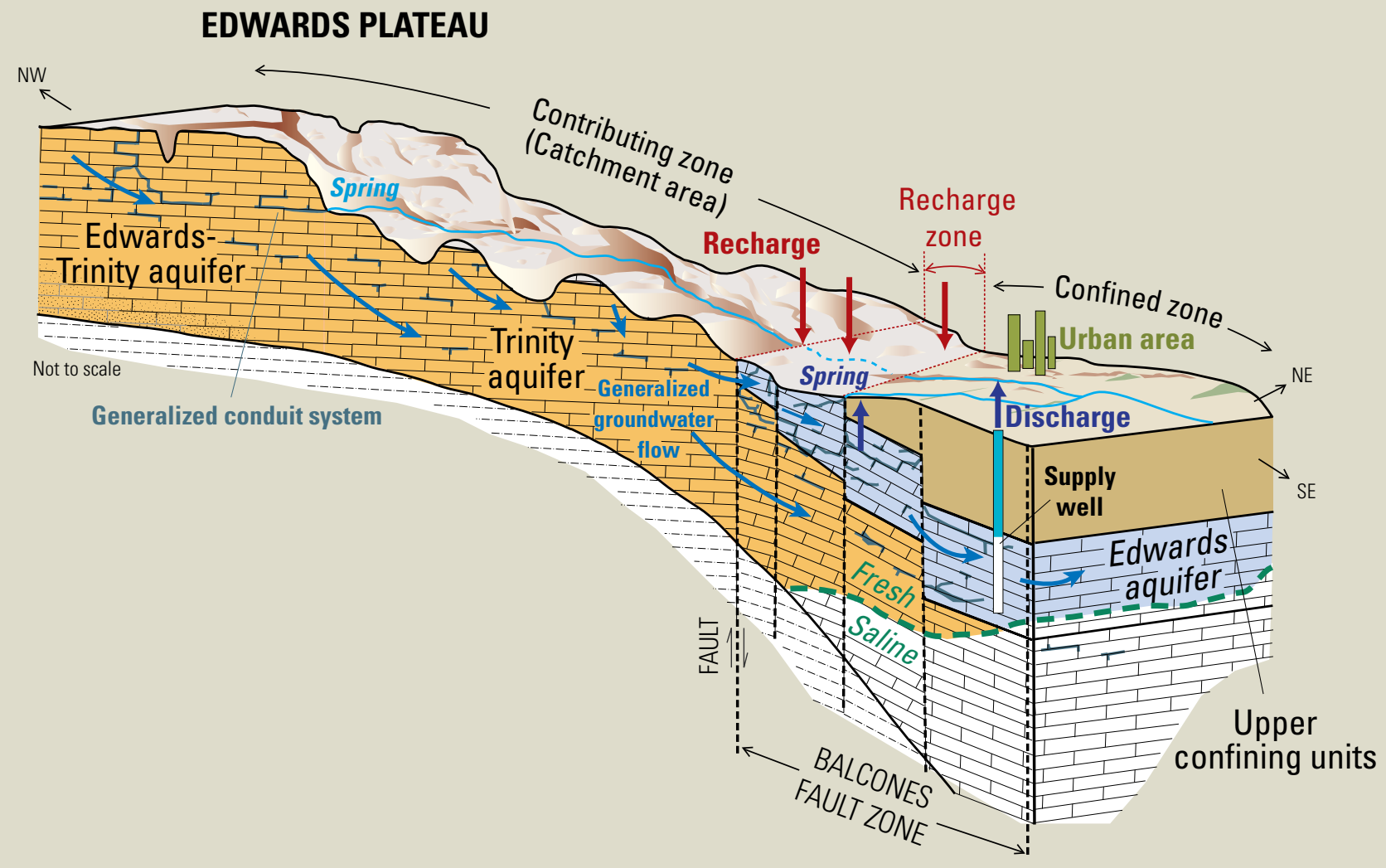

Scientific Investigations Report 2011-5146 



\section{Hydrogeology, Chemical Characteristics, and Water Sources and Pathways in the Zone of Contribution of a Public-Supply Well in San Antonio, Texas}

By MaryLynn Musgrove, Lynne Fahlquist, Gregory P. Stanton, Natalie A. Houston, and Richard J. Lindgren

U.S. Geological Survey National Water-Quality Assessment Program

Scientific Investigations Report 2011-5146 


\title{
U.S. Department of the Interior \\ KEN SALAZAR, Secretary \\ U.S. Geological Survey \\ Marcia K. McNutt, Director
}

\section{U.S. Geological Survey, Reston, Virginia: 2011}

\author{
This and other USGS information products are available at http://store.usgs.gov/ \\ U.S. Geological Survey \\ Box 25286, Denver Federal Center \\ Denver, CO 80225 \\ To learn about the USGS and its information products visit http://www.usgs.gov/ \\ 1-888-ASK-USGS
}

\footnotetext{
Any use of trade, product, or firm names is for descriptive purposes only and does not imply endorsement by the U.S. Government.

Although this report is in the public domain, permission must be secured from the individual copyright owners to reproduce any copyrighted materials contained within this report.
}

Suggested citation:

Musgrove, M., Fahlquist, L., Stanton, G.P., Houston, N.A., and Lindgren, R.J., 2011, Hydrogeology, chemical characteristics, and water sources and pathways in the zone of contribution of a public-supply well in San Antonio, Texas: U.S. Geological Survey Scientific Investigations Report 2011-5146, 194 p. 


\section{Foreword}

The U.S. Geological Survey (USGS) is committed to providing the Nation with reliable scientific information that helps to enhance and protect the overall quality of life and that facilitates effective management of water, biological, energy, and mineral resources (http://www.usgs.gov/). Information on the Nation's water resources is critical to ensuring longterm availability of water that is safe for drinking and recreation and is suitable for industry, irrigation, and fish and wildlife. Population growth and increasing demands for water make the availability of that water, measured in terms of quantity and quality, even more essential to the long-term sustainability of our communities and ecosystems.

The USGS implemented the National Water-Quality Assessment (NAWQA) Program in 1991 to support national, regional, State, and local information needs and decisions related to water-quality management and policy (http://water.usgs.gov/nawqa). The NAWQA Program is designed to answer: What is the quality of our Nation's streams and groundwater? How are conditions changing over time? How do natural features and human activities affect the quality of streams and groundwater, and where are those effects most pronounced? By combining information on water chemistry, physical characteristics, stream habitat, and aquatic life, the NAWQA Program aims to provide science-based insights for current and emerging water issues and priorities. From 1991 to 2001, the NAWQA Program completed interdisciplinary assessments and established a baseline understanding of water-quality conditions in 51 of the Nation's river basins and aquifers, referred to as Study Units (http://water.usgs.gov/nawqa/ studies/study_units.html).

National and regional assessments are ongoing in the second decade (2001-12) of the NAWQA Program as 42 of the 51 Study Units are selectively reassessed. These assessments extend the findings in the Study Units by determining water-quality status and trends at sites that have been consistently monitored for more than a decade, and filling critical gaps in characterizing the quality of surface water and groundwater. For example, increased emphasis has been placed on assessing the quality of source water and finished water associated with many of the Nation's largest community water systems. During the second decade, NAWQA is addressing five national priority topics that build an understanding of how natural features and human activities affect water quality, and establish links between sources of contaminants, the transport of those contaminants through the hydrologic system, and the potential effects of contaminants on humans and aquatic ecosystems. Included are studies on the fate of agricultural chemicals, effects of urbanization on stream ecosystems, bioaccumulation of mercury in stream ecosystems, effects of nutrient enrichment on aquatic ecosystems, and transport of contaminants to public-supply wells. In addition, national syntheses of information on pesticides, volatile organic compounds (VOCs), nutrients, trace elements, and aquatic ecology are continuing.

The USGS aims to disseminate credible, timely, and relevant science information to address practical and effective water-resource management and strategies that protect and restore water quality. We hope this NAWQA publication will provide you with insights and information to meet your needs and will foster increased citizen awareness and involvement in the protection and restoration of our Nation's waters.

The USGS recognizes that a national assessment by a single program cannot address all water-resource issues of interest. External coordination at all levels is critical for cost-effective management, regulation, and conservation of our Nation's water resources. The NAWQA Program, therefore, depends on advice and information from other agencies-Federal, State, regional, interstate, Tribal, and local—as well as nongovernmental organizations, industry, academia, and other stakeholder groups. Your assistance and suggestions are greatly appreciated.

William H. Werkheiser

USGS Associate Director for Water 



\section{Contents}

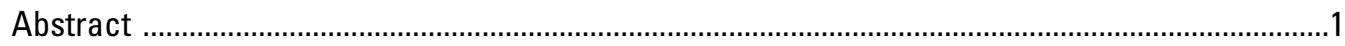

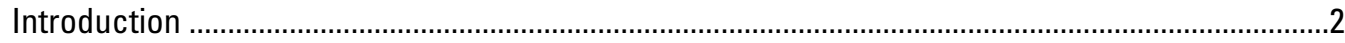

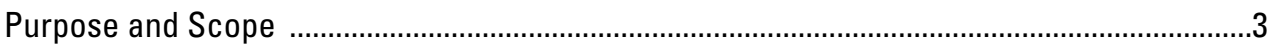

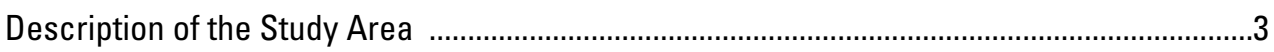

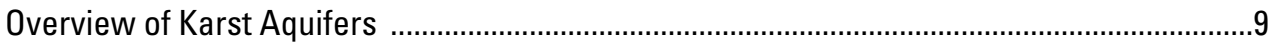

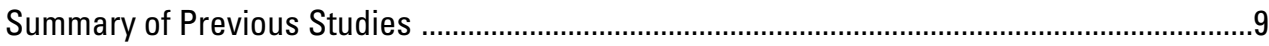

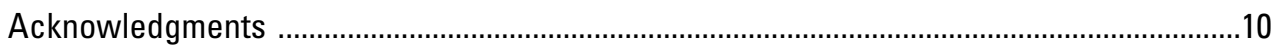

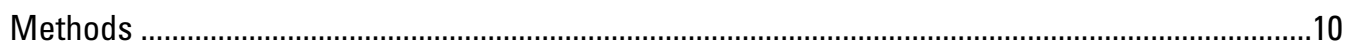

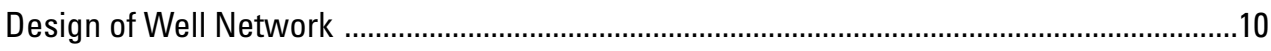

Drilling, Well Installation, Coring, and Core Analysis ..........................................................11

Geophysical and Depth-Dependent Flow Measurements ..................................................12

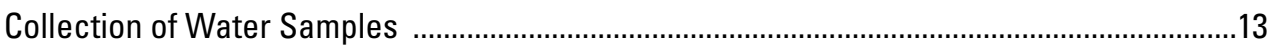

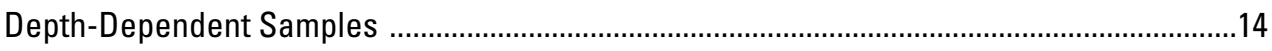

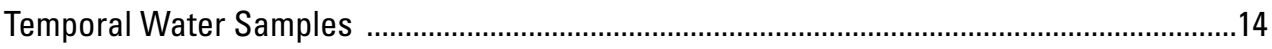

Laboratory Analytical Methods .........................................................................................

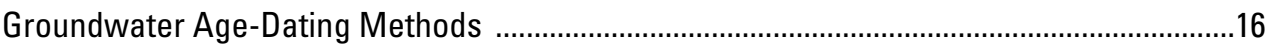

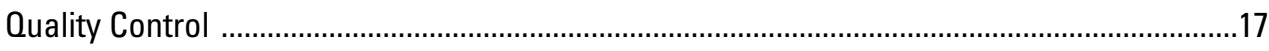

Statistical Methods and Geochemical Modeling ………….............................................20

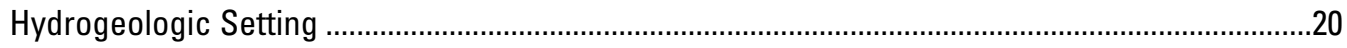

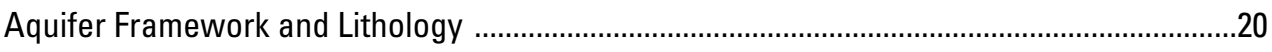

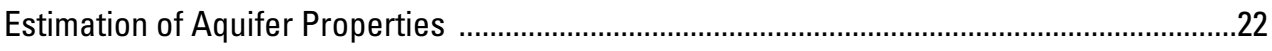

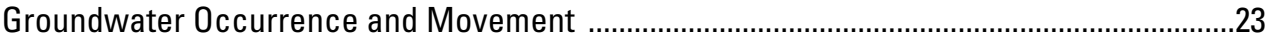

Potential Sources of Contamination .....................................................................................27

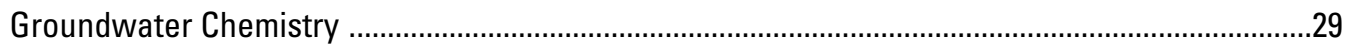

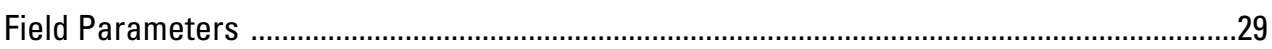

Chemical Composition and Mineral Saturation Indexes .....................................................31

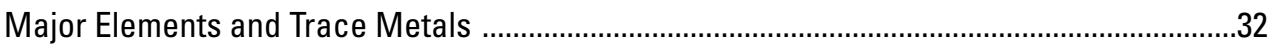

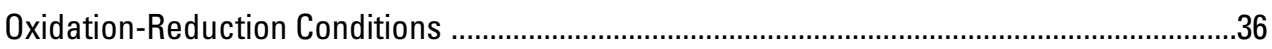

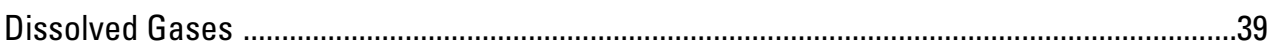

Nutrients and Stable Isotopes of Nitrogen .........................................................................39

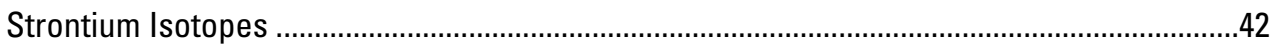

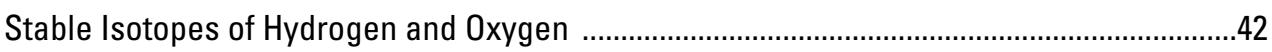

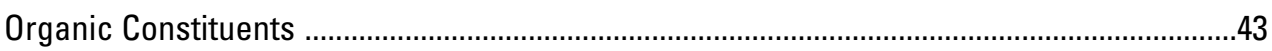

Groundwater Age Tracers and Age Distributions ……………..........................................4

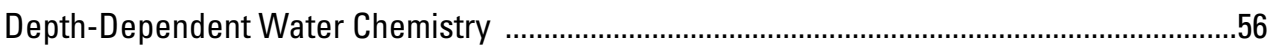

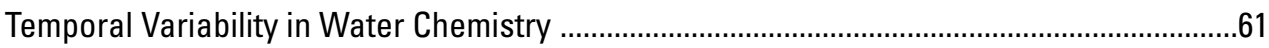

Processes Affecting Transport of Natural and Anthropogenic Contaminants to the Public-

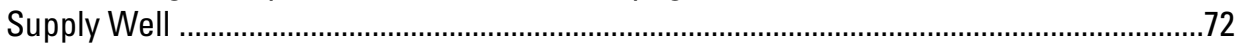

Sources of Water and Solutes and Movement to Supply Wells .............................................72

Supply-Well Vulnerability to Natural and Anthropogenic Contaminants ................................73

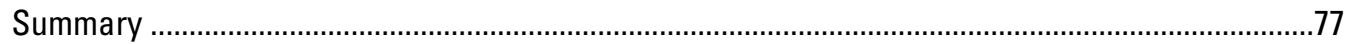

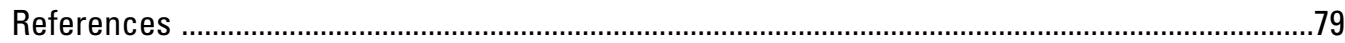




\section{Figures}

1. Map showing hydrogeologic setting and location of regional aquifer publicsupply wells (ranked by pumping quartile) sampled for the study of the transport of anthropogenic and natural contaminants (TANC) to public-supply wells in the San Antonio segment of the Edwards aquifer and the local-scale study area, near San Antonio, south-central Texas, 2004-9

2. Map showing diagrammatic north-northwest-to-south-southeast section showing hydrogeologic framework and generalized groundwater flow directions, Edwards Plateau to Gulf Coastal Plain, San Antonio region, Texas 5

3. Map showing local-scale study area for the study of the transport of anthropogenic and natural contaminants (TANC) to public-supply wells showing the selected public-supply well and well field, monitoring wells, and regional aquifer publicsupply wells (ranked and shown by pumping quartile) near San Antonio, southcentral Texas, 2004-9

4. Schematic east-west (strike) cross section showing location of study area hydrogeologic units (HGUs) as modeled by Lindgren and others (2011b) and relation of HGUs at well-field, monitoring well, and depth-dependent (W4) sample sites, near San Antonio, south-central Texas

5. Graphs showing time series (April 1 to December 31, 2009) climatic and hydrologic data for the south-central Texas study area

6. Graphs showing time series (2004-9) climatic and hydrologic data for the southcentral Texas study area

7. Borehole geophysical data for the public-supply well (W4) near San Antonio, south-central Texas, including, from left to right, natural gamma and caliper logs, fluid conductivity, temperature, flowmeter (under ambient and pumping conditions), stratigraphic unit, and hydrogeologic unit (HGU)

8. Borehole geophysical data for the deep Zarzamora monitoring well (Z-DED) near San Antonio, south-central Texas, including, from left to right, natural gamma and caliper logs, fluid conductivity and temperature, flowmeter, borehole image, stratigraphic unit, and hydrogeologic unit (HGU)

9. Borehole geophysical data for the deep Timberhill monitoring well (T-DED) near San Antonio, south-central Texas, including, from left to right, natural gamma and caliper logs, fluid conductivity and temperature, flowmeter (no appreciable measured flow), borehole image, stratigraphic unit, and hydrogeologic unit (HGU) .....26

10. Map showing land use in the local-scale study area for the study of the transport of anthropogenic and natural contaminants (TANC) to public-supply wells, and location of selected public-supply well and well field, near San Antonio, southcentral Texas

11. Map showing location of potential sources of contamination (PSOCs) in the localscale study area for the study of the transport of anthropogenic and natural contaminants (TANC) to public-supply wells, and location of selected publicsupply well and well field, near San Antonio, south-central Texas

12. Map showing location of potential sources of atrazine contamination in the localscale study area for the study of the transport of anthropogenic and natural contaminants (TANC) to public-supply wells, and location of selected publicsupply well and well field, near San Antonio, south-central Texas

13. Map showing location of potential sources of chloroform contamination in the local-scale study area for the study of the transport of anthropogenic and natural contaminants (TANC) to public-supply wells, and location of selected publicsupply well and well field, near San Antonio, south-central Texas 
14. Map showing location of potential sources of tetrachloroethene (PCE) contamination in the local-scale study area for the study of the transport of anthropogenic and natural contaminants (TANC) to public-supply wells, and location of selected public-supply well and well field, near San Antonio, southcentral Texas

15. Graphs showing relation between well depth and selected physicochemical and geochemical constituents for groundwater samples collected from regional aquifer public-supply wells in the confined part of the San Antonio segment of the Edwards aquifer, south-central Texas, 2004-5

16. Piper or trilinear diagram showing relations between major cations and anions for groundwater samples collected for the study of the transport of anthropogenic and natural contaminants (TANC) to public-supply wells, south-central Texas, 2004-9 ......34

17. Graphs showing relation between well depth and selected mineral saturation indexes for groundwater samples collected for the study of the transport of anthropogenic and natural contaminants (TANC) to public-supply wells, southcentral Texas, 2004-9

18. Graph showing relation between magnesium to calcium molar ratio and dolomite mineral saturation index for groundwater samples collected for the study of the transport of anthropogenic and natural contaminants (TANC) to public-supply wells, south-central Texas, 2004-9

19. Graphs showing relation between well depth and selected geochemical constituents or between calcium and selected geochemical constituents for groundwater samples collected for the study of the transport of anthropogenic and natural contaminants (TANC) to public-supply wells, south-central Texas, 2004-9 ......37

20. Graphs showing relation between well depth and selected geochemical constituents for groundwater samples collected for the study of the transport of anthropogenic and natural contaminants (TANC) to public-supply wells, southcentral Texas, 2004-9

21. Graph showing relation between well depth and nitrate concentration for groundwater samples collected for the study of the transport of anthropogenic and natural contaminants (TANC) to public-supply wells, south-central Texas, 2004-9 ......40

22. Graph showing isotopic composition of nitrate for groundwater samples collected for the study of the transport of anthropogenic and natural contaminants (TANC) to public-supply wells, south-central Texas, 2004-9

23. Graph showing relation between well depth and strontium isotope composition for groundwater samples collected for the study of the transport of anthropogenic and natural contaminants (TANC) to public-supply wells, south-central Texas, 2004-9

24. Graph showing relation between deuterium and oxygen isotopes for groundwater samples collected for the study of the transport of anthropogenic and natural contaminants (TANC) to public-supply wells, south-central Texas, 2004-9...

25. Graph showing detection frequency for the most frequently detected anthropogenic contaminants for groundwater samples collected for the study of the transport of anthropogenic and natural contaminants (TANC) to public-supply wells, southcentral Texas, 2004-9

26. Graphs showing median concentration of the most frequently detected anthropogenic contaminants for groundwater samples collected for the study of the transport of anthropogenic and natural contaminants (TANC) to public-supply wells, south-central Texas, 2004-9. Two scales are shown for selected contaminants for comparison 
27. Graphs showing relation between well depth and concentration for selected organic contaminants for groundwater samples collected for the study of the transport of anthropogenic and natural contaminants (TANC) to public-supply wells, south-central Texas, 2004-9

28. Graph showing relation between apparent age and excess delta helium-4 (terrigenic) for groundwater samples collected for the study of the transport of anthropogenic and natural contaminants (TANC) to public-supply wells, southcentral Texas, 2004-9

29. Graph showing relation between tritium $\left({ }^{3} \mathrm{H}\right)$ concentration and ${ }^{3} \mathrm{H}$ to initial tritium $\left({ }^{3} \mathrm{H}_{0}\right)$ ratio $\left({ }^{3} \mathrm{H} /{ }^{3} \mathrm{H}_{0}\right)$ for groundwater samples collected for the study of the transport of anthropogenic and natural contaminants (TANC) to public-supply wells, southcentral Texas, 2004-9, and lumped-parameter modeled curves for various groundwater age distributions

30. Graph showing relation between apparent age and the tritium $\left({ }^{3} \mathrm{H}\right)$ to initial tritium $\left({ }^{3} \mathrm{H}_{0}\right)$ ratio for groundwater samples collected for the study of the transport of anthropogenic and natural contaminants (TANC) to public-supply wells, southcentral Texas, 2004-9

31. Graphs showing relation between tritium concentration $\left({ }^{3} \mathrm{H}\right)$ and chlorofluorocarbon (CFC) age tracers for groundwater sample collected from the well-field well, W5, for the study of the transport of anthropogenic and natural contaminants (TANC) to public-supply wells, south-central Texas, 2004-9, and lumped-parameter modeled curves for various groundwater age distributions

32. Graphs showing relation between chlorofluorocarbon (CFC) age tracers (CFC-11, CFC-12, and CFC-113) for groundwater sample collected from the well-field well, W5, for the study of the transport of anthropogenic and natural contaminants (TANC) to public-supply wells, south-central Texas, 2004-9, and lumped-parameter modeled curves for various groundwater age distributions

33. Graph showing particle-track age distribution to selected public-supply well for the study of the transport of anthropogenic and natural contaminants (TANC) to public-supply wells, based on local-scale study model results described by Lindgren and others (2011b) in the San Antonio segment of the Edwards aquifer, south-central Texas

34. Graphs showing relation between sample collection date and tritium for groundwater samples collected for the study of the transport of anthropogenic and natural contaminants (TANC) to public-supply wells, south-central Texas, 2004-9 ......57

35. Schematic east-west (strike) cross section showing location of study area hydrogeologic units (HGUs) as modeled by Lindgren and others (2011b), relation of HGUs at selected sample sites, and summary of groundwater apparent-age results based on tritium/helium-3 tracer measurements (piston-flow model ages) near San Antonio, south-central Texas

36. Graphs showing relation between tritium to initial tritium ratio $\left({ }^{3} \mathrm{H} /{ }^{3} \mathrm{H}_{0}\right)$ and selected geochemical constituents for groundwater samples collected for the study of the transport of anthropogenic and natural contaminants (TANC) to public-supply wells, south-central Texas, 2004-9

37. Graphs showing relation between tritium to initial tritium ratio $\left({ }^{3} \mathrm{H} /{ }^{3} \mathrm{H}_{0}\right)$ and selected geochemical constituents for groundwater samples collected for the study of the transport of anthropogenic and natural contaminants (TANC) to publicsupply wells, south-central Texas, 2004-9

38. Graphs showing geochemical results for selected constituents for groundwater samples collected from different depths and under different flow conditions for the study of the transport of anthropogenic and natural contaminants (TANC) to public-supply wells, south-central Texas, 2004-9 
39. Graphs showing historical magnesium to calcium molar ratio data for well-field public-supply wells sampled for the study of the transport of anthropogenic and natural contaminants (TANC) to public-supply wells, south-central Texas

40. Graphs showing geochemical results for selected constituents in groundwater samples collected in response to a rain event (October through November, 2009) for the study of the transport of anthropogenic and natural contaminants (TANC) to public-supply wells, south-central Texas

41. Map showing hydrogeologic setting, location of, and ranges of tetrachloroethene (PCE) concentration (highest value shown where multiple measurements were made during the study period) for regional aquifer public-supply wells sampled for the study of the transport of anthropogenic and natural contaminants (TANC) to public-supply wells in the San Antonio segment of the Edwards aquifer, southcentral Texas, 2004-9

42. Map showing hydrogeologic setting, location of, and ranges of nitrate concentration (highest value shown where multiple measurements were made during the study period) for regional aquifer public-supply wells sampled for the study of the transport of anthropogenic and natural contaminants (TANC) to public-supply wells in the San Antonio segment of the Edwards aquifer, southcentral Texas, 2004-9

43. Graph showing results of forecasting exercise of time-series of hypothetical contaminant concentrations at the selected public-supply well for the study of the transport of anthropogenic and natural contaminants (TANC) to publicsupply wells; results are based on 30 years of contaminant input (at a relative concentration of 1 ) in the modeled contributing area

\section{Tables}

1. Site information for wells sampled for the study of the transport of anthropogenic and natural contaminants (TANC) to public supply wells in the San Antonio segment of the Edwards aquifer near San Antonio, south-central Texas, 2004-9

2. Summary of constituents by group for wells sampled for the study of the transport of anthropogenic and natural contaminants (TANC) to public supply wells in the San Antonio segment of the Edwards aquifer near San Antonio, south-central Texas, 2004-9

3. Summary of depth-dependent sampling for the study of the transport of anthropogenic and natural contaminants (TANC) to public supply wells in the San Antonio segment of the Edwards aquifer near San Antonio, south-central Texas, 2004-9

4. Sample collection for temporal sampling for the study of the transport of anthropogenic and natural contaminants (TANC) to public supply wells in the San Antonio segment of the Edwards aquifer near San Antonio, south-central Texas, 2009

5. Summary of organic content and elemental composition from acid extractions for core materials collected for the study of the transport of anthropogenic and natural contaminants (TANC) to public supply wells in the San Antonio segment of the Edwards aquifer near San Antonio, south-central Texas, 2004-9

6. Summary of X-ray diffraction results for core materials collected for the study of the transport of anthropogenic and natural contaminants (TANC) to public supply wells in the San Antonio segment of the Edwards aquifer near San Antonio, southcentral Texas, 2004-9 
7. Physicochemical measurements for groundwater samples collected for the study of the transport of anthropogenic and natural contaminants (TANC) to public supply wells in the San Antonio segment of the Edwards aquifer near San Antonio, southcentral Texas, 2004-9

8. Dissolved solids and major ion measurements for groundwater samples collected for the study of the transport of anthropogenic and natural contaminants (TANC) to public supply wells in the San Antonio segment of the Edwards aquifer near San Antonio, south-central Texas, 2004-9

9. Trace element measurements for groundwater samples collected for the study of the transport of anthropogenic and natural contaminants (TANC) to public supply wells in the San Antonio segment of the Edwards aquifer near San Antonio, southcentral Texas, 2004-9

10. Dissolved gas and associated data for groundwater samples collected for the study of the transport of anthropogenic and natural contaminants (TANC) to public supply wells in the San Antonio segment of the Edwards aquifer near San Antonio, south-central Texas, 2004-9

11. Nutrient measurements for groundwater samples collected for the study of the transport of anthropogenic and natural contaminants (TANC) to public supply wells in the San Antonio segment of the Edwards aquifer near San Antonio, southcentral Texas, 2004-9

12. Isotope and radionuclide measurements for groundwater samples collected for the study of the transport of anthropogenic and natural contaminants (TANC) to public supply wells in the San Antonio segment of the Edwards aquifer near San Antonio, south-central Texas, 2004-9

13. Wastewater indicator compounds for groundwater samples collected for the study of the transport of anthropogenic and natural contaminants (TANC) to public supply wells in the San Antonio segment of the Edwards aquifer near San Antonio, southcentral Texas, 2004-9

14. Volatile organic and fuel oxygenate compounds for groundwater samples collected for the study of the transport of anthropogenic and natural contaminants (TANC) to public supply wells in the San Antonio segment of the Edwards aquifer near San Antonio, south-central Texas, 2004-9

15. Soluble pesticide compounds for groundwater samples collected for the study of the transport of anthropogenic and natural contaminants (TANC) to public supply wells in the San Antonio segment of the Edwards aquifer near San Antonio, southcentral Texas, 2004-9

16. Polar pesticide compounds for groundwater samples collected for the study of the transport of anthropogenic and natural contaminants (TANC) to public supply wells in the San Antonio segment of the Edwards aquifer near San Antonio, southcentral Texas, 2004-9

17. Acetamide pesticide compounds for groundwater samples collected for the study of the transport of anthropogenic and natural contaminants (TANC) to public supply wells in the San Antonio segment of the Edwards aquifer near San Antonio, southcentral Texas, 2004-9

18. Summary of sulfur hexafluoride and chlorofluorocarbon age-tracer data and piston-flow model results for groundwater samples collected for the study of the transport of anthropogenic and natural contaminants (TANC) to public supply wells in the San Antonio segment of the Edwards aquifer near San Antonio, southcentral Texas, 2004-9 
19. Summary of tritium/helium-3 age-tracer data and piston-flow model results for groundwater samples collected for the study of the transport of anthropogenic and natural contaminants (TANC) to public supply wells in the San Antonio segment of the Edwards aquifer near San Antonio, south-central Texas, 2004-9 .......192

20. Results of forecasting analysis for the study of the transport of anthropogenic and natural contaminants (TANC) to public supply wells in the San Antonio segment of the Edwards aquifer near San Antonio, south-central Texas, 2004-9

\section{Conversion Factors and Abbreviations}

\begin{tabular}{|c|c|c|}
\hline Multiply & By & To obtain \\
\hline \multicolumn{3}{|c|}{ Length } \\
\hline inch (in.) & 25.4 & millimeter (mm) \\
\hline foot (ft) & 0.3048 & meter (m) \\
\hline mile (mi) & 1.609 & kilometer (km) \\
\hline millimeter (mm) & 0.03937 & inch (in.) \\
\hline micrometer $(\mu \mathrm{m})$ & 1,000 & millimeter (mm) \\
\hline \multicolumn{3}{|c|}{ Area } \\
\hline square mile $\left(\mathrm{mi}^{2}\right)$ & 2.590 & square kilometer $\left(\mathrm{km}^{2}\right)$ \\
\hline \multicolumn{3}{|c|}{ Volume } \\
\hline gallon (gal) & 3.785 & liter (L) \\
\hline million gallons (Mgal) & 3,785 & cubic meter $\left(\mathrm{m}^{3}\right)$ \\
\hline cubic centimeter $\left(\mathrm{cm}^{3}\right)$ & 0.06102 & cubic inch (in $\left.{ }^{3}\right)$ \\
\hline milliliter (mL) & 0.03381 & fluid ounce (oz) \\
\hline liter (L) & 0.2642 & gallon (gal) \\
\hline cubic meter $\left(\mathrm{m}^{3}\right)$ & 264.2 & gallon (gal) \\
\hline \multicolumn{3}{|c|}{ Flow rate } \\
\hline gallon per minute (gal/min) & 0.06309 & liter per second (L/s) \\
\hline million gallons per day (Mgal/d) & 0.04381 & cubic meter per second $\left(\mathrm{m}^{3} / \mathrm{s}\right)$ \\
\hline \multicolumn{3}{|c|}{ Mass/weight } \\
\hline gram (g) & 0.3527 & ounce avoirdupois (oz avdp) \\
\hline kilogram (kg) & 2.205 & pound (lb) \\
\hline \multicolumn{3}{|c|}{ Transmissivity* } \\
\hline foot squared per day $\left(\mathrm{ft}^{2} / \mathrm{d}\right)$ & 0.09290 & meter squared per day $\left(\mathrm{m}^{2} / \mathrm{d}\right)$ \\
\hline
\end{tabular}

*Transmissivity: The standard unit for transmissivity is cubic foot per day per square foot times foot of aquifer thickness $\left[\left(\mathrm{ft}^{3} / \mathrm{d}\right) / \mathrm{ft}^{2}\right] \mathrm{ft}$. In this report, the mathematically reduced form, foot squared per day $\left(\mathrm{ft}^{2} / \mathrm{d}\right)$, is used for convenience.

Vertical coordinate information is referenced to the North American Vertical Datum of 1988 (NAVD 88) and to the National Geodetic Vertical Datum of 1929 (NGVD 29) for Bexar County index well (J-17).

Horizontal coordinate information is referenced to the North American Datum of 1983 (NAD 83).

Altitude, as used in this report, refers to distance above the vertical datum. 
Temperature in degrees Celsius $\left({ }^{\circ} \mathrm{C}\right)$ may be converted to degrees Fahrenheit $\left({ }^{\circ} \mathrm{F}\right)$ as follows:

$$
{ }^{\circ} \mathrm{F}=\left(1.8 \mathrm{x}^{\circ} \mathrm{C}\right)+32
$$

Specific conductance is given in microsiemens per centimeter at 25 degrees Celsius $(\mu \mathrm{S} / \mathrm{cm}$ at $\left.25^{\circ} \mathrm{C}\right)$.

Concentrations of chemical constituents in water are given either in milligrams per liter (mg/L) or in micrograms per liter $(\mu \mathrm{g} / \mathrm{L})$.

\section{Explanation of Isotope Units}

The $\delta$ values for stable-isotope ratios discussed in this report are referenced to the following standard materials:

\begin{tabular}{|c|c|c|}
\hline Element & $\mathbf{R}$ & Standard identity and reference \\
\hline Hydrogen & Hydrogen-2/hydrogen-1 & $\begin{array}{l}\text { Vienna Standard Mean Ocean Water (VSMOW) (Casciotti and } \\
\text { others, 2002) }\end{array}$ \\
\hline Oxygen & Oxygen-18/oxygen-16 & $\begin{array}{l}\text { Vienna Standard Mean Ocean Water (VSMOW) (Casciotti and } \\
\text { others, 2002) }\end{array}$ \\
\hline Nitrogen & Nitrogen-15/nitrogen-14 & Nitrogen in air \\
\hline
\end{tabular}




\title{
Hydrogeology, Chemical Characteristics, and Water Sources and Pathways in the Zone of Contribution of a Public-Supply Well in San Antonio, Texas
}

\author{
By MaryLynn Musgrove, Lynne Fahlquist, Gregory P. Stanton, Natalie A. Houston, and Richard J. Lindgren
}

\section{Abstract}

In 2001, the National Water-Quality Assessment (NAWQA) Program of the U.S. Geological Survey initiated a series of studies on the transport of anthropogenic and natural contaminants (TANC) to public-supply wells (PSWs). The main goal of the TANC project was to better understand the source, transport, and receptor factors that control contaminant movement to PSWs in representative aquifers of the United States. Regional- and local-scale study areas were selected from within existing NAWQA study units, including the southcentral Texas Edwards aquifer. The local-scale TANC study area, nested within the regional-scale NAWQA study area, is representative of the regional Edwards aquifer. The PSW selected for study is within a well field of six production wells. Although a single PSW was initially selected, because of constraints of well-field operation, samples were collected from different wells within the well field for different components of the study. Data collected from all of the well-field wells were considered comparable because of similar well construction, hydrogeology, and geochemistry. An additional 38 PSWs (mostly completed in the confined part of the aquifer) were sampled throughout the regional aquifer to characterize water quality. Two monitoring well clusters, with wells completed at different depths, were installed to the east and west of the well field (the Zarzamora and Timberhill monitoring well clusters, respectively). One of the monitoring wells was completed in the overburden to evaluate potential hydrologic connectivity with the Edwards aquifer. Geophysical and flowmeter logs were collected from one of the well-field PSWs to determine zones of contribution to the wellbore. These contributing zones, associated with different hydrogeologic units, were used to select monitoring well completion depths and groundwater sample collection depths for depth-dependent sampling. Depth-dependent samples were collected from the PSW from three different depths and under three different pumping conditions. Additionally, selected monitoring wells and one of the well-field PSWs were sampled several times in response to a rainfall and recharge event to assess short-term (event-scale) temporal variations in water quality. For comparison purposes, groundwater samples were categorized as being from regional aquifer PSWs, from the well field (wellhead samples), from the monitoring wells (excluding the overburden well), from the overburden well, from the PSW depth-dependent sampling, and from temporal sampling. Groundwater samples were analyzed for inorganic, organic, isotopic, and age-dating tracers to characterize geochemical conditions in the aquifer and provide understanding of the mechanisms of mobilization and movement of selected constituents from source areas to a PSW. Sources, tracers, and conditions used to assess water quality and processes affecting the PSW and the aquifer system included (1) carbonate host rock composition; (2) physicochemical constituents; (3) major and trace element concentrations; (4) saturation indices with respect to minerals in aquifer rocks; (5) elemental ratios, such as magnesium to calcium ratios, that are indicative of water-rock interaction processes; (6) oxidation-reduction conditions; (7) nutrient concentrations, in particular nitrate concentrations; (8) the isotopic composition of nitrate, which can point to specific nitrate sources; (9) strontium isotopes; (10) stable isotopes of hydrogen and oxygen; (11) organic contaminant concentrations, including pesticides and volatile organic compounds; (12) age tracers, apparent-age distribution, and dissolved gas data used in age interpretations; (13) depth-dependent water chemistry collected from the PSW under different pumping conditions to assess zones of contribution; and (14) temporal variability in groundwater composition from the PSW and selected monitoring wells in response to an aquifer recharge event.

Geochemical results indicate that the well-field and monitoring well samples were largely representative of groundwater in the regional confined aquifer. Constituents of concern in the Edwards aquifer for the long-term sustainability of the groundwater resource include the nutrient nitrate and anthropogenic organic contaminants. Nitrate concentrations (as nitrogen) for regional aquifer PSWs had a median value of 1.9 milligrams per liter, which is similar to previously reported values for the regional aquifer. Nitrate-isotope compositions for groundwater samples collected from the well-field PSWs and monitoring wells had a narrow range, with values 
indicative of natural soil organic values. A comparison with historical nitrate-isotope values, however, suggests that a component of nitrate in groundwater from biogenic sources might have increased over the last 30 years. Several organic contaminants (the pesticide atrazine, its degradate deethylatrazine, trichloromethane (chloroform; a drinking-water disinfection byproduct), and the solvent tetrachloroethene (PCE)) were widely distributed throughout the regional aquifer and in the local-scale TANC study area at low concentrations (less than 1 microgram per liter). Higher concentrations of PCE were detected in samples from the well-field PSWs and Zarzamora monitoring wells relative to the regional aquifer PSWs. The urban environment is a likely source of contaminants to the aquifer, and these results indicate that one or more local urban sources might be supplying PCE to the Zarzamora monitoring wells and the well-field wells. Samples from the well field also had high concentrations of chloroform relative to the monitoring wells and regional aquifer PSWs. For samples from the regional aquifer PSWs, the most frequently detected organic contaminants generally decreased in concentration with increasing well depth. Deeper wells might intercept longer regional flow paths with higher fractions of older water or water recharged in rural recharge areas in the western part of the aquifer that have been less affected by anthropogenic contaminants. A scenario of hypothetical contaminant loading was evaluated by using results from groundwater-flow-model particle tracking to assess the response of the aquifer to potential contamination. Results indicate that the aquifer responds quickly (less than 1 year to several years) to contaminant loading; however, it takes a relatively long time (decades) for concentrations to reach peak values. The aquifer also responds quickly (less than 1 year to several years) to the removal of contaminant loading; however, it also takes a relatively long time (decades) to reach near background concentrations.

Interpretation of geochemical age tracers in this wellmixed karst system was complicated by contamination of a majority of measured tracers and complexities of extensive mixing. Age-tracer results generally indicated that groundwater samples were composed of young, recently recharged water with piston-flow model ages ranging from less than 1 to 41 years, with a median of 17 years. Although a pistonflow model is typically not valid for karst aquifers, the model ages provide a basis for comparing relative ages of different samples and a reference point for more complex hydrogeologic models for apparent-age interpretations. Young groundwater ages are consistent with particle-tracking results from hydrogeologic modeling for the local-scale TANC study area. Age-tracer results compared poorly with other geochemical indicators of groundwater residence time and anthropogenic effects on water quality, indicating that hydrogeologic conceptual models used in groundwater age interpretations might not adequately account for mixing in this karst system. Groundwater samples collected from the well field under a variety of pumping conditions were relatively homogeneous and well mixed for numerous geochemical constituents (with the notable exception of age tracers). Groundwater contributions to the PSW were dominated by well-mixed, relatively homogeneous groundwater, typical of the regional confined aquifer. Zones of preferential flow were determined for the PSW, but groundwater samples from different stratigraphic units were not geochemically distinct. Variations in chemical constituents in response to a rainfall and aquifer recharge event occurred but were relatively minor in the PSW and monitoring wells. This observation is consistent with the hypothesis that the response to individual recharge events in the confined aquifer, unless intersecting conduit flow paths, might be attenuated by mixing processes along regional flow paths. Results of this study are consistent with the existing conceptual understanding of aquifer processes in this karst system and are useful for water-resource development and management practices.

\section{Introduction}

About a third of the population of the United States receives drinking water from public groundwater systems (Toccalino and Hopple, 2010). The vulnerability of drinkingwater public-supply wells (PSWs) to contamination has raised numerous health concerns. Anthropogenic contaminantssuch as solvents, drinking-water disinfection byproducts, other volatile organic compounds, and pesticides-have been detected in low concentrations in water from PSWs across the United States (Gilliom and others, 2006; Ivahnenko and Zogorski, 2006; Schaap and Zogorski, 2006; Zogorski and others, 2006; Carter and others, 2007; Hopple and others, 2009). Groundwater contamination from nutrients such as nitrate $\left(\mathrm{NO}_{3}\right)$ is widespread (Nolan and others, 1998). Naturally occurring contaminants such as radon, uranium (U), and arsenic (As) also are present in groundwater from many drinking-water wells (Focazio and others, 1999; Sowerby and others, 2000; Welch and others, 2000; Jurgens and others, 2008; Landon and others, 2008). In response to these concerns, the U.S. Geological Survey (USGS) National WaterQuality Assessment (NAWQA) Program began a series of studies in 2001 to assess the vulnerability of PSWs to contamination from compounds commonly found in the environment, specifically with regard to the transport of anthropogenic and naturally occurring contaminants (TANC) to PSWs at regional and local scales at several sites across the United States (Eberts and others, 2005). The TANC project was built on previous NAWQA studies that found low levels of contaminants and mixtures of contaminants in groundwater beneath urban areas (Hamilton and others, 2004). TANC study sites have included a range of hydrogeologic settings and management practices that were selected to be representative of drinkingwater resources used by a majority of the U.S. population.

The goal of the TANC project is to understand the source, transport, and receptor factors that control the movement of contaminants to PSWs in representative aquifers of the United States (Eberts and others, 2005). Specific objectives are to (1) identify the dominant contaminants and their sources in PSWs; (2) assess the effects of natural processes and human 
activities on the occurrence of contaminants in PSWs; (3) identify the factors that are most important for PSW vulnerability assessments in different settings and at different scales; (4) develop simple methods and models for evaluating PSWs for vulnerability to contamination in unstudied areas and from emerging contaminants; and (5) increase understanding of the potential effects of water-resources development and management decisions on the quality of water from PSWs (Eberts and others, 2005). Because subsurface processes and management practices differ among aquifers and public-water systems, PSWs in different parts of the United States are not equally susceptible or vulnerable to contamination (Focazio and others, 2002), even where similar contaminant sources might exist. Concentrations of anthropogenic or natural contaminants can change along groundwater flow paths from recharge or source areas to PSWs as a result of many factors. These factors can be broadly grouped into those concerning sources, including contaminant loading or mobilization; transport, including migration and reaction; and receptors (wells), including PSW operations (Franke and others, 1998; Focazio and others, 2002).

TANC studies were conducted at regional scales of up to thousands of square miles $\left(\mathrm{mi}^{2}\right)$ at 11 locations and at local scales of less than $1,100 \mathrm{mi}^{2}$ at six additional locations; these were delineated from within six NAWQA study units of differing hydrogeology (Connecticut, glacial deposits; Nebraska, unconsolidated sediment; California, unconsolidated sediment; Florida, conduit-dominated karstic carbonate; New Mexico, unconsolidated sediment; and Texas, mixed carbonate). Local-scale study areas were selected that met the following criteria: location in an aquifer previously studied under the NAWQA Program; availability of existing source (raw water) water-quality data from PSWs; previous detection of natural or anthropogenic contaminants in source waters; and previously developed regional groundwater model(s). One of the selected local-scale study areas was the San Antonio segment of the Edwards aquifer, within the South-Central Texas (SCTX) regional study unit of the NAWQA Program (Bush and others, 2000). This report describes the hydrogeology and geochemistry of the 1,098-mi ${ }^{2}$ SCTX local-scale study area, which contains the zone of contribution to a selected PSW, and discusses factors controlling the transport of selected anthropogenic and natural contaminants to PSWs.

\section{Purpose and Scope}

The purposes of this report are to document the hydrogeologic setting, the occurrence and distribution of selected chemical characteristics, and factors controlling transport of selected anthropogenic and natural contaminants to PSWs in the local-scale TANC study area at San Antonio, Texas. A description of the design of the local-scale monitoring well network and methods of data collection and analysis are included. The hydrogeologic setting of the local-scale study area is described, as are general water geochemistry characteristics such as field parameters, oxidation-reduction (redox) conditions, the occurrence and distribution of selected inorganic and organic constituents, and the distribution of interpreted groundwater ages. The occurrence and distribution of contaminants and contaminant point sources are described to help assess factors influencing transport of these anthropogenic and natural contaminants to PSWs in the localscale TANC study area. This report is intended to serve as a foundation for analyses comparing results from this local-scale TANC study area with other TANC study areas.

\section{Description of the Study Area}

The regional-scale NAWQA and local-scale TANC study areas considered in this report (hereinafter, regionalscale study area and local-scale study area, respectively) are in south-central Texas within the Edwards aquifer (fig. 1). The regional-scale study area includes the extent of the San Antonio segment of the Edwards aquifer, which is within a narrow band along the Balcones fault zone from the western groundwater divide in Kinney County to the groundwater divide north of San Marcos Springs in Hays County (fig. 1). The Balcones escarpment is the surface manifestation of the Balcones fault zone (fig. 1). Late Cenozoic faulting of the predominantly flat-lying region along the Balcones fault zone formed a series of high-angle normal en echelon downtoward-the-coast faults. The faulting resulted in a series of blocks of Edwards aquifer rocks that are partially to completely offset and divide the confined and unconfined parts of the aquifer (Maclay and Small, 1983) (fig. 2). The local-scale study area is nested within the larger regional-scale study area (Lindgren and others, 2011a). Although this report focuses on the results of the local-scale study, an understanding of the characteristics of the regional-scale aquifer provides insight into movement of water and solutes along groundwater flow paths to PSWs at the local scale. Characteristics of the regional-scale study area around San Antonio are described by Lindgren and others (2011a). Characteristics of the Edwards aquifer that influence water quality have been previously described by numerous studies, including Bush and others (2000), Fahlquist and Ardis (2004), and Musgrove and others (2010). A hydrogeologic model constructed and calibrated to simulate groundwater flow and age distribution in the local-scale study area is described in a companion report by Lindgren and others (2011b).

The local-scale study area is predominantly in Bexar and Medina Counties and includes the northwestern part of San Antonio (fig. 1). The local-scale study area and model boundary were determined by using the regional-scale hydrogeologic model (Lindgren and others, 2011b) to identify the area contributing recharge (ACR) to the PSW and by bounding the likely ACR with the local-scale model area. The localscale study area includes the active area of the local-scale model (recharge and confined zones) and a small part of the catchment area (contributing zone) north of the Edwards aquifer recharge zone (fig. 3). The local-scale study area is bounded on the west and east by the western and eastern 


\section{EXPLANATION}

Edwards aquife

$\square$ Recharge zone (unconfined)

Confined zone

Barton Springs segment

Abbott and Woodruff, 1986, fig. 1)

- Urban area boundary

- Local-scale study area boundary

- Freshwater/saline-water transition (1,000 milligrams per liter $(\mathrm{mg} / \mathrm{L})$ dissolved solids concentration) (Schultz, 1994)
... Groundwater divide-San Antonio segment of the Edwards aquifer is bound on the easternmost and westernmost ends by groundwater divides

Regional aquifer public-supply wells

(confined and unconfined aquifer), by

pumping quartile-Black dot indicate

well depth is greater than 1,000 feet

1st quartile

2 d quartile

3 d quartile

4th quartile

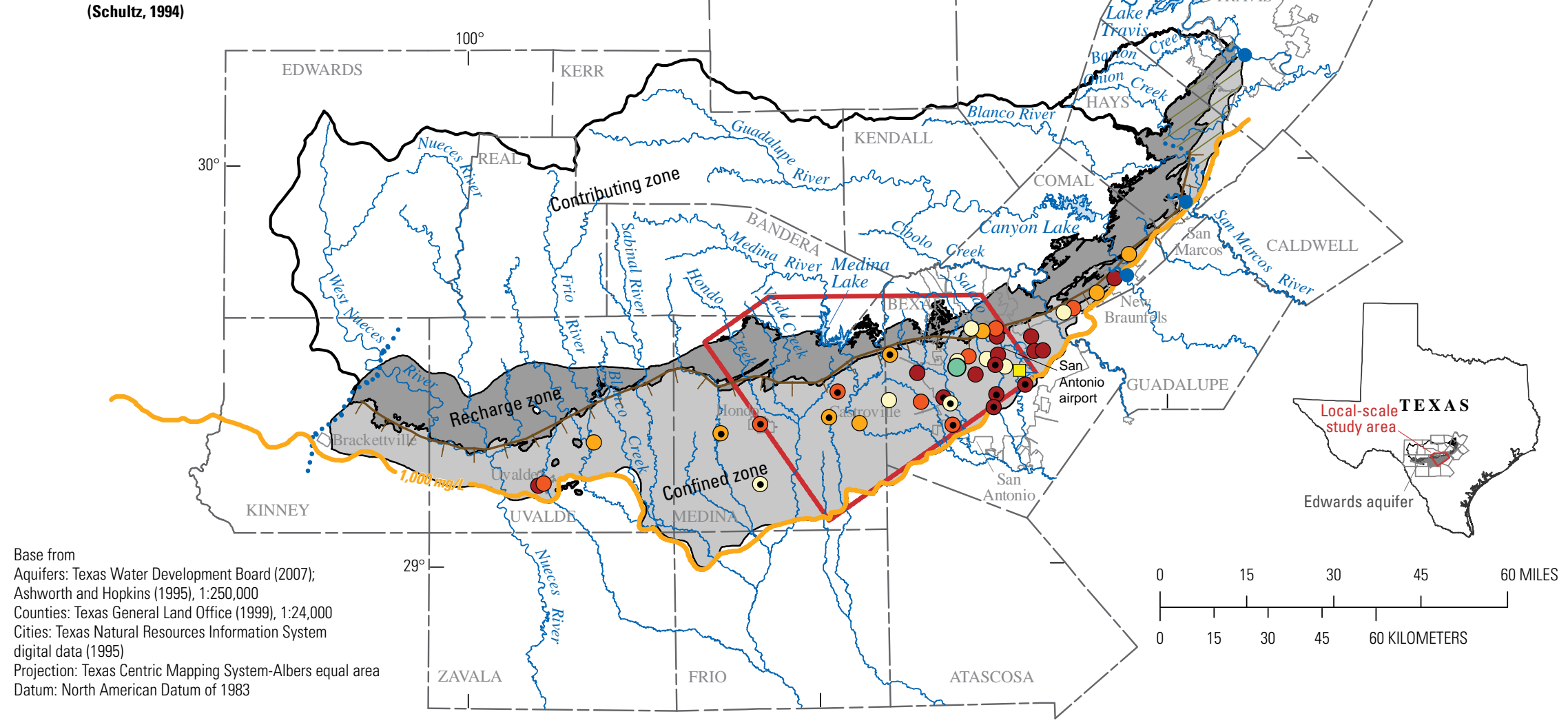

Selected public-supply well

and well field

$\square \quad$ J-17 (Bexar County index well)

us Spring

Figure 1. Hydrogeologic setting and location of regional aquifer public-supply wells (ranked by pumping quartile) sampled for the study of the transport of anthropogenic and natural contaminants (TANC) to public-supply wells in the San Antonio segment of the Edwards aquifer and the local-scale study area, near San Antonio, south-central Texas, $2004-9$ 


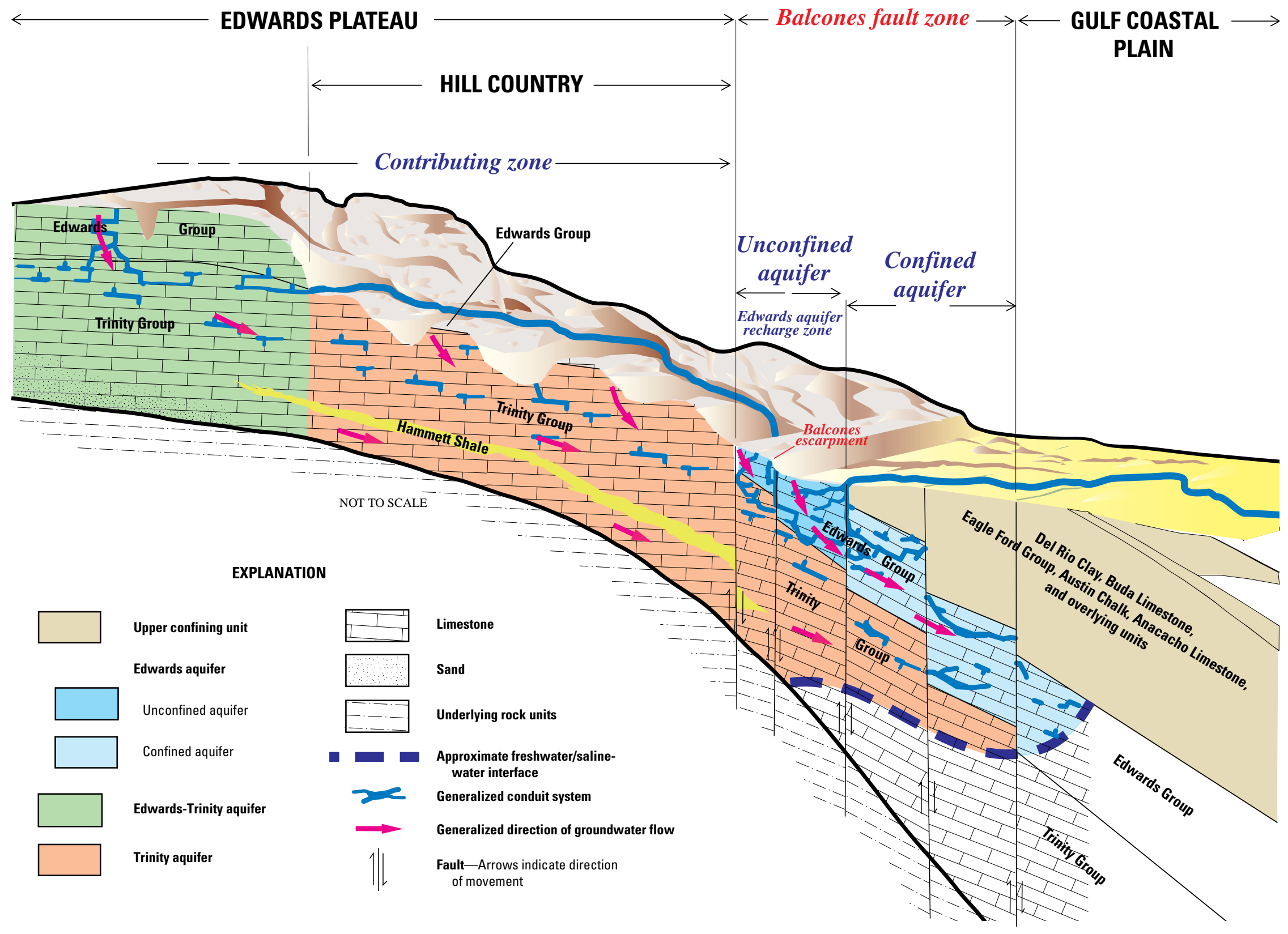

Figure 2. Diagrammatic north-northwest-to-south-southeast section showing hydrogeologic framework and generalized groundwater flow directions, Edwards Plateau to Gulf Coastal Plain, San Antonio region, Texas (modified from Barker and Ardis, 1996, plates 1 and 3). 


\section{EXPLANATION}

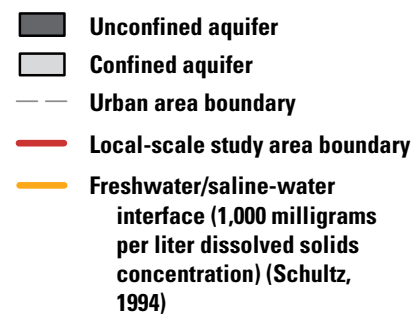

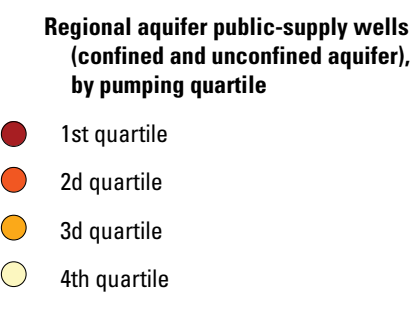

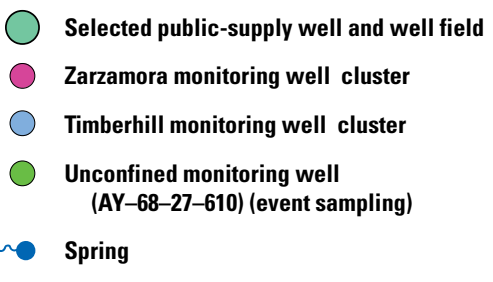

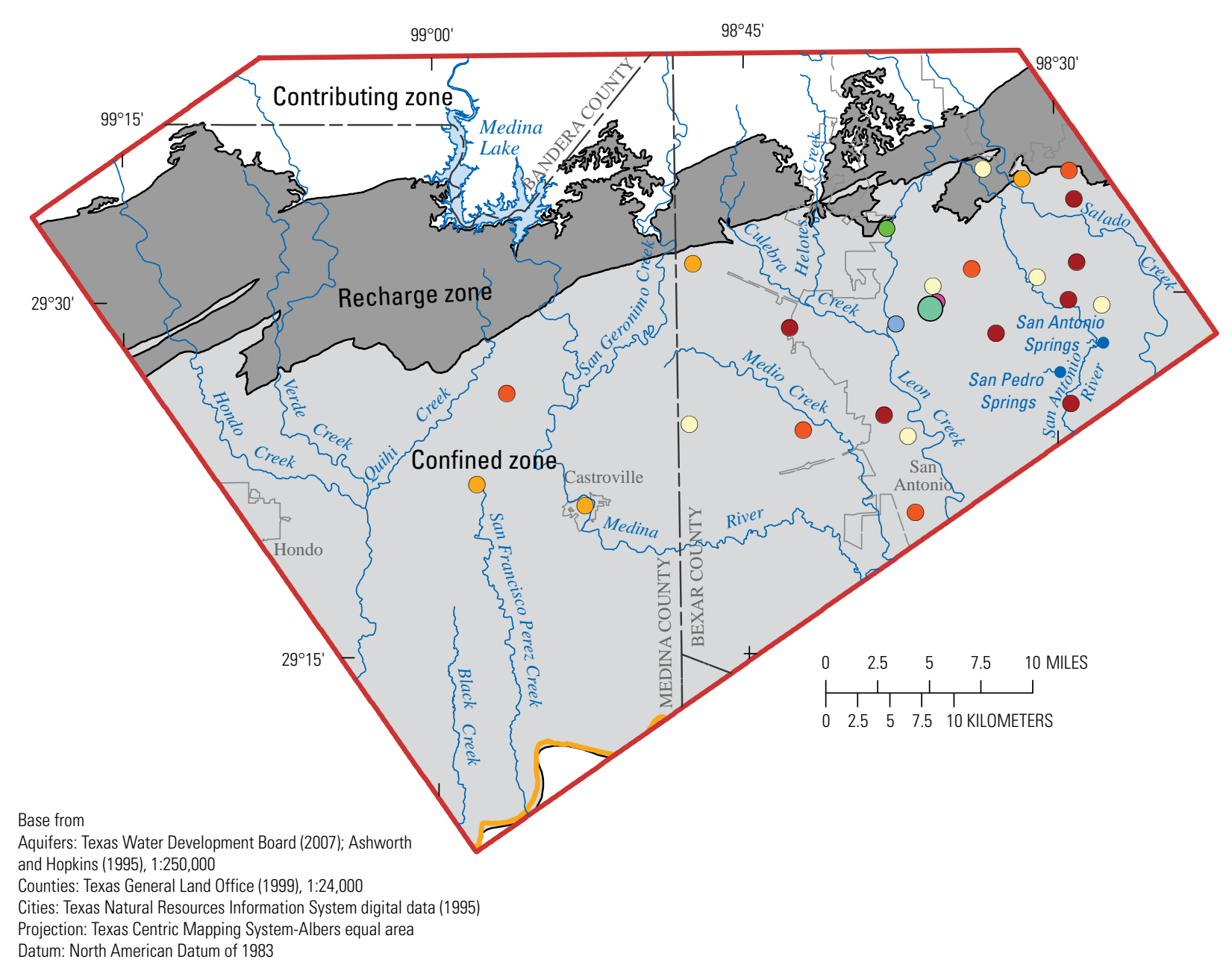

Figure 3. Local-scale study area for the study of the transport of anthropogenic and natural contaminants (TANC) to public-supply wells showing the selected public-supply well and well field, monitoring wells, and regional aquifer public-supply wells (ranked and shown by pumping quartile) near San Antonio, south-central Texas, 2004-9.

extents of the ACR to the selected PSW; these boundaries are near Hondo Creek in Medina County and near Salado Creek in Bexar Country, respectively (fig. 1). It is bounded on the south approximately by the 1,000-milligrams-per-liter ( $\mathrm{mg} / \mathrm{L}$ ) dissolved-solids concentration line (updip boundary of the freshwater/saline-water transition zone). The northern boundary is north of the updip limit of contiguous, outcropping rocks of the Edwards Group, Georgetown Formation, and their westward stratigraphic equivalents (Edwards rocks). The local-scale model area is oriented with the regional direction of groundwater flow and the major faults in the Balcones fault zone (Lindgren and others, 2011b).

The construction and operational practices of the selected PSW are representative of many PSWs that use the Edwards aquifer for supplying the population of the San Antonio metropolitan area. The selected PSW is a primary 
community-water-system PSW, which a public-water purveyor made available for the study. NAWQA-study analyses of groundwater samples from the PSW have detected multiple contaminants at low concentrations (substantially below drinking-water standards). The combination of low concentrations of detected contaminants, typical well construction and operational practices, and cooperation of the water utility prompted the selection of this PSW for the local-scale study. The selected PSW is within a well field of six wells in northwest San Antonio.

Probabilistic assessments of zones of contribution to the selected PSW, based on forward and backward particle tracks that were generated by using two regional groundwater flow models (Lindgren and others, 2004; Lindgren, 2006), were considered in delineating the local-scale study area (fig. 3). Although such determinations are likely unrealistic at a local scale in a fractured karst system, the study area was sufficiently large $\left(1,098 \mathrm{mi}^{2}\right)$ to reasonably approximately probable zones of flow to the selected PSW. The probable zones of contribution selected from models is similar to those represented by previous conceptualizations (Maclay and Land, 1988; Clark and Journey, 2006).

In the local-scale study area, the layered fractured karstic carbonate rocks are approximately 450-500 feet (ft) thick (Rose, 1972) and consist of eight hydrogeologic units (HGUs) previously defined for the Edwards aquifer on the basis of hydrogeologic properties (Maclay, 1995; Stein and Ozuna, 1995). The regional paleogeographic and structural features associated with the Edwards aquifer, and the previously defined stratigraphic units associated with these features, are detailed by Lindgren and others (2011b). A conceptual cross-sectional schematic of the hydrogeology of the localscale study area and well-field and monitoring well sites in the context of HGUs is shown in figure 4. The local-scale model includes four additional HGUs, including one confining HGU in the overburden overlying the aquifer and one confining HGU in the Trinity aquifer underlying the Edwards aquifer (Lindgren and others, 2011b) (fig. 4). Among the eight previously identified units (Stein and Ozuna, 1995), the Kirschberg evaporite member and the leached and collapsed members (composed of the leached and collapsed members, undivided, hereinafter, leached and collapsed) generally are the most porous and permeable units (fig. 4). Two highly conductive HGUs (5 and 9) were added to the base of these two members to represent highly transmissive zones within these two members in the local-scale hydrologic model (Lindgren and others, 2011b) (fig. 4). The cyclic and marine HGU (composed of the cyclic and marine members, undivided; hereinafter cyclic and marine (HGU 3)) within the Person Formation is also considered moderately permeable (Stein and Ozuna, 1995) but was not divided into multiple HGUs.

Land surface elevation in the local-scale study area ranges from $1,745 \mathrm{ft}$ in the northwestern part of the study area in Medina County to $551 \mathrm{ft}$ along the Medina River in southern Bexar County (National Hydrography Dataset Plus,
2010). Mean annual precipitation decreases across the region from east to west, ranging from 32.5 inches (in.) in the eastern part to $27.5 \mathrm{in}$. in the western part of the local-scale study area (Daly and Taylor, 2000). The region is prone to climatic and hydrologic extremes (Griffiths and Strauss, 1985; Jones, 1991); mean annual rainfall at San Antonio International Airport is 29 in., but annual rainfall has ranged from 10 to 52 in. (1893-2009) (National Oceanic and Atmospheric Administration, 2010). Some of the most extreme 1-day-duration storms in the world have occurred along the Balcones escarpment (Slade, 1986). Storms often produce rapid runoff that provides recharge to the aquifer. Droughts lasting from many months to years have been documented in the region since the earliest settlers began keeping records (Texas State Historical Association, 2009). The mean annual maximum temperature (1970-2000), measured in July, is 36.1 degrees Celsius $\left({ }^{\circ} \mathrm{C}\right)$, and the average annual minimum temperature, measured in January, is $1.7^{\circ} \mathrm{C}$ (U.S. Department of Agriculture, 2010). Land use that overlies the (recharge and confined zones of the) Edwards aquifer in the local-scale study area is 35.6 percent rangeland, 27.8 percent forest, 23.1 percent urban/built-up, 11.8 percent agricultural, and 1.7 percent water, wetland, or barren land (Homer and others, 2001). Most of the rangeland, forest, and agricultural land is to the west of San Antonio in Medina County. Most of the outcrop (unconfined zone) is rangeland and forest, and most of the agricultural area overlies the confined part of the aquifer. Nearly all urban/built-up land overlies unconfined and confined parts of the aquifer in the San Antonio area in Bexar County.

The city of San Antonio, the principal urban area in the local-scale study area, includes much of Bexar County in the east-central part of the aquifer region. San Antonio is the seventh largest city in the United States, with a 2007 population of about 1.3 million (U.S. Census Bureau, 2009). Although pumping in the San Antonio area has increased about fivefold since the 1930s, aquifer water-level altitudes have not shown long-term declines because the aquifer readily recharges during periods of rainfall (Bush and others, 2000).

Potential sources of contamination and the fractured karstic hydrogeologic conditions of the Edwards aquifer in the San Antonio area are characteristic of many communities that withdraw water from carbonates and fractured rocks. Potential contamination sources include chlorinated organic solvents from historical chemical use at small commercial facilities typically found in urban areas, $\mathrm{NO}_{3}$ and pesticides from irrigated cultivated and urban land, and As and U from carbonate or marine sediments. Movement of these contaminants through the aquifer system might be enhanced by increased groundwater flow velocities caused by temporal response to rainfall, increased pumping during summer or drought, and increased recharge from precipitation. Moreover, the common practice of constructing supply wells across large (greater than $100 \mathrm{ft}$ ) open intervals of the aquifer to improve well yields can contribute to rapid movement of contaminants (Zinn and Konikow, 2007). 


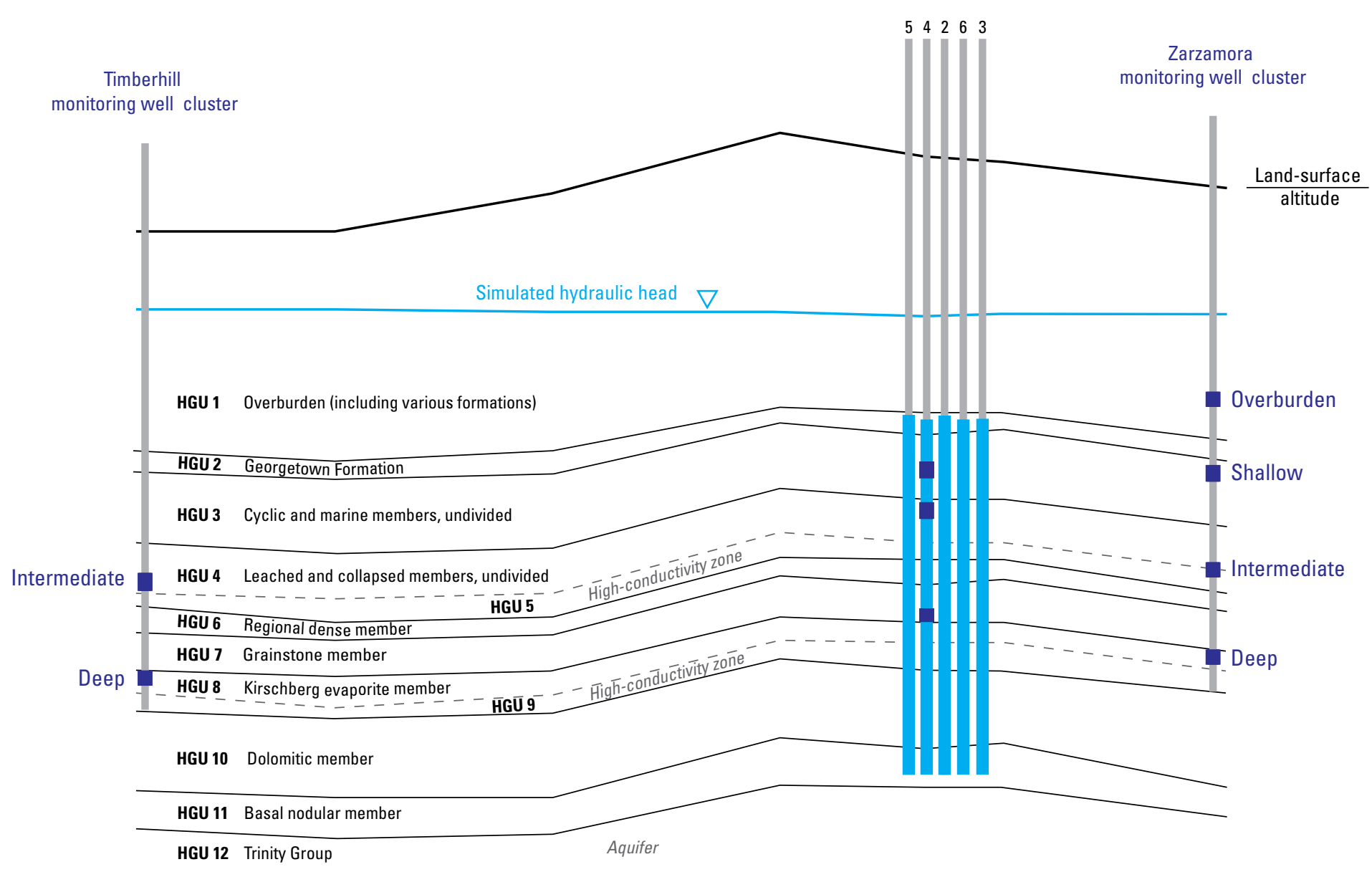

Zarzamora

ing well cluste

HGU 12 Trinity Group

\section{EXPLANATION}

Open interval for well field wells

- Approximate sampling interval for well-field (W4) depth-dependent

samples and monitoring well samples

Figure 4. Schematic east-west (strike) cross section showing location of study area hydrogeologic units (HGUs) as modeled by Lindgren and others (2011b) and relation of HGUs at well-field, monitoring well, and depth-dependent (W4) sample sites, near San Antonio, south-central Texas. HGUs 5 and 9 are highly conductive zones at the base of HGUs 4 and 8, respectively. Relatively small (less than 80 percent) displacement modeled faults are not shown. 


\section{Overview of Karst Aquifers}

Karst aquifers, such as the Edwards aquifer, are composed of soluble host rocks, usually carbonates, that have dissolved preferentially to form large voids and conduits (White, 1988). Karst aquifers tend to be extremely heterogeneous, with orders of magnitude ranges of porosity and permeability. Groundwater transport can be rapid through high-porosity voids and conduits, with little opportunity for subsurface filtration, sorption, or degradation of dissolved or particulate constituents (White, 1988). As a result, karst aquifer systems are particularly susceptible to contamination.

Karst aquifer permeability ranges from matrix permeability, characterized by high storage and low transmissivity, to conduit permeability, characterized by low storage and high transmissivity (Schuster and White, 1971; Atkinson, 1977). Karst aquifers commonly are conceptualized as dual-flow systems that comprise a continuum-flow system with Darcian flow comparable to porous media and a discrete conduit network frequently with turbulent flow conditions (Birk and others, 2003). Most groundwater storage occurs within the aquifer matrix, but most transport occurs within conduits, which often dominate groundwater flow where present (White, 2002). Fluid flow in karst aquifers can be highly variable and difficult to measure or predict.

Recharge to karst aquifers occurs as direct infiltration into karst features such as sinkholes and fractures (focused recharge) and as distributed infiltration into the rock matrix (diffuse recharge); the proportion of focused and diffuse recharge can vary greatly in time and space depending on a number of variables (Worthington, 2003; Mahler and others, 2006). In wells and springs that are dominantly affected by conduit flow, physicochemical properties, concentrations of geochemical constituents, and discharge (from springs) or water-level altitudes (in wells) can change rapidly (minutes to hours to days) following rainfall and aquifer recharge. In contrast, water-level altitudes in wells and springs that are dominantly affected by matrix flow might show little response to recharge events and less variability in physicochemical properties and geochemistry. Natural discharge in karst aquifers often occurs through large springs, which represent a composite (integrator) of all water moving through the aquifer; as a result, variations in spring discharge, physicochemical constituents, and geochemistry provide insight into karst aquifer hydrogeology (White, 2002).

\section{Summary of Previous Studies}

PSW contamination is a potential health threat and has had negative economic effects on communities that need to treat contaminated water or find alternative water supplies. Investigations at multiple spatial scales across the United States have indicated that shallow groundwater quality is affected by land-use activities in many locations but that water quality is less frequently affected at the greater depths where PSWs typically are screened (Nolan and Stoner, 2000; Gilliom and others, 2006; Zogorski and others, 2006). In 1991, the USGS implemented the NAWQA Program to characterize, in a nationally consistent manner, water quality of major surface-water and groundwater resources of the Nation, to determine natural and human factors that affect water quality, and to define trends in water quality (Gilliom and others, 1995). Between 1996 and 2009, the NAWQA Program collected and analyzed groundwater samples from numerous sites throughout the San Antonio segment of the Edwards aquifer in the SCTX study unit; specific NAWQA studies include an analysis of samples collected between 1996 and 2006 (Musgrove and others, 2010) and samples collected as part of the local-scale study, which is the focus of this report. NAWQA analyses of water samples for anthropogenic contaminants in the San Antonio segment of the Edwards aquifer have detected numerous anthropogenic contaminants, mostly at low concentrations, less than 1 microgram per liter $(\mu \mathrm{g} / \mathrm{L})$ (Bush and others, 2000; Fahlquist and Ardis, 2004). Two regional-scale groundwater flow models were previously developed for the regional aquifer by using MODFLOW2000 (Harbaugh and others, 2000): (1) a model that includes simulated, continuously connected conduits and barrier faults that influence flow (Lindgren and others, 2004) and (2) a model without simulated conduits in which flow occurs through small fractures and openings (Lindgren, 2006). Both models were calibrated for steady-state and transient conditions. A hydrogeologic model has been constructed for the local-scale study area, which is described in a companion report by Lindgren and others (2011b).

Previous studies of the Edwards aquifer provide insight into its hydrology and geochemistry. Geochemical processes that affect groundwater geochemistry and water quality include interaction with overlying soils, mineral-solution reactions, and mixing with saline waters from downdip and underlying hydrostratigraphic units (Clement and Sharp, 1988; Oetting and others, 1996; Groschen and Buszka, 1997; Musgrove and Banner, 2004; Musgrove and others, 2010). Geochemical tracers of mineral-solution reactions (such as the molar ratios of magnesium to calcium $(\mathrm{Mg} / \mathrm{Ca})$ concentrations and strontium to calcium $(\mathrm{Sr} / \mathrm{Ca}$ ) concentrations and dolomite mineral saturation indices) can be indicative of groundwater residence time, which is a function of both flow path and water flux (Musgrove and Banner, 2004; Wong, 2008; Musgrove and others, 2010). Previous studies in the San Antonio and Barton Springs segments of the Edwards aquifer have documented extensive surface-water-groundwater interaction, relations between variable hydrologic conditions and water quality, and movement of anthropogenic contaminants and dissolved constituents through the aquifer (Hauwert, Johns, and others, 2004; Hauwert, Samson, and others 2004; Mahler and others, 2006; Garner and Mahler, 2007; Mahler and Massei, 2007; Mahler and Garner, 2009; Musgrove and others, 2010). 


\section{Acknowledgments}

The authors gratefully acknowledge many individuals and organizations that contributed to this study. The City of San Antonio, regulatory authorities, and others (public-water purveyors, Edwards Aquifer Authority, Texas Department of Licensing and Regulation) helped address challenges of obtaining permissions, designing, drilling, and installing monitoring wells in this complex hydrogeologic setting. We are particularly thankful to the public water purveyor that participated in this study. Peer reviews by B.G. Katz and M.K. Landon greatly improved the report.

\section{Methods}

Methods used for this study are described in the sections below, including the design of the well network; drilling, monitoring well installation, coring, and core analysis; collection and analysis of water samples; collection of depth-dependent flow and chemistry data; quality assurance of water-quality data; and a description of statistical and geochemical modeling methods.

\section{Design of Well Network}

The well network was designed so that an existing PSW would be the focus of the study. Monitoring wells were installed to allow monitoring of groundwater at different depths along likely flow paths from potential source areas contributing to the PSW. An additional 38 PSWs that tap the regional aquifer were sampled to characterize water quality throughout the aquifer and over a wide range of pumping conditions (fig. 1 ; table 1 at end of report).

In the selected well field, at least one of the six wells is pumping in the well field at any time. Two wells are routinely pumping during summer months when demand increases, and more than two wells might be pumping during peak demand periods. Annual pumpage from the well field was about 7,840 million gallons (Mgal) in 2008 (TANC study water purveyor, written commun., 2008), and the well field produced about 11 percent of total pumpage provided by the purveyor (one of several purveyors in the greater San Antonio area). The first well in the well field was installed in 1963 (one of four installed in the 1960s), and the sixth well was installed in 1984 (one of two installed in the 1980s). The PSWs are cased with steel in the overlying confining units and are open hole through most or all of the Edwards aquifer. The open interval of the wells were acidified at the time of construction to increase production. Depths to the top of the open interval in the wellbores (at or near the top of the aquifer) at the well field range from 321 to $360 \mathrm{ft}$. Open-interval lengths range from 454 to $495 \mathrm{ft}$. Open-hole diameters range from approximately 30 to 36 in. Open-hole diameters are variable because of vuggy porosity and collapsed limestone. Rated pump capacities for the well-field wells range from 11.2 to 20.7 million gallons per day (Mgal/d) (TANC study water purveyor, written commun., 2008).

One or more wells in the well field were not operational at any given time during the study period. Well 3 (W3) was initially selected for study. However, well 4 (W4) was sampled for depth-dependent sampling because there was no pump in the well, which permitted access for depth-dependent sampling equipment, and well 6 (W6) was sampled for temporal characterization because W3 was not operational at the time of the hydrologic event during which temporal changes were evaluated. As a result, although a single PSW was initially selected, different components of the study collected samples from different PSWs within the well field. Well construction, hydrogeology, and geochemistry among all the PSWs in the well field are similar, and data collected from each of the wells are presumed to be comparable for the purposes of this study.

It was not possible to characterize karstic flow paths to the selected PSW because of the large capture zone for the well and because of the karstic nature of the system. Therefore, two vertically nested monitoring well clusters were installed in proximity to the PSW to evaluate processes close to the PSW. The locations of the two clusters were selected on the basis of the two potential flow zones to the PSW from groundwater modeling results (Lindgren and others, 2011b). The monitoring well clusters were drilled as close to the PSW as possible. The Zarzamora well cluster was about 0.5 mile (mi) to the east-northeast of the PSW, and the Timberhill well cluster was about $1.5 \mathrm{mi}$ to the west (fig. 4).

The Zarzamora monitoring well cluster, consisting of four wells, was installed in August-September 2007 (fig. 4). The first monitoring well (Z-DED) was drilled with the goal of being completed near the top of the karstic Kirschberg evaporite member (HGU 8) in the lower part (Kainer Formation) of the Edwards aquifer. This unit is known to be a prolific water-bearing zone (Maclay, 1995). Information learned from drilling and logging this first deep Edwards monitoring well (Z-DED) was used to determine the target depths of the other two Edwards monitoring wells completed at this location. An intermediate-depth well (Z-IED) was drilled to target the bottom of the leached and collapsed members of the Edwards aquifer (HGUs 4 and 5), also known to be a prolific water-bearing zone (Maclay, 1995). The shallowest well (Z-SED) was completed at the top of the Edwards Group in the cyclic and marine members of the Edwards aquifer (HGU 3). A fourth monitoring well (Z-OVB) was completed in an overburden unit (HGU 1), the overlying water-bearing Buda Limestone (fig. 4). This well (Z-OVB) was constructed to evaluate the possibility of a hydrologic connection between the Edwards aquifer and overlying formations at this location.

The Timberhill monitoring well cluster, consisting of two wells, was installed in April 2008 (fig. 4). Similar to the deep- and intermediate-depth wells at the Zarzamora site, the Timberhill wells were completed near the top of the Kirschberg evaporite member (T-DED) (HGU 8) and near the top of the leached and collapsed members (T-IED) (HGU 4). 
PSWs throughout the regional aquifer were identified, and a subset was selected for sampling to characterize water quality in PSWs throughout the aquifer. A total of 299 PSWs were identified throughout the regional extent of the San Antonio segment of the Edwards aquifer and were separated into four quartiles based on pumpage. Thirty-nine wells (including the selected PSW) were randomly selected for sampling by quartile, spaced at least $0.62 \mathrm{mi}$ apart within a quartile (fig. 1). Fifteen wells from the largest quartile of pumping were selected, and eight were selected from each of the lower three quartiles of pumping. From the largest pumping quartile, 13 of the wells were in Bexar County, 1 in Uvalde County, and 1 in Comal County. Wells from the lower three pumping quartiles were in Uvalde, Medina, Bexar, and Comal Counties. Water samples were collected from the top quartile wells (in 2004) and the lower three quartile wells (in 2005) and were analyzed for major ions, nutrients, trace elements, dissolved organic carbon (DOC), ultraviolet (UV) absorbance, pesticide compounds (including breakdown products), and volatile organic compounds (VOCs). A subset (8 of 15) of the top quartile wells were resampled for a subset of organic compounds in 2005. Results from the top quartile wells are described in Carter and others (2007) and Hopple and others (2009), and results from all of the 39 PSWs are described in Musgrove and others (2010).

\section{Drilling, Well Installation, Coring, and Core Analysis}

Monitoring well design was reviewed and approved by Edwards Aquifer Authority and San Antonio Water System permitting authorities and met requirements of the Texas Department of Licensing and Regulation. Monitoring wells were installed by USGS by using an air rotary drill rig and generally followed procedures modified from Lapham and others (1995) for drilling in karstic limestone. Equipment was decontaminated by steamcleaning between drill sites.

The design was similar for all Edwards aquifer monitoring wells. A 14-in.-diameter hole was drilled to a depth of approximately $20 \mathrm{ft}$, where a 12.75 -in.-diameter surface protector casing was installed and cemented. This protector casing was used to prevent excavated materials from entering the borehole during drilling. An 11-in.-diameter borehole was then drilled through overlying confining units (Austin Chalk, Eagle Ford Group, Buda Limestone, and Del Rio Clay) to a $10-\mathrm{ft}$ depth into the Georgetown Formation at the top of the Edwards aquifer. Thickness of confining units was approximately $320 \mathrm{ft}$ at the Zarzamora location and $385 \mathrm{ft}$ at the Timberhill location. A 6.63-in.-diameter steel casing was installed to this depth to isolate the overlying units from the Edwards aquifer. Cement was subsequently installed in stages by tremie technique to prevent loss of cement to voids. After waiting 24 hours for cement surrounding the steel casing to cure, a 6-in. borehole was drilled to the desired depth in the Edwards aquifer. A schedule 80, 2.5-in.-diameter polyvinyl chloride
(PVC) casing was installed in the borehole to a depth of about $10 \mathrm{ft}$ above the targeted zone. The PVC casing was reduced to 2 in. diameter at this depth. About $3 \mathrm{ft}$ of 2-in.-diameter PVC casing was added below the reducer. Two bell-shaped rubber formation packers (shale traps) were clamped around this casing to make a seal between the PVC pipe and formation above the screen. A screen of desired length was installed below the formation packers. Screen slot size was 0.04 in. (0.040 slot). Screen lengths ranged from 10 to $30 \mathrm{ft}$ depending on the presence and sizes of voids identified from geophysical logs and whether the well could be completed in the desired zone. Steel casing was not required for the overburden well (Z-OVB). Bentonite pellets were poured from land surface to seal the zone between the depth of shale traps to a depth inside steel casing. Bentonite and Portland cement were used to seal the well from about $20 \mathrm{ft}$ below to about $3 \mathrm{ft}$ above land surface. Wells were completed with a surface cement wellpad, locking metal shroud, and locking cap for PVC pipe. Wells were developed by jetting after drilling was completed. Completed wells were subsequently pumped until stabilization of field properties (water temperature, specific conductance, $\mathrm{pH}$, dissolved oxygen, and turbidity).

Cores were collected by using a 4-in.-diameter, 10 -ft-long core barrel at eight selected intervals: three in the overburden units and five in the Edwards aquifer. The intervals in the overburden units included Austin Chalk/Eagle Ford Group contact, Eagle Ford Group/Buda Limestone contact, and the Buda Limestone/Del Rio Clay contact (fig. 2). Intervals in the Edwards aquifer included Del Rio Clay/Georgetown Formation contact, leached and collapsed members, regional dense member/grainstone member contact, grainstone member, and Kirschberg evaporite member HGUs (fig. 4).

Core samples were collected aerobically, and then subsets of material were collected from each core and placed in airtight jars under a nitrogen $(\mathrm{N})$ atmosphere to minimize oxidation reactions. Samples were stored chilled to about $4^{\circ} \mathrm{C}$ until treatment. Solid materials to be analyzed for inorganic (selected major ion and trace element) chemical analysis were removed from the airtight containers and were crushed to less than 2 millimeters (mm) diameter at the University of Texas at San Antonio Geoscience Laboratory. Crushed samples were returned to a $\mathrm{N}$ atmosphere and sent to the USGS National Research Program Inorganic Chemistry Laboratory in Reston, Va., for chemical analysis of selected ions. Crushed samples under a $\mathrm{N}$ atmosphere also were sent to the USGS National Water Quality Laboratory in Denver, Colo., for analysis of percent total carbon and percent inorganic carbon. Bulk samples were sent to the USGS National Research Program Clay Mineralogy X-ray Diffraction Laboratory in Reston, Va., for $\mathrm{X}$-ray diffraction (XRD) analysis. Selected major, minor, and trace element concentrations of core samples were determined from two acid extractions (leaches): 6 normal $(\mathrm{N})$ hydrochloric acid (HCl) (Cornwell and Morse, 1987; Brugam and others, 1988), and 10 percent nitric acid $\left(\mathrm{HNO}_{3}\right)$ (Rabinowitz and Bellinger, 1988). Identical extraction procedures for each acid were used; $5.0 \pm 0.5$ grams (g) of crushed core sample was 
weighed into a 50-milliliter $(\mathrm{mL})$ polycarbonate centrifuge tube. One 15-mL aliquot of acid was added. The tube was left open to the atmosphere for 30 minutes to permit the evolution of carbon dioxide $\left(\mathrm{CO}_{2}\right)$ gas from sediments with high carbonate content and then was tightly capped. Extractions were performed on an "as received" basis; that is, wet. Analytical concentrations were corrected to dry weight after calculating for moisture content. Sample tubes were placed on a shaker table at room temperature for 6 hours to ensure complete mixing. Samples were centrifuged, and the supernatant (leachate) was withdrawn with 20 -mL polycarbonate disposable syringes and filtered through 0.45 -micrometer $(\mu \mathrm{m})$ disposable polycarbonate filters into $10-\mathrm{mL}$ centrifuge tubes. The leachate was analyzed for selected major ions and trace elements by using inductively coupled plasma-emission spectrophotometry (ICPES). Leachates derived from the $6 \mathrm{~N} \mathrm{HCl}$ extractions were diluted to $1.2 \mathrm{~N} \mathrm{HCl}$, and leachates from the 10 percent $\mathrm{HNO}_{3}$ extractions were diluted to 2 percent $\mathrm{HNO}_{3}$ prior to analysis with the ICP-ES. Further dilution (5-20 times) was required for analysis of As, lead, selenium, and $U$ with inductively coupled plasma-mass spectroscopy (ICP-MS). Concentrations for As are not reported for the $\mathrm{HCl}$ extractions because of mass interference of As with chloride (Cl). Concentrations derived from the leachate analyses are semiquantitative because a small amount of residual solids remained after extractions. The methods for XRD scans, carbonate digestions, and calculations of semiquantitative weight percents are described in detail in Webster and Jones (1994). XRD was performed on bulk samples and on samples that were digested to remove carbonate so that residual particulates of less than 1 $\mathrm{mm}$ size could be analyzed. In some cases, a second digestion was performed. The qualitative carbonate digestion technique was designed to release clay minerals bound within grains of carbonate. Excess carbonate was abundant after chemical treatments, but enough clay was separated to make reasonable phase identifications. Any mineral with quantifiable principal or secondary peaks resolved significantly above background was identified. Some trace identifications could not be quantitatively discriminated from background and were identified as trace. Although qualitative weight percent abundance is provided in the data (table 6 at end of report), identifications are listed in the order of the relative intensity of principal peaks where not quantified. Peak intensity is proportional to weight percent in an indirect and sometimes unreliable way. XRD weight percent calculations have large errors because peak intensities routinely vary by 10 percent or more from one scan to the next, even when the same slide is analyzed.

\section{Geophysical and Depth-Dependent Flow Measurements}

Borehole geophysical logs such as caliper, normal resistivity, induction conductivity, and natural gamma, as well as fluid resistivity and temperature, and vertical flow rates were collected in PSW W4 and in the deepest monitoring wells in the two monitoring well nests (Z-DED and T-DED). W4 was logged through 30-in.-diameter steel casing from land surface datum (LSD) to $320 \mathrm{ft}$ below LSD and through open hole from $321 \mathrm{ft}$ to the depth of $753 \mathrm{ft}$ (total depth of hole is $816 \mathrm{ft}$ ) below LSD with the production pump removed. For flow measurements in PSW W4, a temporary turbine pump was lowered below the existing water-level depth such that the intake was a few feet above the bottom of the steel casing, allowing for drawdown and a pumping rate of 650-850 gallons per minute (gal/min). This pump was used to stress the well to simulate production conditions during the pumped flowmeter logging and depth-dependent water sample collection. This pumping rate, however, is considerably lower (by one to two orders of magnitude) than typical well production rates and rated pump capacities (TANC study water purveyor, written commun., 2008). The monitoring wells were logged in open hole prior to completion under ambient conditions.

Fluid resistivity logs provide a record of the capacity of the borehole fluid to conduct electrical current (Keys, 1997). Changes of fluid resistivity are measured by ring electrodes inside a housing that allows borehole fluid to flow through it. The best fluid resistivity logging results are achieved when logging downward into boreholes containing ambient water that has had sufficient time to stabilize. Ideally, fluid resistivity logs are collected as the first logging run to record ambient conditions before other probes have passed through the borehole and vertically mixed the borehole fluid. Curve deflections on the fluid resistivity log might indicate horizontal or vertical flow movement, stratification of borehole fluid, or screen openings in cased wells. The fluid resistivity values can also be used in conjunction with other geophysical measurements and logs. Fluid conductivity, the reciprocal of fluid resistivity, was compared with measured specific conductance values. The fluid conductivity values for this study were recorded at the ambient borehole temperature and were not corrected to a standard temperature. A Century model 8044 multiparameter E-log probe (Century Geophysical Corporation, Tulsa, Okla.) was used to $\log$ fluid resistivity and temperature. Calibration of the fluid resistivity logging probes was completed with solutions of known conductivity/resistivity in a two-point calibration. Fluid resistivity and temperature logs were completed in W4 during ambient conditions (well field off) and with the well field pumping (well field on).

Natural gamma logs provide a record of gamma radiation detected at depth in a borehole and are useful in determining lithologies and contact depths of the strata penetrated by the borehole. Fine-grained sediments that contain abundant clay tend to be more radioactive than quartz-rich sandstones or carbonates (Keys, 1997). The natural gamma log was run simultaneously with the fluid resistivity log and was recorded in natural gamma counts per second by using a natural gamma sensor with a sodium iodide detector built into a Century 8144c multiparameter probe. The natural gamma sensor, factory calibrated, requires no field calibration. Natural gamma count rates, which typically increase in the proximity of clay and shale, might also increase slightly when adjacent to any 
bentonite seals in the wells. The caliper log was measured by using a three-arm caliper, which measures the diameter of the borehole by using a three-arm configuration that can be opened downhole.

The electromagnetic (EM) flowmeter probe measures the vertical flow rate and direction of vertical flow in a borehole by using the principle of Faraday's Law of Induction. The EM flowmeter probe consists of an electromagnet and two electrodes oriented 180 degrees apart and 90 degrees to the magnetic field inside a hollow cylinder or tube. The voltage induced by a conductor moving at right angles through the magnetic field is directly proportional to the velocity of the conductor (water) through the field (Century Geophysical Corporation, 2010). The direction of vertical water flow is determined by the polarity of the response, with upward flow being positive and downward flow being negative. Downward and upward flow were calibrated at a rate of $1 \mathrm{gal} / \mathrm{min}$ through the tool in a controlled environment with a bypass factor calculated for high flow within the wellbore. Flowmeter and fluid properties data for W4 were collected for four different pumping conditions: (1) no pumping in the PSW or well field (an operationally rare condition) ("ambient 1"); (2) no pumping in the PSW, but with pumping nearby well(s) in the well field (greater than 7,000 gal/min) (“ambient 2"); (3) PSW pumping (850 gal/min), no other pumping in the well field ("moderate”); (4) PSW pumping (850 gal/min) and with pumping of nearby well(s) in the well field (greater than 7,000 gal/min) ("normal").

\section{Collection of Water Samples}

Groundwater samples were collected from PSWs in the regional aquifer, monitoring wells (Timberhill and Zarzamora wells and an overburden well), and well-field PSWs during 2004-9 (table 1). Well-field samples included wellhead samples (W2, W3, W4, W5, and W6) and depth-dependent (W4) and temporal (time series in response to a rainfall/recharge event) samples (W6). Temporal samples also were collected from the Zarzamora Edwards aquifer monitoring wells and an upgradient unconfined monitoring well (AY-68-27-610). For the purposes of comparing water chemistry, groundwater samples were categorized as being from regional aquifer PSWs, from the well field (wellhead samples), from the monitoring wells (Zarzamora and Timberhill monitoring well clusters, excluding the overburden well), from the overburden monitoring well, from the PSW depth-dependent sampling, and from temporal sampling (from the PSW and selected monitoring wells (including an upgradient unconfined monitoring well)). Constituents analyzed for are summarized in table 2 at end of report. It was not possible to collect a surface discharge (wellhead) sample during the depth-dependent sample collection from W4; alternatively, this sample was approximated by placing the sample pump intake just below the bottom of the turbine pump intake (near the bottom of the casing at $320 \mathrm{ft}$ of depth). The water sample collected from this intake point was assumed to represent discharge at the surface and is considered hereinafter as the wellhead sample from W4. Depth-dependent and temporal samples are described in more detail in the two following sections.

Sampling protocols used for this study are described in detail in Koterba and others (1995), Koterba (1998), Lapham and others (1995), and U.S. Geological Survey (variously dated). Groundwater samples were collected and processed in a mobile water-quality laboratory. Existing pumps, permanently installed in each PSW (except W4), were used to deliver water to the land surface. In most cases, a permanent spigot near the wellhead was used as the sampling point. In a few instances, plumbing connections near the wellhead were modified temporarily for sampling purposes. Water was transferred from the wellhead spigot to the mobile laboratory by using Teflon ${ }^{\circledR}$ (DuPont ${ }^{\mathrm{TM}}$ ) tubing with stainless steel fittings. To minimize risk of contamination, sample collection and preservation took place in chambers consisting of clear polyethylene bags supported by plastic frames, much like laboratory glove boxes. Equipment that came in contact with the water sample was cleaned between each well sampling by using a progression of (1) dilute phosphate-free detergent to remove both organic and inorganic residues, (2) deionized water rinse to remove detergent, (3) methanol wash to remove organic residue, and (4) deionized water rinse to remove any remaining methanol residue. Monitoring wells were sampled by using a portable positive displacement groundwater sample pump.

Wells were purged before sampling. During the initial pumping period, measurements of field parameters (specific conductance, $\mathrm{pH}$, temperature, dissolved oxygen) were routinely monitored in a sealed flowthrough cell. Turbidity was monitored by collecting periodic water samples from a discharge tube and analyzing with a portable field turbidimeter. Water samples were collected after stable measurements of these properties were achieved (Koterba and others, 1995; U.S. Geological Survey, variously dated). Water was redirected by way of a manifold to the sample chamber inside the mobile laboratory for sample collection.

Additional parameters measured at the time of sample collection were carbonate alkalinity, ferrous and total iron, and sulfide. Alkalinity was measured by using an inflection point titration method (Rounds, 2003). Iron species and sulfide were analyzed by field spectrophotometric methods, and results are considered qualitative. Additional samples were collected for analysis of major ions (mineral analysis), nutrients ( $\mathrm{N}$ and phosphorus compounds), DOC, UV absorbance (organic carbon), trace elements (mostly metals), pesticide compounds (pesticides and their degradates), VOCs, and wastewater indicator compounds. Samples for analysis of selected isotopes, radon gas, radium-226 and radium-228, and age-dating compounds and isotopes (chlorofluorocarbons (CFCs, specifically CFC-11, -12, and -113), sulfur hexafluoride $\left(\mathrm{SF}_{6}\right)$, tritium $\left({ }^{3} \mathrm{H}\right)$, helium-3 ( $\left.{ }^{3} \mathrm{He}\right)$, and associated dissolved gases) were collected at a subset of wells. Most analyses were performed at the USGS National Water Quality Laboratory. Dissolved gases, 
CFCs, and $\mathrm{SF}_{6}$ were analyzed at the USGS Reston Chlorofluorocarbon Laboratory in Virginia. Helium-3 was analyzed at the Gas Extraction Laboratory of Lamont-Doherty Earth Observatory in Palisades, N.Y. Tritium was analyzed at the Gas Extraction Laboratory of Lamont-Doherty Earth Observatory or at the USGS Isotope Tracers of Biogeochemical and Hydrologic Processes Laboratory in Menlo Park, Calif. (Thatcher and others, 1977). Age-dating analyses and methods are further described below in the section "Groundwater AgeDating Methods.”

\section{Depth-Dependent Samples}

Geophysical and flowmeter logs were collected from W4 to determine zones of contribution to the wellbore prior to sampling; the W4 borehole was selected because it did not contain a production pump. Prior to logging and sampling, a "test" turbine pump, capable of pumping up to $850 \mathrm{gal} / \mathrm{min}$, was installed in the borehole of W4 to approximate PSW pumping conditions. Although the test pump did not pump at the capacity of production pumps, it was deemed sufficient to stress the well for the purpose of this study. As described earlier in the section "Geophysical and Depth-Dependent Flow Measurements," four pumping conditions were logged with the flowmeter: ambient 1 , ambient 2 , moderate, and normal. The normal pumping condition (for example, with one or two wells in the well field pumping at total discharge rates from approximately 7,778 to $28,270 \mathrm{gal} / \mathrm{min}$ ) was likely to be most representative of pumping conditions associated with the production of supply water. Each of the pumping conditions produced different results for stratigraphic zones that contributed water to the well. This information was used to select three depth intervals for depth-dependent sampling under three of the four pumping conditions: ambient 1 (hereinafter, ambient), moderate, and normal.

Selected depths for sampling based on zones of flow within the well were (1) shallow (380 ft), which was just above the high-conductivity zone, (2) intermediate (430 ft), and (3) deep (540 ft), which are associated with three different HGUs, specifically, (1) the cyclic and marine members (HGU 3), (2) the leached and collapsed members (HGUs 4 and 5), and (3) above the Kirschberg evaporite member (HGUs 8 and 9) in the grainstone member of the Edwards Group (HGU 7), respectively (fig. 4). Depth-dependent samples were collected by suspending 2.5-in.-diameter PVC casing (tubing) to the three selected depths. A positive displacement sample pump (1.8-in. outside diameter) was placed inside the PVC casing and used to collect water samples from the three selected depths. This approach is similar to that used by Izbicki (2004) to collect samples from discrete depths in production wells under pumping conditions. The PVC tubing was purged of three casing volumes prior to sampling. Water samples were collected at the selected depth intervals for each of the three pumping conditions as defined above (ambient, moderate, and normal). An additional sample was collected under the moderate condition from below the existing casing of the wellbore to approximate the wellhead sample for W4. Depth-dependent sampling details for the PSW, as well as sampling of the monitoring wells completed at different depths, are shown in table 3 at end of report.

\section{Temporal Water Samples}

Selected monitoring wells and one of the well-field PSWs (W6) were sampled several times in response to a rainfall and recharge event that occurred in October 2009 to assess shortterm (event-scale) temporal variations in water quality for the TANC study area. Sampled monitoring wells were three Zarzamora wells (Z-SED, Z-IED, and Z-DED) and an upgradient unconfined monitoring well (AY-68-27-610) (table 1). Well AY-68-27-610 is one of the shallow/urban unconfined monitoring wells described by Musgrove and others (2010). It is approximately $4.5 \mathrm{mi}$ to the north of the well field (fig. 3).

A baseline sample was collected from these five wells on April 8 through 14, 2009. At that time, it was believed that heavy spring rains were likely. However, an extended drought continued in the region throughout the summer of 2009, as evidenced by declining water levels in the Bexar County index well (J-17) (fig. 1), indicative of very dry regional conditions (fig. 5). From June through August 2009, a total of approximately 1.4 in. of rain was recorded at the San Antonio airport. The sampled storm event was preceded by 6.35 in. of rain in September, which resulted in an increase in water level close to that observed when the baseline sample was collected in April (fig. 5). Between October 3 and 4, 2009, 6.06 in. of rain was recorded at the San Antonio airport, and no additional rain was recorded until October 9, 2009. The first event samples were collected from October 4 through October 6, 2009. A total of six samples, including the baseline sample, were collected from each designated well through November 19, 2009 (table 4 at end of report). An additional 6.73 in. of rain was recorded at the San Antonio airport between October 9 and November 19, 2009. As a result, the response in the study area to the designated rain and recharge event cannot be distinguished from subsequent rain and recharge during the event sampling interval.

\section{Laboratory Analytical Methods}

Depending on sampling event, samples were analyzed for a variety of constituents, including major ions, nutrients, UV absorbance, DOC, pesticides and pesticide degradates, VOCs and wastewater indicator compounds, fuel oxygenates, stable and radiogenic isotopes ( $\mathrm{N}$, oxygen, hydrogen, strontium), trace elements, radon-222 gas, or radium-226 and -228 (table 2). The above constituents were not collected in every sample; rather, they were collected for particular study objectives. Selected groundwater samples were analyzed for dissolved gases and geochemical age-dating compounds and isotopes: $\mathrm{CFCs}, \mathrm{SF}_{6},{ }^{3} \mathrm{H}$, and ${ }^{3} \mathrm{He}$. 

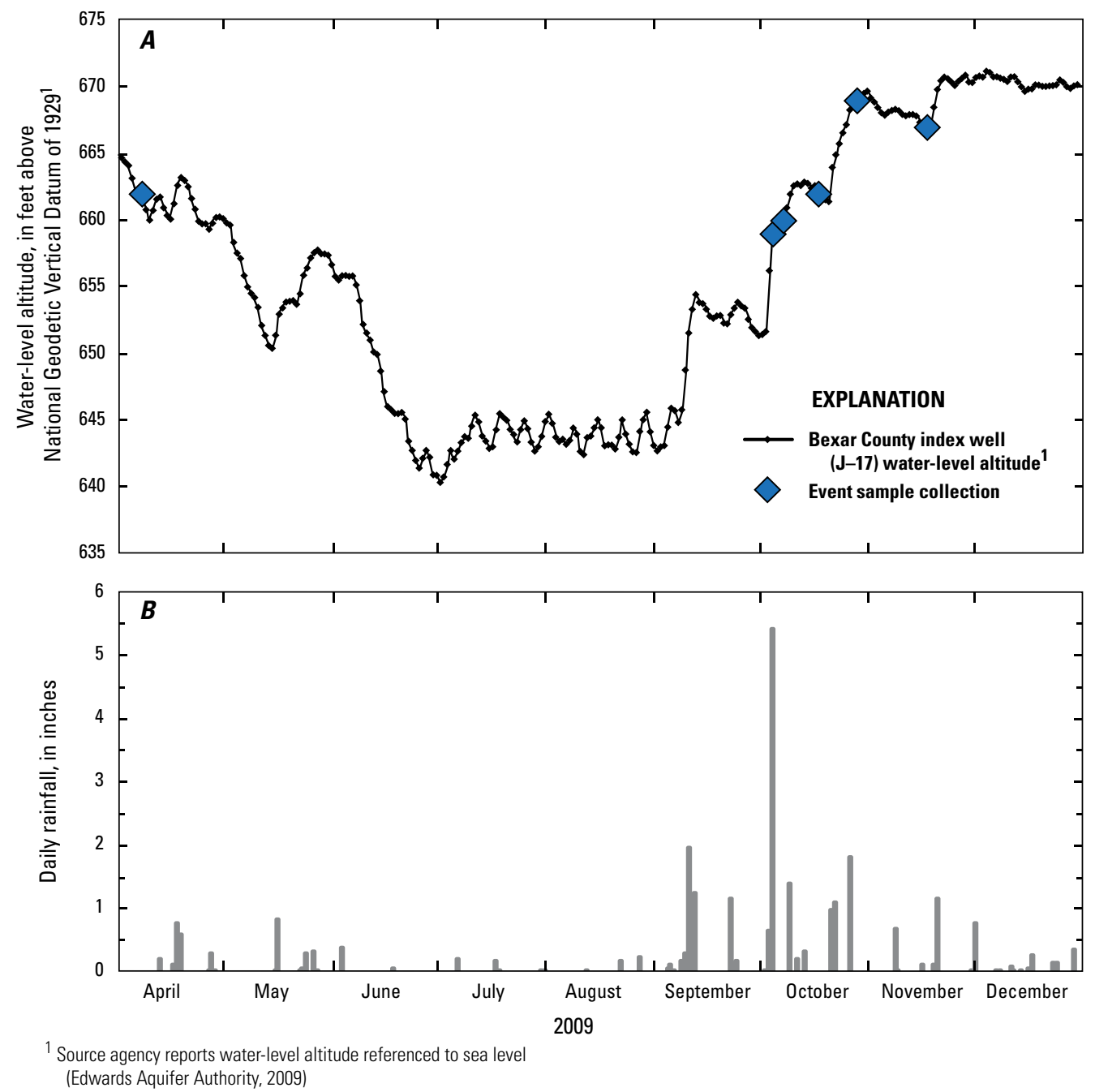

Figure 5. Time series (April 1 to December 31, 2009) climatic and hydrologic data for the south-central Texas study area. A, Bexar County index well (J-17) water-level altitude (Edwards Aquifer Authority, 2009), and dates of sample collection for event sampling (well field W6). B, San Antonio rainfall (recorded at the San Antonio International Airport) (National Oceanic and Atmospheric Administration, 2010).

Samples for major ions, trace elements, and nutrients were filtered through a $0.45-\mu \mathrm{m}$ capsule filter and analyzed by using ICP-ES, ICP-MS, ion-exchange chromatography, and colorimetry procedures described in Fishman and Friedman (1989), Faires (1993), Fishman (1993), McClain (1993), Garbarino (1999), Garbarino and others (2006), and Patton and Kryskalla (2003). Hydrogen sulfide was measured in the field by using colorimetric methods (Hach Company, 2002). Water samples for radon-222 were collected in a syringe prior to contact with the atmosphere and injected into a mineraloil-based scintillation solution in a 30 -mL glass scintillation vial. The sample was shipped overnight to the laboratory and analyzed by liquid-scintillation counting methods (Prichard and Gesell, 1977; American Society for Testing and Materials, $1996)$. Samples for stable isotopes of hydrogen $(\delta D)$, oxygen $\left(\delta^{18} \mathrm{O}\right)$, and $\mathrm{NO}_{3}\left(\delta^{15} \mathrm{~N}\right.$ and $\delta^{18} \mathrm{O}$ of $\left.\mathrm{NO}_{3}\right)$ were analyzed by the USGS Stable Isotope Laboratory in Reston, Va. Isotope data are presented in delta $(\delta)$ notation as the ratio of the heavy to the light isotope, normalized to a standard (eq. 1).

$$
\delta_{\text {sample }}=1,000\left[\left(\mathrm{R}_{\text {sample }} / \mathrm{R}_{\text {standard }}\right)-1\right]
$$

where

$$
\begin{aligned}
& \mathrm{R}_{\text {sample }} \text { is the ratio of the heavy to the light isotope in the } \\
& \text { sample and } \\
& \mathrm{R}_{\text {standard }} \text { is the ratio of the heavy to the light isotope in the } \\
& \text { standard. }
\end{aligned}
$$

$\delta \mathrm{D}$ and $\delta^{18} \mathrm{O}$ were analyzed by using an isotope ratiomass spectrometer by hydrogen gas-water equilibration and $\mathrm{CO}_{2}$-water equilibration techniques, respectively, and are 
reported relative to Vienna Standard Mean Ocean Water (Epstein and Mayeda, 1953; Coplen and others, 1991; Coplen, 1994; Révész and Coplen, 2008a, 2008b). Nitrate isotopes $\left(\delta^{15} \mathrm{~N}\right.$ and $\delta^{18} \mathrm{O}$ of $\mathrm{NO}_{3}$ ) were analyzed by bacterial conversion of $\mathrm{NO}_{3}$ to nitrous oxide and reported relative to $\mathrm{N}_{2}$ gas in air and Vienna Standard Mean Ocean Water, respectively (Sigman and others, 2001; Casciotti and others, 2002; Révész and Casciotti, 2007).

VOCs, pesticides, pesticide degradates, DOC, major ions, trace elements, nutrients, and radon-222 were analyzed by the USGS National Water Quality Laboratory. Samples for VOCs and fuel oxygenates were unfiltered and determined by gas chromatography and mass spectrometry by using methods described in Connor and others (1998) and Rose and Sandstrom (2003). Pesticides samples were filtered by using a 0.7$\mu \mathrm{m}$ glass-fiber filter and analyzed by carbon- 18 solid-phase extraction and capillary column gas chromatography and mass spectrometry (Zaugg and others, 1995; Lindley and others, 1996; Furlong and others, 2001; Sandstrom and others, 2001; Lee and Strahan, 2003; Madsen and others, 2003). Wastewater indicator compounds were collected similarly to pesticide samples and were analyzed as described in Zaugg and others (2002).

DOC samples were collected by forcing raw water samples through a $0.45-\mu \mathrm{m}$ glass-fiber filter by using high-purity $\mathrm{N}_{2}$ gas. DOC samples were analyzed by methods described by Brenton and Arnett (1993). Nitrogen species concentrations are reported as $\mathrm{N}$ (for example, $\mathrm{NO}_{3}$ as $\mathrm{N}$; hereinafter, $\mathrm{NO}_{3}$ ), and phosphorus species concentrations are reported as phosphorus (P).

\section{Groundwater Age-Dating Methods}

To facilitate comparison of results between groundwater age tracers, multiple tracers were measured in selected groundwater samples, including concentrations of CFCs, $\mathrm{SF}_{6},{ }^{3} \mathrm{H}$, and the ratio of the parent/daughter isotopes ${ }^{3} \mathrm{H} /{ }^{3} \mathrm{He}$. Because the solubility of atmospheric tracers varies as a function of temperature, dissolved gas concentrations (argon, $\mathrm{CO}_{2}$, methane, $\mathrm{N}_{2}$, and oxygen) were also measured to estimate the temperature of groundwater at the time of recharge, as well as to calculate the amount of excess air and excess N. Excess air is that which is trapped in pores (for example, after a rapid water table rise) and subsequently dissolved in groundwater to concentrations above ambient conditions. Excess $\mathrm{N}$ reflects reactions with $\mathrm{N}$ species, such as denitrification. Helium-4 $\left({ }^{4} \mathrm{He}\right)$ was also measured to determine whether the ${ }^{3} \mathrm{H} /{ }^{3} \mathrm{He}$ agetracer method was suitable.

Anthropogenic activities have released $\mathrm{SF}_{6}$, CFCs, and ${ }^{3} \mathrm{H}$ into the atmosphere in low concentrations since the 1940s and 1950s (Schlosser and others, 1988, 1989; Busenberg and Plummer, 1992, 2000; Solomon and others, 1992). Precipitation incorporates these constituents from the atmosphere, and as a result, groundwater recharge carries a chemical or isotopic signature that can be related to atmospheric conditions at the time of recharge. The ${ }^{3} \mathrm{H} /{ }^{3} \mathrm{He}$ method is based on the radioactive decay of ${ }^{3} \mathrm{H}$ to ${ }^{3} \mathrm{He}$. Each age-tracer technique has associated uncertainties and might be affected differently by aquifer processes. Because all physical and chemical processes that might affect age-tracer results cannot be accounted for, results using these techniques are reported as apparent ages. $\mathrm{CFC}$ and $\mathrm{SF}_{6}$ dating techniques are described in Busenberg and Plummer (1992, 2000, respectively). Techniques for ${ }^{3} \mathrm{H} /{ }^{3} \mathrm{He}$ dating are described by Schlosser and others (1988, 1989) and Solomon and Cook (1999).

Dissolved helium (He) in groundwater is derived from both atmospheric and terrigenic (from earth) sources. The atmospheric component includes air-soluble He and excess-air $\mathrm{He}$ (He derived from excess air) that results from dissolution of air bubbles trapped just below the water table. Another atmospheric source of $\mathrm{He}\left(\right.$ as $\left.{ }^{3} \mathrm{He}\right)$ is from decay of ${ }^{3} \mathrm{H}$ in recently (less than 60 years old) recharged water; ${ }^{3} \mathrm{H}$ concentrations in rainfall, some of which became recharge, during the mid-20th century were increased substantially by atmospheric testing of nuclear weapons (Michel, 1989). The He derived from ${ }^{3} \mathrm{H}$ decay is the He component of interest for the ${ }^{3} \mathrm{H} /{ }^{3} \mathrm{He}$ age-tracer method. Helium is also produced by the radioactive decay of $U$ and thorium in crustal rocks and aquifer solids (crustal $\mathrm{He}$ ) and from upward diffusion or advection of $\mathrm{He}$ from the mantle (mantle He). Together, crustal and mantle He are termed terrigenic He (Solomon, 2000). Potential sources of terrigenic He in the Edwards aquifer include igneous rock intrusions, oil and gas hydrocarbons that are widely present in Edwards Group rocks downdip from the freshwater zone of the Edwards aquifer, rocks composing the underlying and adjacent Trinity aquifer, and rocks underlying the Trinity aquifer. Corrections for atmospherically derived excess He are included in estimating ages. If excess He concentrations are higher than those which result from atmospheric sources, then it is generally not possible to estimate an age with the ${ }^{3} \mathrm{H} /{ }^{3} \mathrm{He}$ age-tracer method.

Samples for age-dating and dissolved gas analyses were collected according to protocols described by the U.S. Geological Survey Reston Chlorofluorocarbon Laboratory (2010). Dissolved gas samples, including samples to be screened for ${ }^{4} \mathrm{He}$, were collected in preweighed, previously evacuated $150-\mathrm{mL}$ glass septum bottles. Upon removal of the rubber stopper, a sample discharge tube was placed at the bottom of the sample bottle. After the sample bottle was initially filled, it was placed in a 1-liter (L) beaker filled with sample water such that the top of the sample bottle was under water. The sample discharge tube flowed continuously during this process until three or more sample-bottle volumes had flowed from the sample discharge tube into the septum bottle. The sample discharge tube was removed, and a rubber stopper containing a needle was inserted into the top of the septum bottle while still submerged. The needle was removed after the stopper was securely placed. Septum bottles were stored inverted and chilled until analysis. CFC samples were collected in 125$\mathrm{mL}$ glass bottles that were sealed with screw caps lined with aluminum foil. Sample bottles were filled by using a similar method as the dissolved gas samples. Bottle caps were kept 
under water until after they were applied to the top of the sample bottle. Bottle caps were taped to prevent loosening, and samples were stored inverted at room temperature until analysis. $\mathrm{SF}_{6}$ samples were collected in 1-L glass bottles and sealed with polyseal screw caps. The sample discharge tube was placed at the bottom of the sample bottles, and sample water flowed into the bottles for three or more sample-bottle volumes. The sample tube was removed, and samples were capped such that no headspace was allowed to form prior to sealing the sample bottle. Sample caps were taped, and samples were stored at room temperature until analysis. ${ }^{3} \mathrm{H}$ samples were collected in 1-L polyethylene bottles. The sample discharge tube was placed at the bottom of the sample bottle until the bottle was filled such that a small headspace remained. Sample bottles were sealed with polyseal screw caps, and the caps were taped. Samples were stored at room temperature until analysis. ${ }^{3} \mathrm{He}$ samples were collected in copper tubes mounted on trays that contained clamps at each end. The sample discharge tube was attached to the inlet side of the copper tube, and a plastic tube $\left(\right.$ Tygon $^{\circledR}$, Saint-Gobain Performance Plastics) containing a valve was attached at the outlet side of the copper tube. Sample water flowed through the copper tube with some back pressure applied by way of the attached valve. The copper tube was gently tapped to remove any bubbles that might have formed during the sampling procedure. After the copper tube was purged with three sample volumes, the clamps on the copper trays were tightly closed to seal the copper tubes, and the external tubing was removed. Samples were stored at room temperature until analysis.

Groundwater samples were analyzed for dissolved gases, $\mathrm{SF}_{6}$, and CFCs at the USGS Reston Chlorofluorocarbon Laboratory in Virginia. Dissolved gases were extracted from headspaces of glass samplers and analyzed by gas chromatography (Busenberg and others, 1998). Analytical methods for $\mathrm{SF}_{6}$ followed those described by Busenberg and Plummer (2000). CFCs were analyzed by using purge and trap gas chromatography with electron-capture detector (GC-ECD) (Bullister, 1984; Bullister and Weiss, 1988; Busenberg and Plummer, 1992). Groundwater samples for ${ }^{3} \mathrm{H}$ and ${ }^{3} \mathrm{He}$ were analyzed by the Gas Extraction Laboratory of Lahmont-Doherty Earth Observatory in Palisades, New York, by using quantitative gas extraction followed by mass spectrometric techniques; methods are described by Clark and others (1976), Ludin and others (1998), and Schlosser and others (1989). The ${ }^{3} \mathrm{H} /{ }^{3} \mathrm{He}$ methods included analysis of concentrations of ${ }^{4} \mathrm{He}$ and neon (Ne), which are used in ${ }^{3} \mathrm{H} /{ }^{3} \mathrm{He}$ age-tracer calculations.

In spite of the analytical precision available for measurement of many geochemical age tracers, there are numerous uncertainties associated with groundwater age interpretations (Phillips and Castro, 2003; Bethke and Johnson, 2008). Age interpretation for a sample that consists of water of a single age might be relatively simple but becomes increasingly complex for a sample that consists of a mixture of water; that is, a mixture of water "parcels," each of which has a discrete age (Böhlke, 2006). Age-interpretation complexities associated with mixing might be especially important in karst aquifers, where each component of a complex network of conduits, fractures, and matrix porosity might have a different groundwater age and a well or spring might discharge water from any combination of porosity types (Plummer and Busenberg, 2005; Long and Putnam, 2006). Models for the hypothetical concentrations of age tracers in water samples with different age distributions that consider the effects of hydrologic processes such as dispersion, exponential mixing, and binary mixing of shallow and deep groundwater have been developed to facilitate interpretation of geochemical age tracers (Böhlke, 2006; Long and Putnam, 2006). Age-tracer concentrations were compared with results expected from different lumpedparameter models by using atmospheric input data for tracers and using age-date tracer modeling software developed by Böhlke (2006). Lumped-parameter models assume a steadystate flow system and also assume that selected tracers behave like a water molecule.

\section{Quality Control}

Quality-control (QC) samples are collected and analyzed to evaluate bias and variability of environmental samples. Bias is systematic error inherent in a method or caused by some artifact of the measurement system. Variability is the degree of variation in independent measurements that results from repeated application of the process under specified conditions (T.L. Schertz, U.S. Geological Survey, written commun., 1997). QC data are particularly useful for analyzing and interpreting water quality data analyzed for small concentrations, including those measured at $\mu \mathrm{g} / \mathrm{L}$ levels for many constituents in this study. QC samples collected and analyzed for this study consisted of three types of samples collected onsite: blanks, replicate environmental samples, and environmental matrixspike samples. In addition to QC samples submitted from the field, the USGS National Water Quality Laboratory analyzes laboratory blanks, replicates, and spikes. QC data stored in USGS databases are available upon request.

Blank samples test for bias from introduction of contaminants to environmental samples. Three types of blank samples were analyzed in this study: source-solution, equipment, and field. Source-solution blanks consist of high-purity organics-free or inorganics-free water, prepared and tested by the USGS National Water Quality Laboratory for the NAWQA Program. Source-solution blanks were collected with associated equipment or field blanks and were occasionally analyzed for VOCs, DOC, trace elements, or nutrients. Source-solution blanks document the purity of the high-purity waters used to collect field and equipment blanks. A total of 22 blanks (combination of inorganic, organic, field, and equipment) were collected during this study in comparison with 97 environmental samples.

Equipment and field blanks were analyzed for concentrations of a combination of major ions, nutrients, DOC, trace elements, pesticide compounds, or VOCs. Two equipment blanks were collected during the study period prior to collection of the first environmental samples to indicate whether 
the equipment or sample collection process would bias the data. Both equipment blanks contained several inorganic constituents, primarily trace metals. Trace metals detected at low concentrations (less than $1 \mu \mathrm{g} / \mathrm{L}$ ) included aluminum, cadmium, chromium, manganese, nickel, and vanadium. Zinc was detected in both equipment blanks at concentrations of about 2 and $3 \mu \mathrm{g} / \mathrm{L}$, and lead was detected in one equipment blank at a concentration of about $2 \mu \mathrm{g} / \mathrm{L}$. The source of these metals, though at low concentrations, is unknown. Stainless steel fittings were replaced as a result of these detections, and these metals were not evaluated for this study. Calcium (Ca), sodium (Na), silica $(\mathrm{Si})$, sulfate $\left(\mathrm{SO}_{4}\right)$, and iodide $(\mathrm{I})$ also were detected at low concentrations (less than $1 \mathrm{mg} / \mathrm{L}$ ) in one equipment blank, well below concentrations observed in environmental samples. DOC and phenol were detected at low concentrations (less than $1 \mathrm{mg} / \mathrm{L}$ and less than $1 \mu \mathrm{g} / \mathrm{L}$, respectively) in one equipment blank. Occurrences of DOC and phenol are discussed below.

Field blanks were collected at periodic intervals onsite to indicate whether analytical bias occurred from sample collection, cleaning protocols, or contamination of the mobile laboratory. Eleven (organic and inorganic) field blank suites were collected following environmental sample collection and subsequent equipment cleaning. Field blanks were processed the same as environmental samples_-by pumping high-purity water through cleaned sample collection equipment, including filter apparatuses, where applicable. DOC was detected in two field blanks. DOC was detected at very high concentrations (greater than $100 \mathrm{mg} / \mathrm{L}$ ) in one of the field blanks collected in 2005 and was attributed to insufficient removal of methanol during cleaning. Several environmental samples had DOC concentrations that were higher (greater than $10 \mathrm{mg} / \mathrm{L}$ ) than expected, and it is presumed that the cleaning procedure during 2004-5 affected the concentrations of these samples. Environmental DOC concentrations measured in 2004-5 are considered suspect and are marked with a "V" in data tables, indicating possible contamination. The cleaning process was corrected during the sampling period with additional deionized water rinsing to remove methanol from sampling equipment. Among samples collected in 2004-5 and analyzed for the wastewater schedule, phenol, benzophenone, and 4-nonylphenol were sometimes detected, mostly below method reporting levels, in field blanks and environmental samples. Concentrations in three field blank samples were higher than those in environmental samples. Results for these organic compounds and for caffeine and camphor, on USGS National Water Quality Laboratory Schedule 1433, were not considered to reflect environmental concentrations because of analytical limitations during the study period (Zaugg and Leiker, 2006). The VOCs toluene and styrene were detected at low concentrations (less than $0.09 \mu \mathrm{g} / \mathrm{L}$ ) in two field blanks and one sourcesolution blank. The high-purity blank water might have been the source for toluene and styrene, which were not evaluated in this study. Benzene was detected at a low concentration $(0.018 \mu \mathrm{g} / \mathrm{L})$ in one field blank; that blank also contained toluene, indicating a possible contamination with fuel used to power field generators. One field blank contained chloroform (trichloromethane) at a concentration of $0.017 \mu \mathrm{g} / \mathrm{L}$, which is below the long-term method reporting level $(0.03 \mu \mathrm{g} / \mathrm{L})$ and in the range of environmental data evaluated in this study. Chloroform is rarely found in blanks when examining all groundwater QC blanks collected during 1996-2009 by the NAWQA Program in this study area; therefore, the presence of chloroform at such a low concentration, in one field blank, although unexplained, is not considered problematic for interpretation in this study. No pesticide compounds were detected in blanks.

Some trace elements were detected at low concentrations (less than $1 \mu \mathrm{g} / \mathrm{L}$ ) in field blanks: chromium, cobalt, manganese, nickel, silver, strontium, and zinc. Aluminum was detected in two field blanks; one sample contained aluminum $(3.8 \mu \mathrm{g} / \mathrm{L})$ above the method reporting level. Aluminum and vanadium were each detected in a source-solution blank. The high-purity blank water might have been a source for low concentrations of these constituents in some blank samples. The more likely source for some trace elements in blank samples is corrosion of stainless steel fittings. One field blank sample contained a low concentration (less than $1 \mathrm{mg} / \mathrm{L}$ ) of Ca, and two field blanks contained low concentrations of silica. Concentrations of these constituents are orders of magnitude below those of environmental samples. Three field blank samples contained total $\mathrm{N}$, and two of the sample concentrations were above the method reporting level. The detections in field blanks were well below those measured in environmental samples.

Replicate samples are used to evaluate variability in measurements associated with analytical processes, sample collection protocols, or natural variation. Eleven replicate samples were collected sequentially after environmental samples and analyzed for a combination of major ions, nutrients, DOC, trace elements, radon, pesticide compounds, VOCs, or wastewater indicator compounds. Precision can be evaluated by comparing concentrations between environmental and replicate samples. Precision is expressed as relative percent difference (RPD) and is computed as

$$
\mathrm{RPD}=\left\{\left|\mathrm{C}_{1}-\mathrm{C}_{2}\right| \div\left[\left(\mathrm{C}_{1}+\mathrm{C}_{2}\right) \div 2\right]\right\} \times 100,
$$

where

$$
\begin{gathered}
\mathrm{C}_{1} \text { is the concentration of an analyte measured in the } \\
\text { environmental sample, in concentration units; and } \\
\mathrm{C}_{2} \text { is the concentration of the analyte measured in the } \\
\text { replicate sample, in the same concentration units. }
\end{gathered}
$$

Consideration of the magnitude of concentrations being evaluated should be given when evaluating RPDs. For example, the RPD computed from environmental and replicate concentrations of 100 and $101 \mathrm{mg} / \mathrm{L}$ is 1.0, the RPD computed from environmental and replicate concentrations of 10 and 11 $\mathrm{mg} / \mathrm{L}$ is 9.5 , and the RPD computed from environmental and replicate concentrations of 1 and $2 \mathrm{mg} / \mathrm{L}$ is 67 . Although the 
difference between environmental and replicate concentrations is the same in each of the examples, the difference evaluated relative to the mean of the measured concentrations increases as the concentrations being evaluated decrease. Constituents measured at small concentrations might yield a large RPD. RPDs were computed only from pairs of analytes that were detected. If one or both analyses in a constituent pair were reported as less than the applicable detection limit, then that constituent pair was not evaluated.

Most mean RPDs computed for the analytes were less than 5 , indicating excellent reproducibility. In general, mean RPDs computed for this study indicate that the amount of variability in measurements between environmental and replicate samples is acceptable. Relatively large RPDs (greater than 20 percent) resulted for a number of constituents that occurred at low concentrations: aluminum (two replicates), boron, chromium, copper, fluoride (F), iron, lead, manganese (two replicates), selenium, thallium, zinc (three replicates), radium-226, atrazine, deethylatrazine, and metsulfuron-methyl. Although the RPDs were relatively high, concentrations for these replicate pairs were low. Concentrations of copper, lead, nickel, zinc, and DOC in one replicate-sample pair resulted in large RPDs (greater than 30 percent) for those constituents. Even though concentrations were relatively low, the cause of the large sample variability in these constituents might be indicative of the natural variability of aquifer chemistry at this location or might be a result from sample collection procedures at this site or analytical variability at low concentrations close to the Mimimum Reporting Level (MRL). These constituents are not described in this report.

Field spikes are used to assess bias and variability from groundwater matrix interference or degradation of organic constituent concentrations during sample processing, storage, and analysis. Field spikes are environmental samples to which a known volume and concentration of analytes is added. Analytical recoveries of the spiked constituents are expressed as percentages of expected (theoretical) concentrations. Computed field-spike recoveries are compared to theoretical and lab recoveries to evaluate matrix interferences or degradation of organic compounds (pesticides and VOCs).

Recovery (percentage) is computed as

$$
\text { Recovery }=\left[\left(\mathrm{C}_{\text {spiked }}-\mathrm{C}_{\text {unspiked }}\right) \div \mathrm{C}_{\text {expected }}\right] \times 100 \text {, }
$$

where

$\mathrm{C}_{\text {spiked }}$ is the measured concentration of analyte in the spiked environmental sample, in micrograms per liter; and

$\mathrm{C}_{\text {unspiked }}$ is the measured concentration of analyte in the unspiked environmental sample, in micrograms per liter.

$\mathrm{C}_{\text {expected }}$ is the theoretical concentration of analyte in the spiked environmental sample, in micrograms per liter, and is computed as

$$
\mathrm{C}_{\text {expected }}=\mathrm{C}_{\text {solution }} \times \mathrm{V}_{\text {spike }} \div \mathrm{V}_{\text {sample }} \text {, }
$$

where

$\mathrm{C}_{\text {solution }}$ is the concentration of analyte in spiked environmental solution, in micrograms per milliliter;

$\mathrm{V}_{\text {spike }}$ is the volume of spike added to environmental sample, in milliliters; and

$\mathrm{V}_{\text {sample }}$ is the volume of environmental sample, in liters.

Organic compound spikes and spike replicates were added to environmental samples and their replicates, resulting in 11 spiked samples for a combination of VOCs or pesticide compounds. Mean percent recoveries were computed for the most frequently detected compounds: atrazine, 98.7 percent; deethylatrazine, 44.0 percent; tetrachloroethene (PCE), 97.9 percent; chloroform, 113 percent. The mean percent recoveries for spikes of atrazine and PCE were similar to laboratory surrogate recoveries; therefore, concentrations measured in environmental samples probably represent actual concentrations. A high (greater than 100 percent) mean percent recovery for chloroform indicates a high bias for this compound. Therefore, actual concentrations of chloroform probably were less than reported concentrations. Results for deethylatrazine were qualified as estimated ("E") by the USGS National Water Quality Laboratory under laboratory reporting conventions used during the study period. A remark code of "E" was used when compounds were identified, but concentrations could not be accurately quantified. Analytical recoveries typically were lower than expected for deethylatrazine; therefore, concentrations were qualified (Sandstrom and others, 2001). Actual concentrations of deethylatrazine probably were higher than reported concentrations.

In addition to field spikes, surrogate compounds are added to environmental samples in the laboratory at the time of analysis. Surrogates are compounds that have a range of expected (observed in the laboratory in 2004-9) recoveries, usually near 100 percent, and are used to verify that analyses are acceptable. Surrogate compounds, which generally do not occur in nature, are similar in physical and chemical properties to analytes of interest. At the laboratory, they are added to samples to provide information on matrix effects and potential gross sample-processing problems. Surrogate compound concentrations were evaluated for analytical schedules containing the most frequently detected organic compounds (atrazine, deethylatrazine, PCE, and chloroform). Organic compound analyses for the most part were within laboratory QC limits, indicating that analytical instrument performance was satisfactory. Three surrogates (1,2-dichloroethane- $\mathrm{d}_{4}$; 1,4-bromofluorobenzene; and toluene- $d_{8}$ ) were added to the VOC analytical schedule, and two surrogates (alpha-HCH- $\mathrm{d}_{6}$ and diazinon- $\mathrm{d}_{10}$ ) were added to the selected pesticide schedule. The VOC surrogates were within the acceptable laboratory QC limits for all VOC samples. Recoveries for environmental surrogates of alpha-HCH- $\mathrm{d}_{6}$ ranged from 53.3 to 129 percent. The highest and lowest environmental surrogate alpha- $\mathrm{HCH}-\mathrm{d}_{6}$ values 
were outside the acceptable limit range of 64-121 percent. Eleven environmental surrogate samples for diazinon- $d_{10}$ were below acceptable QC limits, indicating that recoveries for diazinon (and similar compounds) might be suspect. Diazinon was not frequently detected; therefore, it was not evaluated in this report.

For samples with complete ion analyses, the percent difference in the charge balance between cations (positively charged) and anions (negatively charged) is used as a QC check on the quality of the major ion analyses; the percent difference was less than 2 percent in all but three samples. In two of these samples the percent difference was about 4.5 percent, still within acceptable limits of about 5 percent difference. The percent difference for one sample was considered unacceptable at 12 percent. The alkalinity measurement for that sample was low when compared to the dataset and was considered as estimated rather than quantified.

\section{Statistical Methods and Geochemical Modeling}

Nonparametric statistical tests were used for all data interpretation. A nonnormal distribution is a common characteristic of water-resource data (Helsel and Hirsch, 2002), and as a result, nonparametric methods are generally better suited than are traditional parametric methods to evaluate water-resource data. The Kendall's tau coefficient is a nonparametric, rank-based test used to measure the strength of the monotonic relation between $\mathrm{x}$ and $\mathrm{y}$ (linear and nonlinear) and is resistant to the effects of outliers (Helsel and Hirsch, 2002). The tau coefficient ranges from -1 to 1 ; a value of 0 indicates no correlation, and values approaching -1 or 1 indicate an increasing strength of correlation. The tau coefficient values generally will be lower than values of traditional correlation coefficients for linear associations of the same strength; for example, a strong linear correlation of greater than or equal to ( $\geq$ ) 0.9 corresponds to a tau value of about $\geq 0.7$ (Helsel and Hirsch, 2002). Independent groups of data were compared for differences by using the Mann-Whitney U test. For this report, statistical results with p-values less than 0.05 were considered statistically significant and are reported. Estimated values (less than the laboratory method reporting level) were considered at the estimated concentration.

The geochemical modeling program PHREEQC (Parkhurst, 1995) was used to calculate ion speciation and mineral saturation states. The precipitation or dissolution of mineral phases can be an important control on fluid composition. In a carbonate aquifer, such as the Edwards aquifer, the dissolution or precipitation of minerals such as calcite and dolomite, which compose the aquifer rocks, will add or remove carbonate constituents. Water-rock interaction with gypsum, a trace mineral present in the Edwards Group (Maclay and Small, 1983), might affect groundwater $\mathrm{SO}_{4} / \mathrm{Cl}$ ratios and $\mathrm{SO}_{4}$ concentrations; downdip saline-zone groundwater, for example, shows evidence of incongruent gypsum dissolution (Oetting and others, 1996). A saturation index (SI) of 0 indicates equilibrium conditions, a value greater than 0 indicates saturation with respect to a mineral phase and the potential for precipitation, and a value less than 0 indicates undersaturation with respect to a mineral phase and the potential for dissolution.

\section{Hydrogeologic Setting}

The south-central Texas Edwards aquifer developed in Early Cretaceous-age limestone and dolomite rocks that are extensively faulted, fractured, and karstified. Like many karst aquifers, the Edwards aquifer is characterized by hydrologic variability. Water-level altitudes in the aquifer can rise rapidly in response to rainfall and corresponding recharge and can be accompanied by increases in springflow; conversely, waterlevel altitudes and springflow decrease during periods of low rainfall and recharge. Records of San Antonio rainfall (recorded at the San Antonio International Airport) (National Oceanic and Atmospheric Administration, 2010), discharge at Comal Springs, and water-level altitudes at well J-17 (Edwards Aquifer Authority, 2009) illustrate the hydrologic variability of the Edwards aquifer (fig. 6).

\section{Aquifer Framework and Lithology}

The Cretaceous strata of south-central Texas regionally include three aquifers: the Edwards aquifer in the Balcones fault zone and the Trinity and Edwards-Trinity aquifers in the Edwards Plateau (fig. 2). The aquifer is composed of carbonate rocks of the Georgetown Formation (not shown in fig. 2) and Edwards Group (or their stratigraphic equivalents), which range in thickness from approximately 450 to $550 \mathrm{ft}$ (Burchett and others, 1986) (fig. 2). The Georgetown Formation overlies the Edwards Group and is part of the Edwards aquifer. The less permeable upper member of the Glen Rose Limestone, which is the uppermost part of the Trinity aquifer, underlies the Edwards aquifer and acts as a lower confining unit across much of the region. Where confined, the aquifer is overlain by the Del Rio Clay and other units with relatively low permeability. Depositional stratigraphy of the carbonate facies are discussed in more detail in Lindgren and others (2011b).

The San Antonio segment of the Edwards aquifer is about $180 \mathrm{mi}$ long from west to east, ranges from 5 to $40 \mathrm{mi}$ wide from north to south (Maclay, 1995), and is characterized by relatively high transmissivities (summarized by Lindgren, 2006; Lindgren and others, 2011a, 2011b). The northern limit of the recharge zone (outcrop) defines the northern aquifer boundary. The aquifer is bounded to the south by the downdip limit of potable water in the aquifer, below which groundwater salinity rises rapidly downgradient (Abbott, 1975; Sharp and Banner, 1997). The freshwater/saline-water interface (Schultz, 1994) represents the transition $(1,000 \mathrm{mg} / \mathrm{L}$ dissolved-solids concentration) from a zone of more active flow with fresh groundwater to a downdip zone of less active flow with saline groundwater. The downdip saline zone is characterized by 

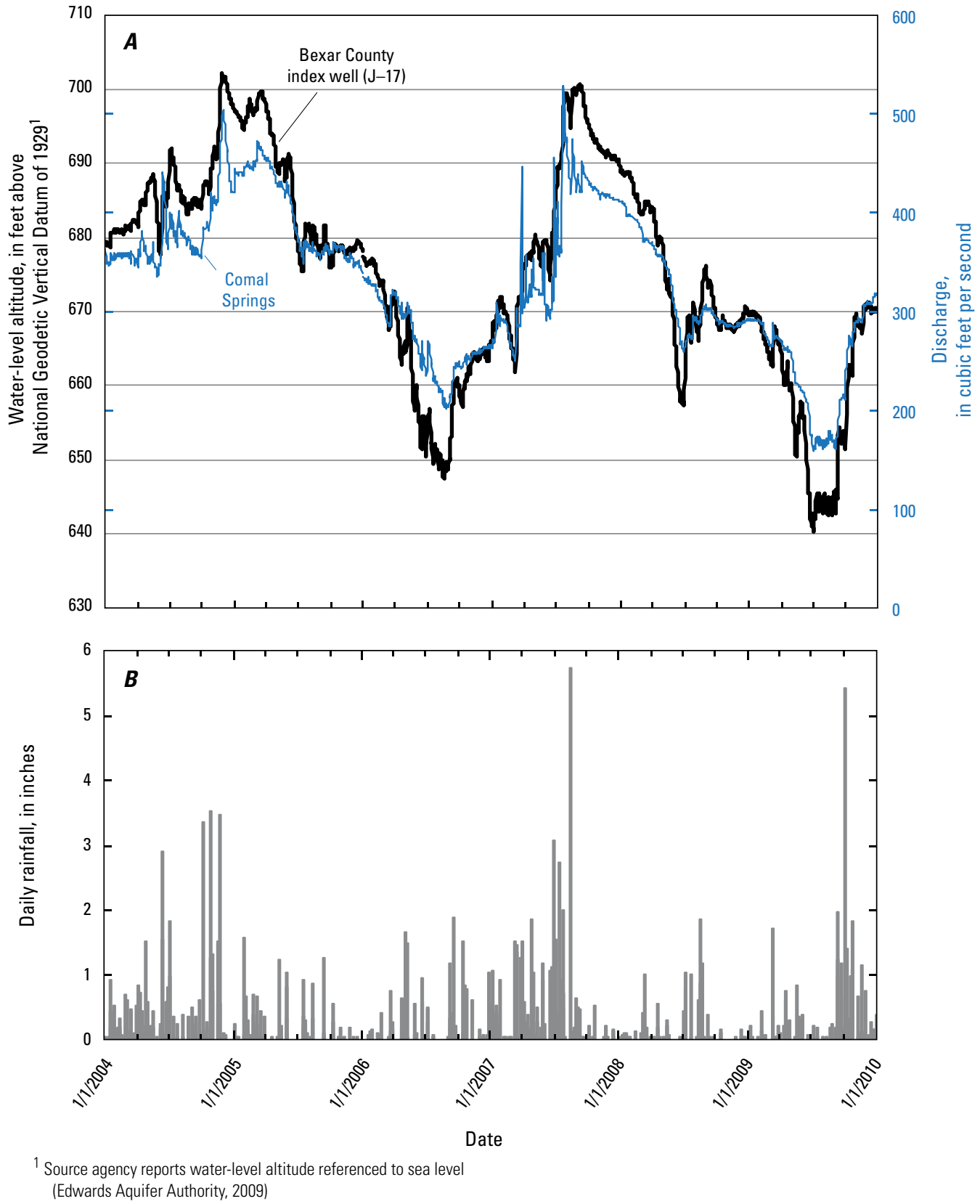

Figure 6. Time series (2004-9) climatic and hydrologic data for the south-central Texas study area. $A$, Bexar County index well (J-17) water-level altitude and Comal Springs discharge (Edwards Aquifer Authority, 2009). B, San Antonio daily rainfall (recorded at the San Antonio International Airport) (National Oceanic and Atmospheric Administration, 2010).

numerous complex saline hydrochemical facies (Clement and Sharp, 1988; Oetting and others, 1996) which might locally influence groundwater geochemistry in the freshwater zone (Musgrove and others, 2010). A small number of volcanic and intrusive igneous rocks locally cross-cut the aquifer, which might also affect groundwater geochemistry on a local scale.

Three core samples were collected from the overburden (Austin Chalk/Eagle Ford Group contact, Buda Limestone/ Del Rio Clay contact), one sample from the contact of the overburden units with the top of the Edwards aquifer (Del Rio Clay/Georgetown Formation contact); and four samples were collected from selected HGUs of the Edwards Group (leached and collapsed members, regional dense member/grainstone member contact, grainstone member, Kirschberg evaporite member) (fig. 4; tables 5 and 6 at end of report). For the most part, bulk samples were largely dominated by the carbonate mineral calcite (42.2-96.5 percent, based on relative peak intensity), with lesser amounts of quartz (trace-44.3 percent where present), clays (3.2-26.3 percent), and dolomite (trace to 31.5 percent) (table 6 ). These minerals were present in varying proportions in each of the core samples. Original deposits in the region of aragonite, calcite, dolomite, and gypsum 
have been extensively replaced by calcite within the aquifer and form a highly porous and heterogeneous limestone rock. Dolomite and dolomitic limestone abundance varies spatially as well as stratigraphically (Maclay and Small, 1983, 1984). Mixing-zone dissolution near the downdip freshwater/salinewater interface, driven by gypsum dissolution, has created high porosity and high permeability where dolomite has been dissolved (Maclay and Small, 1984; Hovorka and others, 1998).

One or two digestions (dissolution) were performed on bulk core samples to remove most of the calcite so that mineral phases of less than $1 \mathrm{~mm}$ could be identified. Residual clays were present in all samples and, where identified, included kaolinite, illite, smectite, and chlorite. Kaolinite was generally the most abundant clay. Other minerals present in small amounts in some digested samples included goethite (Del Rio Clay/Georgetown Formation contact, possibly Kirschberg evaporite member), pyrite (Buda Limestone/Del Rio Clay contact, regional dense member/grainstone member contact), possibly hornblende (Del Rio Clay/Georgetown Formation contact, regional dense member/grainstone member contact), feldspar (Austin Chalk/Eagle Ford Group contact), and possibly anhydrite or oriented feldspar (Buda Limestone/ Del Rio Clay contact).

Total carbon and inorganic carbon were analyzed in core samples (table 5). Solid phase particles (less than $2 \mathrm{~mm}$ ) contained concentrations of total carbon that ranged from 59 to 129 grams per kilogram (g/kg) (median 113) and inorganic carbon that ranged from 54 to $118 \mathrm{~g} / \mathrm{kg}$ (median 110). Almost no organic carbon was present in several of the samples.

\section{Estimation of Aquifer Properties}

Extensive data have been collected on the hydraulic properties of the Edwards aquifer in the San Antonio region, in particular, permeability, hydraulic conductivity, transmissivity, anisotropy, and storativity. An interpretation of the distribution of relative permeability by HGU of the Edwards aquifer and its confining units is based on field observations, stratigraphic studies by Rose (1972), and data from test-drilling and geophysical-logging programs (Maclay and Small, 1983). These distributions apply to the confined zone and might not be strictly applicable to the unconfined zone. Permeability in the Edwards aquifer - which includes matrix, fracture, and conduit permeability — varies over eight orders of magnitude (Hovorka and others, 1998). The carbonate matrix of the aquifer is very permeable; however, in many intervals, the very high permeabilities resulting from conduits and fractures dwarf the matrix contribution. The highest matrix permeability occurs in downdip parts of the aquifer, where the mixing of freshwater and saline water has maximized dolomite dissolution (Hovorka and others, 1998).

Transmissivity and hydraulic conductivity of the Edwards aquifer each vary over several orders of magnitude (detailed in Lindgren and others, 2011b). Local-scale variability in specific capacity, transmissivity, and hydraulic conductivity is likely quite large; even closely spaced measurements might differ by a factor of 1,000 (Hovorka and others, 1998). The difference likely reflects the variable contributions of matrix, fracture, and conduit permeability to the measured average values obtained in aquifer tests. Vertical variations in permeability in the Edwards aquifer indicate that the entire aquifer is highly permeable and highly variable. Anisotropy of an aquifer is indicated when the permeability shows variations with the direction of measurement at any given point in a geologic formation. An anisotropic aquifer will have a dominant permeability in one or more directions depending upon geologic and hydrologic conditions. The quantitative magnitude of anisotropy of the Edwards aquifer is largely unknown but might be influenced by the presence of barrier faults with large vertical displacements and the development of conduits. The amount and distribution of water in the Edwards aquifer are related to the development of porosity and the storage characteristics of the aquifer. Hovorka and others (1996) estimated that Edwards aquifer porosity varies vertically from lows of $4-12$ percent to highs of 20-42 percent, with an average for the entire aquifer of 18 percent. Kuniansky and others (2001) found that an effective porosity of 1-3 percent was needed to match estimated traveltimes derived from geochemical mixing models.

Flowmeter and geophysical data provide insight into hydraulic properties of the Edwards aquifer, specifically with respect to head differences and vertical gradients within the aquifer, as well as with respect to well-field dynamics. An understanding of the effect of pumping conditions on flow in a PSW might contribute to knowledge of how contaminants migrate to the PSW and how contaminant concentrations might vary in time and space. Vertical flow was measured at several discrete depths throughout the portion of the W4 borehole that is open to the Edwards aquifer. Paillet (2000) showed that two quasi-steady flow profiles measured in a borehole can be combined with a measurement of the water-level difference between pumping and nonpumping conditions (drawdown) to calculate estimates of zone transmissivity and far-field hydraulic head conditions. The flowmeter measurements in W4 were calculated by using the drawdown during pumping, the measured flow through the flowmeter tool, and a flow bypass factor by using the diameter of the tool and the borehole diameter at the depth of the measurement. The corrected measurements were entered into an analytical model which utilizes the Thiem equation (Thiem, 1906) and plotted with lines of model fit representing the four dynamic conditions of flow (ambient 1 , ambient 2, moderate, normal). With these lines of model-fitted flow and observed and calculated drawdown, transmissivity was calculated to approximate aquifer conditions at four selected zones in the well. The estimated transmissivity values with increasing depths were

Zone 1: 340-415 ft below LSD, estimated to be 33,901 square feet per day $\left(\mathrm{ft}^{2} / \mathrm{d}\right)$,

Zone 2: 415-600 ft below LSD, estimated to be 2,396 ft²/d, Zone 3: 600-675 ft below LSD, estimated to be $17,693 \mathrm{ft}^{2} / \mathrm{d}$, and

Zone 4: 675-755 ft below LSD, estimated to be $8,339 \mathrm{ft}^{2} / \mathrm{d}$. 
The total transmissivity for the well, estimated as the sum of these four zones, was $62,329 \mathrm{ft}^{2} / \mathrm{d}$. This estimate is consistent with transmissivities estimated by other methods (Lindgren and others, 2004; Lindgren, 2006) for this general area.

The movement of water in the PSW borehole was variable under different pumping conditions. Flowmeter data and resulting estimated hydraulic properties for W4 are shown in figure 7. The large casing diameter (30 in.) and variable borehole diameter (15-36 in.) are shown on the caliper log and represent the enlarged borehole after acidification. The large diameter has an effect on other logs such as the natural gamma and flowmeter logs. The natural gamma counts per second were somewhat lower than expected in the strata penetrated because of the large spherical zone of detection of the natural gamma tool. Flowmeter values also were affected by the variable borehole diameter; therefore, a correction factor was generated for flowmeter values on the basis of the borehole diameter. The correction factor is a calculated flow bypass, which calculates the surface area of the borehole by using caliper data and the surface area of the skirt/tool; the ratio of these is the percentage of flow that the tool measures. Because the borehole diameter varied throughout the borehole, an individual correction factor was calculated for each measurement/ depth. Fluid conductivity and temperature probes are generally used only to measure the fluid flowing through the tool and, thus, do not represent any horizontal variation of the fluid qualities across a large diameter borehole.

Four lines of model fit of the flowmeter data, representing the four dynamic conditions of flow (ambient 1, ambient 2, moderate, normal) are also shown (fig. 7). Arrows indicate the direction of flow under each of the pumping conditions toward the borehole (toward the model line) or away from the borehole (away from the model line) and up or down the borehole. During condition 1 (“ambient 1"), there were small amounts of mostly downward vertical flow in the wellbore (fig. 7). Water entered the borehole from the cyclic and marine members (HGU 3) (between zones 1 and 2), flowed downward, and exited the borehole in the dolomitic member (HGU 10). During condition 2 (“ambient 2") flow in the wellbore was mostly upward. Water was pulled into the borehole from the Kirschberg evaporite member (HGU 8) (zone 3). Flow was upward and exited the borehole in a highly transmissive zone (zone 2) at the top of the leached and collapsed members (HGU 4). During condition 3 ("moderate”), nearly all water entered the borehole from the cyclic and marine members (HGU 3) in the upper part of the well. That flow was subdivided into two zones, coming from zone 1 and above zone 2. During condition 4 ("normal”), flow in the wellbore was complex, with water both entering and exiting. The borehole gained water from the dolomitic member (HGU 10) (zone 4) and Kirschberg evaporite member (HGU 8) (zone 3) in the lower part of the borehole. Some water exited the borehole at the top of the leached and collapsed members (HGU 4) (zone 2). The borehole gained a large amount of water again at the top of the cyclic and marine members (HGU 3) (zone 1).
Fluid conductivity and temperature were logged in the vertical extent of the W4 borehole in ambient conditions, both with the well field off ("ambient 1") and with the well field on (“ambient 2"); differences in fluid conductivity and temperature were minor (less than 1 percent) and close to analytical uncertainties. These results are consistent with other geochemical data that indicate that water from W4 and other wells in the well field is relatively well mixed and homogeneous under a range of pumping conditions. The two deepest monitoring wells in each of the monitoring well clusters (Z-DED and T-DED) were logged in open hole under ambient conditions prior to completion; results are summarized in figures 8 and 9 , respectively. Although logs were collected during ambient conditions, some downward flow ( $8.6 \mathrm{gal} / \mathrm{min})$ was detected in the Z-DED borehole. This flow might have been caused by nearby pumping stress from the PSW well field (approximately $0.5 \mathrm{mi}$ to the west). As discussed above, most of the flow in the PSW entered the wellbore from the leached and collapsed members. Ambient flow in Z-DED also entered the borehole in the leached and collapsed members and exited into the Kirschberg evaporite member. If the two wells were hydraulically connected, then a linkage of outflow to the Kirschberg evaporite member at the Z-DED borehole and inflow to W4 is plausible. Throughout the zone of highest flow in Z-DED, fluid conductance consistently measured about 300 microsiemens per centimeter $(\mu \mathrm{S} / \mathrm{cm})$, and temperature was about $21.0^{\circ} \mathrm{C}$. These results are considerably different from measured values for the monitoring wells (table 7 at end of report) and might reflect differences in measurement tools and calibrations. In the deep Timberhill monitoring well (T-DED), approximately $1.5 \mathrm{mi}$ west of the PSW well field, there was little or no measureable flow throughout the entire section of the well open to the Edwards aquifer. The fluid conductance consistently measured about $500 \mu \mathrm{S} / \mathrm{cm}$, and temperature was about $21.4^{\circ} \mathrm{C}$. This well appeared to have little or no connection to outside pumping stresses, including those from the PSW well field.

\section{Groundwater Occurrence and Movement}

The groundwater flow system of the Edwards aquifer in the San Antonio region includes the Edwards Plateau catchment or contributing zone, the recharge (outcrop) zone, and the confined zone (fig. 1). Streams flowing south and east toward the Gulf of Mexico drain the Edwards Plateau contributing zone and recharge the aquifer by streamflow losses across the Balcones fault zone, where the porous and permeable limestone of the Edwards Group outcrops. The recharge zone consists of approximately 1,250 $\mathrm{mi}^{2}$ of Edwards Group limestone exposed at the surface (Hamilton and others, 2008) (fig. 1). Most stream base flow and much of the stormflow recharges the aquifer through open solution channels (Maclay and Land, 1988). The majority of recharge to the regional aquifer occurs as losing streams flow across the recharge zone, with estimates of recharge from streams ranging from 60 to 80 percent (Klemt and others, 1979; Maclay and Land, 1988; 


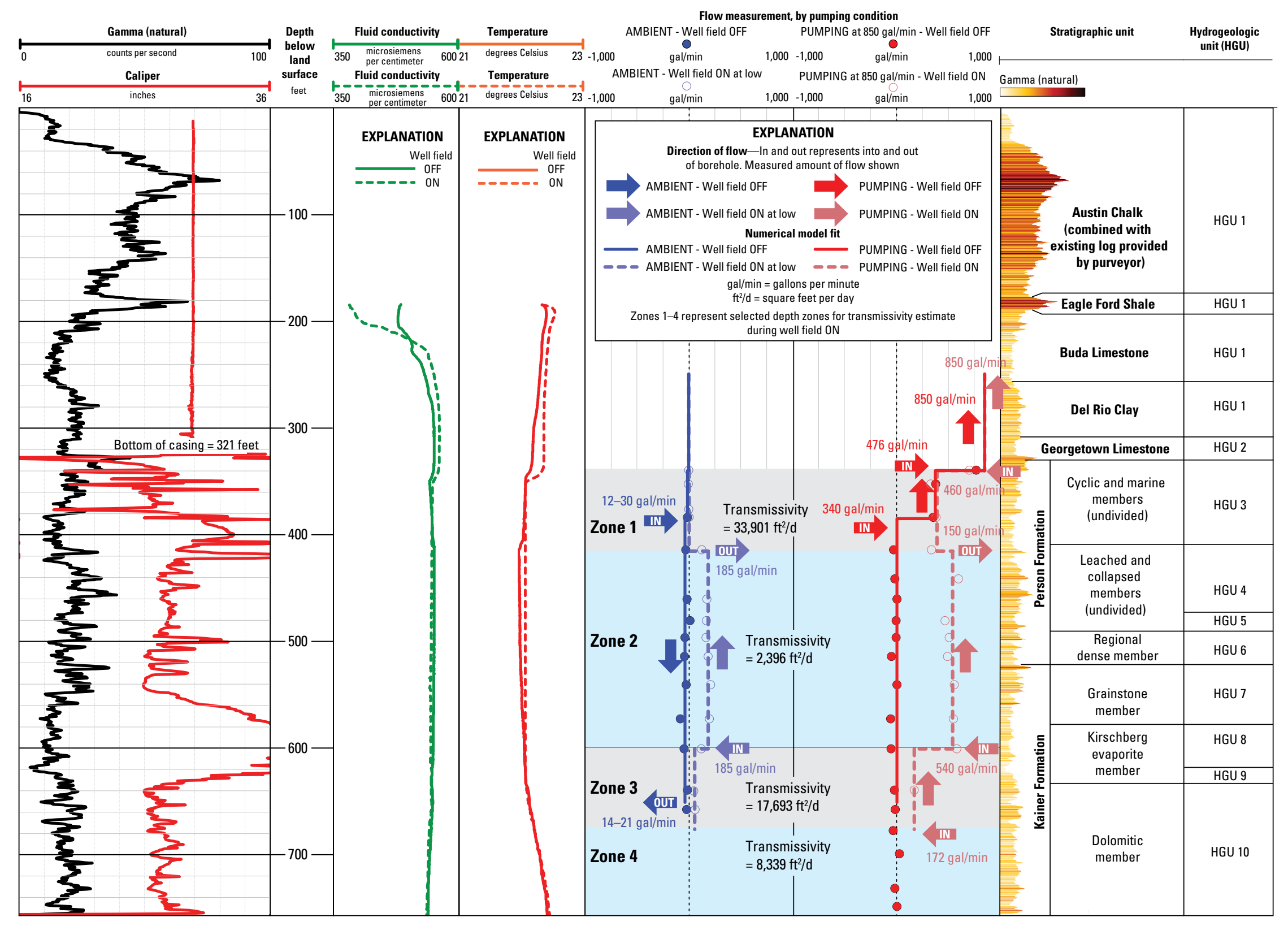

Figure 7. Borehole geophysical data for the public-supply well (W4) near San Antonio, south-central Texas, including, from left to right, natural gamma and caliper logs, fluid conductivity, temperature, flowmeter (under ambient and pumping conditions), stratigraphic unit, and hydrogeologic unit (HGU). 


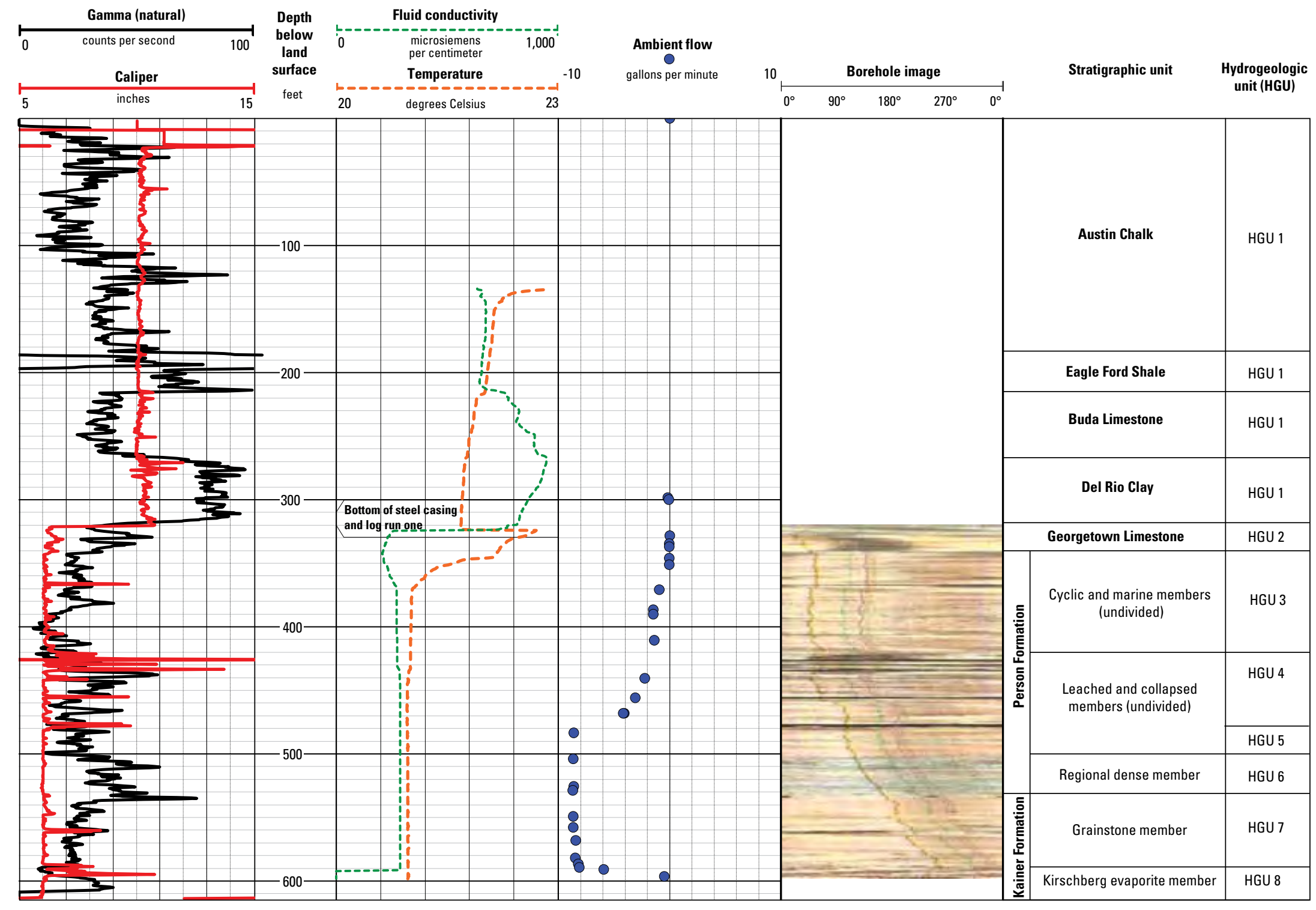

Figure 8. Borehole geophysical data for the deep Zarzamora monitoring well (Z-DED) near San Antonio, south-central Texas, including, from left to right, natural gamma and caliper logs, fluid conductivity and temperature, flowmeter, borehole image, stratigraphic unit, and hydrogeologic unit (HGU). 


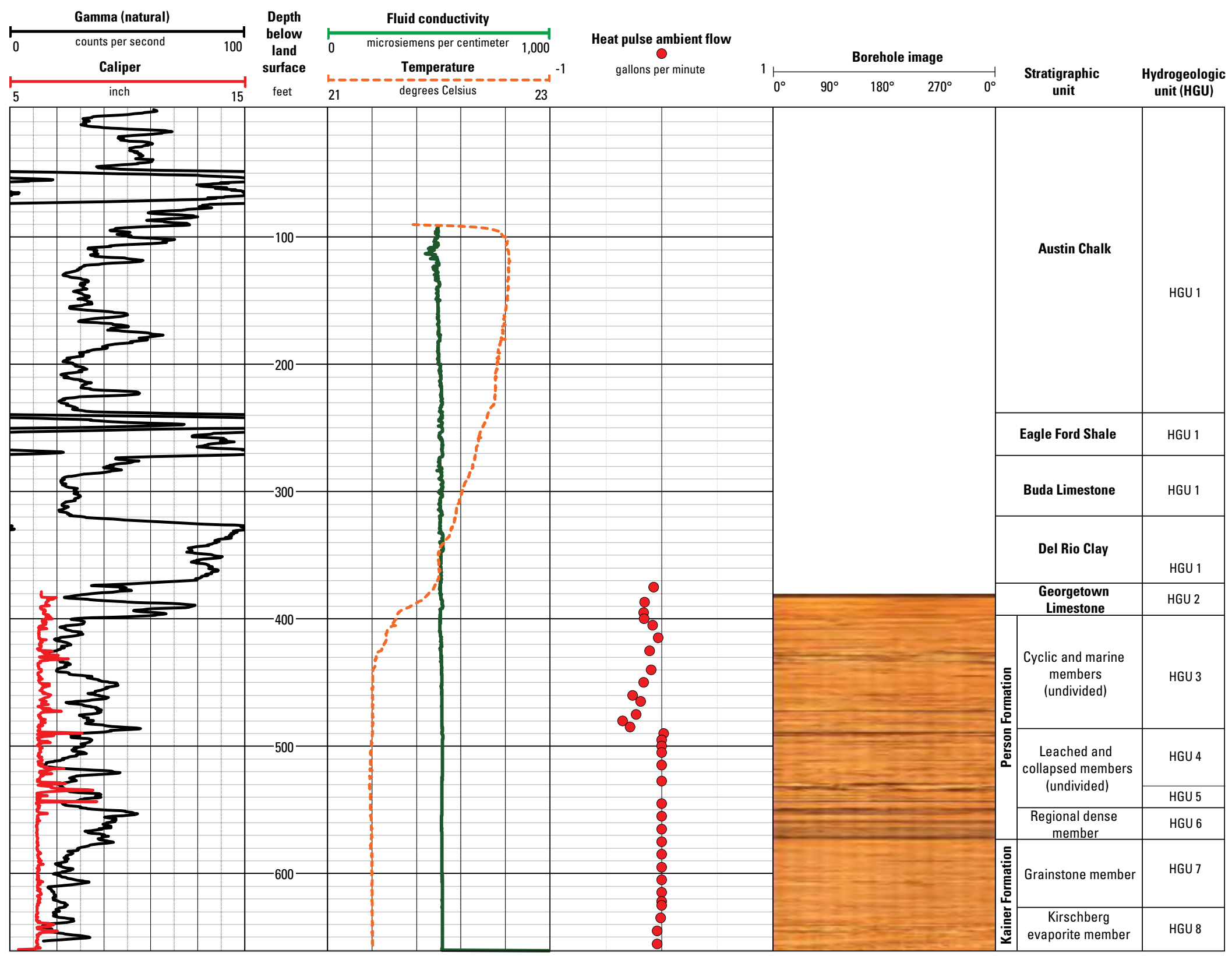

Figure 9. Borehole geophysical data for the deep Timberhill monitoring well (T-DED) near San Antonio, south-central Texas, including, from left to right, natural gamma and caliper logs, fluid conductivity and temperature, flowmeter (no appreciable measured flow), borehole image, stratigraphic unit, and hydrogeologic unit (HGU). 
Thorkildsen and McElhaney, 1992; Ockerman, 2005). Most of the remaining recharge occurs as direct infiltration on the recharge zone, with some recharge occurring by leakage from the underlying Trinity aquifer (Sharp and Banner, 1997; Mace and Hovorka, 2000; Lindgren and others, 2004). Estimates of the combined recharge to the San Antonio segment of the Edwards aquifer from stream seepage and infiltration of rainfall range from a low of 53.9 million cubic meters $\left(\mathrm{m}^{3}\right)$ during 1956 to a high of 3,066 million $\mathrm{m}^{3}$ during 1992 (Hamilton and others, 2003). The long-term (1934-2002) mean annual recharge to the Edwards aquifer is 862.2 million $\mathrm{m}^{3}$ (median 688.1 million $\mathrm{m}^{3}$ ) and for 1993-2002 is 979.6 million $\mathrm{m}^{3}$ (median 710.9 million $\mathrm{m}^{3}$ ) (Hamilton and others, 2003). In the local-scale study area, major streams crossing the recharge zone are the Medina River and Hondo and Salado Creeks (fig. 3). Much of the annual flow of the Medina River is impounded in Medina Lake (U.S. Army Corps of Engineers, 1965). Of the volume impounded, about one-half seeps into the Edwards aquifer from the lake and its irrigation facilities (U.S. Army Corps of Engineers, 1965).

Karst features and faults provide pathways for water to move from stream channels to the water table of the unconfined aquifer in the recharge zone. Water that recharges in the recharge zone moves from the unconfined to confined parts of the aquifer through generally southeasterly flow paths. Regional groundwater flow in the confined zone is to the east and northeast with natural discharge occurring at large springs, predominantly Comal and San Marcos Springs (fig. 1). Conduits are likely major contributors to flow (Hovorka and others, 1998, 2004; Worthington, 2004). Faults can either increase or decrease total transmissivity (Hovorka and others, 1998) and might serve as either conduits or barriers to flow (George, 1952; Holt, 1959; Maclay and Small, 1983, 1984; Maclay and Land, 1988; Maclay, 1995; Groschen, 1996; Clark and Journey, 2006). The potentiometric surface varies considerably depending on hydrologic conditions (fig. 6). Domestic, livestock, municipal, agricultural, and industrial withdrawals, by way of wells, also contribute to groundwater discharge throughout the region (Hamilton and others, 2008). Recharge and discharge are not evenly distributed across the aquifer; most recharge occurs in the westernmost catchments, whereas most discharge occurs in the eastern area. The proportion of discharge by wells relative to springs varies from year to year; springflow typically exceeds well discharge in wet years, and well discharge typically exceeds springflow in dry years (Hamilton and others, 2008). Comal Springs (fig. 1), one of the major aquifer discharge points, is hydrologically isolated from large sources of local recharge (Ogden and others, 1986). As such, Comal Springs represents the integration of the regional flow system of the San Antonio segment of the aquifer, and its flow rate and geochemistry provide an indicator of regional hydrologic conditions. Several wells in the aquifer, such as the Bexar County index well (J-17), intersect major flow paths and respond quickly to changes in recharge and pumping; water-level altitude variations in well $\mathrm{J}-17$ are assumed to reflect Edwards aquifer water-level changes on a regional scale and are also indicative of regional hydrologic conditions. Previous studies indicate that groundwater flow is focused in highly permeable units and is affected by faulting throughout the aquifer (Abbott, 1975; Woodruff and Abbott, 1979; Maclay and Small, 1986; Maclay and Land, 1988; Sharp, 1990).

\section{Potential Sources of Contamination}

Natural contaminants such as As, U, or radon generally are not problematic with respect to public drinking-water quality for the Edwards aquifer. Although these contaminants are commonly detected, they rarely occur at concentrations of concern for drinking-water quality. Nitrate can result from natural and anthropogenic sources, and concentrations might be increasing with the increase in human activities in the region (Musgrove and others, 2010); however, concentrations are not high with respect to drinking-water quality. A small number of organic contaminants are routinely detected in the Edwards aquifer at low concentrations (Musgrove and others, 2010).

Land use often is considered when evaluating potential sources of contaminants to groundwater (Brawley and others, 2000; Hiscock and others, 2007; McMahon and others, 2008). Land use in the recharge zone for the PSW (Lindgren and others, 2011b) is 91.6 percent rangeland and forest, 7.6 percent urban/built-up, and 0.8 percent water, wetland, barren, and agricultural (fig. 10). Agricultural land use in the recharge zone for the PSW is insignificant at 0.04 percent. In the localscale study area, urban/built-up land use is the most likely nonpoint source of potential contaminants.

A database containing locations of points of potential sources of contaminants (PSOCs) was previously compiled by the Texas Commission on Environmental Quality (TCEQ) (written commun., 2006) and examined for the local-scale study area; more than 10,000 PSOCs were identified (fig. 11). Potential sources of contaminants include, but are not limited to, locations that manufacture or store chemicals, cemeteries, retail centers that store and sell chemicals, oilfield-related activities, water and wastewater treatment facilities, landfills, and pipelines. Most of the PSOCs were in the San Antonio metropolitan area, with an additional large number of oilfieldrelated PSOCs in the southern part of the study area overlying the downdip limit of the freshwater zone of the aquifer.

The TCEQ PSOC database (written commun., 2006) was examined specifically for the most frequently detected anthropogenic compounds: atrazine, chloroform, and PCE (figs. 12, 13 , and 14 , respectively), results of which indicate that the urban environment dominates potential sources for these compounds. There were 688 potential point sources of atrazine identified, and most were in the urban San Antonio area. Most of the potential locations were sites of manufacture, sales, or application of pesticides; municipal solid waste facilities; and industrial wastewater outfalls, among others. There were 831 potential point sources of chloroform identified (fig. 13), and most sources were in the San Antonio urban area. Sources of chloroform included municipal solid waste facilities; metal 


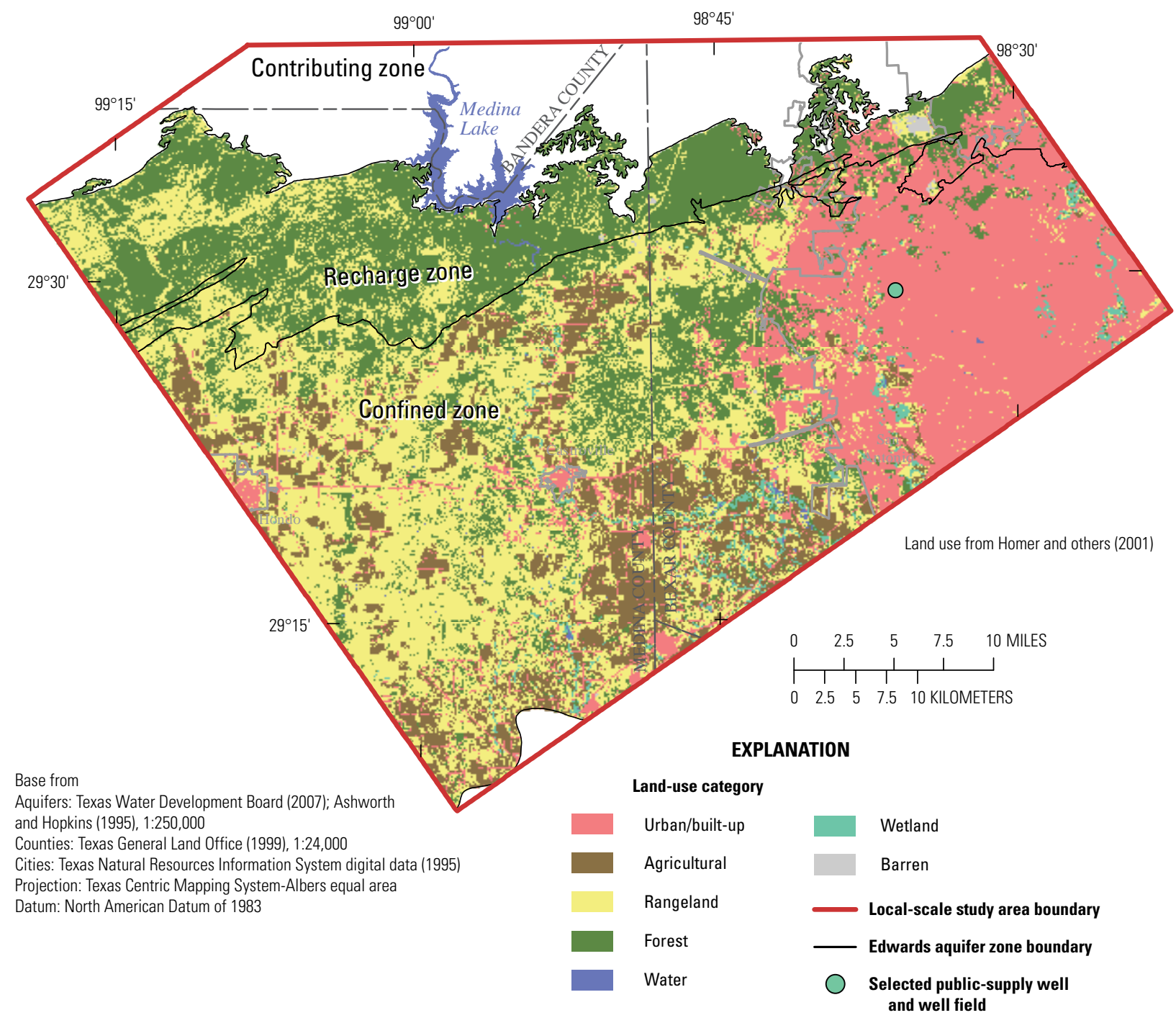

Figure 10. Land use in the local-scale study area for the study of the transport of anthropogenic and natural contaminants (TANC) to public-supply wells, and location of selected public-supply well and well field, near San Antonio, south-central Texas.

plating businesses; industrial wastewater outfalls; pesticide manufacturing, sales, or application locations; pipelines; plastic manufacturing; and wastewater treatment, among others. There were 1,991 potential sources of PCE identified (fig. 14). Like the other compounds, most potential sources of PCE were in the urban area, and a few were in the San Antonio area recharge zone. Potential sources of PCE included air transportation facilities, auto parts and repair businesses, dry cleaners, industrial wastewater outfalls, municipal solid waste facilities, new and used oil sites, paint shops, sites of manufacture or sales of pesticides, and sites of plastic manufacturing, among others. The TCEQ PSOC database provides insight into potential sources of contaminants but is not necessarily comprehensive of all potential sources; additional contaminant sources, for example, include application of pesticides on urban lawns, return flows from treated wastewater applied on the landscape, septic systems, and swimming pools.
An additional potential source of PCE, a U.S. Environmental Protection Agency (USEPA) Superfund site about 2.6 mi northwest of the PWS well field with PCE- and TCEcontaminated groundwater in overburden units, was identified during the time period of the TANC project (U.S. Environmental Protection Agency, 2011; hereinafter, Bandera Road Groundwater Plume). Some groundwater wells, three of which were completed at the top of the Edwards aquifer, contained PCE at concentrations above the USEPA public drinkingwater standard (U.S. Environmental Protection Agency, 2011) ( $5 \mu \mathrm{g} / \mathrm{L}$ ). Model particle tracks indicate that groundwater flow paths in this area are from the contamination site to the southsoutheast toward the well field; however, water-level and dyetracer data in the vicinity of the Bandera Road Groundwater Plume indicate that water might be moving more westward in the area immediately upgradient of the well field and that barrier faults in the vicinity may inhibit flow (C. Villarreal, 


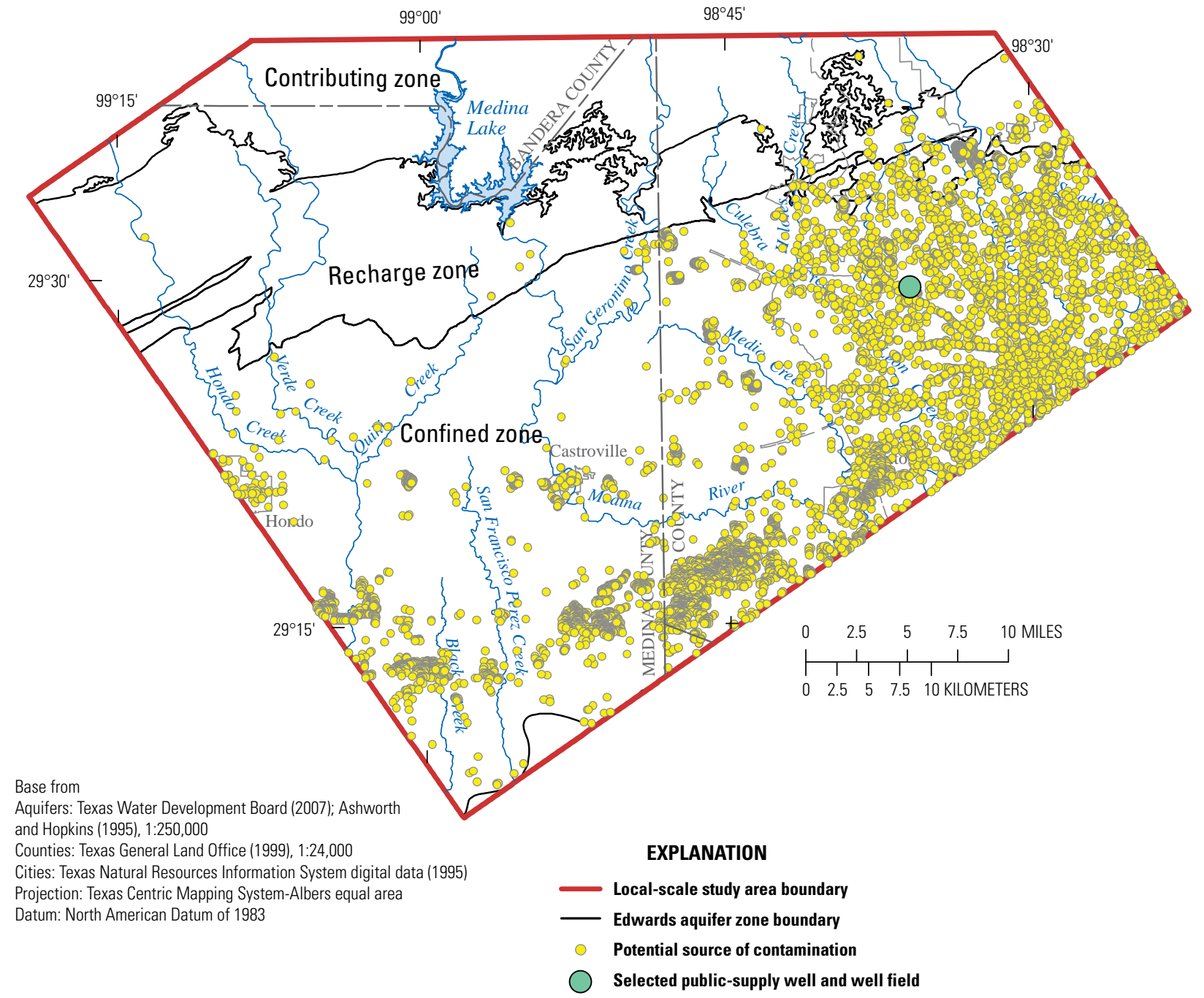

Figure 11. Location of potential sources of contamination (PSOCs) in the local-scale study area for the study of the transport of anthropogenic and natural contaminants (TANC) to public-supply wells, and location of selected public-supply well and well field, near San Antonio, south-central Texas; based on Texas Commission of Environmental Quality potential sources of contamination (PSOC) database (written commun., 2006).

U.S. Environmental Protection Agency, written commun.). The Bandera Road Groundwater Plume is currently (2011) the only identified USEPA superfund site with PCE contamination that is upgradient of the well field. No hydrologic connection between the Bandera Road Groundwater Plume and the well field has been documented, however, and other sources are possible.

\section{Groundwater Chemistry}

This section describes the chemical characteristics of groundwater samples with respect to water types, field parameters, SIs for selected minerals, reduction-oxidation (redox) conditions, dissolved gases, major and trace element and nutrient concentrations, isotopic compositions, organic constituents, and age tracers. Special emphasis is placed on understanding groundwater chemistry in the context of waterrock interaction processes, groundwater flow patterns and flow paths, residence time, and mixing, and temporal variations in groundwater chemistry.

\section{Field Parameters}

Field parameter (physicochemical) data indicated that well-field and monitoring well samples are representative of groundwater in the regional confined aquifer. The well-field and monitoring well samples had relatively narrow ranges in field parameters (table 7) with median values for specific conductance, $\mathrm{pH}$, temperature, dissolved oxygen concentration, 


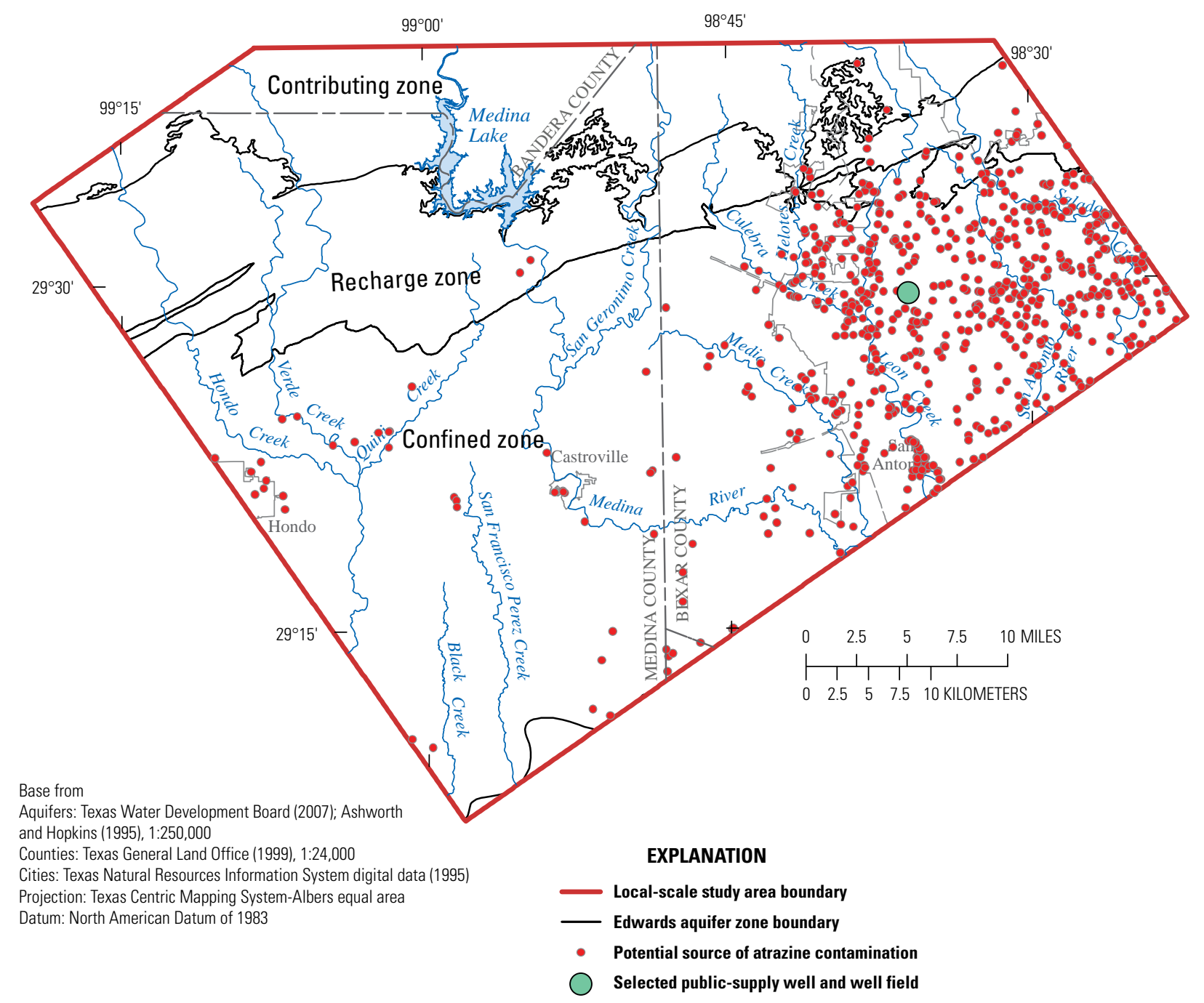

Figure 12. Location of potential sources of atrazine contamination in the local-scale study area for the study of the transport of anthropogenic and natural contaminants (TANC) to public-supply wells, and location of selected public-supply well and well field, near San Antonio, south-central Texas; based on Texas Commission of Environmental Quality potential sources of contamination (PSOC) database (written commun., 2006).

and alkalinity $\left(\mathrm{CaCO}_{3}\right)$ of $586 \mu \mathrm{S} / \mathrm{cm}, 7.1,24.0^{\circ} \mathrm{C}, 4.3 \mathrm{mg} / \mathrm{L}$, and $258 \mathrm{mg} / \mathrm{L}$, respectively. The sample collected from the overburden well (Z-OVB) was chemically distinct from the well-field and monitoring well samples, with higher specific conductance $(971 \mu \mathrm{S} / \mathrm{cm})$ and temperature $\left(28.3^{\circ} \mathrm{C}\right)$ values. These results indicate that the overburden unit is likely not a dominant source of water to the PSW or the aquifer in the study area. Measured values for field parameters for the wellfield and monitoring well samples were otherwise similar to those measured for regional aquifer PSWs (table 7), as well as those described by Musgrove and others (2010) for the regional aquifer.

Results for several field parameters for samples from regional (confined) aquifer PSWs were correlated with well depth; both $\mathrm{pH}$ and temperature increase with well depth
(Kendall's tau $=0.26$ and 0.39 , respectively), whereas specific conductance and alkalinity decrease with well depth (Kendall's tau $=-0.35$ and -0.33 , respectively) (fig. 15). The relation between dissolved oxygen concentration and well depth was not statistically significant. These relations between field parameters and well depth were not evident for the monitoring wells, although the monitoring wells cover a more limited depth range than do the regional aquifer PSWs. The observed relation of decreasing specific conductance with depth for samples from the regional (confined) aquifer PSWs is somewhat counterintuitive. In the absence of other sources of salinity, specific conductance values would be expected to generally increase along aquifer flow paths as a result of progressive mineral-solution reactions. Additionally, deeper groundwater in the Edwards aquifer can be affected by mixing with more 


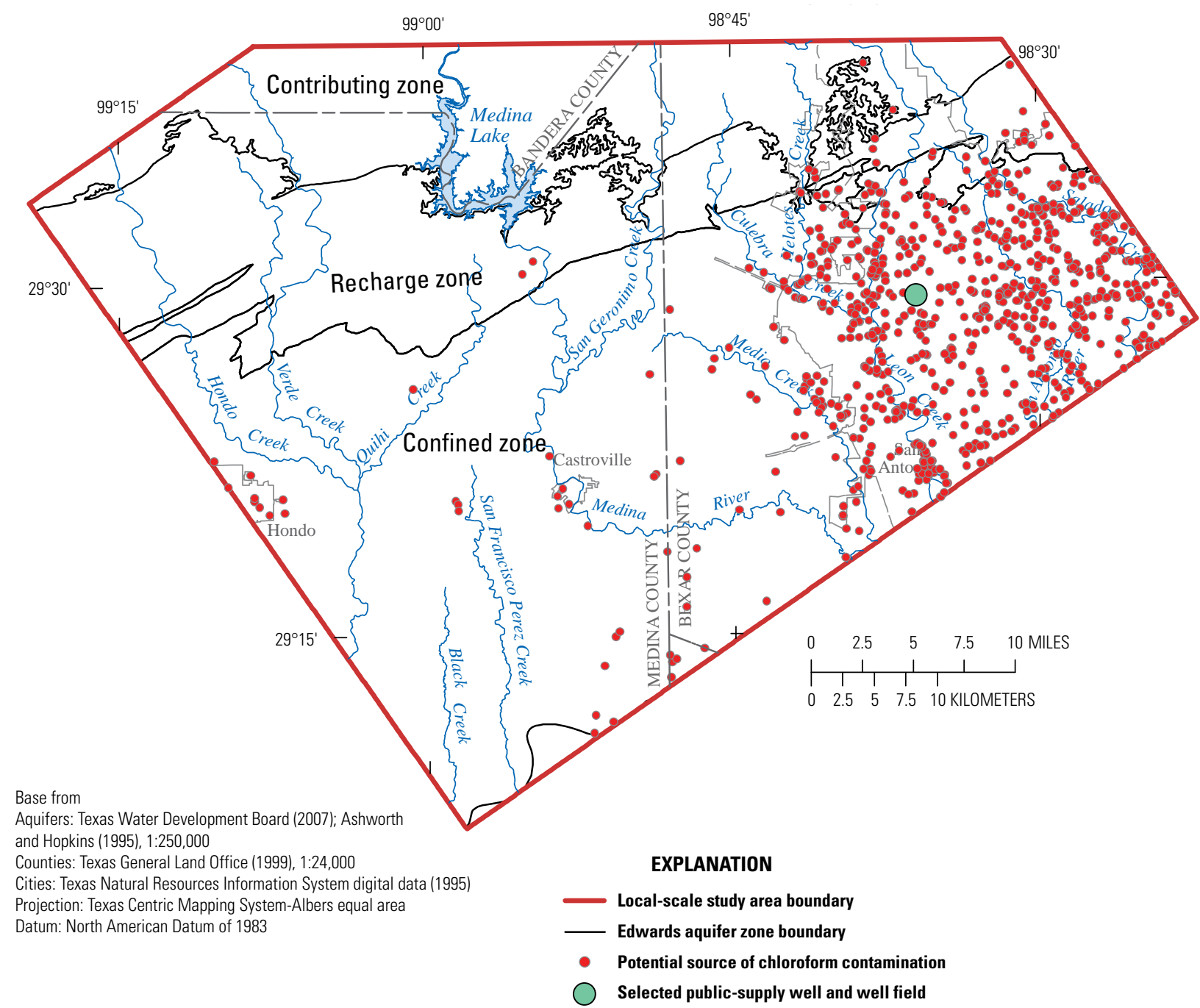

Figure 13. Location of potential sources of chloroform contamination in the local-scale study area for the study of the transport of anthropogenic and natural contaminants (TANC) to public-supply wells, and location of selected public-supply well and well field, near San Antonio, south-central Texas; based on Texas Commission of Environmental Quality potential sources of contamination (PSOC) database (written commun., 2006).

saline downdip water. However, at the regional aquifer scale, specific conductance values in shallow/urban unconfined Edwards aquifer groundwater samples are higher relative to deeper unconfined and confined groundwater samples, which indicates that urban land use affects water quality and might be a potential source of dissolved constituents to groundwater (Musgrove and others, 2010).

\section{Chemical Composition and Mineral Saturation Indexes}

Groundwater samples from the well-field and monitoring wells and regional aquifer PSWs exhibited a relatively narrow range in major ion compositions. A trilinear ("Piper”) diagram
(Piper, 1953) is a useful tool for evaluating the relative abundance of major cations and anions and classifying major water types. Groundwater samples are mostly a dilute calcium bicarbonate facies, with similar compositions in all sample types and locations (well-field wells, monitoring wells, and regional aquifer PSWs) except the overburden monitoring well (Z-OVB) (fig. 16). Regional aquifer PSW samples show the most variability, with cation concentrations ranging between about 20-40 percent $\mathrm{Mg}$ and between about 60-80 percent Ca (fig. 16). With respect to anions, groundwater composition is less variable. $\mathrm{Cl}$ concentration exceeds 20 percent in only the overburden monitoring well.

Saturation indices (SIs) with respect to calcite, dolomite, and gypsum reflect the carbonate mineralogy of the aquifer host rocks (fig. 17; table 8 at end of report). All groundwater 


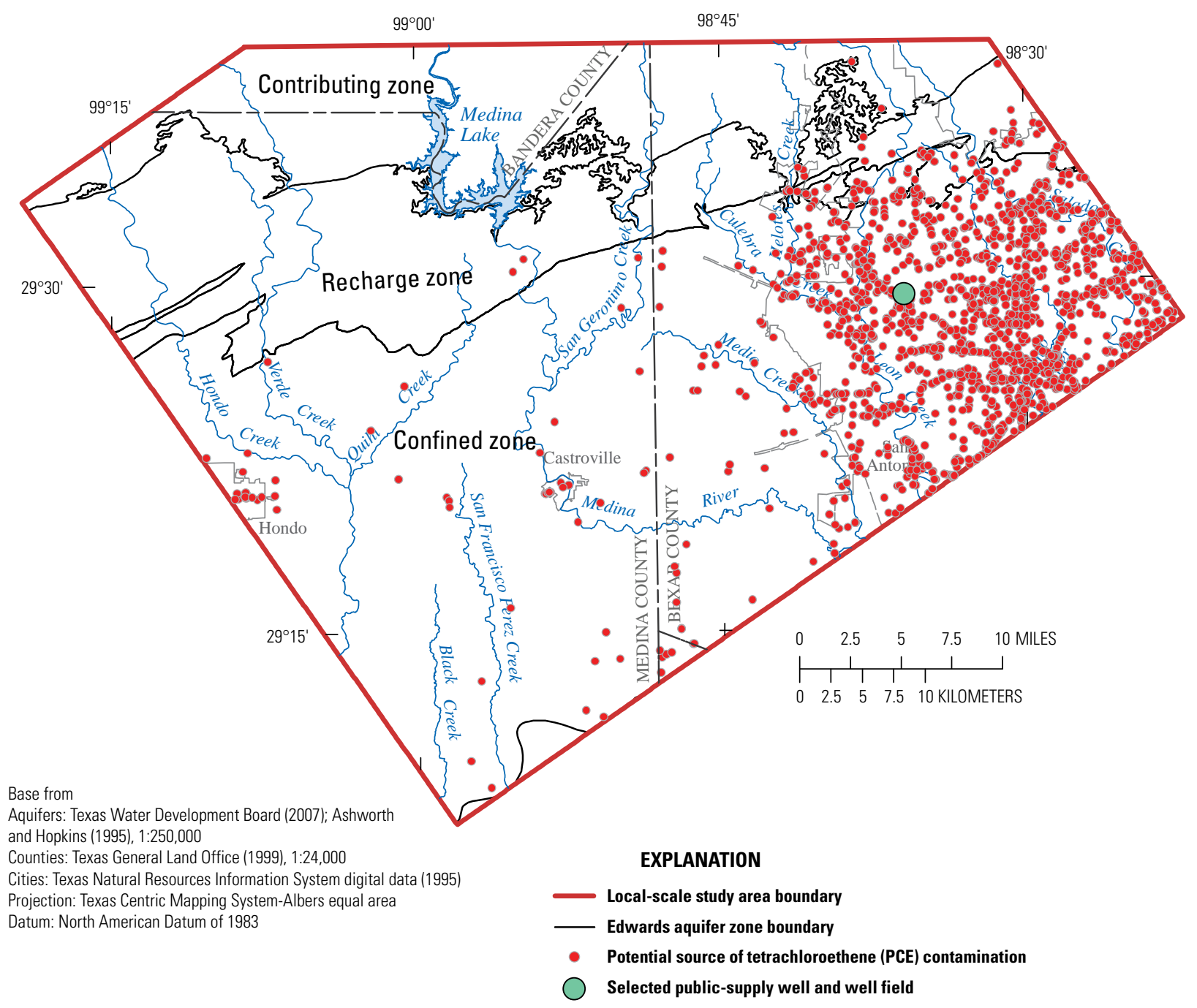

Figure 14. Location of potential sources of tetrachloroethene (PCE) contamination in the local-scale study area for the study of the transport of anthropogenic and natural contaminants (TANC) to public-supply wells, and location of selected public-supply well and well field, near San Antonio, south-central Texas; based on Texas Commission of Environmental Quality potential sources of contamination (PSOC) database (written commun., 2006).

samples were near saturation with respect to calcite ( -0.5 to 0.5 ) and very undersaturated with respect to gypsum (less than -1.7). Dolomite SIs range from undersaturated to near saturation. Dolomite SIs for samples from the well-field and monitoring wells were mostly near saturation to undersaturated $(-0.48$ to -0.11 , median $=-0.28)$, whereas results for the regional aquifer PSW samples have a larger range (-1.36 to 0.26 , median $=-0.34$ ) and are correlated with well depth (fig. 17; Kendall's tau =0.25). Musgrove and others (2010) reported that water from the confined part of the aquifer is generally closer to equilibrium than is water from the unconfined part of the aquifer with respect to calcite and dolomite, reflecting greater extents of water-rock interaction. Increasing dolomite SIs in the regional Edwards aquifer have been previously proposed to be an indicator of increasing extents of progressive water-rock interaction processes and relative groundwater residence time (Musgrove and others, 2010). This hypothesis is further supported by the correlation between dolomite SIs and $\mathrm{Mg} / \mathrm{Ca}$ molar ratios for regional groundwater as discussed in Musgrove and others (2010) and the correlation shown for regional aquifer PSWs (a subset of the regional groundwater wells detailed in Musgrove and others, 2010) in fig. 18 (Kendall's tau $=0.35$ ). This relation is not evident in the well-field and monitoring wells (fig. 18), which cover a more limited depth range than do the regional aquifer PSWs.

\section{Major Elements and Trace Metals}

Major element concentrations and groundwater facies (fig. 16) associated with samples collected from regional 

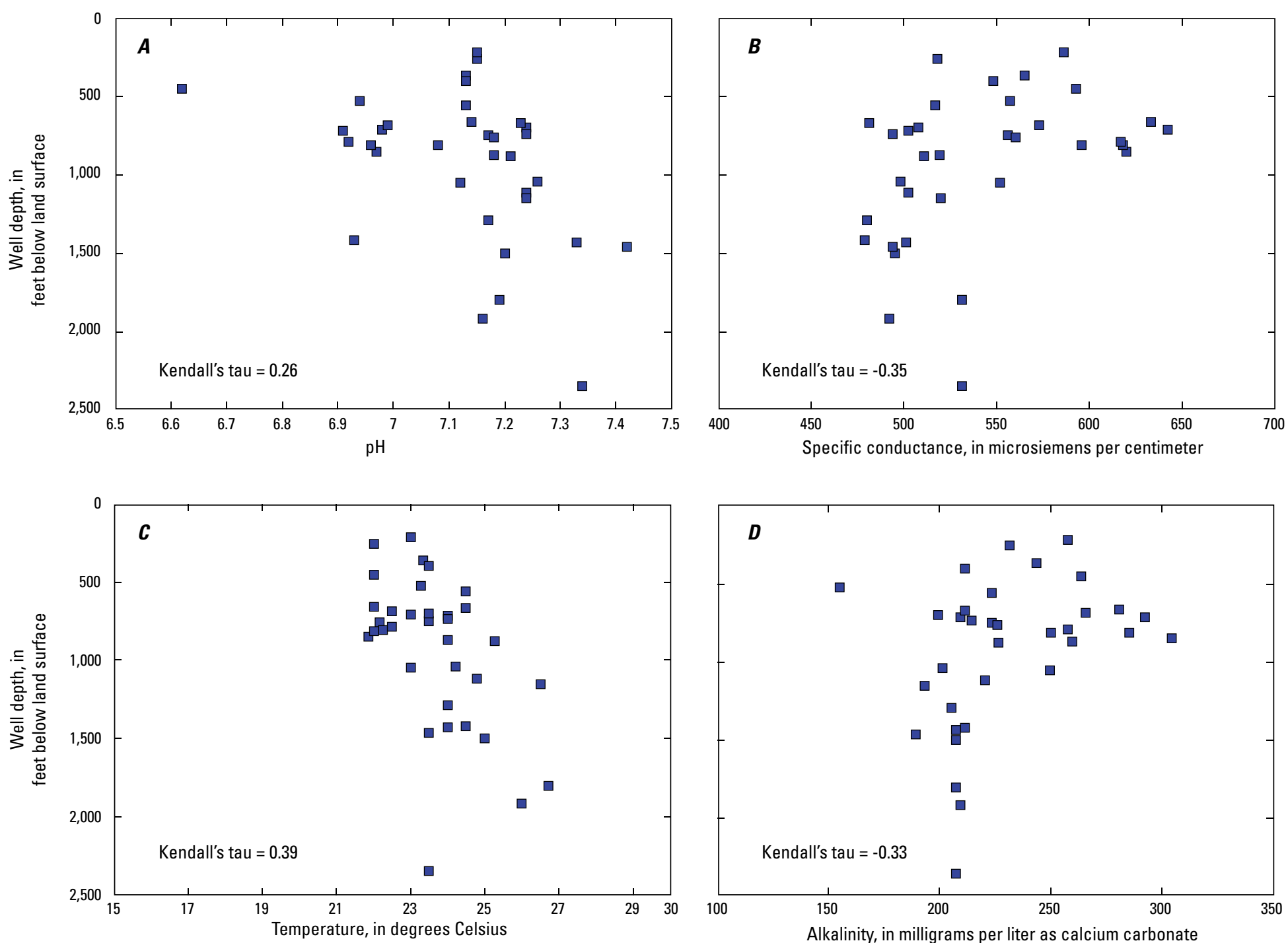

\section{EXPLANATION}

— Regional public-supply well

(confined aquifer)

Figure 15. Relation between well depth and selected physicochemical and geochemical constituents for groundwater samples collected from regional aquifer public-supply wells in the confined part of the San Antonio segment of the Edwards aquifer, south-central Texas, 2004-5. $A$, pH. $B$, Specific conductance. $C$, Temperature. $D, A$ lkalinity. 


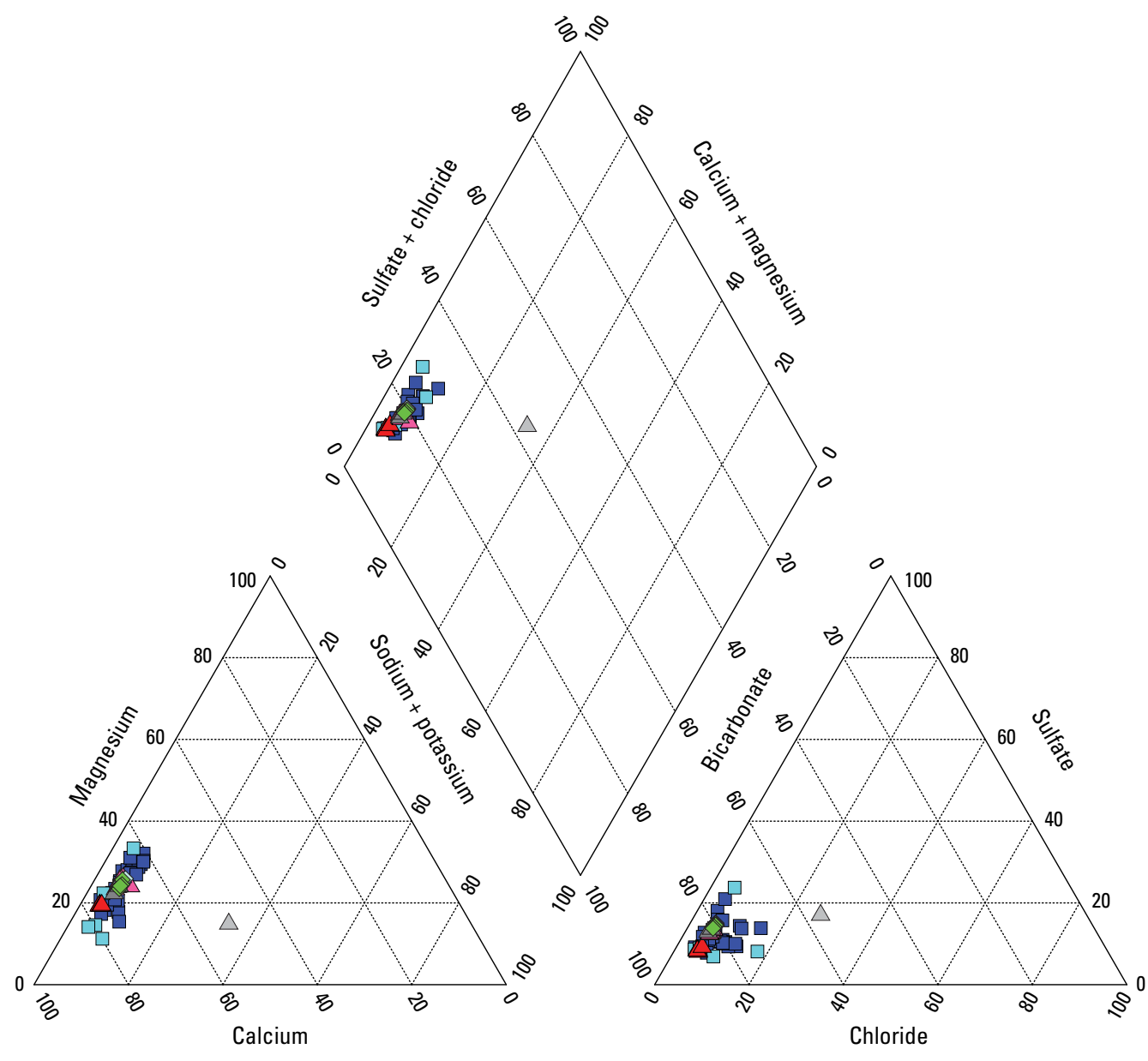

PERCENT

\section{EXPLANATION}

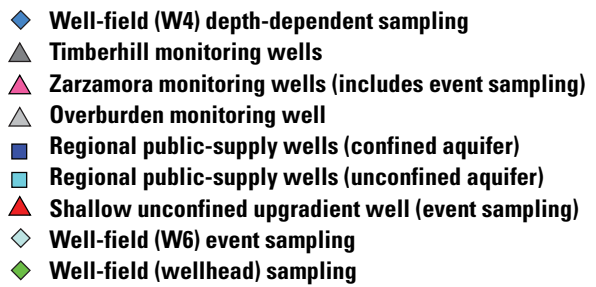

Figure 16. Piper or trilinear diagram showing relations between major cations and anions for groundwater samples collected for the study of the transport of anthropogenic and natural contaminants (TANC) to public-supply wells, south-central Texas, 2004-9.

aquifer PSWs, well-field wells, and monitoring wells reflect the carbonate composition of the aquifer host rock and carbonate geochemical reactions. As noted earlier, major element concentrations (table 8) and groundwater facies for TANC study samples, with the exception of the overburden monitoring well, showed little variation (fig. 16). Geochemical processes of water-rock interaction and progressive groundwater evolution in carbonate groundwater (for example, by processes of calcite recrystallization, incongruent dolomite dissolution, and prior precipitation of calcite along flow paths) can result in increases in $\mathrm{Mg} / \mathrm{Ca}$ and $\mathrm{Sr} / \mathrm{Ca}$ molar ratios with increasing groundwater residence time over multiple time scales (Plummer, 1977; Trudgill and others, 1980; Lohmann, 1988; Fairchild and others, 2000; Musgrove and Banner, 2004). Given this evolution pathway, $\mathrm{Mg} / \mathrm{Ca}$ and $\mathrm{Sr} / \mathrm{Ca}$ ratios typically increase along flow paths with increasing extents of water-rock interaction. Fluid evolution and water-rock interaction processes noted from the results of this study are consistent with results for the regional Edwards aquifer as discussed in Musgrove and others (2010). Calcium 


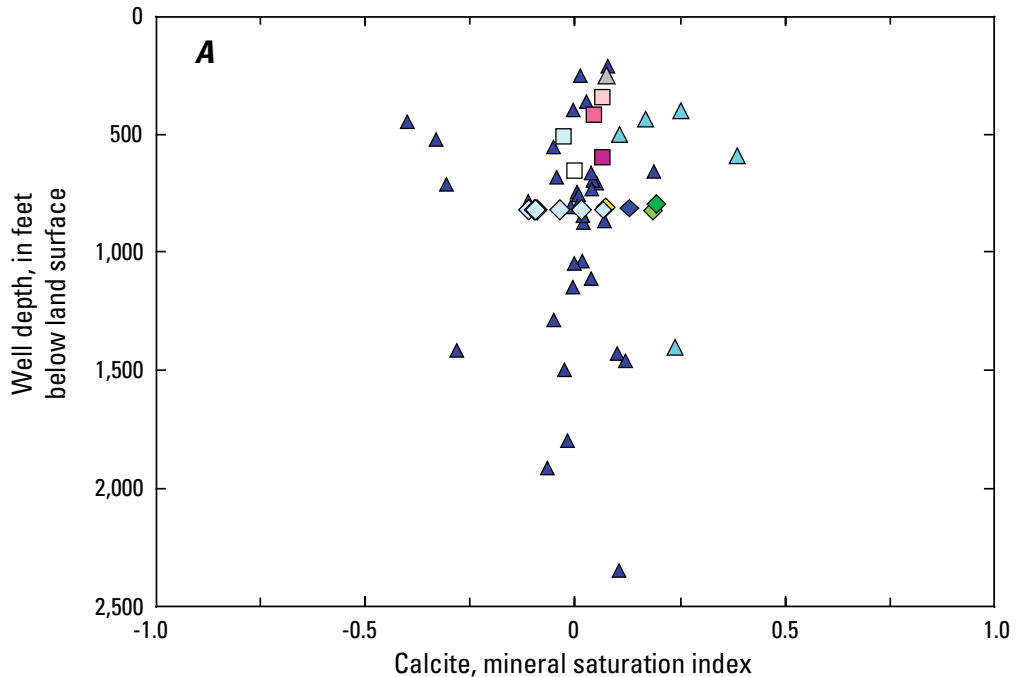

\section{EXPLANATION}

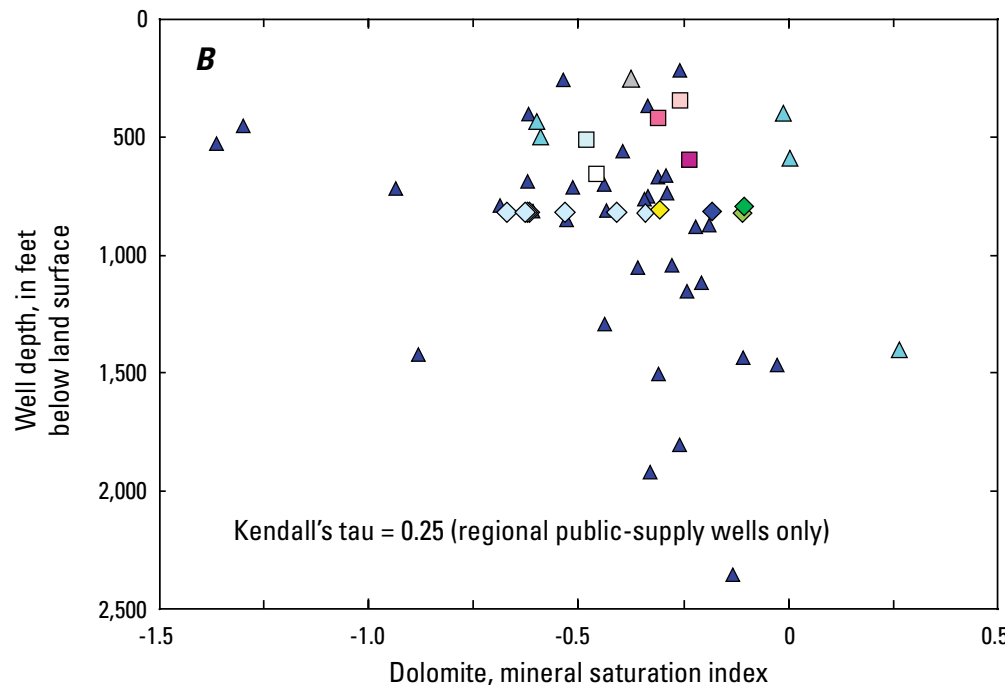

\footnotetext{
Timberhill monitoring well sample

$\square \quad$ Intermediate (T-IED)

$\square \quad$ Deep (T-DED)

Zarzamora monitoring well sample

$\square \quad$ Shallow (Z-SED)

$\square \quad$ Intermediate (Z-IED)

- Deep (Z-DED)

$\triangle \quad$ Overburden monitoring well (Z-OVB) sample
}

Regional public-supply well sample

$\Delta \quad$ Confined

$\triangle$ Unconfined

Well-field (wellhead) well sample

$\diamond \quad$ W2

$\diamond \quad$ W3

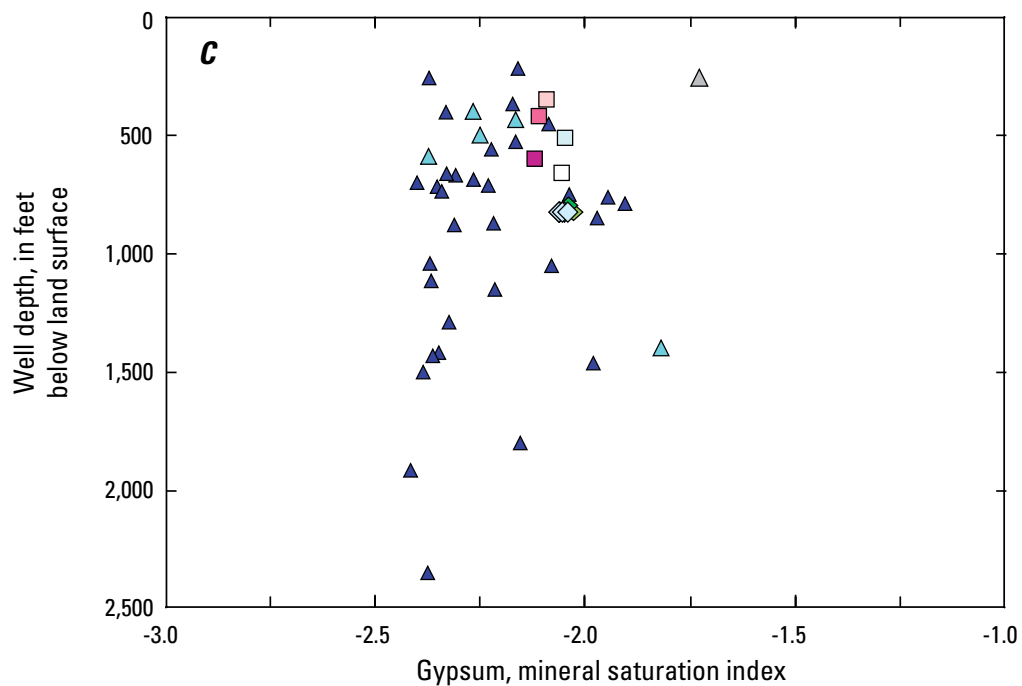

$\diamond \quad$ W4

$\diamond \quad$ W5

$\diamond \quad W_{6}$

Figure 17. Relation between well depth and selected mineral saturation indexes for groundwater samples collected for the study of the transport of anthropogenic and natural contaminants (TANC) to public-supply wells, south-central Texas, 2004-9. $A$, Calcite. $B$, Dolomite. C, Gypsum. 

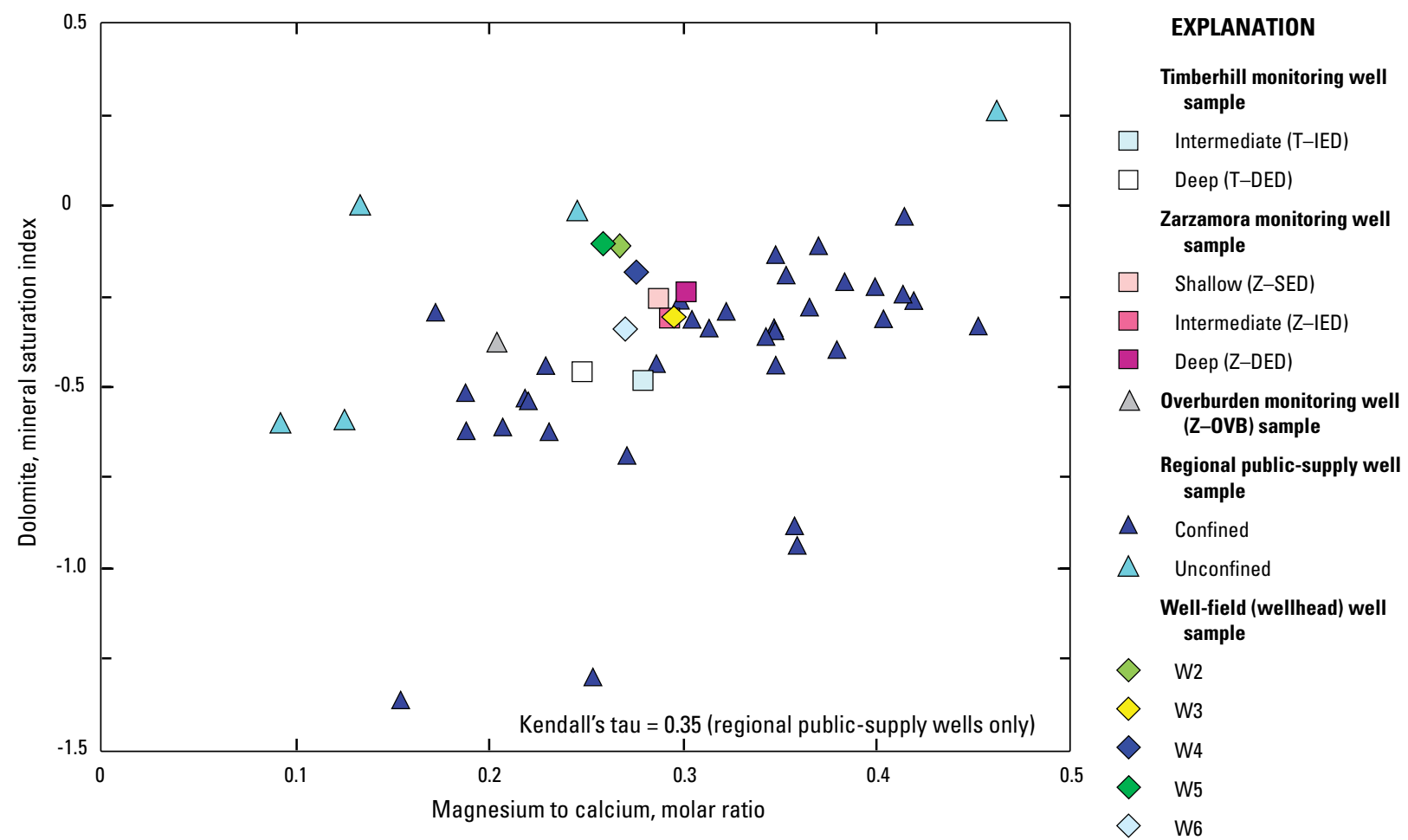

Figure 18. Relation between magnesium to calcium molar ratio and dolomite mineral saturation index for groundwater samples collected for the study of the transport of anthropogenic and natural contaminants (TANC) to public-supply wells, south-central Texas, $2004-9$.

concentrations in regional aquifer PSW samples decreased with depth and were negatively correlated with $\mathrm{Mg} / \mathrm{Ca}$ and $\mathrm{Sr} /$ Ca ratios (fig. 19). Mineral-solution reactions, including the precipitation of calcite along flow paths, can result in increasing $\mathrm{Mg} / \mathrm{Ca}$ and $\mathrm{Sr} / \mathrm{Ca}$ ratios with respect to Ca concentrations (fig. 19). $\mathrm{Mg} / \mathrm{Ca}$ and $\mathrm{Sr} / \mathrm{Ca}$ ratios for regional groundwater samples increased with depth (fig. 20), which is indicative of greater extents of water-rock interaction associated with longer flow paths. $\mathrm{Mg} / \mathrm{Ca}$ and $\mathrm{Sr} / \mathrm{Ca}$ ratios for TANC groundwater samples were well correlated (Kendall's tau $=0.78$ ). Other than for carbonate-associated elements (Ca, Mg, Sr), major element and trace metal concentrations and elemental ratios (such as $\mathrm{Cl}$ to bromide $(\mathrm{Cl} / \mathrm{Br})$ ) are not strongly correlated with depth. Sr concentrations were well correlated with lithium and $\mathrm{F}$ concentrations (Kendall's tau $=0.55$ and 0.50 , respectively) in regional aquifer PSW samples. These relations might be an indication of small amounts of mixing with downdip saline-zone groundwater, which has relatively high concentrations of these constituents.

Natural contaminants such as $U$ and As are a waterquality concern in some aquifer systems, but in the Edwards aquifer these constituents generally have low and relatively uniform concentrations (table 9 at end of report). The USEPA maximum contaminant level (MCL) is $30 \mu \mathrm{g} / \mathrm{L}$ for $\mathrm{U}$ and is $10 \mu \mathrm{g} / \mathrm{L}$ for As. Uranium and As concentrations in well-field well, monitoring well, and regional aquifer PSW samples are well below these MCLs. Uranium concentrations range from 0.56 to $1.17 \mu \mathrm{g} / \mathrm{L}$, with a median value of $0.84 \mu \mathrm{g} / \mathrm{L}$. Arsenic concentrations range from 0.31 to $0.75 \mu \mathrm{g} / \mathrm{L}$, with a median value of $0.44 \mu \mathrm{g} / \mathrm{L}$.

Both $\mathrm{U}$ and As concentrations in aquifer host rock core samples were generally low (less than 3 milligrams per kilogram (mg/kg)), with one higher As value of $9.9 \mathrm{mg} / \mathrm{kg}$ measured in the leached and collapsed members) (table 5). The oxidation of pyrite in limestone is a potential source of As (Appelo and Postma, 2005). Pyrite is a recognized trace mineral in the Edwards Group downgradient of the freshwater/ saline-water transition zone but is generally not present in the Edwards Group in the freshwater part of the aquifer (Maclay and Small, 1983). U and As concentrations do not vary significantly with depth in regional aquifer PSWs or in the monitoring wells.

\section{Oxidation-Reduction Conditions}

Oxidation-reduction (redox) conditions are an important control on geochemical processes in groundwater that affect a variety of contaminants, including the speciation of elements such as As, iron (Fe), and sulfur and the transformation/ biodegradation of $\mathrm{NO}_{3}$ and some organic compounds. Redox 

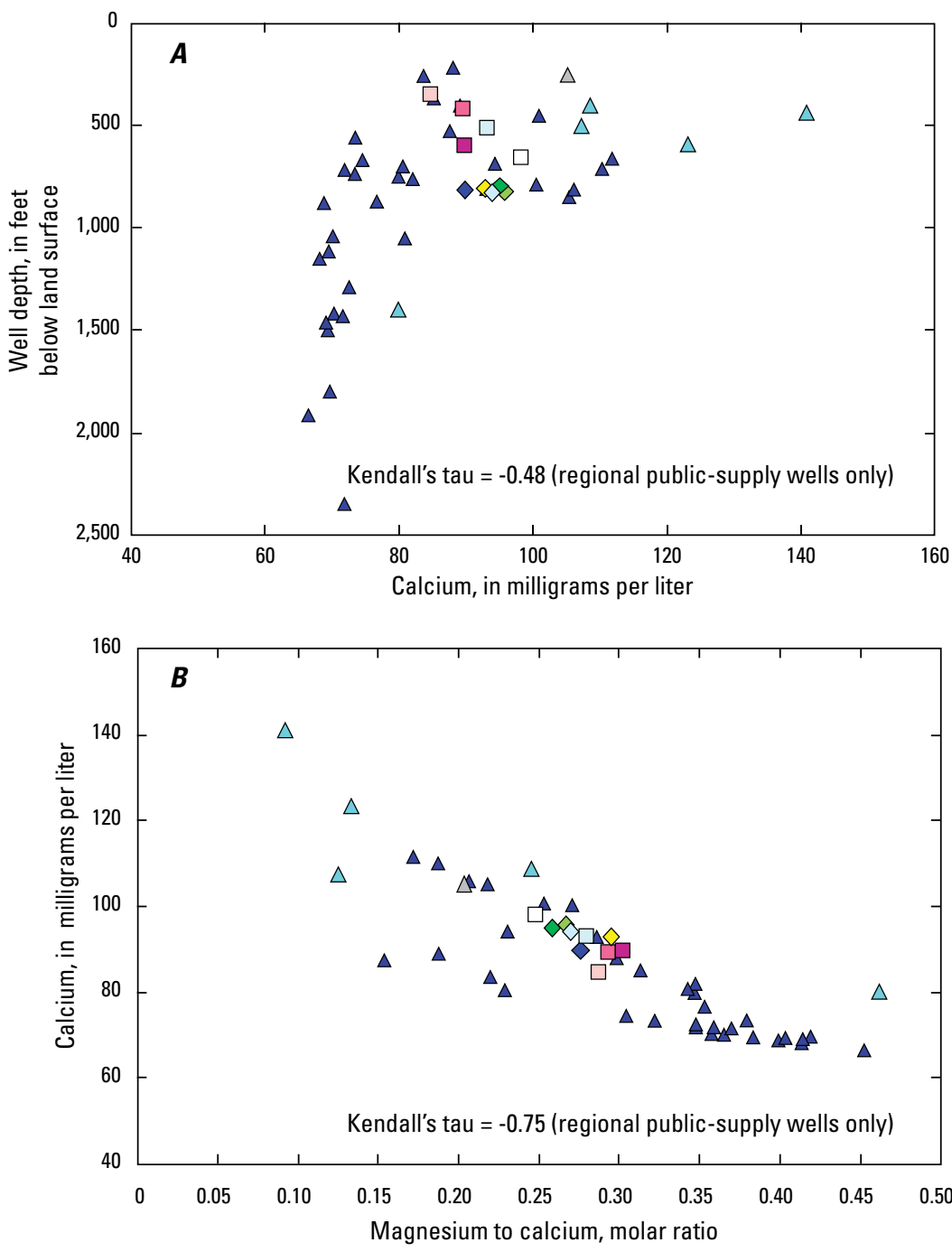

\section{EXPLANATION}
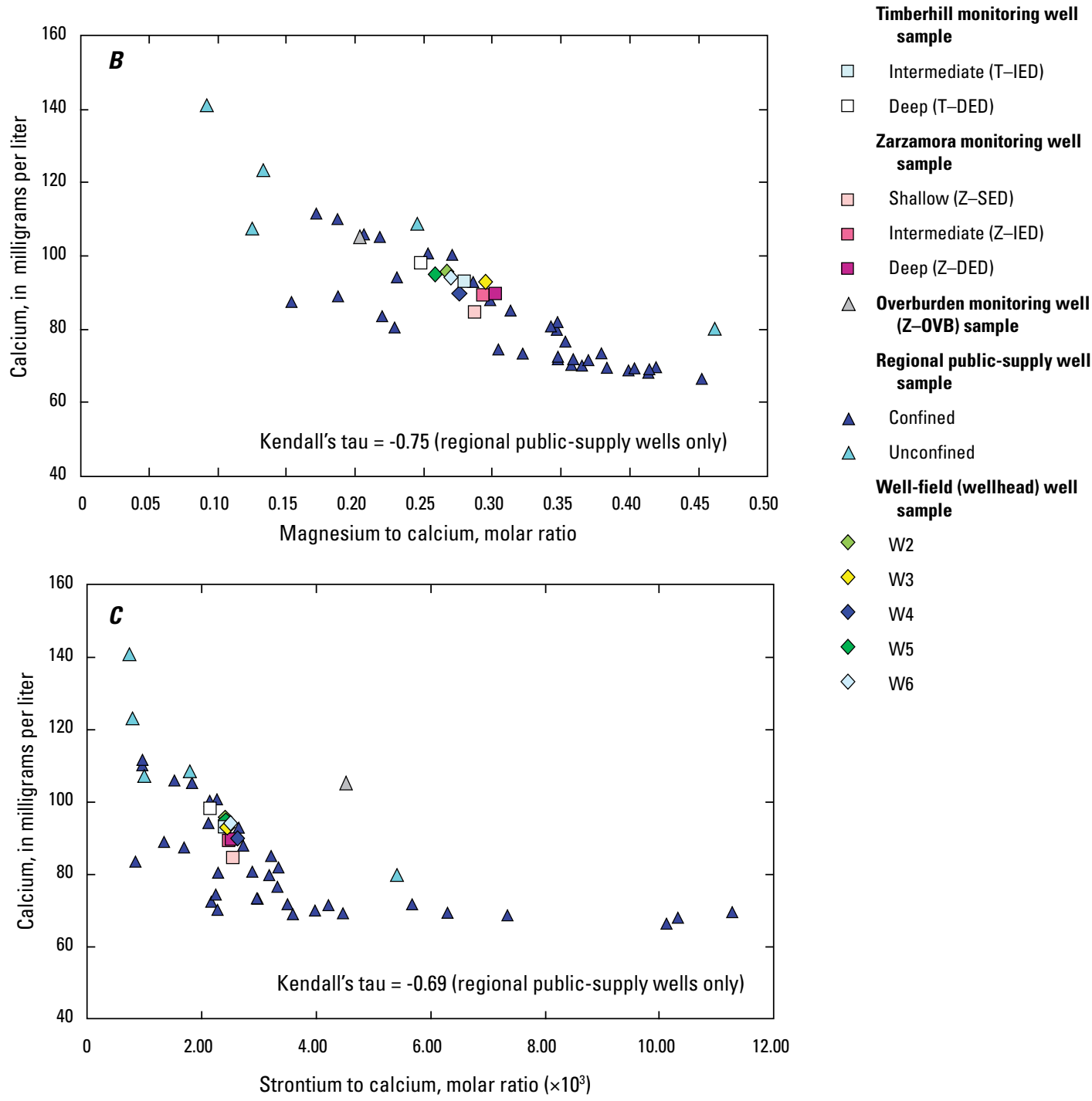

Figure 19. Relation between well depth and selected geochemical constituents or between calcium and selected geochemical constituents for groundwater samples collected for the study of the transport of anthropogenic and natural contaminants (TANC) to public-supply wells, south-central Texas, 2004-9. $A$, Relation between well depth and calcium concentration. $B$, Relation between magnesium to calcium molar ratio and calcium concentration. $C$, Relation between strontium to calcium molar ratio $\left(\times 10^{3}\right)$ and calcium concentration. 

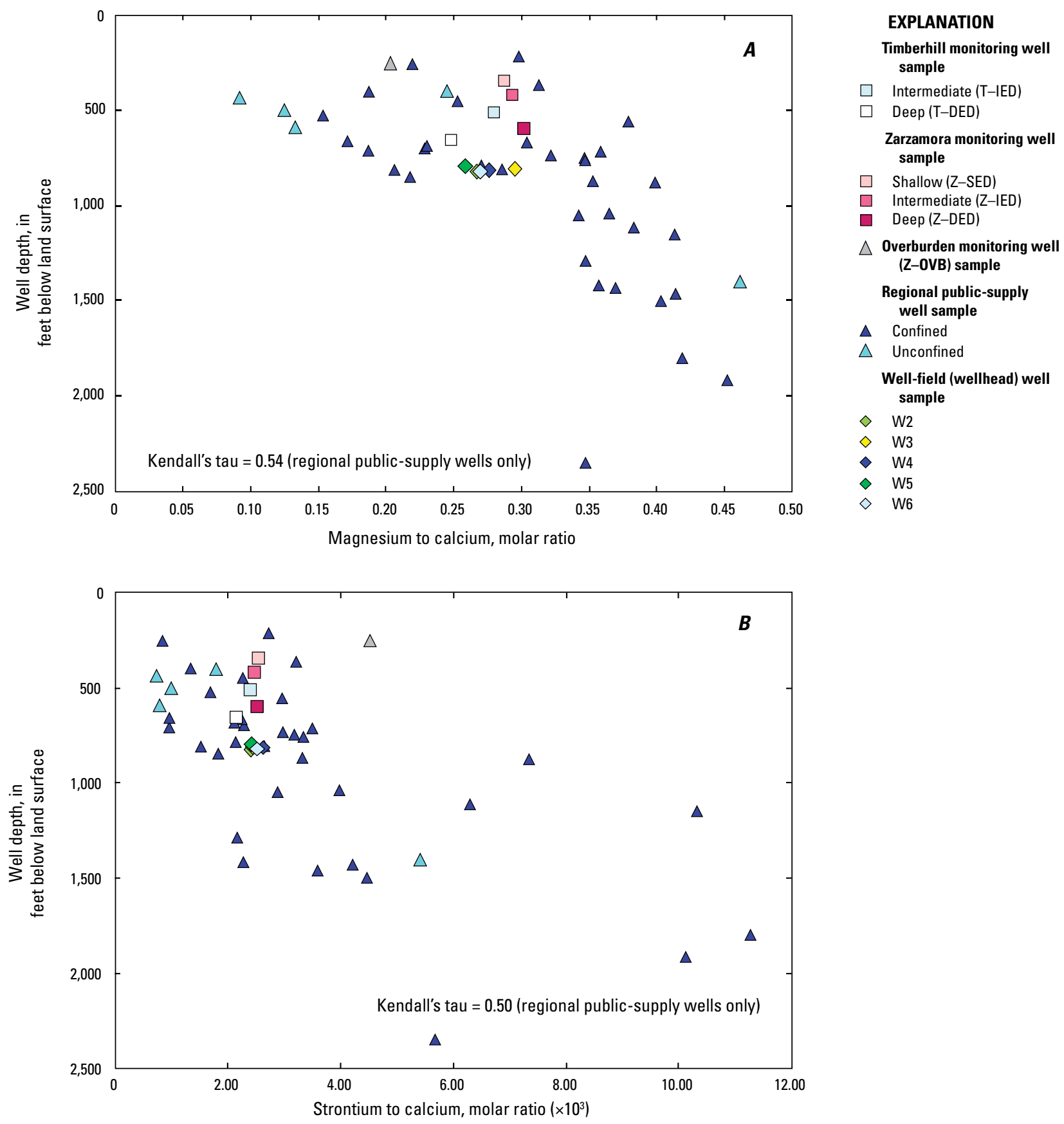

Figure 20. Relation between well depth and selected geochemical constituents for groundwater samples collected for the study of the transport of anthropogenic and natural contaminants (TANC) to public-supply wells, south-central Texas, 2004-9. A, Magnesium to calcium molar ratio. $B$, Strontium to calcium molar ratio $\left(\times 10^{3}\right)$.

conditions in groundwater were evaluated with the classification of McMahon and Chapelle (2008) by using the software of Jurgens and others (2009), which is based on concentrations of dissolved oxygen, $\mathrm{NO}_{3}$, manganese $(\mathrm{Mn}), \mathrm{Fe}, \mathrm{SO}_{4}$, and sulfide $\left(\mathrm{H}_{2} \mathrm{~S}\right)$. On the basis of this redox classification, it was found that the freshwater part of the San Antonio segment of the Edwards aquifer is generally oxic (oxygen reducing), which is defined by concentrations of dissolved oxygen greater than $0.5 \mathrm{mg} / \mathrm{L}$, Mn less than $0.05 \mathrm{mg} / \mathrm{L}$, and Fe less than $0.1 \mathrm{mg} / \mathrm{L}\left(\mathrm{NO}_{3}\right.$ and $\mathrm{SO}_{4}$ concentrations are not considered when dissolved oxygen concentration is greater than $0.5 \mathrm{mg} / \mathrm{L}$ ). Dissolved oxygen concentrations in the regional aquifer PSW samples ranged from 1.53 to $9.39 \mathrm{mg} / \mathrm{L}$, with a median value of $5.1 \mathrm{mg} / \mathrm{L}$ (table 7). Conditions are oxic in the local-scale study area, with a median dissolved oxygen value similar to that for the regional aquifer PSW samples, 
but with a narrower range; dissolved oxygen concentrations for well-field and monitoring well samples ranged from 3.65 to $5.26 \mathrm{mg} / \mathrm{L}$, with a median value of $4.6 \mathrm{mg} / \mathrm{L}$ (table 7 ). The dissolved oxygen concentration in the overburden monitoring well (Z-OVB) was similar, with a value of $4.98 \mathrm{mg} / \mathrm{L}$ (table 7).

In the vicinity of the freshwater/saline-water interface (fig. 1), dissolved oxygen concentrations decrease, and $\mathrm{NO}_{3}$-reducing/Mn-reducing conditions are widely present (described by concentrations of less than $0.5 \mathrm{mg} / \mathrm{L}$ dissolved oxygen, less than $0.5 \mathrm{mg} / \mathrm{L} \mathrm{NO}_{3}$, greater than $0.1 \mathrm{mg} / \mathrm{L} \mathrm{Mn}$, greater than $0.5 \mathrm{mg} / \mathrm{L} \mathrm{SO}_{4}$, and an $\mathrm{Fe}$ to $\mathrm{H}_{2} \mathrm{~S}$ ratio between 0.3 and 10 ). It is possible that mixed redox or anoxic conditions could occur locally in the freshwater part of the aquifer as a result of point source occurrences of contamination from spills, leaking septic areas, or wastewater lines, or from mixing with less oxic water from the Trinity Group or overlying units (for example, the Buda Limestone or Austin Chalk).

\section{Dissolved Gases}

Dissolved gas concentrations (argon, methane, $\mathrm{CO}_{2}, \mathrm{~N}_{2}$, oxygen, and $\mathrm{He}$ ) were measured to estimate properties used in age-tracer calculations, including the temperature of groundwater at the time of recharge and the amounts of excess air. Measured and calculated results, excluding He, are shown in table 10 at end of report; He results are described in the section “Groundwater Age Tracers and Age Distributions” later in the report. Concentrations of $\mathrm{N}_{2}$ and argon are consistent with atmospheric equilibration during groundwater recharge with excess air added during recharge. Calculated excess air concentrations range from 1.9 to 11.0 cubic centimeters per kilogram at standard temperature and pressure $\left(\mathrm{cm}^{3} \mathrm{STP} /\right.$ $\mathrm{kg}$ ), with a median value of $5.8 \mathrm{~cm}^{3} \mathrm{STP} / \mathrm{kg}$. Most groundwater contains excess air, which is generally attributed to air entrainment during recharge (Heaton and Vogel, 1981). Excess air concentrations are typically from near 0 to $3 \mathrm{~cm}^{3} \mathrm{STP} / \mathrm{kg}$, although higher values have been measured (Busenberg and Plummer, 2000) and might be associated with some flow conditions in fractured rocks or in aquifers with rapid variations in water table elevation such as karst (Busenberg and Plummer, 1992; L.N. Plummer, U.S. Geological Survey, oral commun., 2009). No excess $N_{2}$, such as would occur from denitrification of $\mathrm{NO}_{3}$, was detected in any dissolved gas samples (table 10). These results are consistent with an absence of denitrification in the sampled groundwater based on oxic conditions.

\section{Nutrients and Stable Isotopes of Nitrogen}

Nutrients are defined as those elements important to plant growth and survival and include the primary mineral nutrients $\mathrm{N}$, phosphorus, and potassium. Anthropogenic activity has transformed the global $\mathrm{N}$ cycle, and elevated nutrient concentrations in water resources are an issue of worldwide concern (Schlesinger and others, 2006; Galloway and others, 2008).
Nitrogen is the most soluble of these nutrients, which generally occurs as nitrate $\left(\mathrm{NO}_{3}\right)$, nitrite $\left(\mathrm{NO}_{2}\right)$, and ammonium $\left(\mathrm{NH}_{4}\right)$ in groundwater (Hem, 1992). Ammonium strongly adsorbs on mineral surfaces, whereas $\mathrm{NO}_{3}$ and $\mathrm{NO}_{2}$ are readily transported in water (Hem, 1992). Reduction of $\mathrm{NO}_{3}$ to $\mathrm{NO}_{2}$ (denitrification) occurs in anoxic conditions. Anthropogenic $\mathrm{N}$ sources include agricultural fertilizer, animal wastes, septic systems, municipal sewage-treatment systems, leaking sewerlines, and $\mathrm{N}$ oxide emissions. Atmospheric deposition and precipitation, decaying organic matter, and soil mineralization processes are also potential $\mathrm{N}$ sources. Natural $\mathrm{N}$ sources are not common in limestone and dolomitic aquifer rocks; thus, $\mathrm{N}$ concentrations greater than the prevailing background concentration likely represent anthropogenic sources. National background concentrations of $\mathrm{NO}_{3}$ have been estimated to be $1.0 \mathrm{mg} / \mathrm{L}$ for groundwater (Dubrovsky and others, 2010).

Concentrations of $\mathrm{NO}_{2}$ were negligible where detected and below laboratory method reporting levels for most samples (table 11 at end of report), which is consistent with generally oxic conditions in the aquifer. As a result, measured concentrations of $\mathrm{NO}_{3}+\mathrm{NO}_{2}$ primarily represent concentrations of $\mathrm{NO}_{3}$; where $\mathrm{NO}_{2}$ was detected, $\mathrm{NO}_{3}$ concentrations were calculated as the difference between $\mathrm{NO}_{3}+\mathrm{NO}_{2}$ and $\mathrm{NO}_{2}$.

All measured $\mathrm{NO}_{3}$ concentrations were below the MCL of $10 \mathrm{mg} / \mathrm{L}$ for drinking water (U.S. Environmental Protection Agency, 1993). The overburden monitoring well (Z-OVB) sample had the highest $\mathrm{NO}_{3}$ concentration, with a value of $3.82 \mathrm{mg} / \mathrm{L}$. Groundwater samples from regional aquifer PSWs had $\mathrm{NO}_{3}$ concentrations ranging from 0.73 to 3.12 , with a median of $1.86 \mathrm{mg} / \mathrm{L}$. The median for samples from regional (confined) aquifer PSWs was $1.87 \mathrm{mg} / \mathrm{L}$, which is similar to the previously reported median values for regional groundwater in the aquifer $(1.67 \mathrm{mg} / \mathrm{L})$ (Musgrove and others, 2010). Well-field and monitoring well samples had a slightly narrower range of $\mathrm{NO}_{3}$ concentrations $(1.65-2.74 \mathrm{mg} / \mathrm{L})$ (table 11) with a similar median value of $2.04 \mathrm{mg} / \mathrm{L}$.

Concentrations of $\mathrm{NO}_{3}$ for regional aquifer PSW samples showed a decrease in concentration with depth (Kendall's tau $=-0.25$ ) (fig. 21). This relation is not evident for well-field and monitoring well samples, which cover a more limited depth range than do the regional aquifer PSWs (fig. 21). Land use might affect $\mathrm{NO}_{3}$ concentrations in Edwards aquifer groundwater; higher $\mathrm{NO}_{3}$ concentrations have been measured in groundwater from shallow unconfined monitoring wells in the urban San Antonio area. These patterns are consistent with either greater amounts of anthropogenically derived $\mathrm{NO}_{3}$ in the urban environment and (or) dilution of ambient $\mathrm{NO}_{3}$ by surface-water recharge (Musgrove and others, 2010).

Nitrate isotopes $\left(\delta^{15} \mathrm{~N}\right.$ and $\delta^{18} \mathrm{O}$ of $\mathrm{NO}_{3}$ ) have been widely applied to trace the cycling and sources of $\mathrm{NO}_{3}$ in hydrologic systems (Kendall, 1998). Different sources or reservoirs of $\mathrm{NO}_{3}$ have characteristic isotopic "signatures" that reflect the source of the $\mathrm{NO}_{3}$ (Kendall, 1998; Mengis and others, 2001). Values shown on figure 22 reflect typical ranges of major $\mathrm{NO}_{3}$ reservoirs, although the boundaries are not absolute (Kendall, 1998), and local endmember values of these sources have not 


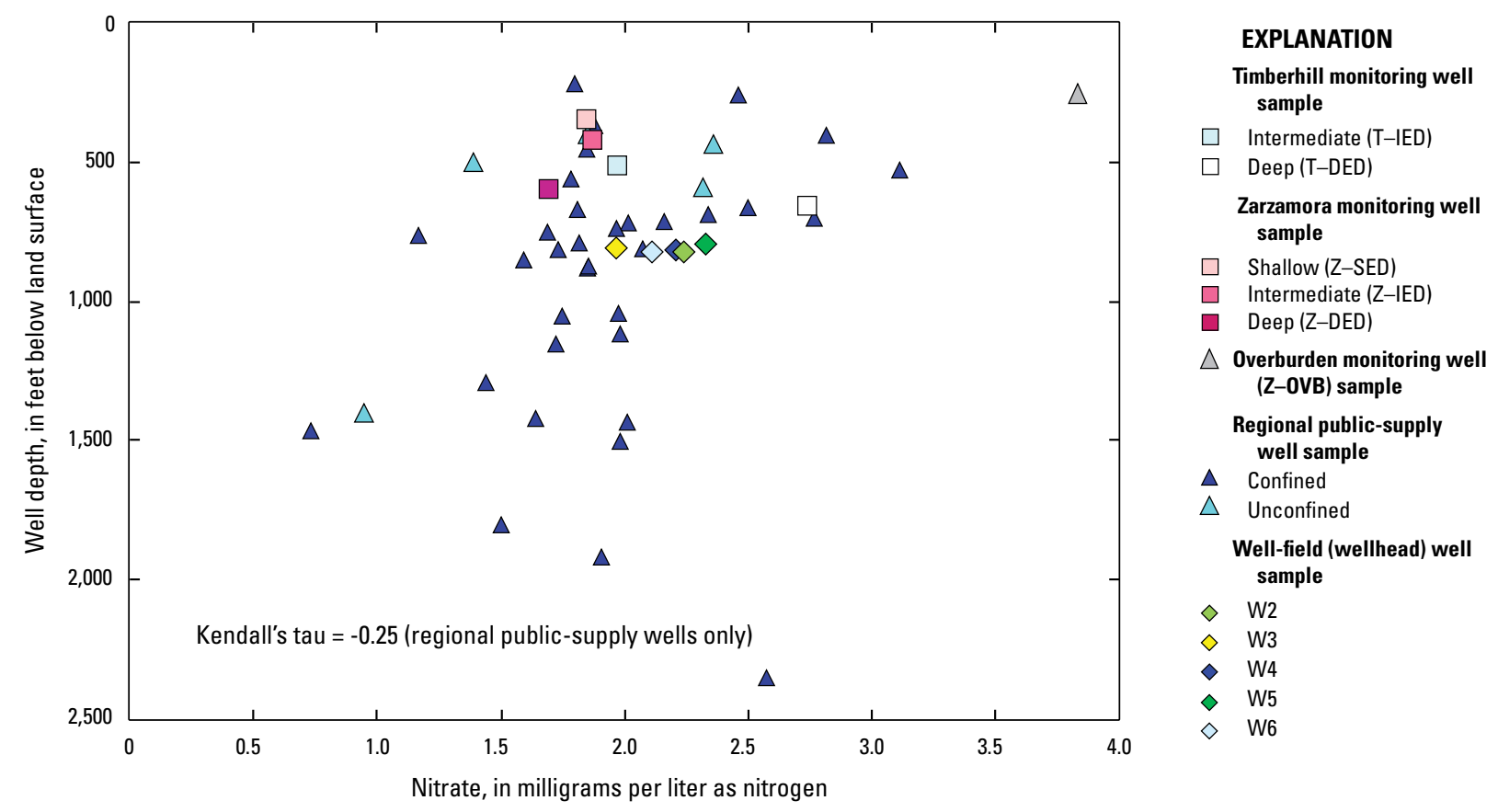

Figure 21. Relation between well depth and nitrate concentration for groundwater samples collected for the study of the transport of anthropogenic and natural contaminants (TANC) to public-supply wells, south-central Texas, 2004-9.

been determined. Additionally, the isotopic composition of the $\mathrm{NO}_{3}$ in a water sample might reflect a single source or a mix of sources with different isotopic compositions. The isotopic signature can also be modified by biogeochemical processes, such as denitrification (fig. 22). Nitrate-isotope samples were collected from well-field and monitoring wells, including depth-dependent sampling in W4, and from the overburden well (Z-OVB) (table 12). Results for $\delta^{15} \mathrm{~N}$ range from 6.84 per mil to 8.16 per mil with a median of 7.91 per mil; results for $\delta^{18} \mathrm{O}$ range from 4.59 per mil to 5.52 per mil, with a median of 5.23 per mil. Nitrate-isotope results for all TANC study samples, excluding the overburden well, are within a very narrow range that is within analytical uncertainty ( \pm 0.5 per mil) (fig. 22). The overburden well, in the Buda Limestone, has a slightly lower $\delta^{15} \mathrm{~N}$ value (6.84 per mil) (fig. 22). Based on the ranges of different $\mathrm{NO}_{3}$ sources shown in figure 22 (Kendall, 1998; Mengis and others, 2001), $\delta^{15} \mathrm{~N}$ values for TANC groundwater samples are mostly within the range of natural soil organic values, near the higher values that transition to $\mathrm{NO}_{3}$ sourced from human and (or) animal waste (fig. 22). Samples collected from Barton Springs (the main discharge point for the Barton Springs segment of the aquifer) during 2008-10 under a range of flow conditions have similar median $\mathrm{NO}_{3}$-isotope values $\left(7.57\right.$ per mil for $\delta^{15} \mathrm{~N}$ and 5.58 per mil for $\delta^{18} \mathrm{O}$ ) (Mahler and others, 2011).

Nitrate-isotope results confirm that denitrification is not an important process affecting $\mathrm{NO}_{3}$ in the Edwards aquifer. This finding is consistent with oxic conditions throughout the aquifer and the absence of excess $\mathrm{N}_{2}$ gas, an indicator of denitrification, in all samples collected for this study. Denitrification has been identified as an important process in other shallow (Panno and others, 2001) and deep karst aquifers (Katz and others, 2007).

The median $\delta^{15} \mathrm{~N}$ composition of Edwards aquifer groundwater collected for this study (7.91 per mil) is higher than historical values. A previous study of regional unconfined $(n=33)$ and confined $(n=34)$ groundwater in the Edwards aquifer measured median $\delta^{15} \mathrm{~N}$ values of 6.60 and 6.00 per mil, respectively (Kreitler and Browning, 1983). Higher $\delta^{15} \mathrm{~N}$ values are likely indicative of $\mathrm{NO}_{3}$ from human and (or) animal waste, including septic systems and wastewater sources (fig. 22). Historical regional Edwards aquifer $\delta^{15} \mathrm{~N}$ values from Kreitler and Browning (1983) (n=67) are statistically different (based on Mann-Whitney U testing) from recent results for samples collected during the TANC study $(n=20)$. This comparison suggests that $\mathrm{NO}_{3}$ sources to groundwater in the Edwards aquifer, although primarily in the soil organic $\mathrm{N}$ range, might include a potential component of manure and (or) septic/sewage sources. Kreitler and Browning (1983) did not measure $\delta^{18} \mathrm{O}$ compositions; thus, only historical $\delta^{15} \mathrm{~N}$ results were compared. This comparison with historical measurements of $\delta^{15} \mathrm{~N}$ should be interpreted with caution, however, because interlaboratory and intermethod comparisons could not be made. Nonetheless, other data are consistent with the possibility that $\delta^{15} \mathrm{~N}$ values for TANC study samples are higher than historical values as a result of changes in potential $\mathrm{NO}_{3}$ sources and loadings to the aquifer. The median $\mathrm{NO}_{3}$ concentration for regional confined groundwater samples collected by 


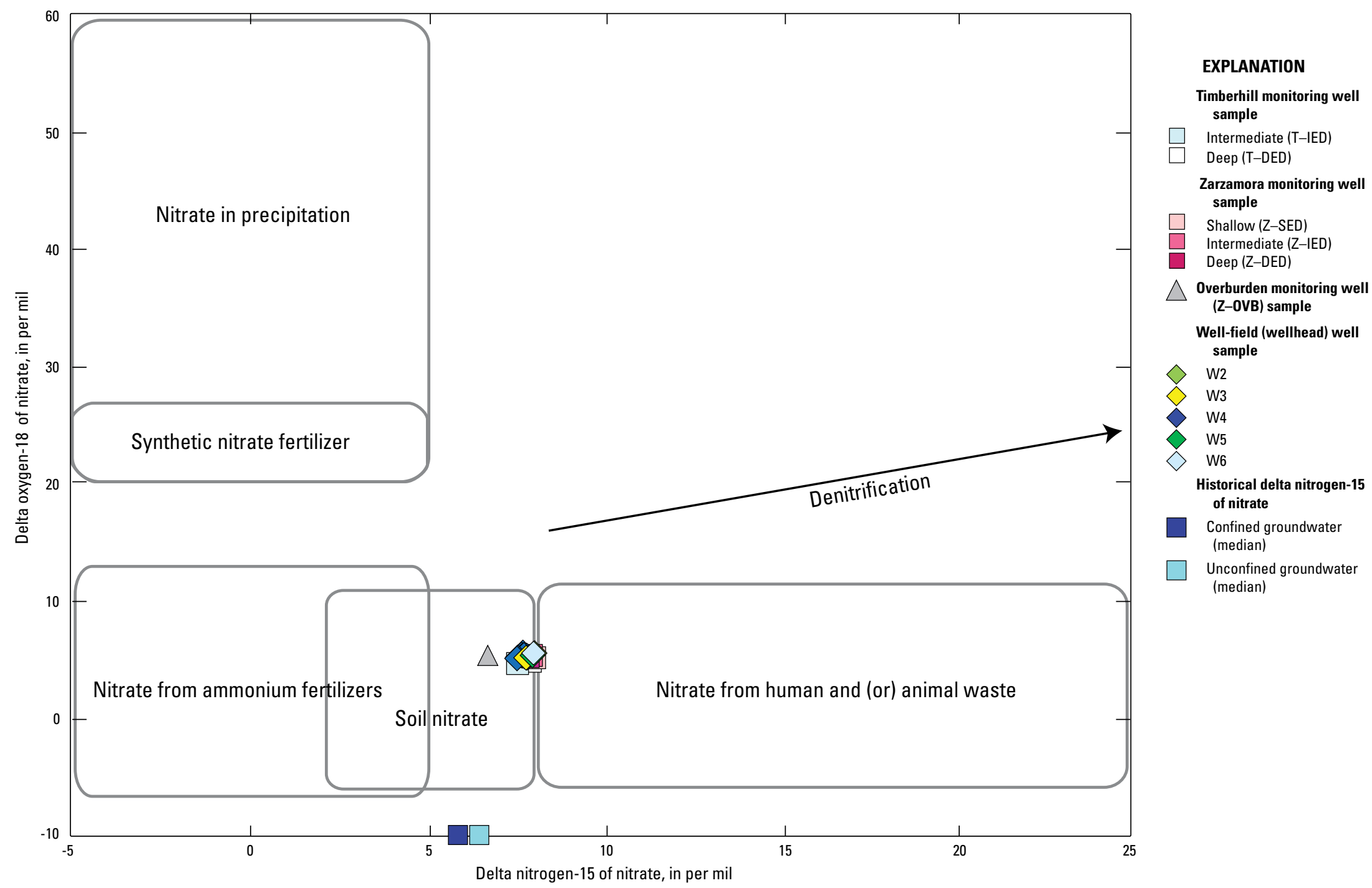

Figure 22. Isotopic composition of nitrate for groundwater samples collected for the study of the transport of anthropogenic and natural contaminants (TANC) to public-supply wells, south-central Texas, 2004-9. Historical data for delta nitrogen-15 $\left(\delta^{15} \mathrm{~N}\right)$ of nitrate shown for comparison are based on results from Kreitler and Browning (1983) (delta oxygen-18 of nitrate $\left(\delta^{18} 0\right)$ was not measured for historical samples). Common fields of $\delta^{15} \mathrm{~N}$ and $\delta^{18} 0$ are modified from Kendall (1998), Mengis and others (2001), and Silva and others (2002). 
Kreitler and Browning (1983) was $1.40 \mathrm{mg} / \mathrm{L}$, which is significantly lower than that for regional aquifer PSW samples. An upward trend for $\mathrm{NO}_{3}$ concentrations (1938-2006) in the San Antonio segment of the aquifer was previously proposed by Musgrove and others (2010). Mahler and others (2011) found that nitrate concentrations for recent (2008-10) samples from the Barton Springs segment of the aquifer are elevated relative to historical (1990-2008) samples. Additionally, Mahler and others (2011) found that recent (2008-10) $\delta^{15} \mathrm{~N}$ values for samples from Barton Springs were significantly higher than historical values (1990-94).

\section{Strontium Isotopes}

Strontium isotopes $\left({ }^{87} \mathrm{Sr} /{ }^{86} \mathrm{Sr}\right)$ are a useful tracer in the hydrologic cycle, in particular for sources of dissolved constituents to a fluid (Banner, 2004). Strontium (Sr) isotopes in hydrology have been used to trace flow paths, mineral-solution reactions, and variations in recharge and flow routes in a number of different groundwater settings (McNutt and others, 1990; Banner and others, 1994). In the Edwards aquifer, ${ }^{87} \mathrm{Sr} /{ }^{86} \mathrm{Sr}$ values have been applied previously in conjunction with element ratios $(\mathrm{Mg} / \mathrm{Ca}, \mathrm{Sr} / \mathrm{Ca})$ as a tracer of water-rock interaction, groundwater residence time, recharge, unsaturated zone flow-routes, and the influence of soil composition on groundwater geochemistry (Oetting and others, 1996; Musgrove and Banner, 2004; Garner, 2005; Wong and others, 2011). Sr isotope ratios in the Edwards aquifer generally decrease with increasing water-rock interaction, approaching values similar to those of the host limestone aquifer rocks (Oetting and others, 1996; Sharp and Banner, 1997; Musgrove and Banner, 2004; Musgrove and others, 2010). Cretaceousage carbonate host rocks that compose the Edwards aquifer have ${ }^{87} \mathrm{Sr} /{ }^{86} \mathrm{Sr}$ values ranging from 0.7074 to 0.7077 (Koepnick and others, 1985; Oetting, 1995). Higher ${ }^{87} \mathrm{Sr} /{ }^{86} \mathrm{Sr}$ values for groundwater relative to the aquifer host rocks are indicative of a source of more radiogenic $\mathrm{Sr}$ (enriched in ${ }^{87} \mathrm{Sr}$ ) to the groundwater, which has been proposed to be a result of chemical interaction of groundwater with overlying soils and proportionally less interaction with aquifer host rocks (Musgrove and Banner, 2004). The Sr isotope composition of regional Edwards aquifer groundwater demonstrates a progression toward lower ${ }^{87} \mathrm{Sr} /{ }^{86} \mathrm{Sr}$ values with increased mineral-solution reactions as allowed by increased residence time and longer flow paths; Sr isotope results are consistent with a characterization of confined groundwater samples from the well-field and monitoring wells as more geochemically evolved relative to shallow and unconfined groundwater (Musgrove and others, 2010).

Sr isotopes were not measured for regional aquifer PSWs; thus, only values for the well-field and monitoring wells are evaluated. The strontium isotope composition of well-field and monitoring well samples had a relatively narrow range (0.70767-0.70784). The median value of 0.70772 is very close to the range of the carbonate host rocks, indicative of relatively geochemically evolved groundwater (that is, groundwater that has undergone extensive mineral-solution reaction with the carbonate host rocks). Values for the wellfield samples and samples from the Zarzamora monitoring wells are mostly within analytical uncertainty of each other; values for the samples from the Timberhill monitoring wells are slightly elevated in comparison (median of 0.70783 ). The ${ }^{87} \mathrm{Sr} /{ }^{86} \mathrm{Sr}$ value for the sample from the overburden monitoring well (Z-OVB) (0.70785) was also slightly elevated in comparison, similar to values for the Timberhill monitoring wells. Slightly higher ${ }^{87} \mathrm{Sr} /{ }^{86} \mathrm{Sr}$ values for the Timberhill monitoring wells might reflect differences in flow paths supplying these wells or might indicate that groundwater from these wells are less geochemically evolved than is groundwater from the well-field and Zarzamora monitoring wells. ${ }^{87} \mathrm{Sr} r{ }^{86} \mathrm{Sr}$ values for the Buda Limestone have not been characterized. Both the Zarzamora and Timberhill monitoring well values decrease slightly with depth, although since results for most of the monitoring wells are within analytical uncertainty of each other, any ${ }^{87} \mathrm{Sr} /{ }^{86} \mathrm{Sr}$ trend with depth in the monitoring wells is poorly constrained (fig. 23). A trend of decreasing ${ }^{87} \mathrm{Sr} /{ }^{86} \mathrm{Sr}$ with depth, however, would be consistent with more geochemically evolved groundwater associated with deeper flow paths in the aquifer.

\section{Stable Isotopes of Hydrogen and Oxygen}

Stable isotope ratios of hydrogen and oxygen ( $\delta \mathrm{D}$ and $\delta^{18} \mathrm{O}$ ) are commonly used to study hydrologic processes and have been applied to assess groundwater origin, mixing, and evaporation, as well as hydrograph separation and the response of karst systems to storms, aquifer recharge, subsurface flow routing (diffuse relative to conduit), and antecedent conditions (Craig, 1961; Gat, 1981; Lakey and Krothe, 1996; Jones and others, 2000; Desmarais and Rojstaczer, 2002; Maloszewski and others, 2002). Well-field and monitoring well samples were analyzed for $\delta \mathrm{D}$ and $\delta^{18} \mathrm{O}$; results showed little variability, with median values of -22.7 per mil and -4.1 per mil, respectively (table 12 at end of report). A comparison of these data with both the global meteoric water line (GMWL), which represents a regression line for the isotopic composition of rainfall around the globe (Craig, 1961), and the local meteoric water line (LMWL) (Pape and others, 2010) indicates that groundwater samples were meteoric in origin (fig. 24). On the basis of stable isotope and other geochemical results, a small number of regional groundwater samples have been previously interpreted to be affected by mixing with (a) downdip saline water, (b) recent recharge associated with tropical cyclonic storms, or (c) recharge water that has undergone evaporation (Musgrove and others, 2010). Regional aquifer PSW samples were not analyzed for $\delta \mathrm{D}$ and $\delta^{18} \mathrm{O}$, but previous results for Edwards aquifer groundwater indicate that confined groundwater is less variable relative to shallow/urban unconfined and unconfined groundwater (Musgrove and others, 2010). The absence of variability in $\delta \mathrm{D}$ and $\delta^{18} \mathrm{O}$ results 

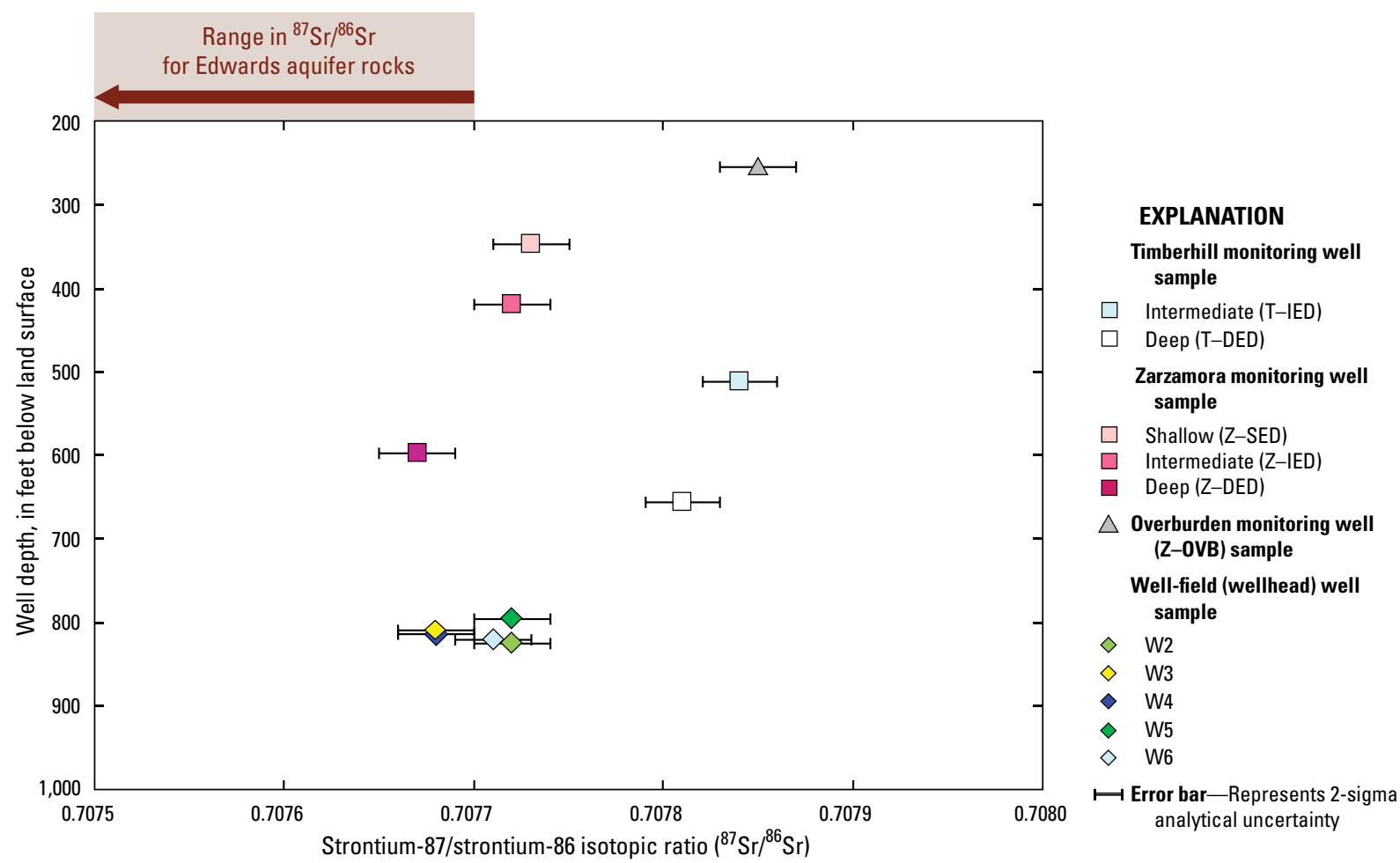

Figure 23. Relation between well depth and strontium isotope composition for groundwater samples collected for the study of the transport of anthropogenic and natural contaminants (TANC) to public-supply wells, south-central Texas, 2004-9. Range for Cretaceousage carbonate rocks that compose the Edwards aquifer (0.7074 to 0.7077) from Koepnick and others (1985) and Oetting (1995).

for samples from TANC well-field and monitoring wells is consistent with the study characterization of the PSW samples as well-mixed, homogeneous, confined groundwater that is typical of the regional aquifer.

\section{Organic Constituents}

The presence of organic constituents that do not occur naturally in hydrologic systems, such as pesticides and VOCs, is a direct result of anthropogenic activities. Anthropogenic organic contaminants are of concern in groundwater and drinking-water supplies because of their potential detrimental effects on the environment and to human health. Many of these compounds are relatively soluble and thus can be present in groundwater if anthropogenic sources are present. Pesticides and pesticide degradation products generally include toxic compounds used to kill or control plants (herbicides), insects (insecticides), fungi (fungicides), and rodents (rodenticides). VOCs are carbon-based compounds that readily volatilize and are commonly found in paints, solvents, gasoline-related compounds, refrigerants, fumigants, and other industrial compounds. VOCs include trihalomethanes (THMs), which are a byproduct created by the disinfection of drinking water by chlorination. The frequency of detection and spatial distribution of anthropogenic contaminants provide insight into their potential sources, as well as into effects of anthropogenic activities on water quality.

Samples for organic constituents on the analytical schedule for wastewater indicator compounds were collected from regional aquifer PSWs (table 13 at end of report). Results from these analyses were almost entirely nondetections, so these constituents are not discussed further.

Pesticides and VOCs were analyzed in samples collected from the well-field and monitoring wells and the regional aquifer PSWs. A subset of the regional aquifer PSWs $(n=39)$ that were sampled in 2004 were resampled in 2005 for only pesticides $(n=8)$ and VOCs $(n=7)$. TANC results for organic contaminants were consistent with previous studies that have documented the occurrence of anthropogenic organic contaminants in the Edwards aquifer at low concentrations (Bush and others, 2000; Fahlquist and Ardis, 2004; Musgrove and others, 2010). Pesticides and VOCs were detected in all analyzed well categories, including well-field wells, monitoring wells, and regional aquifer PSWs. Detected concentrations of organic constituents were mostly less than $1 \mu \mathrm{g} / \mathrm{L}$ and were typically orders of magnitude below USEPA MCLs for those constituents for which MCLs currently exist. The detection of at least one pesticide compound and (or) VOC in samples from most of the regional aquifer PSWs collected in 2004 through 2005 


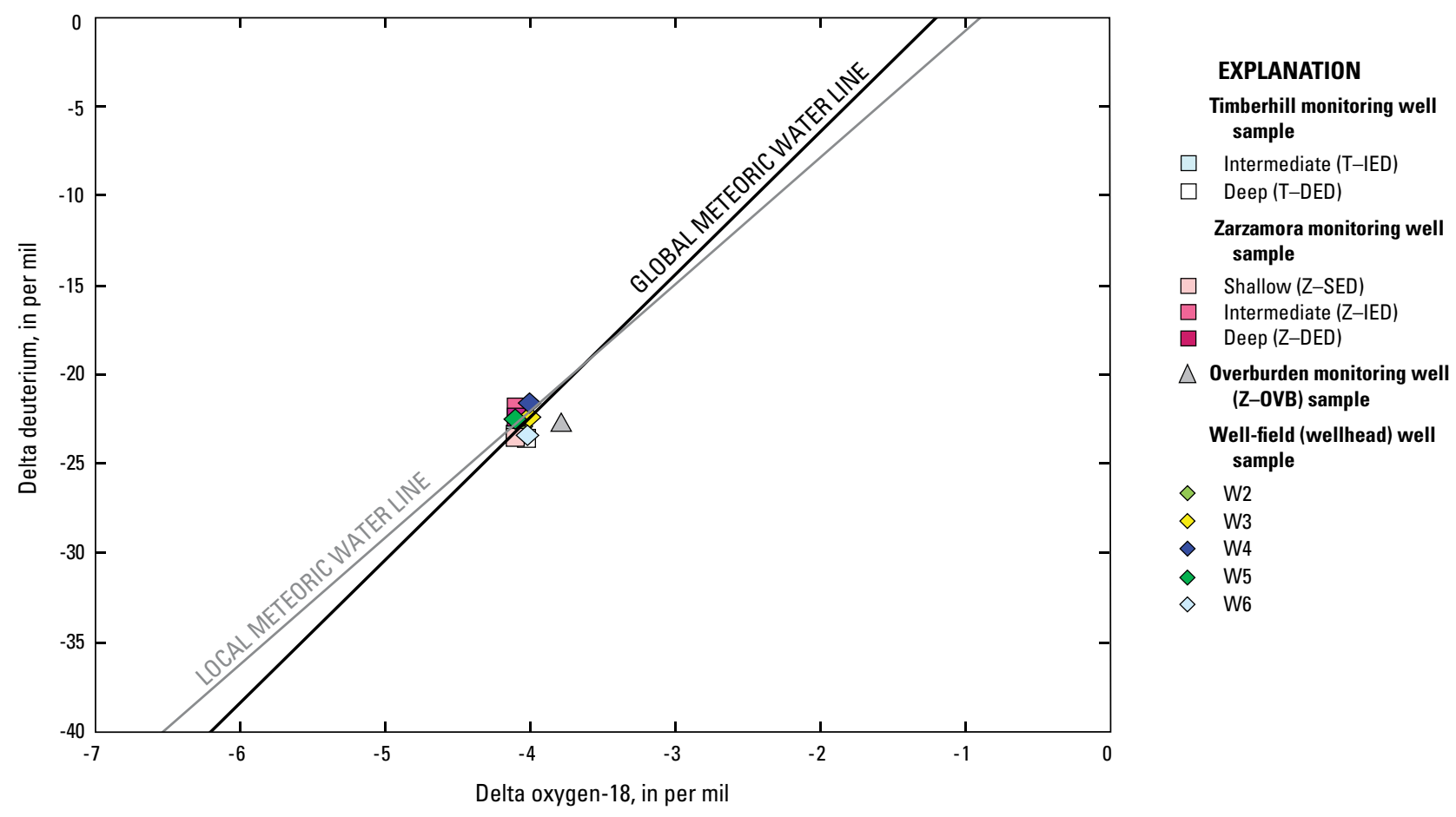

Figure 24. Relation between deuterium and oxygen isotopes for groundwater samples collected for the study of the transport of anthropogenic and natural contaminants (TANC) to public-supply wells, south-central Texas, 2004-9. Local and global meteoric water lines are shown for comparison, based on Pape and others (2010) and Craig (1961), respectively.

(tables $14-17$ at end of report) indicates that some fraction of groundwater in the regional Edwards aquifer is affected by anthropogenic activities.

One or more pesticide compounds were detected in 79 percent of the regional aquifer PSW samples, and one or more VOCs were detected in 87 percent of these samples. The number of organic compounds detected in any single groundwater sample ranged from 0 to 10 , with a median of 5 . A total of 17 pesticide compounds and 11 VOCs were detected; most were detected infrequently. A small number of compounds were consistently and frequently detected ( $\geq 50$ percent of samples) in regional aquifer PSW samples, indicating that there are likely widespread, low-level inputs of these constituents from multiple sources. The most frequently detected organic constituents were (1) the pesticide atrazine, (2) the atrazine degradate 2-chloro-4-isopropylamino-6-amino-s-triazine (CIAT, also known as deethylatrazine or, hereinafter, DEA), (3) the THM chloroform, and (4) the solvent PCE, which were detected in $60,74,72$, and 50 percent of samples from regional aquifer PSWs, respectively (fig. 25). In samples from the regional aquifer PSWs, median concentrations of atrazine, DEA, chloroform, and PCE were $0.005 \mu \mathrm{g} / \mathrm{L}, 0.006 \mu \mathrm{g} / \mathrm{L}$, $0.020 \mu \mathrm{g} / \mathrm{L}$ and $0.008 \mu \mathrm{g} / \mathrm{L}$, respectively (fig. 26). These concentrations are orders of magnitude below the USEPA MCLs for these compounds, which are $3 \mu \mathrm{g} / \mathrm{L}$ for atrazine, $80 \mu \mathrm{g} / \mathrm{L}$ for total THMs, including chloroform, and $5 \mu \mathrm{g} / \mathrm{L}$ for PCE. Other pesticides that were frequently detected were simazine and prometon, which were detected in 38 and 30 percent of the regional aquifer PSW samples, respectively (fig. 25). The atrazine degradates deisopropylatrazine (or 2-chloro-6-ethylamino-4-amino-s-triazine (hereinafter, CEAT)) and hydroxyatrazine (or 2-hydroxy-4-isopropylamino-6-ethylamino-s-triazine (hereinafter, OIET)) were analyzed for in only a subset of the regional aquifer PSW samples $(\mathrm{n}=15)$ and were detected in 25 and 15 percent of those samples, respectively. In the regional aquifer PSW samples, median concentrations of CEAT, OIET, simazine, and prometon were below laboratory method reporting levels of $0.08 \mu \mathrm{g} / \mathrm{L}, 0.032 \mu \mathrm{g} / \mathrm{L}, 0.005 \mu \mathrm{g} / \mathrm{L}$, and $0.010 \mu \mathrm{g} / \mathrm{L}$, respectively. The THMs bromoform, dibromochloromethane, and bromodichloromethane were detected in 26, 17, and 17 percent of the regional aquifer PSW samples, respectively. In regional aquifer PSW samples, total THM concentrations ranged from below laboratory method reporting levels to $3.178 \mu \mathrm{g} / \mathrm{L}$, with a median value of $0.023 \mu \mathrm{g} / \mathrm{L}$.

The frequent detection of atrazine, DEA, chloroform, and PCE, as well as the common detection of simazine and prometon at low concentrations, is consistent with constituent occurrence patterns in the Edwards aquifer previously noted by Mahler and others (2006) and Musgrove and others (2010). Lindsey and others (2009) report similar findings for other carbonate aquifers in similar land use settings. Where detected, organic constituents tend to co-occur; that is, concentrations of the most frequently detected organic compounds are correlated. For example, for the regional aquifer PSW samples, 


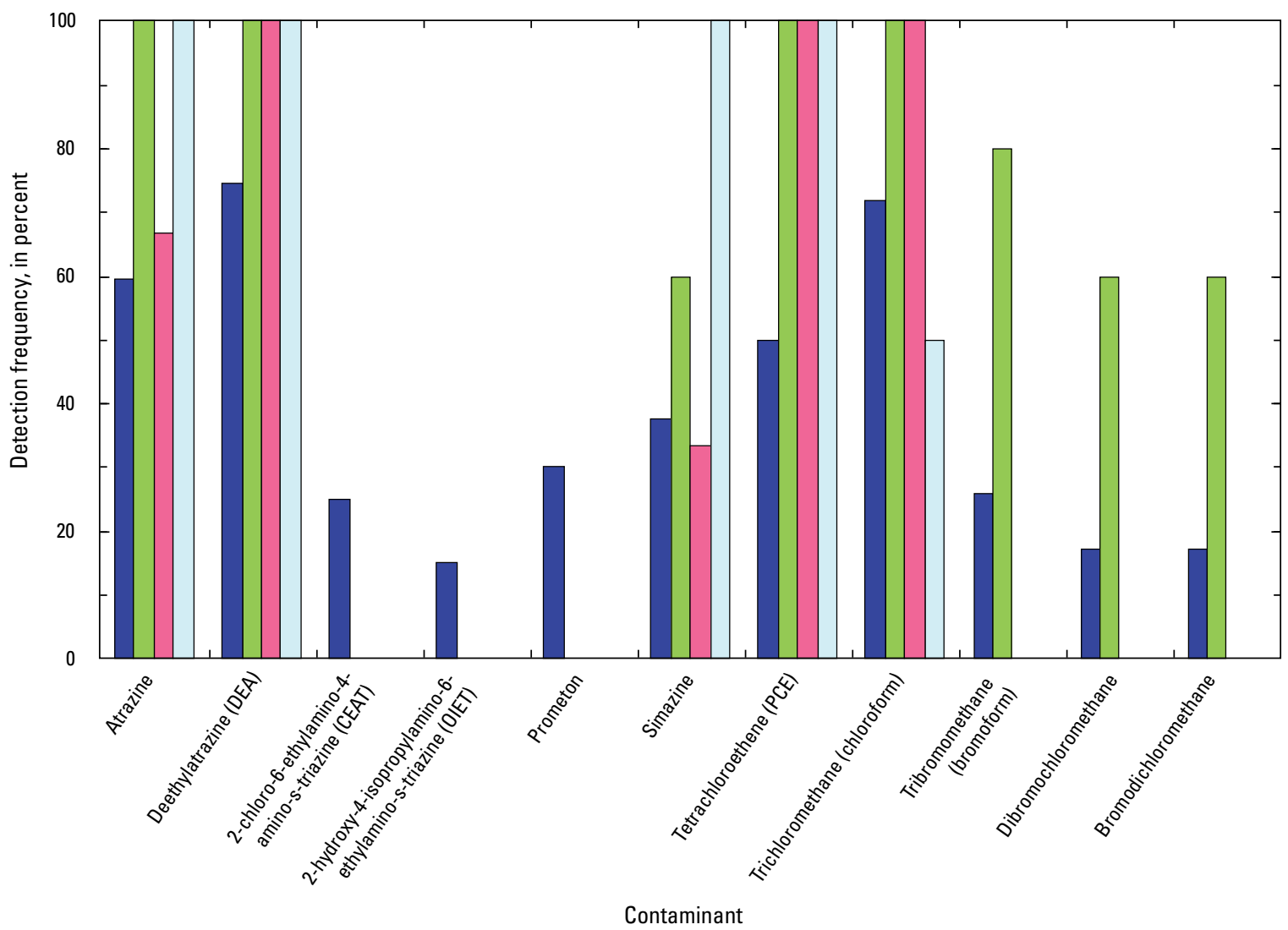

EXPLANATION

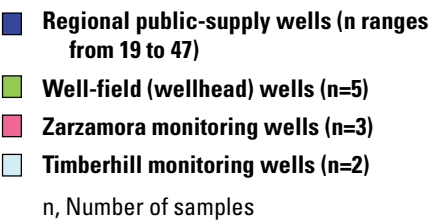

Figure 25. Detection frequency for the most frequently detected anthropogenic contaminants for groundwater samples collected for the study of the transport of anthropogenic and natural contaminants (TANC) to public-supply wells, south-central Texas, 2004-9.

concentrations of atrazine were correlated with concentrations of DEA, simazine, PCE, and chloroform (Kendall's tau $=0.69$, $0.55,0.56,0.46$, respectively).

Atrazine, DEA, simazine, chloroform, and PCE were frequently detected in the well-field $(\mathrm{n}=5)$ and monitoring well $(n=5)$ samples, though at different frequencies (fig. 25) and median concentrations (fig. 26) than in the regional aquifer PSW samples. DEA and PCE were detected in 100 percent of the well-field and monitoring well samples. Atrazine and chloroform were detected in 100 percent of the well-field samples; simazine was detected in 60 percent of these samples, and prometon was not detected. Bromoform and dibromochloromethane were detected in 80 and 60 percent of the well-field samples, respectively. Detection frequencies for the two sets of monitoring wells were different for some organic constituents (fig. 25); atrazine and simazine were detected in 100 percent of the Timberhill monitoring well samples $(n=2)$ but had lower detection frequencies in the Zarzamora monitoring well samples $(\mathrm{n}=3)$. For the Timberhill monitoring wells, chloroform was detected in only the deeper well sample.

A comparison of median concentrations for the most frequently detected organic constituents in the different well categories provides insight into potential sources and transport of anthropogenic constituents to the well field. Median concentrations of atrazine, DEA, and PCE in the regional aquifer PSW samples $(0.005,0.006$, and $0.008 \mu \mathrm{g} / \mathrm{L}$, respectively) are representative of regional confined groundwater on the basis of their similarity with this groundwater category as detailed by Musgrove and others (2010). Median concentrations of these contaminants, however, are significantly higher (on the basis of Mann-Whitney U testing) in the well-field and monitoring well samples compared to the regional aquifer PSW samples (fig. 26); this result may indicate that the well field is affected by some additional, and likely local, source(s) 

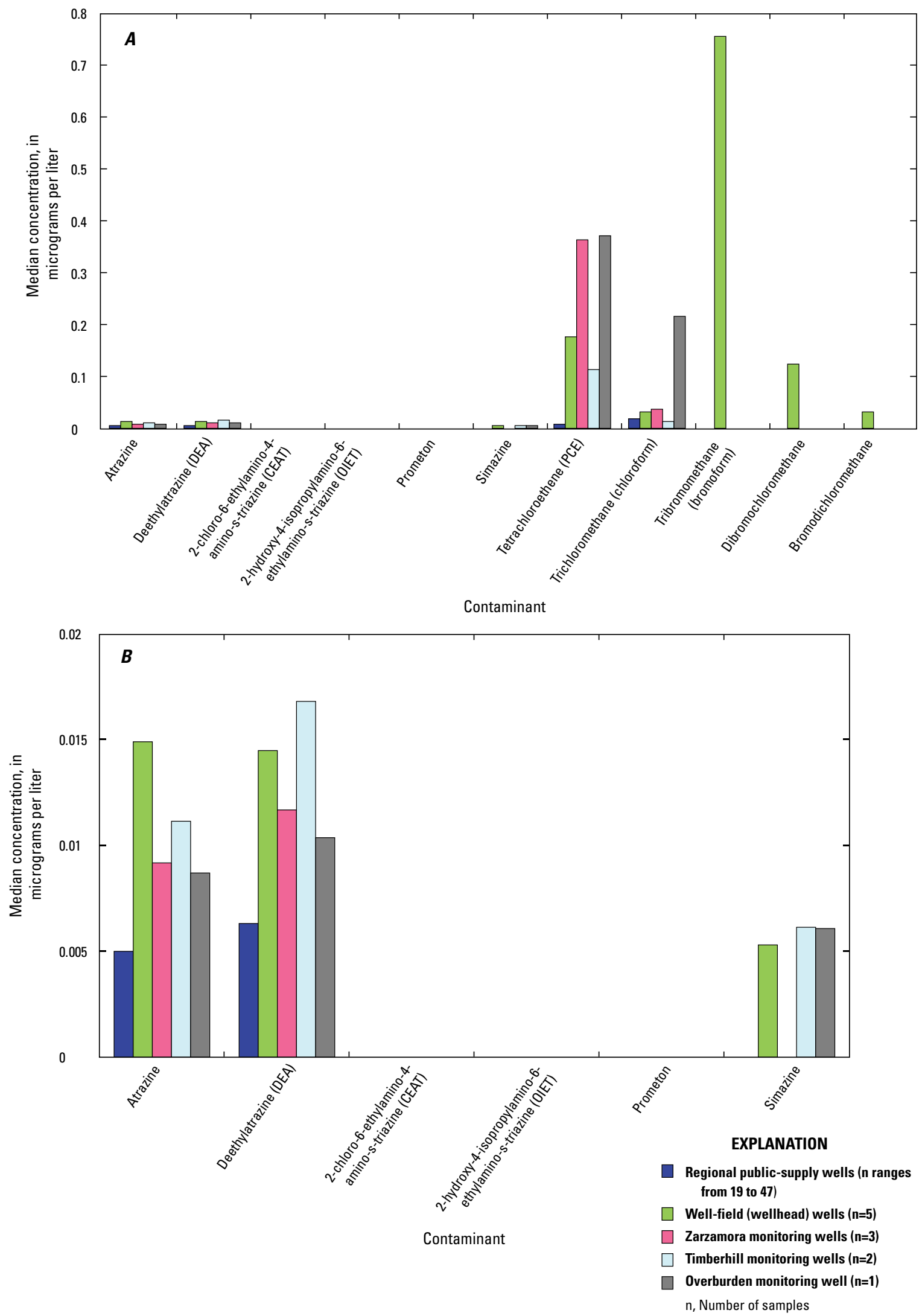

Figure 26. Median concentration of the most frequently detected anthropogenic contaminants for groundwater samples collected for the study of the transport of anthropogenic and natural contaminants (TANC) to public-supply wells, south-central Texas, 2004-9. Two scales are shown for selected contaminants for comparison. $A$, Full scale. $B$, Reduced scale. 
of these contaminants. A previous evaluation of organic constituents in the Edwards aquifer found that the urban environment is a potential source of anthropogenic contaminants to the aquifer; shallow/urban unconfined groundwater had higher median concentrations of atrazine, DEA, and PCE (0.008, 0.009 , and $0.027 \mu \mathrm{g} / \mathrm{L}$, respectively) and a higher frequency of detection than did regional confined groundwater (Musgrove and others, 2010). Median concentrations of PCE are significantly higher (on the basis of Mann-Whitney U testing), in particular, in the well-field samples $(0.176 \mu \mathrm{g} / \mathrm{L})$ and the Zarzamora monitoring well samples $(0.365 \mu \mathrm{g} / \mathrm{L})$ in comparison with both regional aquifer PSW samples (fig. 26) and shallow/ urban unconfined groundwater described by Musgrove and others (2010).

The most frequently detected organic contaminants generally showed a trend of decreasing concentration with depth for the regional aquifer PSW samples; atrazine, simazine, PCE, and chloroform concentrations were correlated with well depth (Kendall's tau $=-0.36,-0.37,-0.28,-0.25$, respectively). More specifically, the relation with well depth for most of the frequently detected organic contaminants tends to be bimodal (fig. 27). Median concentrations and the frequency of detection for atrazine, DEA, simazine, PCE, and chloroform in the regional aquifer PSW samples are consistently higher for wells that are less than $1,000 \mathrm{ft}$ in depth. For wells that are greater than $1,000 \mathrm{ft}$ deep, median concentrations for these organic contaminants are all less than the laboratory method reporting levels. The concentration difference between the two groups (that is, wells less than 1,000 and greater than 1,000 ft deep) for all of these organic contaminants is statistically significant on the basis of Mann-Whitney U testing. About half of the deep (greater than 1,000 ft deep) regional (confined) aquifer PSWs are near or along the southern boundary of the confined segment of the aquifer (fig. 1). These deeper confined PSWs might intersect downgradient regional flow paths that have been less affected by anthropogenic contaminants. Samples from these deep wells (greater than 1,000 ft deep) show other evidence for a large component of more geochemically evolved and potentially older waters, such as higher $\mathrm{Mg} / \mathrm{Ca}$ ratios and dolomite SIs, both of which have been shown to be qualitative indicators of residence time in this aquifer (Musgrove and others, 2010). Both $\mathrm{Mg} / \mathrm{Ca}$ ratios and dolomite SIs were significantly different between samples collected from shallower wells (less than 1,000 ft deep) and those collected from deeper wells (greater than 1,000 ft deep) on the basis of Mann-Whitney U testing. It is possible that groundwater from these deep wells might be affected by mixing with a component of downdip saline-zone water, which might dilute concentrations of anthropogenic contaminants. However, there is no clear indication that such mixing has likely occurred; for example, concentrations of ions associated with the saline zone (for example, $\mathrm{Cl}, \mathrm{SO}_{4}, \mathrm{Sr}$, and $\mathrm{F}$ ) were not statistically different for samples from the regional (confined) aquifer PSWs with well depths greater than $1,000 \mathrm{ft}$, with the exception of Sr. These results are consistent with a previous study of low-level VOC concentrations in the San Antonio area that found fewer VOC detections in deeper wells and proposed that these deep wells might intercept regional flow paths that contain higher fractions of water recharged in rural areas in the western portion of the aquifer (Plummer and others, 2008).

The frequent detection of chloroform at low concentrations in samples from the well-field wells, monitoring wells, and regional aquifer PSWs is consistent with widespread detection of chloroform in other studies in the Edwards aquifer (Mahler and others, 2006; Musgrove and others, 2010), in other carbonate aquifers (Lindsey and others, 2009), and in many aquifers across the United States (Zogorski and others, 2006). This frequent detection in a variety of well types and land-use settings has been partly attributed to the recycling of chlorinated waters (Moran and others, 2002; Zogorski and others, 2006). Anthropogenic sources of chloroform include drinking-water treatment processes, leaking water and wastewater lines, septic systems, and recharge from irrigation with treated water. Public-water-supply sources also include the possible use of treated water as a downhole well-pump lubricant. Natural sources of chloroform include volcanic gases, biomass burning, marine algae, and soil microorganisms (Ivahnenko and Barbash, 2004).

In addition to chloroform, other THMs that are also a byproduct of drinking-water treatment processes-bromoform, dibromochloromethane, and bromodichloromethanewere frequently detected (80, 60 , and 60 percent, respectively) in the well-field samples (fig. 25). The median bromoform concentration for the well-field samples $(0.756 \mu \mathrm{g} / \mathrm{L})$ was higher than the median concentration of any other organic constituent in any other sample category (fig. 26). Higher concentrations of brominated THMs relative to chloroform is unusual, as chloroform is the THM produced in the highest concentrations during chlorination (Ivahnenko and Barbash, 2004). Ivahnenko and Barbash (2004) indicate that the formation of brominated THMs might occur in the presence of unusually high bromide concentrations, which is not the case for the Edwards aquifer. The source of bromoform to the wellfield samples is likely local to the well field but is currently unknown.

\section{Groundwater Age Tracers and Age Distributions}

Groundwater age estimates have been used to determine recharge rates, estimate rates of geochemical and microbiological processes, calibrate groundwater flow models, evaluate aquifer susceptibility to contamination, and improve waterresource management (Plummer, 2005). Groundwater age estimates are based on the measurement of a dissolved solute, gas, or isotope in groundwater that has been transported through the aquifer to the point of sampling. As such, groundwater age estimates are model dependent, based on an interpretation of recharge and flow mechanisms, and might be affected by a variety of physical and geochemical processes (Cook and Böhlke, 2000; Plummer, 2005).

Age tracers-concentrations of CFCs (CFC-11, CFC-12, and $\mathrm{CFC}-113), \mathrm{SF}_{6},{ }^{3} \mathrm{H}$ and the ratio of the parent/daughter 


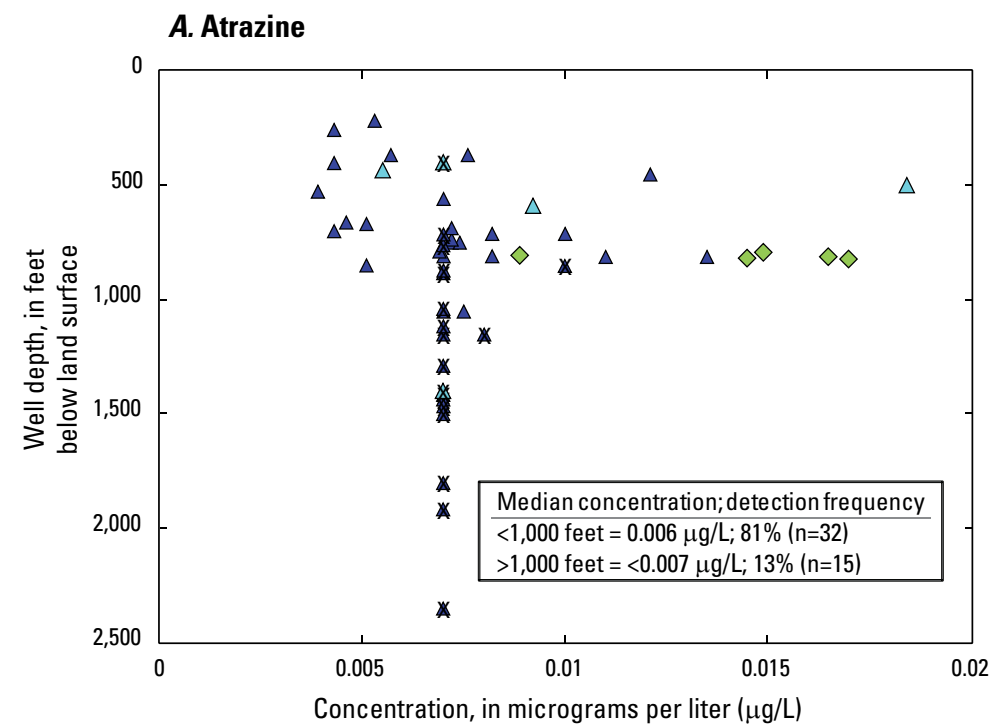

\section{B. Tetrachloroethene (PCE)}
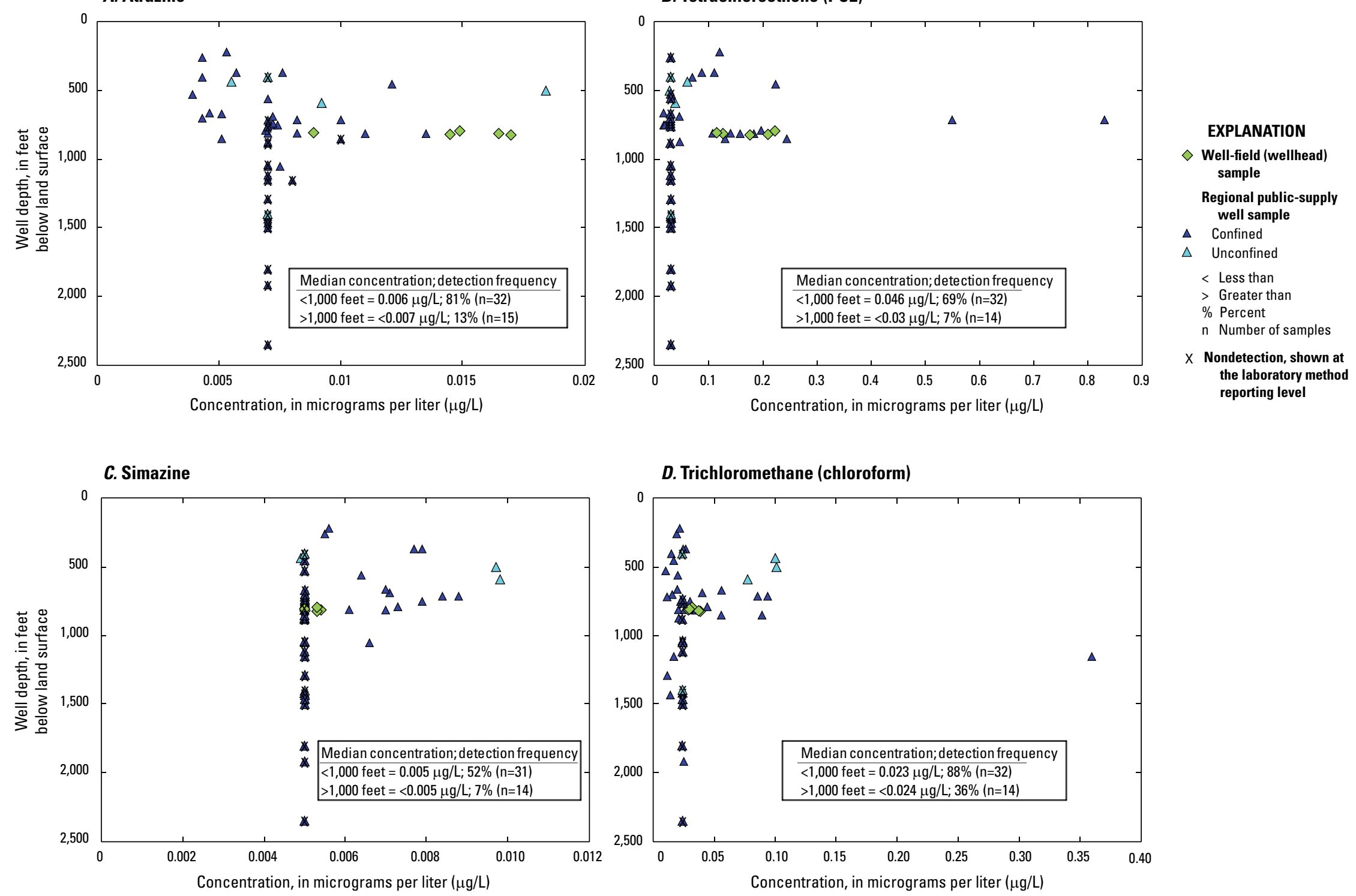

Figure 27. Relation between well depth and concentration for selected organic contaminants for groundwater samples collected for the study of the transport of anthropogenic and natural contaminants (TANC) to public-supply wells, south-central Texas, 2004-9. A, Atrazine. B, Tetrachloroethene (PCE). C, Simazine. D, Trichloromethane (chloroform). 
isotopes ${ }^{3} \mathrm{H} /{ }^{3} \mathrm{He}$, and dissolved gases (methane, $\mathrm{CO}_{2}$, $\mathrm{He}$, $\mathrm{N}_{2}$, oxygen, argon, and $\mathrm{Ne}$ ) - were measured for most of the well-field and monitoring well samples, as well as for the W4 depth-dependent samples. Groundwater age tracers were not measured on samples from the regional aquifer PSWs, but previous NAWQA studies have measured a variety of age tracers in shallow/urban unconfined groundwater and unconfined groundwater samples, as well as ${ }^{3} \mathrm{H}$ in confined groundwater from the regional aquifer (Musgrove and others, 2010). Those results, with a median apparent groundwater age of 20 years (based on a piston-flow model interpretation), indicate that the Edwards aquifer is dominated by “young” or "modern" water, with extensive mixing of groundwater, likely of different ages. "Young" groundwater is defined as water recharged within approximately the past 50 years, the time scale of which is largely defined by the dating range of applicable tracers (Plummer and Friedman, 1999; Plummer and Busenberg, 2005). "Modern" groundwater has been similarly defined; that is, as water that has recharged within the past few decades in a system with an active hydrologic cycle (Clark and Fritz, 1997). Similar to Musgrove and others (2010), this report considers modern groundwater to represent samples with apparent ages that belong to the present day; that is, within 10 years of the time of sampling. This report considers "old" groundwater as that recharged prior to 50 years ago. Previous studies of age tracers and dye-tracing tests in the Edwards aquifer have documented a range of possible groundwater traveltimes and groundwater mixing, largely dominated by young and modern water (Pearson and others, 1975; Campana and Mahin, 1985; Ogden and others, 1986; Johnson and Schindel, 2008; Johnson and others, 2010). Apparent groundwater age in the Edwards aquifer has been demonstrated to vary temporally as a result of changes in hydrologic conditions; that is, variability in hydrologic conditions results in different mixtures of groundwater of different apparent ages (Musgrove and others, 2010). Temporal variability in apparent age results for karst groundwater in response to changes in hydrologic conditions has also been demonstrated in the Floridan aquifer (Katz, 2004; Happell and others, 2006). These results indicate that a one-time sampling of groundwater age tracers in karst might not be representative over a range of hydrologic conditions.

Because of contamination effects and age interpretation complexities (which are described in more detail below), age interpretations were based largely on ${ }^{3} \mathrm{H} /{ }^{3} \mathrm{He}$ results, even though other age tracers were measured. Thus, a comparison of independent apparent ages determined by different dating tracers was not possible. Interpretation of age-tracer results were complicated by some natural background or low-level anthropogenic contamination of groundwater samples by non-atmospheric sources of some tracers; that is, the measured tracer concentration in the groundwater sample was greater than that theoretically possible, on the basis of equilibrium of the groundwater sample with the maximum atmospheric concentration. As a result, most of the age-dating tracer results did not yield resolvable apparent groundwater ages. These results are consistent with previous efforts to interpret results of groundwater age tracers in the Edwards aquifer, which indicated that low-level contamination issues in the aquifer are common, in particular with respect to $\mathrm{CFC}$ and $\mathrm{SF}_{6}$ tracers (Thompson and Hayes, 1979; Musgrove and others, 2010). Contamination from CFCs might be particularly associated with urban areas (Musgrove and others, 2010). Possible urban CFC sources include septic tanks, leaking sewerlines and storage tanks, sewage treatment plant effluent, and industrial wastes (Plummer and Busenberg, 2005). An early study of CFCs identified a plume of CFC-11 in the Edwards aquifer from a proposed point source in the urban San Antonio area to the northeast along a regional flow gradient (Thompson and Hayes, 1979). Age-tracer results for all samples analyzed for $\mathrm{SF}_{6}$ and all but one location analyzed for CFCs indicated that samples were contaminated with excess tracer and that age interpretations were not resolvable (table 18 at end of report) from these compounds. CFC results for one of the well-field samples (W5) yielded independent age interpretations based on CFC-11, CFC-12, and CFC-113 tracers (table 18). However, these resolvable ages might still be affected by excess CFC from widespread low-level aquifer contamination and, as a result, might still be questionable.

Interpreting groundwater ages with ${ }^{3} \mathrm{H}$ is qualitative, but ${ }^{3} \mathrm{H}$ concentrations can provide insight into distinguishing between prebomb and postbomb water based on the history of ${ }^{3} \mathrm{H}$ input to the atmosphere from nuclear weapons testing. Based on its relatively short half-life (12.3 years), the presence of ${ }^{3} \mathrm{H}$ in groundwater is indicative of recent groundwater recharge (Clark and Fritz, 1997; Plummer, 2005). The input of ${ }^{3} \mathrm{H}$ to the atmosphere as a result of nuclear testing dominated the concentrations of ${ }^{3} \mathrm{H}$ in rainfall for about 50 years, with concentrations increasing above natural levels beginning in the early 1950s and peaking in the 1960s. Concentrations of ${ }^{3} \mathrm{H}$ in recent rainfall (since 2006) have globally decreased to approximately prebomb background levels (Clark and Fritz, 1997; Phillips and Castro, 2003; R.L. Michel, U.S. Geological Survey, written commun., 2009). Concentrations of ${ }^{3} \mathrm{H}$ in the well-field and monitoring well samples (excluding the overburden well) (2007-8; $n=19$ ) ranged from less than 1 to $2.23{ }^{3} \mathrm{H}$ units (TU), with a median of $1.97 \mathrm{TU}$ (table 19 at end of report). An additional sample collected from the shallow Zarzamora monitoring well (Z-SED) in 2009 had a ${ }^{3} \mathrm{H}$ concentration of $1.74 \mathrm{TU}$. The overburden monitoring well sample (Z-OVB) had a ${ }^{3} \mathrm{H}$ concentration of $1.30 \mathrm{TU}$. Tritium concentrations showed no relation with well depth or sampling depth. Groundwater ${ }^{3} \mathrm{H}$ concentrations were compared to a local ${ }^{3} \mathrm{H}$ input function derived from a combination of ${ }^{3} \mathrm{H}$ concentrations measured in rainfall at Waco, Tex. (1961-87) and ${ }^{3} \mathrm{H}$ concentrations measured in rainfall at Vienna, Austria (1961-2006) (International Atomic Energy Agency/World Meteorological Organization, 2008). Results for ${ }^{3} \mathrm{H}$ concentration from this study and from Musgrove and others (2010) are indicative of dominantly young and modern groundwater throughout the Edwards aquifer.

The decay of ${ }^{3} \mathrm{H}$ produces the stable isotope ${ }^{3} \mathrm{He}$; the ratio of parent to daughter isotopes is used to estimate the time 
since recharge (Plummer and others, 1993). Tritium decay, however, is not the only possible source of ${ }^{3} \mathrm{He}$, and determining the amount of ${ }^{3} \mathrm{He}$ from the decay of ${ }^{3} \mathrm{H}$ (tritiogenic ${ }^{3} \mathrm{He}$, or ${ }^{3} \mathrm{H}_{\text {trit }}$ ) requires an assessment of other possible ${ }^{3} \mathrm{He}$ sources. Excess air, introduced to groundwater when entrapped air bubbles dissolve, is common in groundwater and is usually the source of most additional ${ }^{3} \mathrm{He}$ (Busenberg and Plummer, 2000). Ne concentrations are used in excess-air correction calculations. Helium can also be introduced to groundwater from terrigenic sources $\left(\mathrm{He}_{\text {terr }}\right)$ because it is produced by the decay of uranium-series (U-series) radionuclides. Age calculations are sensitive to the amount of terrigenic helium-4 $\left({ }^{4} \mathrm{He}_{\text {terr }}\right)$. ${ }^{4} \mathrm{He}_{\text {terr }}$ (relative to the total ${ }^{4} \mathrm{He}$ ) for samples which yielded resolvable apparent ages ranged from near 0 to 20.3 percent, with an average value of around 7 percent (table 19). Two samples had negative values for ${ }^{4} \mathrm{He}_{\text {terr }}$, which might indicate a loss of ${ }^{3} \mathrm{He}$ and yield an older estimated age. ${ }^{4} \mathrm{He}_{\text {terr }}$ values for both of these samples, however, were close to 0 , and the negative values might also reflect analytical uncertainties for very young samples with low ${ }^{4} \mathrm{He}_{\text {terr }}$ values. For these two samples, age calculations were not corrected for ${ }^{4} \mathrm{He}_{\text {terr }}$, and calculated apparent ages were relatively young ( 0.8 and 3.4 years). A large fraction of ${ }^{4} \mathrm{He}_{\text {terr }}$ (greater than 10 percent) is an additional source of uncertainty in age calculations, which are dependent on the ${ }^{3} \mathrm{He} /{ }^{4} \mathrm{He}$ ratio of the $\mathrm{He}_{\text {terr }}$ (Plummer, 2005). The highest $\Delta^{4} \mathrm{He}_{\text {terr }}$ values $\left({ }^{4} \mathrm{He}_{\text {terr }}\right.$ as a percentage of measured $\mathrm{He}$ ) for samples with resolvable ages were associated with the Timberhill monitoring wells (17.5 and 20.3 percent). There was no significant relation between $\Delta^{4} \mathrm{He}_{\text {terr }}$ and U concentration in the water samples, and $U$ concentrations in well-field well and monitoring well samples had a narrow range ( 0.80 $1.17 \mu \mathrm{g} / \mathrm{L}$ ). Terrigenic ${ }^{4} \mathrm{He}$ likely accumulates from U-series decay in aquifer host carbonates where $\mathrm{U}$ is present in low concentrations (up to $1.7 \mathrm{mg} / \mathrm{kg}$ ) (table 5) or from migration from other sources such as deep crustal rocks (Hunt and others, 2010). Values of $\Delta^{4} \mathrm{He}_{\text {terr }}$ (percent) increased with interpreted age (Kendall's tau $=0.89$ ) (fig. 28), which suggests that $\Delta^{4} \mathrm{He}_{\text {terr }}$ values might provide an indicator of relative residence time in this aquifer (Hunt and others, 2010).

Results for ${ }^{3} \mathrm{H} /{ }^{3} \mathrm{He}$ measurements were used to estimate groundwater ages in 15 samples, including those from the monitoring wells ( $n=5)$, well-field $(n=4)$ and depth-dependent sampling from $\mathrm{W} 4(\mathrm{n}=6)$. Apparent ages (summarized in table 19) were not resolvable for several samples, including the well field sample (W5) that had CFC results. Measured ${ }^{3} \mathrm{H}$ concentrations in the overburden well (1.30 TU) and in one of the W4 depth-dependent samples (less than $1 \mathrm{TU}$ ) were too low to obtain a corresponding ${ }^{3} \mathrm{H} /{ }^{3} \mathrm{He}$ interpreted age. Results for several additional samples did not yield resolvable age interpretations because of effects of probable degassing during sample collection (negative $\Delta^{4} \mathrm{He}_{\text {terr }}$ or $\Delta \mathrm{Ne}$ values) (table 19).

An evaluation of geochemical age-dating tracers in a complex karst system such as the Edwards aquifer requires consideration of flow-system dynamics. Lumped-parameter models were used to represent different conceptual flowsystem characteristics, specifically, a piston-flow model,

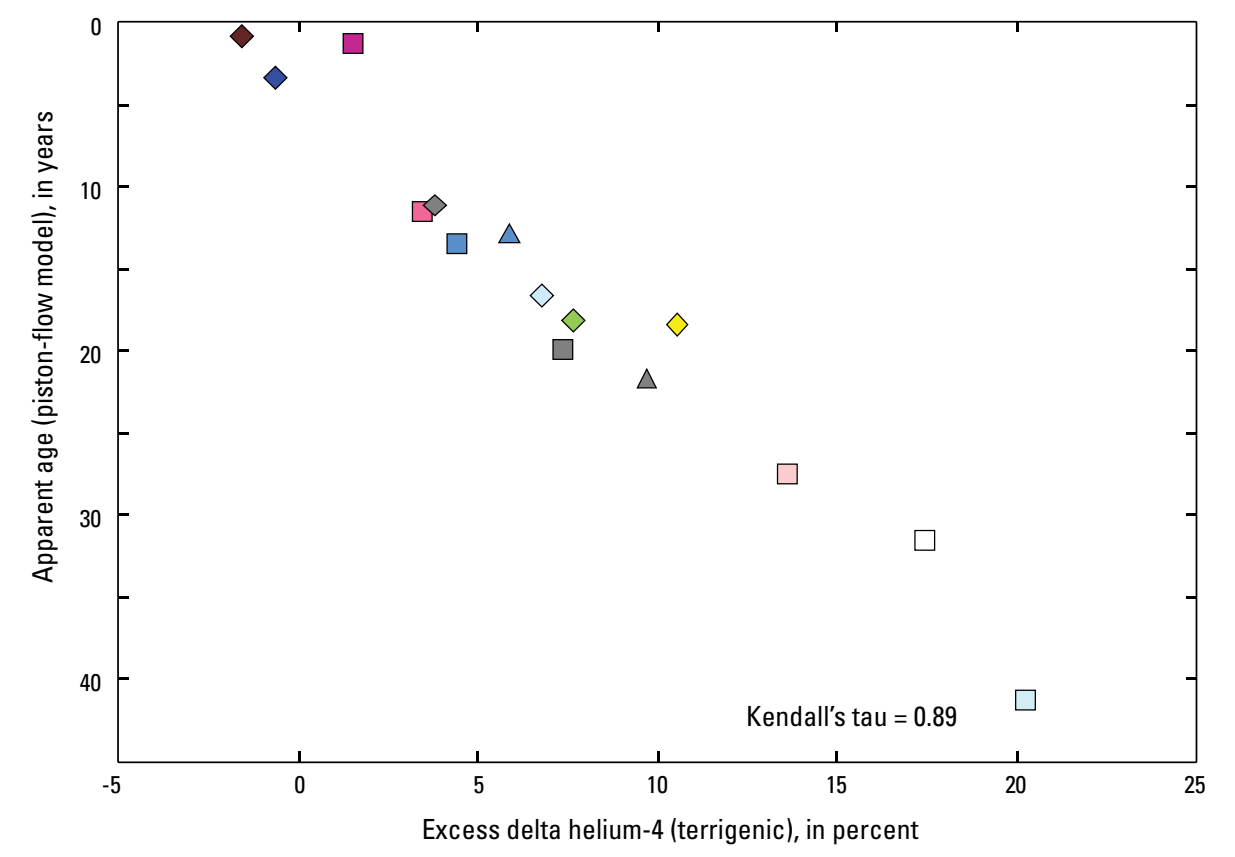

\section{EXPLANATION}

Timberhill monitoring well
sample
Intermediate (T-IED)
Deep (T-DED)
Zarzamora monitoring well
sample
Shallow (Z-SED)
Intermediate (Z-IED)
Deep (Z-DED)
Well-field (wellhead) well
sample
W2
W3
W4
W5
W6
Well-field (W4)
depth-dependent
sample, by pumping
condition-depth
Ambient-intermediate
Ambient-deep
Moderate-shallow
Moderate-intermediate
Moderate-deep
Normal-shallow

Figure 28. Relation between apparent age and excess delta helium-4 (terrigenic) for groundwater samples collected for the study of the transport of anthropogenic and natural contaminants (TANC) to public-supply wells, south-central Texas, 2004-9. 
an exponential mixing model, and several combinations of binary mixing models of older water with younger water. A piston-flow model, which is the simplest and most commonly assumed transport model, assumes that the tracer concentrations were not altered by transport processes (Plummer and Busenberg, 2005). This simplified approach assumes that no mixing or dispersion affects the tracer concentration and that all groundwater flow lines have similar velocity. A piston-flow model likely does not adequately represent a mixed groundwater sample with a range of ages, which is especially valid for karst aquifers (Long and Putnam, 2006). In spite of these uncertainties in age interpretation, piston-flow model ages provide an initial reference point for comparison of different age tracers and time scales of flow processes in the aquifer. An exponential mixing model describes a hydrologic transport model in which the mean residence time of groundwater is exponentially distributed; that is, groundwater is a mixture of recharge from past years. Groundwater contributions to well or spring discharge would be dominated by the most recent recharge and decrease exponentially in proportion to older recharge. An exponential mixing model might represent a reasonable approximation of a homogeneous unconsolidated aquifer but, like the piston-flow model, is likely not an adequate representation of a karst aquifer, where traveltimes can vary widely between matrix-flow-dominated and conduitflow-dominated endmembers. The mean age of the exponential mixture was varied in evaluating exponential models. Binary mixing models assume that groundwater is composed of a mixture of two endmembers of different ages, for example relatively young (modern) water (recharged within the past 10 years) mixed with relatively older water (recharged several or more decades ago with little to no detectable tracer concentrations). Lumped-parameter models of binary mixtures were evaluated for a variety of young and old age combinations; for example, piston-flow models for both endmembers, a pistonflow model for the old endmember and an exponential flow model for the young endmember, and an exponential flow model for the old endmember and a piston-flow model for the young endmember. For modeling purposes, both endmembers of a binary mixture can be any age, but for purposes of this effort it was assumed that one endmember was modern (that is, recharged within the past zero to 5 years) and the other was young to old (that is, recharged 30-70 years ago, which includes that time period for which there would be little to no detectable tracer concentrations). For binary mixtures of modern and old water, the ${ }^{3} \mathrm{H} /{ }^{3} \mathrm{He}$ method is particularly useful for determining the age of the younger fraction; the isotopic ratio is nearly independent of dilution with old ${ }^{3} \mathrm{H}$-free water (Plummer and others, 1998). Plots of age-frequency distributions based on tracer-tracer concentrations for collected samples relative to theoretical curves for different lumpedparameter models can provide insight into the distribution of apparent ages in an aquifer, age mixtures at wells, and the representativeness of different hydrogeologic concepts of the flow system.
Lumped-parameter-model results for different hydrogeologic conceptual models and different mixtures of age combinations did not clearly indicate that any one conceptual hydrogeologic model can account for the range of measured age-tracer concentrations. For the tracer-tracer plot showing the relation between ${ }^{3} \mathrm{H}$ and ${ }^{3} \mathrm{H} /{ }^{3} \mathrm{H}_{0}$, most of the samples plot above the piston-flow-model curve and slightly above the exponential model curve (fig. 29). The sample with the lowest ${ }^{3} \mathrm{H} /{ }^{3} \mathrm{H}_{0}$ ratio and oldest interpreted age (T-IED) plots well below the piston-flow-model curve but close to the exponential model curve. The ${ }^{3} \mathrm{H}_{0}$ value is the sum of the measured concentrations of ${ }^{3} \mathrm{H}$ and ${ }^{3} \mathrm{He}_{\text {trit }}$ (tritiogenic ${ }^{3} \mathrm{H}$, derived from the decay of ${ }^{3} \mathrm{H}$ ) and represents the initial ${ }^{3} \mathrm{H}$ concentration at the time of recharge. The ratio of tritium to initial tritium $\left({ }^{3} \mathrm{H} /{ }^{3} \mathrm{H}_{0}\right)$ is a proxy for the relative age of water; values near zero represent older water, whereas a value approaching 1 represents younger water (Böhlke, 2002). ${ }^{3} \mathrm{H} /{ }^{3} \mathrm{H}_{0}$ values are correlated with piston-flow groundwater ages (Kendall's tau $=-1.0$ ) (fig. 30). The W4 depth-dependent ambient-deep sample deviated from the trend of this relation relative to the rest of the samples; the cause of this deviation is unclear. Other lumpedparameter models shown on tracer-tracer plots (figs. 29, 31, and 32) are for an exponential model with a mean groundwater model age of 3 years, a combined piston-flow/exponentialflow model, and binary mixture models with modern and young endmember ages of 0.5 and 30 years (binary mix 1 with piston-flow models for both endmembers; binary mix 2 with an exponential-flow model for the modern endmember and a piston-flow model for the young endmember; and binary mix 3 with a piston-flow model for the modern endmember and an exponential-flow model for the young endmember). These potential mixture ages are consistent with particle-track results from a calibrated groundwater-flow model for the local-scale study area, described by Lindgren and others (2011b). These modeling results indicate that approximately 48 percent of particle tracks to the study PSW are within a 0- to less than 2-year range of traveltimes, an additional 40 percent are within the 2to less than 5-year range of traveltimes, an additional 8 percent are within the 5- to less than 10-year range of traveltimes, and 4 percent have a greater than 10 year traveltime (fig. 33). While different lumped-parameter models might account for different samples on the basis of tracer-tracer plots (fig. 29), no prevailing model accounts for the range of age-tracer results and consistently seems to describe the flow system.

An exponential-flow mixing model can be used to estimate the mean age of groundwater in a sample; the W4 well-field sample and the depth-dependent samples for normal pumping conditions fall close to the exponential-flow model (fig. 29). A comparison of model estimates with ${ }^{3} \mathrm{H}_{0}$ values suggests that samples from the monitoring wells and well field compose a large range of mean ages, from close to 0 to approaching 50 years (fig. 34A). A similar comparison of ${ }^{3} \mathrm{H}$ concentrations with model-estimated mean ages does not allow for distinguishing different mean ages between samples as a result of the narrow range of ${ }^{3} \mathrm{H}$ concentrations and the convergence of model curves for the narrow range of sample 


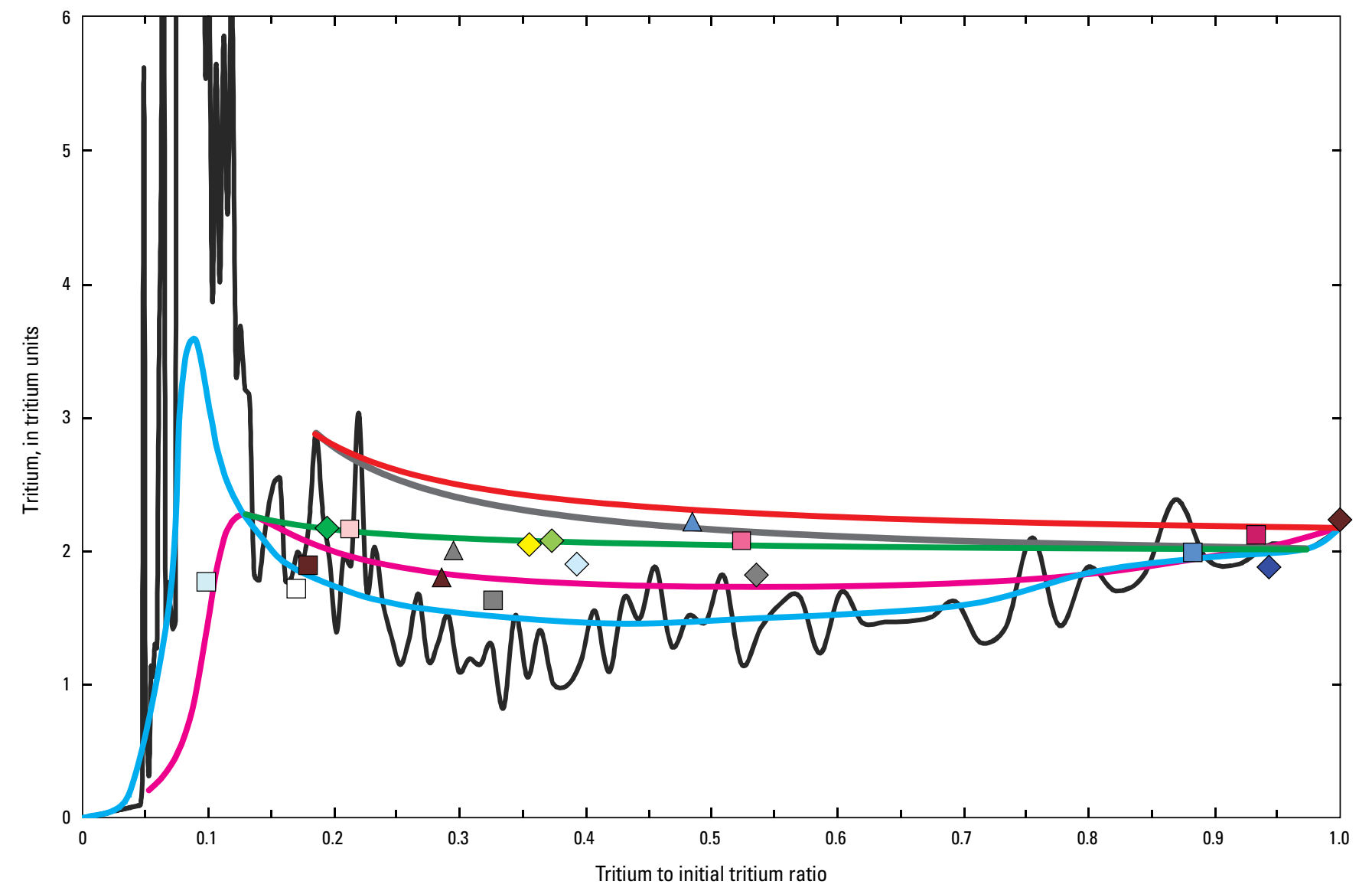

\begin{tabular}{|c|c|}
\hline & $\begin{array}{l}\text { EXPLANATION } \\
\text { Lumped-parameter } \\
\text { flow model }\end{array}$ \\
\hline & $\begin{array}{l}\text { Piston } \\
\text { Exponential } \\
\text { Piston-exponential } \\
\text { Binary mix } 1 \\
\text { Binary mix } 2 \\
\text { Binary mix } 3\end{array}$ \\
\hline & $\begin{array}{l}\text { Timberhill monitoring well } \\
\text { sample }\end{array}$ \\
\hline & $\begin{array}{l}\text { Intermediate (T-IED) } \\
\text { Deep (T-DED) }\end{array}$ \\
\hline & $\begin{array}{l}\text { Zarzamora monitoring well } \\
\text { sample }\end{array}$ \\
\hline & $\begin{array}{l}\text { Shallow (Z-SED) } \\
\text { Intermediate (Z-IED) } \\
\text { Deep (Z-DED) }\end{array}$ \\
\hline & $\begin{array}{l}\text { Well-field (wellhead) well } \\
\text { sample }\end{array}$ \\
\hline & W2 \\
\hline & W3 \\
\hline & W4 \\
\hline & W5 \\
\hline & W6 \\
\hline & $\begin{array}{l}\text { Well-field (W4) } \\
\text { depth-dependent } \\
\text { sample, by pumping } \\
\text { condition-depth }\end{array}$ \\
\hline & $\begin{array}{l}\text { Ambient-intermediate } \\
\text { Ambient-deep }\end{array}$ \\
\hline & $\begin{array}{l}\text { Moderate-shallow } \\
\text { Moderate-intermediate } \\
\text { Moderate-deep }\end{array}$ \\
\hline & $\begin{array}{l}\text { Normal-shallow } \\
\text { Normal-intermediate } \\
\text { Normal-deep }\end{array}$ \\
\hline
\end{tabular}

Figure 29. Relation between tritium $\left({ }^{3} \mathrm{H}\right)$ concentration and ${ }^{3} \mathrm{H}$ to initial tritium $\left({ }^{3} \mathrm{H}_{0}\right)$ ratio $\left({ }^{3} \mathrm{H} /{ }^{3} \mathrm{H}_{0}\right)$ for groundwater samples collected for the study of the transport of anthropogenic and natural contaminants (TANC) to public-supply wells, south-central Texas, 2004-9, and lumped-parameter modeled curves for various groundwater age distributions. 

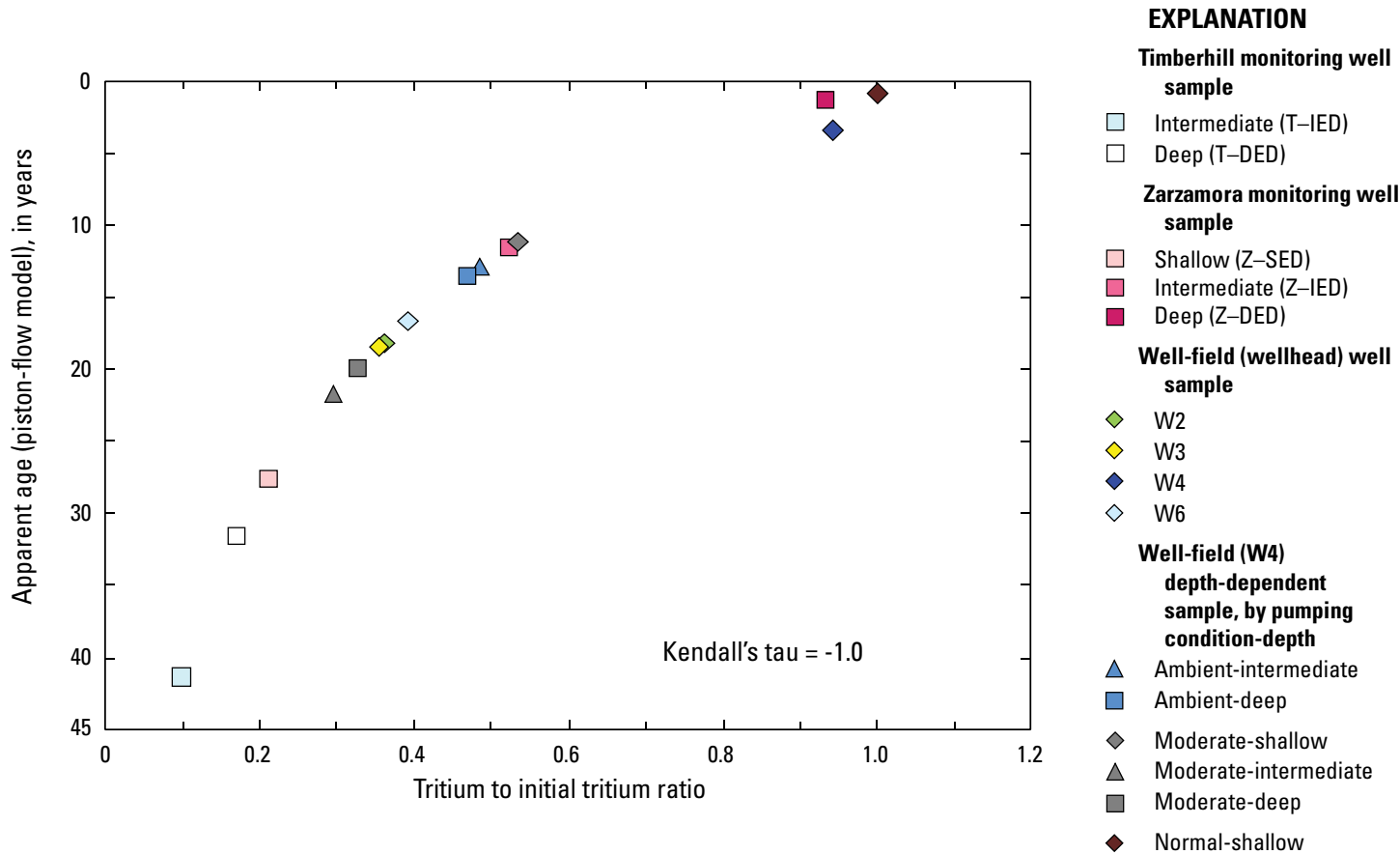

Figure 30. Relation between apparent age and the tritium $\left({ }^{3} \mathrm{H}\right)$ to initial tritium $\left({ }^{3} \mathrm{H}_{0}\right)$ ratio for groundwater samples collected for the study of the transport of anthropogenic and natural contaminants (TANC) to public-supply wells, south-central Texas, 2004-9.

collection dates (fig. 34B). Based on wellbore flow characteristics, flow to W4 under normal pumping conditions (with multiple wells in the well field pumping) is sourced from multiple stratigraphic units in the Edwards section (fig. 7). The mean exponential model age for the W4 well-field sample, which is assumed to represent conditions of water quality for water produced from the PSW, was younger than the other wellhead samples and most of the depth-dependent samples, with a model (apparent) age of approximately 3 years.

Tracer-tracer plots for CFC concentrations show mean results for only the single well-field PSW (W5) for which CFC concentrations were not contaminated for age-tracer purposes. CFC concentrations for CFC- 11 relative to CFC-12 and for CFC-11 relative to CFC-113 indicate that tracer concentrations might have been affected by tracer contamination or degradation because sample concentrations plot far outside the area of different flow models (fig. 32). CFC degradation, which can occur in anoxic environments, is unlikely because of the generally oxic condition of the aquifer (Plummer, 2005). The widespread CFC contamination throughout the aquifer (this study; Musgrove and others, 2010) indicates that potential CFC contamination of the W5 well is also plausible. On the tracer-tracer plot for CFC-12 relative to CFC-113, the W5 sample plots in between an exponential-flow model curve and a combined piston-exponential model curve (fig. 32). Results for the W5 sample on tracer-tracer plots for CFC-12 and CFC113 concentrations relative to the measured ${ }^{3} \mathrm{H}$ concentration (fig. 31) are generally consistent with either the piston-flow or exponential-flow lumped-parameter models. It is difficult, however, to evaluate any particular flow model based on a single sample, and results for sample W5 are not consistent with any single lumped-parameter model. These results indicate that apparent ages on the basis of CFC concentrations for the sample from W5 should be interpreted with caution. Piston-flow-model interpreted ages for W5 (mean) were 38.7, 30.9, and 26.4 years based on CFC-11, CFC-12, and CFC-113 tracers, respectively. An exponential model yields a mean age of approximately 17 years for this sample based on the ${ }^{3} \mathrm{H}_{0}$ concentration (fig. 34), although this approach is not ideal because a ${ }^{3} \mathrm{H} /{ }^{3} \mathrm{He}$ age was not resolvable for this sample.

A comparison of model ages provides insight into flowsystem dynamics supplying water to the well field. Pistonflow-model groundwater ages based on ${ }^{3} \mathrm{H} /{ }^{3} \mathrm{He}$ results for all samples, including depth-dependent samples (which are discussed in more detail in the subsequent section), range from 0.8 to 41.3 years, with a median of 16.6 years. Pistonflow-model groundwater ages (fig. 35) are inversely stratified for both sets of monitoring wells, with younger ages for the deeper monitoring wells. The oldest apparent ages are for the Timberhill monitoring wells (41.3 and 31.6 years, 

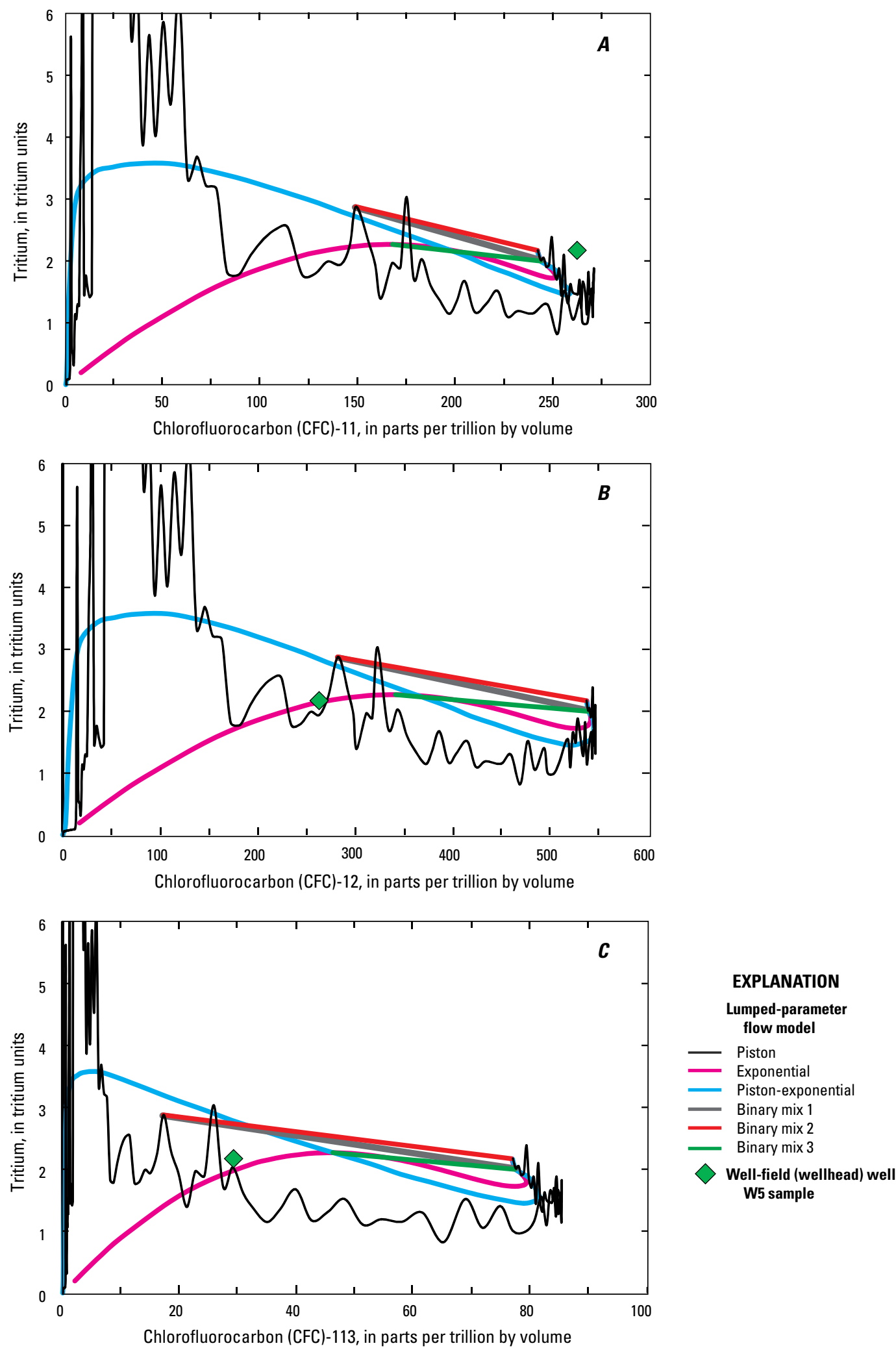

Figure 31. Relation between tritium concentration $\left({ }^{3} \mathrm{H}\right)$ and chlorofluorocarbon $(\mathrm{CFC})$ age tracers for groundwater sample collected from the well-field well, W5, for the study of the transport of anthropogenic and natural contaminants (TANC) to public-supply wells, south-central Texas, 2004-9, and lumped-parameter modeled curves for various groundwater age distributions. $A$, Relation between tritium and CFC-11. B, Relation between tritium and CFC-12. C, Relation between tritium and CFC-113. 

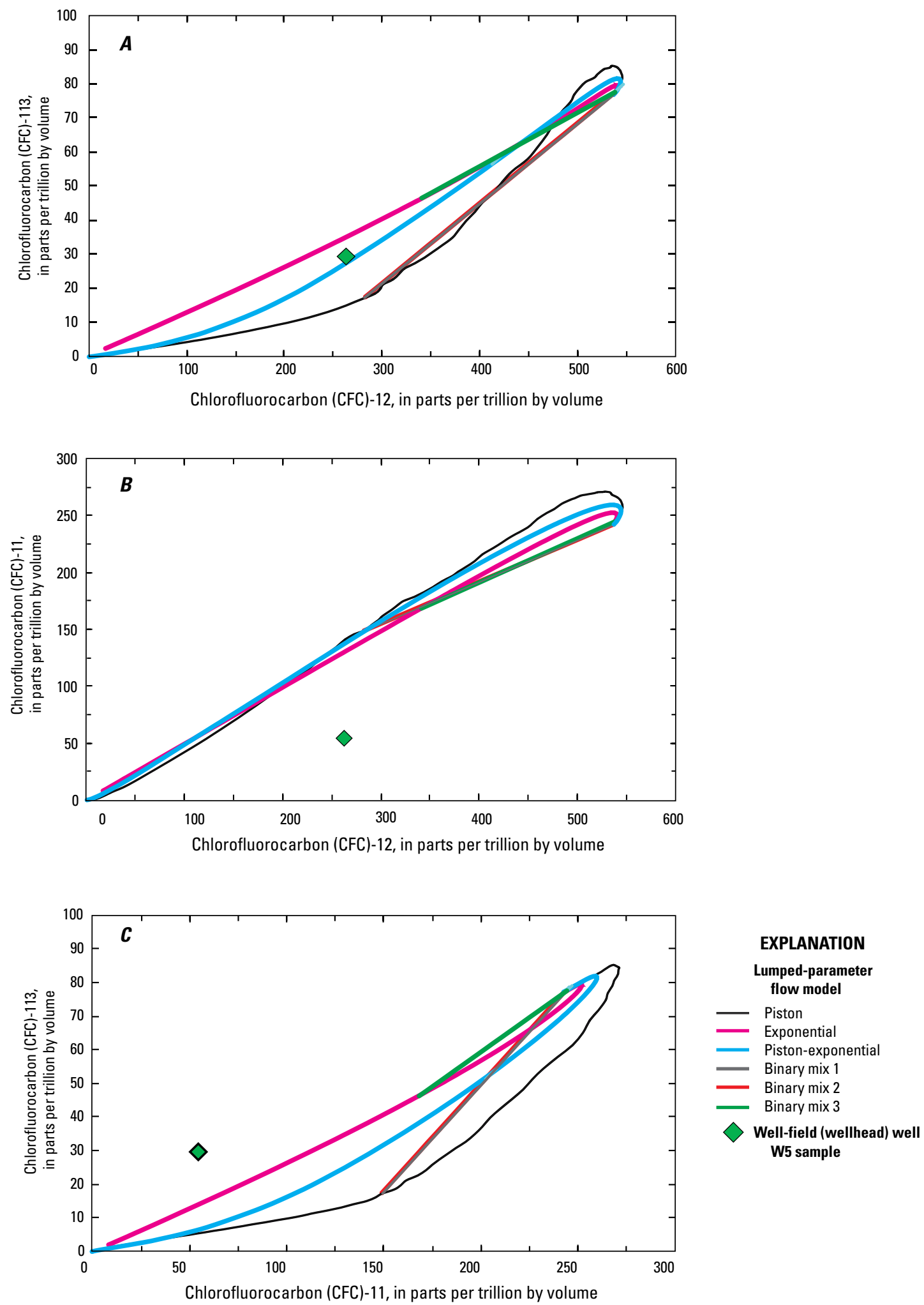

Figure 32. Relation between chlorofluorocarbon (CFC) age tracers (CFC-11, CFC-12, and CFC-113) for groundwater sample collected from the well-field well, W5, for the study of the transport of anthropogenic and natural contaminants (TANC) to public-supply wells, south-central Texas, 2004-9, and lumped-parameter modeled curves for various groundwater age distributions. $A$, Relation between CFC-12 and CFC-113. B, Relation between CFC-12 and CFC-11. C, Relation between CFC-11 and CFC-113. 


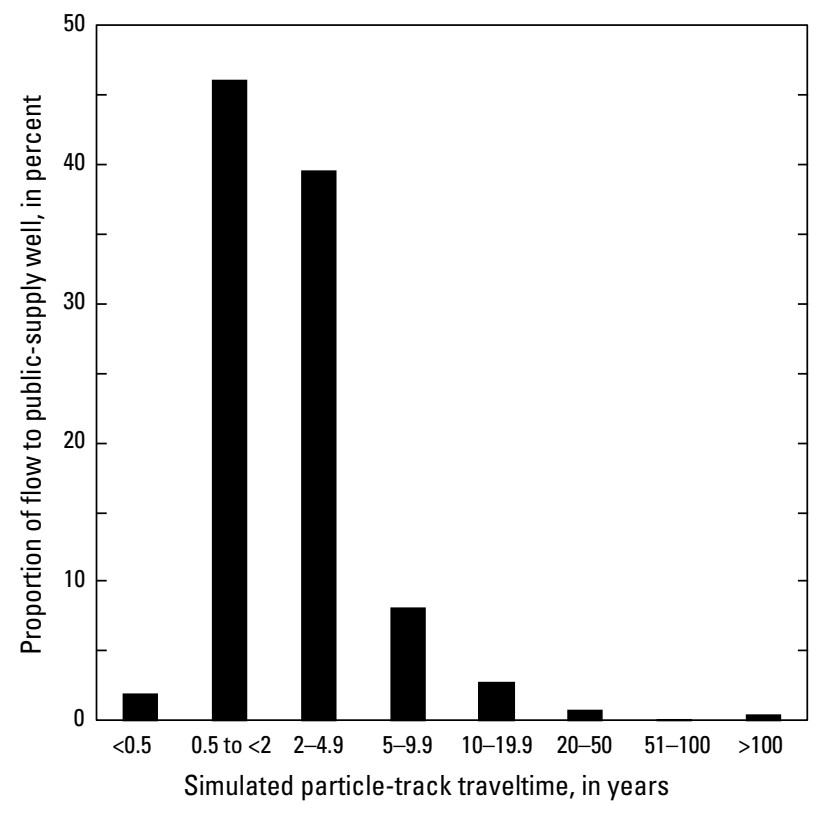

Figure 33. Particle-track age distribution to selected publicsupply well for the study of the transport of anthropogenic and natural contaminants (TANC) to public-supply wells, based on local-scale study model results described by Lindgren and others (2011b) in the San Antonio segment of the Edwards aquifer, southcentral Texas.

respectively, for the intermediate and deep monitoring wells). Apparent ages for the Zarzamora monitoring wells (excluding the overburden well) are quite young in the deepest well (1.3 years); the apparent age for the shallow Zarzamora monitoring well (27.5) approaches the deeper Timberhill monitoring well age. Apparent ages based on ${ }^{3} \mathrm{H} /{ }^{3} \mathrm{He}$ results for the well-field samples are similar (16.6-18.4 years), with the exception of W4, which yielded a much younger age (3.4 years). Depthdependent samples had apparent ages ranging from 0.8 to 21.7 years, but the ages were not consistently related to depth or to pumping condition (fig. 35; table 19). These results are consistent with extensive mixing in this complex karst hydrogeologic system. The range of piston-flow-model ages for TANC study samples is similar to the range reported for Edwards aquifer unconfined groundwater samples by Musgrove and others (2010) of 1 to 52 years and with a median of 20 years.

Selected geochemical constituents were compared with the ratio of ${ }^{3} \mathrm{H} /{ }^{3} \mathrm{H}_{0}$, which, as noted earlier, is a proxy for the relative age of water (with relative ages becoming younger as ${ }^{3} \mathrm{H} /{ }^{3} \mathrm{H}_{0}$ values approach 1) (B öhlke, 2002). Inorganic geochemical parameters compared to ${ }^{3} \mathrm{H} /{ }^{3} \mathrm{H}_{0}$ included specific conductance, $\mathrm{Mg} / \mathrm{Ca}$ molar ratios, ${ }^{87} \mathrm{Sr} /{ }^{86} \mathrm{Sr}$ values, and dolomite SI. Specific conductance generally increases with increased groundwater residence time. Dolomite SIs, $\mathrm{Mg} / \mathrm{Ca}$ ratios, and Sr isotopes have been demonstrated to be qualitative indicators of residence time in the Edwards aquifer (Musgrove and others, 2010). With longer residence time and greater extents of water-rock interaction, dolomite SIs approach equilibrium,
$\mathrm{Mg} / \mathrm{Ca}$ ratios increase, and ${ }^{87} \mathrm{Sr} /{ }^{86} \mathrm{Sr}$ values decrease toward values similar to the host aquifer rocks. A comparison of these constituents with ${ }^{3} \mathrm{H} /{ }^{3} \mathrm{H}_{0}$ ratios, however, does not indicate a consistent relation with interpreted groundwater age (fig. 36). The relation of ${ }^{3} \mathrm{H} /{ }^{3} \mathrm{H}_{0}$ with specific conductance and $\mathrm{Mg} / \mathrm{Ca}$ ratios was not statistically significant. The relation of ${ }^{3} \mathrm{H} /{ }^{3} \mathrm{H}_{0}$ with dolomite SIs and ${ }^{87} \mathrm{Sr} /{ }^{86} \mathrm{Sr}$ values was significant (Kendall's tau $=0.36$ and -0.34 , respectively). The relation was inverse, however, to that expected for these constituents with groundwater age: dolomite SIs approach equilibrium in younger apparent-age samples, and ${ }^{87} \mathrm{Sr} /{ }^{86} \mathrm{Sr}$ values approach values similar to the aquifer rocks in younger apparent-age samples. The relation of ${ }^{3} \mathrm{H} /{ }^{3} \mathrm{H}_{0}$ with dolomite SIs and ${ }^{87} \mathrm{Sr} /{ }^{86} \mathrm{Sr}$ values was strongly influenced by values for the Timberhill monitoring wells; if these data were not considered, the relations were no longer statistically significant.

Similar to inorganic constituents, anthropogenic organic constituents were not clearly related to apparent age. Concentrations and detections of anthropogenic contaminants are generally expected to be higher in younger groundwater. However, the relation of ${ }^{3} \mathrm{H} /{ }^{3} \mathrm{H}_{0}$ with the number of detections of organic contaminants and with atrazine, DEA, and PCE concentrations was not significant (fig. 37). The relation with other frequently detected organic contaminants, such as simazine and chloroform, also was not significant.

The absence of significant relations of inorganic geochemical indicators and anthropogenic constituents to apparent age indicates that mixing processes in this aquifer are complex and that hydrogeologic conceptual models used in groundwater age interpretations might not adequately account for mixing in this karst system. Age tracers in this aquifer provide insight into the young nature of the groundwater but might not readily allow for distinguishing the mixed water history or be well suited to distinguish relatively small differences in groundwater age as a result of mixing processes. This hypothesis is consistent with the relatively homogeneous geochemistry for many constituents in groundwater samples collected from the regional aquifer PSWs and from the well-field and monitoring wells.

\section{Depth-Dependent Water Chemistry}

Variations in depth-dependent geochemical results can provide insight into water quality of different parts of the aquifer that might contribute water to the PSW, as well as differences in water quality in the Edwards aquifer relative to overburden units. Variations in geochemical results from different pumping conditions can provide insight into the distribution of groundwater flow paths contributing water to the PSW. Previous studies indicate that groundwater flow in the Edwards aquifer is focused in highly permeable units and is affected by faulting (Abbott, 1975; Woodruff and Abbott, 1979; Maclay and Small, 1986; Maclay and Land, 1988; Sharp, 1990; Lindgren and others, 2011b).

As described earlier in the sections "Geophysical and Depth-Dependent Flow Measurements" and 

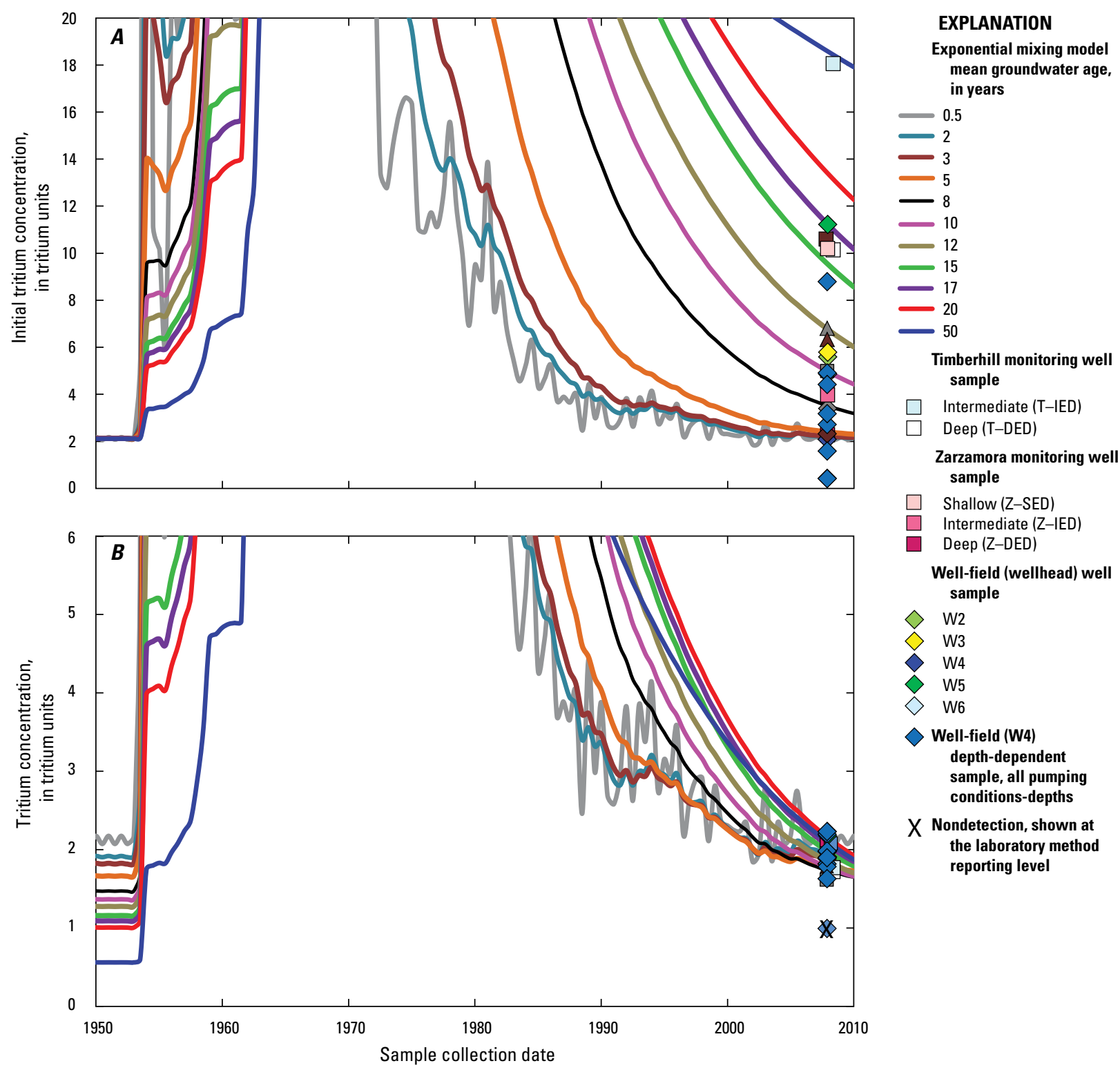

reporting leve

Figure 34. Relation between sample collection date and tritium for groundwater samples collected for the study of the transport of anthropogenic and natural contaminants (TANC) to public-supply wells, south-central Texas, 2004-9. $A$, Relation between sample collection date and initial tritium concentration $\left({ }^{3} \mathrm{H}_{0}\right)$. $B$, Relation between sample collection date and tritium concentration $\left({ }^{3} \mathrm{H}\right)$. Both $A$ and $B$ are shown with exponential mixing model based trendlines for expected ${ }^{3} \mathrm{H}_{0}$ and ${ }^{3} \mathrm{H}$ concentrations for selected mean groundwater ages.

"Depth-Dependent Samples," flow measurements and groundwater samples were collected from W4 from three different depths (fig. 4) and under three different pumping conditions (ambient, moderate, and normal) to characterize the water quality of different parts of the aquifer that might contribute water to the PSW. The normal pumping condition is likely to be most representative of pumping conditions associated with the production of supply water and should have chemistry similar to surface discharge samples (wellhead samples) collected from the well field under normal production operations.
As noted earlier, it was not possible to collect a surface discharge (wellhead) sample from W4; a sample was instead collected with the sample pump directly near the bottom of the casing (at a depth of approximately $320 \mathrm{ft}$ ).

Flow measurement results indicated that the distribution of the flow of water entering W4 during normal pumping conditions was complex but likely largely originated from the Kirschberg evaporite member (HGUs 8 and 9) and the combined leached and collapsed and cyclic and marine members (HGUs 3-5), with some contribution from the lower dolomitic 


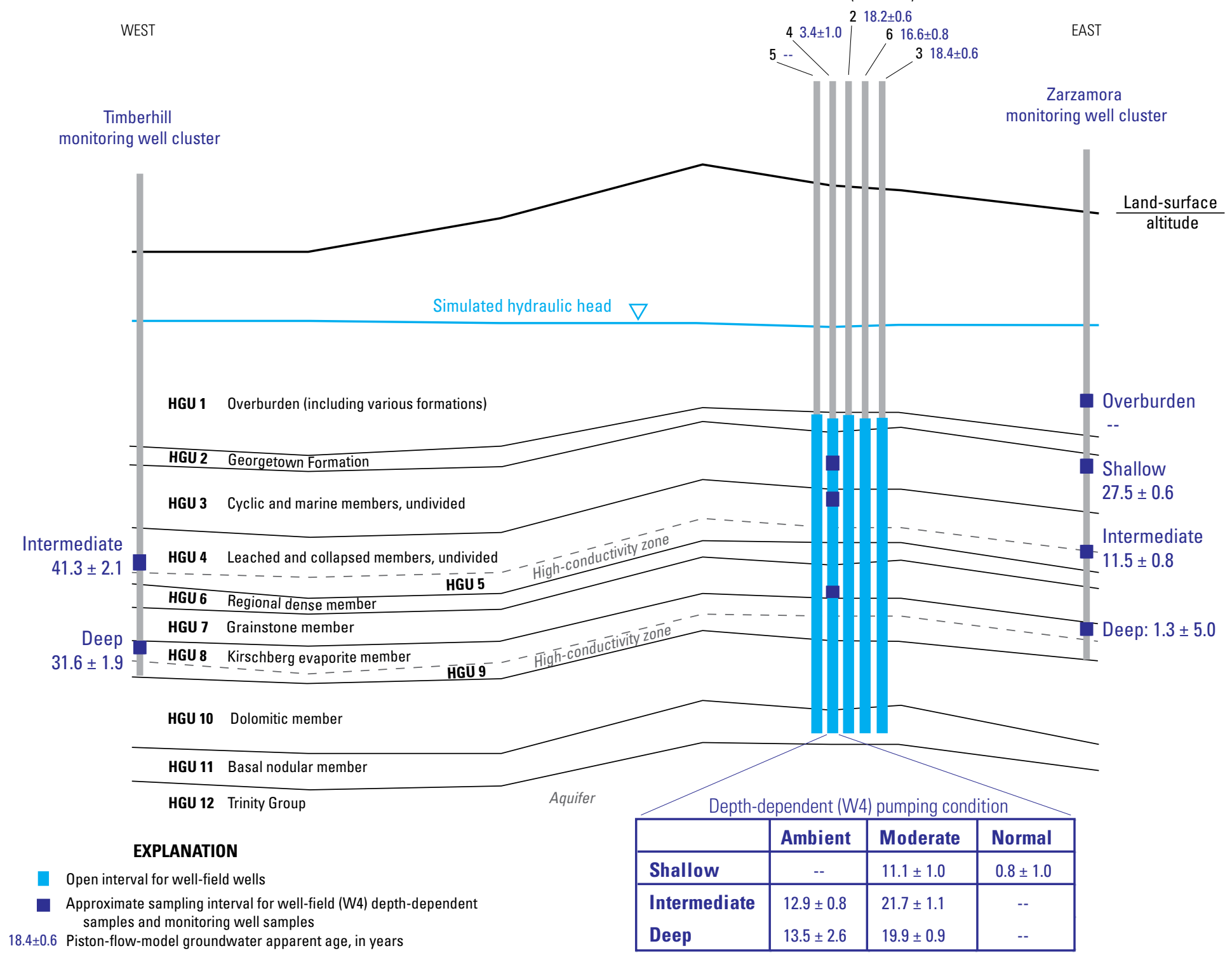

Zarzamora

monitoring well cluster

monitoring well cluste 

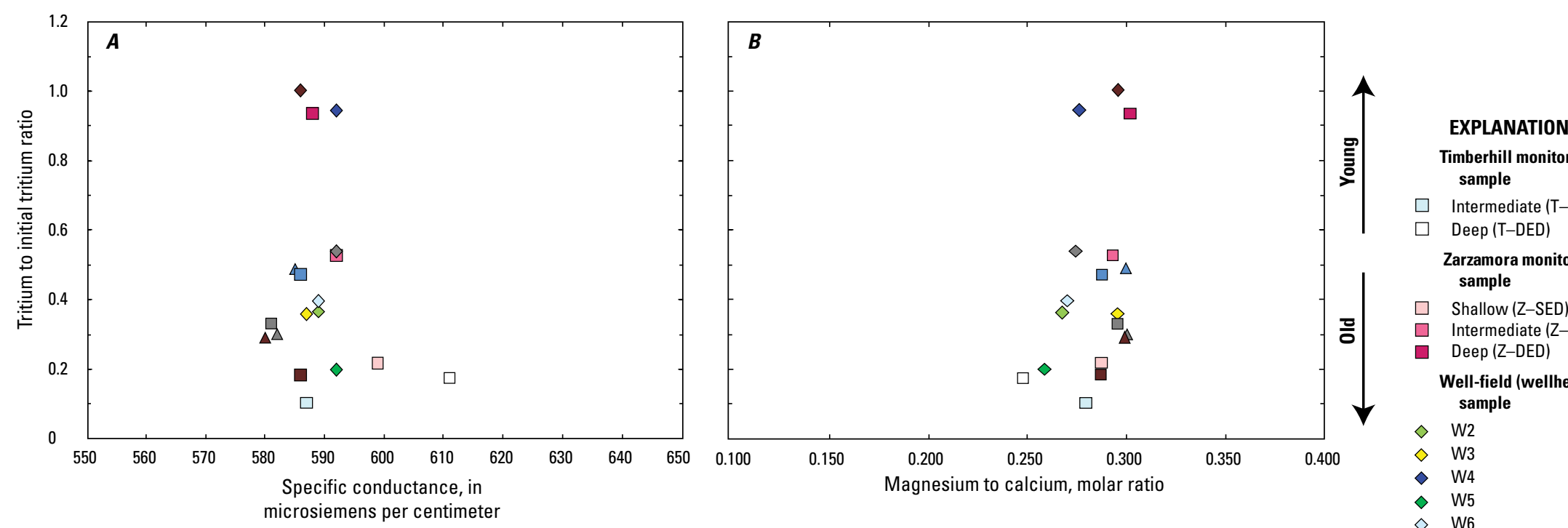

Timberhill monitoring well sample

$\square \quad$ Intermediate (T-IED)

$\square \quad$ Deep (T-DED)

Zarzamora monitoring well sample

$\square \quad$ Shallow (Z-SED)

$\square \quad$ Intermediate (Z-IED)

- Deep (Z-DED)

Well-field (wellhead) well sample

$\diamond \quad W 2$

$\diamond W 3$

$\diamond W 4$

$\diamond W 4$
$\diamond \quad W 5$

microsiemens per centimeter
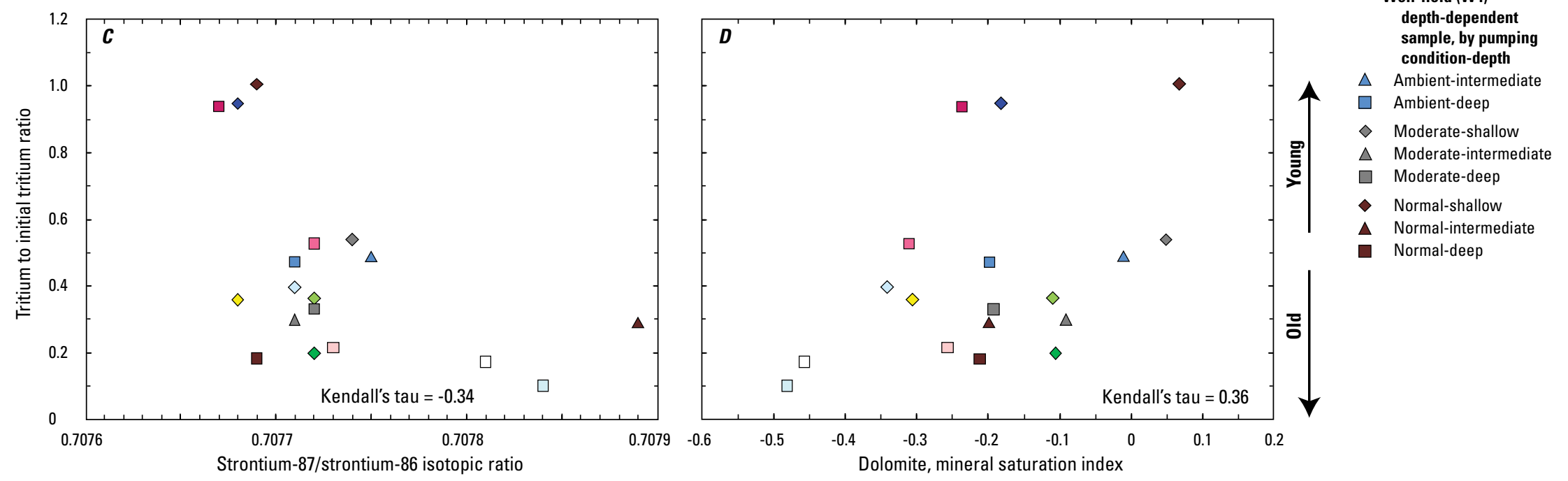

Figure 36. Relation between tritium to initial tritium ratio $\left({ }^{3} \mathrm{H} /{ }^{3} \mathrm{H}_{0}\right)$ and selected geochemical constituents for groundwater samples collected for the study of the transport of anthropogenic and natural contaminants (TANC) to public-supply wells, south-central Texas, 2004-9. A, Specific conductance. B, Magnesium to calcium molar ratio. $C$, Strontium isotope composition. $D$, Dolomite mineral saturation index. 

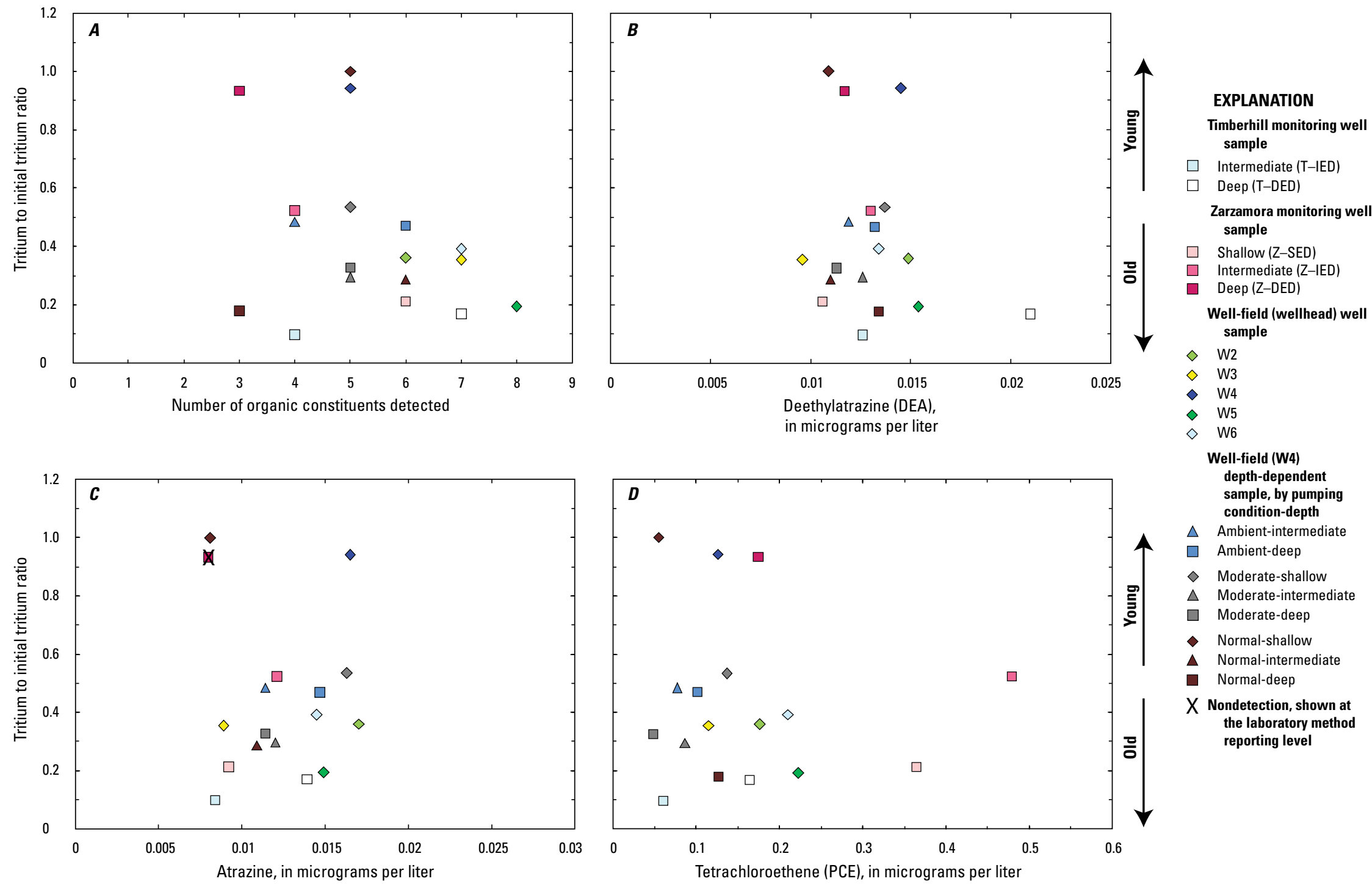

$\square \quad$ Deep (T-DED)

Zarzamora monitoring well sample

$\square \quad$ Shallow (Z-SED)

$\square \quad$ Intermediate (Z-IED)

Well-field (wellhead) well

sample

$\diamond \quad W 2$

$\diamond \quad W 3$

$\diamond W_{4}$

$\diamond$ W5

$\diamond$ W6

Well-field (W4) depth-dependent sample, by pumpin

Ambient-intermedia

oderate-shallow

Moderate-deep

Normal-shallow

Normal-intermediate

Normal-deep

the laboratory metho reporting level

Figure 37. Relation between tritium to initial tritium ratio $\left({ }^{3} \mathrm{H} /{ }^{3} \mathrm{H}_{0}\right)$ and selected geochemical constituents for groundwater samples collected for the study of the transport of anthropogenic and natural contaminants (TANC) to public-supply wells, south-central Texas, 2004-9. A, Number of organic constituents detected. $B$, Deethylatrazine (DEA) concentration. C, Atrazine concentration. D, Tetrachloroethene (PCE) concentration. 
member (HGU 10) (fig. 7). Under one pumping condition (described below), some loss of flow in the leached and collapsed members (HGUs 4 and 5) was observed. Intermediate depth-dependent samples were collected within the leached and collapsed members (HGUs 4 and 5), and the shallow depth-dependent samples were collected within the cyclic and marine members (HGU 3). The deep depth-dependent samples were collected from within the grainstone member (HGU 7) but are considered representative of water flowing upward in the wellbore from the Kirschberg evaporite member (HGUs 8 and 9) and dolomitic member (HGU 10).

Depth-dependent samples collected from W4 during normal pumping conditions indicated that, although much of the groundwater was coming from high-conductivity zones, the water quality throughout different HGUs was relatively homogeneous, indicative of substantial mixing in the aquifer. Geochemical results were compared for different sampling depths and flow conditions, as well as with samples from the monitoring wells. For comparison purposes between the depth-dependent samples and monitoring well samples, results were compared by HGU (fig. 38). A comparison by sample depth for the depth-dependent samples and well depth for the monitoring well samples is complicated by inferred faulting between the well-field and monitoring well locations. Faulting is inferred because of widespread occurrence in the study area and because of observed differences in depths to HGUs between the well-field PSWs and monitoring wells in the Zarzamora monitoring well cluster.

There were generally minor differences in physicochemical properties and chemical and isotopic constituents in depthdependent samples (fig. 38); this observation is consistent with the hypothesis that water from the PSW is relatively well mixed and homogeneous regardless of pumping conditions. However, several constituents show some differences in depth profiles under different pumping conditions. The sample collected from the intermediate sampling interval (HGUs 4 and 5) under normal pumping conditions had a higher ${ }^{87} \mathrm{Sr} /{ }^{86} \mathrm{Sr}$ value (0.70789) than under ambient or moderate pumping conditions (fig. 38K). This value is higher than those for well-field samples, which had a narrow ${ }^{87} \mathrm{Sr} /{ }^{86} \mathrm{Sr}$ range of 0.70768 to 0.70772. The sample collected from the intermediate and deep sampling intervals also had a higher boron (B) concentration under normal pumping conditions than under ambient and moderate pumping conditions (fig. 38N). Sr isotope compositions in the regional aquifer generally decrease to lower values with increased residence time, whereas B concentrations tend to be higher in the confined part of the aquifer (Musgrove and others, 2010). Although the ${ }^{87} \mathrm{Sr} /{ }^{86} \mathrm{Sr}$ and B concentration results for these depth-dependent samples were different from the remainder of the W4 and monitoring well samples, they were within the range of variability for the regional aquifer (Musgrove and others, 2010). Samples from the Timberhill monitoring wells had similar elevated ${ }^{87} \mathrm{Sr} /{ }^{86} \mathrm{Sr}$ values (fig. 38K). Samples collected from the Timberhill monitoring wells also had lower dolomite SIs, and the sample collected from the deep Timberhill monitoring well (T-DED) had a slightly lower $\mathrm{Mg} / \mathrm{Ca}$ ratio. These results are consistent with the Timberhill monitoring well samples representing less geochemically evolved groundwater, although this hypothesis contrasts with apparent-age results for these samples (which had the oldest interpreted ages of 41.3 and 31.6 years for the intermediate and deep Timberhill monitoring well samples, respectively). When compared with the depth-dependent samples, results for the monitoring well samples show some minor differences in major ion concentrations, with slightly higher alkalinity and Ca concentrations and slightly lower $\mathrm{SO}_{4}$ concentrations and dolomite SIs, although the values are within the range of variability for the regional aquifer (Musgrove and others, 2010).

PCE concentrations in samples from the shallow and intermediate Zarzamora monitoring wells (Z-SED and ZIED) were elevated with respect to the W4 depth-dependent samples, as well as with respect to regional aquifer PSW samples (fig. 38W; fig. 26; table 14). As discussed earlier (in the section "Organic Constituents"), PCE concentrations in samples from W4 were higher than the median for those from regional (confined) aquifer PSWs. These results suggest that the shallower Zarzamora monitoring wells and W4 have some hydraulic connection with urban contaminant sources. The most notable geochemical variability for the depth-dependent and monitoring well samples is for results of age-tracer data and corresponding model (apparent) ages (fig. 38). As discussed earlier (in the section "Groundwater Age Tracers and Age Distribution"), the variability in apparent-age results and their relation with other geochemical constituents indicates that age interpretations might not adequately account for extensive mixing processes in this complex karst system.

The water sample collected from the overburden monitoring well (Z-OVB) was markedly different in geochemistry from W4 depth-dependent samples, well-field samples, and monitoring well samples, with higher specific conductance, higher alkalinity, and higher concentrations of major ions and trace elements, $\mathrm{NO}_{3}$, chloroform, and PCE and a different composition with respect to stable isotopes (fig. 38). These results indicate that there is likely not a substantial hydrologic connection between the overburden units and the Edwards aquifer at this location although, as noted earlier, higher concentrations of PCE in samples from the shallow and intermediate Zarzamora monitoring wells (Z-SED and Z-IED) are similar to the value measured in the sample from the overburden well.

\section{Temporal Variability in Water Chemistry}

Karst aquifers are characterized by extreme variability and rapid response to changes in environmental, climatic, and hydrologic conditions, which exert a fundamental control on groundwater geochemistry and water quality (for example, Hess and White, 1993; Desmarais and Rojstaczer, 2002; Vesper and White, 2004; Winston and Criss, 2004). Temporal variability in hydrologic conditions for the Edwards aquifer is apparent in data for rainfall, aquifer recharge, water-level 


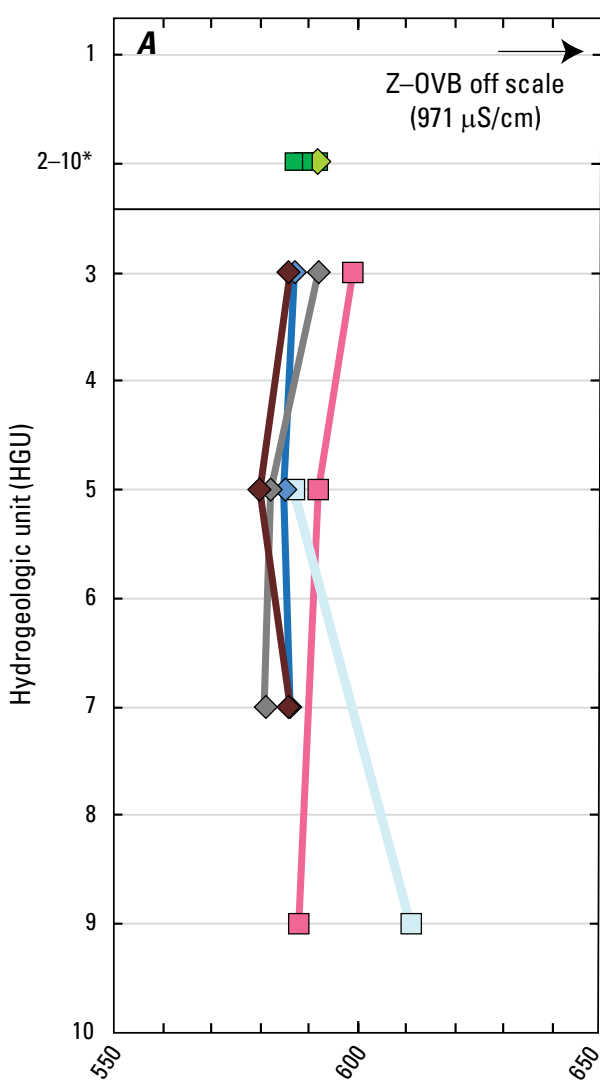

Specific conductance, in microsiemens per centimeter $(\mu \mathrm{S} / \mathrm{cm})$ at 25 degrees Celsius
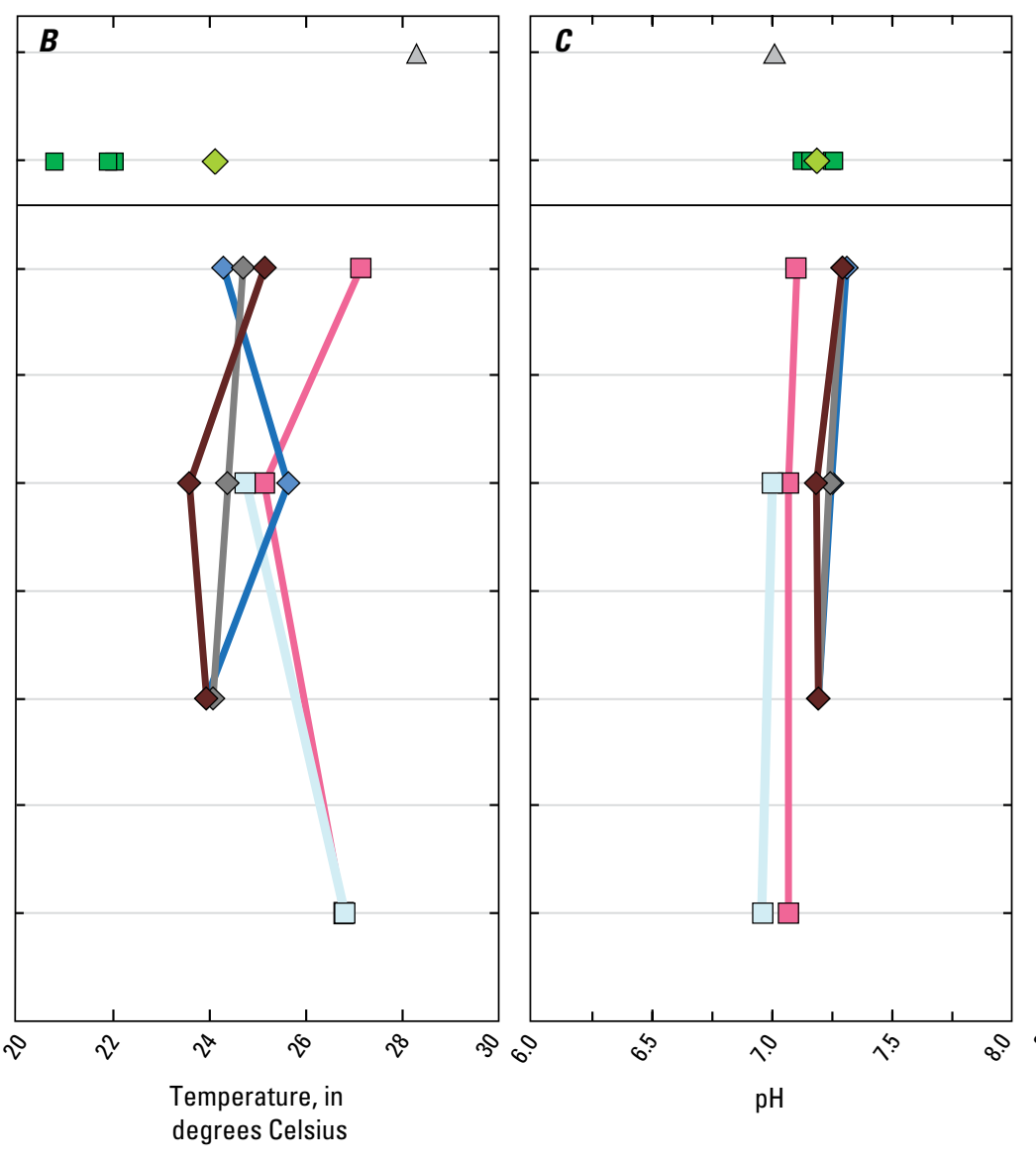

$\mathrm{pH}$

EXPLANATION

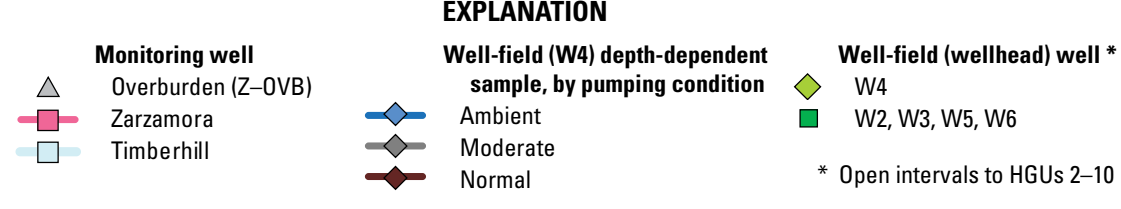

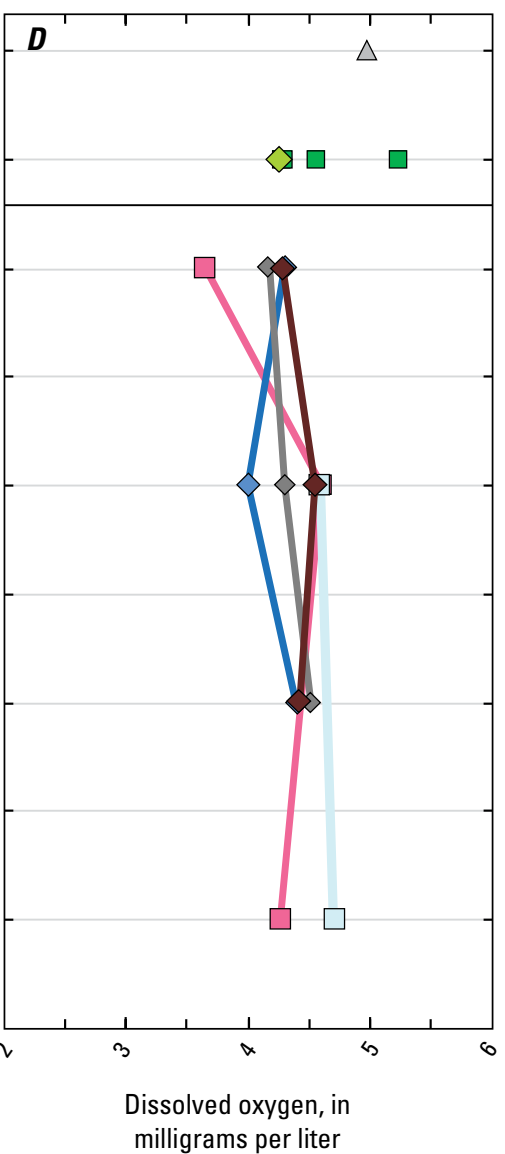

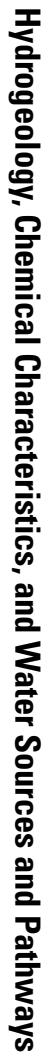

Figure 38. Geochemical results for selected constituents for groundwater samples collected from different depths and under different flow conditions for the study of the transport of anthropogenic and natural contaminants (TANC) to public-supply wells, south-central Texas, 2004-9. Results are presented on the basis of associated hydrogeologic unit (HGU) for monitoring-well samples and public-supply well depth-dependent samples; results for well-field samples and the overburden monitoring well are shown for comparison. $A$, Specific conductance. $B$, Temperature. $C$, pH. D, Dissolved oxygen concentration. 

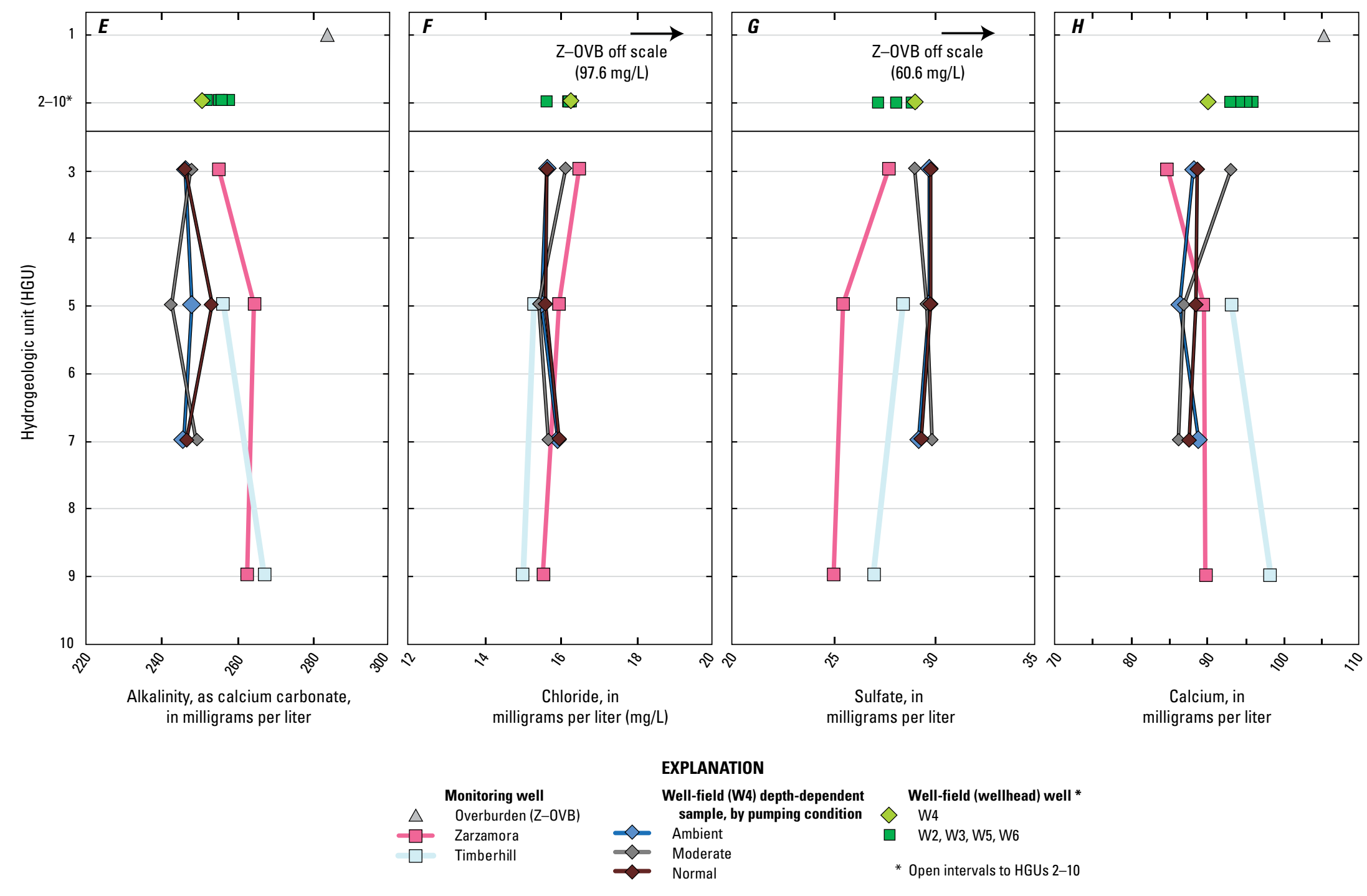


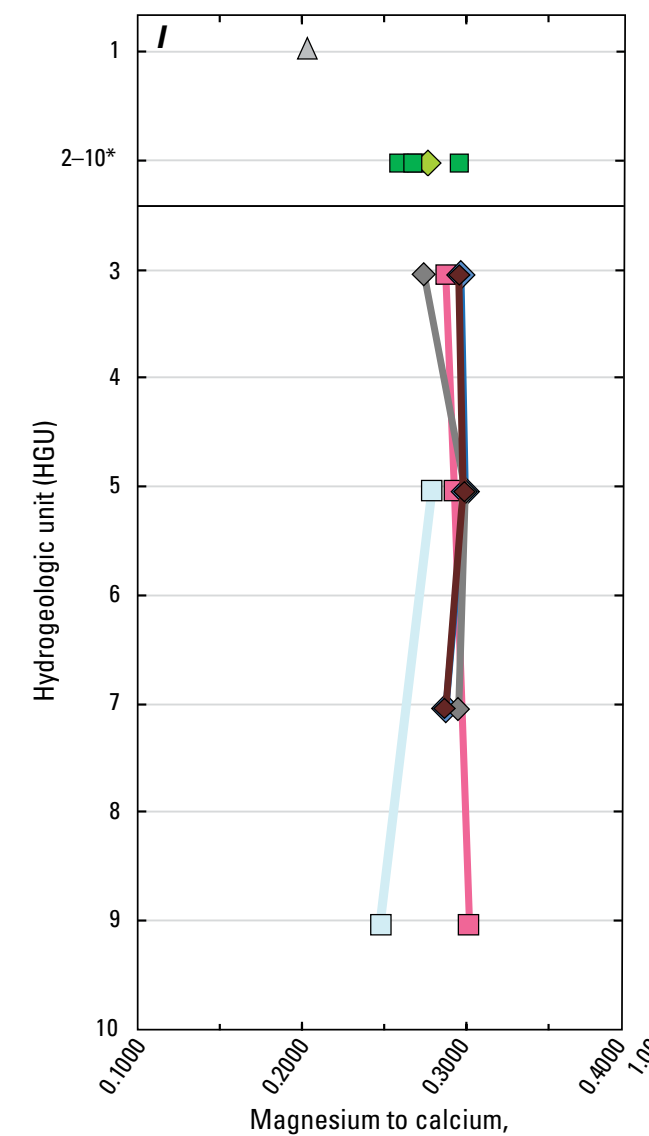

molar ratio

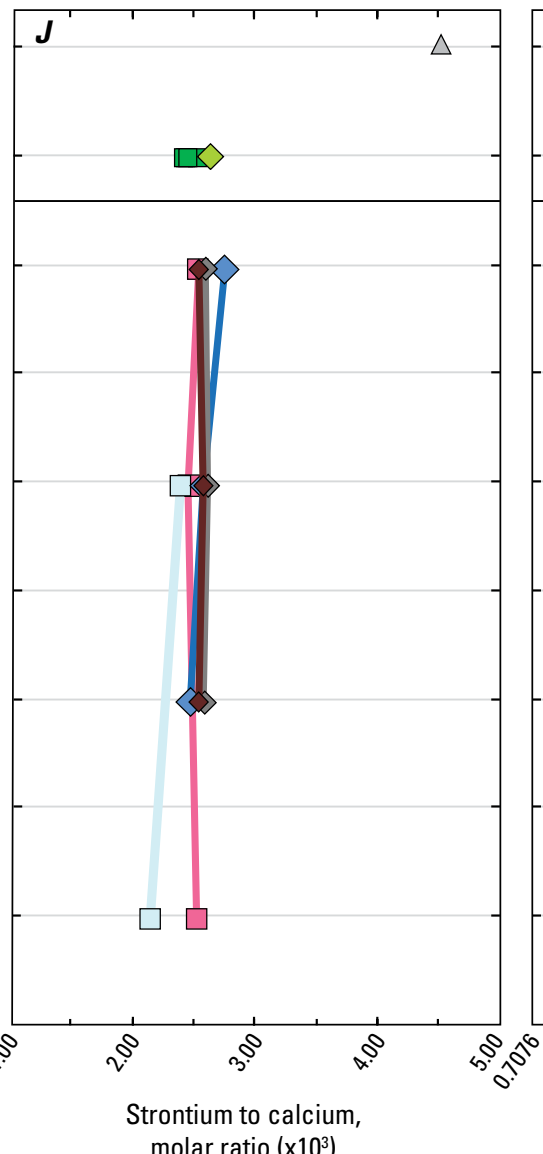

molar ratio $\left(\times 10^{3}\right)$

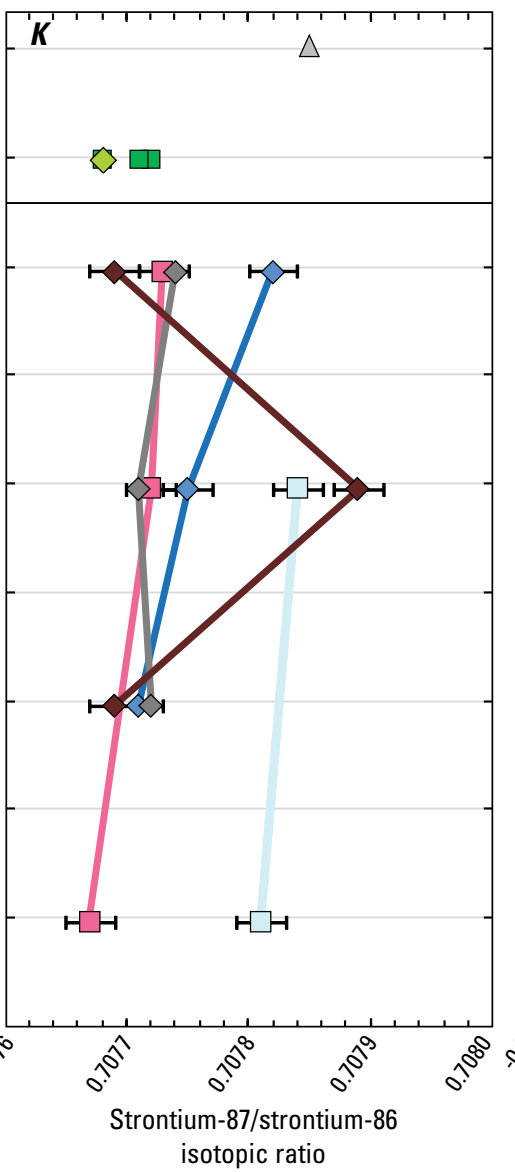

isotopic ratio

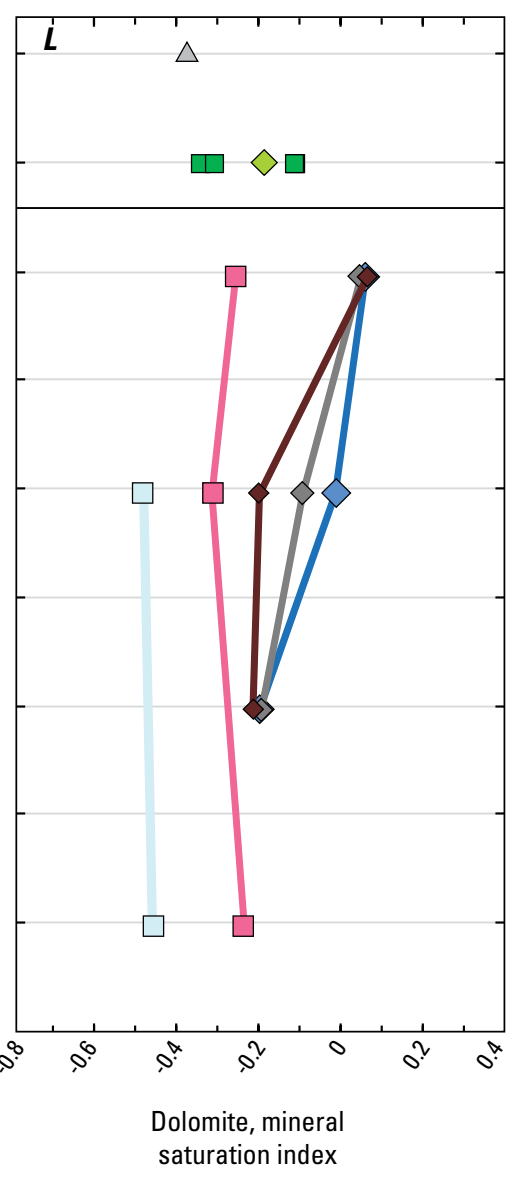

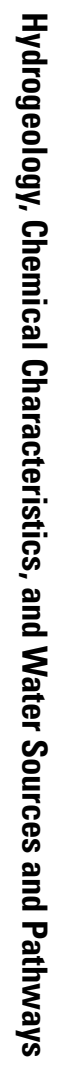

\section{EXPLANATION}

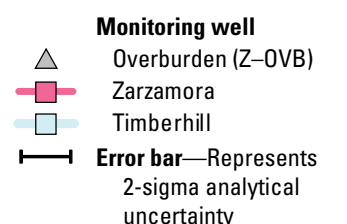

Well-field (W4) depth-dependent sample, by pumping condition $\curvearrowright$ Ambient

Moderate

Well-field (wellhead) well *

Normal

$\diamond \quad W_{4}$

W2, W3, W5, W6

* Open intervals to HGUs 2-10

uncertainty

Figure 38. I, Magnesium to calcium molar ratio. J, Strontium to calcium molar ratio $\left(\times 10^{3}\right) . K$, Strontium isotope composition. L, Dolomite mineral saturation index.-Continued 

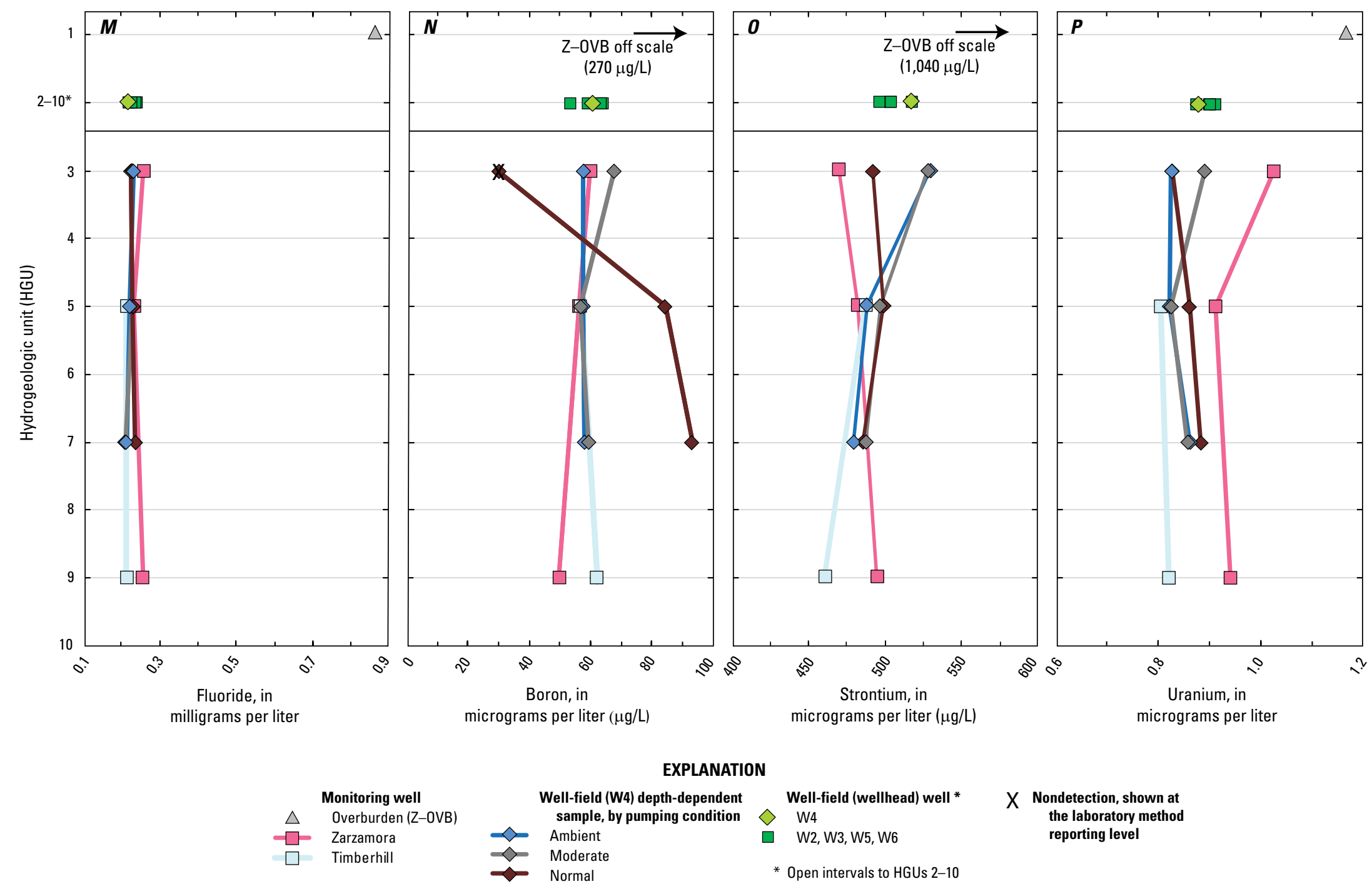
$X$ Nondetection, shown at the laboratory metho reporting level

$\begin{array}{lllll}\triangle \quad \text { Overburden (Z-OVB) } & \checkmark & \text { sample, by pumping condition } & \diamond & \text { W4 } \\ \square \quad \text { Zarzamora } & \checkmark & \text { Ambient } & \text { W2, W3, W5, W6 } \\ \square & \text { Timberhill } & \checkmark & \text { Moderate } & \\ & & \checkmark & \text { Normal } & \text { * Open intervals to HGUs 2-10 }\end{array}$




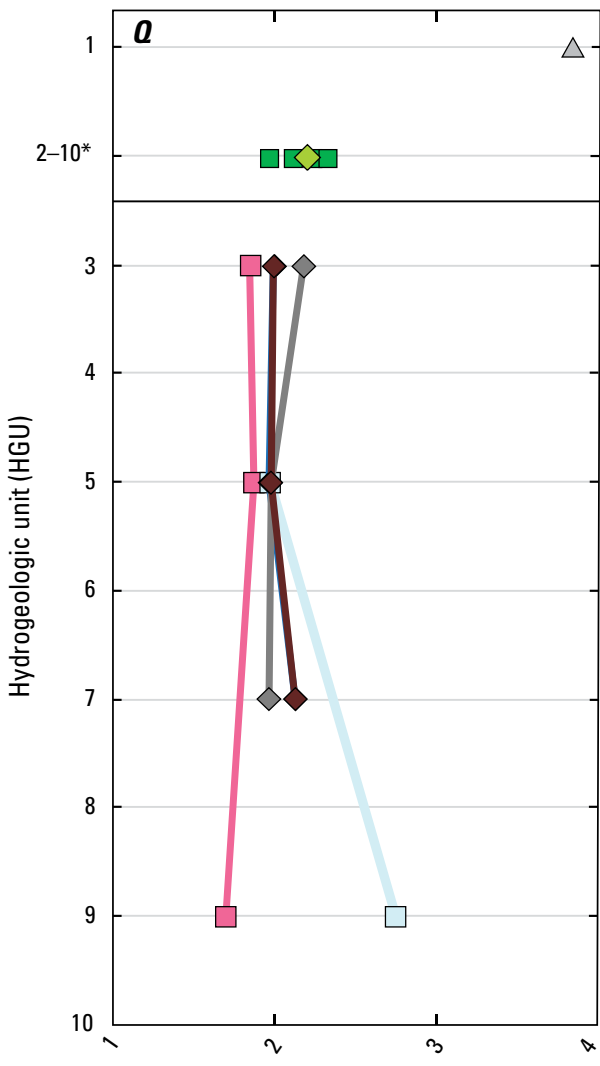

Nitrate, in milligrams per liter as nitrogen

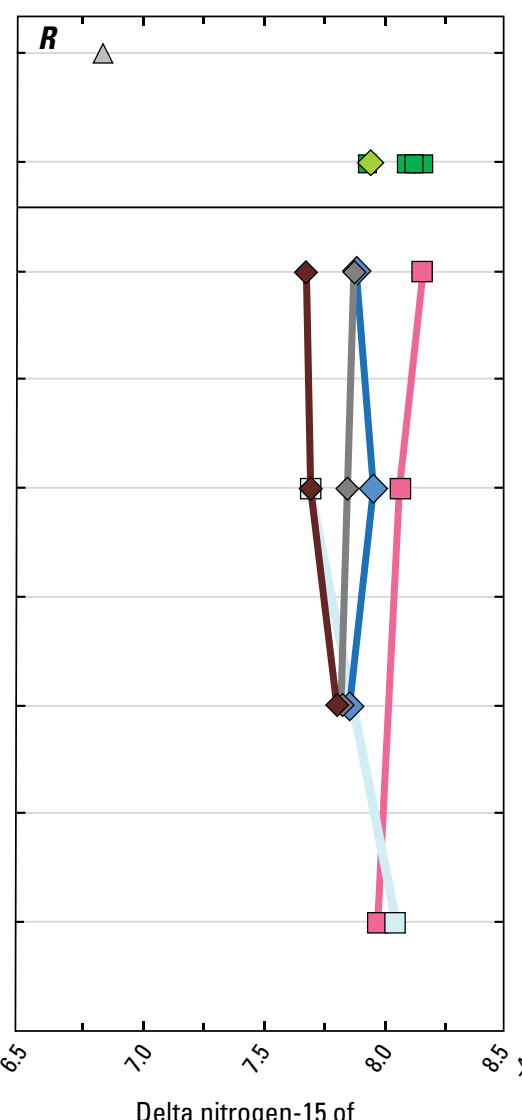

nitrate, in $p$

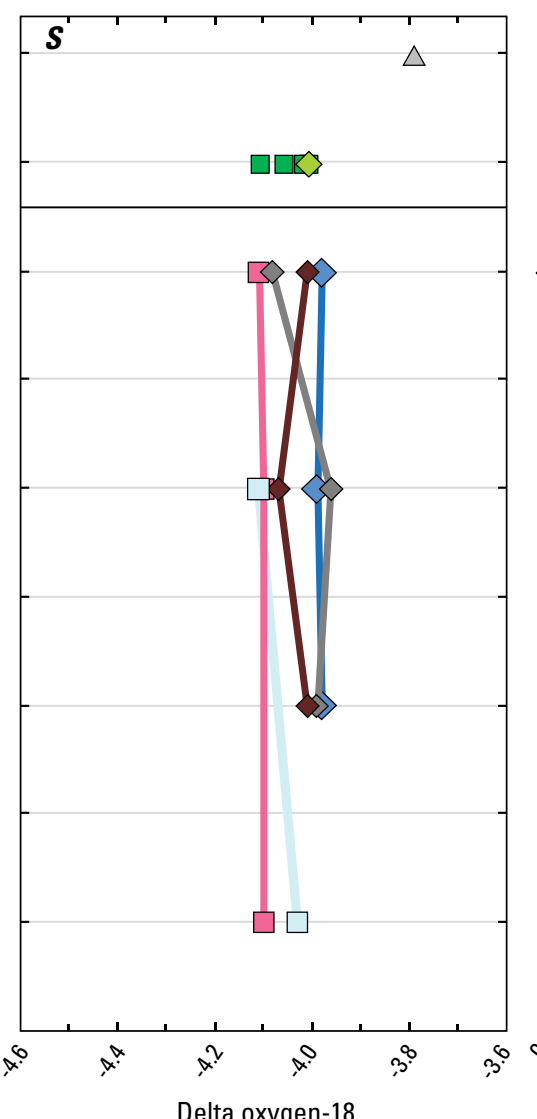

in per mil

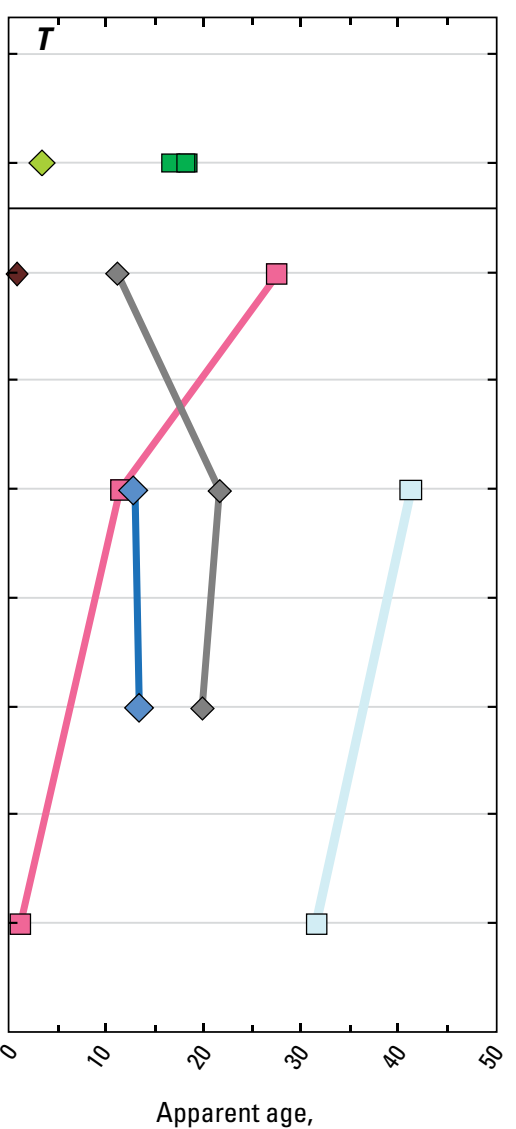

in years (piston-flow model)

\section{EXPLANATION}

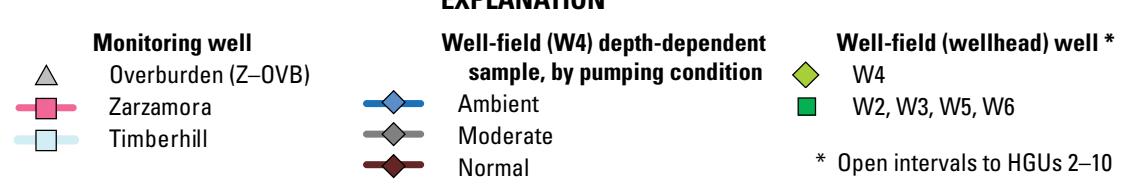

Figure 38. $\quad Q$, Nitrate concentration. $R$, Delta nitrogen-15 of nitrate composition. $S$, Delta oxygen-18 composition. $T$, Groundwater apparent age (based on tritium and helium-3 age tracers).-Continued 

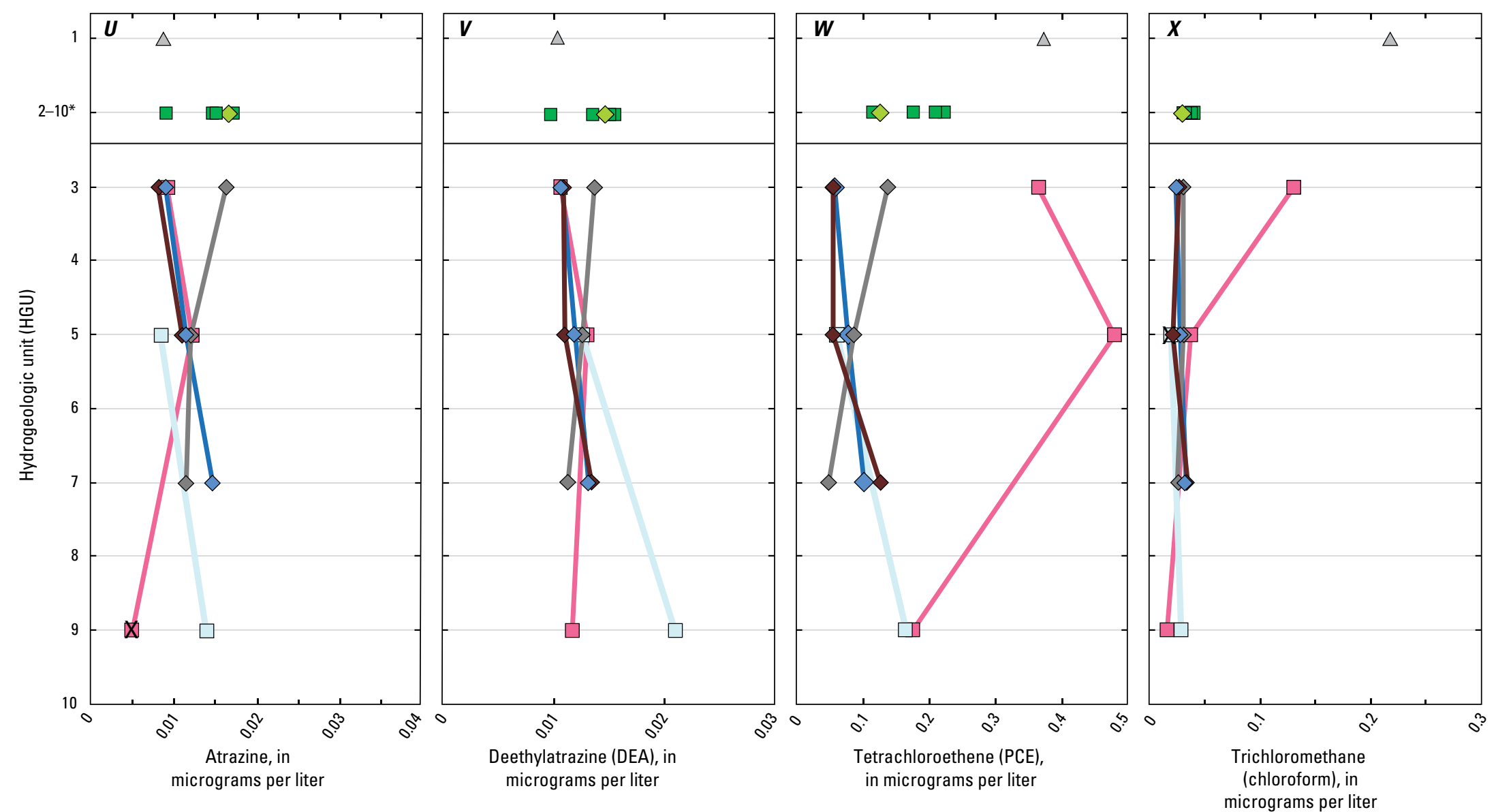

EXPLANATION

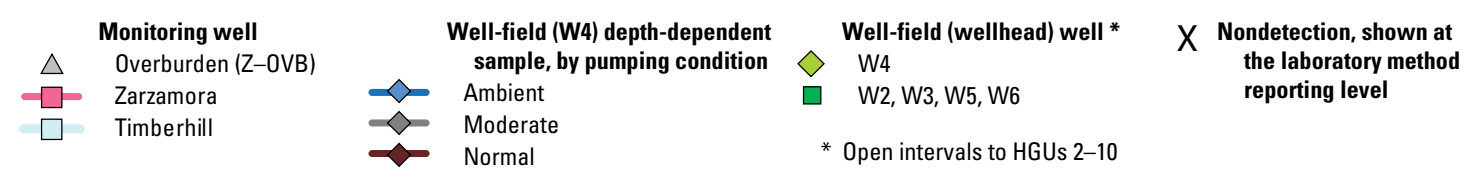

Figure 38. U, Atrazine concentration. $V$, Deethylatrazine (DEA) concentration. $W$, Tetrachloroethene (PCE) concentration. $X$, Trichloromethane (chloroform) concentration.Continued 
altitudes in wells, and springflow (for example, fig. 6). Temporal changes in hydrologic conditions such as water-level altitudes, recharge, groundwater traveltimes, and flow routing affect hydrogeologic processes, including water-rock interaction processes, and dilution and mixing of recharge, which affect water quality. Rapidly changing hydrologic conditions and a continuum of flow pathways from matrix flow to conduit flow imply that hydrogeologic processes might operate on different temporal and spatial scales in different parts of the aquifer. For example, groundwater dominated by matrix/ diffuse flow or less affected by focused recharge might exhibit less temporal variability than would groundwater affected by focused recharge and conduit flow.

Previous work in the Edwards aquifer has demonstrated temporal variability in geochemistry and water quality over multiple time scales in response to changes in hydrologic conditions (Musgrove and Banner, 2004; Mahler and others, 2006; Mahler and Massei, 2007; Mahler, 2008; Musgrove and others, 2010; Wong and others, 2011). In conjunction with samples collected for this study, historical data for samples collected from two wells in the well field extend over an 11-year period, from 1998 through 2009. Historical data collected from these two PSWs (W3 and W6) indicate that geochemistry of the confined groundwater produced by the well field has varied in response to changes in hydrologic conditions over this time period. For example, variability in $\mathrm{Mg} / \mathrm{Ca}$ molar ratios, indicative of geochemical evolution processes, is consistent with regional-scale changes in hydrologic conditions. Higher $\mathrm{Mg} / \mathrm{Ca}$ ratios in PSW groundwater samples, indicative of longer groundwater residence times, are correlated with lower water levels in the Bexar County index well (J-17); lower water levels reflect drier regional hydrologic conditions (figs. 6 and 39). The small range of variability for historical samples from the well field relative to regional aquifer variability (Musgrove and others, 2010), as well as similar $\mathrm{Mg} / \mathrm{Ca}$ ratios relative to the median value for the regional aquifer PSW samples (0.32), is consistent with the hypothesis that the well-field PSWs produce water typical of the confined regional aquifer. In comparison with groundwater from shallow unconfined wells, groundwater from most confined aquifer wells, unless intersecting a fastflow conduit, is likely dominated by longer residence time matrix flow, which would be accompanied by attenuation of inputs from storm and recharge events. The geochemistry of matrix groundwater is likely less variable and changes more slowly in response to longer term regional hydrologic conditions. Relatively rapid changes in geochemistry have been documented for unconfined wells in the vicinity of the local-scale study area (Musgrove and others, 2010), but the time scales of geochemical variability for the confined aquifer in response to recharge events has, to date, been largely undocumented.

One of the well-field PSWs (W6) and four selected monitoring wells (Zarzamora monitoring wells Z-SED, Z-IED, and Z-DED and an upgradient unconfined monitoring well,
AY-68-27-610) were sampled several times in response to a storm event that supplied recharge to the aquifer in October 2009 (fig. 5; table 4). Event sampling is described earlier in the section "Collection of Water Samples."

Time-series results for water-level altitudes and (or) geochemical constituents from W6 and sampled monitoring wells during the period of event sampling were compared with the regional water-level altitude in the Bexar County index well (J-17) (fig. 40). Water-table altitudes rose in the Bexar County index well (J-17), reflecting regional hydrologic conditions, as well as in the sampled monitoring wells, in response to the recharge event (fig. 40) (water-level altitudes were not measured in W6). The geochemistry in the upgradient monitoring well is notably distinct from that of W6 and the Zarzamora monitoring wells. The upgradient well is characterized by higher specific conductance, $\mathrm{Sr}$ isotope composition, and concentrations of $\mathrm{NO}_{3}$ and chloroform and by lower $\mathrm{Mg} / \mathrm{Ca}$ molar ratios, dolomite SIs, and PCE concentrations (fig. 40). The lower $\mathrm{Mg} / \mathrm{Ca}$ ratios and dolomite SIs and higher Sr isotope compositions measured in samples from the upgradient monitoring well are consistent with the hypothesis that groundwater from the upgradient unconfined recharge zone has undergone less water-rock interaction than has groundwater sampled from confined PSWs and Zarzamora monitoring wells. This is consistent with results for shallow unconfined monitoring wells presented in Musgrove and others (2010), which indicated that groundwater from the shallow unconfined aquifer is less geochemically evolved relative to the deeper unconfined and confined part of the aquifer. Higher concentrations of $\mathrm{NO}_{3}(2.62-2.99 \mathrm{mg} / \mathrm{L})$ and chloroform (0.066-0.192 $\mu \mathrm{g} / \mathrm{L})$ in samples from the upgradient unconfined monitoring well might be indicative of local sources of these constituents to this well; these concentrations are higher than the median values for shallow/urban unconfined groundwater $(1.85 \mathrm{mg} / \mathrm{L}$ and $0.032 \mu \mathrm{g} / \mathrm{L}$, respectively) as described by Musgrove and others (2010). Lower PCE concentrations in samples from the upgradient unconfined monitoring well indicate that this well is not affected by local PCE sources, unlike the well-field wells and the Zarzamora monitoring wells.

Geochemical variability in response to the sampled recharge event is generally small in the well-field PSW and the monitoring wells in comparison to the range of geochemical variability observed in the regional aquifer. These results are consistent with the hypothesis that the response to individual recharge events in the confined aquifer, unless intersecting conduit flow paths, might be attenuated by mixing processes along regional flow paths. Nonetheless, numerous geochemical constituents in W6 and the monitoring wells changed in response to the sampled recharge event. Recharging water associated with a rain event would likely be more dilute than groundwater with longer residence time; although specific conductance showed minor variability in response to the recharge event, $\mathrm{Cl}$ concentrations showed a dilution curve (an initial decrease, then subsequent increase) in W6 and the monitoring wells as regional water levels rise, consistent with 

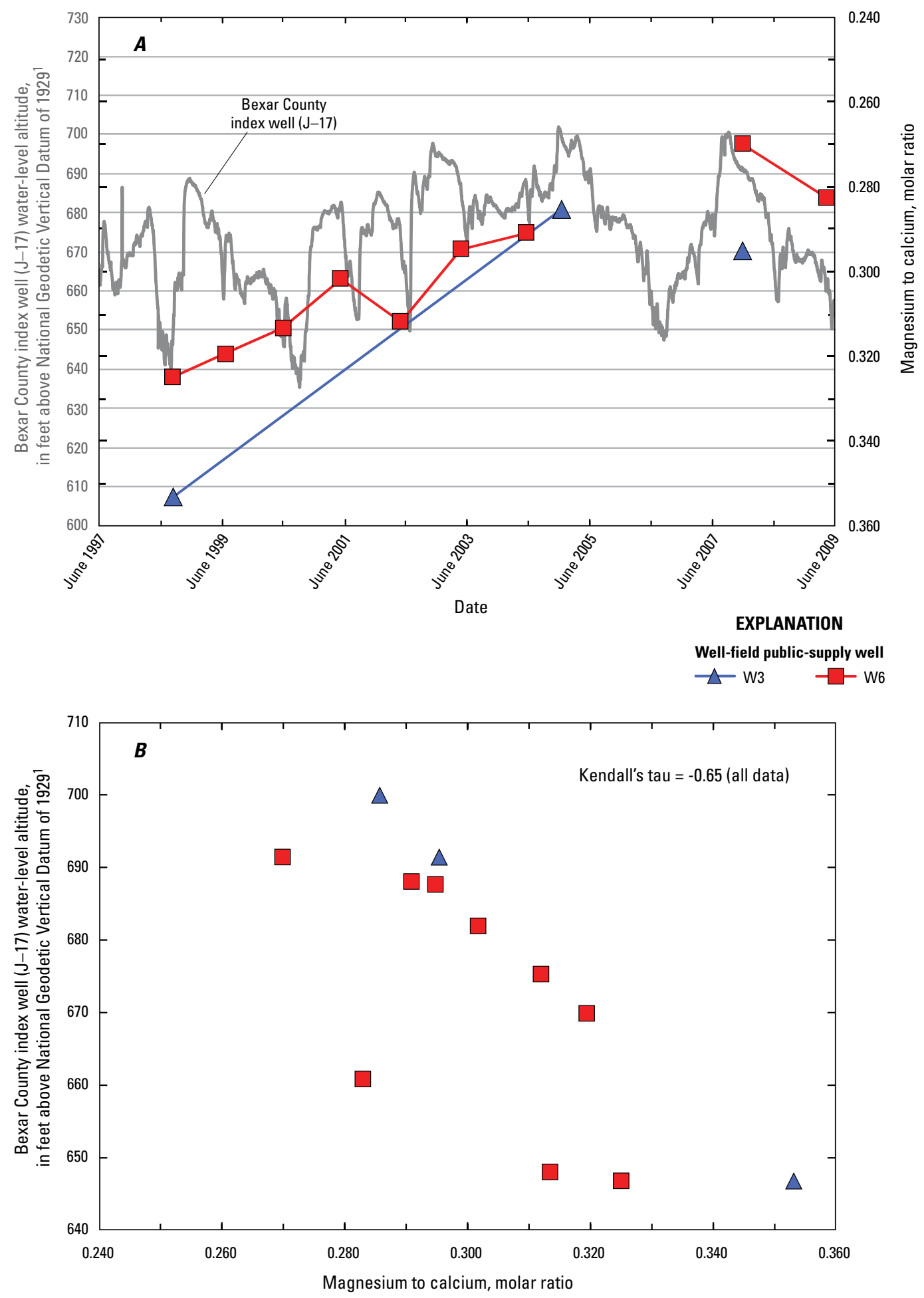

1 Source agency reports water-leve

EXPLANATION

altitude referenced to sea level

Well-field public-supply well (Edwards Aquifer Authority, 2009)

$\triangle$ W3

W6

Figure 39. Historical magnesium to calcium molar ratio data for well-field public-supply wells sampled for the study of the transport of anthropogenic and natural contaminants (TANC) to public-supply wells, south-central Texas. A, Time-series (1997-2009) of Bexar County index well (J-17) water-level altitude (Edwards Aquifer Authority, 2009) and historical magnesium to calcium molar ratios for TANC study well-field wells (W3 and W6). B, Relation between Bexar County index well (J-17) water level altitude and historical magnesium to calcium molar ratios for TANC study well-field wells (W3 and W6). 

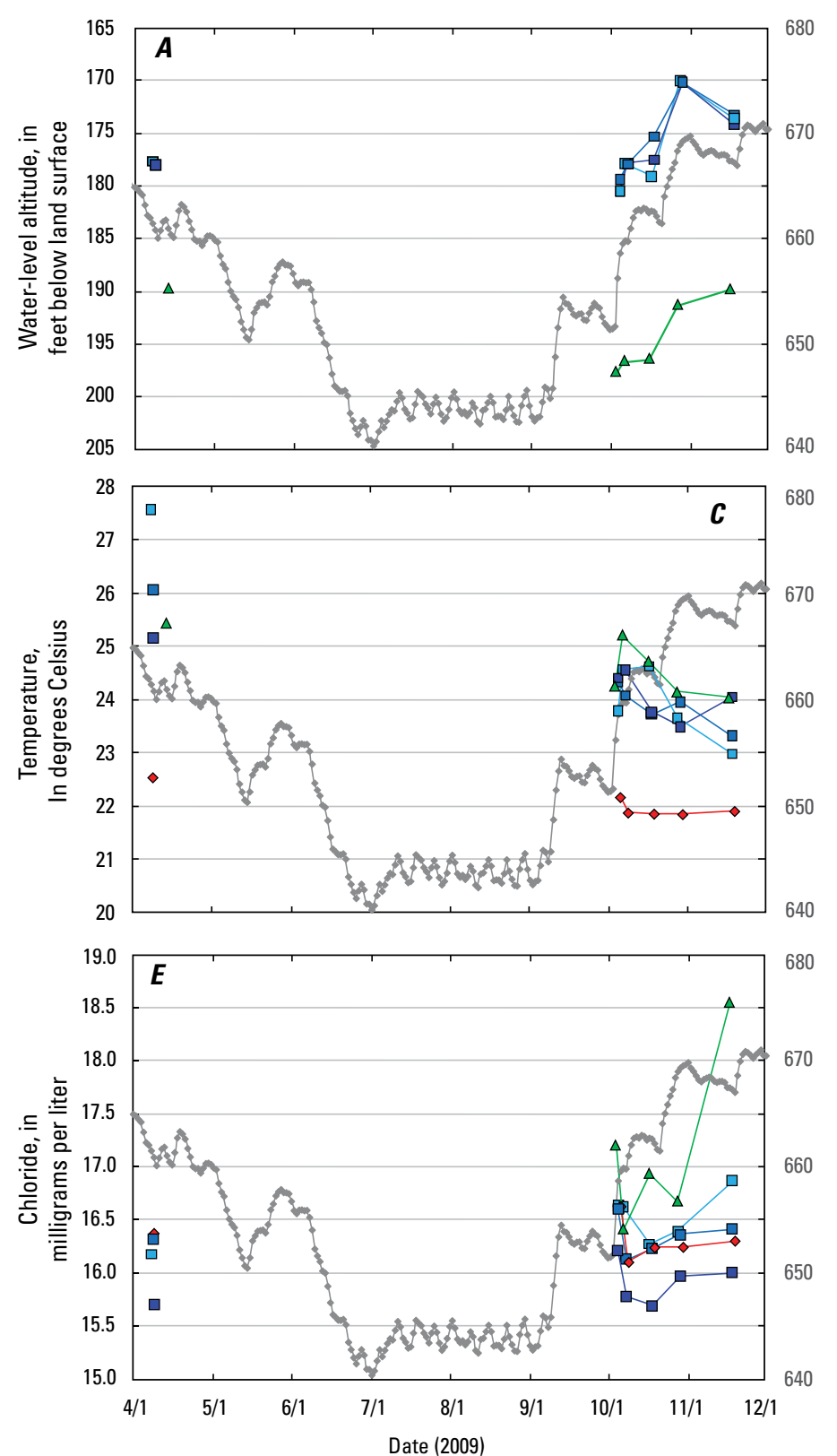
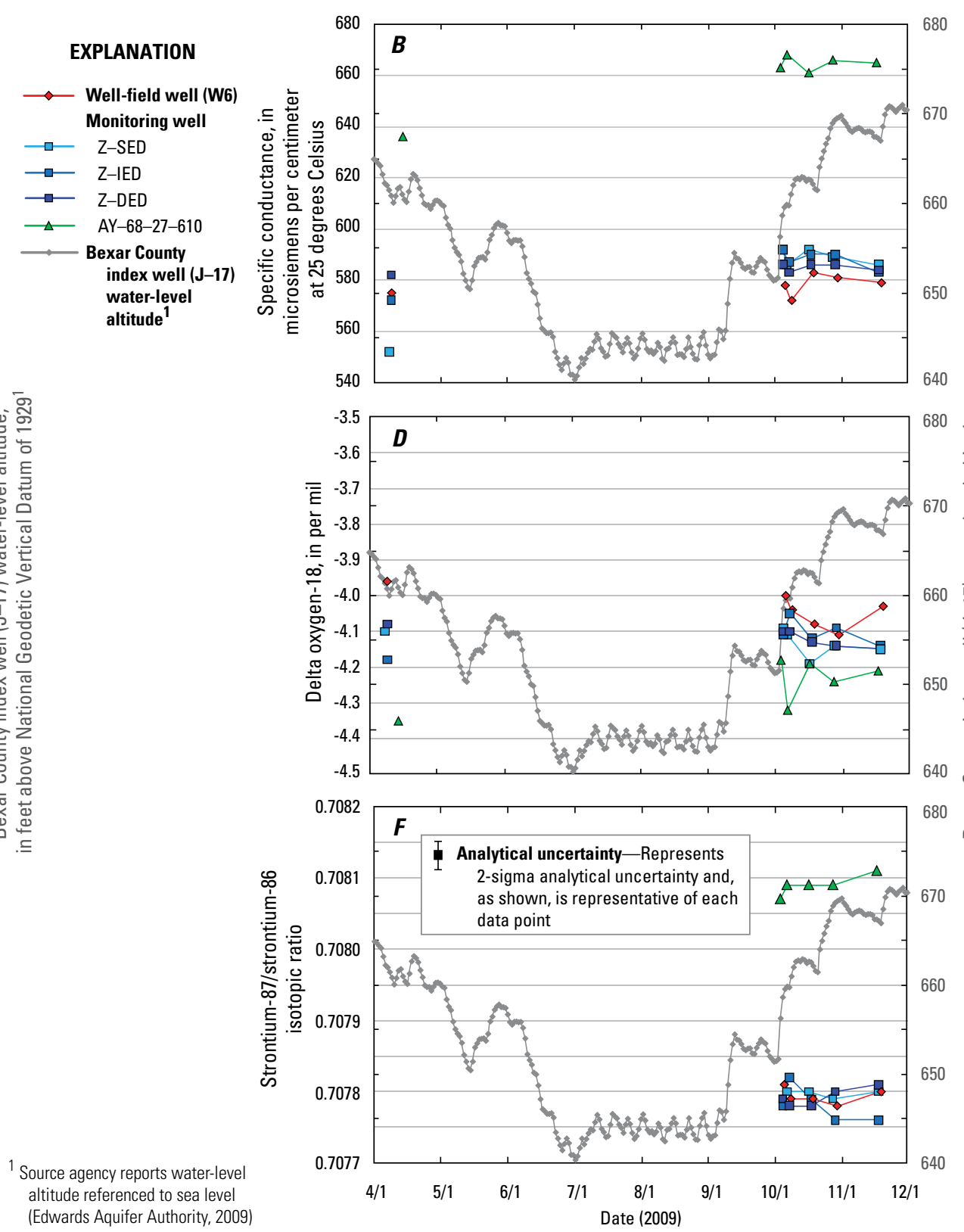

ठ

Figure 40. Geochemical results for selected constituents in groundwater samples collected in response to a rain event (October through November, 2009) for the study of the transport of anthropogenic and natural contaminants (TANC) to public-supply wells, south-central Texas. Water-level altitude in Bexar Country index well (J-17) is shown for comparison. $A$, Water-level altitude. $B$, Specific conductance. $C$, Temperature. $D$, Delta oxygen-18 composition. $E$, Chloride concentration. $F$, Strontium isotope composition. 

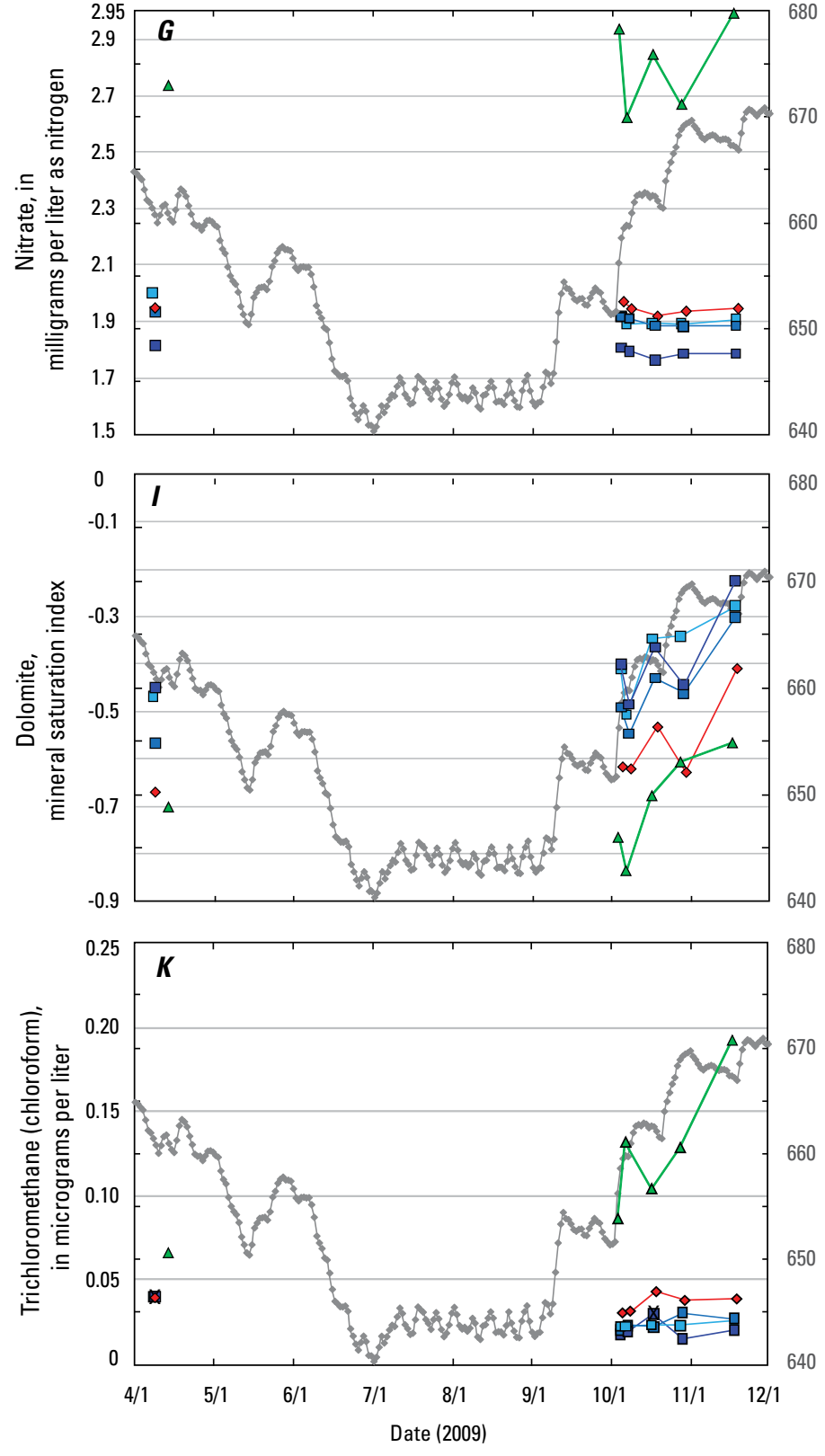

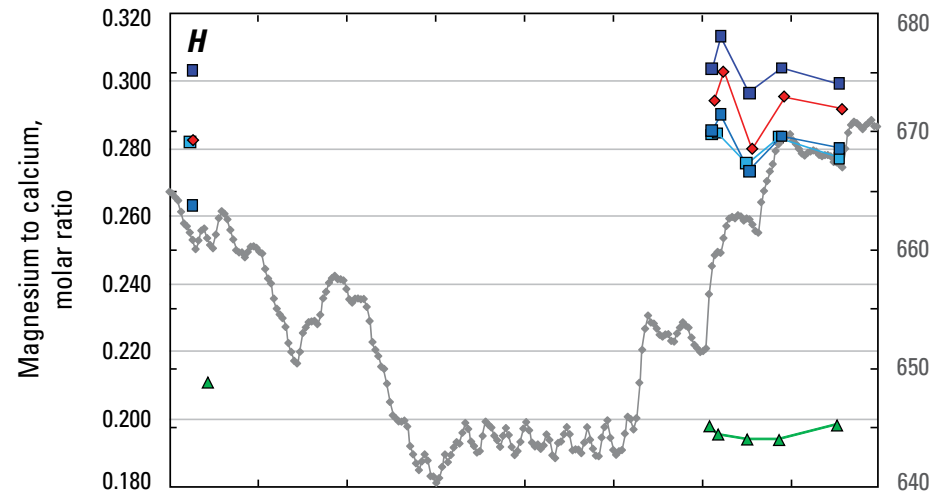

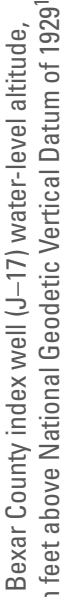

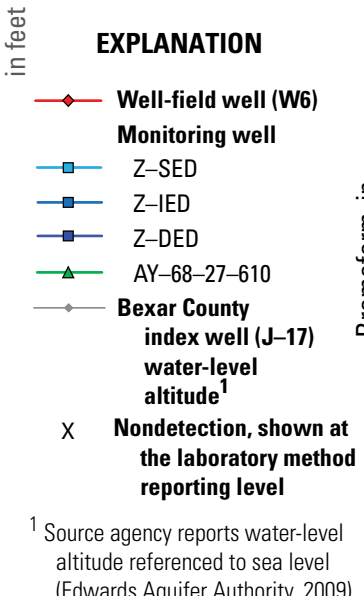

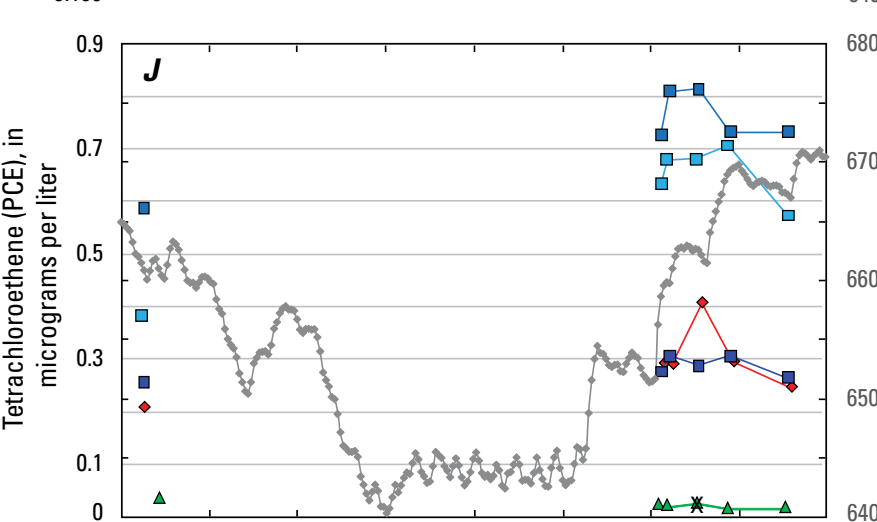

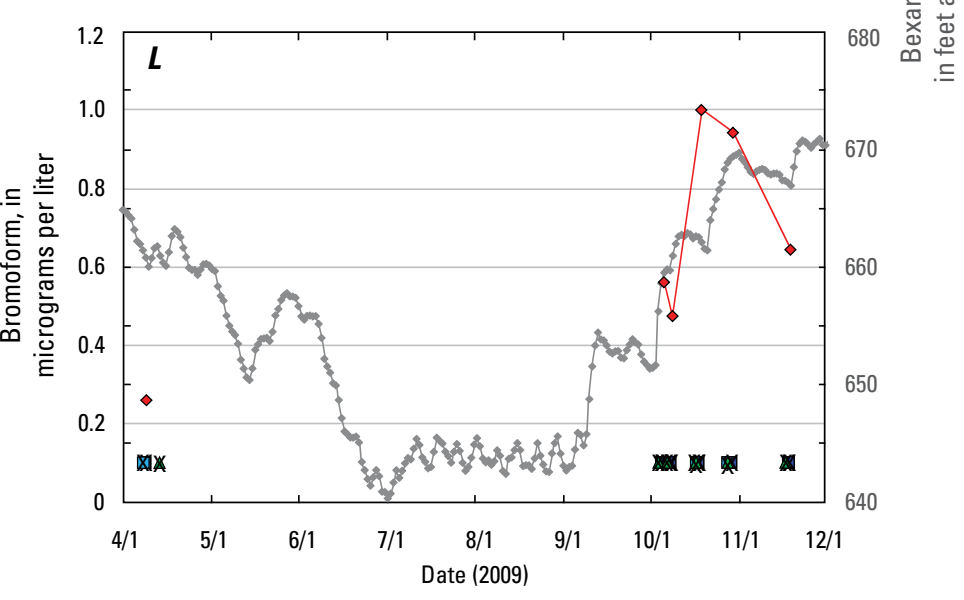

Figure 40. $G$, Nitrate concentration. $H$, Magnesium to calcium molar ratio. I, Dolomite mineral saturation index. J, Tetrachloroethene (PCE) concentration. $K$, Trichloromethane (chloroform) concentration. L, Bromoform concentration.-Continued 
temporary dilution during the event following by a return to ambient conditions (fig. 40E). The decrease in $\mathrm{Cl}$ concentration was accompanied by decreases in $\mathrm{NO}_{3}$ concentration and $\mathrm{Mg} / \mathrm{Ca}$ ratios (fig. 40). $\mathrm{Mg} / \mathrm{Ca}$ ratios at W6 and the Zarzamora monitoring wells showed a dilution curve, as did dolomite SIs. These results are consistent with previous studies that have proposed that aquifer $\mathrm{NO}_{3}$ concentrations are diluted by incoming recharge; lower $\mathrm{Mg} / \mathrm{Ca}$ ratios and dolomite SIs are consistent with shorter residence times that would be associated with recent, less geochemically evolved recharge (Musgrove and others, 2010). The increase in regional water levels associated with the recharge event is also accompanied by an increase and subsequent decrease in PCE concentrations in W6 and the two shallowest Zarzamora monitoring wells (Z-SED and Z-IED), characteristic of a breakthrough curve. This response is consistent with other PSW results, which indicate that the well field and in particular the Zarzamora monitoring wells are affected by a local PCE source and receive recharge with higher PCE concentrations.

Chloroform concentrations were low at W6 and the Zarzamora monitoring wells relative to the upgradient monitoring well, where chloroform concentration increased during the event sampling period (fig. 40K). Bromoform was not detected at any of the monitoring wells during event sampling, but concentrations show a breakthrough curve at W6. This result is consistent with relatively high bromoform concentrations measured in the well field in comparison with regional aquifer PSW and monitoring well samples (fig. 26) and indicates that W6 is affected by a local bromoform source. Chloroform and bromoform are drinking-water chlorination byproducts that are commonly detected nationwide, which is in part attributed to the recycling of chlorinated waters (Zogorski and others, 2006). Backflow to supply wells or the possible use of treated water as a downhole lubricant of well pumps are potential sources of chloroform and bromoform to supply wells.

\section{Processes Affecting Transport of Natural and Anthropogenic Contaminants to the Public-Supply Well}

\section{Sources of Water and Solutes and Movement to Supply Wells}

Surface water from losing streams is the primary source of recharge in the regional aquifer and the local-scale study area. Stable isotopes of $\delta \mathrm{D}$ and $\delta^{18} \mathrm{O}$ indicate that this water is meteoric in origin. Some evaporation might affect recharge and associated groundwater near specific recharge locations (Musgrove and others, 2010). Groundwater compositions and dissolved-ion sources reflect processes of water-rock interaction with the host limestone aquifer rocks. Previous studies indicate that groundwater in the unconfined part of the aquifer geochemically evolves to the composition of groundwater in the confined part of the aquifer (Musgrove and others, 2010). Groundwater flow in the San Antonio segment of the aquifer is generally west to east, although model-derived and tracer-inferred flow characteristics can vary markedly in this karst aquifer (Lindgren and others, 2009). The major components of model-derived groundwater flow in the TANC local-scale model area are (1) from the recharge zone southward into the confined zone and (2) from west to east in the confined zone (Lindgren and others, 2011b).

Anthropogenic sources that might influence groundwater quality include septic systems, leakage from municipal water and wastewater systems, and general industrial, commercial, or residential use of fertilizers, pesticides, and VOCs. There are only minor agricultural areas in the region (fig. 10), and these are primarily downgradient of the local-scale study area. There are point sources in the study area and vicinity of the well field for some of these contaminants (figs. 11-14), although nonpoint sources are also likely given the widespread detections of these contaminants in samples from the regional aquifer PSWs. Previous work has indicated that the urban environment is a potential source of organic contaminants to the aquifer (Musgrove and others, 2010).

Results for TANC study groundwater samples had no anthropogenic contaminants at levels of regulation, but they did contain several organic contaminants at low concentrations (mostly less than $1 \mu \mathrm{g} / \mathrm{L}$ ). Frequent low-level detection of several pesticides and VOCs in samples from the regional aquifer PSWs indicates that sources of pesticides and VOCs are widely distributed in the regional Edwards aquifer. The primary pesticides detected were atrazine, its degradate DEA, and, at less frequent detections, simazine and prometon. The primary VOCs detected were PCE and chloroform, and there were less frequent detections of other THMs (bromoform, dibromochloromethane, and bromodichloromethane). PCE detections and concentrations in samples from the well-field wells and Zarzamora monitoring wells were higher than those for samples from the regional aquifer PSWs. There are point sources in the vicinity of the well field for PCE, including a known plume (Bandera Road Groundwater Plume) to the northwest of the well field. Groundwater flow directions are consistent with the possibility that this might be a possible source of PCE to the well-field wells and Zarzamora monitoring wells, although other sources are also possible. Spatial variations in PCE in the study area indicate that higher PCE concentrations are associated with the urban San Antonio area, with a cluster of higher concentrations in the direct vicinity and north of the well field (fig. 41).

Nitrate concentrations in the aquifer were below levels of regulation for drinking water. Well-field samples had a median $\mathrm{NO}_{3}$ concentration of $2.2 \mathrm{mg} / \mathrm{L}$. Nitrate concentrations in the regional groundwater wells suggest that $\mathrm{NO}_{3}$ in the aquifer likely results from nonpoint sources, although a few wells with $\mathrm{NO}_{3}$ concentrations greater than $3 \mathrm{mg} / \mathrm{L}$ might be affected 
by local $\mathrm{NO}_{3}$ sources (fig. 42). Previous studies have proposed that surface-water recharge dilutes background groundwater $\mathrm{NO}_{3}$ concentrations, and lower $\mathrm{NO}_{3}$ concentrations are generally associated with groundwater collected from unconfined recharge-zone wells (Mahler and others, 2006; Musgrove and others, 2010). Nitrate concentrations are also generally higher in samples from the urban San Antonio area than outside (Musgrove and others, 2010; fig. 42). Oxic conditions indicate that denitrification is not an important process in this aquifer, and thus, no natural $\mathrm{NO}_{3}$ attenuation is likely to occur. Near the downgradient saline-zone boundary, however, deeper Edwards aquifer groundwater can be locally affected by mixing with more saline and less oxic downdip water. A small number of groundwater samples from regional wells show evidence for mixing with more saline and less oxic downdip groundwater, which might also be associated with downdip water moving up along faults (Oetting and others, 1996; Musgrove and others, 2010). Groundwater in the local-scale and regional-scale study areas contains no natural contaminants (such as U and As) at levels of concern, and aquifer conditions are not conducive to increases in concentrations of these contaminants.

Results for age tracers indicate that groundwater reaching the well field had a median apparent age of 17 years. The largest fraction of water reaching W4, however, might be younger, with a piston-flow-model age of 3 years. These results are consistent with particle-tracking results from hydrologic modeling for the study area (Lindgren and others, 2011b) indicating that greater than 85 percent of particle tracks to W4 have traveltimes of less than 5 years and that greater than 95 percent have traveltimes less than 10 years (fig. 33). Apparent ages are not well correlated with other geochemical tracers of residence time (for example, $\mathrm{Mg} / \mathrm{Ca}$ ratios, dolomite SIs, and Sr isotopes) (fig. 36). Aquifer units were found to have zones of preferential flow, although samples dominated by groundwater from different stratigraphic units were not geochemically distinct. Aquifer units are composed of Cretaceous-age limestone with minor variations in geochemistry (tables 5 and 6). Groundwater collected from W4 was relatively homogeneous and well mixed under a variety of pumping conditions for numerous geochemical constituents, with a notable exception of age tracers. These results suggest that mixing processes in the aquifer are complex and that hydrogeologic conceptual models used for age interpretations might not adequately account for mixing processes in this aquifer.

\section{Supply-Well Vulnerability to Natural and Anthropogenic Contaminants}

Like many karst aquifers, high porosity and permeability and rapid flow of recharging surface water through conduits, with little to no filtration, render the Edwards aquifer highly susceptible to contamination. Constituents of concern in the Edwards aquifer for the long-term sustainability of the groundwater resource include $\mathrm{NO}_{3}$ and organic contaminants.
Measured concentrations of $\mathrm{NO}_{3}$ and organic contaminants are currently low relative to levels of regulation. Nonetheless, the dominance of very young groundwater in the TANC study area and, specifically, groundwater that reaches the well field indicates that the aquifer and water supply are vulnerable to contamination.

Other TANC studies have determined that changes in pumping conditions can affect water quality (Katz and others, 2007; Landon and others, 2008; Jurgens and others, 2008; Brown and others, 2009; Bexfield and others, 2011). In contrast, for the Edwards aquifer TANC study area, although changes in pumping conditions might change the distribution of groundwater flow paths contributing water to the well field, under all pumping conditions the majority of the groundwater was young and, as such, is susceptible to anthropogenic contaminants. Borehole imaging of W4 revealed large solution features, consistent with high connectivity throughout the aquifer. Although zones of preferential flow were determined for W4, groundwater samples from different stratigraphic units could not be distinguished geochemically, and no water-quality effects were discernable on the basis of sample stratigraphy. The location of the PSW within an urban area increases the vulnerability of the water supply and its potential susceptibility to contamination.

Groundwater geochemistry and water quality in the Edwards aquifer is affected by changes in hydrologic conditions. Temporal changes in hydrologic conditions such as water-level altitudes, recharge, groundwater traveltimes, and flow routing affect hydrogeologic processes, including the extent of variability in water-rock interaction processes, dilution of recharge, and associated geochemistry. Specifically for the Edwards aquifer, drier hydrologic conditions are likely associated with lower concentrations of atrazine and higher concentrations of nitrate (Musgrove and others, 2010), but this relation for individual wells is likely affected by specific flow paths. For example, groundwater dominated by matrix/ diffuse flow or less affected by focused recharge might be less variable in water quality than groundwater affected by focused recharge and conduit flow.

Water-quality data from the regional aquifer PSWs and well-field monitoring wells, collected over a range of depths in the Edwards aquifer, show little variability. Regional (confined) aquifer PSW samples from the same stratigraphic units where the aquifer is deeper in the subsurface (samples from wells greater than $1,000 \mathrm{ft}$ in depth), however, show notable chemical differences from the rest of the regional aquifer, with lower concentrations of organic contaminants and geochemical evidence for more evolved groundwater compositions.

Understanding how land use affects water quality of PSWs is important because of the strong influence of land use on water quality and the rapid pace at which changes in land use are occurring in the urban part of the study area. This understanding has practical implications with respect to human health (McMahon and others, 2008) but might be complicated by spatial and temporal variations in land use (Brawley and others, 2000; Hiscock and others, 2007) and by 
EXPLANATION

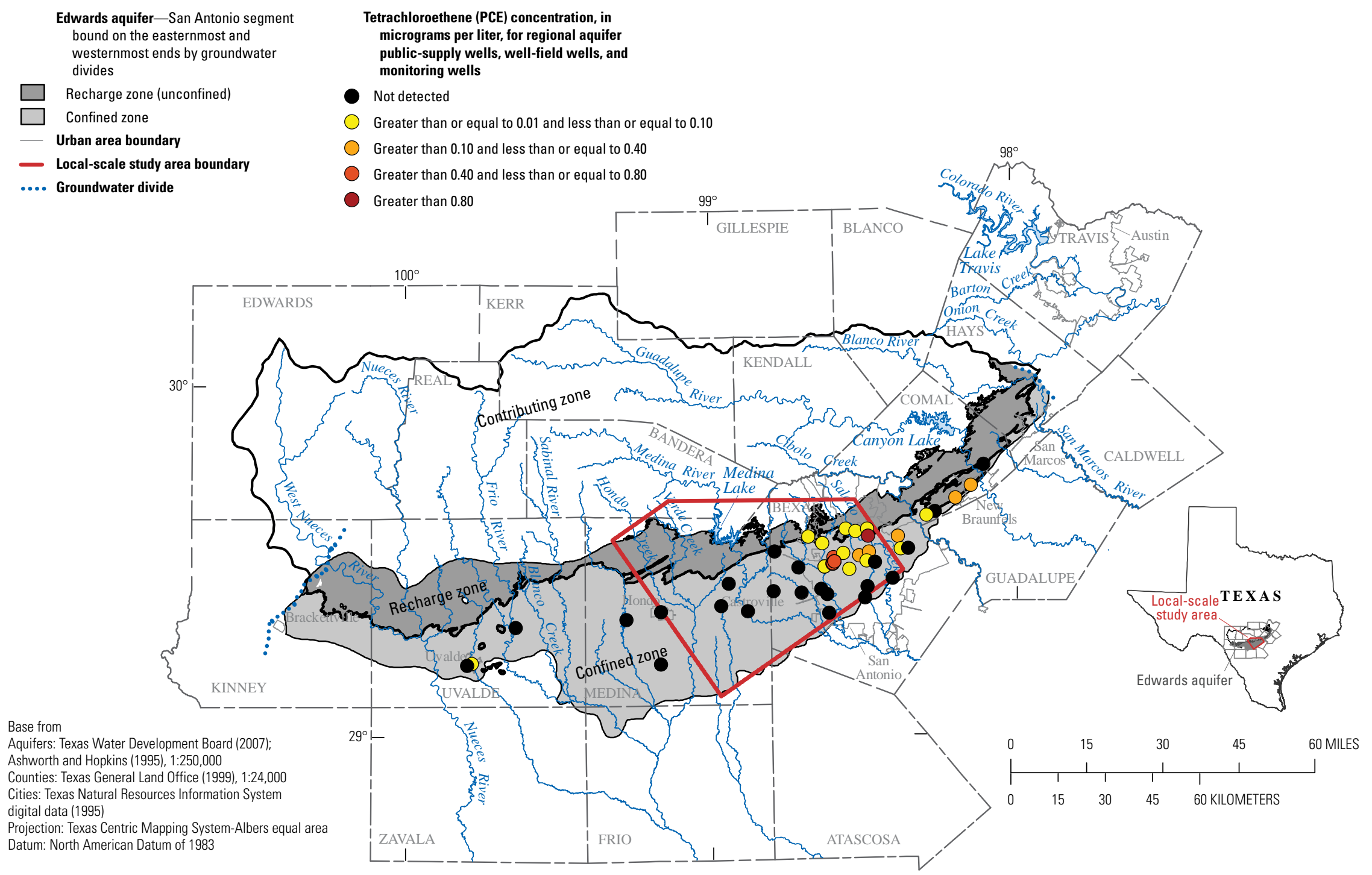

Figure 41. Hydrogeologic setting, location of, and ranges of tetrachloroethene (PCE) concentration (highest value shown where multiple measurements were made during the study period) for regional aquifer public-supply wells sampled for the study of the transport of anthropogenic and natural contaminants (TANC) to public-supply wells in the San Antonio segment of the Edwards aquifer, south-central Texas, 2004-9. 


\section{EXPLANATION}

Edwards aquifer-San Antonio segment bound on the easternmost and westernmost ends by groundwate

Recharge zone (unconfined)

$\square$ Confined zone

\section{Urban area boundary}

- Local-scale study area boundary

.... Groundwater divide
Nitrate concentration, in milligrams per liter,

for regional aquifer public-supply wells,

well-field wells, and monitoring wells

- Not detected

Less than or equal to 1.0

Greater than 1.0 and less than or equal to 2.0

Greater than 2.0 and less than or equal to 3.0

- Greater than 3.0

Figure 42. Hydrogeologic setting, location of, and ranges of nitrate concentration (highest value shown where multiple measurements were made during the study period) for regional aquifer public-supply wells sampled for the study of the transport of anthropogenic and natural contaminants (TANC) to public-supply wells in the San Antonio segment of the Edwards aquifer, south-central Texas, 2004-9. 
mixing waters of different age and source in long well screens that are typical in PSWs (Kauffman and others, 2001; Böhlke, 2002; Weissmann and others, 2002; Osenbrück and others, 2006; Eberts and others, 2006). Age distributions of water captured by individual long-screen wells in some aquifer settings might span years to millennia or more (Kauffman and others, 2001; Weissmann and others, 2002; McMahon and others, 2004; Plummer and others, 2004; Sturchio and others, 2004; Clark and others, 2007; Starn and Brown, 2007; Crandall and others, 2008; Jurgens and others, 2008). These age distributions in captured water could have positive and negative consequences for the quality of water from a PSW, such as dilution of contaminant concentrations and long lag times in responding to land use change or best management practices. An important implication of long lag times is that, in spite of corrective management actions, contaminant concentrations in water from PSWs could increase in the future (before eventually decreasing) as the fraction of already contaminated young recharge captured by wells increases (Fogg and others, 1999; Böhlke, 2002; Fogg and LaBolle, 2006).

Although TANC study results for the local-scale study area indicate that long lag times are not a likely feature of the Edwards aquifer, understanding the potential response of water quality in the PSW to land-use changes, and the resulting time scales of response in the PSW, is useful for water resource management. A post-MODPATH spreadsheet model (L.J. Kauffman, U.S. Geological Survey, written commun., 2011) that incorporates MODPATH particle-tracking results (Pollock, 1994) and contaminant reaction (degradation) processes was used to analyze the response of water quality in the selected PSW to land-use change. The water-quality response to land-use change was dependent on age distributions of water captured by the PSW. Groundwater flow and particletracking simulations are described by Lindgren and others (2011b). Flow and traveltimes associated with the particle tracking to the PSW were used to estimate relative contaminant concentrations in the PSW; a hypothetical conservative (nonreactive) contaminant was modeled. A relative contaminant concentration was assigned to each particle on the basis of the traveltime and by assuming an input concentration history of the contaminant in the contributing area (recharge zone), as described below. Flux-weighted average contaminant concentrations for the PSW were determined by summing the product of concentrations assigned to each particle by the total flow associated with that particle and dividing by the total flow.

Simulated age distribution for contributing-area particles of the PSW ranged from less than 1 to 342 years, with a median of 2.0 years (fig. 33). Particle-track results indicate that 99 percent of the PSW water was less than 50 years old and that 88 percent of the water was less than 5 years old. Younger water (less than 50 years old) is more likely to be affected by human activities, and if present, most anthropogenic contaminants would be associated with younger water. As previously described, these model results concur with the conceptual understanding that a large fraction of water in the
Edwards aquifer, and particularly in the PSW, is young (less than 50 years old). Water samples from the PSW, other wells in the well field, and other PSWs completed in the regional aquifer contained detectable concentrations of a small number of some pesticides and VOCs (fig. 25; tables 14-17). Natural attenuation processes are also likely to be limited in flow systems with young groundwater, in particular for conditions or contaminants where degradation processes are slow (Chapelle and Bradley, 1999; McMahon and others, 2008), such as is the case in this oxic aquifer. In flow systems with a higher fraction of older water (that is, greater than 50 years old), that fraction could dilute anthropogenic contaminant concentrations when waters of different ages mix within the aquifer and the open borehole of a PSW (Osenbrück and others, 2006).

In a model-forecasting exercise, slug inputs were used to examine the range in lag times, dilution, and degradation that might be expected at the PSW. Results of this exercise might be representative of a rapid land-use change overlying the contributing area (recharge area) of a PSW in this aquifer and might represent how quickly the aquifer responds to mitigation. A hypothetical contaminant was introduced over the PSW-model-contributing area continuously for 30 years. Contaminant input concentrations were equal to 1 , and all simulated concentrations for the well were relative to this unit value. After 30 years, the contaminant input returned to zero. The hypothetical responses at the PSW for (1) a simulation with no contaminant degradation and (2) a simulation with degradation at a first-order reaction kinetics degradation rate

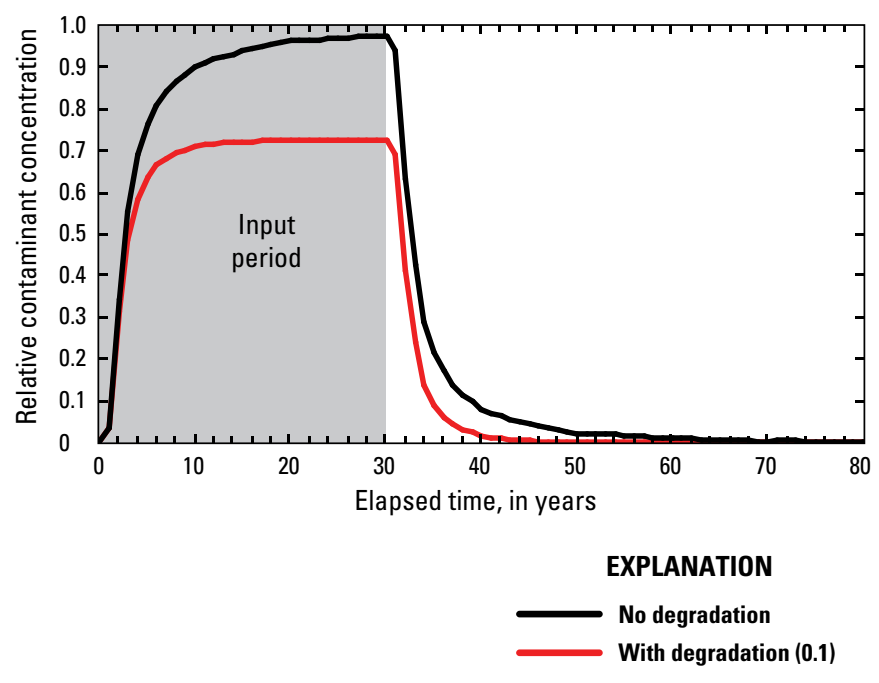

Figure 43. Results of forecasting exercise of time-series of hypothetical contaminant concentrations at the selected publicsupply well for the study of the transport of anthropogenic and natural contaminants (TANC) to public-supply wells; results are based on 30 years of contaminant input (at a relative concentration of 1) in the modeled contributing area (based on model and particle-track results described in Lindgren and others, 2011b). 
of $0.1 /$ year (10 percent per year) are illustrated in figure 43 . For both responses (curves in fig. 43), concentrations at the PSW began to rise within 1 year after loading began and rose quickly to reach 50 percent of peak concentration in 3 and 4 years, respectively. The nondegradation curve continued to rise rapidly until about 5 years, when 77 percent of peak concentration was reached. Concentrations continued to rise for both curves until peak concentrations were reached at the end of the input period of 30 years. Maximum concentrations were 98 percent of input for the nondegradation curve and 73 percent of input for the with-degradation curve. Once the input was stopped after 30 years, both simulations responded with a rapid drop in concentration. Concentration decreased to about 50 percent of input in 3 years in the nondegradation simulation and in a little more than 2 years for the degradation simulation. Concentration decreased to 25 percent of input in about 5 years and in less than 4 years, respectively. Although peak concentrations dropped quickly after input ceased, 32 and 12 years were required, respectively, to flush 99 percent of the hypothetical contaminant and achieve near-background conditions (table 20 at end of report).

Lag times would be expected to be shorter for wells with large fractions of young water (McMahon and others, 2008), such as observed for this study, than for wells with smaller fractions of young water. The effect of short-circuit pathways, for example karst conduits, in the flow system on the movement of young water to the PSW could greatly alter contaminant arrival times compared to what might be expected from advection in a system without short circuiting. This observation is particularly valid for karst such as the Edwards aquifer: numerous voids are present in wells completed in this aquifer, including the PSW. The simulated concentrations show rapid initial response at the beginning and end of chemical input, followed by more gradual response as older water moves through the system. The nature of karst groundwater flow, where flow dominantly occurs via conduit flow paths, could lead to relatively rapid water-quality responses to land-use changes.

This analysis did not consider chemical storage and traveltimes in the unsaturated zone, dispersion/diffusion, or transient flow conditions in the aquifer, which might yield substantially different results. Storage of large amounts of chemical mass in, and long transit times through, unsaturated zones could result in longer flushing times, as well as longer arrival and lag times, in the aquifer. The impact of not considering dispersion is likely minimized because the focus herein is for large pumping wells and nonpoint sources of contamination. Transient conditions in the flow system could result in more complex areas contributing recharge and more complex groundwater age distributions than were assessed here and should be considered in future studies (Franke and others, 1998; Rock and Kupfersberger, 2002). Spatial variability in input, which would likely have considerable effect on concentrations and movement of contaminants, also was not considered. Short-circuit pathways, such as karst conduits, in some PSW contributing areas can affect age distributions by allowing relatively rapid movement of young water to the open interval of the PSW. The spatial component of landuse change is important because the complex distribution of particle traveltimes within the contributing areas strongly influences contaminant arrival times and degradation reaction progress. Results from this and other similar exercises (McMahon and others, 2008) indicate that time scales for change in the quality of water from the PSW could be on the order of a few years to decades for land-use changes that occur over days to decades, which has implications for source-water protection strategies that rely on land-use change to achieve water-quality objectives.

\section{Summary}

In 2001, the National Water-Quality Assessment (NAWQA) Program of the U.S. Geological Survey initiated a series of studies on the transport of anthropogenic and natural contaminants (TANC) to public-supply wells (PSWs). The main goal of the TANC project was to better understand the source, transport, and receptor factors that control contaminant movement to PSWs in representative aquifers of the United States. Regional- and local-scale study areas were selected from within existing NAWQA study units, including southcentral Texas. This report describes the hydrogeology and geochemistry of the local-scale TANC study near San Antonio, Tex., and discusses factors that might control transport of selected anthropogenic and natural contaminants to a publicsupply well within a productive well field. The study area is within the San Antonio segment of the Edwards aquifer, a highly productive karst aquifer developed in Cretaceous-age carbonates. Like many karst aquifers, the Edwards aquifer is subject to rapid changes in flow and discharge rates, waterlevel altitudes, and water quality and as a result is susceptible to contamination. An understanding of the source, transport, and receptor factors that control contaminant movement to PSWs in the Edwards aquifer is important for water-management practices and the long-term sustainability of the groundwater resource. Results for a variety of geochemical constituents and tracers were compared for groundwater samples from regional aquifer PSWs (mostly from the confined part of the aquifer), from the well field (wellhead samples), from the monitoring wells (Zarzamora and Timberhill monitoring well clusters), from a monitoring well in the overburden, from the PSW depth-dependent sampling, and from temporal sampling in response to a rainfall and recharge event (from the PSW and selected monitoring wells).

Constituents of concern in the Edwards aquifer for the long-term sustainability of the groundwater resource include anthropogenic organic contaminants and the nutrient nitrate. Natural contaminants, such as arsenic or uranium, are not of concern for the Edwards aquifer, and oxic aquifer conditions are not conducive to increases in concentrations of these contaminants. Geochemical and isotopic data are useful tracers of recharge, groundwater flow, fluid mixing, and water-rock 
interaction processes that affect water quality. Sources of dissolved constituents to the Edwards aquifer and to the PSW include dissolution of and geochemical interaction with overlying soils and calcite and dolomite minerals that compose the aquifer. The well-field and monitoring well samples had relatively narrow ranges in field parameters and most geochemical constituents were, for the most part, similar in composition to samples from regional aquifer PSWs. Groundwater samples were mostly a dilute calcium bicarbonate or calcium magnesium bicarbonate facies. Mineral saturation indices with respect to calcite, dolomite, and gypsum reflect the carbonate mineralogy of the aquifer host rocks. TANC study results for molar ratios of magnesium to calcium and strontium to calcium, and for strontium isotopes, were used to assess relative extents of water-rock interaction associated with shorter and longer flow paths. Molar ratios of magnesium to calcium and strontium to calcium in carbonate groundwater typically increase along flow paths; strontium isotopes in Edwards aquifer groundwater typically decrease along flow paths, toward values similar to the limestone aquifer rocks. Oxidation-reduction conditions were oxic, which is typical of the regional aquifer, except very close to the downgradient transition, which had more saline, less oxic water.

Nitrate concentrations for samples collected during this study from regional aquifer PSWs (specifically, PSWs in the confined part of the aquifer) were below drinking-water standards and had a similar median value (1.9 milligrams per liter) to regional aquifer samples from the confined part of the aquifer collected in previous studies. Nitrate-isotope results for the well-field and monitoring well samples indicate that soil organic nitrogen is the dominant source of nitrate in the regional aquifer. A comparison with historical nitrate-isotope values, however, suggests that a possible component of nitrate in groundwater from biogenic sources might have increased over the last 30 years. Results for stable isotopes of hydrogen and oxygen for groundwater samples from the well-field wells and monitoring wells indicated that the groundwater is meteoric in origin. A small number of organic contaminants were routinely or frequently detected in groundwater samples collected for this study. These were the pesticides atrazine; its degradate deethylatrazine; the drinking-water disinfection byproduct, trichloromethane (chloroform); and the solvent tetrachloroethene (PCE). Detected concentrations of all organic constituents were low (mostly less than 1 microgram per liter), which is consistent with previous NAWQA findings. The common detection of these anthropogenic contaminants indicates that the aquifer is vulnerable to contamination and effects on water-quality that result from anthropogenic activities. The geochemistry of groundwater from the PSW was similar to that of samples collected from PSWs throughout the extent of the regional confined aquifer. These results indicate that water from the PSW is generally representative of the regional confined aquifer. All samples collected from the well field and specifically those collected from different depths in the PSW under a variety of pumping conditions were relatively homogeneous and well mixed for numerous geochemical constituents, with the notable exception of age tracers. Although multiple age tracers were sampled, because of contamination effects and age-interpretation complexities, all age interpretations were based on tritium/helium-3 results. Apparent ages based on a piston-flow model for samples from the well field and monitoring wells ranged from less than 1 to 41 years, with a median of 17 years. Apparent ages were inversely stratified for both sets of monitoring wells, with older ages for the deeper monitoring wells. Results for depth-depending samples from the PSW yielded a range of apparent ages (less than 1 to 22 years) but with no consistency with respect to depth or stratigraphic unit contributing to the PSW. Selected geochemical constituents that might provide independent information about groundwater residence time (for example, magnesium to calcium molar ratios, dolomite mineral saturation indices, and strontium isotope ratios) or the extent of impact from anthropogenic activities (for example, the number of organic contaminants detected, concentration of selected organic contaminants) were compared to age-tracer results for groundwater samples. Results of this comparison were not consistent with the range of interpreted apparent ages or age-tracer results, indicating that hydrogeologic conceptual models used in groundwater age interpretations might not adequately account for mixing in this karst system. Mixing processes in this aquifer are complex, and although age tracers provide insight into the young nature of the groundwater, they might not readily allow for distinguishing the mixed water history of water at a PSW or be well suited to distinguish relatively small differences in groundwater age as a result of mixing processes. Nonetheless, age interpretations, indicating that water supplied to the PSW is young, were consistent with particle-tracking results from a companion hydrogeologic modeling study.

One of the well-field PSWs and four selected monitoring wells were sampled several times in response to a storm event that recharged the regional aquifer. Geochemical variability in response to the sampled recharge event was generally small in the well-field PSW and monitoring wells in comparison to the range of geochemical variability observed in the regional aquifer. Several geochemical constituents, however, showed consistent variability in the PSW and monitoring wells that corresponded with associated changes in hydrologic conditions in response to the sampled recharge event. The observed temporal variations in water chemistry were consistent with the hypothesis that the response to individual recharge events in the confined aquifer, unless intersecting conduit flow paths, might be attenuated by mixing processes along regional flow paths.

Anthropogenic sources that might influence groundwater water quality at the PSW include septic systems, leakage from municipal water and wastewater systems, and general industrial, commercial, or residential use of pesticides and volatile organic compounds. Although the urban San Antonio environment is a likely source of anthropogenic contaminants to the PSW, sampling of regional aquifer PSWs indicates that a few specific organic contaminants are widely distributed 
throughout the aquifer at low concentrations. There are point sources in the vicinity of the well field for PCE. Higher concentrations of PCE were detected in samples from the well field and Zarzamora monitoring wells relative to the regional aquifer PSWs, which is consistent with the possibility that a local urban source (or sources) might be supplying PCE to these wells. Under all pumping conditions, the majority of water from the PSW was young and, as such, susceptible to contamination. Although zones of preferential flow were determined for the PSW, groundwater samples from different stratigraphic units were not geochemically distinct. Results from groundwater-flow-model particle tracking were used to evaluate a hypothetical contaminant-loading scenario to assess the potential response of the aquifer to contamination. Results indicate that the aquifer responds rapidly (less than 1 year to several years) to contaminant loading; however, it takes a relatively long time (decades) for concentrations to reach the highest values. The aquifer also responds quickly (less than 1 year to several years) to the removal of contaminant loading; again however, it takes a relatively long time (decades) to reach near background concentrations. These results corroborate the existing conceptual understanding of aquifer behavior to contaminant loading.

\section{References}

Abbott, P.L., 1975, On the hydrology of the Edwards Limestone, south-central Texas: Journal of Hydrology, v. 24, p. 251-269.

Abbott, P.L., and Woodruff, C.M., Jr., 1986, eds., The Balcones escarpment-Geology, hydrology, ecology and social development in central Texas: Geological Society of America, 200 p.

American Society for Testing and Materials, 1996, Annual book of ASTM standards, section 11-Water and environmental technology: American Society for Testing and Materials, v. 11.02, D-5072-98, p. 674-676.

Appelo, C.A.J., and Postma, D., 2005, Geochemistry, groundwater, and pollution (2d ed.): A.A. Balkema Publishers, 649 p.

Atkinson, T.C., 1977, Diffuse flow and conduit flow in limestone terrain in the Mendip Hills, Somerset (Great Britain): Journal of Hydrology, v. 35, p. 93-110.

Banner, J.L., 2004, Radiogenic isotopes_-Systematics and applications to earth surface processes and chemical stratigraphy: Earth Science Reviews, v. 65, p. 141-194.

Banner, J.L., Musgrove, M., and Capo, R.C., 1994, Tracing ground-water evolution in a limestone aquifer using $\mathrm{Sr}$ isotopes-Effects of multiple sources of dissolved ions and mineral-solution reactions: Geology, v. 22, p. 687-690.
Barker, R.A., and Ardis, A.F., 1996, Hydrogeologic framework of the Edwards-Trinity aquifer system, west-central Texas: U.S. Geological Survey Professional Paper 1421-B, 61 p.

Bethke, C.M., and Johnson, T.M., 2008, Groundwater age and groundwater age dating: Annual Reviews of Earth and Planetary Science, v. 36, p. 121-152.

Bexfield, L.M., Jurgens, B.C., Crilley, D.M., and Christenson, S.C., 2011, Hydrogeology, water chemistry, and transport processes in the zone of contribution of a public-supply well in Albuquerque, New Mexico: U.S. Geological Survey Scientific Investigations Report 2011-5182, 114 p.

Birk, Steffen, Bauer, Sebastian, Liedl, Rudolf, and Sauter, Martin, 2003, Coupling a pipe-network to MODFLOW to predict the evolution of karst aquifers, in Poeter, E.P., Zheng, C., Hill, M.C., and Doherty, John, eds., MODFLOW and more 2003_-Understanding through modeling, Golden, Colo., September 16-19, 2003, Proceedings: Colorado School of Mines, p. 65-69.

Böhlke, J.K., 2002, Groundwater recharge and agricultural contamination: Hydrogeology Journal, v. 10, p. 153-179.

Böhlke, J.K., 2006, Tracermodel 1. Excel workbook for calculation and presentation of environmental tracer data for simple groundwater mixtures, in Use of chlorofluorocarbons in hydrology_A guidebook, section III.3: Vienna, Austria, International Atomic Energy Agency, STI/ PUB/1238, p. 239-243.

Brawley, J.W., Collins, G., Kremer, J.N., Sham, C.H., and Valiela, I., 2000, A time-dependent model of nitrogen loading to estuaries from coastal Watersheds: Journal of Environmental Quality, v. 29, p. 1448-1461.

Brenton, R.W., and Arnett, T.L., 1993, Methods of analysis by the U.S. Geological Survey National Water Quality Laboratory-Determination of dissolved organic carbon by ultraviolet-light promoted persulfate oxidation and infrared spectrometry: U.S. Geological Survey Open-File Report 92-480, 12 p.

Brown, C.J., Starn, J.J., Stollenwerk, K.G., Mondazzi, R.A., and Trombley, T.J., 2009, Aquifer chemistry and transport processes in the zone of contribution to a public-supply well in Woodbury, Connecticut, 2002-06: U.S. Geological Survey Scientific Investigations Report 2009-5051, 158 p. (Also available at http://pubs.usgs.gov/sir/2009/5051/).

Brugam, R.B., Shakraverty, S., and Lamkin, J., 1988, Sediment chemistry of lakes formed by surface-mining for coal in the Midwestern USA: Hydrobiologica, v. 164, p. 221-233.

Bullister, J.L., 1984, Atmospheric chlorofluoromethanes as tracers of ocean circulation and mixing-Studies in the 
Greenland and Norwegian seas: San Diego (La Jolla), Calif., University of California, Ph.D. dissertation, 172 p.

Bullister, J.L., and Weiss, R.F., 1988, Determination of $\mathrm{CCl}_{3} \mathrm{~F}$ and $\mathrm{CCl}_{2} \mathrm{~F}_{2}$ in seawater and air: Deep-Sea Research, v. 35, no. 5, p. 839-854.

Burchett, C.R., Rettman, P.L., and Boning, C.W., 1986, The Edwards aquifer, extremely productive, but....A sole-source water supply for San Antonio and surrounding counties in south-central Texas: San Antonio, Edwards Underground Water District Report, 38 p.

Busenberg, E., and Plummer, L.N., 1992, Use of chlorofluorocarbons $\left(\mathrm{CCl}_{3} \mathrm{~F}\right.$ and $\left.\mathrm{CCl}_{2} \mathrm{~F}_{2}\right)$ as hydrologic tracers and age-dating tools-The alluvium and terrace system of central Oklahoma: Water Resources Research, v. 28, no. 9, p. 2257-2283.

Busenberg, E., and Plummer, L.N., 2000, Dating young groundwater with sulfur hexafluoride-Natural and anthropogenic sources of sulfur hexafluoride: Water Resources Research, v. 36, p. 3011-3030.

Busenberg, E., Plummer, L.N., Bartholomay, R.C., and Wayland, J.E., 1998, Chlorofluorocarbons, sulfur hexafluoride, and dissolved permanent gases in ground water from selected sites in and near the Idaho National Engineering and Environmental Laboratory, Idaho, 1994-1997: U.S. Geological Survey Open-File Report 98-274, 72 p.

Bush, P.W., Ardis, A.F., Fahlquist, L., Ging, P.B., Hornig, C.E., and Lanning-Rush, J., 2000, Water quality in south-central Texas, Texas, 1996-98: U.S. Geological Survey Circular 1212, $32 \mathrm{p}$.

Campana, M.E., and Mahin, D.A., 1985, Model-derived estimates of groundwater mean ages, recharge rates, effective porosities and storage in a limestone aquifer: Journal of Hydrology, v. 76, p. 247-264.

Carter, J.M., Delzer, G.C., Kingsbury, J.A., and Hopple, J.A., 2007, Concentration data for anthropogenic organic compounds in ground water, surface water, and finished water of selected community water systems in the United States, 2002-05: U.S. Geological Survey Data Series 268, 31 p.

Casciotti, K.L., Sigman, D.M., Galanter Hastings, M., Böhlke, J.K., and Hilkert, A., 2002, Measurement of the oxygen isotopic composition of nitrate in seawater and freshwater using the denitrifier method: Analytical Chemistry, v. 74, p. $4905-4912$.

Century Geophysical Corporation, 2010, Home Web page: accessed September 14, 2010, at http://www.century-geo. $\mathrm{com} /$.

Chapelle, F.H., and Bradley, P.M., 1999, Selecting remediation goals by assessing the natural attenuation capacity of ground-water systems, in Morganwalp, D.W., and Buxton,
H.T., eds., Subsurface Contamination from Point Sources, U.S. Geological Survey Toxic Substances Hydrology Program, Charleston, South Carolina, March 8-12, 1999, Proceedings of the Technical Meeting: U.S. Geological Survey Water-Resources Investigations Report 99-4018C, v. 3, p. 7-19.

Clark, A.K., and Journey, C.A., 2006, Flow paths in the Edwards aquifer, northern Medina and northeastern Uvalde Counties, Texas, based on hydrologic identification and geochemical characterization and simulation: U.S. Geological Survey Scientific Investigations Report 2006-5200, 48 p.

Clark, B.R., Landon, M.K., Kauffman, L.J., and Hornberger, G.Z., 2007, Simulations of ground-water flow, transport, age, and particle tracking at the local scale near York, Nebraska, for a study of transport of anthropogenic and natural contaminants (TANC) to public-supply wells: U.S. Geological Survey Scientific Investigations Report 20075068, 47 p.

Clark, I.D., and Fritz, P., 1997, Environmental isotopes in hydrogeology: Boca Raton, Fla., Lewis Publishers, 328 p.

Clark, W.B., Jenkins, W.J., and Top, Z., 1976, Determination of tritium by mass spectrometric measurement of ${ }^{3} \mathrm{He}$ : International Journal of Applied Radiation and Isotopes, v. 27 , p. 515-522.

Clement, T.J., and Sharp, J.M., Jr., 1988, Hydrogeochemical facies in the bad-water zone of the Edwards aquifer, central Texas, in Ground Water Geochemistry Conference, Proceedings: Dublin, Ohio, National Water Well Association, p. 127-149.

Connor, B.F., Rose, D.L., Noriega, M.C., Murtagh, L.K., and Abney, S.R., 1998, Methods of analysis by the U.S. Geological Survey National Water Quality LaboratoryDetermination of 86 volatile organic compounds in water by gas chromatography/mass spectrometry, including detections less than reporting limits: U.S. Geological Survey Open-File Report 97-829, 78 p.

Cook, P.G., and Böhlke, J.K., 2000, Determining timescales for groundwater flow and solute transport, in Cook, P.G., and Herczeg, A., eds., Environmental tracers in subsurface hydrology: Boston, Mass., Kluwer Academic Publishers, p. 1-30.

Coplen, T.B., 1994, Reporting of stable hydrogen, carbon, and oxygen isotopic abundances: Pure and Applied Chemistry, v. 66, p. 273-276.

Coplen, T.B., Wildman, J.D., and Chen, J., 1991, Improvements in the gaseous hydrogen-water equilibration technique for hydrogen isotope ratio analysis: Analytical Chemistry, v. 63, p. 910-912. 
Cornwell, J.C., and Morse, J.W., 1987, The characterization of iron sulfide minerals in anoxic marine sediments: Marine Chemistry, v. 22, p. 193-206.

Craig, H., 1961, Isotopic variations in meteoric waters: Science, v. 133, p. 1702-1703.

Crandall, C.A., Kauffman, L.J., Katz, B.G., Metz, P.A., McBride, W.S., and Berndt, M.P., 2008, Simulations of groundwater flow and particle tracking analysis in the area contributing recharge to a public-supply well near Tampa, Florida, 2002-05: U.S. Geological Survey Scientific Investigations Report 2008-5231, 53 p.

Daly, Chris, and Taylor, George, 2000 United States average annual precipitation, 1961-1990: accessed March 2011 at http://nationalatlas.gov/metadata/prism0p020.html.

Desmarais, K., and Rojstaczer, S., 2002, Inferring source waters from measurements of carbonate spring responses to storms: Journal of Hydrology, v. 260, p. 118-134.

Dubrovsky, N.M., Burow, K.R., Clark, G.M., Gronberg, J.M., Hamilton, P.A., Hitt, K.J., Mueller, D.K., Munn, M.D., Nolan, B.T., Puckett, L.J., Rupert, M.G., Short, T.M., Spahr, N.E., Sprague, L.A., and Wilber, W.G., 2010, The quality of our Nation's waters-Nutrients in the Nation's streams and groundwater, 1992-2004: U.S. Geological Survey Circular 1350, $174 \mathrm{p}$.

Eberts, S.M., Böhlke, J.K., and Kauffman, L.J., 2006, Application of ground water dating techniques for evaluating the susceptibility of aquifers and public-supply wells to contamination [abs.]: National Monitoring Conference: Concurrent Session F: F3-Assessing Ground Water Vulnerability Through Mechanistic Methods II, May 7-11, 2006, San Jose, California: accessed March 2011 at http://ct.water.usgs.gov/nawqa/references.htm.

Eberts, S.M., Erwin, M.L., and Hamilton, P.A., 2005, Assessing the vulnerability of public-supply wells to contamination from urban, agricultural, and natural sources: U.S. Geological Survey Fact Sheet 2005-3022, 4 p.

Edwards Aquifer Authority, 2009, The Edwards aquifer-Aquifer levels: accessed September 2010 at http:// edwardsaquifer.org.

Epstein, S., and Mayeda, T., 1953, Variation of ${ }^{18} \mathrm{O}$ content of waters from natural sources: Geochimica et Cosmochimica Acta, v. 4, p. 213-224.

Fahlquist, Lynne, and Ardis, A.F., 2004, Quality of water in the Trinity and Edwards aquifers, south-central Texas, 1996-98: U.S. Geological Survey Scientific Investigations Report 2004-5201, 17 p.

Fairchild, I.J., Borsato, A., Tooth, A.F., Frisia, S., Hawkesworth, C.J., Huang, H., McDermott, F., and Spiro,
B., 2000, Controls on trace element (Sr-Mg) compositions of carbonate cave waters-Implications for speleothem climatic records: Chemical Geology, v. 166, p. 255-269.

Faires, L.M., 1993, Methods of analysis by the U.S. Geological Survey National Water Quality LaboratoryDetermination of metals in water by inductively coupled plasma-mass spectrometry: U.S. Geological Survey OpenFile Report 92-634, 28 p.

Fishman, M.J., 1993, Methods of analysis by the U.S. Geological Survey National Water Quality LaboratoryDetermination of inorganic and organic constituents in water and fluvial sediments: U.S. Geological Survey OpenFile Report 93-125, 217 p.

Fishman, M.J., and Friedman, L.C., 1989, Methods for the determination of inorganic substances in water and fluvial sediments: U.S. Geological Survey Techniques of WaterResources Investigations, book 5, chap. A1, 545 p.

Focazio, M.J., Reilly, T.E., Rupert, M.G., and Helsel, D.R., 2002, Assessing ground-water vulnerability to contamination-Providing scientifically defensible information for decision makers: U.S. Geological Survey Circular 1224, $33 \mathrm{p}$.

Focazio, M.J., Welch, A.H., Watkins, S.A., Helsel, D.R., and Horn, M.A., 1999, A retrospective analysis on the occurrence of arsenic in ground-water resources of the United States and limitations in drinking-water-supply characterizations: U.S. Geological Survey Water-Resources Investigations Report 99-4279, 21 p.

Fogg, G.E., and LaBolle, E.M., 2006, Motivation of synthesis, with an example on groundwater quality sustainability: Water Resources Research, v. 42, W03S05, doi:10.1029/2005WR004372.

Fogg, G.E., LaBolle, E.M., and Weissmann, G.S., 1999, Groundwater vulnerability assessment-Hydrogeologic perspective and example from Salinas Valley, California, in Corwin, D.L., Loague, K., and Ellsworth, T.R., eds., Assessment of non-point source pollution in the vadose zone: Washington, D.C., American Geophysical Union Geophysical Monograph Series, v. 108, p. 45-61.

Franke, O.L., Reilly, T.E., Pollock, D.W., and LaBaugh, J.W., 1998, Estimating areas contributing recharge to wellsLessons learned from previous studies: U.S. Geological Survey Circular 1174, 14 p.

Furlong, E.T., Anderson, B.D., Werner, S.L., Solvier, P.P., Coffey, L.J., and Burkhardt, M.R., 2001, Methods of analysis by the U.S. Geological Survey National Water Quality Laboratory-Determination of pesticides in water by graphitized carbon-based solid-phase extraction and high performance liquid chromatography/mass spectrometry: U.S. Geological Survey Water-Resources Investigations Report 01-4134, 73 p. 
Galloway, J.N., Townsend, A.R., Erisman, J.W., Bekunda, M., Cai, Z., Freney, J.R., Martinelli, L.A., Seitzinger, S.P., and Sutton, M.A., 2008, Transformation of the nitrogen cycleRecent trends, questions, and potential solutions: Science, v. 320, p. 889-892.

Garbarino, J.R., 1999, Methods of analysis by the U.S. Geological Survey National Water Quality LaboratoryDetermination of dissolved arsenic, boron, lithium, selenium, strontium, thallium, and vanadium using inductively coupled plasma-mass spectrometry: U.S. Geological Survey Open-File Report 99-093, 31 p.

Garbarino, J.R., Kanagy, L.K., and Cree, M.E., 2006, Determination of elements in natural-water, biota, sediment and soil samples using collision/reaction cell inductively coupled plasma-mass spectrometry: U.S. Geological Survey Techniques and Methods, book 5, sec. B, chap.1, 88 p.

Garner, B.D., 2005, Geochemical evolution of ground water in the Barton Springs segment of the Edwards aquifer, Austin, Tex.: University of Texas at Austin, M.S. thesis, 317 p.

Garner, B.D., and Mahler, B.J., 2007, Relation of specific conductance in ground water to intersection of flow paths by wells, and associated major ion and nitrate geochemistry, Barton Springs segment of the Edwards aquifer, Austin, Texas, 1978-2003: U.S. Geological Survey Scientific Investigations Report 2007-5002, 171 p.

Gat, J.R., 1981, Groundwater, in Gat, J.R., and Gonfiantini, R., eds., Stable isotope hydrology-Deuterium and oxygen-18 in the water cycle: Vienna, Austria, International Atomic Energy Agency, p. 223-240.

George, W.O., 1952, Geology and ground-water resources of Comal County, Texas: U.S. Geological Survey WaterSupply Paper 1138, 126 p.

Gilliom, R.J., Alley, W.M., and Gurtz, M.E., 1995, Design of the National Water-Quality Assessment ProgramOccurrence and distribution of water-quality conditions: U.S. Geological Survey Circular 1112, 33 p.

Gilliom, R.J., Barbash, J.E., Crawford, C.G., Hamilton, P.A., Martin, J.D., Nakagaki, N., Nowell, L.H., Scott, J.C., Stackelberg, P.E., Thelin, G.P., and Wolock, D.M., 2006, Pesticides in the Nation's streams and ground water, 1992-2001: U.S. Geological Survey Circular 1291, 172 p.

Griffiths, J.F., and Strauss, R.F., 1985, The variety of Texas weather: Weatherwise, v. 38, p. 137-141.

Groschen, G.E., 1996, Hydrogeologic factors that affect the flowpath of water in selected zones of the Edwards aquifer, San Antonio region, Texas: U.S. Geological Survey WaterResources Investigations Report 96-4046, 73 p.

Groschen, G.E., and Buszka, P.M., 1997, Hydrogeologic framework and geochemistry of the Edwards aquifer salinewater zone, south-central Texas: U.S. Geological Survey Water-Resources Investigations Report 97-4133, $47 \mathrm{p}$.

Hach Company, 2002, DR/2400 Spectrophotometer procedures manual: Loveland, Colo., 450 p.

Hamilton, J.M., Johnson, S., Esquilin, R., Thompson, E.L., Luevano, G., Wiatrek, A., Mireles, J., Gloyd, T., Sterzenback, J., Hoyt, J.R., and Schindel, G., 2003, Edwards Aquifer Authority hydrogeological data report for 2002: San Antonio, Edwards Aquifer Authority, 134 p. (Also available at www.edwardsaquifer.org.).

Hamilton, J.M., Johnson, S., Mireles, J., Esquilin, R., Burgoon, C., Luevano, G., Gregory, D., Gloyd, R., Sterzenback, J., Mendoza, R., and Schindel, G.M., 2008, Edwards Aquifer Authority hydrogeologic data report for 2007: Edwards Aquifer Authority Report 08-02, 229 p.

Hamilton, P.A., Miller, T.L., and Myers, D.N., 2004, Water quality in the Nation's stream and aquifers-Overview of selected findings, 1991-2001: U.S. Geological Survey Circular 1265, 20 p.

Happell, J.D., Opsahl, S., Top, Z., and Chanton, J.P., 2006, Apparent $\mathrm{CFC}$ and ${ }^{3} \mathrm{H} /{ }^{3} \mathrm{He}$ age differences in water from Floridan aquifer springs: Journal of Hydrology, v. 319, p. 410-426.

Harbaugh, A.W., Banta, E.R., Hill, M.C., and McDonald, M.G., 2000, MODFLOW-2000, the U.S. Geological Survey modular ground-water model-User guide to modularization concepts and the ground-water flow process: U.S. Geological Survey Open-File Report 00-92, 121 p.

Hauwert, N.M., Johns, D.A., Hunt, B.B., Beery, J., Smith, B.A., and Sharp, J.M., Jr., 2004, Flow systems of the Edwards aquifer Barton Springs segment interpreted from groundwater tracing and associated field studies, in Edwards Water Resources in Central Texas-Retrospective and Prospective, South Texas Geological Society and Austin Geological Society Symposium, San Antonio, Tex., May 21-24, 2004, 13 p.

Hauwert, N.M., Samson, J.W., Johns, D.A., and Aley, T.J., 2004, Groundwater tracing study of the Barton Springs segment of the Edwards aquifer, southern Travis and northern Hays Counties, Texas: Barton Springs/Edwards Aquifer Conservation District and City of Austin Watershed Protection and Development Review Department, 110 p., apps.

Heaton, T.H.E., and Vogel, J.C., 1981, Excess air in groundwater: Journal of Hydrology, v. 50, p. 201-216.

Helsel, D.R., and Hirsch, R.M., 2002, Hydrologic analysis and interpretation-Statistical methods in water resources: U.S. Geological Survey Techniques of Water-Resources 
Investigations, book 4, chap. A3, accessed September 2008 at http://pubs.usgs.gov/twri/twri4a3/html/pdf_new.html.

Hem, J.D., 1992, Study and interpretation of the chemical characteristics of natural water (3d ed.): U.S. Geological Survey Water-Supply Paper 2254, 263 p.

Hess, J.W., and White, W.B., 1993, Groundwater geochemistry of the carbonate karst aquifer, south-central Kentucky, U.S.A.: Applied Geochemistry, v. 8, p. 189-204.

Hiscock, K., Lovett, A., Saich, A., Dockery, T., Johnson, P., Sandu, C., Sünnenberg, G., Appleton, K., Harris, B., and Greaves, J., 2007, Modeling land-use scenarios to reduce groundwater nitrate pollution-The European Water4All project: Quarterly Journal of Engineering Geology and Hydrogeology, v. 40, p. 417-434.

Holt, C.L.R., Jr., 1959, Geology and ground-water resources of Medina County, Texas: U.S. Geological Survey WaterSupply Paper 1422, 213 p. [Also published as Texas Board of Water Engineers Bulletin 5601, 278 p., 1956.]

Homer, C.G., Huang, C., Yang, L., Wylie, B.K., and Coan, M.J., 2001, National Land Cover Database 2001 (NLCD 2001): Sioux Falls, S. Dak., U.S. Geological Survey, EROS Data Center, MRLC Project, accessed October 2007 at http://seamless.usgs.gov/.

Hopple, J.A., Delzer, G.C., and Kingsbury, J.A., 2009, Anthropogenic organic compounds in source water of selected community water systems that use groundwater, 2002-05: U.S. Geological Survey Scientific Investigations Report 2009-5200, 76 p.

Hovorka, S.D., Dutton, A.R., Ruppel, S.C., and Yeh, J.S., 1996, Edwards aquifer ground-water resources-Geologic controls on porosity development in platform carbonates, South Texas: Austin, University of Texas, Bureau of Economic Geology Report of Investigations 238, 75 p.

Hovorka, S.D., Mace, R.E., and Collins, E.W., 1998, Permeability structure of the Edwards aquifer, south Texas-Implications for aquifer management: Austin, University of Texas, Bureau of Economic Geology Report of Investigations 250, 55 p.

Hovorka, S.D., Phu, T., Nicot, J.P., and Lindley, A., 2004, Refining the conceptual model for flow in the Edwards aquifer-Characterizing the role of fractures and conduits in the Balcones fault zone segment: Contract report to Edwards Aquifer Authority, 53 p.

Hovorka, S.D., Ruppel, S.C., Dutton, A.R., and Yeh, J.S., 1993, Edwards aquifer storage assessment, Kinney County to Hays County, Texas: San Antonio, Edwards Underground Water District, 109 p.
Hunt, A.G., Lambert, R.B., and Fahlquist, Lynne, 2010, Sources of groundwater based on helium analyses in and near the freshwater/saline-water transition zone of the San Antonio segment of the Edwards aquifer, southcentral Texas, 2002-03: U.S. Geological Survey Scientific Investigations Report 2010-5030, 15 p.

International Atomic Energy Agency/World Meteorological Organization, 2008, Global Network of Isotopes in Precipitation, the GNIP database: accessed July 2008 at http://www.iaea.org/water.

Ivahnenko, T., and Barbash, J.E., 2004, Chloroform in the hydrologic system-Sources, transport, fate, occurrence, and effects on human health and aquatic organisms: U.S. Geological Survey Scientific Investigations Report 20045137, 34 p.

Ivahnenko, T., and Zogorski, J.S., 2006, Sources and occurrence of chloroform and other trihalomethanes in drinkingwater supply wells in the United States, 1986-2001: U.S. Geological Survey Scientific Investigations Report 20065015, 13 p.

Izbicki, J.A., 2004, A small-diameter sample pump for collection of depth-dependent samples from production wells under pumping conditions: U.S. Geological Survey Fact Sheet 2004-3096, 2 p.

Johnson, S.B., and Schindel, G.M., 2008, Evaluation of the option to designate a separate San Marcos pool for critical period management: San Antonio, Tex., Edwards Aquifer Authority, 109 p.

Johnson, S.B., Schindel, G.M., and Veni, G., 2010, Tracing groundwater flowpaths in the Edwards aquifer recharge zone, Panther Springs Creek Basin, northern Bexar County, Texas: Edwards Aquifer Authority Report 10-01, 112 p.

Jones, B.D., 1991, Texas-Floods and droughts, in Paulson, R.W., Chase, E.B., Roberts, R.S., and Moody, D.W., compilers, National water summary 1988-89-Hydrologic events and floods and droughts: U.S. Geological Survey Water-Supply Paper 2375, p. 513-520.

Jones, I.C., Banner, J.L., and Humphrey, J.D., 2000, Estimating recharge in a tropical karst aquifer: Water Resources Research, v. 36, p. 1289-1299.

Jurgens, B.C., Burow, K.R., Dalgish, B.A., and Shelton, J.L., 2008, Hydrogeology, water chemistry, and factors affecting the transport of contaminants in the zone of contribution of a public-supply well in Modesto, eastern San Joaquin Valley, California: U.S. Geological Survey Scientific Investigations Report 2008-5156, 78 p.

Jurgens, B.C., McMahon, P.B., Chapelle, F.H., and Eberts, S.M., 2009, An Excel workbook for identifying redox processes in ground water: U.S. Geological Survey Open-File Report 2009-1004, 8 p. 
Katz, B.G., 2004, Sources of nitrate contamination and age of water in large karstic springs of Florida: Environmental Geology, v. 46, p. 689-706.

Katz, B.G., Crandall, C.A., Metz, P.A., McBride, W.S., and Berndt, M.P., 2007, Chemical characteristics, water sources and pathways, and age distribution of ground water in the contributing recharge area of a public-supply well near Tampa, Florida, 2002-05: U.S. Geological Survey Scientific Investigations Report 2007-5139, 85 p.

Kauffman, L.J., Baehr, A.L., Ayers, M.A., and Stackelberg, P.E., 2001, Effects of land use and travel time on the distribution of nitrate in the Kirkwood-Cohansey aquifer system in southern New Jersey: U.S. Geological Survey WaterResources Investigations Report 01-4117, 49 p.

Kendall, C., 1998, Tracing sources and cycling of nitrate in catchments, in Kendall, C., and McDonnell, J. J., eds., Isotope tracers in catchment hydrology: Amsterdam, Elsevier, p. 519-576.

Keys, W.S., 1997, A practical guide to borehole geophysics in environmental investigations: Boca Raton, Fla., CRC Lewis Publishers, $176 \mathrm{p}$.

Klemt, W.B., Knowles, T.R., Edler, G.R., and Sieh, T.W., 1979, Ground-water resources and model applications for the Edwards (Balcones fault zone) aquifer in the San Antonio region: Texas Water Development Board Report 239, 88 p.

Koepnick, R.B., Burke, W.H., Denison, R.E., Hetherington, E.A., Nelson, H.F., Otto, J.B., and Waite, L.E., 1985, Construction of the seawater ${ }^{87} \mathrm{Sr} /{ }^{86} \mathrm{Sr}$ curve for the Cenozoic and Cretaceous-Supporting data: Chemical Geology (Isotope Geoscience Section), v. 58, p. 55-81.

Koterba, M.T., 1998, Ground-water data-collection protocols and procedures for the National Water-Quality Assessment Program-Collection, documentation, and compilation of required site, well, subsurface, and landscape data for wells: U.S. Geological Survey Water-Resources Investigations Report 98-4107, 91 p.

Koterba, M.T., Wilde, F.D., and Lapham, W.W., 1995, Ground-water data-collection protocols and procedures for the National Water-Quality Assessment ProgramCollection and documentation of water-quality samples and related data: U.S. Geological Survey Open-File Report 95-399, 113 p.

Kreitler, C.W., and Browning, L.A., 1983, Nitrogen-isotope analysis of groundwater nitrate in carbonate aquifersNatural sources versus human pollution: Journal of Hydrology, v. 61, p. 285-301.

Kuniansky, E.L., Fahlquist, Lynne, and Ardis, A.F., 2001, Travel times along selected flow paths of the Edwards aquifer, central Texas, in Kuniansky, E.L., ed., 2001, U.S. Geological Survey Karst Interest Group Proceedings, St. Petersburg, Florida, February 13-16, 2001: U.S. Geological Survey Water-Resources Investigations Report 01-4011, p. 69-77.

Lakey, B., and Krothe, N.C., 1996, Stable isotopic variation of storm discharge from a perennial karst spring: Water Resources Research, v. 32, p. 721-731.

Landon, M.K., Clark, B.R., McMahon, P.B., McGuire, V.L., and Turco, M.J., 2008, Hydrogeology, chemical-characteristics and transport processes in the zone of contribution of a public-supply well in York, Nebraska: U.S. Geological Survey Scientific Investigations Report 2008-5050, 149 p.

Lapham, W.W., Wilde, F.D., and Koterba, M.T., 1995, Ground-water data-collection protocols and procedures for the National Water-Quality Assessment ProgramSelection, installation, and documentation of wells, and collection of related data: U.S. Geological Survey Open-File Report 95-398, 69 p.

Lee, E.A., and Strahan, A.P., 2003, Methods of analysis by the U.S. Geological Survey Organic Geochemistry Research Group-Determination of acetamide herbicides and their degradation products in water using online solid-phase extraction and liquid chromatography/mass spectrometry: U.S. Geological Survey Open-File Report 03-173, 17 p.

Lindgren, R.J., 2006, Diffuse-flow conceptualization and simulation of the Edwards aquifer, San Antonio region, Texas: U.S. Geological Survey Scientific Investigations Report 2006-5319, 48 p.

Lindgren, R.J., Dutton, A.R., Hovorka, S.D., Worthington, S.R.H., and Painter, Scott, 2004, Conceptualization and simulation of the Edwards aquifer, San Antonio region, Texas: U.S. Geological Survey Scientific Investigations Report 2004-5277, 143 p.

Lindgren, R.J., Houston, N.A., Musgrove, M., Fahlquist, L., and Kauffman, L.J., 2011a, Hydrogeologic setting and groundwater flow simulations of the south-central Texas regional study area, Texas, section 3 of Eberts, S.M., ed., Hydrogeologic settings and ground-water flow simulations for regional studies of the transport of anthropogenic and natural contaminants to public-supply wells: U.S. Geological Survey Professional Paper 1737-B, p. 3-1 to 3-51.

Lindgren, R.J., Houston, N.A., Musgrove, M., Fahlquist, L.S., and Kauffman, L.J., 2011b, Simulations of groundwater flow and particle tracking analysis in the zone of contribution of a public-supply well in San Antonio, Texas: U.S. Geological Survey Scientific Investigations Report 20115149, 93 p. 
Lindgren, R.J., Taylor, C.J., and Houston, N.A., 2009, Description and evaluation of numerical groundwater flow models for the Edwards aquifer, south-central Texas: U.S. Geological Survey Scientific Investigations Report 20095183, 25 p.

Lindley, C.E., Stewart, J.T., and Sandstrom, M.W., 1996, Determination of low concentrations of acetochlor in water by automated solid-phase extraction and gas chromatography with mass selective detection: Journal of AOAC International, v. 79, no. 4, p. 962-966.

Lindsey, B.D., Berndt, M.P., Katz, B.G., Ardis, A.F., and Skach, K.A., 2009, Factors affecting water quality in selected carbonate aquifers in the United States, 1993-2005: U.S. Geological Survey Scientific Investigations Report 2008-5240, 117 p.

Lohmann, K.C., 1988, Geochemical patterns of meteoric diagenetic systems and their application to studies of paleokarst, in James, N.P., and Choquette, P.W., eds., Paleokarst: New York, Springer-Verlag, p. 58-80.

Long, A.J., and Putnam, L.D., 2006, Translating CFCbased piston ages into probability density functions of ground-water age in karst: Journal of Hydrology, v. 330, p. 735-747.

Ludin, A., Weppernig, R., Bonisch, G., and Schlosser, P., 1998, Mass spectrometric measurement of helium isotopes and tritium: Palisades, New York, Lamont-Doherty Earth Observatory, Technical Report 98-06.

Mace, R.E., and Hovorka, S.D., 2000, Estimating porosity and permeability in a karstic aquifer using core plugs, well tests, and outcrop measurements, in Sasowsky, I.D., and Wicks, C.M., Groundwater flow and contaminant transport in carbonate aquifers: Brookfield, Vt., A.A. Balkema, p. 93-111.

Maclay, R.W., 1995, Geology and hydrology of the Edwards aquifer in the San Antonio area, Texas: U.S. Geological Survey Water-Resources Investigations Report 95-4186, $64 \mathrm{p}$.

Maclay, R.W., and Land, L.F., 1988, Simulation of flow in the Edwards aquifer, San Antonio region, Texas, and refinements of storage and flow concepts: U.S. Geological Survey Water-Supply Paper 2336-A, 48 p.

Maclay, R.W., and Small, T.A., 1983, Hydrostratigraphic subdivisions and fault barriers of the Edwards aquifer, south-central Texas, U.S.A.: Journal of Hydrology, v. 61, p. 127-146.

Maclay, R.W., and Small, T.A., 1984, Carbonate geology and hydrology of the Edwards aquifer in the San Antonio area, Texas: U.S. Geological Survey Open-File Report 83-537, $72 \mathrm{p}$. [Also published as Texas Water Development Board Report 296, 90 p., 1986.]
Maclay, R.W., and Small, T.A., 1986, Carbonate geology and hydrology of the Edwards aquifer in the San Antonio area, Texas: Texas Water Development Board Report 296, 90 p.

Madsen, J.E., Sandstrom, M.W., and Zaugg, S.D., 2003, Methods of analysis by the U.S. Geological Survey National Water Quality Laboratory-A method supplement for the determination of fipronil and degradates in water by gas chromatography/mass spectrometry: U.S. Geological Survey Open-File Report 02-462, 11 p.

Mahler, B.J., 2008, Statistical analysis of major ion and trace element geochemistry of water, 1986-2006, at seven wells transecting the freshwater/saline-water interface of the Edwards aquifer, San Antonio, Texas: U.S. Geological Survey Scientific Investigations Report 2008-5224, 46 p.

Mahler, B.J., and Garner, B.D., 2009, Using nitrate to quantify quick flow in a karst aquifer: Ground Water, v. 47, p. $350-360$.

Mahler, B.J., Garner, B.D., Musgrove, M., Guilfoyle, A.L., and Rao, M.V., 2006, Recent (2003-05) water quality of Barton Springs, Austin, Texas, with emphasis on factors affecting variability: U.S. Geological Survey Scientific Investigations Report 2006-5299, 83 p., 5 apps.

Mahler, B.J., and Massei, Nicolas, 2007, Anthropogenic contaminants as tracers in an urbanizing karst aquifer: Journal of Contaminant Hydrology, v. 91, p. 81-106.

Mahler, B.J., Musgrove, M., Herrington, C., and Sample, T., 2011, Recent (2008-2010) concentrations and isotopic compositions of nitrate and concentrations of wastewater compounds in the Barton Springs zone, south-central Texas, and their potential relation to urban development in the contributing zone: U.S. Geological Survey Scientific Investigations Report 2011-5018, 39 p.

Maloszewski, P., Stichler, W., Zuber, A., and Rank, D., 2002, Identifying the flow systems in a karstic-fissured-porous aquifer, the Schneealpe, Austria, by modeling of environmental ${ }^{18} \mathrm{O}$ and ${ }^{3} \mathrm{H}$ isotopes: Journal of Hydrology, v. 256, p. $48-59$.

McClain, Betty, 1993, Methods of analysis by the U.S. Geological Survey National Water Quality LaboratoryDetermination of chromium in water by graphite furnace atomic absorption spectrophotometry: U.S. Geological Survey Open-File Report 93-499, 16 p.

McMahon, P.B., Böhlke, J.K., and Christenson, S.C., 2004, Geochemistry, radiocarbon ages, and paleorecharge conditions along a transect in the central High Plains aquifer, southwestern Kansas, USA: Applied Geochemistry, v. 19, p. 1655-1686.

McMahon, P.B., Burow, K.R., Kauffman, L.J., Eberts, S.M., Böhlke, J.K., and Gurdak, J.J., 2008, Simulated 
response of water quality in public supply wells to land use change: Water Resources Research, v. 44, W00A06, doi:10.1029/2007WR006731.

McMahon, P.B., and Chapelle, F.H., 2008, Redox processes and water quality of selected principal aquifer systems: Ground Water, v. 46, no. 2, p. 259-271.

McNutt, R.H., Frape, S.K., Fritz, P., Jones, M.G., and MacDonald, I.M., 1990, The ${ }^{87} \mathrm{Sr} /{ }^{86} \mathrm{Sr}$ values of Canadian Shield brines and fracture minerals with applications to groundwater mixing, fracture history, and geochronology: Geochimica et Cosmochimica Acta, v. 54, p. 205-215.

Mengis, M., Ulrich, W., Bernasconi, S.M., and Wehrli, B., 2001, Limitations of using $\delta^{18} \mathrm{O}$ for the source identification of nitrate in agricultural soils: Environmental Science and Technology, v. 35, p. 1840-1844.

Michel, R.L., 1989, Tritium deposition over the continental United States, 1953-1983, in Atmospheric Deposition, International Association of Hydrological Sciences Symposium, Baltimore, Maryland, May 11-12, 1989, Proceedings: United Kingdom, International Association of Hydrological Sciences Publication 179, p. 109-115.

Moran, M.J., Lapham, W.W., Rowe, B.L., and Zogorski, J.S., 2002, Occurrence and status of volatile organic compounds in ground water from rural, untreated, self-supplied domestic wells in the United States, 1986-99: U.S. Geological Survey Water-Resources Investigations Report 02-4085, $51 \mathrm{p}$.

Musgrove, M., and Banner, J.L., 2004, Controls on the spatial and temporal variability of vadose dripwater geochemistry_Edwards aquifer, central Texas: Geochimica et Cosmochimica Acta, v. 68, p. 1007-1020.

Musgrove, M., Fahlquist, L., Houston, N.A., Lindgren, R.J., and Ging, P.B., 2010, Geochemical evolution processes and water-quality observations based on results of the National Water-Quality Assessment Program in the San Antonio segment of the Edwards aquifer, 1996-2006: U.S. Geological Survey Scientific Investigations Report 2010-5129, 93 p. (Available at http://pubs.usgs.gov/sir/2010/5129/.)

National Hydrography Dataset Plus, 2010, NHDPlus Data: Herndon, Va., Horizon Systems Corporation, accessed November 2010 at http://www.horizon-systems.com/ nhdplus/data.php.

National Oceanic and Atmospheric Administration, 2010, National Climatic Data Center, climatological data, San Antonio International Airport, San Antonio, Texas, cooperative station identifier 417945: accessed November 2010 at http://www.ncdc.noaa.gov/oa/ncdc.html.

Nolan, B.T., Ruddy, B.C., Hitt, K.J., and Helsel, D.R., 1998, A national look at nitrate contamination of ground water: Water Conditioning and Purification, v. 39, p. 76-79.
Nolan, B.T., and Stoner, J.D., 2000, Nutrients in ground waters of the conterminous United States, 1992-1995: Environmental Science and Technology, v. 34, no. 7, p. 1156-1165.

Ockerman, D.J., 2005, Simulation of streamflow and estimation of recharge to the Edwards aquifer in the Hondo Creek, Verde Creek, and San Geronimo Creek watersheds, south-central Texas, 1951-2003: U.S. Geological Survey Scientific Investigations Report 2005-5252, 37 p.

Oetting, G.C., 1995, Evolution of fresh and saline groundwaters in the Edwards aquifer-Geochemical and Sr isotopic evidence for regional fluid mixing and fluid-rock interaction: Austin, University of Texas at Austin, unpublished M.A. thesis, $204 \mathrm{p}$.

Oetting, G.C., Banner, J.L., and Sharp, J.M., Jr., 1996, Geochemical evolution of saline groundwaters in the Edwards aquifer, central Texas-Regional stratigraphic, tectonic, and hydrodynamic controls: Journal of Hydrology, v. 181, p. 251-283.

Ogden, A.E., Quick, R.A., and Rothermel, S.R., 1986, Hydrochemistry of the Comal, Hueco, and San Marcos Springs, Edwards aquifer, Texas, in Abbott, P.L., and Woodruff, C.M., Jr., eds., The Balcones escarpmentGeology, hydrology, ecology and social development in central Texas: Geological Society of America, p. 115-130.

Osenbrück, K., Fiedler, S., Knöller, K., Weise, S.M., Sültenfuß, J., Oster, H., and Strauch, G., 2006, Timescales and development of groundwater pollution by nitrate in drinking water wells of the Jahna-Aue, Saxonia, Germany: Water Resources Research, v. 42, W12416, doi:10.1029/2006WR004977.

Paillet, F.L., 2000, A field technique for estimating aquifer parameters using flow log data: Ground Water, v. 38, p. 510-521.

Panno, S.V., Hackey, K.C., Hwang, H.H., and Kelly, W.R., 2001, Determination of the sources of nitrate contamination in karst springs using isotopic and chemical indicators: Chemical Geology, v. 179, p. 113-128.

Pape, J.R., Banner, J.L., Mack, L.E., Musgrove, M., and Guilfoyle, A., 2010, Controls on oxygen isotope variability in precipitation and cave drip waters, central Texas, USA: Journal of Hydrology, v. 385, p. 203-215.

Parkhurst, D.L., 1995, User's guide to PHREEQC—A computer program for speciation, reaction-path, advective-transport, and inverse geochemical calculations: U.S. Geological Survey Water-Resources Investigations Report 95-4227, $143 \mathrm{p}$.

Patton, C.J., and Kryskalla, J.R., 2003, Methods of analysis by the U.S. Geological Survey National Water Quality 
Laboratory-Evaluation of alkaline persulfate digestion as an alternative to Kjeldahl digestion for determination of total and dissolved nitrogen and phosphorus in water: U.S. Geological Survey Water-Resources Investigations Report 03-4174, 33 p.

Pearson, F.J., Jr., Rettman, P.L., and Wyerman, T.A., 1975, Environmental tritium in the Edwards aquifer, central Texas, 1963-71: U.S. Geological Survey Open-File Report 74-362, $32 \mathrm{p}$.

Phillips, F.M., and Castro, M.C., 2003, Groundwater dating and residence-time measurements, in Holland, H.D., and Turekian, K.K., eds., Treatise on geochemistry—v. 5, Surface and ground water, weathering, and soils (Drever, J.I., volume ed.): Oxford, Oxford University Press, p. 451-497.

Piper, A.M., 1953, A graphic procedure in the geochemical interpretation of water analysis: U.S. Geological Survey Ground Water Note No. 12.

Plummer, L.N., 1977, Defining reactions and mass transfer in part of the Floridan aquifer: Water Resources Research, v. 13, p. 801-812.

Plummer, L.N., 2005, Dating of young groundwater, in Aggarwal, P.K., Gat, J.R., and Froelich, K.F.O., eds., Isotopes in the water cycle-Past, present, and future of a developing science: Dordrecht, Netherlands, Springer, p. $193-220$.

Plummer, L.N., Bexfield, L.M., Anderholm, S.K., Sanford, W.E., and Busenberg, E., 2004, Hydrochemical tracers in the middle Rio Grande Basin, USA-1. Conceptualization of groundwater flow: Hydrogeology Journal, v. 12, p. 359-388.

Plummer, L.N., and Busenberg, E., 2005, Chlorofluorocarbons, in Cook, P.G., and Herczeg, A., eds., Environmental tracers in subsurface hydrology: Boston, Mass., Kluwer Academic Publishers, 552 p., accessed July 22, 2009, at http://water.usgs.gov/lab/chlorofluorocarbons/background/.

Plummer, L.N., Busenberg, E., Drenkard, S., Schlosser, P., McConnell, J.B., Michel, R.L., Ekwurzel, B., and Weppemig, R., 1998, Flow of river water into a karstic limestone aquifer. 2. Dating the young fraction in groundwater mixtures in the Upper Floridan aquifer near Valdosta, Georgia: Applied Geochemistry, v. 13 no. 8, p. 1017-1043.

Plummer, L.N., Busenberg, E., Eberts, S.M., Bexfield, L.M., Brown, C.J., Fahlquist, L.S., Katz, B.G., and Landon, M.K., 2008, Low-level detection of halogenated volatile organic compounds in groundwater-Use in vulnerability assessments: Journal of Hydrologic Engineering, v. 13, p. 1049-1068.
Plummer, L.N., and Friedman, L.C., 1999, Tracing and dating young ground water: U.S. Geological Survey Fact Sheet 134-99, 4 p.

Plummer, L.N., Michel, R.L., Thurman, E.M., and Glynn, P.D., 1993, Environmental tracers for age-dating young ground water, chap. 11 of Alley, W.M., ed., Regional ground-water quality: Van Nostrand Reinhold, p. 255-294.

Pollock, D.W., 1994, User's Guide for MODPATH/ MODPATH-PLOT, Version 3-A particle tracking postprocessing package for MODFLOW, the U.S. Geological Survey finite-difference ground-water flow model: U.S. Geological Survey Open-File Report 94-464, 6 chap.

Prichard, H.M., and Gesell, T.F., 1977, Rapid measurements of radon-222 concentrations in water with a commercial liquid scintillation counter: Health Physics, v. 33, p. 577-581.

Rabinowitz, M.B., and Bellinger, D.C., 1988, Soil leadblood relationship among Boston children: Bulletin of Environmental Contamination and Toxicology, v. 41, p. 791-797.

Révész, Kinga, and Casciotti, Karen, 2007, Determination of the $\delta\left({ }^{15} \mathrm{~N} /{ }^{14} \mathrm{~N}\right)$ and $\delta\left({ }^{18} \mathrm{O} /{ }^{16} \mathrm{O}\right)$ of nitrate in water: RSIL Lab Code 2900, chap. C17 of Révész, Kinga, and Coplen, T.B., eds., Methods of the Reston Stable Isotope Laboratory: Reston, Va., U.S. Geological Survey Techniques and Methods, book 10, sec. C, chap. 17, 24 p.

Révész, Kinga, and Coplen, T.B., 2008a, Determination of the $\delta\left({ }^{18} 0 /{ }^{16} 0\right)$ of water: RSIL lab code 489 , chap. C2 of Révész, Kinga, and Coplen, T.B., eds., Methods of the Reston Stable Isotope Laboratory: U.S. Geological Survey Techniques and Methods, book 10, sec. C, chap. 2, 28 p.

Révész, Kinga, and Coplen, T.B., 2008b, Determination of the $\delta\left({ }^{2} \mathrm{H} /{ }^{1} \mathrm{H}\right)$ of water: RSIL lab code 1574 , chap. C1 of Révész, Kinga, and Coplen, T.B., eds., Methods of the Reston Stable Isotope Laboratory: U.S. Geological Survey Techniques and Methods, book 10, sec. C, chap. 1, 27 p.

Rock, G., and Kupfersberger, H., 2002, Numerical delineation of transient capture zones: Journal of Hydrology, v. 269, p. 134-149.

Rose, D.L., and Sandstrom, M.W., 2003, Methods of analysis by the U.S. Geological Survey National Water Quality Laboratory-Determination of gasoline oxygenates, selected degradates, and BTEX in water by heated purge and trap/gas chromatography/mass spectrometry: U.S. Geological Survey Water-Resources Investigations Report 03-4079, $31 \mathrm{p}$.

Rose, P.R., 1972, Edwards Group, surface and subsurface, central Texas: Austin, University of Texas, Bureau of Economic Geology Report of Investigations 74, 198 p. 
Rounds, S.A., 2003, Alkalinity and acid neutralizing capacity (version 3.0), in Wilde, F.D. and Radtke, D.B., eds., National field manual for the collection of water-quality data: U.S. Geological Survey Techniques of WaterResources Investigations, book 9, chap. A6, sec. 6.6, 53 p. (Available at http://water.usgs.gov/owq/FieldManual/ Chapter6/section6.6.)

Sandstrom, M.W., Stroppel, M.E., Foreman, W.T., and Schroeder, M.P., 2001, Methods of analysis by the U.S. Geological Survey National Water Quality LaboratoryDetermination of moderate-use pesticides and selected degradates in water by C-18 solid-phase extraction and gas chromatography/ mass spectrometry: U.S. Geological Survey Water- Resources Investigations Report 01-4098, $70 \mathrm{p}$.

Schaap, B.D., and Zogorski, J.S., 2006, Occurrence of trihalomethanes in the Nation's ground water and drinking-water supply wells, 1985-2002: U.S. Geological Survey Scientific Investigations Report 2006-5068, 64 p.

Schlesinger, W.H., Reckhow, K.H., and Bernhardt, E.S., 2006, Global change-The nitrogen cycle and rivers: Water Resources Research, v. 42, W03S06, doi:10.1029/ 2005WR004300.

Schlosser, Peter, Stute, Martin, Dorr, H., Sonntag, C., and Munnich, K.O., 1988, Tritium $/{ }^{3} \mathrm{He}$ dating of shallow groundwater: Earth and Planetary Science Letters, v. 89, p. 353-362.

Schlosser, P., Stute, M., Sonntag, C., and Munnich, K.O., 1989, Tritiogenic ${ }^{3} \mathrm{He}$ in shallow groundwater: Earth and Planetary Science Letters, v. 94, p. 245-256.

Schultz, A.L., 1994, 1994 review and update of the position of the Edwards aquifer freshwater/saline-water interface from Uvalde to Kyle, Texas: Edwards Underground Water District Report 94-05, 31 p.

Schuster, E.T., and White, W.B., 1971, Seasonal fluctuations in the chemistry of limestone springs-A possible means for characterizing carbonate aquifers: Journal of Hydrology, v. 14 , p. $93-128$.

Sharp, J.M., Jr., 1990, Stratigraphic, geomorphic and structural controls of the Edwards aquifer, Texas, U.S.A., in Simpson, E.S., and Sharp, J.M., Jr., eds., International Association of Hydrogeologists, Selected Papers from the 28th International Geological Congress, Washington, D.C., July 9-19, 1989: Heise, Hannover, v. 1, p. 67-82.

Sharp, J.M., Jr., and Banner, J.L., 1997, The Edwards aquifer-A resource in conflict: Geological Society of America (GSA) Today, v. 7, p. 1-9.

Sigman, D.M., Casciotti, K.L., Andreani, M., Barvord, C., Galanter, M., and Böhlke, J.K., 2001, A bacterial method for the nitrogen isotopic analysis of nitrate in seawater and freshwater: Analytical Chemistry, v. 73, p. 4145-4153.

Silva, S.R., Ging, P.B., Lee, R.W., Ebbert, J.C., Tesoriero, A.J., and Inkpen, E.L., 2002, Forensic application of nitrogen and oxygen isotopes in tracing nitrate sources in urban environments: Environmental Forensics, v. 3, p. 125-130.

Slade, R.M., Jr., 1986, Large rainstorms along the Balcones escarpment in central Texas, in Abbott, P.L., and Woodruff, C.M., Jr., eds., The Balcones escarpment-Geology, hydrology, ecology and social development in central Texas: Geological Society of America, p. 15-19.

Solomon, D.K., 2000, ${ }^{4} \mathrm{He}$ in groundwater, in Cook, P.G., and Herczeg, A.L., eds., Environmental tracers in subsurface hydrology: New York, Kluwer Academic Publishers, p. 425-439.

Solomon, D.K., and Cook, P.G., 1999, ${ }^{3} \mathrm{H}$ and ${ }^{3} \mathrm{He}$, in Cook, P., and Herczeg, A., eds., Environmental tracers in subsurface hydrology: New York, Kluwer Academic Publishers, p. 397-424.

Solomon, D.K., Poreda, R.J., Schiff, S.L., and Cherry, J.A., 1992, Tritium and helium-3 as groundwater age tracers in the Borden aquifer: Water Resources Research, v. 28, no. 3, p. 741-755.

Sowerby, J.R., Carter, K.C., Dragovitsch, S.T., and Byer, J.C., 2000, Occurrence of radon in Florida's public water supplies: Florida Department of Environmental Protection, $31 \mathrm{p}$.

Starn, J.J., and Brown, C.J., 2007, Simulations of groundwater flow and residence time near Woodbury, Connecticut: U.S. Geological Survey Scientific Investigations Report 2007-5210, 56 p.

Stein, W.G., and Ozuna, G.B., 1995, Geologic framework and hydrogeologic characteristics of the Edwards aquifer recharge zone, Bexar County, Texas: U.S. Geological Survey Water-Resources Investigations Report 95-4030, $8 \mathrm{p}$.

Sturchio, N.C., Du, X., Purtschert, R., Lehmann, B.E., Sultan, M., Patterson, L.J., Lu, Z.-T., Müller, P., Bigler, T., Bailey, K., O’Connor, T.P., Young, L., Lorenzo, R., Becker, R., El Alfy, Z., El Kaliouby, B., Dawood, Y., and Abdallah, A.M.A., 2004, One million year old groundwater in the Sahara revealed by krypton-81 and chlorine-36: Geophysical Research Letters, v. 31, L05503, doi:10.1029/2003GL019234.

Texas State Historical Association, 2009, The handbook of Texas online-Droughts: available at http://www. tshaonline.org/handbook/online/articles/DD/ybd1.html. 
Thatcher, L.L., Janzer, V.J., and Edwards, K.W., 1977, Methods for determination of radioactive substances in water and fluvial sediments: U.S. Geological Survey Techniques of Water-Resources Investigations, book 5, chap. A5, 95 p.

Thiem, G., 1906, Hydrologishe methoden: Leipzig, J.M. Gebhardt, 56 p.

Thompson, G.M., and Hayes, J.M., 1979, Trichlorofluoromethane in groundwater-A possible tracer and indicator of groundwater age: Water Resources Research, v. 14, no. 3, p. 546-554.

Thorkildsen, D.F., and McElhaney, P.D., 1992, Model refinement and applications for the Edwards (Balcones fault zone) aquifer in the San Antonio region, Texas: Texas Water Development Board Report 340, 33 p.

Toccalino, P.L. and Hopple, J.A., 2010, Quality of water from public-supply wells in the United States, 1993-2007Overview of major findings: U.S. Geological Survey Circular 1346, 58 p.

Trudgill, S.T., Laidlaw, I.M.S., and Smart, P.L., 1980, Soil water residence times and solute uptake on a dolomite bedrock-Preliminary results: Earth Surface Processes, v. 5, p. $91-100$.

U.S. Army Corps of Engineers, 1965, Survey report on Edwards underground reservoir, Guadalupe, San Antonio, and Nueces Rivers and tributaries, Texas: Forth Worth, Tex., U.S. Army Corps of Engineers, Fort Worth District, and San Antonio, Tex., Edwards Underground Water District, 2 v.

U.S. Census Bureau, 2009, Population estimates: accessed August 8, 2011, at http://www.census.gov/popest/metro/ CBSA-est2009-annual.html.

U.S. Department of Agriculture, 2010, Geospatial Data Gateway: U.S. Department of Agriculture, Natural Resources Conservation Service, accessed November 2010 at http://datagateway.nrcs.usda.gov/.

U.S. Environmental Protection Agency, 1993, Health advisories for drinking water contaminants: U.S. Environmental Protection Agency, Office of Water: Ann Arbor, Mich., Lewis Publishers.

U.S. Environmental Protection Agency, 2010, Public drinking water systems programs-Overview: U.S. Environmental Protection Agency, accessed September 4, 2010, at http:// water.epa.gov/infrastructure/drinkingwater/pws/index.cfm.

U.S. Environmental Protection Agency, 2011, Bandera Road ground water plume: U.S. Environmental Protection Agency, Region 6, accessed March 2011 at http://www.epa. gov/earth1r6/6sf/pdffiles/0606565.pdf.
U.S. Geological Survey, variously dated, National field manual for the collection of water-quality data: U.S. Geological Survey Techniques of Water-Resources Investigations, book 9, chaps. A1-A9, accessed October 2004 at http://water. usgs.gov/owq/FieldManual/.

U.S. Geological Survey Reston Chlorofluorocarbon Laboratory, 2010, Web page: accessed November 2010 at http://water.usgs.gov/lab/.

Vesper, D.J., and White, W.B., 2004, Storm pulse chemographs of saturation index and carbon dioxide pressureImplications for shifting recharge sources during storm events in the karst aquifer at Fort Campbell, Kentucky/ Tennessee, USA: Hydrogeology Journal, v. 12, p. 135-143.

Webster, D.M., and Jones, B.F., 1994, Paleoenvironmental implications of lacustrine clay minerals from the Double Lakes formation, southern High Plains, Texas, in Renaut, R.W., and Last, W.M., eds., Sedimentology and geochemistry of modern and ancient lakes: Society of Environmental and Professional Engineers Special Publication No. 50, p. $159-172$.

Weissmann, G.S., Zhang, Y., LaBolle, E.M., and Fogg, G.E., 2002, Dispersion of groundwater age in an alluvial aquifer system: Water Resources Research, v. 38, 1198, doi:10.1029/2001WR000907.

Welch, A.H., Westjohn, D.B., Helsel, D.R., and Wanty, R.B., 2000, Arsenic in ground water of the United StatesOccurrence and geochemistry: Ground Water, v. 38, no. 4, p. 589-604.

White, W.B., 1988, Geomorphology and hydrology of karst terrains: New York, Oxford University Press, 464 p.

White, W.B., 2002, Karst hydrology—Recent developments and open questions: Engineering Geology, v. 65, p. 85-105.

Winston, W.E., and Criss, R.E., 2004, Dynamic hydrologic and geochemical response in a perennial karst spring: Water Resources Research, v. 40, W05106, doi:10.1029/ 2004WR003054.

Wong, C., 2008, Geochemical evolution of karst vadose water and brush clearing impacts on recharge in central Texas: Austin, University of Texas at Austin, unpublished M.S. thesis, $182 \mathrm{p}$.

Wong, C., Banner, J.L., and Musgrove, M., 2011, Seasonal drip-water $\mathrm{Mg} / \mathrm{Ca}$ and $\mathrm{Sr} / \mathrm{Ca}$ variations driven by cave ventilation-Implications for and modeling of speleothem paleoclimate records: Geochimica et Cosmochimica Acta, v. 75, p. 3514-3529.

Woodruff, C.M., Jr., and Abbott, P.L., 1979, Drainage-basin evolution and aquifer development in karstic limestone 
terrain, south-central Texas, U.S.A.: Earth Surface Processes, v. 4, p. 319-334.

Worthington, S.R.H., 2003, A comprehensive strategy for understanding flow in carbonate aquifers: Speleogenesis and Evolution of Karst Aquifers, v. 1, p. 1-8.

Worthington, S.R.H., 2004, Conduits and turbulent flow in the Edwards aquifer: Dundas, Ontario, Canada, Worthington Groundwater, contract report to Edwards Aquifer Authority, San Antonio, Tex., 41 p.

Zaugg, S.D., and Leiker, T.J., 2006, Review of method performance and improvements for determining wastewater compounds (schedule 1433): U.S. Geological Survey National Water Quality Laboratory Technical Memorandum 2006.1 [variously paged].

Zaugg, S.D., Sandstrom, M.W., Smith, S.G., and Fehlberg, K.M., 1995, Methods of analysis by the U.S. Geological Survey National Water Quality Laboratory-Determination of pesticides in water by C-18 solid-phase extraction of capillary-column gas chromatography/mass spectrometry with selected-ion monitoring: U.S. Geological Survey Open-File Report 95-181, 60 p.

Zaugg, S.D., Smith, S.G., Schroeder, M.P., Barber, L.B., and Burkhardt, M.R., 2002, Methods of analysis by the U.S. Geological Survey National Water Quality LaboratoryDetermination of wastewater compounds by polystyrenedivinylbenzene solid-phase extraction and capillary-column gas chromatography/mass spectrometry: U.S. Geological Survey Water-Resources Investigations Report 01-4186, $37 \mathrm{p}$.

Zinn, B.A., and Konikow, L.F., 2007, Effects of intraborehole flow on groundwater age distribution: Hydrogeology Journal, v. 15, p. 633-643.

Zogorski, J.S., Carter, J.M., Ivahnenko, T., Lapham, W.W., Moran, M.J., Rowe, B.L., Squillace, P.J., and Toccalino, P.L., 2006, The quality of our Nation's water-Volatile organic compounds in the Nation's ground water and drinking-water supply wells: U.S. Geological Survey Circular 1292, 101 p. 
Table 1. Site information for wells sampled for the study of the transport of anthropogenic and natural contaminants (TANC) to public supply wells in the San Antonio segment of the Edwards aquifer near San Antonio, south-central Texas, 2004-9.

[By sample category and by aquifer category (unconfined, confined). USGS, U.S. Geological Survey; NAD 83, North American Datum of 1983; Y, yes; N, no; --, not measured, known, or applicable; *, sampled 6 times for temporal response to rainfall; psw, public-supply well; **, sampled 9 times for vertically discrete samples; ft, feet; NAVD 1988, North American Vertical Datum of 1988; gal/min, gallons per minute; in., inches; PVC, polyvinyl chloride; $\dagger$, borehole diameter (diam.), screen is 2.5 -in. diam.; $\$$, borehole diam., screen is 4.5 -in. diam.]

\begin{tabular}{|c|c|c|c|c|c|c|c|c|c|c|c|c|}
\hline $\begin{array}{c}\text { USGS } \\
\text { identification } \\
\text { number }\end{array}$ & $\begin{array}{l}\text { State well } \\
\text { number }\end{array}$ & $\begin{array}{l}\text { Local } \\
\text { identifier }\end{array}$ & $\begin{array}{c}\text { Latitude } \\
\text { (decimal } \\
\text { degrees), } \\
\text { NAD } 83 \\
\text { datum }\end{array}$ & $\begin{array}{c}\text { Longitude } \\
\text { (decimal } \\
\text { degrees), } \\
\text { NAD } 83 \\
\text { datum }\end{array}$ & County & $\begin{array}{l}\text { Aquifer } \\
\text { category }\end{array}$ & $\begin{array}{c}\text { Within } \\
\text { supply- } \\
\text { well scale } \\
\text { model area }\end{array}$ & $\begin{array}{c}\text { Pumpage } \\
\text { quartile } \\
\text { (2004) }\end{array}$ & Network & $\begin{array}{c}\text { Year } \\
\text { of first } \\
\text { sample }\end{array}$ & $\begin{array}{l}\text { Year of } \\
\text { second } \\
\text { sample }\end{array}$ & $\begin{array}{c}\text { Year of } \\
\text { third } \\
\text { sample }\end{array}$ \\
\hline \multicolumn{13}{|c|}{ Monitoring wells } \\
\hline 292943098354401 & AY-68-36-135 & Z-OVB & 29.49531 & -98.59564 & Bexar & -- & $\mathrm{Y}$ & -- & discrete interval, overburden & 2007 & -- & -- \\
\hline 292943098354402 & AY-68-36-133 & Z-SED & 29.49540 & -98.59559 & Bexar & confined & $\mathrm{Y}$ & -- & discrete interval, temporal & 2007 & $2009 *$ & -- \\
\hline 292943098354403 & AY-68-36-134 & Z-IED & 29.49519 & -98.59558 & Bexar & confined & $\mathrm{Y}$ & -- & discrete interval, temporal & 2007 & $2009 *$ & -- \\
\hline 292943098354404 & AY-68-36-132 & Z-DED & 29.49545 & -98.59566 & Bexar & confined & $\mathrm{Y}$ & -- & discrete interval, temporal & 2007 & $2009 *$ & -- \\
\hline 292851098374401 & AY-68-35-315 & T-IED & 29.48074 & -98.62901 & Bexar & confined & $\mathrm{Y}$ & -- & discrete interval & 2008 & -- & -- \\
\hline 292851098374402 & AY-68-35-314 & T-DED & 29.48073 & -98.62916 & Bexar & confined & $\mathrm{Y}$ & -- & discrete interval & 2008 & -- & -- \\
\hline 293252098380801 & AY-68-27-610 & Parkwood & 29.54778 & -98.63556 & Bexar & unconfined & $\mathrm{Y}$ & -- & temporal & $2009 *$ & -- & -- \\
\hline \multicolumn{13}{|c|}{ Well-field wells } \\
\hline 292919098360501 & AY-68-36-103 & W2 & -- & -- & Bexar & confined & $\mathrm{Y}$ & $1 \mathrm{st}$ & wellfield & 2007 & -- & -- \\
\hline 292925098360201 & AY-68-36-104 & W3 & -- & -- & Bexar & confined & $\mathrm{Y}$ & $1 \mathrm{st}$ & wellfield, psw survey & 2004 & 2005 & 2007 \\
\hline 292916098360701 & AY-68-36-105 & W4 & -- & -- & Bexar & confined & $\mathrm{Y}$ & $1 \mathrm{st}$ & wellfield, depth dependent & $2007 * *$ & -- & -- \\
\hline 292920098360601 & AY-68-36-130 & W5 & -- & -- & Bexar & confined & $\mathrm{Y}$ & $1 \mathrm{st}$ & wellfield & 2007 & -- & -- \\
\hline 292923098360301 & AY-68-36-131 & W6 & -- & -- & Bexar & confined & $\mathrm{Y}$ & $1 \mathrm{st}$ & wellfield, temporal & 2007 & $2009 *$ & -- \\
\hline \multicolumn{13}{|c|}{ Regional aquifer public-supply wells } \\
\hline 293359098290301 & $\mathrm{AY}-68-29-414$ & -- & -- & -- & Bexar & confined & $\mathrm{Y}$ & $1 \mathrm{st}$ & psw survey & 2004 & 2005 & -- \\
\hline 293358098231101 & AY $-68-29-610$ & -- & -- & -- & Bexar & confined & $\mathrm{N}$ & $1 \mathrm{st}$ & psw survey & 2004 & 2005 & -- \\
\hline 293120098285801 & AY $-68-29-714$ & -- & -- & -- & Bexar & confined & $\mathrm{N}$ & $1 \mathrm{st}$ & psw survey & 2004 & 2005 & -- \\
\hline 293145098224201 & AY-68-29-929 & -- & -- & -- & Bexar & confined & $\mathrm{N}$ & $1 \mathrm{st}$ & psw survey & 2004 & -- & -- \\
\hline 293119098211201 & AY $-68-30-718$ & -- & -- & -- & Bexar & confined & $\mathrm{N}$ & $1 \mathrm{st}$ & psw survey & 2004 & -- & -- \\
\hline 292843098425101 & $\mathrm{AY}-68-35-106$ & -- & -- & -- & Bexar & confined & $\mathrm{Y}$ & $1 \mathrm{st}$ & psw survey & 2004 & -- & -- \\
\hline 292459098382101 & $\mathrm{AY}-68-35-913$ & -- & -- & -- & Bexar & confined & $\mathrm{Y}$ & $1 \mathrm{st}$ & psw survey & 2004 & -- & -- \\
\hline 292822098325401 & AY $-68-36-206$ & -- & -- & -- & Bexar & confined & $\mathrm{Y}$ & $1 \mathrm{st}$ & psw survey & 2004 & 2005 & -- \\
\hline 292944098292301 & AY $-68-37-105$ & -- & -- & -- & Bexar & confined & $\mathrm{Y}$ & $1 \mathrm{st}$ & psw survey & 2004 & 2005 & -- \\
\hline 292522098291901 & AY $-68-37-426$ & -- & -- & -- & Bexar & confined & $\mathrm{Y}$ & $1 \mathrm{st}$ & psw survey & 2004 & -- & -- \\
\hline 292643098241801 & $\mathrm{AY}-68-37-601$ & -- & -- & -- & Bexar & confined & $\mathrm{N}$ & $1 \mathrm{st}$ & psw survey & 2004 & 2005 & -- \\
\hline 292328098294601 & $\mathrm{AY}-68-37-705$ & -- & -- & -- & Bexar & confined & $\mathrm{N}$ & $1 \mathrm{st}$ & psw survey & 2004 & -- & -- \\
\hline 294225098080301 & DX-68-23-601 & -- & -- & -- & Comal & confined & $\mathrm{N}$ & $1 \mathrm{st}$ & psw survey & 2004 & 2005 & -- \\
\hline 291210099475601 & YP-69-50-506 & -- & -- & -- & Uvalde & confined & $\mathrm{N}$ & $1 \mathrm{st}$ & psw survey & 2004 & -- & -- \\
\hline
\end{tabular}


Table 1. Site information for wells sampled for the study of the transport of anthropogenic and natural contaminants (TANC) to public supply wells in the San Antonio segment of the Edwards aquifer near San Antonio, south-central Texas, 2004-9._Continued

[By sample category and by aquifer category (unconfined, confined). USGS, U.S. Geological Survey; NAD 83, North American Datum of 1983; Y, yes; N, no; --, not measured, known, or applicable; *, sampled 6 times for temporal response to rainfall; psw, public-supply well; **, sampled 9 times for vertically discrete samples; ft, feet; NAVD 1988, North American Vertical Datum of 1988; gal/min, gallons per minute; in., inches; PVC, polyvinyl chloride; $\dagger$, borehole diameter (diam.), screen is 2.5 -in. diam.; $\$$, borehole diam., screen is 4.5 -in. diam.]

\begin{tabular}{|c|c|c|c|c|c|c|c|c|c|c|c|c|}
\hline $\begin{array}{c}\text { USGS } \\
\text { identification } \\
\text { number }\end{array}$ & $\begin{array}{l}\text { State well } \\
\text { number }\end{array}$ & $\begin{array}{l}\text { Local } \\
\text { identifier }\end{array}$ & $\begin{array}{c}\text { Latitude } \\
\text { (decimal } \\
\text { degrees), } \\
\text { NAD 83 } \\
\text { datum }\end{array}$ & $\begin{array}{c}\text { Longitude } \\
\text { (decimal } \\
\text { degrees), } \\
\text { NAD 83 } \\
\text { datum }\end{array}$ & County & $\begin{array}{l}\text { Aquifer } \\
\text { category }\end{array}$ & $\begin{array}{c}\text { Within } \\
\text { supply- } \\
\text { well scale } \\
\text { model area }\end{array}$ & $\begin{array}{c}\text { Pumpage } \\
\text { quartile } \\
\text { (2004) }\end{array}$ & Network & $\begin{array}{c}\text { Year } \\
\text { of first } \\
\text { sample }\end{array}$ & $\begin{array}{l}\text { Year of } \\
\text { second } \\
\text { sample }\end{array}$ & $\begin{array}{c}\text { Year of } \\
\text { third } \\
\text { sample }\end{array}$ \\
\hline 293111098340901 & AY-68-28-807 & -- & -- & -- & Bexar & confined & $\mathrm{Y}$ & $2 d$ & psw survey & 2005 & -- & -- \\
\hline 293512098291701 & AY $-68-29-109$ & -- & -- & -- & Bexar & unconfined & $\mathrm{Y}$ & $2 d$ & psw survey & 2005 & -- & \\
\hline 292424098421501 & $\mathrm{AY}-68-35-810$ & -- & -- & -- & Bexar & confined & $\mathrm{Y}$ & $2 d$ & psw survey & 2005 & -- & -- \\
\hline 292053098365501 & $\mathrm{AY}-68-44-110$ & -- & -- & -- & Bexar & confined & $\mathrm{Y}$ & $2 d$ & psw survey & 2005 & -- & -- \\
\hline 293807098155301 & DX-68-22-901 & -- & -- & -- & Comal & confined & $\mathrm{N}$ & $2 d$ & psw survey & 2005 & -- & -- \\
\hline 292604098563201 & TD-68-33-501 & -- & -- & -- & Medina & confined & $\mathrm{Y}$ & $2 d$ & psw survey & 2005 & -- & -- \\
\hline 292116099095501 & TD-69-47-305 & -- & -- & -- & Medina & confined & $\mathrm{N}$ & $2 d$ & psw survey & 2005 & -- & -- \\
\hline 291232099470301 & YP-69-50-339 & -- & -- & -- & Uvalde & confined & $\mathrm{N}$ & $2 d$ & psw survey & 2005 & -- & -- \\
\hline 293128098473101 & AY-68-26-814 & -- & -- & -- & Bexar & unconfined & $\mathrm{Y}$ & 3d & psw survey & 2005 & -- & -- \\
\hline 293451098313201 & $\mathrm{AY}-68-28-601$ & -- & -- & -- & Bexar & unconfined & $\mathrm{Y}$ & 3d & psw survey & 2005 & -- & -- \\
\hline 294604098060801 & DX-68-16-708 & -- & -- & -- & Comal & unconfined & $\mathrm{N}$ & $3 d$ & psw survey & 2005 & -- & -- \\
\hline 294019098114701 & DX-68-23-504 & -- & -- & -- & Comal & confined & $\mathrm{N}$ & $3 d$ & psw survey & 2005 & -- & -- \\
\hline 292215098580201 & TD $-68-41-103$ & -- & -- & -- & Medina & confined & $\mathrm{Y}$ & $3 d$ & psw survey & 2005 & -- & -- \\
\hline 292119098524901 & TD-68-41-308 & -- & -- & -- & Medina & confined & $\mathrm{Y}$ & $3 d$ & psw survey & 2005 & -- & -- \\
\hline 291943099163301 & TD-69-46-601 & -- & -- & -- & Medina & confined & $\mathrm{N}$ & 3d & psw survey & 2005 & -- & -- \\
\hline 291840099382601 & YP-69-43-606 & -- & -- & -- & Uvalde & confined & $\mathrm{N}$ & 3d & psw survey & 2005 & -- & -- \\
\hline 293518098332601 & $\mathrm{AY}-68-28-203$ & -- & -- & -- & Bexar & unconfined & $\mathrm{Y}$ & 4th & psw survey & 2005 & -- & -- \\
\hline 293023098355401 & AY $-68-28-702$ & -- & -- & -- & Bexar & confined & $\mathrm{Y}$ & 4th & psw survey & 2005 & -- & -- \\
\hline 293042098305201 & $\mathrm{AY}-68-28-913$ & -- & -- & -- & Bexar & confined & $\mathrm{Y}$ & 4th & psw survey & 2005 & -- & -- \\
\hline 292442098474501 & $\mathrm{AY}-68-34-803$ & -- & -- & -- & Bexar & confined & $\mathrm{Y}$ & 4th & psw survey & 2005 & -- & -- \\
\hline 292405098371201 & $\mathrm{AY}-68-36-704$ & -- & -- & -- & Bexar & confined & $\mathrm{Y}$ & 4th & psw survey & 2005 & -- & -- \\
\hline 292931098274601 & $\mathrm{AY}-68-37-124$ & -- & -- & -- & Bexar & confined & $\mathrm{Y}$ & 4th & psw survey & 2005 & -- & -- \\
\hline 293729098173101 & $\mathrm{DX}-68-30-215$ & -- & -- & -- & Comal & confined & $\mathrm{N}$ & 4th & psw survey & 2005 & -- & -- \\
\hline 291219099095601 & TD-69-55-604 & -- & -- & -- & Medina & confined & $\mathrm{N}$ & 4th & psw survey & 2005 & -- & -- \\
\hline
\end{tabular}


Table 1. Site information for wells sampled for the study of the transport of anthropogenic and natural contaminants (TANC) to public supply wells in the San Antonio segment of the Edwards aquifer near San Antonio, south-central Texas, 2004-9.-Continued

[By sample category and by aquifer category (unconfined, confined). USGS, U.S. Geological Survey; NAD 83, North American Datum of 1983; Y, yes; N, no; --, not measured, known, or applicable; *, sampled 6 times for temporal response to rainfall; psw, public-supply well; **, sampled 9 times for vertically discrete samples; ft, feet; NAVD 1988, North American Vertical Datum of 1988; gal/min, gallons per minute; in., inches; PVC, polyvinyl chloride; $\dagger$, borehole diameter (diam.), screen is 2.5 -in. diam.; $\$$, borehole diam., screen is 4.5 -in. diam.

\begin{tabular}{|c|c|c|c|c|c|c|c|c|c|c|c|}
\hline $\begin{array}{c}\text { USGS } \\
\text { identification } \\
\text { number }\end{array}$ & $\begin{array}{l}\text { Well } \\
\text { type }\end{array}$ & $\begin{array}{l}\text { Water } \\
\text { use }\end{array}$ & $\begin{array}{l}\text { Casing } \\
\text { material }\end{array}$ & $\begin{array}{l}\text { Land- } \\
\text { surface } \\
\text { altitude } \\
\text { (ft above } \\
\text { NAVD } \\
\text { 1988) }\end{array}$ & $\begin{array}{l}\text { Rated } \\
\text { pump } \\
\text { capacity } \\
\text { (gal/min) }\end{array}$ & $\begin{array}{c}\text { Well } \\
\text { depth } \\
\text { (ft below } \\
\text { land } \\
\text { surface) }\end{array}$ & $\begin{array}{l}\text { Depth to top } \\
\text { of open or } \\
\text { screened } \\
\text { interval } \\
\text { (ft from land } \\
\text { surface) }\end{array}$ & $\begin{array}{l}\text { Depth to bot- } \\
\text { tom of open } \\
\text { or screened } \\
\text { interval } \\
\text { (ft from land } \\
\text { surface) }\end{array}$ & $\begin{array}{c}\text { Length } \\
\text { of open } \\
\text { interval } \\
\text { (ft) }\end{array}$ & $\begin{array}{l}\text { Diam- } \\
\text { eter of } \\
\text { open } \\
\text { interval } \\
\text { (in.) }\end{array}$ & $\begin{array}{c}\text { Formation(s) of } \\
\text { open interval }\end{array}$ \\
\hline \multicolumn{12}{|c|}{ Monitoring wells } \\
\hline 292943098354401 & Observation & Unused & Steel, PVC & 848 & -- & 280 & 203 & 243 & 40 & $11 \dagger$ & Buda Limestone \\
\hline 292943098354402 & Observation & Unused & Steel, PVC & 848 & -- & 345 & 335 & 345 & 10 & $5.9 \dagger$ & Cyclic and marine members, undivided \\
\hline 292943098354403 & Observation & Unused & Steel, PVC & 848 & -- & 480 & 397 & 417.5 & 20.5 & $5.9 \dagger$ & Leached and collapsed members, undivided \\
\hline 292943098354404 & Observation & Unused & Steel, PVC & 848 & -- & 616 & 586 & 596.5 & 10.5 & $5.9 \dagger$ & Kirschberg evaporite member \\
\hline 292851098374401 & Observation & Unused & Steel, PVC & 795 & -- & 520 & 480 & 510 & 30 & $5.9 \dagger$ & Leached and collapsed members, undivided \\
\hline 292851098374402 & Observation & Unused & Steel, PVC & 795 & -- & 660 & 645 & 655 & 10 & $5.9 \dagger$ & Kirschberg evaporite member \\
\hline 293252098380801 & Observation & Unused & Steel, PVC & 896 & -- & 229 & 149 & 229 & 80 & $6.5 \neq$ & $\begin{array}{l}\text { Leached and collapsed members, undivided to } \\
\text { grainstone member }\end{array}$ \\
\hline \multicolumn{12}{|c|}{ Well-field wells } \\
\hline 292919098360501 & Withdrawal & Public & Steel & 910 & 8,750 & 824 & 342 & 824 & 482 & 30 & All of Edwards \\
\hline 292925098360201 & Withdrawal & Public & Steel & 890 & 7,778 & 808 & 322 & 808 & 486 & 30 & All of Edwards \\
\hline 292916098360701 & Withdrawal & Public & Steel & 890 & 7,778 & 816 & 321 & 816 & 495 & 30 & All of Edwards \\
\hline 292920098360601 & Withdrawal & Public & Steel & 903 & 13,958 & 795 & 341 & 795 & 454 & 36 & All of Edwards \\
\hline 292923098360301 & Withdrawal & Public & Steel & 906 & 14,375 & 820 & 360 & 820 & 460 & 36 & All of Edwards \\
\hline \multicolumn{12}{|c|}{ Regional aquifer public-supply wells } \\
\hline 293359098290301 & Withdrawal & Public & Steel & 840 & 3,200 & 710 & 380 & 710 & 330 & 16 & Most of Edwards \\
\hline 293358098231101 & Withdrawal & Public & Steel & 828 & 7,500 & 811 & 359 & 811 & 452 & 30 & All of Edwards \\
\hline 293120098285801 & Withdrawal & Public & Steel & 758 & 8,701 & 848 & 408 & 848 & 440 & 30 & All of Edwards \\
\hline 293145098224201 & Withdrawal & Public & Steel & 813 & 9,722 & 870 & 409 & 870 & 461 & 30 & All of Edwards \\
\hline 293119098211201 & Withdrawal & Public & Steel & 895 & 3,100 & 877 & 530 & 877 & 347 & -- & Most of Edwards \\
\hline 292843098425101 & Withdrawal & Public & Steel & 955 & 8,264 & 760 & 460 & 750 & 290 & 36 & Most of Edwards \\
\hline 292459098382101 & Withdrawal & Public & Steel & 754 & 8,472 & 1,040 & 594 & 1,040 & 446 & 30 & All of Edwards \\
\hline 292822098325401 & Withdrawal & Public & Steel & 756 & 3,194 & 748 & 537 & 748 & 211 & 18 & Top of Edwards \\
\hline 292944098292301 & Withdrawal & Public & Steel & 710 & 9,722 & 1,050 & 574 & 1,044 & 470 & 30 & All of Edwards \\
\hline 292522098291901 & Withdrawal & Public & Steel & 640 & 8,958 & 1,114 & 774 & 1,114 & 340 & 24 & Most of Edwards \\
\hline 292643098241801 & Withdrawal & Public & Steel & 686 & 3,472 & 1,150 & 1,012 & 1,150 & 138 & 20 & Top of Edwards \\
\hline 292328098294601 & Withdrawal & Public & Steel & 601 & 8,472 & 1,800 & 1,333 & 1,800 & 467 & 30 & $\begin{array}{l}\text { Most of Edwards (from cyclic and marine mem- } \\
\text { bers, undivided, to bottom) }\end{array}$ \\
\hline 294225098080301 & Withdrawal & Public & Steel & 680 & 2,100 & 365 & 92 & 365 & 273 & -- & One-half of Edwards \\
\hline 291210099475601 & Withdrawal & Public & Steel & 900 & 500 & 525 & 191 & 525 & 334 & 12 & Most of Edwards \\
\hline
\end{tabular}


Table 1. Site information for wells sampled for the study of the transport of anthropogenic and natural contaminants (TANC) to public supply wells in the San Antonio segment of the Edwards aquifer near San Antonio, south-central Texas, 2004-9.-Continued

[By sample category and by aquifer category (unconfined, confined). USGS, U.S. Geological Survey; NAD 83, North American Datum of 1983; Y, yes; N, no; --, not measured, known, or applicable; *, sampled 6 times for temporal response to rainfall; psw, public-supply well; **, sampled 9 times for vertically discrete samples; ft, feet; NAVD 1988, North American Vertical Datum of 1988; gal/min, gallons per minute; in., inches; PVC, polyvinyl chloride; $\dagger$, borehole diameter (diam.), screen is 2.5 -in. diam.; $¥$, borehole diam., screen is 4.5 -in. diam.]

\begin{tabular}{|c|c|c|c|c|c|c|c|c|c|c|c|}
\hline $\begin{array}{c}\text { USGS } \\
\text { identification } \\
\text { number }\end{array}$ & $\begin{array}{l}\text { Well } \\
\text { type }\end{array}$ & $\begin{array}{l}\text { Water } \\
\text { use }\end{array}$ & $\begin{array}{l}\text { Casing } \\
\text { material }\end{array}$ & $\begin{array}{c}\text { Land- } \\
\text { surface } \\
\text { altitude } \\
\text { (ft above } \\
\text { NAVD } \\
\text { 1988) }\end{array}$ & $\begin{array}{c}\text { Rated } \\
\text { pump } \\
\text { capacity } \\
\text { (gal/min) }\end{array}$ & $\begin{array}{c}\text { Well } \\
\text { depth } \\
\text { (ft below } \\
\text { land } \\
\text { surface) }\end{array}$ & $\begin{array}{l}\text { Depth to top } \\
\text { of open or } \\
\text { screened } \\
\text { interval } \\
\text { (ft from land } \\
\text { surface) }\end{array}$ & $\begin{array}{l}\text { Depth to bot- } \\
\text { tom of open } \\
\text { or screened } \\
\text { interval } \\
\text { (ft from land } \\
\text { surface) }\end{array}$ & $\begin{array}{c}\text { Length } \\
\text { of open } \\
\text { interval } \\
\text { (ft) }\end{array}$ & $\begin{array}{l}\text { Diam- } \\
\text { eter of } \\
\text { open } \\
\text { interval } \\
\text { (in.) }\end{array}$ & $\begin{array}{l}\text { Formation(s) of } \\
\text { open interval }\end{array}$ \\
\hline 293111098340901 & Withdrawal & Public & Steel & 1,000 & 3,333 & 685 & 420 & 685 & 265 & 20 & Half of Edwards \\
\hline 293512098291701 & Withdrawal & Public & Steel & 975 & 250 & 460 & 230 & 460 & 230 & -- & One-half of Edwards \\
\hline 292424098421501 & Withdrawal & Public & Steel & 835 & 1,710 & 735 & 548 & 735 & 187 & -- & Less than one-half of Edwards \\
\hline 292053098365501 & Withdrawal & Public & Steel & 668 & 3,472 & 1,916 & 1,380 & 1,916 & 536 & 30 & All of Edwards \\
\hline 293807098155301 & Withdrawal & Public & Steel & 760 & 1,850 & 255 & 148 & 255 & 107 & -- & Top of Edwards \\
\hline 292604098563201 & Withdrawal & Public & Steel & 1,035 & 650 & 1,462 & 1,190 & 1,462 & 272 & -- & One-half of Edwards \\
\hline 292116099095501 & Withdrawal & Public & Steel & 910 & 1,200 & 1,418 & 1,206 & 1,418 & 212 & -- & One-half of Edwards \\
\hline 291232099470301 & Withdrawal & Public & Steel & 904 & 1,200 & 400 & 260 & 400 & 140 & -- & Top of Edwards \\
\hline 293128098473101 & Withdrawal & Public & Steel & 1,040 & 153 & 1,400 & 900 & 1,400 & 500 & 8 & All of Edwards \\
\hline 293451098313201 & Withdrawal & Public & Steel & 963 & 160 & 500 & 40 & 500 & 460 & -- & All of Edwards \\
\hline 294604098060801 & Withdrawal & Public & Steel & 802 & 150 & 400 & 200 & 400 & 200 & 6.5 & Top of Edwards \\
\hline 294019098114701 & Withdrawal & Public & Steel & 750 & 750 & 215 & 119 & 215 & 96 & -- & Top of Edwards \\
\hline 292215098580201 & Withdrawal & Public & Steel & 1,012 & 750 & 1,431 & 1,280 & 1,431 & 151 & 10 & Very top of Edwards \\
\hline 292119098524901 & Withdrawal & Public & Steel & 758 & 320 & 715 & 700 & 715 & 15 & -- & Top of Edwards \\
\hline 291943099163301 & Withdrawal & Public & Steel & 884 & 265 & 1,289 & 920 & 1,289 & 369 & -- & Most of Edwards \\
\hline 291840099382601 & Withdrawal & Public & Steel & 1,000 & 700 & 698 & 206 & 698 & 492 & -- & All of Edwards \\
\hline 293518098332601 & Withdrawal & Public & Steel & 985 & 250 & 435 & 162 & 435 & 273 & 8 & One-half of Edwards \\
\hline 293023098355401 & Withdrawal & Public & Steel & 840 & 1,320 & 450 & 397 & 450 & 53 & -- & Top of Edwards \\
\hline 293042098305201 & Withdrawal & Public & Steel & 815 & 1,500 & 787 & 448 & 787 & 339 & 20 & Most of Edwards \\
\hline 292442098474501 & Withdrawal & Public & Steel & 900 & 2,450 & 680 & 392 & 680 & 288 & 15 & One-half of Edwards \\
\hline 292405098371201 & Withdrawal & Public & Steel & 720 & 1,850 & 1,500 & 1,108 & 1,500 & 392 & -- & Most of Edwards \\
\hline 292931098274601 & Withdrawal & Public & Steel & 813 & 1,000 & 557 & 390 & 557 & 167 & -- & Top of Edwards \\
\hline 293729098173101 & Withdrawal & Public & Steel & 870 & 2,000 & 660 & 185 & 660 & 475 & -- & All of Edwards \\
\hline 291219099095601 & Withdrawal & Public & Steel & 900 & 500 & 2,350 & 2,100 & 2,350 & 250 & 8 & One-half of Edwards \\
\hline
\end{tabular}


Table 2. Summary of constituents by group for wells sampled for the study of the transport of anthropogenic and natural contaminants (TANC) to public supply wells in the San Antonio segment of the Edwards aquifer near San Antonio, south-central Texas, 2004-9.

[By sample category. USGS, U.S. Geological Survey; *, did not analyze in first temporal sample; --, not sampled; **,did not analyze in first three temporal samples; psw, public-supply well; ${ }^{87} \mathrm{Sr} /{ }^{86} \mathrm{Sr}$, strontium-87/strontium-86; $\delta \mathrm{D}$, delta deuterium; $\delta^{18} \mathrm{O}$, delta oxygen-18; $\delta^{15} \mathrm{~N}$, delta nitrogen- 15 ; $\mathrm{NO}_{3}$, nitrate $]$

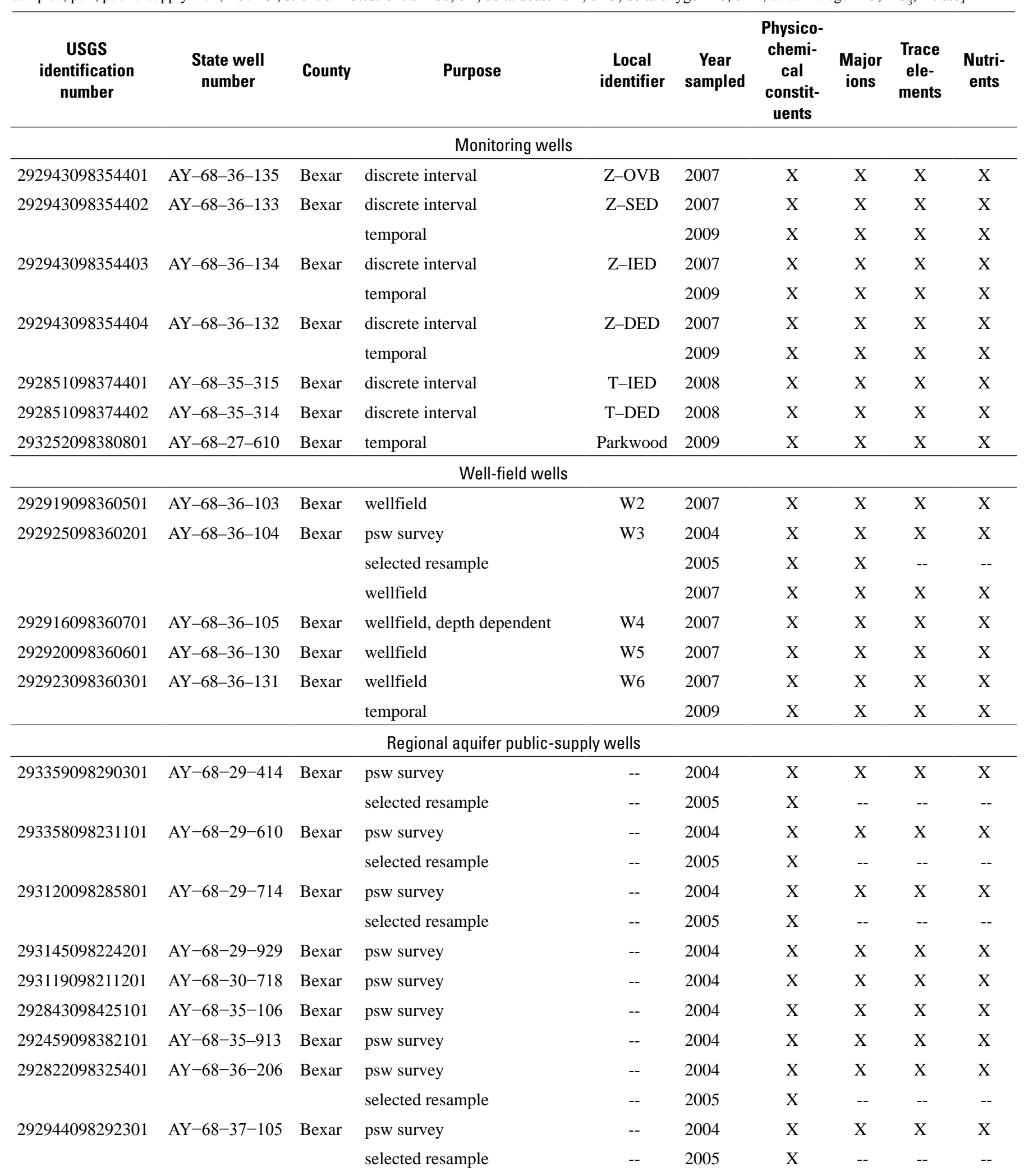


Table 2. Summary of constituents by group for wells sampled for the study of the transport of anthropogenic and natural contaminants (TANC) to public supply wells in the San Antonio segment of the Edwards aquifer near San Antonio, south-central Texas, 2004-9.

-Continued

[By sample category. USGS, U.S. Geological Survey; *, did not analyze in first temporal sample; --, not sampled; **, did not analyze in first three temporal samples; psw, public-supply well; ${ }^{87} \mathrm{Sr} /{ }^{86} \mathrm{Sr}$, strontium-87/strontium- $86 ; \delta \mathrm{D}$, delta deuterium; $\delta^{18} \mathrm{O}$, delta oxygen- $18 ; \delta^{15} \mathrm{~N}$, delta nitrogen-15; $\mathrm{NO}{ }_{3}$, nitrate]

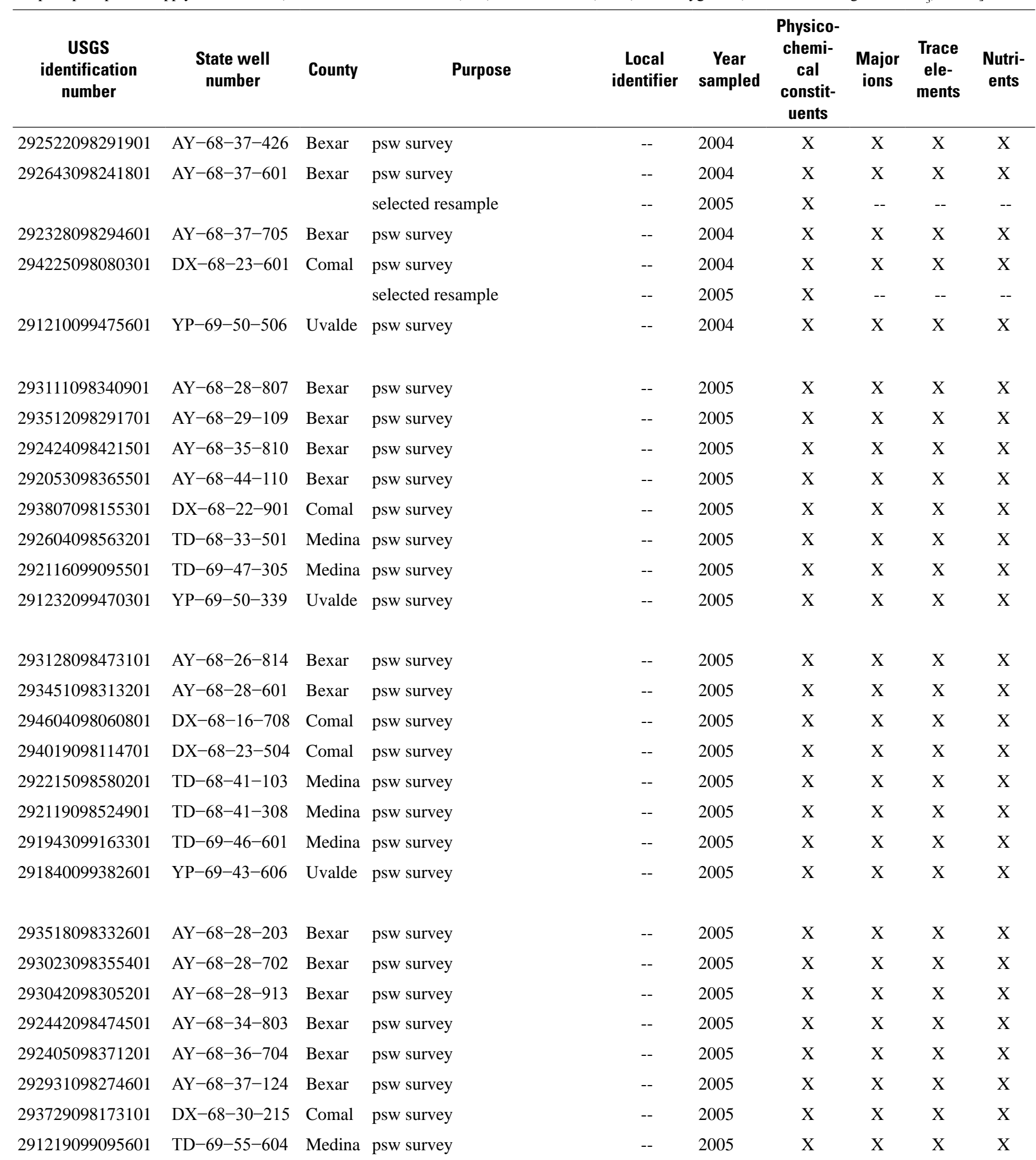


Table 2. Summary of constituents by group for wells sampled for the study of the transport of anthropogenic and natural contaminants (TANC) to public supply wells in the San Antonio segment of the Edwards aquifer near San Antonio, south-central Texas, 2004-9.

-Continued

[By sample category. USGS, U.S. Geological Survey; *, did not analyze in first temporal sample; --, not sampled; **,did not analyze in first three temporal samples; psw, public-supply well; ${ }^{87} \mathrm{Sr} /{ }^{86} \mathrm{Sr}$, strontium-87/strontium- $86 ; \delta \mathrm{D}$, delta deuterium; $\delta^{18} \mathrm{O}$, delta oxygen-18; $\delta^{15} \mathrm{~N}$, delta nitrogen-15; $\mathrm{NO}{ }_{3}$, nitrate]

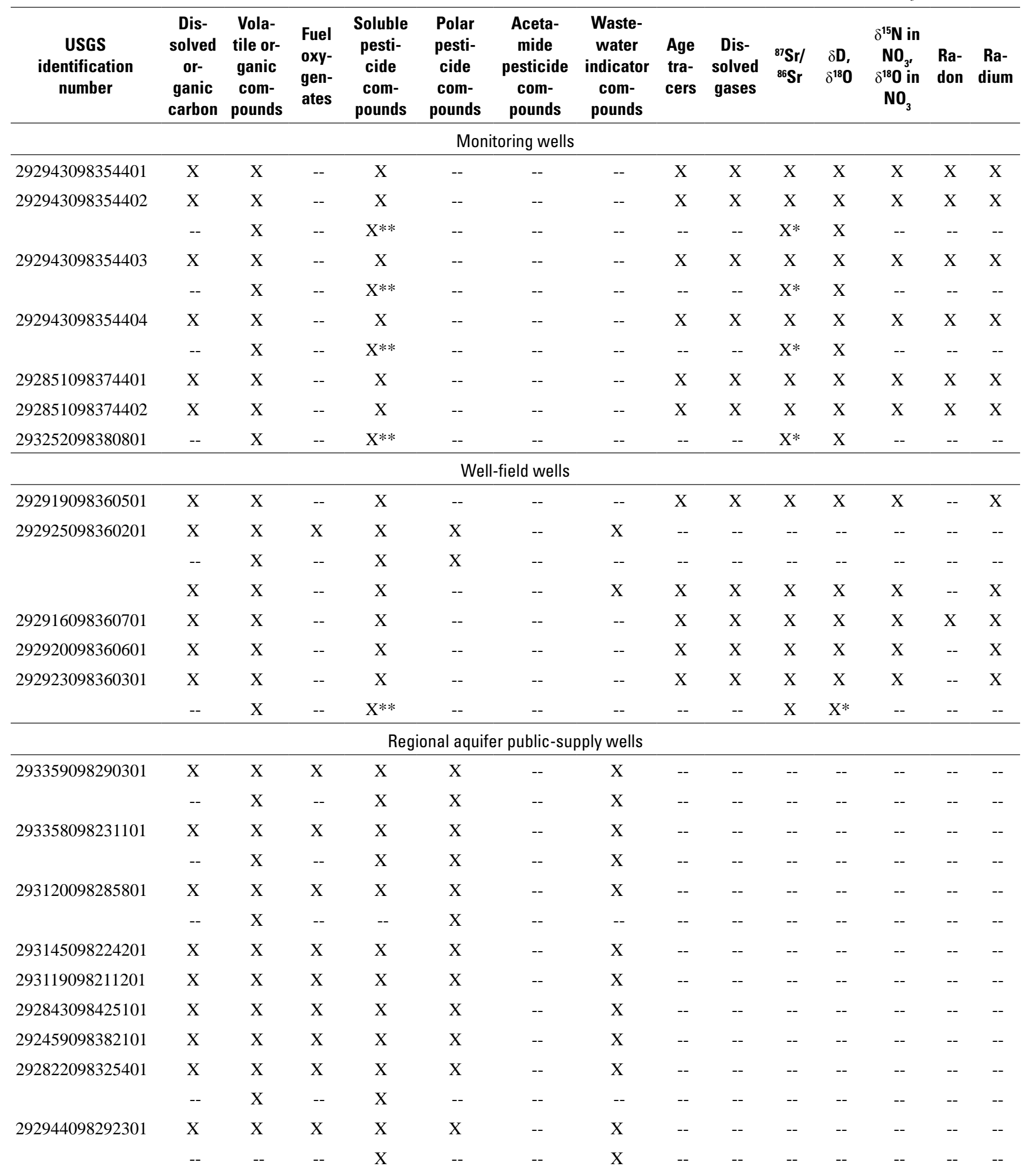


Table 2. Summary of constituents by group for wells sampled for the study of the transport of anthropogenic and natural contaminants (TANC) to public supply wells in the San Antonio segment of the Edwards aquifer near San Antonio, south-central Texas, 2004-9.

-Continued

[By sample category. USGS, U.S. Geological Survey; *, did not analyze in first temporal sample; --, not sampled; **,did not analyze in first three temporal samples; psw, public-supply well; ${ }^{87} \mathrm{Sr} /{ }^{86} \mathrm{Sr}$, strontium-87/strontium-86; $\delta \mathrm{D}$, delta deuterium; $\delta^{18} \mathrm{O}$, delta oxygen- $18 ; \delta^{15} \mathrm{~N}$, delta nitrogen- 15 ; $\mathrm{NO}_{3}$, nitrate ]

\begin{tabular}{|c|c|c|c|c|c|c|c|c|c|c|c|c|c|c|}
\hline $\begin{array}{c}\text { USGS } \\
\text { identification } \\
\text { number }\end{array}$ & $\begin{array}{c}\text { Dis- } \\
\text { solved } \\
\text { or- } \\
\text { ganic } \\
\text { carbon }\end{array}$ & $\begin{array}{l}\text { Vola- } \\
\text { tile or- } \\
\text { ganic } \\
\text { com- } \\
\text { pounds }\end{array}$ & $\begin{array}{l}\text { Fuel } \\
\text { oxy- } \\
\text { gen- } \\
\text { ates }\end{array}$ & $\begin{array}{l}\text { Soluble } \\
\text { pesti- } \\
\text { cide } \\
\text { com- } \\
\text { pounds } \\
\end{array}$ & $\begin{array}{l}\text { Polar } \\
\text { pesti- } \\
\text { cide } \\
\text { com- } \\
\text { pounds }\end{array}$ & $\begin{array}{l}\text { Aceta- } \\
\text { mide } \\
\text { pesticide } \\
\text { com- } \\
\text { pounds }\end{array}$ & $\begin{array}{l}\text { Waste- } \\
\text { water } \\
\text { indicator } \\
\text { com- } \\
\text { pounds }\end{array}$ & $\begin{array}{l}\text { Age } \\
\text { tra- } \\
\text { cers }\end{array}$ & $\begin{array}{l}\text { Dis- } \\
\text { solved } \\
\text { gases }\end{array}$ & $\begin{array}{l}{ }^{87} \mathrm{Sr} / \\
{ }^{86} \mathrm{Sr}\end{array}$ & $\begin{array}{l}\delta \mathbf{D}, \\
\delta^{18} \mathbf{0}\end{array}$ & $\begin{array}{c}\delta^{15} \mathbf{N} \text { in } \\
\mathbf{N O}_{3^{\prime}} \\
\delta^{18} \mathbf{~ i n ~}^{-} \\
\mathbf{N O}_{3}\end{array}$ & $\begin{array}{l}\text { Ra- } \\
\text { don }\end{array}$ & $\begin{array}{l}\text { Ra- } \\
\text { dium }\end{array}$ \\
\hline 292522098291901 & $\mathrm{X}$ & $\mathrm{X}$ & $\mathrm{X}$ & $\mathrm{X}$ & $\mathrm{X}$ & -- & $\mathrm{X}$ & -- & -- & -- & -- & -- & -- & -- \\
\hline \multirow[t]{2}{*}{292643098241801} & $X$ & $X$ & $X$ & $X$ & $X$ & -- & X & -- & -- & -- & -- & -- & -- & -- \\
\hline & -- & $\mathrm{X}$ & -- & -- & $\mathrm{X}$ & -- & -- & -- & -- & -- & -- & -- & -- & -- \\
\hline 292328098294601 & $\mathrm{X}$ & $\mathrm{X}$ & $\mathrm{X}$ & $\mathrm{X}$ & $\mathrm{X}$ & -- & $\mathrm{X}$ & -- & -- & -- & -- & -- & -- & -- \\
\hline \multirow[t]{2}{*}{294225098080301} & $\mathrm{X}$ & $\mathrm{X}$ & $\mathrm{X}$ & $\mathrm{X}$ & $\mathrm{X}$ & -- & $\mathrm{X}$ & -- & -- & -- & -- & -- & -- & -- \\
\hline & -- & $\mathrm{X}$ & -- & $\mathrm{X}$ & -- & -- & -- & -- & -- & -- & -- & -- & -- & -- \\
\hline 291210099475601 & $\mathrm{X}$ & $\mathrm{X}$ & $\mathrm{X}$ & $\mathrm{X}$ & $\mathrm{X}$ & -- & $\mathrm{X}$ & -- & -- & -- & -- & -- & -- & -- \\
\hline 293111098340901 & $\mathrm{X}$ & $\mathrm{X}$ & $\mathrm{X}$ & $\mathrm{X}$ & -- & $\mathrm{X}$ & -- & -- & -- & -- & -- & -- & -- & -- \\
\hline 293512098291701 & $\mathrm{X}$ & $\mathrm{X}$ & $\mathrm{X}$ & $\mathrm{X}$ & -- & $\mathrm{X}$ & $\mathrm{X}$ & -- & -- & -- & -- & -- & -- & -- \\
\hline 292424098421501 & $\mathrm{X}$ & $\mathrm{X}$ & $\mathrm{X}$ & $\mathrm{X}$ & -- & $\mathrm{X}$ & $\mathrm{X}$ & -- & -- & -- & -- & -- & -- & -- \\
\hline 292053098365501 & $\mathrm{X}$ & $\mathrm{X}$ & $\mathrm{X}$ & $\mathrm{X}$ & -- & $\mathrm{X}$ & -- & -- & -- & -- & -- & -- & -- & -- \\
\hline 293807098155301 & $\mathrm{X}$ & $\mathrm{X}$ & $\mathrm{X}$ & $\mathrm{X}$ & -- & $\mathrm{X}$ & $\mathrm{X}$ & -- & -- & -- & -- & -- & -- & -- \\
\hline 292604098563201 & $\mathrm{X}$ & $\mathrm{X}$ & $\mathrm{X}$ & $\mathrm{X}$ & -- & $\mathrm{X}$ & $\mathrm{X}$ & -- & -- & -- & -- & -- & -- & -- \\
\hline 292116099095501 & $\mathrm{X}$ & $\mathrm{X}$ & $\mathrm{X}$ & $\mathrm{X}$ & -- & $\mathrm{X}$ & $\mathrm{X}$ & -- & -- & -- & -- & -- & -- & -- \\
\hline 291232099470301 & $\mathrm{X}$ & $\mathrm{X}$ & $\mathrm{X}$ & $\mathrm{X}$ & -- & $\mathrm{X}$ & $\mathrm{X}$ & -- & -- & -- & -- & -- & -- & -- \\
\hline 293128098473101 & $\mathrm{X}$ & $\mathrm{X}$ & $\mathrm{X}$ & $\mathrm{X}$ & -- & $\mathrm{x}$ & $\mathrm{x}$ & -- & -- & -- & -- & -- & -- & -- \\
\hline 293451098313201 & $\mathrm{X}$ & $\mathrm{X}$ & $\mathrm{X}$ & $\mathrm{X}$ & -- & $\mathrm{X}$ & $\mathrm{X}$ & -- & -- & -- & -- & -- & -- & -- \\
\hline 294604098060801 & $\mathrm{X}$ & $\mathrm{X}$ & $\mathrm{X}$ & $\mathrm{X}$ & -- & $\mathrm{X}$ & $\mathrm{X}$ & -- & -- & -- & -- & -- & -- & -- \\
\hline 294019098114701 & $\mathrm{X}$ & $\mathrm{X}$ & $\mathrm{X}$ & $\mathrm{X}$ & -- & $\mathrm{X}$ & $\mathrm{X}$ & -- & -- & -- & -- & -- & -- & -- \\
\hline 292215098580201 & $\mathrm{X}$ & $\mathrm{X}$ & $\mathrm{X}$ & $\mathrm{X}$ & -- & $\mathrm{X}$ & $\mathrm{X}$ & -- & -- & -- & -- & -- & -- & -- \\
\hline 292119098524901 & $\mathrm{X}$ & $\mathrm{X}$ & $\mathrm{X}$ & $\mathrm{X}$ & -- & $\mathrm{X}$ & $\mathrm{X}$ & -- & -- & -- & -- & -- & -- & -- \\
\hline 291943099163301 & $\mathrm{X}$ & $\mathrm{X}$ & $\mathrm{X}$ & $\mathrm{X}$ & -- & $\mathrm{X}$ & $\mathrm{X}$ & -- & -- & -- & -- & -- & -- & -- \\
\hline 291840099382601 & $\mathrm{X}$ & $\mathrm{X}$ & $\mathrm{X}$ & $\mathrm{X}$ & -- & $\mathrm{X}$ & $\mathrm{X}$ & -- & -- & -- & -- & -- & -- & -- \\
\hline 293518098332601 & $\mathrm{X}$ & $\mathrm{X}$ & $\mathrm{X}$ & $\mathrm{X}$ & -- & $\mathrm{X}$ & $\mathrm{X}$ & -- & -- & -- & -- & -- & -- & -- \\
\hline 293023098355401 & $\mathrm{X}$ & $\mathrm{X}$ & $\mathrm{X}$ & $\mathrm{X}$ & -- & $\mathrm{X}$ & $\mathrm{X}$ & -- & -- & -- & -- & -- & -- & -- \\
\hline 293042098305201 & $\mathrm{X}$ & $\mathrm{X}$ & $\mathrm{X}$ & $\mathrm{X}$ & -- & $\mathrm{X}$ & $\mathrm{X}$ & -- & -- & -- & -- & -- & -- & -- \\
\hline 292442098474501 & $\mathrm{X}$ & $\mathrm{X}$ & $\mathrm{X}$ & $\mathrm{X}$ & -- & $\mathrm{X}$ & $\mathrm{X}$ & -- & -- & -- & -- & -- & -- & -- \\
\hline 292405098371201 & $\mathrm{X}$ & $\mathrm{X}$ & $\mathrm{X}$ & $\mathrm{X}$ & -- & $\mathrm{X}$ & $\mathrm{X}$ & -- & -- & -- & -- & -- & -- & -- \\
\hline 292931098274601 & $\mathrm{X}$ & $\mathrm{X}$ & $\mathrm{X}$ & $\mathrm{X}$ & -- & $\mathrm{X}$ & $\mathrm{X}$ & -- & -- & -- & -- & -- & -- & -- \\
\hline 293729098173101 & $\mathrm{X}$ & $\mathrm{X}$ & $\mathrm{X}$ & $\mathrm{X}$ & -- & $\mathrm{X}$ & -- & -- & -- & -- & -- & -- & -- & -- \\
\hline 291219099095601 & $\mathrm{X}$ & $\mathrm{X}$ & $\mathrm{X}$ & $\mathrm{X}$ & -- & $\mathrm{X}$ & $\mathrm{X}$ & -- & -- & -- & -- & -- & -- & -- \\
\hline
\end{tabular}


Table 3. Summary of depth-dependent sampling for the study of the transport of anthropogenic and natural contaminants (TANC) to public supply wells in the San Antonio segment of the Edwards aquifer near San Antonio, south-central Texas, 2004-9.

[By sample category. USGS, U.S. Geological Survey; ft, feet; --, not applicable; DDS, depth-dependent sampling]

\begin{tabular}{|c|c|c|c|c|c|c|c|c|c|c|c|}
\hline $\begin{array}{c}\text { USGS } \\
\text { identification } \\
\text { number }\end{array}$ & $\begin{array}{l}\text { State well } \\
\text { number }\end{array}$ & $\begin{array}{l}\text { Local } \\
\text { identifier }\end{array}$ & $\begin{array}{l}\text { Sample } \\
\text { pump } \\
\text { intake } \\
\text { depth } \\
\text { (ft below } \\
\text { land } \\
\text { surface) }\end{array}$ & $\begin{array}{l}\text { Well } \\
\text { depth } \\
\text { (ft } \\
\text { below } \\
\text { land } \\
\text { sur- } \\
\text { face) }\end{array}$ & $\begin{array}{l}\text { Depth } \\
\text { to top } \\
\text { of open } \\
\text { interval } \\
\text { (ft below } \\
\text { land } \\
\text { surface) }\end{array}$ & $\begin{array}{l}\text { Depth to } \\
\text { bottom } \\
\text { of open } \\
\text { interval } \\
\text { (ft below } \\
\text { land } \\
\text { surface) }\end{array}$ & $\begin{array}{l}\text { Length } \\
\text { of open } \\
\text { interval } \\
\text { (ft below } \\
\text { land } \\
\text { surface) }\end{array}$ & $\begin{array}{l}\text { Formation } \\
\text { at pump } \\
\text { intake } \\
\text { depth }\end{array}$ & $\begin{array}{l}\text { Contributing } \\
\text { formation(s) or } \\
\text { flow zone(s) }\end{array}$ & $\begin{array}{l}\text { Hydro- } \\
\text { geo- } \\
\text { logic } \\
\text { unit } \\
\text { (HGU) }\end{array}$ & Comments \\
\hline \multicolumn{12}{|c|}{ Zarzamora monitoring wells } \\
\hline 292943098354402 & AY-68-36-133 & Z-SED & -- & 345 & 335 & 345 & 10 & -- & $\begin{array}{l}\text { Georgetown Formation } \\
\text { and cyclic and marine } \\
\text { members, undivided }\end{array}$ & 2 and 3 & -- \\
\hline 292943098354403 & AY-68-36-134 & Z-IED & -- & 480 & 397 & 417.5 & 20.5 & -- & $\begin{array}{l}\text { Bottom of cyclic and } \\
\text { marine members, } \\
\text { undivided }\end{array}$ & 3 & -- \\
\hline 292943098354404 & AY-68-36-132 & Z-DED & -- & 616 & 586 & 596.5 & 10.5 & -- & $\begin{array}{l}\text { Top of Kirschberg evapo- } \\
\text { rite member }\end{array}$ & 8 & $\begin{array}{l}\text { Unable to screen to bottom of open } \\
\text { interval because of well collapse }\end{array}$ \\
\hline \multicolumn{12}{|c|}{ Timberhill monitoring wells } \\
\hline 292851098374401 & AY-68-35-315 & T- IED & -- & 520 & 480 & 510 & 30 & -- & $\begin{array}{l}\text { Mostly top of leached and } \\
\text { collapsed members, } \\
\text { undivided, and possi- } \\
\text { bly some from bottom } \\
\text { of cyclic and marine } \\
\text { members, undivided }\end{array}$ & $\begin{array}{l}\text { mostly } \\
4 \text { (pos- } \\
\text { sibly } \\
\text { some 3) }\end{array}$ & $\begin{array}{l}\text { Unable to screen shorter interval } \\
\text { because of well collapse }\end{array}$ \\
\hline 292851098374402 & AY-68-35-314 & T-DED & -- & 660 & 645 & 655 & 10 & -- & $\begin{array}{l}\text { Kirschberg evaporite } \\
\text { member }\end{array}$ & 8 & -- \\
\hline \multicolumn{12}{|c|}{ Well-field public-supply well (W4) } \\
\hline \multirow[t]{4}{*}{292916098360701} & AY-68-36-105 & $\begin{array}{l}\text { W4 (DDS } \\
\text { "well- } \\
\text { head") }\end{array}$ & 320 & 816 & 320 & 320 & 496 & $\begin{array}{l}\text { Georgetown } \\
\text { Formation }\end{array}$ & $\begin{array}{l}\text { All contributing flow } \\
\text { zones }\end{array}$ & $2-10$ & $\begin{array}{l}\text { Represents wellhead sample, above } \\
\text { all (4) high-flow zones }\end{array}$ \\
\hline & & $\begin{array}{l}\text { W4 (DDS } \\
\text { shallow) }\end{array}$ & 380 & 816 & 380 & 380 & -- & $\begin{array}{l}\text { Near middle } \\
\text { of cyclic } \\
\text { and } \\
\text { marine } \\
\text { members }\end{array}$ & $\begin{array}{l}\text { Cyclic and marine mem- } \\
\text { bers, undivided }\end{array}$ & 3 & $\begin{array}{l}\text { Targeted middle of cyclic and marine } \\
\text { members where flow was being } \\
\text { gained or lost to borehole (under } \\
\text { different pumping conditions); } \\
\text { below high-transmissivity zone at } \\
\text { top of cyclic and marine members, } \\
\text { undivided }\end{array}$ \\
\hline & & $\begin{array}{l}\text { W4 (DDS } \\
\text { intermedi- } \\
\quad \text { ate) }\end{array}$ & 430 & 816 & 430 & 430 & -- & $\begin{array}{l}\text { Middle/top } \\
\text { of leached } \\
\text { and col- } \\
\text { lapsed } \\
\text { members }\end{array}$ & $\begin{array}{l}\text { Leached and collapsed } \\
\text { members, undivided }\end{array}$ & 4 and 5 & $\begin{array}{l}\text { Targeted middle of leached and col- } \\
\text { lapsed members, coincident with } \\
\text { high flow zone; in middle of high } \\
\text { transmissivity zone in leached and } \\
\text { collapsed members, undivided }\end{array}$ \\
\hline & & $\begin{array}{l}\text { W4 (DDS } \\
\text { deep) }\end{array}$ & 540 & 816 & 580 & 580 & -- & $\begin{array}{l}\text { Grainstone } \\
\text { member }\end{array}$ & $\begin{array}{l}\text { Kirschberg evaporite } \\
\text { member }\end{array}$ & $\begin{array}{l}8 \text { (also } \\
\text { possibly } \\
\text { from } 9 \\
\text { and 10) }\end{array}$ & $\begin{array}{l}\text { Targeted flow upward from Kirsch- } \\
\text { berg evaporite member or below; } \\
\text { above two high-flow zones, one in } \\
\text { Kirschberg evaporite member and } \\
\text { one in dolomitic member }\end{array}$ \\
\hline
\end{tabular}


Table 4. Sample collection for temporal sampling for the study of the transport of anthropogenic and natural contaminants (TANC) to public supply wells in the San Antonio segment of the Edwards aquifer near San Antonio, south-central Texas, 2009.

\begin{tabular}{cc}
\hline Sample number & Sample collection dates \\
\hline Pre-storm & $4 / 9 / 2009-4 / 14 / 2009$ \\
Storm 1 & $10 / 4 / 2009-10 / 6 / 2009$ \\
Storm 2 & $10 / 7 / 2009-10 / 9 / 2009$ \\
Storm 3 & $10 / 17 / 2009-0 / 19 / 2009$ \\
Storm 4 & $10 / 28 / 2009-10 / 30 / 2009$ \\
Storm 5 & $11 / 17 / 2009-11 / 19 / 2009$ \\
\hline
\end{tabular}


Table 5. Summary of organic content and elemental composition from acid extractions for core materials collected for the study of the transport of anthropogenic and natural contaminants (TANC) to public supply wells in the San Antonio segment of the Edwards aquifer near San Antonio, south-central Texas, 2004-9.

[USGS, U.S. Geological Survey; ft, feet; LSD, land surface datum; <2 mm, less than 2 millimeters (size of particulates analyzed); g/kg, grams per kilogram; mg/kg, milligrams per kilogram; --, not analyzed; na, not available; N, normal; $\mathrm{HCl}$, hydrochloric acid; \%, percent; $\mathrm{HNO}_{3}$, nitric acid]

\begin{tabular}{|c|c|c|c|c|c|c|c|c|c|}
\hline $\begin{array}{c}\text { USGS } \\
\text { identification } \\
\text { number }\end{array}$ & $\begin{array}{c}\text { State well } \\
\text { number }\end{array}$ & $\begin{array}{l}\text { Local } \\
\text { identi- } \\
\text { fier }\end{array}$ & $\begin{array}{l}\text { Sample } \\
\text { identifier }\end{array}$ & $\begin{array}{c}\text { Date } \\
\text { collected }\end{array}$ & Geologic or hydrogeologic unit & $\begin{array}{l}\text { Depth to top } \\
\text { of sample } \\
\text { interval } \\
\text { (ft from LSD) }\end{array}$ & $\begin{array}{c}\text { Depth to bot- } \\
\text { tom of sample } \\
\text { interval } \\
\text { (ft from LSD) }\end{array}$ & $\begin{array}{c}\text { Total } \\
\text { carbon, } \\
<2 \mathrm{~mm} \\
(\mathrm{~g} / \mathrm{kg})\end{array}$ & $\begin{array}{c}\text { Inorganic } \\
\text { carbon, } \\
<2 \mathrm{~mm} \\
(\mathrm{~g} / \mathrm{kg})\end{array}$ \\
\hline & & & & & & & & \multicolumn{2}{|c|}{ Carbon analysis } \\
\hline \multirow[t]{9}{*}{292943098354403} & AY-68-36-134 & Z-IED & TX 175A & 8/17/2007 & Austin Chalk-Eagle Ford Group contact & 175.0 & 176.5 & 104 & 103 \\
\hline & & & TX 175B & & & 175.0 & 176.5 & -- & -- \\
\hline & & & TX 175C & & & 175.0 & 176.5 & -- & -- \\
\hline & & & TX 209 & 8/18/2007 & Eagle Ford Group-Buda Limestone contact & 209.0 & 210.5 & 129 & 54 \\
\hline & & & TX 260 & 8/18/2007 & Buda Limestone-Del Rio Clay contact & 260.0 & 261.5 & 112 & 117 \\
\hline & & & TX 314A & 8/18/2007 & Del Rio Clay-Georgetown Formation contact & 314.0 & 315.5 & 59 & 56 \\
\hline & & & TX 314B & & & 314.0 & 315.5 & -- & -- \\
\hline & & & TX 314C & & & 314.0 & 315.5 & -- & -- \\
\hline & & & TX 444 & 8/24/2007 & Leached and collapsed members, undivided & 444.0 & 446.0 & 118 & 118 \\
\hline \multirow[t]{5}{*}{292943098354404} & AY-68-36-132 & Z-DED & TX 526 & 8/13/2007 & Regional dense member-grainstone member contact & 525.0 & 527.0 & 100 & 101 \\
\hline & & & TX 550A & $8 / 14 / 2007$ & Grainstone member & 550.0 & 551.0 & 114 & 116 \\
\hline & & & TX 550B & & & 550.0 & 551.0 & -- & -- \\
\hline & & & TX 550C & & & 550.0 & 551.0 & -- & -- \\
\hline & & & TX 589 & $8 / 14 / 2007$ & Kirschberg evaporite member (fragments) & 589.0 & 591.0 & 117 & 116 \\
\hline
\end{tabular}


Table 5. Summary of organic content and elemental composition from acid extractions for core materials collected for the study of the transport of anthropogenic and natural contaminants (TANC) to public supply wells in the San Antonio segment of the Edwards aquifer near San Antonio, south-central Texas, 2004-9. - Continued

[USGS, U.S. Geological Survey; ft, feet; LSD, land surface datum; <2 mm, less than 2 millimeters (size of particulates analyzed); g/kg, grams per kilogram; mg/kg, milligrams per kilogram; --, not analyzed; na, not available; $\mathrm{N}$, normal; $\mathrm{HCl}$, hydrochloric acid; \%, percent; $\mathrm{HNO}_{3}$, nitric acid]

\begin{tabular}{|c|c|c|c|c|c|c|c|c|c|c|c|c|c|c|c|c|c|c|}
\hline $\begin{array}{c}\text { Sample } \\
\text { identifier }\end{array}$ & $\begin{array}{c}\text { Alumi- } \\
\text { num } \\
\text { (mg/kg) }\end{array}$ & $\begin{array}{l}\text { Barium } \\
\text { (mg/kg) }\end{array}$ & $\begin{array}{c}\text { Iron } \\
\text { (mg/kg) }\end{array}$ & $\begin{array}{l}\text { Potas- } \\
\text { sium } \\
(\mathrm{mg} / \mathrm{kg}\end{array}$ & $\begin{array}{c}\text { Manga- } \\
\text { nese } \\
\text { (mg/kg) }\end{array}$ & $\begin{array}{l}\text { Sodium } \\
\text { (mg/kg) }\end{array}$ & $\begin{array}{c}\text { Silica } \\
\text { (mg/kg) }\end{array}$ & $\begin{array}{l}\text { Magne- } \\
\text { sium } \\
(\mathbf{m g} / \mathbf{k g})\end{array}$ & $\begin{array}{c}\text { Lead } \\
(\mathrm{mg} / \mathrm{kg})\end{array}$ & $\begin{array}{l}\text { Uranium } \\
\text { (mg/kg) }\end{array}$ & $\begin{array}{l}\text { Arsenic } \\
(\mathrm{mg} / \mathrm{kg})\end{array}$ & $\begin{array}{l}\text { Sele- } \\
\text { nium } \\
\text { (mg/kg) }\end{array}$ & $\begin{array}{l}\text { Cal- } \\
\text { cium } \\
(\mathbf{g} / \mathbf{k g})\end{array}$ & $\begin{array}{c}\text { Calcium } \\
\text { carbon- } \\
\text { ate } \\
(\mathbf{g} / \mathbf{k g})\end{array}$ & $\begin{array}{c}\text { Mag- } \\
\text { nesium } \\
\text { carbon- } \\
\text { ate } \\
(\mathbf{g} / \mathbf{k g})\end{array}$ & $\begin{array}{l}\text { Cal- } \\
\text { cium } \\
\text { (per- } \\
\text { cent) }\end{array}$ & $\begin{array}{c}\text { Calcium } \\
\text { carbon- } \\
\text { ate } \\
\text { (per- } \\
\text { cent) }\end{array}$ & $\begin{array}{c}\text { Mag- } \\
\text { nesium } \\
\text { carbon- } \\
\text { ate } \\
\text { (percent) }\end{array}$ \\
\hline \multicolumn{19}{|c|}{ *Elemental analysis after hydrochloric acid (6N HCl, cold) leach } \\
\hline TX 175A & 390 & 9.2 & 540 & 400 & 462 & 230 & 200 & 3,800 & 0.19 & 1.3 & -- & $<0.5$ & 290 & 724 & 13.2 & 29.0 & 72.4 & 1.32 \\
\hline TX 175B & 330 & 8.6 & 490 & 340 & 430 & 190 & 180 & 3,300 & .15 & 1.2 & -- & $<.5$ & 303 & 757 & 11.5 & 30.3 & 75.7 & 1.15 \\
\hline TX 175C & 290 & 7.9 & 450 & 300 & 390 & 180 & 160 & 2,800 & .17 & 1.4 & -- & $<.5$ & 308 & 769 & 9.72 & 30.8 & 76.9 & .97 \\
\hline TX 209 & 1,100 & 17 & 4,700 & 880 & 120 & 160 & 450 & 1,000 & .48 & 2.2 & -- & $<.5$ & 112 & 280 & 3.47 & 11.2 & 28.0 & .35 \\
\hline TX 260 & 200 & 4.2 & 470 & 210 & 660 & 110 & 170 & 1,900 & $<.05$ & .7 & -- & $<.5$ & 350 & 874 & 6.59 & 35.0 & 87.4 & .66 \\
\hline TX 314A & 1,400 & 56 & 8,300 & 690 & 410 & 130 & 360 & 1,200 & 7.31 & .9 & -- & $<.5$ & 158 & 395 & 4.16 & 15.8 & 39.5 & .42 \\
\hline TX 314B & 1,600 & 48 & 9,300 & 830 & 400 & 140 & 410 & 1,200 & 7.74 & .9 & -- & $<.5$ & 156 & 390 & 4.16 & 15.6 & 39.0 & .42 \\
\hline TX 314C & 1,300 & 46 & 7,500 & 710 & 360 & 110 & 410 & 1,300 & 7.46 & .9 & -- & $<.5$ & 162 & 405 & 4.51 & 16.2 & 40.5 & .45 \\
\hline TX 444 & 34 & 1.3 & $<20$ & 41 & 17 & 270 & 33 & 40,000 & $<.05$ & .3 & -- & $<.5$ & 109 & 272 & 139 & 10.9 & 27.2 & 13.9 \\
\hline TX 526 & 300 & 4.4 & 600 & 330 & 21 & 150 & 200 & 5,200 & .47 & 1.3 & -- & $<.5$ & 260 & 649 & 18.0 & 26.0 & 64.9 & 1.80 \\
\hline TX 550A & 35 & 1.4 & 110 & 16 & 15 & 47 & 140 & 1,100 & .13 & 1.7 & -- & $<.5$ & 345 & 861 & 3.82 & 34.5 & 86.1 & .38 \\
\hline TX 550B & 64 & 1.5 & 110 & 13 & 27 & 50 & 130 & 1,100 & .11 & 1.3 & -- & $<.5$ & 275 & 687 & 3.82 & 27.5 & 68.7 & .38 \\
\hline TX 550C & 35 & 1.5 & 120 & 16 & 15 & 48 & 100 & 1,100 & .12 & 1.6 & -- & $<.5$ & 335 & 836 & 3.82 & 33.5 & 83.6 & .38 \\
\hline TX 589 & 36 & 2.4 & 130 & 14 & 13 & 41 & 84 & 15,000 & $<.05$ & .8 & -- & $<.5$ & 333 & 832 & 52.1 & 33.3 & 83.2 & 5.21 \\
\hline \multicolumn{19}{|c|}{${ }^{*}$ Elemental analysis after nitric acid $\left(10 \% \mathrm{HNO}_{3}\right)$ leach } \\
\hline TX 175A & 54 & 5.2 & 140 & 94 & 240 & 120 & 130 & 2,200 & .05 & .2 & 1.1 & .10 & 150 & 375 & 7.63 & 15.0 & 37.5 & .76 \\
\hline TX 175B & 59 & 4.3 & 170 & 79 & 200 & 90 & 120 & 2,100 & .04 & .2 & 1.0 & .13 & 164 & 410 & 7.29 & 16.4 & 41.0 & .73 \\
\hline TX 175C & 43 & 4.3 & 180 & 75 & 190 & 100 & 75 & 2,100 & .06 & .3 & .9 & .13 & 163 & 407 & 7.29 & 16.3 & 40.7 & .73 \\
\hline TX 209 & 360 & 12 & 670 & 390 & 100 & 140 & 150 & 820 & 2.80 & 1.3 & 7.9 & .75 & 96 & 240 & 2.85 & 9.60 & 24.0 & .28 \\
\hline TX 260 & 31 & 2.4 & 140 & 52 & 340 & 44 & 44 & 1,700 & .09 & 1.5 & 22 & $<.1$ & 166 & 415 & 5.90 & 16.6 & 41.5 & .59 \\
\hline TX 314A & 380 & 27 & 740 & 330 & 290 & 110 & 160 & 1,000 & 1.70 & .4 & 2.4 & $<.1$ & 157 & 392 & 3.47 & 15.7 & 39.2 & .35 \\
\hline TX 314B & 420 & 33 & 740 & 370 & 330 & 120 & 200 & 1,000 & 1.60 & .4 & 1.6 & .25 & 153 & 382 & 3.47 & 15.3 & 38.2 & .35 \\
\hline TX 314C & 420 & 34 & 680 & 360 & 330 & 120 & 180 & 1,100 & 1.60 & .4 & 1.4 & $<.1$ & 155 & 387 & 3.82 & 15.5 & 38.7 & .38 \\
\hline TX 444 & $<20$ & .3 & $<20$ & $<5$ & $<5$ & 35 & $<20$ & 5,900 & .01 & .1 & 9.9 & $<.1$ & 15 & 37 & 20.5 & 1.50 & 3.75 & 2.05 \\
\hline TX 526 & 65 & 2.8 & 200 & 98 & 10 & 68 & 180 & 2,900 & .18 & .4 & 2.4 & $<.1$ & 150 & 375 & 10.1 & 15.0 & 37.5 & 1.01 \\
\hline TX 550A & $<20$ & 1.0 & $<20$ & 12 & 7 & 12 & 30 & 540 & .06 & .3 & 1.7 & $<.1$ & 173 & 432 & 1.87 & 17.3 & 43.2 & .19 \\
\hline TX 550B & $<20$ & 1.0 & $<20$ & 12 & 8 & 13 & 40 & 540 & $<.01$ & .2 & 1.3 & $<.1$ & 161 & 402 & 1.87 & 16.1 & 40.2 & .19 \\
\hline TX 550C & $<20$ & 1.1 & $<20$ & 11 & 8 & 13 & 30 & 560 & $<.01$ & .6 & 1.2 & $<.1$ & 168 & 419 & 1.94 & 16.8 & 41.9 & .19 \\
\hline TX 589 & $<20$ & 2.1 & $<20$ & 13 & 8 & 21 & 29 & 7,400 & .01 & $<.1$ & .1 & $<.1$ & 139 & 347 & 25.7 & 13.9 & 34.7 & 2.57 \\
\hline
\end{tabular}

Elemental analyses are based on leaches, not complete dissolution of samples (residue remaining after leach for most samples). 


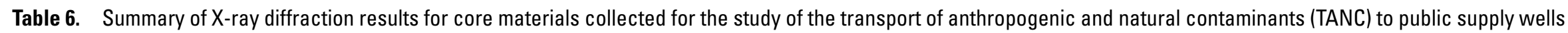
in the San Antonio segment of the Edwards aquifer near San Antonio, south-central Texas, 2004-9.

[USGS, U.S. Geological Survey; <, less than; mm, millimeter; \%, percent]

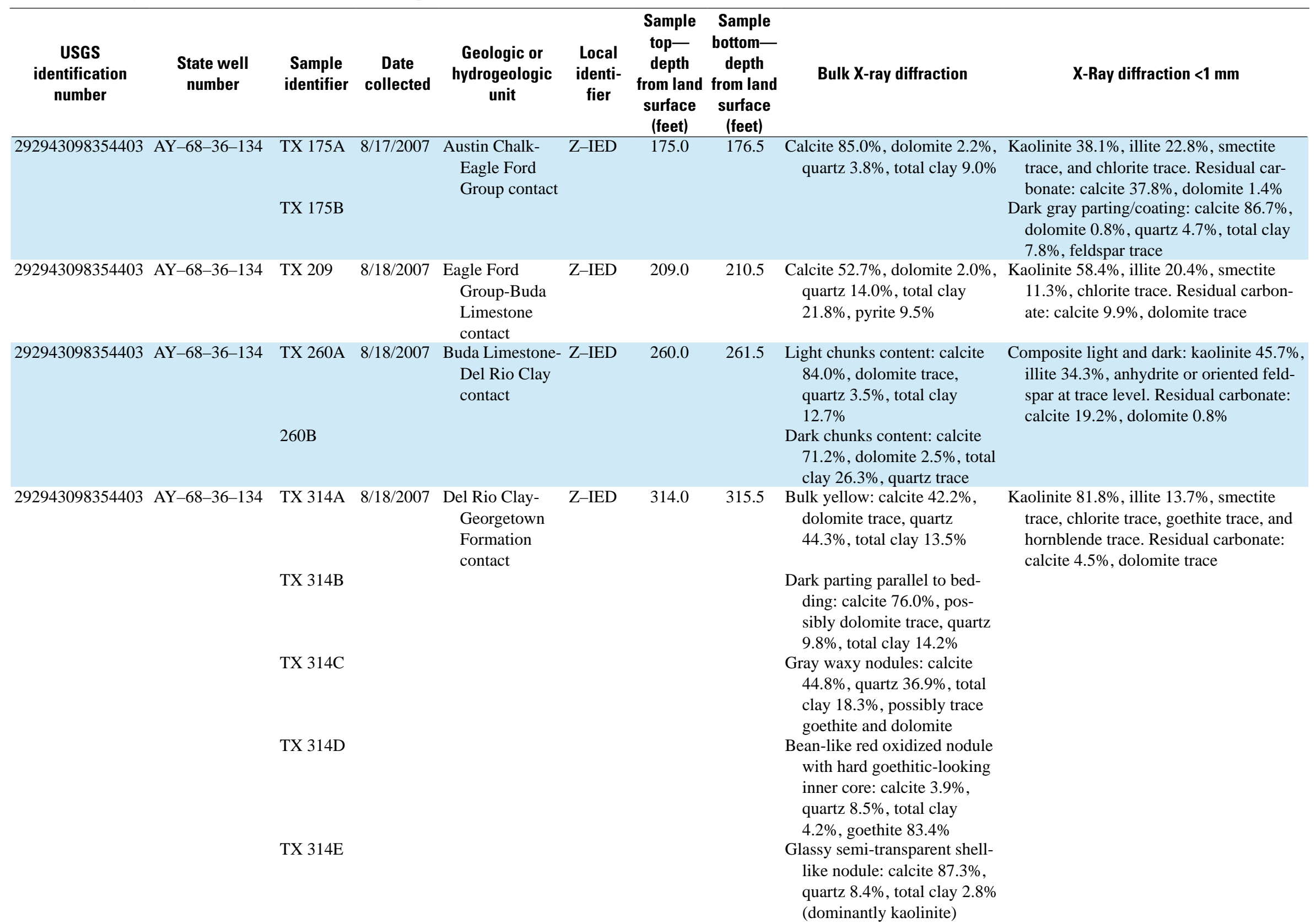


Table 6. Summary of X-ray diffraction results for core materials collected for the study of the transport of anthropogenic and natural contaminants (TANC) to public supply wells in the San Antonio segment of the Edwards aquifer near San Antonio, south-central Texas, 2004-9.-Continued

[USGS, U.S. Geological Survey; <, less than; mm, millimeter; \%, percent]

\begin{tabular}{|c|c|c|c|c|c|c|c|c|c|}
\hline $\begin{array}{c}\text { USGS } \\
\text { identification } \\
\text { number }\end{array}$ & $\begin{array}{l}\text { State well } \\
\text { number }\end{array}$ & $\begin{array}{c}\text { Sample } \\
\text { identifier }\end{array}$ & $\begin{array}{l}\text { Date } \\
\text { collected }\end{array}$ & $\begin{array}{l}\text { Geologic or } \\
\text { hydrogeologic } \\
\text { unit }\end{array}$ & $\begin{array}{l}\text { Local } \\
\text { identi- } \\
\text { fier }\end{array}$ & $\begin{array}{l}\text { Sample } \\
\text { top- } \\
\text { depth } \\
\text { from land } \\
\text { surface } \\
\text { (feet) }\end{array}$ & $\begin{array}{l}\text { Sample } \\
\text { bottom- } \\
\text { depth } \\
\text { from land } \\
\text { surface } \\
\text { (feet) }\end{array}$ & Bulk X-ray diffraction & $X$-Ray diffraction $<1 \mathrm{~mm}$ \\
\hline 292943098354403 & AY-68-36-134 & TX 444B & $8 / 24 / 2007$ & $\begin{array}{l}\text { Leached and } \\
\text { collapsed } \\
\text { members, } \\
\text { undivided }\end{array}$ & Z-IED & 444.0 & 446.0 & $\begin{array}{l}\text { Calcite } 52.4 \% \text {, dolomite } \\
31.5 \% \text {, total clay } 11.2 \% \text {, } \\
\text { and quartz } 4.5 \%\end{array}$ & $\begin{array}{l}\text { Re-digestion; residual carbonate: calcite } \\
52.4 \% \text {, dolomite } 31.5 \% \text {, with traces of } \\
\text { kaolinite } 9.5 \% \text {, illite } 6.9 \% \text {, smectite, } \\
\text { and chlorite } \\
\text { Residual carbonate: dolomite } 76.1 \% \text {, ka- } \\
\text { olinite } 19.2 \% \text {, illite } 5.0 \% \text {, and smectite } \\
\text { and chlorite traces }\end{array}$ \\
\hline 292943098354404 & AY-68-36-132 & TX 526 & 8/13/2007 & $\begin{array}{l}\text { Regional dense } \\
\text { member- } \\
\text { grainstone } \\
\text { member } \\
\text { contact }\end{array}$ & Z-DED & 525.0 & 526.0 & $\begin{array}{l}\text { Calcite } 73.8 \% \text {, dolomite } 2.1 \% \text {, } \\
\text { quartz } 6.5 \% \text {, total clay } \\
\text { 8.3\%, pyrite } 9.4 \%\end{array}$ & $\begin{array}{l}\text { Kaolinite } 50.5 \% \text {, illite } 20.6 \% \text {, smectite } \\
\text { (poorly expandable) trace, chlorite } \\
\text { trace, and hornblende trace. Residual } \\
\text { carbonate: calcite } 27.2 \% \text {, dolomite } 1.6 \%\end{array}$ \\
\hline \multirow[t]{2}{*}{292943098354404} & AY-68-36-132 & TX 550A & $8 / 14 / 2007$ & $\begin{array}{r}\text { Grainstone } \\
\text { member }\end{array}$ & Z-DED & 550.0 & 551.0 & $\begin{array}{l}\text { Calcite } 96.5 \% \text {, dolomite trace, } \\
\text { total clay } 3.2 \%\end{array}$ & $\begin{array}{l}\text { Calcite dilutes trace amounts of clay. Re- } \\
\text { digestion: kaolinite } 14.1 \% \text {, illite } 2.2 \% \text {. } \\
\text { Residual carbonate: calcite } 82.9 \% \text {, } \\
\text { dolomite } 0.9 \%\end{array}$ \\
\hline & & TX 550B & & & & & & & $\begin{array}{l}\text { Kaolinite } 35.8 \% \text {, illite } 3.5 \% \text {, smectite } \\
\text { trace. Calcite dominates the scan. Resid- } \\
\text { ual carbonate: calcite } 58.9 \% \text {, dolomite } \\
0.9 \%\end{array}$ \\
\hline \multirow[t]{4}{*}{292943098354404} & AY-68-36-132 & TX 589A & 8/14/2007 & $\begin{array}{l}\text { Kirschberg evap- } \\
\text { orite member } \\
\text { (fragments) }\end{array}$ & Z-DED & 589.0 & 591.0 & $\begin{array}{l}\text { Calcite } 94.3 \% \text {, dolomite } 2.5 \% \text {, } \\
\text { total clay } 3.2 \%\end{array}$ & $\begin{array}{l}\text { Re-digestion (too much calcite). Traces of } \\
\text { kaolinite } 4.4 \% \text {, illite } 0.4 \% \text {, and smec- } \\
\text { tite. Residual carbonate: calcite } 87.6 \% \text {, } \\
\text { dolomite } 7.5 \% \\
\text { Re-digestion: kaolinite } 17.8 \% \text {, illite } 0.7 \% \text {, } \\
\text { smectite trace. Residual carbonate: } \\
\text { calcite } 2.9 \% \text {, dolomite } 78.6 \%\end{array}$ \\
\hline & & TX 589B & & & & & & & $\begin{array}{l}\text { Dense yellow chunk: calcite } 99.9 \% \text {, } \\
\text { traces of quartz, total clay, and possibly } \\
\text { goethite. No weight percent calculation } \\
\text { because of high calcite content. Princi- } \\
\text { pal peaks for trace minerals too close to } \\
\text { background. }\end{array}$ \\
\hline & & TX 589C & & & & & & & $\begin{array}{l}\text { Clear crystals in deep vug: calcite } 64.0 \% \text {, } \\
\text { dolomite } 25.8 \% \text {, total clay } 10.1 \%\end{array}$ \\
\hline & & TX 589D & & & & & & & $\begin{array}{l}\text { Red crystals in shallow vug: calcite } \\
87.9 \% \text {, dolomite } 0.9 \% \text {, traces of total } \\
\text { clay } 11.3 \% \text { (slightly more clay than } \\
\text { sample TX 589C) }\end{array}$ \\
\hline
\end{tabular}


Table 7. Physicochemical measurements for groundwater samples collected for the study of the transport of anthropogenic and natural contaminants (TANC) to public supply wells in the San Antonio segment of the Edwards aquifer near San Antonio, south-central Texas, 2004-9.

[By sample category. USGS, U.S. Geological Survey; PSW, public-supply well; ft, feet; NTRU, nephelometric turbidity ratiometric unit; mmHg, millimeters of mercury; $\mathrm{mg} / \mathrm{L}$, milligrams per liter; $\mu \mathrm{S} / \mathrm{cm}$, microsiemens per centimeter; ${ }^{\circ} \mathrm{C}$, degrees Celsius; $\mathrm{CaCO}_{3}$, calcium carbonate; --, not measured; E, estimated; $\mathrm{MW}$, monitoring well; OVB, overburden]

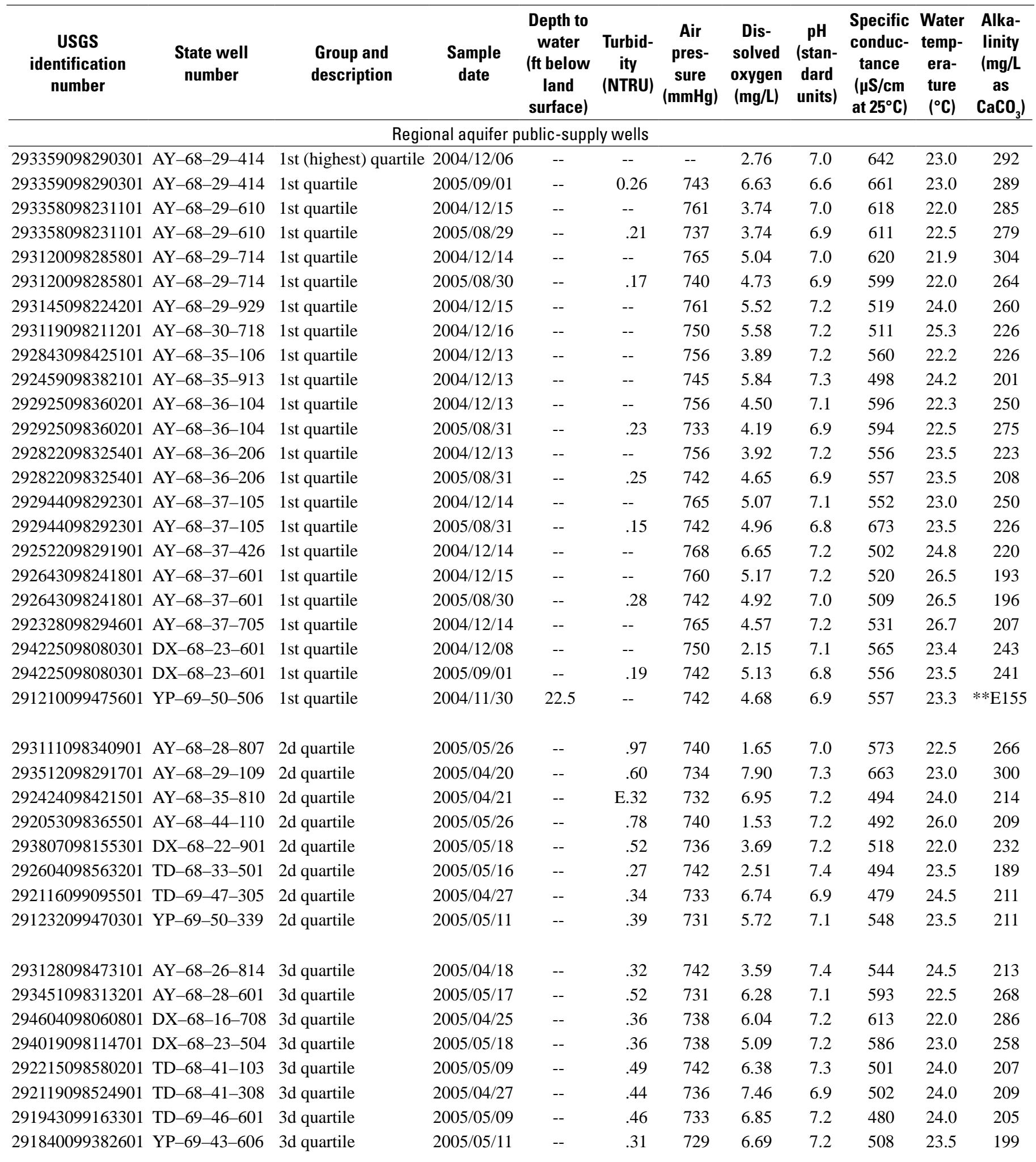


Table 7. Physicochemical measurements for groundwater samples collected for the study of the transport of anthropogenic and natural contaminants (TANC) to public supply wells in the San Antonio segment of the Edwards aquifer near San Antonio, south-central Texas, 2004-9.-Continued

[By sample category. USGS, U.S. Geological Survey; PSW, public-supply well; ft, feet; NTRU, nephelometric turbidity ratiometric unit; mmHg, millimeters of mercury; $\mathrm{mg} / \mathrm{L}$, milligrams per liter; $\mu \mathrm{S} / \mathrm{cm}$, microsiemens per centimeter; ${ }^{\circ} \mathrm{C}$, degrees Celsius; $\mathrm{CaCO}_{3}$, calcium carbonate; --, not measured; E, estimated; $\mathrm{MW}$, monitoring well; OVB, overburden]

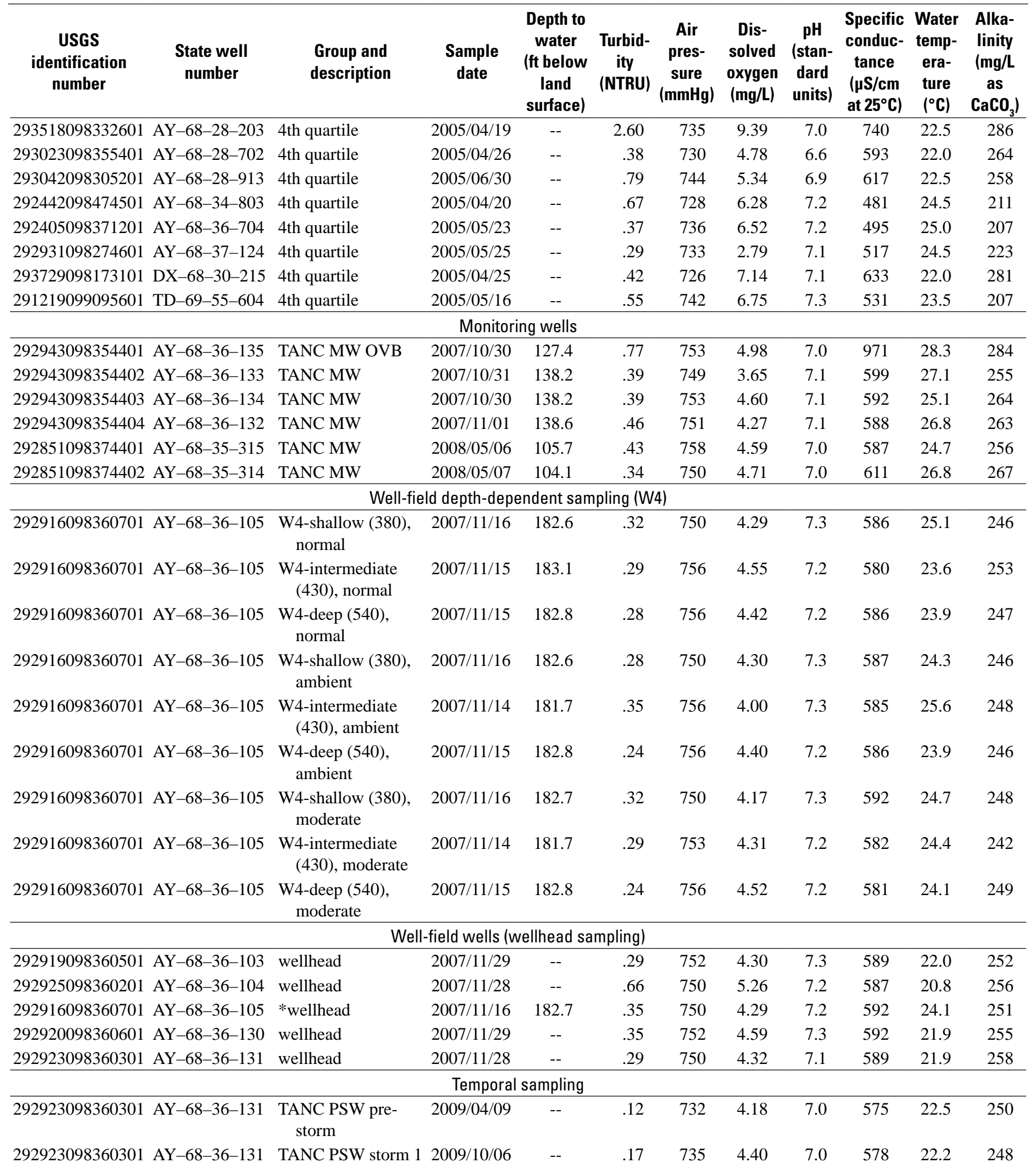


Table 7. Physicochemical measurements for groundwater samples collected for the study of the transport of anthropogenic and natural contaminants (TANC) to public supply wells in the San Antonio segment of the Edwards aquifer near San Antonio, south-central Texas, 2004-9.-Continued

[By sample category. USGS, U.S. Geological Survey; PSW, public-supply well; ft, feet; NTRU, nephelometric turbidity ratiometric unit; mmHg, millimeters of mercury; $\mathrm{mg} / \mathrm{L}$, milligrams per liter; $\mu \mathrm{S} / \mathrm{cm}$, microsiemens per centimeter; ${ }^{\circ} \mathrm{C}$, degrees Celsius; $\mathrm{CaCO}_{3}$, calcium carbonate; --, not measured; E, estimated; $\mathrm{MW}$, monitoring well; OVB, overburden]

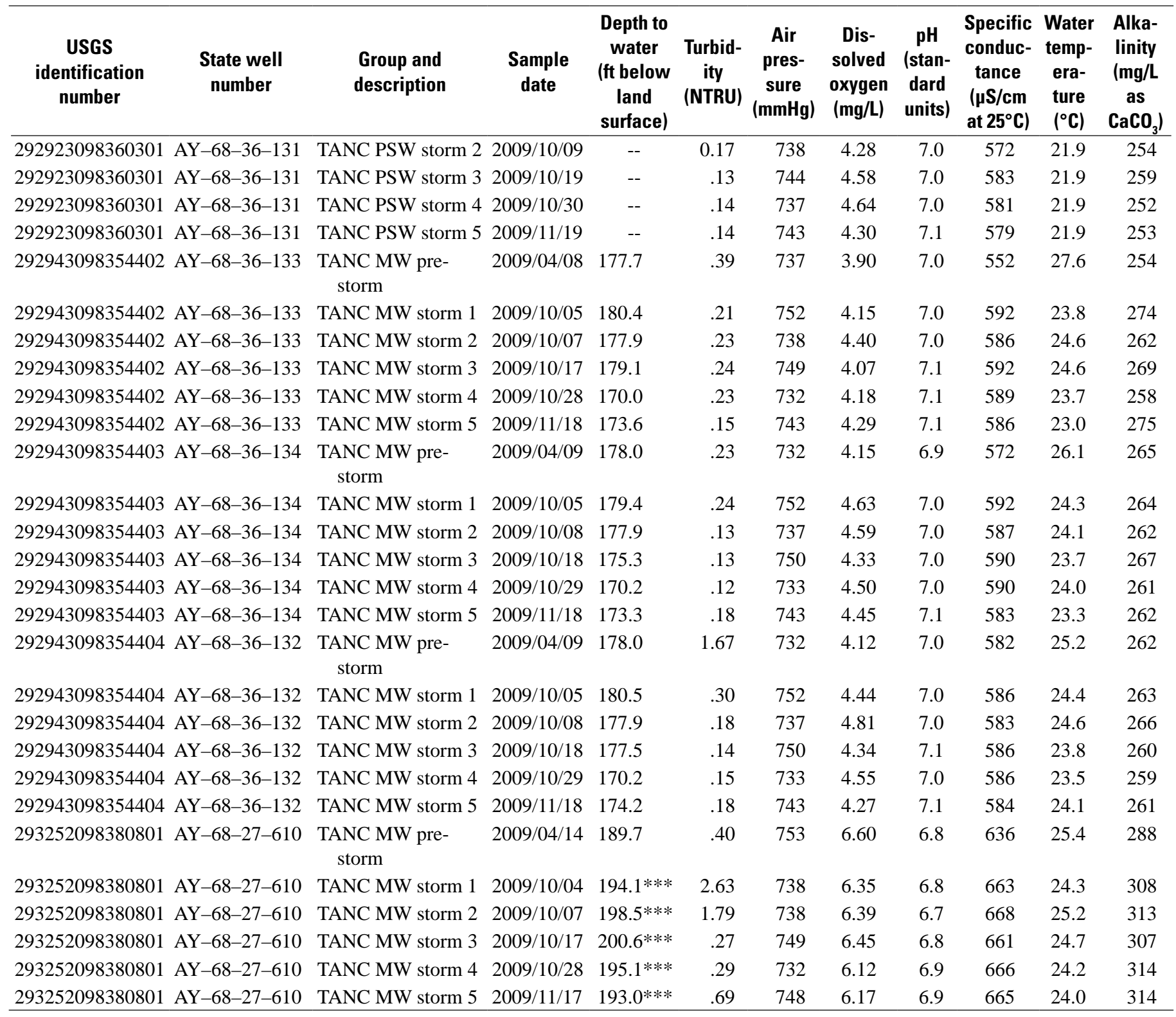

* Sample collected from top of open interval during depth-dependent sampling.

** Alkalinity is low and considered suspect.

*** Data from Edwards Aquifer Authority. 
Table 8. Dissolved solids and major ion measurements for groundwater samples collected for the study of the transport of anthropogenic and natural contaminants (TANC) to public supply wells in the San Antonio segment of the Edwards aquifer near San Antonio, south-central Texas, 2004-9.

[By sample category. USGS, U.S. Geological Survey; MW, monitoring well; OVB, overburden; PSW, public-supply well; mg/L, milligrams per liter; ${ }^{\circ} \mathrm{C}$, degrees Celsius; --, not measured; E, estimated; <, nondetection less than laboratory method reporting level]

\begin{tabular}{|c|c|c|c|c|c|c|c|}
\hline $\begin{array}{c}\text { USGS } \\
\text { identification } \\
\text { number }\end{array}$ & $\begin{array}{c}\text { State well } \\
\text { number }\end{array}$ & $\begin{array}{l}\text { Group and } \\
\text { description }\end{array}$ & $\begin{array}{c}\text { Sample } \\
\text { date }\end{array}$ & $\begin{array}{c}\text { Dissolved solids } \\
\text { (residue on evapora- } \\
\left.\text { tion, dried at } 180^{\circ} \mathrm{C}\right) \\
(\mathrm{mg} / \mathrm{L})\end{array}$ & $\begin{array}{c}\text { Calcium } \\
\text { (mg/L) }\end{array}$ & $\begin{array}{l}\text { Magnesium } \\
(\mathrm{mg} / \mathrm{L})\end{array}$ & $\begin{array}{l}\text { Potassium } \\
\text { (mg/L) }\end{array}$ \\
\hline \multicolumn{8}{|c|}{ Regional aquifer public-supply wells } \\
\hline 293359098290301 & AY-68-29-414 & 1st (highest) quartile & $2004 / 12 / 06$ & 362 & 110 & 12.5 & 1.25 \\
\hline 293359098290301 & AY-68-29-414 & 1st quartile & $2005 / 09 / 01$ & -- & -- & -- & -- \\
\hline 293358098231101 & AY-68-29-610 & 1st quartile & $2004 / 12 / 15$ & 360 & 106 & 13.3 & 2.59 \\
\hline 293358098231101 & AY-68-29-610 & 1st quartile & $2005 / 08 / 29$ & -- & -- & -- & -- \\
\hline 293120098285801 & AY-68-29-714 & 1st quartile & $2004 / 12 / 14$ & 352 & 105 & 13.9 & 1.41 \\
\hline 293120098285801 & AY-68-29-714 & 1st quartile & $2005 / 08 / 30$ & -- & -- & -- & -- \\
\hline 293145098224201 & AY-68-29-929 & 1st quartile & 2004/12/15 & 296 & 76.6 & 16.4 & 1.44 \\
\hline 293119098211201 & AY-68-30-718 & 1st quartile & $2004 / 12 / 16$ & 284 & 68.8 & 16.6 & 1.26 \\
\hline 292843098425101 & AY-68-35-106 & 1st quartile & $2004 / 12 / 13$ & 313 & 82.0 & 17.3 & 1.32 \\
\hline 292459098382101 & AY-68-35-913 & 1st quartile & 2004/12/13 & 272 & 70.1 & 15.5 & 1.22 \\
\hline 292925098360201 & AY-68-36-104 & 1st quartile & $2004 / 12 / 13$ & 336 & 93.0 & 16.1 & 1.62 \\
\hline 292925098360201 & AY-68-36-104 & 1st quartile & $2005 / 08 / 31$ & -- & -- & -- & -- \\
\hline 292822098325401 & AY-68-36-206 & 1st quartile & $2004 / 12 / 13$ & 315 & 79.9 & 16.8 & 1.47 \\
\hline 292822098325401 & AY-68-36-206 & 1st quartile & $2005 / 08 / 31$ & -- & -- & -- & -- \\
\hline 292944098292301 & AY-68-37-105 & 1st quartile & $2004 / 12 / 14$ & 315 & 80.8 & 16.8 & 1.49 \\
\hline 292944098292301 & AY-68-37-105 & 1st quartile & $2005 / 08 / 31$ & -- & -- & -- & -- \\
\hline 292522098291901 & AY-68-37-426 & 1st quartile & $2004 / 12 / 14$ & 273 & 69.5 & 16.1 & 1.29 \\
\hline 292643098241801 & AY-68-37-601 & 1st quartile & $2004 / 12 / 15$ & 291 & 68.1 & 17.1 & 1.31 \\
\hline 292643098241801 & AY-68-37-601 & 1st quartile & 2005/08/30 & -- & -- & -- & -- \\
\hline 292328098294601 & AY-68-37-705 & 1st quartile & $2004 / 12 / 14$ & 292 & 69.6 & 17.7 & 1.40 \\
\hline 294225098080301 & DX-68-23-601 & 1st quartile & $2004 / 12 / 08$ & 318 & 85.1 & 16.2 & 1.47 \\
\hline 294225098080301 & DX-68-23-601 & 1st quartile & 2005/09/01 & -- & -- & -- & -- \\
\hline 291210099475601 & YP-69-50-506 & 1st quartile & $2004 / 11 / 30$ & 294 & 87.5 & 8.15 & 1.14 \\
\hline 293111098340901 & AY-68-28-807 & 2d quartile & $2005 / 05 / 26$ & 343 & 94.2 & 13.2 & 1.23 \\
\hline 293512098291701 & AY-68-29-109 & 2d quartile & $2005 / 04 / 20$ & 361 & 123 & 9.93 & .79 \\
\hline 292424098421501 & AY-68-35-810 & 2d quartile & $2005 / 04 / 21$ & 279 & 73.4 & 14.3 & 1.19 \\
\hline 292053098365501 & AY-68-44-110 & 2d quartile & $2005 / 05 / 26$ & 278 & 66.4 & 18.2 & 1.19 \\
\hline 293807098155301 & DX-68-22-901 & 2d quartile & $2005 / 05 / 18$ & 299 & 83.6 & 11.1 & .89 \\
\hline 292604098563201 & TD-68-33-501 & 2d quartile & $2005 / 05 / 16$ & 285 & 69.1 & 17.3 & 1.34 \\
\hline 292116099095501 & TD-69-47-305 & 2d quartile & $2005 / 04 / 27$ & 270 & 70.3 & 15.2 & 1.17 \\
\hline 291232099470301 & YP-69-50-339 & 2d quartile & $2005 / 05 / 11$ & 309 & 89.0 & 10.1 & 1.05 \\
\hline 293128098473101 & AY-68-26-814 & 3d quartile & $2005 / 04 / 18$ & 327 & 80.0 & 22.4 & 1.50 \\
\hline 293451098313201 & AY-68-28-601 & 3d quartile & $2005 / 05 / 17$ & 344 & 107 & 8.12 & 1.18 \\
\hline 294604098060801 & DX-68-16-708 & 3d quartile & $2005 / 04 / 25$ & 344 & 109 & 16.1 & 1.18 \\
\hline 294019098114701 & DX-68-23-504 & 3d quartile & $2005 / 05 / 18$ & 332 & 88.0 & 15.9 & 1.40 \\
\hline
\end{tabular}


Table 8. Dissolved solids and major ion measurements for groundwater samples collected for the study of the transport of anthropogenic and natural contaminants (TANC) to public supply wells in the San Antonio segment of the Edwards aquifer near San Antonio, south-central Texas, 2004-9.-Continued

[By sample category. USGS, U.S. Geological Survey; MW, monitoring well; OVB, overburden; PSW, public-supply well; mg/L, milligrams per liter; ${ }^{\circ} \mathrm{C}$, degrees Celsius; --, not measured; E, estimated; <, nondetection less than laboratory method reporting level]

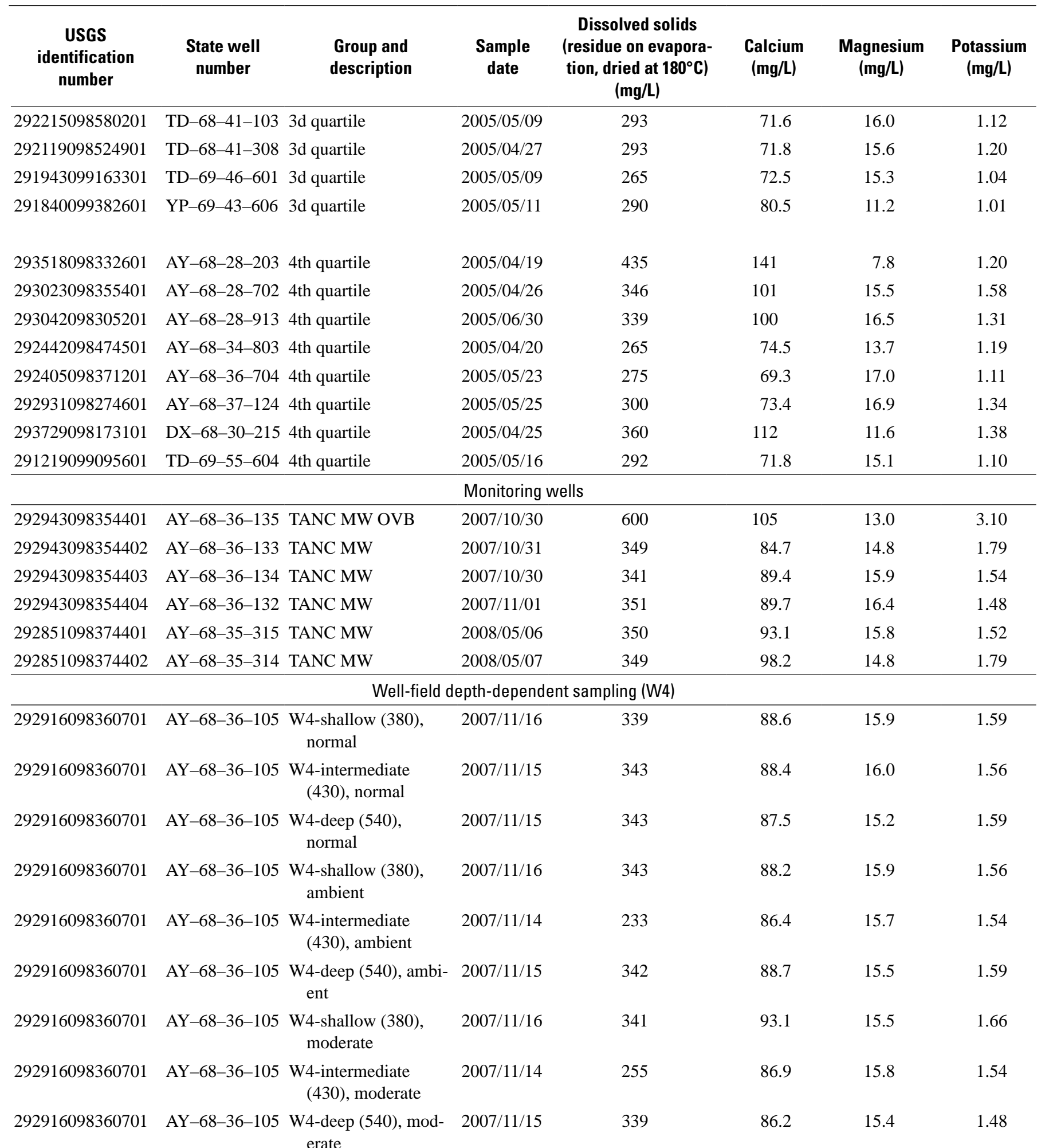


Table 8. Dissolved solids and major ion measurements for groundwater samples collected for the study of the transport of anthropogenic and natural contaminants (TANC) to public supply wells in the San Antonio segment of the Edwards aquifer near San Antonio, south-central Texas, 2004-9.-Continued

[By sample category. USGS, U.S. Geological Survey; MW, monitoring well; OVB, overburden; PSW, public-supply well; mg/L, milligrams per liter; ${ }^{\circ} \mathrm{C}$, degrees Celsius; --, not measured; E, estimated; <, nondetection less than laboratory method reporting level]

\begin{tabular}{|c|c|c|c|c|c|c|}
\hline $\begin{array}{c}\text { USGS } \\
\text { identification } \\
\text { number }\end{array}$ & $\begin{array}{l}\text { Group and } \\
\text { description }\end{array}$ & $\begin{array}{l}\text { Sample } \\
\text { date }\end{array}$ & $\begin{array}{c}\text { Dissolved solids } \\
\text { (residue on evapora- } \\
\text { tion, dried at } 180^{\circ} \mathrm{C} \text { ) } \\
\text { (mg/L) }\end{array}$ & $\begin{array}{c}\text { Calcium } \\
\text { (mg/L) }\end{array}$ & $\begin{array}{c}\text { Magnesium } \\
\text { (mg/L) }\end{array}$ & $\begin{array}{l}\text { Potassium } \\
\text { (mg/L) }\end{array}$ \\
\hline \multicolumn{7}{|c|}{ Well-field wells (wellhead sampling) } \\
\hline 292919098360501 & AY-68-36-103 wellhead & $2007 / 11 / 29$ & 346 & 95.8 & 15.5 & 1.72 \\
\hline 292920098360601 & AY-68-36-130 wellhead & $2007 / 11 / 29$ & 350 & 95.0 & 14.9 & 1.57 \\
\hline 292923098360301 & AY-68-36-131 wellhead & $2007 / 11 / 28$ & 357 & 94.0 & 15.4 & 1.59 \\
\hline \multicolumn{7}{|c|}{ Temporal sampling } \\
\hline 292923098360301 & AY-68-36-131 TANC PSW pre-storm & 2009/04/09 & 342 & 87.7 & 15.0 & 1.47 \\
\hline 292923098360301 & AY-68-36-131 TANC PSW storm 4 & 2009/10/30 & 340 & 90.9 & 16.3 & 1.47 \\
\hline 292923098360301 & AY-68-36-131 TANC PSW storm 5 & 2009/11/19 & 350 & 90.9 & 16.1 & 1.51 \\
\hline 292943098354402 & AY-68-36-133 TANC MW pre-storm & 2009/04/08 & 348 & 93.6 & 16.0 & 1.61 \\
\hline 292943098354402 & AY-68-36-133 TANC MW storm 1 & 2009/10/05 & 342 & 91.5 & 15.8 & 1.50 \\
\hline 292943098354402 & AY-68-36-133 TANC MW storm 2 & 2009/10/07 & 338 & 90.0 & 15.5 & 1.45 \\
\hline 292943098354402 & AY-68-36-133 TANC MW storm 3 & 2009/10/17 & 364 & 93.8 & 15.7 & 1.47 \\
\hline 292943098354402 & AY-68-36-133 TANC MW storm 4 & $2009 / 10 / 28$ & 344 & 94.7 & 16.3 & 1.51 \\
\hline 292943098354402 & AY-68-36-133 TANC MW storm 5 & 2009/11/18 & 351 & 93.4 & 15.7 & 1.47 \\
\hline 292943098354403 & AY-68-36-134 TANC MW pre-storm & 2009/04/09 & 345 & 92.9 & 14.8 & 1.43 \\
\hline 292943098354404 & AY-68-36-132 TANC MW storm 1 & 2009/10/05 & 341 & 87.9 & 16.2 & 1.41 \\
\hline 292943098354404 & AY-68-36-132 TANC MW storm 2 & 2009/10/08 & 334 & 86.5 & 16.4 & 1.43 \\
\hline 292943098354404 & AY-68-36-132 TANC MW storm 3 & 2009/10/18 & 412 & 92.7 & 16.7 & 1.41 \\
\hline 292943098354404 & AY-68-36-132 TANC MW storm 4 & 2009/10/29 & 348 & 93.2 & 17.2 & 1.47 \\
\hline 292943098354404 & AY-68-36-132 TANC MW storm 5 & 2009/11/18 & 344 & 91.2 & 16.5 & 1.47 \\
\hline 293252098380801 & AY-68-27-610 TANC MW pre-storm & 2009/04/14 & 370 & 104 & 13.3 & .98 \\
\hline 293252098380801 & AY-68-27-610 TANC MW storm 1 & 2009/10/04 & 386 & 115 & 13.8 & .95 \\
\hline 293252098380801 & AY-68-27-610 TANC MW storm 2 & 2009/10/07 & 379 & 115 & 13.6 & .91 \\
\hline 293252098380801 & AY-68-27-610 TANC MW storm 3 & 2009/10/17 & 408 & 115 & 13.5 & .95 \\
\hline 293252098380801 & AY-68-27-610 TANC MW storm 4 & $2009 / 10 / 28$ & 388 & 118 & 13.8 & .96 \\
\hline 293252098380801 & AY-68-27-610 TANC MW storm 5 & 2009/11/17 & 386 & 111 & 13.4 & .92 \\
\hline
\end{tabular}


Table 8. Dissolved solids and major ion measurements for groundwater samples collected for the study of the transport of anthropogenic and natural contaminants (TANC) to public supply wells in the San Antonio segment of the Edwards aquifer near San Antonio, south-central Texas, 2004-9.-Continued

[By sample category. USGS, U.S. Geological Survey; MW, monitoring well; OVB, overburden; PSW, public-supply well; mg/L, milligrams per liter; ${ }^{\circ} \mathrm{C}$, degrees Celsius; --, not measured; E, estimated; <, nondetection less than laboratory method reporting level]

\begin{tabular}{|c|c|c|c|c|c|c|c|c|c|c|}
\hline $\begin{array}{c}\text { USGS } \\
\text { identification } \\
\text { number }\end{array}$ & $\begin{array}{l}\text { Sodium } \\
\text { (mg/L) }\end{array}$ & $\begin{array}{c}\text { Bromide } \\
\text { (mg/L) }\end{array}$ & $\begin{array}{c}\text { Chloride } \\
\text { (mg/L) }\end{array}$ & $\begin{array}{c}\text { Fluoride } \\
\text { (mg/L) }\end{array}$ & $\begin{array}{l}\text { lodide } \\
\text { (mg/L) }\end{array}$ & $\begin{array}{l}\text { Sulfate } \\
\text { (mg/L) }\end{array}$ & $\begin{array}{l}\text { Silica } \\
\text { (mg/L) }\end{array}$ & $\begin{array}{c}\text { Calcite, } \\
\text { mineral } \\
\text { saturation } \\
\text { index }\end{array}$ & $\begin{array}{l}\text { Dolomite, } \\
\text { mineral } \\
\text { saturation } \\
\text { index }\end{array}$ & $\begin{array}{c}\text { Gypsum, } \\
\text { mineral } \\
\text { saturation } \\
\text { index }\end{array}$ \\
\hline \multicolumn{11}{|c|}{ Regional aquifer public-supply wells } \\
\hline 293359098290301 & 11.7 & E0.20 & 18.3 & 0.21 & 0.003 & 16.2 & 14.4 & 0.11 & -0.13 & -2.38 \\
\hline 293359098290301 & -- & -- & -- & -- & -- & -- & -- & -- & -- & -- \\
\hline 293358098231101 & -- & -- & -- & -- & -- & -- & -- & -- & -- & -- \\
\hline 293120098285801 & 9.85 & .15 & 15.0 & .22 & .002 & 3.9 & 12.6 & .02 & -.53 & -1.97 \\
\hline 293120098285801 & -- & -- & -- & -- & -- & -- & -- & -- & -- & -- \\
\hline 293145098224201 & 10.4 & .15 & 16.6 & .24 & .002 & 22.1 & 14.0 & .07 & -.19 & -2.22 \\
\hline 292925098360201 & 10.4 & .15 & 15.6 & .27 & E.001 & 28.1 & 13.5 & .01 & -.43 & -2.05 \\
\hline 292925098360201 & -- & -- & -- & -- & -- & -- & -- & -- & -- & -- \\
\hline 292822098325401 & 10.6 & .13 & 16.3 & .25 & .002 & 32.3 & 13.9 & .01 & -.34 & -2.04 \\
\hline 292822098325401 & -- & -- & -- & -- & -- & -- & -- & -- & -- & -- \\
\hline 292944098292301 & 10.9 & .15 & 16.3 & .23 & .002 & 29.2 & 14.1 & -.00 & -.36 & -2.08 \\
\hline 292944098292301 & -- & -- & -- & -- & -- & -- & -- & -- & -- & -- \\
\hline 292522098291901 & 10.7 & .14 & 21.0 & .23 & .002 & 16.6 & 13.4 & .02 & -.28 & -2.37 \\
\hline 292643098241801 & 11.3 & .15 & 23.6 & .33 & .002 & 24.2 & 13.5 & -.00 & -.24 & -2.22 \\
\hline 292643098241801 & -- & -- & -- & -- & -- & -- & -- & -- & -- & -- \\
\hline 293512098291701 & 12.4 & .10 & 26.5 & .15 & $<.002$ & 1.7 & 14.7 & .04 & -.31 & -2.31 \\
\hline 292424098421501 & 9.46 & .081 & 16.8 & .22 & $<.002$ & 16.6 & 13.4 & .04 & -.29 & -2.34 \\
\hline 292053098365501 & 10.1 & .090 & 20.9 & .28 & $<.002$ & 15.5 & 13.3 & -.07 & -.33 & -2.42 \\
\hline 293807098155301 & 6.21 & .090 & 10.5 & .15 & E.002 & 13.6 & 11.3 & .01 & -.54 & -2.37 \\
\hline 292604098563201 & 7.10 & .085 & 10.8 & .21 & $<.002$ & 4.8 & 12.6 & .12 & -.03 & -1.98 \\
\hline 292116099095501 & 8.13 & .071 & 12.7 & .24 & $<.002$ & 16.9 & 13.6 & -.28 & -.88 & -2.35 \\
\hline 291232099470301 & 13.9 & .11 & 26.9 & .12 & $<.002$ & 14.4 & 13.6 & -.00 & -.62 & -2.33 \\
\hline 293128098473101 & 7.86 & .075 & 14.0 & .37 & E.001 & 56.0 & 13.1 & .24 & .26 & -1.82 \\
\hline 293451098313201 & 8.42 & .10 & 14.6 & .16 & E.001 & 15.2 & 13.7 & .11 & -.59 & -2.25 \\
\hline 294604098060801 & 7.91 & .069 & 13.3 & .20 & $<.002$ & 15.2 & 13.3 & .25 & -.01 & -2.27 \\
\hline 294019098114701 & 7.91 & .10 & 15.1 & .21 & E.001 & 22.6 & 13.4 & .08 & -.26 & -2.16 \\
\hline
\end{tabular}


Table 8. Dissolved solids and major ion measurements for groundwater samples collected for the study of the transport of anthropogenic and natural contaminants (TANC) to public supply wells in the San Antonio segment of the Edwards aquifer near San Antonio, south-central Texas, 2004-9.-Continued

[By sample category. USGS, U.S. Geological Survey; MW, monitoring well; OVB, overburden; PSW, public-supply well; mg/L, milligrams per liter; ${ }^{\circ} \mathrm{C}$, degrees Celsius; --, not measured; E, estimated; <, nondetection less than laboratory method reporting level]

\begin{tabular}{|c|c|c|c|c|c|c|c|c|c|c|}
\hline $\begin{array}{c}\text { USGS } \\
\text { identification } \\
\text { number }\end{array}$ & $\begin{array}{l}\text { Sodium } \\
\text { (mg/L) }\end{array}$ & $\begin{array}{c}\text { Bromide } \\
\text { (mg/L) }\end{array}$ & $\begin{array}{c}\text { Chloride } \\
\text { (mg/L) }\end{array}$ & $\begin{array}{c}\text { Fluoride } \\
\text { (mg/L) }\end{array}$ & $\begin{array}{l}\text { lodide } \\
\text { (mg/L) }\end{array}$ & $\begin{array}{l}\text { Sulfate } \\
\text { (mg/L) }\end{array}$ & $\begin{array}{l}\text { Silica } \\
\text { (mg/L) }\end{array}$ & $\begin{array}{c}\text { Calcite, } \\
\text { mineral } \\
\text { saturation } \\
\text { index }\end{array}$ & $\begin{array}{c}\text { Dolomite, } \\
\text { mineral } \\
\text { saturation } \\
\text { index }\end{array}$ & $\begin{array}{c}\text { Gypsum, } \\
\text { mineral } \\
\text { saturation } \\
\text { index }\end{array}$ \\
\hline 292215098580201 & 9.56 & 0.086 & 18.6 & 0.21 & $<0.002$ & 16.2 & 13.2 & 0.10 & -0.11 & -2.36 \\
\hline 292119098524901 & 10.7 & .10 & 20.8 & .26 & .002 & 16.5 & 13.2 & -.31 & -.94 & -2.35 \\
\hline 291943099163301 & 7.45 & .070 & 12.0 & .19 & $<.002$ & 17.3 & 13.4 & -.05 & -.44 & -2.33 \\
\hline 291840099382601 & 10.9 & .10 & 21.9 & .13 & $<.002$ & 13.1 & 13.2 & .04 & -.44 & -2.40 \\
\hline 293518098332601 & 20.2 & .14 & 51.8 & .12 & E.002 & 15.8 & 14.2 & .17 & -.60 & -2.17 \\
\hline 293023098355401 & 10.0 & .088 & 15.7 & .26 & E.001 & 24.2 & 13.0 & -.40 & -1.30 & -2.09 \\
\hline 293042098305201 & 10.5 & .10 & 16.1 & .22 & E.001 & 37.4 & 12.4 & -.11 & -.69 & -1.91 \\
\hline 292442098474501 & 8.03 & .037 & 11.9 & .21 & $<.002$ & 17.6 & 13.5 & .04 & -.31 & -2.31 \\
\hline 292405098371201 & 10.3 & .10 & 20.0 & .19 & $<.002$ & 15.9 & 13.2 & -.02 & -.31 & -2.39 \\
\hline 292931098274601 & 10.6 & .086 & 16.1 & .21 & $<.002$ & 22.3 & 13.8 & -.05 & -.40 & -2.22 \\
\hline 293729098173101 & 11.0 & .083 & 20.4 & .18 & E.001 & 12.6 & 14.0 & .19 & -.29 & -2.33 \\
\hline 291219099095601 & 11.6 & .12 & 25.4 & .17 & $<.002$ & 15.7 & 13.1 & .12 & -.03 & -1.98 \\
\hline \multicolumn{11}{|c|}{ Monitoring wells } \\
\hline 292943098354401 & 78.4 & .33 & 97.6 & .86 & .006 & 60.6 & 26.7 & .07 & -.37 & -1.73 \\
\hline 292943098354402 & 13.2 & .10 & 16.5 & .26 & .004 & 27.7 & 11.3 & .06 & -.26 & -2.09 \\
\hline 292943098354403 & 10.7 & .094 & 15.9 & .23 & E.001 & 25.4 & 11.7 & .04 & -.31 & -2.11 \\
\hline 292943098354404 & 9.89 & .10 & 15.5 & .26 & E.001 & 25.0 & 10.9 & .07 & -.24 & -2.12 \\
\hline 292851098374401 & 10.6 & .10 & 15.3 & .22 & E.001 & 28.4 & 11.8 & -.03 & -.48 & -2.05 \\
\hline 292851098374402 & 10.5 & .11 & 15.0 & .22 & E.002 & 26.9 & 12.5 & -.00 & -.46 & -2.06 \\
\hline \multicolumn{11}{|c|}{ Well-field depth-dependent sampling (W4) } \\
\hline 292916098360701 & 10.7 & .095 & 15.6 & .23 & $<.002$ & 29.7 & 12.0 & .23 & .07 & -2.05 \\
\hline 292916098360701 & 10.8 & .10 & 15.6 & .23 & $<.002$ & 29.7 & 11.7 & .11 & -.20 & -2.04 \\
\hline 292916098360701 & 10.9 & .10 & 15.9 & .24 & E.001 & 29.3 & 11.7 & .11 & -.21 & -2.05 \\
\hline 292916098360701 & 10.6 & .10 & 15.6 & .23 & $<.002$ & 29.7 & 11.9 & .23 & .06 & -2.05 \\
\hline 292916098360701 & 10.7 & .10 & 15.5 & .22 & $<.002$ & 29.7 & 12.4 & .19 & -.01 & -2.05 \\
\hline 292916098360701 & 11.0 & .10 & 15.9 & .21 & $<.002$ & 29.2 & 11.9 & .11 & -.20 & -2.05 \\
\hline 292916098360701 & 11.4 & .11 & 16.1 & .23 & E.001 & 29.0 & 12.7 & .24 & .05 & -2.04 \\
\hline 292916098360701 & 10.8 & .10 & 15.4 & .23 & $<.002$ & 29.5 & 12.4 & .15 & -.09 & -2.05 \\
\hline 292916098360701 & 10.4 & .095 & 15.7 & .21 & $<.002$ & 29.8 & 11.8 & .11 & -.19 & -2.05 \\
\hline
\end{tabular}


Table 8. Dissolved solids and major ion measurements for groundwater samples collected for the study of the transport of anthropogenic and natural contaminants (TANC) to public supply wells in the San Antonio segment of the Edwards aquifer near San Antonio, south-central Texas, 2004-9.-Continued

[By sample category. USGS, U.S. Geological Survey; MW, monitoring well; OVB, overburden; PSW, public-supply well; mg/L, milligrams per liter; ${ }^{\circ} \mathrm{C}$, degrees Celsius; --, not measured; E, estimated; <, nondetection less than laboratory method reporting level]

\begin{tabular}{|c|c|c|c|c|c|c|c|c|c|c|}
\hline $\begin{array}{c}\text { USGS } \\
\text { identification } \\
\text { number }\end{array}$ & $\begin{array}{l}\text { Sodium } \\
\text { (mg/L) }\end{array}$ & $\begin{array}{c}\text { Bromide } \\
\text { (mg/L) }\end{array}$ & $\begin{array}{c}\text { Chloride } \\
\text { (mg/L) }\end{array}$ & $\begin{array}{c}\text { Fluoride } \\
\text { (mg/L) }\end{array}$ & $\begin{array}{l}\text { lodide } \\
\text { (mg/L) }\end{array}$ & $\begin{array}{l}\text { Sulfate } \\
\text { (mg/L) }\end{array}$ & $\begin{array}{l}\text { Silica } \\
\text { (mg/L) }\end{array}$ & $\begin{array}{c}\text { Calcite, } \\
\text { mineral } \\
\text { saturation } \\
\text { index }\end{array}$ & $\begin{array}{c}\text { Dolomite, } \\
\text { mineral } \\
\text { saturation } \\
\text { index }\end{array}$ & $\begin{array}{c}\text { Gypsum, } \\
\text { mineral } \\
\text { saturation } \\
\text { index }\end{array}$ \\
\hline \multicolumn{11}{|c|}{ Well-field wells (wellhead sampling) } \\
\hline 292919098360501 & 11.5 & 0.10 & 16.2 & 0.23 & $<0.002$ & 28.8 & 12.4 & 0.18 & -0.11 & -2.03 \\
\hline 292925098360201 & 10.8 & .083 & 15.6 & .24 & $<.002$ & 28.1 & 11.8 & .07 & -.31 & -2.05 \\
\hline 292916098360701 & 11.0 & .10 & 16.2 & .22 & E.001 & 29.0 & 12.3 & .13 & -.18 & -2.05 \\
\hline 292920098360601 & 11.4 & .089 & 16.2 & .22 & $<.002$ & 28.1 & 12.3 & .19 & -.11 & -2.04 \\
\hline 292923098360301 & 11.2 & .091 & 16.2 & .24 & $<.002$ & 27.1 & 12.2 & .07 & -.34 & -2.06 \\
\hline \multicolumn{11}{|c|}{ Temporal sampling } \\
\hline 292923098360301 & 10.3 & .090 & 16.4 & .23 & -- & 29.2 & 12.1 & -.11 & -.67 & -2.05 \\
\hline 292923098360301 & 10.4 & .094 & 16.6 & .24 & -- & 28.4 & 12.7 & -.09 & -.62 & -2.06 \\
\hline 292923098360301 & 10.9 & .10 & 16.1 & .24 & -- & 28.6 & 12.0 & -.10 & -.62 & -2.06 \\
\hline 292923098360301 & 10.6 & .090 & 16.2 & .26 & -- & 27.3 & 12.0 & -.04 & -.53 & -2.06 \\
\hline 292923098360301 & 11.0 & .091 & 16.2 & .25 & -- & 28.2 & 12.1 & -.10 & -.63 & -2.05 \\
\hline 292923098360301 & 10.8 & .086 & 16.3 & .27 & -- & 29.1 & 12.0 & .02 & -.41 & -2.04 \\
\hline 292943098354402 & 11.4 & .16 & 16.2 & .19 & -- & 25.9 & 12.4 & -.04 & -.47 & -2.09 \\
\hline 292943098354402 & 10.5 & .11 & 16.6 & .23 & -- & 25.9 & 12.2 & .01 & -.41 & -2.09 \\
\hline 292943098354402 & 10.5 & .11 & 16.6 & .22 & -- & 26.2 & 11.7 & -.04 & -.51 & -2.09 \\
\hline 292943098354402 & 10.4 & .11 & 16.3 & .24 & -- & 25.9 & 11.8 & .04 & -.35 & -2.09 \\
\hline 292943098354402 & 10.9 & .11 & 16.4 & .22 & -- & 25.6 & 11.8 & .05 & -.34 & -2.09 \\
\hline 292943098354402 & 10.6 & .11 & 16.9 & .20 & -- & 26.9 & 11.8 & .09 & -.28 & -2.07 \\
\hline 292943098354403 & 9.86 & .10 & 16.3 & .23 & -- & 25.9 & 11.6 & -.07 & -.57 & -2.09 \\
\hline 292943098354403 & 10.1 & .10 & 16.6 & .23 & -- & 25.7 & 12.1 & -.04 & -.49 & -2.10 \\
\hline 292943098354403 & 10.4 & .11 & 16.1 & .23 & -- & 25.7 & 11.4 & -.07 & -.55 & -2.11 \\
\hline 292943098354403 & 10.2 & .11 & 16.2 & .24 & -- & 25.6 & 11.8 & .01 & -.43 & -2.09 \\
\hline 292943098354403 & 10.9 & .10 & 16.4 & .26 & -- & 25.4 & 11.9 & -.02 & -.46 & -2.09 \\
\hline 292943098354403 & 10.3 & .10 & 16.4 & .25 & -- & 25.9 & 11.6 & .07 & -.30 & -2.09 \\
\hline 292943098354404 & 10.9 & .14 & 15.7 & .20 & -- & 27.2 & 12.5 & -.03 & -.45 & -2.06 \\
\hline 292943098354404 & 9.39 & .10 & 16.2 & .24 & -- & 25.8 & 11.9 & -.00 & -.40 & -2.11 \\
\hline 292943098354404 & 9.90 & .10 & 15.8 & .25 & -- & 25.9 & 11.2 & -.05 & -.48 & -2.11 \\
\hline 292943098354404 & 9.83 & .10 & 15.7 & .25 & -- & 25.5 & 11.5 & .02 & -.36 & -2.10 \\
\hline 292943098354404 & 10.5 & .10 & 16.0 & .24 & -- & 25.4 & 11.5 & -.02 & -.44 & -2.10 \\
\hline 292943098354404 & 9.89 & .10 & 16.0 & .26 & -- & 26.2 & 11.4 & .09 & -.22 & -2.09 \\
\hline 293252098380801 & 8.83 & .12 & -- & -- & -- & -- & 13.4 & -.08 & -.70 & -- \\
\hline 293252098380801 & 9.45 & .13 & 17.2 & .17 & -- & 13.2 & 13.5 & -.09 & -.77 & -2.31 \\
\hline 293252098380801 & 9.54 & .13 & 16.4 & .16 & -- & 14.7 & 13.0 & -.13 & -.84 & -2.27 \\
\hline 293252098380801 & 9.33 & .13 & 16.9 & .16 & -- & 14.2 & 12.8 & -.05 & -.68 & -2.29 \\
\hline 293252098380801 & 10.2 & .12 & 16.7 & .15 & -- & 14.6 & 13.0 & -.01 & -.61 & -2.27 \\
\hline 293252098380801 & 9.89 & .15 & 18.5 & .13 & -- & 17.9 & 13.0 & .01 & -.57 & -2.19 \\
\hline
\end{tabular}

* Sample collected from top of open interval during depth-dependent sampling. 
Table 9. Trace element measurements for groundwater samples collected for the study of the transport of anthropogenic and natural contaminants (TANC) to public supply wells in the San Antonio segment of the Edwards aquifer near San Antonio, south-central Texas, 2004-9.

[By sample category. USGS, U.S. Geological Survey; MW, monitoring well; OVB, overburden; PSW, public-supply well; $\mu$ g/L, micrograms per liter; --, not measured; E, estimated; $<$, nondetection less than laboratory method reporting level]

\begin{tabular}{|c|c|c|c|c|c|c|c|c|c|c|c|c|}
\hline $\begin{array}{c}\text { USGS } \\
\text { identification } \\
\text { number }\end{array}$ & $\begin{array}{l}\text { State well } \\
\text { number }\end{array}$ & $\begin{array}{l}\text { Group and } \\
\text { description }\end{array}$ & $\begin{array}{c}\text { Sample } \\
\text { date }\end{array}$ & $\begin{array}{c}\text { Alum- } \\
\text { inum } \\
\text { ( } \mu \mathrm{g} / \mathrm{L})\end{array}$ & $\begin{array}{l}\text { Ant- } \\
\text { imony } \\
(\mu \mathrm{g} / \mathrm{L})\end{array}$ & $\begin{array}{c}\text { Ars- } \\
\text { enic } \\
(\mu \mathrm{g} / \mathrm{L})\end{array}$ & $\begin{array}{l}\text { Bar- } \\
\text { ium } \\
(\mu \mathrm{g} / \mathrm{L})\end{array}$ & $\underset{\substack{\text { Bium } \\
(\mu \mathrm{g} / \mathrm{L})}}{\substack{\text { Beryl- } \\
\text { lium }}}$ & $\begin{array}{l}\text { Bo- } \\
\text { ron } \\
(\mu \mathrm{g} / \mathrm{L})\end{array}$ & $\begin{array}{l}\text { Cad- } \\
\text { mium } \\
(\mu \mathrm{g} / \mathrm{L})\end{array}$ & $\begin{array}{l}\text { Chrom- } \\
\text { ium } \\
\text { ( } \mu \mathrm{g} / \mathrm{L})\end{array}$ & $\begin{array}{c}\text { Co- } \\
\text { balt } \\
(\mu \mathrm{g} / \mathrm{L})\end{array}$ \\
\hline
\end{tabular}

Regional aquifer public-supply wells

\begin{tabular}{llll}
\hline 293359098290301 & AY-68-29-414 & 1st (highest) \\
293359098290301 & AY-68-29-414 & 1st quartile \\
293358098231101 & AY-68-29-610 & 1st quartile \\
293358098231101 & AY-68-29-610 & 1st quartile \\
293120098285801 & AY-68-29-714 & 1st quartile \\
293120098285801 & AY-68-29-714 & 1st quartile \\
293145098224201 & AY-68-29-929 & 1st quartile \\
293119098211201 & AY-68-30-718 & 1st quartile \\
292843098425101 & AY-68-35-106 & 1st quartile \\
292459098382101 & AY-68-35-913 & 1st quartile \\
292925098360201 & AY-68-36-104 & 1st quartile \\
292925098360201 & AY-68-36-104 & 1st quartile \\
292822098325401 & AY-68-36-206 & 1st quartile \\
292822098325401 & AY-68-36-206 & 1st quartile \\
292944098292301 & AY-68-37-105 & 1st quartile \\
292944098292301 & AY-68-37-105 & 1st quartile \\
292522098291901 & AY-68-37-426 & 1st quartile \\
292643098241801 & AY-68-37-601 & 1st quartile \\
292643098241801 & AY-68-37-601 & 1st quartile \\
292328098294601 & AY-68-37-705 & 1st quartile \\
294225098080301 & DX-68-23-601 & 1st quartile \\
291210099475601 & YP-69-50-506 & 1st quartile
\end{tabular}

293111098340901 AY-68-28-807 2d quartile 293512098291701 AY-68-29-109 2d quartile 292424098421501 AY-68-35-810 2d quartile 292053098365501 AY-68-44-110 2d quartile 293807098155301 DX-68-22-901 2d quartile 292604098563201 TD-68-33-501 2d quartile 292116099095501 TD-69-47-305 2d quartile 291232099470301 YP-69-50-339 2d quartile

293128098473101 AY-68-26-814 3d quartile 293451098313201 AY-68-28-601 3d quartile 294604098060801 DX-68-16-708 3d quartile 294019098114701 DX-68-23-504 3d quartile 292215098580201 TD-68-41-103 3d quartile 292119098524901 TD-68-41-308 3d quartile 291943099163301 TD-69-46-601 3d quartile 291840099382601 YP-69-43-606 3d quartile quartile 2004/12/06 E1.13 $<0.2$

\begin{tabular}{|c|c|c|c|c|c|c|c|c|c|}
\hline 2005/09/01 & -- & -- & -- & -- & -- & -- & -- & -- & -- \\
\hline 2004/12/15 & $<1.6$ & $<.2$ & .40 & 42.5 & $<.06$ & 57.0 & $<.04$ & $<.8$ & .25 \\
\hline 005/08/29 & -- & -- & -- & -- & -- & -- & -- & -- & -- \\
\hline 2004/12/14 & $<1.6$ & $<.2$ & .39 & 34.8 & $<.06$ & 41.8 & $<.04$ & $<.8$ & .30 \\
\hline $005 / 08 / 30$ & -- & -- & -- & -- & -- & -- & -- & -- & -- \\
\hline 2004/12/15 & E1.26 & $<.2$ & .46 & 49.8 & $<.06$ & 57.0 & $<.04$ & E.49 & .18 \\
\hline $004 / 12 / 16$ & $<1.6$ & $<.2$ & .54 & 103 & $<.06$ & 50.7 & $<.04$ & $<.8$ & .13 \\
\hline 2004/12/13 & $<1.6$ & $<.2$ & .37 & 31.0 & $<.06$ & 59.1 & $<.04$ & $<.8$ & .22 \\
\hline 2004/12/13 & E.80 & $<.2$ & .56 & 47.2 & $<.06$ & 57.1 & $<.04$ & $<.8$ & .18 \\
\hline 2004/12/13 & $<1.6$ & $<.2$ & .45 & 37.0 & $<.06$ & 62.5 & $<.04$ & $<.8$ & .35 \\
\hline 005/08/31 & -- & -- & -- & -- & -- & -- & -- & -- & -- \\
\hline 2004/12/13 & $<1.6$ & $<.2$ & .44 & 38.4 & $<.06$ & 55.7 & $<.04$ & $<.8$ & .22 \\
\hline 2005/08/31 & -- & -- & -- & -- & -- & -- & -- & -- & -- \\
\hline 2004/12/14 & $<1.6$ & $<.2$ & .36 & 40.8 & $<.06$ & 69.0 & $<.04$ & $<.8$ & .15 \\
\hline 2005/08/31 & -- & -- & -- & -- & -- & -- & -- & -- & -- \\
\hline 2004/12/14 & E.82 & $<.2$ & .57 & 58.5 & $<.06$ & 43.2 & $<.04$ & $<.8$ & .18 \\
\hline 2004/12/15 & $<1.6$ & $<.2$ & .48 & 126 & $<.06$ & 46.3 & $<.04$ & $<.8$ & .14 \\
\hline 2005/08/30 & -- & -- & -- & -- & -- & -- & -- & -- & -- \\
\hline 2004/12/14 & $<1.6$ & $<.2$ & .57 & 121 & $<.06$ & 67.0 & E.02 & $<.8$ & .13 \\
\hline 2004/12/08 & $<1.6$ & $<.2$ & .51 & 49.7 & $<.06$ & 58.3 & $<.04$ & 3.58 & .17 \\
\hline 2004/11/30 & $<1.6$ & $<.2$ & .68 & 60.8 & $<.06$ & 89.5 & $<.04$ & $<.8$ & .25 \\
\hline $2005 / 05 / 26$ & E1.34 & $<.2$ & .45 & 27.4 & $<.06$ & 74.5 & $<.04$ & $<.8$ & .19 \\
\hline $2005 / 04 / 20$ & $<1.6$ & $<.2$ & .75 & 52.7 & $<.06$ & 42.6 & $<.04$ & $<.8$ & .53 \\
\hline 2005/04/21 & $<1.6$ & $<.2$ & .38 & 46.5 & $<.06$ & 49.8 & $<.04$ & $<.8$ & .23 \\
\hline $2005 / 05 / 26$ & E1.25 & $<.2$ & .53 & 60.1 & $<.06$ & 70.8 & $<.04$ & $<.8$ & .13 \\
\hline 2005/05/18 & $<1.6$ & $<.2$ & .41 & 30.7 & $<.06$ & 41.6 & $<.04$ & $<.8$ & .27 \\
\hline 2005/05/16 & E. 80 & $<.2$ & .53 & 33.1 & $<.06$ & 59.5 & $<.04$ & $<.8$ & .19 \\
\hline $2005 / 04 / 27$ & $<1.6$ & $<.2$ & .48 & 38.6 & $<.06$ & 52.2 & $<.04$ & $<.8$ & .10 \\
\hline 2005/05/11 & 2.04 & $<.2$ & .62 & 53.0 & $<.06$ & 64.6 & $<.04$ & $<.8$ & .14 \\
\hline 2005/04/18 & E.85 & $<.2$ & .36 & 30.7 & $<.06$ & 78.7 & $<.04$ & $<.8$ & .18 \\
\hline 2005/05/17 & $<1.6$ & $<.2$ & .48 & 42.6 & $<.06$ & 51.1 & $<.04$ & $<.8$ & .29 \\
\hline $2005 / 04 / 25$ & $<1.6$ & $<.2$ & .38 & 34.6 & $<.06$ & 46.3 & $<.04$ & $<.8$ & .15 \\
\hline 2005/05/18 & 1.81 & $<.2$ & .42 & 46.9 & $<.06$ & 65.1 & $<.04$ & E.65 & .26 \\
\hline 2005/05/09 & E1.03 & $<.2$ & .47 & 48.3 & $<.06$ & 69.0 & $<.04$ & $<.8$ & .13 \\
\hline 2005/04/27 & E.84 & $<.2$ & .50 & 44.3 & $<.06$ & 67.6 & $<.04$ & $<.8$ & .11 \\
\hline 2005/05/09 & $<1.6$ & $<.2$ & .38 & 37.1 & E.03 & 50.8 & $<.04$ & $<.8$ & .13 \\
\hline 2005/05/11 & $<1.6$ & $<.2$ & .51 & 51.4 & E.04 & 53.5 & $<.04$ & $<.8$ & .13 \\
\hline
\end{tabular}


Table 9. Trace element measurements for groundwater samples collected for the study of the transport of anthropogenic and natural contaminants (TANC) to public supply wells in the San Antonio segment of the Edwards aquifer near San Antonio, south-central Texas, 2004-9.-Continued

[By sample category. USGS, U.S. Geological Survey; MW, monitoring well; OVB, overburden; PSW, public-supply well; $\mu$ g/L, micrograms per liter; --, not measured; E, estimated; $<$, nondetection less than laboratory method reporting level]

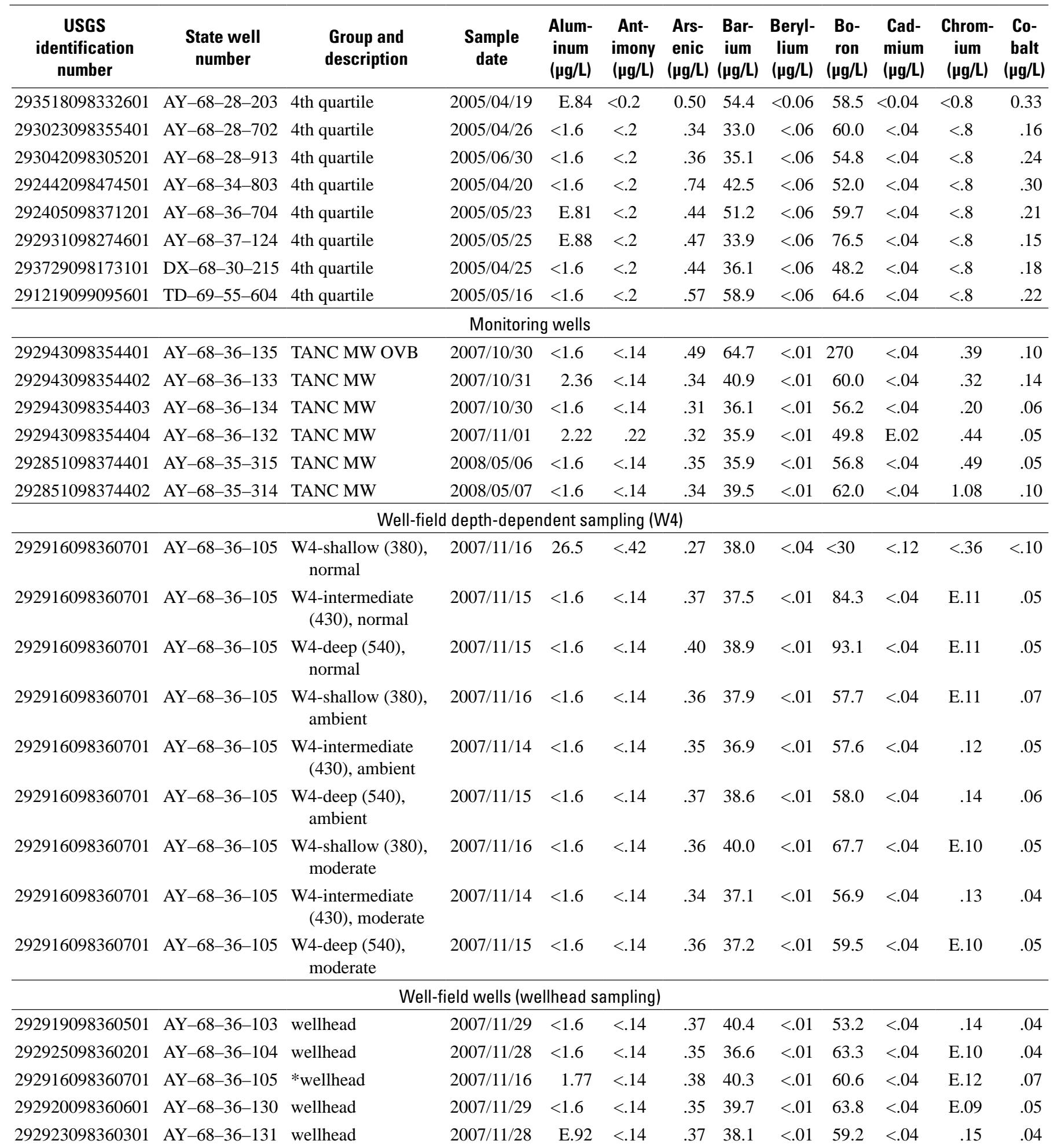


Table 9. Trace element measurements for groundwater samples collected for the study of the transport of anthropogenic and natural contaminants (TANC) to public supply wells in the San Antonio segment of the Edwards aquifer near San Antonio, south-central Texas, 2004-9.-Continued

[By sample category. USGS, U.S. Geological Survey; MW, monitoring well; OVB, overburden; PSW, public-supply well; $\mu$ g/L, micrograms per liter; --, not measured; E, estimated; $<$, nondetection less than laboratory method reporting level]

\begin{tabular}{|c|c|c|c|c|c|c|c|c|c|c|c|c|}
\hline $\begin{array}{c}\text { USGS } \\
\text { identification } \\
\text { number }\end{array}$ & $\begin{array}{l}\text { ate well } \\
\text { umber }\end{array}$ & $\begin{array}{l}\text { id } \\
\text { on }\end{array}$ & $\begin{array}{l}\text { mple } \\
\text { ate }\end{array}$ & $\begin{array}{l}\text { Alum- } \\
\text { inum } \\
(\mu \mathrm{g} / \mathrm{L})\end{array}$ & $\begin{array}{c}\text { Ant- } \\
\text { imony } \\
\text { ( } \mu \mathrm{g} / \mathrm{L})\end{array}$ & $\begin{array}{l}\text { Ars- } \\
\text { enic } \\
(\mu \mathrm{g} / \mathrm{L})\end{array}$ & $\begin{array}{l}\text { Bar- } \\
\text { ium } \\
(\mu \mathrm{g} / \mathrm{L})\end{array}$ & $\begin{array}{c}\text { Beryl- } \\
\text { lium } \\
\text { ( } \mathrm{gg} / \mathrm{L})\end{array}$ & $\begin{array}{l}\text { Bo- } \\
\text { ron } \\
\text { ( } \mu g / L)\end{array}$ & $\begin{array}{l}\text { Cad- } \\
\text { mium } \\
(\mu g / L)\end{array}$ & $\begin{array}{c}\text { Chrom- } \\
\text { ium } \\
\text { ( } \mu \mathrm{g} / \mathrm{L})\end{array}$ & $\begin{array}{c}\text { Co- } \\
\text { balt } \\
(\mu \mathrm{g} / \mathrm{L})\end{array}$ \\
\hline \multicolumn{13}{|c|}{ Temp } \\
\hline 1 & 1 & $\begin{array}{r}\text { TANC } \\
\text { sto }\end{array}$ & 2 & $<4$ & $\mathrm{~F}$ & 0.38 & 6 & $<0.02$ & 6 & $<0.02$ & 22 & 0 \\
\hline 29230 & AY-68- & TANC PSW storm 1 & & 11 & & .48 & & $<.01$ & & $<$. & 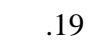 & 17 \\
\hline 292923098360301 & AY-68-36-131 & TANC PSW storm 2 & 2009/10/09 & $<3.4$ & E.03 & .41 & 36.4 & $<.01$ & 58.8 & $<.02$ & .2 & .15 \\
\hline 292923098360301 & AY-68-36-131 & TANC PSW storm 3 & 2009/10/19 & $<3.4$ & & .36 & 37.5 & $<.01$ & 66.1 & $<.02$ & .1 & 18 \\
\hline 92923098360301 & AY-68-36-131 & TANC PSW storm 4 & 2009/10/30 & $<3.4$ & E.03 & .39 & 36.8 & $<.01$ & 56.6 & $<.02$ & E.11 & .15 \\
\hline 301 & AY-68-3 & TANC & 9 & $<3$ & & .43 & & 01 & .6 & & & to \\
\hline 354402 & AY-68-36-133 & & 20 & $<4$ & & .34 & 40.2 & $<.02$ & 57.5 & $<.02$ & .2 & .14 \\
\hline 2929430 & AY-68-36-133 & TANC MW storm 1 & 200 & 7.35 & $\mathrm{E}$ & .38 & 39.2 & $<.01$ & 58.7 & $<.02$ & .3 & .19 \\
\hline 2929430 & AY-68-36-133 & TAN & 200 & $<3.4$ & $\mathrm{E}$ & .38 & 38.8 & E.01 & 3.0 & $<.1$ & .2 & .20 \\
\hline 292943098354402 & AY-68-36-133 & TANC MW storm 3 & 2009/10/17 & $<3$ & $\mathrm{E}$ & .36 & 39.0 & $<.01$ & 60.3 & $<$. & .2 & .21 \\
\hline 92943098354402 & AY-68-36-133 & TANC MW storm 4 & $2009 / 10 / 28$ & $<3.4$ & 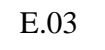 & .36 & 38.2 & $<.01$ & 56.5 & & & .17 \\
\hline 292943098354402 & AY-68-36-133 & TANC $\mathrm{N}$ & 2009/11/18 & E2.2 & E.03 & .64 & 38.3 & $<.01$ & 60.8 & $<.0$ & .1 & .21 \\
\hline 4403 & AY-68- & $\begin{array}{r}\text { TAN } \\
\text { stc }\end{array}$ & 200 & 4 & -- & .34 & 2 & $<.02$ & 5 & 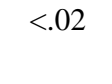 & .27 & .13 \\
\hline 4403 & AY-68 & MW storm 1 & 20 & & -- & .39 & & 01 & & & & 24 \\
\hline 292943098354403 & AY-68-36-134 & TANC MW storm 2 & 200 & $<3$ & -- & .37 & 35.7 & $<.01$ & 61.2 & $<.0$ & .2 & .19 \\
\hline 292943098354403 & Y-68-36-134 & TANC MW storm 3 & 2009/10/18 & $<3$ & -- & .36 & 36 & $<.01$ & 6 & $<.0$ & .2 & .20 \\
\hline 292943098354403 & AY-68-36-134 & TANC MW storm 4 & 2009/10/29 & $<3$ & -- & .38 & 36.3 & $<.01$ & 58.5 & $<.02$ & E.11 & .22 \\
\hline 292943098354403 & AY-68-36-134 & TANC MW storm 5 & 2009/11/18 & $<3$ & -- & .34 & 36.4 & $<.01$ & 60.4 & $<.02$ & E.10 & .16 \\
\hline 354404 & Y-68-36-132 & $\begin{array}{r}\text { TAN } \\
\text { st }\end{array}$ & 200 & $<4$ & -- & .32 & 36.0 & $<.02$ & 54.2 & $<.02$ & 26 & .14 \\
\hline 29294 & -132 & TANC & & $<3$ & -- & .38 & 3 & $<.01$ & & & & .19 \\
\hline 292943098354404 & AY-68-36-132 & TANC MW storm 2 & 2009/10/08 & $<3$ & -- & .34 & 33.9 & $<.01$ & 54.1 & $<.0$ & .2 & .16 \\
\hline 292943098354404 & AY-68-36-132 & TANC MW storm 3 & 2009/10/18 & E2.26 & -- & .33 & 35.0 & $<.01$ & 60.7 & $<.02$ & .21 & .20 \\
\hline 2929430 & AY-68-36-132 & TANC MW storm 4 & 2009/10/29 & $<3$ & -- & .32 & 34.9 & $<.01$ & 52.4 & $<.02$ & E.11 & .16 \\
\hline 292943098354404 & AY-68-36-132 & TANC MW storm 5 & 2009/11/18 & 3.68 & -- & .32 & 35.5 & $<.01$ & 58.8 & $<.02$ & E.12 & .21 \\
\hline 293252098380801 & AY-68-27-610 & $\begin{array}{l}\text { TANC MW pre- } \\
\text { storm }\end{array}$ & 2009/04/14 & $<4$ & $<.04$ & .30 & 37.2 & $<.02$ & 41.0 & $<.02$ & .20 & .50 \\
\hline 293252 & AY-68-27-610 & TANC MW storm 1 & & $<3$. & & .34 & 38.9 & $<.01$ & 44.7 & $<.02$ & .57 & .23 \\
\hline 293252098380801 & AY-68-27-610 & TANC MW storm 2 & & $<3.4$ & $<.0$ & .37 & 39.5 & $<.01$ & 45.0 & $<.02$ & .42 & .25 \\
\hline & 10 & $n 3$ & 17 & $<$ & & .33 & 38.9 & $<.01$ & 48.1 & $<.02$ & .33 & .22 \\
\hline 293252098380801 & AY-68-27-610 & TANC MW storm 4 & 2009/10/28 & $<3.4$ & $<$ & .37 & 39.7 & E.01 & 51.0 & $<.02$ & .18 & .26 \\
\hline 9325209838080 & AY-68-27-610 & TANC MW storm 5 & 2009/11/17 & $<3.4$ & .054 & .35 & 39.5 & $<.01$ & 47.9 & $<.02$ & .17 & .2 \\
\hline
\end{tabular}


Table 9. Trace element measurements for groundwater samples collected for the study of the transport of anthropogenic and natural contaminants (TANC) to public supply wells in the San Antonio segment of the Edwards aquifer near San Antonio, south-central Texas, 2004-9.-Continued

[By sample category. USGS, U.S. Geological Survey; MW, monitoring well; OVB, overburden; PSW, public-supply well; $\mu$ g/L, micrograms per liter; --, not measured; E, estimated; $<$, nondetection less than laboratory method reporting level]

\begin{tabular}{|c|c|c|c|c|c|c|c|c|c|c|c|c|c|c|c|c|}
\hline $\begin{array}{c}\text { USGS } \\
\text { identification } \\
\text { number }\end{array}$ & $\begin{array}{c}\text { Cop- } \\
\text { per } \\
(\mu \mathrm{g} / \mathrm{L})\end{array}$ & $\begin{array}{c}\text { Iron } \\
(\mu \mathrm{g} / \mathrm{L})\end{array}$ & $\begin{array}{c}\text { Ferrous } \\
\text { (II) iron } \\
\text { ( } \mu \mathrm{g} / \mathrm{L})\end{array}$ & $\begin{array}{c}\text { Total } \\
\text { iron } \\
(\mu \mathrm{g} / \mathrm{L})\end{array}$ & $\begin{array}{c}\text { Lead } \\
(\mu \mathrm{g} / \mathrm{L})\end{array}$ & $\begin{array}{l}\text { Lith- } \\
\text { ium } \\
\text { ( } \mu \mathrm{g} / \mathrm{L})\end{array}$ & $\begin{array}{l}\text { Mang- } \\
\text { anese } \\
(\mu \mathrm{g} / \mathrm{L})\end{array}$ & $\begin{array}{c}\text { Molyb- } \\
\text { denum } \\
\text { ( } \mu \mathrm{g} / \mathrm{L})\end{array}$ & $\begin{array}{c}\text { Nick- } \\
\text { el } \\
(\mu \mathrm{g} / \mathrm{L})\end{array}$ & $\begin{array}{c}\text { Selen- } \\
\text { ium } \\
(\mu \mathrm{g} / \mathrm{L})\end{array}$ & $\begin{array}{c}\text { Sil- } \\
\text { ver } \\
(\mu \mathrm{g} / \mathrm{L})\end{array}$ & $\begin{array}{c}\text { Stron- } \\
\text { tium } \\
(\mu \mathrm{g} / \mathrm{L})\end{array}$ & $\begin{array}{l}\text { Thal- } \\
\text { lium } \\
\text { ( } \mu \mathrm{g} / \mathrm{L}\end{array}$ & $\begin{array}{l}\text { Uran- } \\
\text { ium } \\
(\mu \mathrm{g} / \mathrm{L})\end{array}$ & $\begin{array}{c}\text { Vanad- } \\
\text { ium } \\
\text { ( } \mu \mathrm{g} / \mathrm{L})\end{array}$ & $\begin{array}{c}\text { Zinc } \\
(\mu \mathrm{g} / \mathrm{L})\end{array}$ \\
\hline \multicolumn{17}{|c|}{ Regional aquifer public-supply wells } \\
\hline 293359098290301 & 3.04 & $<6$ & -- & -- & 0.30 & 3.07 & $<0.2$ & E0.36 & 2.78 & E0.36 & $<0.20$ & 232 & $<0.04$ & 0.97 & 3.62 & 2.17 \\
\hline 293359098290301 & -- & -- & -- & -- & -- & -- & -- & -- & -- & -- & -- & -- & -- & -- & -- & -- \\
\hline 293120098285801 & 1.97 & $<6$ & -- & -- & 1.03 & 3.67 & $<.2$ & .65 & 5.61 & .70 & $<.20$ & 421 & $<.04$ & .93 & 2.47 & 5.29 \\
\hline 293120098285801 & -- & -- & -- & -- & -- & -- & -- & -- & -- & -- & -- & -- & -- & -- & -- & -- \\
\hline 293145098224201 & 3.13 & $<6$ & -- & -- & 1.29 & 4.44 & $<.2$ & 1.28 & 5.12 & .56 & $<.20$ & 556 & .08 & .91 & 3.18 & 10.6 \\
\hline 293119098211201 & 3.11 & $<6$ & -- & -- & .35 & 7.66 & $<.2$ & .90 & .83 & .69 & $<.20$ & 1,100 & .05 & .77 & 3.30 & 2.34 \\
\hline 292925098360201 & -- & -- & -- & -- & -- & -- & -- & -- & -- & -- & -- & -- & -- & -- & -- & -- \\
\hline 292822098325401 & 4.59 & $<6$ & -- & -- & .92 & 4.91 & $<.2$ & .77 & 3.26 & .66 & $<.20$ & 555 & $<.04$ & .94 & 2.87 & 8.86 \\
\hline 292822098325401 & -- & -- & -- & -- & -- & -- & -- & -- & -- & -- & -- & -- & -- & -- & -- & -- \\
\hline 292944098292301 & 5.43 & $<6$ & -- & -- & 2.21 & 5.10 & $<.2$ & .73 & 1.41 & .50 & $<.20$ & 509 & E.03 & .90 & 2.81 & 23.6 \\
\hline 292944098292301 & -- & -- & -- & -- & -- & -- & -- & -- & -- & -- & -- & -- & -- & -- & -- & -- \\
\hline 292522098291901 & 1.58 & $<6$ & -- & -- & 5.03 & 5.31 & $<.2$ & .87 & 2.48 & .82 & $<.20$ & 955 & .04 & .85 & 3.91 & 9.95 \\
\hline 292643098241801 & 6.84 & $<6$ & -- & -- & 1.80 & 10.6 & $<.2$ & 2.52 & 1.49 & .76 & $<.20$ & 1,540 & .07 & .94 & 3.49 & 4.92 \\
\hline 292643098241801 & -- & -- & -- & -- & -- & -- & -- & -- & -- & -- & -- & -- & -- & -- & -- & -- \\
\hline 292328098294601 & 1.14 & $<6$ & -- & -- & 3.47 & 12.5 & $<.2$ & 7.79 & 8.74 & .88 & $<.20$ & 1,710 & .14 & 1.16 & 4.41 & 2.00 \\
\hline 292053098365501 & 1.45 & $<6$ & -- & .05 & .13 & 3.90 & $<.2$ & 1.16 & 3.08 & .91 & $<.20$ & 1,470 & $<.04$ & .82 & 3.88 & 1.19 \\
\hline 293807098155301 & 2.77 & $<6$ & -- & .00 & .16 & 2.82 & $<.2$ & E. 40 & 3.95 & .51 & $<.20$ & 154 & $<.04$ & .56 & 2.53 & 4.19 \\
\hline 292604098563201 & 2.01 & $<6$ & -- & .00 & .68 & 4.85 & $<.2$ & .77 & 2.77 & .65 & $<.20$ & 542 & $<.04$ & .72 & 2.51 & .71 \\
\hline 292116099095501 & 4.26 & $<6$ & -- & .01 & .83 & 2.68 & $<.2$ & .70 & .28 & .73 & $<.20$ & 350 & E.03 & .77 & 2.88 & 5.43 \\
\hline 291232099470301 & 2.68 & $<6$ & -- & .01 & .20 & 2.42 & $<.2$ & .62 & 1.13 & .59 & $<.20$ & 261 & E.04 & .79 & 5.81 & 1.89 \\
\hline 293128098473101 & 1.63 & 6.78 & -- & $<.01$ & .14 & 5.66 & .34 & 1.11 & 3.40 & .67 & $<.20$ & 945 & E.02 & .92 & 3.60 & 4.18 \\
\hline 293451098313201 & 2.56 & $<6$ & -- & .01 & .09 & 3.45 & E.16 & E.35 & 4.38 & .61 & $<.20$ & 235 & $<.04$ & .72 & 3.01 & 29.2 \\
\hline 294604098060801 & 3.46 & $<6$ & -- & .05 & .55 & 3.19 & $<.2$ & .42 & .37 & .74 & $<.20$ & 426 & $<.04$ & .86 & 2.64 & 2.69 \\
\hline 294019098114701 & 2.48 & $<6$ & -- & .02 & .42 & 6.64 & $<.2$ & .63 & 4.40 & .77 & $<.20$ & 524 & $<.08$ & .74 & 2.73 & 2.73 \\
\hline 292215098580201 & 5.54 & $<6$ & -- & .03 & .74 & 3.84 & E.11 & .65 & 1.51 & .82 & $<.20$ & 659 & E.03 & .72 & 4.69 & 11.3 \\
\hline 292119098524901 & 0.41 & $<6$ & -- & .01 & .12 & 3.82 & $<.2$ & .60 & .37 & .68 & $<.20$ & 549 & E.03 & .73 & 3.17 & 4.88 \\
\hline 291943099163301 & 3.14 & $<6$ & -- & .01 & .26 & 2.57 & $<.2$ & .61 & 1.03 & .54 & $<.20$ & 343 & $<.04$ & .73 & 3.40 & 6.28 \\
\hline 291840099382601 & 2.13 & $<6$ & -- & .01 & .20 & 2.14 & $<.2$ & .54 & 1.02 & .66 & $<.20$ & 402 & E.02 & .71 & 4.15 & 2.50 \\
\hline
\end{tabular}


Table 9. Trace element measurements for groundwater samples collected for the study of the transport of anthropogenic and natural contaminants (TANC) to public supply wells in the San Antonio segment of the Edwards aquifer near San Antonio, south-central Texas, 2004-9.-Continued

[By sample category. USGS, U.S. Geological Survey; MW, monitoring well; OVB, overburden; PSW, public-supply well; $\mu$ g/L, micrograms per liter; --, not measured; E, estimated; $<$, nondetection less than laboratory method reporting level]

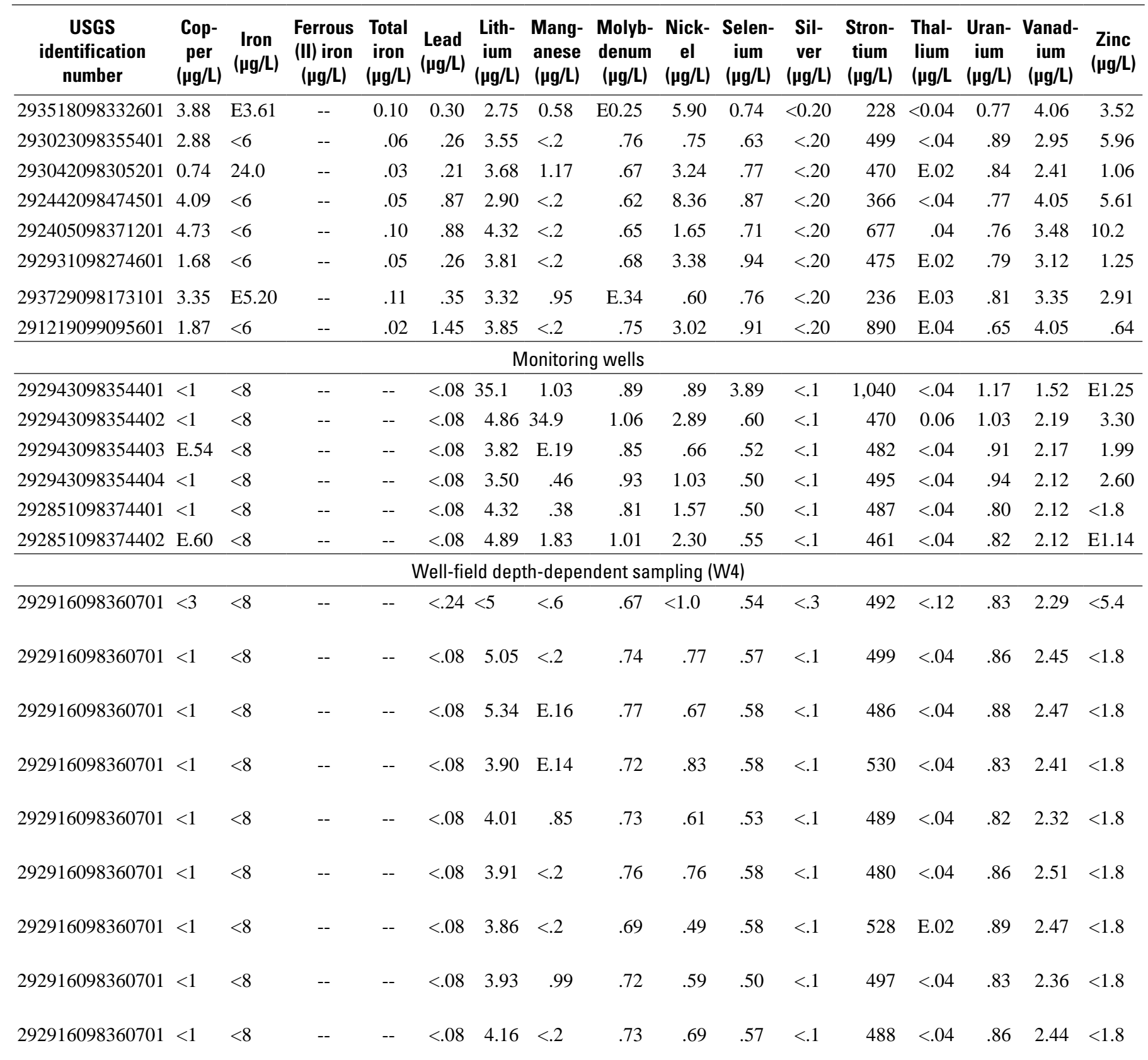

Well-field wells (wellhead sampling)

\begin{tabular}{|c|c|c|c|c|c|c|c|c|c|c|c|c|c|c|c|c|}
\hline 292919098360501 & 1.39 & $<8$ & -- & -- & .16 & 3.75 & $<.2$ & .68 & .71 & .57 & $<.1$ & 504 & $<.04$ & .90 & 2.23 & 3.84 \\
\hline 292925098360201 & 4.26 & $<8$ & -- & -- & 1.53 & 4.48 & $<.2$ & .75 & .69 & .57 & $<.1$ & 496 & $<.04$ & .87 & 2.31 & 2.93 \\
\hline 292916098360701 & $<1$ & $<8$ & -- & -- & $<.08$ & 3.98 & E.10 & .73 & .83 & .61 & $<.1$ & 517 & $<.04$ & .88 & 2.54 & .9 \\
\hline 292920098360601 & 4.38 & $<8$ & -- & -- & .90 & 4.26 & $<.2$ & .74 & .81 & .59 & $<.1$ & 503 & $<.04$ & .91 & 2.44 & $2 .($ \\
\hline 292923098360301 & 3.71 & $<8$ & -- & -- & .39 & 3.99 & .25 & .72 & .59 & .59 & $<.1$ & 518 & $<.04$ & .90 & 2.34 & E1. \\
\hline
\end{tabular}


Table 9. Trace element measurements for groundwater samples collected for the study of the transport of anthropogenic and natural contaminants (TANC) to public supply wells in the San Antonio segment of the Edwards aquifer near San Antonio, south-central Texas, 2004-9.-Continued

[By sample category. USGS, U.S. Geological Survey; MW, monitoring well; OVB, overburden; PSW, public-supply well; $\mu$ g/L, micrograms per liter; --, not measured; E, estimated; $<$, nondetection less than laboratory method reporting level]

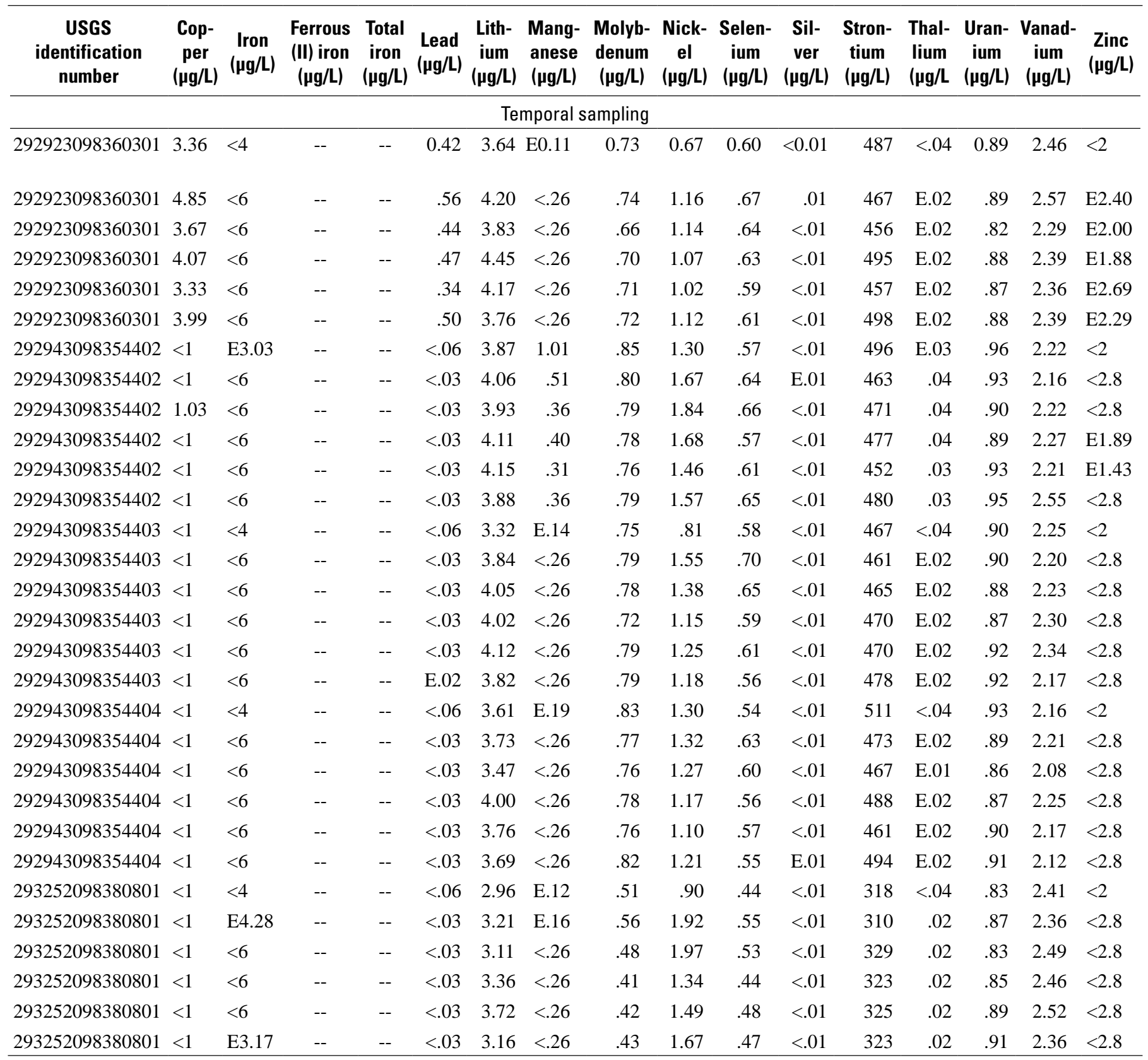

* Sample collected from top of open interval during depth-dependent sampling. 
Table 10. Dissolved gas and associated data for groundwater samples collected for the study of the transport of anthropogenic and natural contaminants (TANC) to public supply wells in the San Antonio segment of the Edwards aquifer near San Antonio, south-central Texas, 2004-9.

[By sample category. mg/L, milligrams per liter; $\mathrm{cm}^{3} \mathrm{STP} / \mathrm{kg}$, cubic centimeters per kilogram at standard temperature $\left(20^{\circ} \mathrm{C}\right)$ and pressure $(1 \mathrm{atmosphere})$; --, not measured or calculated]

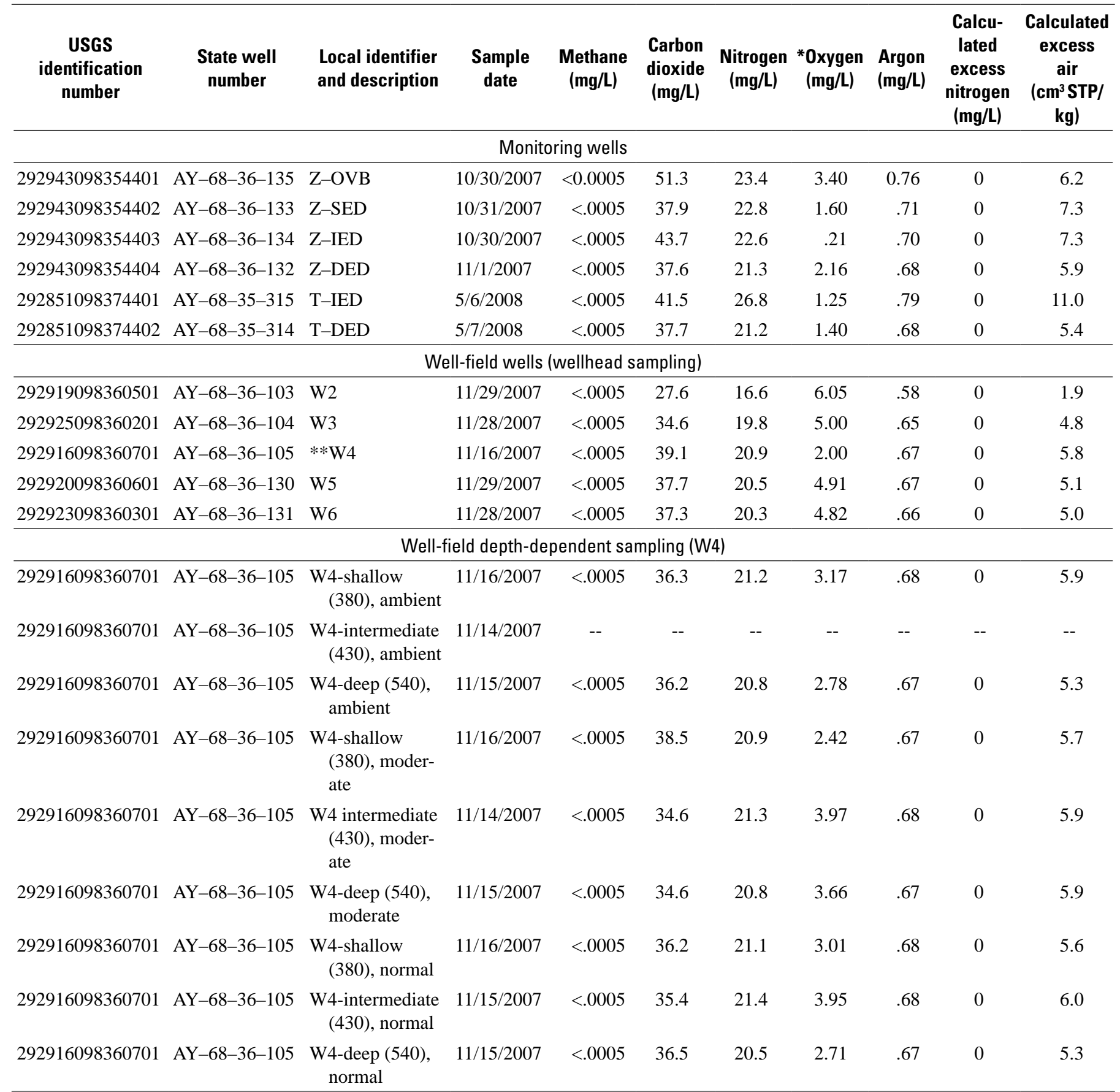

* Similar to dissolved oxygen in table 9 ; however, determined by laboratory rather than field method.

** Sample collected from top of open interval during depth-dependent sampling. 
Table 11. Nutrient measurements for groundwater samples collected for the study of the transport of anthropogenic and natural contaminants (TANC) to public supply wells in the San Antonio segment of the Edwards aquifer near San Antonio, south-central Texas, 2004-9.

[By sample category. USGS, U.S. Geological Survey; MW, monitoring well; OVB, overburden; PSW, public-supply well; mg/L, milligrams per liter; N, nitrogen; P, phosphorus; --, not measured; E, estimated; V, contamination; <, nondetection less than laboratory method reporting level]

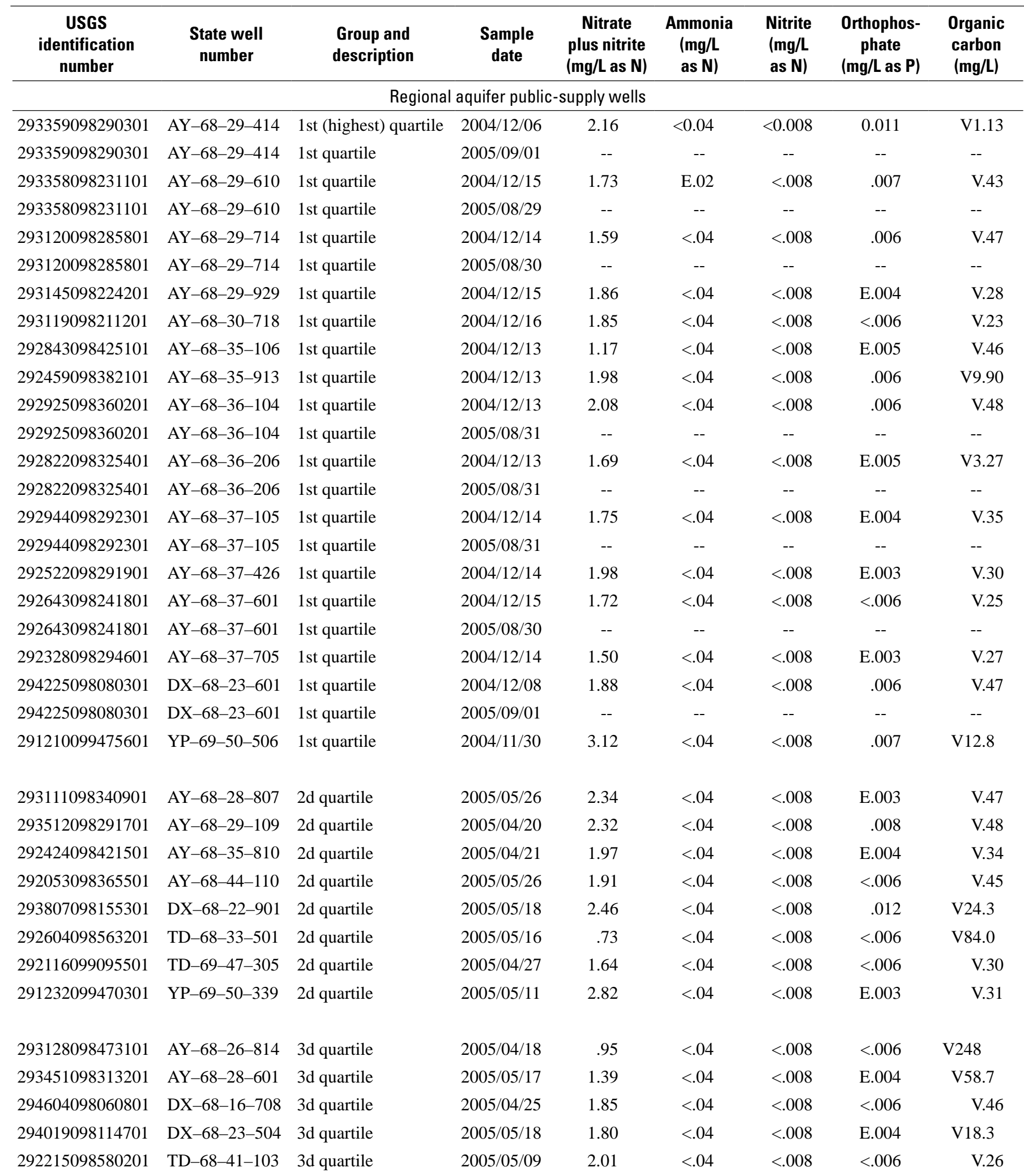


Table 11. Nutrient measurements for groundwater samples collected for the study of the transport of anthropogenic and natural contaminants (TANC) to public supply wells in the San Antonio segment of the Edwards aquifer near San Antonio, south-central Texas, 2004-9.-Continued

[By sample category. USGS, U.S. Geological Survey; MW, monitoring well; OVB, overburden; PSW, public-supply well; mg/L, milligrams per liter; N, nitrogen; P, phosphorus; --, not measured; E, estimated; V, contamination; <, nondetection less than laboratory method reporting level]

\begin{tabular}{|c|c|c|c|c|c|c|c|c|}
\hline $\begin{array}{c}\text { USGS } \\
\text { identification } \\
\text { number }\end{array}$ & $\begin{array}{l}\text { State well } \\
\text { number }\end{array}$ & $\begin{array}{l}\text { Group and } \\
\text { description }\end{array}$ & $\begin{array}{l}\text { Sample } \\
\text { date }\end{array}$ & $\begin{array}{c}\text { Nitrate } \\
\text { plus nitrite } \\
\text { (mg/L as N) }\end{array}$ & $\begin{array}{c}\text { Ammonia } \\
\text { (mg/L } \\
\text { as } \mathrm{N})\end{array}$ & $\begin{array}{l}\text { Nitrite } \\
\text { (mg/L } \\
\text { as N) }\end{array}$ & $\begin{array}{c}\text { Orthophos- } \\
\text { phate } \\
\text { (mg/L as P) }\end{array}$ & $\begin{array}{c}\text { Organic } \\
\text { carbon } \\
\text { (mg/L) }\end{array}$ \\
\hline 292119098524901 & TD-68-41-308 & 3d quartile & $2005 / 04 / 27$ & 2.02 & $<0.04$ & $<0.008$ & $<0.006$ & V0.34 \\
\hline 291943099163301 & TD-69-46-601 & 3d quartile & 2005/05/09 & 1.44 & $<.04$ & $<.008$ & E.005 & V.28 \\
\hline 291840099382601 & YP-69-43-606 & 3d quartile & 2005/05/11 & 2.77 & $<.04$ & $<.008$ & $<.006$ & V.32 \\
\hline 293023098355401 & AY-68-28-702 & 4th quartile & $2005 / 04 / 26$ & 1.85 & $<.04$ & $<.008$ & $<.006$ & V.57 \\
\hline 293042098305201 & AY-68-28-913 & 4th quartile & $2005 / 06 / 30$ & 1.82 & $<.04$ & $<.008$ & E.003 & V15.6 \\
\hline 292442098474501 & AY-68-34-803 & 4th quartile & $2005 / 04 / 20$ & 1.81 & $<.04$ & $<.008$ & $<.006$ & V.37 \\
\hline 292405098371201 & AY-68-36-704 & 4th quartile & $2005 / 05 / 23$ & 1.98 & $<.04$ & $<.008$ & $<.006$ & V2.02 \\
\hline \multicolumn{9}{|c|}{ Monitoring wells } \\
\hline 292943098354401 & AY-68-36-135 & TANC MW OVB & $2007 / 10 / 30$ & 3.83 & $<.02$ & E.001 & .010 & 7.23 \\
\hline 292943098354402 & AY-68-36-133 & TANC MW & 2007/10/31 & 1.86 & $<.02$ & .013 & .006 & .53 \\
\hline 292943098354403 & AY-68-36-134 & TANC MW & 2007/10/30 & 1.87 & $<.02$ & $<.002$ & .008 & 1.03 \\
\hline 292943098354404 & AY-68-36-132 & TANC MW & 2007/11/01 & 1.69 & $<.02$ & .005 & .007 & .44 \\
\hline 292851098374401 & AY-68-35-315 & TANC MW & 2008/05/06 & 1.97 & E.01 & $<.002$ & .011 & .41 \\
\hline 292851098374402 & AY-68-35-314 & TANC MW & 2008/05/07 & 2.74 & $<.02$ & $<.002$ & .010 & .60 \\
\hline \multicolumn{9}{|c|}{ Well-field depth-dependent sampling (W4) } \\
\hline 292916098360701 & AY-68-36-105 & $\begin{array}{l}\text { W4-shallow (380), } \\
\text { normal }\end{array}$ & $2007 / 11 / 16$ & 1.99 & $<.02$ & $<.002$ & .008 & E.36 \\
\hline 292916098360701 & AY-68-36-105 & $\begin{array}{l}\text { W4-intermediate } \\
\text { (430), ambient }\end{array}$ & $2007 / 11 / 14$ & 1.97 & $<.02$ & $<.002$ & E.006 & .44 \\
\hline 292916098360701 & AY-68-36-105 & $\begin{array}{l}\text { W4-deep (540), } \\
\text { ambient }\end{array}$ & 2007/11/15 & 2.12 & $<.02$ & $<.002$ & .009 & .45 \\
\hline 292916098360701 & AY-68-36-105 & $\begin{array}{l}\text { W4-shallow (380), } \\
\text { moderate }\end{array}$ & 2007/11/16 & 2.18 & $<.02$ & $<.002$ & .009 & .43 \\
\hline 292916098360701 & AY-68-36-105 & $\begin{array}{l}\text { W4-intermediate } \\
\text { (430), moderate }\end{array}$ & $2007 / 11 / 14$ & 1.97 & $<.02$ & $<.002$ & .008 & .56 \\
\hline 292916098360701 & AY-68-36-105 & $\begin{array}{l}\text { W4-deep (540), } \\
\text { moderate }\end{array}$ & 2007/11/15 & 1.97 & $<.02$ & $<.002$ & .008 & E.39 \\
\hline \multicolumn{9}{|c|}{ Well-field wells (wellhead sampling) } \\
\hline 292919098360501 & AY-68-36-103 & wellhead & $2007 / 11 / 29$ & 2.24 & $<.02$ & $<.002$ & .008 & E. 40 \\
\hline 292925098360201 & AY-68-36-104 & wellhead & $2007 / 11 / 28$ & 1.97 & $<.02$ & $<.002$ & .008 & .42 \\
\hline
\end{tabular}


Table 11. Nutrient measurements for groundwater samples collected for the study of the transport of anthropogenic and natural contaminants (TANC) to public supply wells in the San Antonio segment of the Edwards aquifer near San Antonio, south-central Texas, 2004-9.-Continued

[By sample category. USGS, U.S. Geological Survey; MW, monitoring well; OVB, overburden; PSW, public-supply well; mg/L, milligrams per liter; N, nitrogen; P, phosphorus; --, not measured; E, estimated; V, contamination; <, nondetection less than laboratory method reporting level]

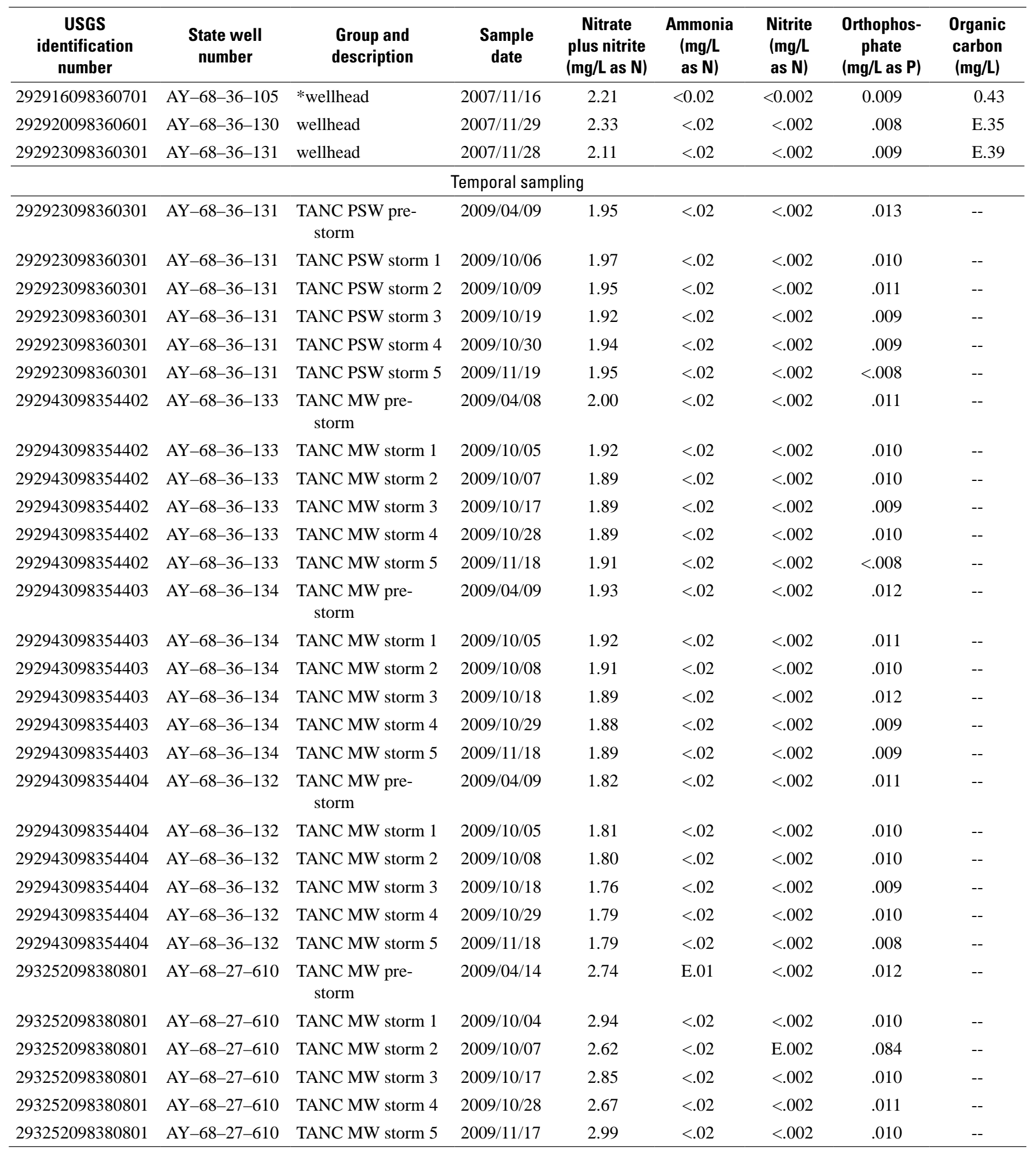

\footnotetext{
${ }^{*}$ Sample collected from top of open interval during depth-dependent sampling.
} 
Table 12. Isotope and radionuclide measurements for groundwater samples collected for the study of the transport of anthropogenic and natural contaminants (TANC) to public supply wells in the San Antonio segment of the Edwards aquifer near San Antonio, southcentral Texas, 2004-9.

[By sample category. USGS, U.S. Geological Survey; MW, monitoring well; OVB, overburden; PSW, public-supply well; pCi/L, picoCuries per liter; $\delta^{18} \mathrm{O}$, delta oxygen-18; $\delta \mathrm{D}$, delta deuterium; ${ }^{87} \mathrm{Sr} /{ }^{86} \mathrm{Sr}$, strontium-87/strontium-86; $\delta^{15} \mathrm{~N}$, delta nitrogen-15; $\mathrm{NO}_{3}$, nitrate; --, not measured; R, result less than sample-specific critical level]

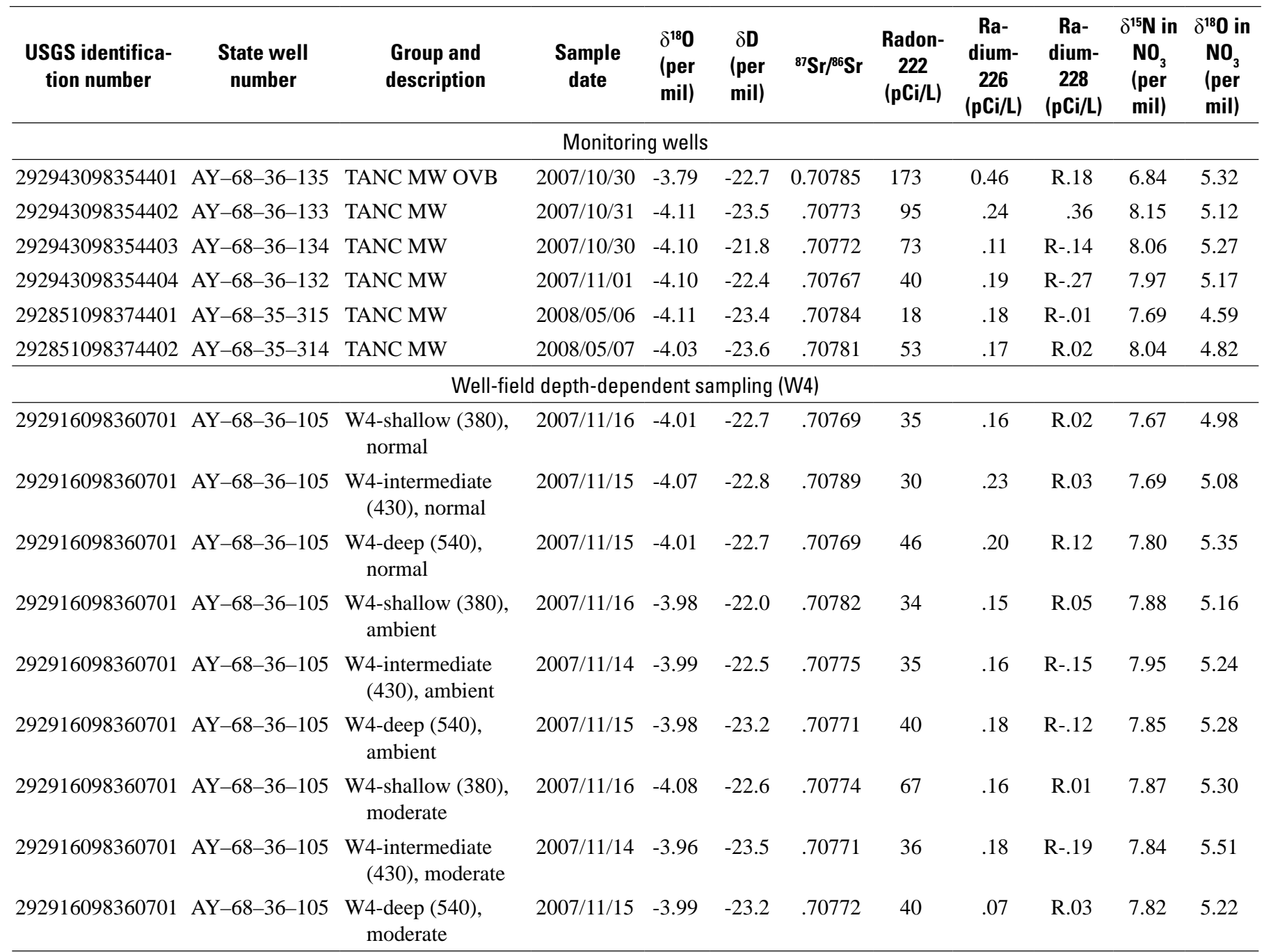

\begin{tabular}{|c|c|c|c|c|c|c|c|c|c|c|c|}
\hline \multicolumn{12}{|c|}{ Well-field wells (wellhead sampling) } \\
\hline 292919098360501 & AY-68-36-103 & wellhead & $2007 / 11 / 29$ & -4.06 & -22.9 & .70772 & -- & .20 & R.08 & 8.16 & 5.45 \\
\hline 292925098360201 & AY-68-36-104 & wellhead & $2007 / 11 / 28$ & -4.01 & -22.4 & .70768 & -- & .16 & R.02 & 7.93 & 5.15 \\
\hline 292920098360601 & AY-68-36-130 & wellhead & 2007/11/29 & -4.11 & -22.5 & .70772 & -- & .20 & R.05 & 8.09 & 5.35 \\
\hline 292923098360301 & AY-68-36-131 & wellhead & $2007 / 11 / 28$ & -4.02 & -23.4 & .70771 & -- & .18 & R.20 & 8.12 & 5.52 \\
\hline 292923098360301 & AY-68-36-131 & $\begin{array}{l}\text { TANC PSW pre- } \\
\text { storm }\end{array}$ & $2009 / 04 / 09$ & -3.96 & -22.7 & -- & -- & -- & -- & -- & -- \\
\hline 292923098360301 & AY-68-36-131 & TANC PSW storm 1 & 2009/10/06 & -4.00 & -21.8 & .70781 & -- & -- & -- & -- & -- \\
\hline 292923098360301 & AY-68-36-131 & TANC PSW storm 2 & 2009/10/09 & -4.04 & -21.3 & .70779 & -- & -- & -- & -- & -- \\
\hline 292923098360301 & AY-68-36-131 & TANC PSW storm 3 & 2009/10/19 & -4.08 & -21.8 & .70779 & -- & -- & -- & -- & -- \\
\hline
\end{tabular}


Table 12. Isotope and radionuclide measurements for groundwater samples collected for the study of the transport of anthropogenic and natural contaminants (TANC) to public supply wells in the San Antonio segment of the Edwards aquifer near San Antonio, southcentral Texas, 2004-9.-Continued

[By sample category. USGS, U.S. Geological Survey; MW, monitoring well; OVB, overburden; PSW, public-supply well; pCi/L, picoCuries per liter; $\delta^{18} \mathrm{O}$, delta oxygen-18; $\delta \mathrm{D}$, delta deuterium; ${ }^{87} \mathrm{Sr} /{ }^{86} \mathrm{Sr}$, strontium-87/strontium- $86 ; \delta^{15} \mathrm{~N}$, delta nitrogen-15; $\mathrm{NO}_{3}$, nitrate; --, not measured; R, result less than sample-specific critical level]

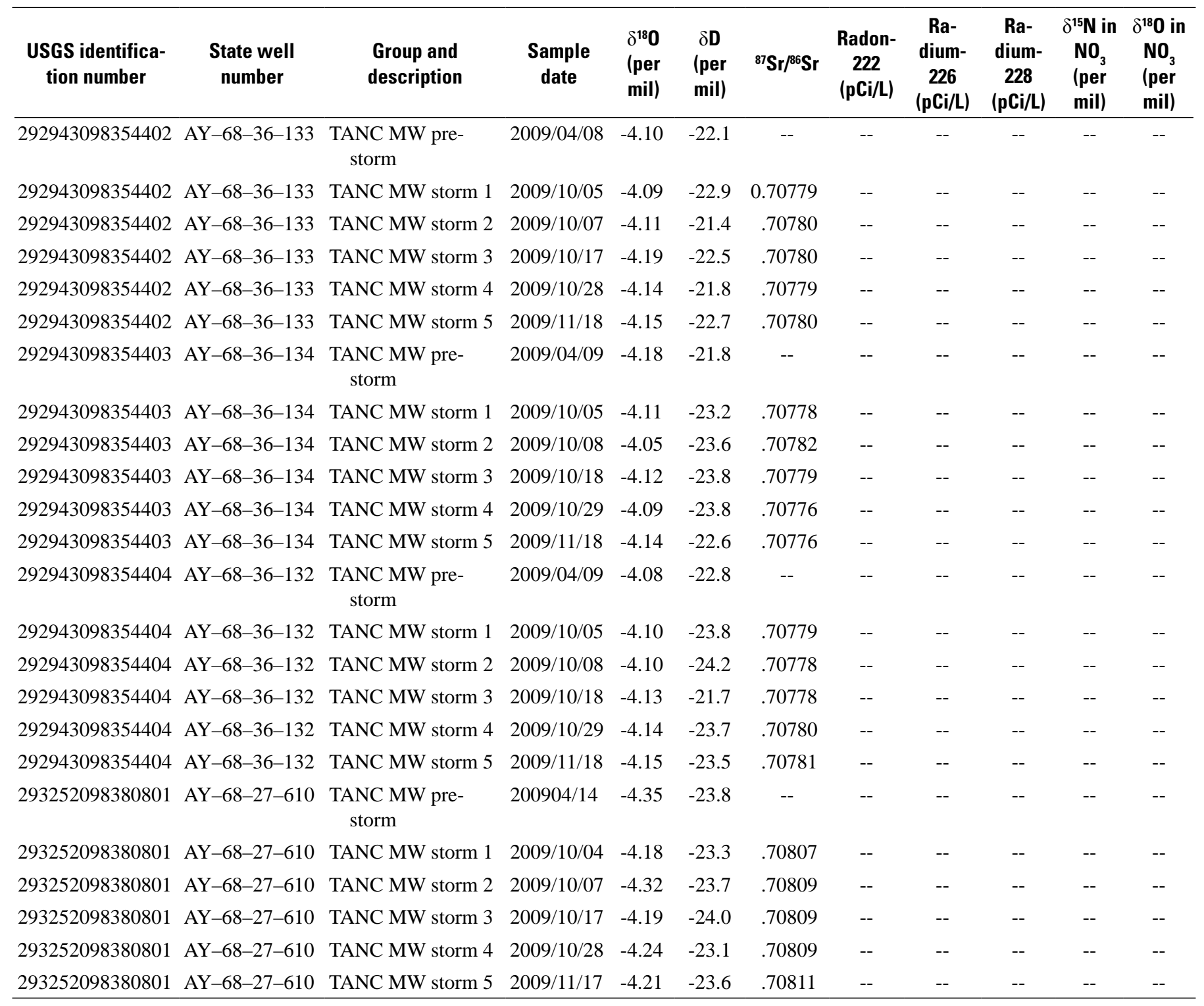

* Sample collected from top of open interval during depth-dependent sampling. 
Table 13. Wastewater indicator compounds for groundwater samples collected for the study of the transport of anthropogenic and natural contaminants (TANC) to public supply wells in the San Antonio segment of the Edwards aquifer near San Antonio, south-central Texas, 2004-9.

[By sample category. USGS, U.S. Geological Survey; $\mu \mathrm{g} / \mathrm{L}$, micrograms per liter; <, nondetection less than laboratory method reporting level; --, not measured; V, contaminated]

\begin{tabular}{|c|c|c|c|c|c|c|c|c|c|c|c|c|c|}
\hline $\begin{array}{c}\text { USGS } \\
\text { identification } \\
\text { number }\end{array}$ & $\begin{array}{c}\text { State well } \\
\text { number }\end{array}$ & $\begin{array}{l}\text { Group and } \\
\text { description }\end{array}$ & $\begin{array}{c}\text { Sample } \\
\text { date }\end{array}$ & $\begin{array}{c}\text { 1,4-Di- } \\
\text { chloro- } \\
\text { benzene } \\
(\mu \mathrm{g} / \mathrm{L})\end{array}$ & $\begin{array}{l}\text { 1-Methyl- } \\
\text { naphth- } \\
\text { alene } \\
\text { ( } \mu \mathrm{g} / \mathrm{L})\end{array}$ & $\begin{array}{c}\text { 2,6-Di- } \\
\text { methyl- } \\
\text { naphth- } \\
\text { alene } \\
\text { ( } \mu \mathrm{g} / \mathrm{L} \text { ) }\end{array}$ & $\begin{array}{l}\text { 2-Methyl- } \\
\text { naphth- } \\
\text { alene } \\
(\mu \mathrm{g} / \mathrm{L})\end{array}$ & $\begin{array}{l}\text { 3-beta- } \\
\text { Copro- } \\
\text { stanol } \\
(\mu \mathrm{g} / \mathrm{L})\end{array}$ & $\begin{array}{c}\text { 3-Methyl- } \\
\text { 1H-indole } \\
\text { ( } \mu \mathrm{g} / \mathrm{L})\end{array}$ & $\begin{array}{c}\text { 3-tert- } \\
\text { Butyl- } \\
\text { 4-hydroxy- } \\
\text { anisole } \\
\text { ( } \mu \mathrm{g} / \mathrm{L})\end{array}$ & $\begin{array}{c}\text { 4-Cumyl- } \\
\text { phenol } \\
\text { ( } \mu \mathrm{g} / \mathrm{L} \text { ) }\end{array}$ & $\begin{array}{c}\text { 4-n- } \\
\text { Octyl- } \\
\text { phenol } \\
(\mu \mathrm{g} / \mathrm{L})\end{array}$ & $\begin{array}{c}\text { 4-Nonyl- } \\
\text { phenol } \\
\text { (sum of } \\
\text { isomers) } \\
\text { ( } \mu \mathrm{g} / \mathrm{L})\end{array}$ \\
\hline \multicolumn{14}{|c|}{ Regional aquifer public-supply wells } \\
\hline 293359098290301 & AY-68-29-414 & 1st (highest) quartile & $2004 / 12 / 06$ & $<0.5$ & $<0.5$ & $<0.5$ & $<0.5$ & $<2.0$ & $<1.0$ & $<5.0$ & $<1.0$ & $<1.0$ & $\mathrm{~V} 1.10$ \\
\hline 293359098290301 & AY-68-29-414 & 1st quartile & $2005 / 09 / 01$ & $<.5$ & $<.5$ & $<.5$ & $<.5$ & $<2.0$ & $<1.0$ & $<5.0$ & $<1.0$ & $<1.0$ & $<5.0$ \\
\hline 293358098231101 & AY-68-29-610 & 1st quartile & $2004 / 12 / 15$ & $<.5$ & $<.5$ & $<.5$ & $<.5$ & $<2.0$ & $<1.0$ & $<5.0$ & $<1.0$ & $<1.0$ & V.470 \\
\hline 293358098231101 & AY-68-29-610 & 1st quartile & $2005 / 08 / 29$ & $<.5$ & $<.5$ & $<.5$ & $<.5$ & $<2.0$ & $<1.0$ & $<5.0$ & $<1.0$ & $<1.0$ & V1.10 \\
\hline 293120098285801 & AY-68-29-714 & 1st quartile & $2004 / 12 / 14$ & $<.5$ & $<.5$ & $<.5$ & $<.5$ & $<2.0$ & $<1.0$ & $<5.0$ & $<1.0$ & $<1.0$ & $<5.0$ \\
\hline 293120098285801 & AY-68-29-714 & 1st quartile & $2005 / 08 / 30$ & -- & -- & -- & -- & -- & -- & -- & -- & -- & -- \\
\hline 293145098224201 & AY-68-29-929 & 1st quartile & $2004 / 12 / 15$ & $<.5$ & $<.5$ & $<.5$ & $<.5$ & $<2.0$ & $<1.0$ & $<5.0$ & $<1.0$ & $<1.0$ & V.510 \\
\hline 293119098211201 & AY-68-30-718 & 1st quartile & $2004 / 12 / 16$ & $<.5$ & $<.5$ & $<.5$ & $<.5$ & $<2.0$ & $<1.0$ & $<5.0$ & $<1.0$ & $<1.0$ & $<5.0$ \\
\hline 292843098425101 & AY-68-35-106 & 1st quartile & $2004 / 12 / 13$ & $<.5$ & $<.5$ & $<.5$ & $<.5$ & $<2.0$ & $<1.0$ & $<5.0$ & $<1.0$ & $<1.0$ & $<5.0$ \\
\hline 292459098382101 & AY-68-35-913 & 1st quartile & $2004 / 12 / 13$ & $<.5$ & $<.5$ & $<.5$ & $<.5$ & $<2.0$ & $<1.0$ & $<5.0$ & $<1.0$ & $<1.0$ & $<5.0$ \\
\hline 292925098360201 & AY-68-36-104 & 1st quartile & $2004 / 12 / 13$ & $<.5$ & $<.5$ & $<.5$ & $<.5$ & $<2.0$ & $<1.0$ & $<5.0$ & $<1.0$ & $<1.0$ & $<5.0$ \\
\hline 292925098360201 & AY-68-36-104 & 1st quartile & $2005 / 08 / 31$ & -- & -- & -- & -- & -- & -- & -- & -- & -- & -- \\
\hline 292822098325401 & AY-68-36-206 & 1st quartile & $2004 / 12 / 13$ & $<.5$ & $<.5$ & $<.5$ & $<.5$ & $<2.0$ & $<1.0$ & $<5.0$ & $<1.0$ & $<1.0$ & $<5.0$ \\
\hline 292822098325401 & AY-68-36-206 & 1st quartile & $2005 / 08 / 31$ & -- & -- & -- & -- & -- & -- & -- & -- & -- & -- \\
\hline 292944098292301 & AY-68-37-105 & 1st quartile & $2004 / 12 / 14$ & $<.5$ & $<.5$ & $<.5$ & $<.5$ & $<2.0$ & $<1.0$ & $<5.0$ & $<1.0$ & $<1.0$ & V.470 \\
\hline 292944098292301 & AY-68-37-105 & 1st quartile & $2005 / 08 / 31$ & $<.5$ & $<.5$ & $<.5$ & $<.5$ & $<2.0$ & $<1.0$ & $<5.0$ & $<1.0$ & $<1.0$ & V2.00 \\
\hline 292522098291901 & AY-68-37-426 & 1st quartile & $2004 / 12 / 14$ & $<.5$ & $<.5$ & $<.5$ & $<.5$ & $<2.0$ & $<1.0$ & $<5.0$ & $<1.0$ & $<1.0$ & $<5.0$ \\
\hline 292643098241801 & AY-68-37-601 & 1st quartile & $2004 / 12 / 15$ & $<.5$ & $<.5$ & $<.5$ & $<.5$ & $<2.0$ & $<1.0$ & $<5.0$ & $<1.0$ & $<1.0$ & V.670 \\
\hline 292643098241801 & AY-68-37-601 & 1st quartile & $2005 / 08 / 30$ & -- & -- & -- & -- & -- & -- & -- & -- & -- & -- \\
\hline 292328098294601 & AY-68-37-705 & 1st quartile & $2004 / 12 / 14$ & $<.5$ & $<.5$ & $<.5$ & $<.5$ & $<2.0$ & $<1.0$ & $<5.0$ & $<1.0$ & $<1.0$ & $<5.0$ \\
\hline 294225098080301 & DX-68-23-601 & 1st quartile & $2004 / 12 / 08$ & $<.5$ & $<.5$ & $<.5$ & $<.5$ & $<2.0$ & $<1.0$ & $<5.0$ & $<1.0$ & $<1.0$ & $<5.0$ \\
\hline 294225098080301 & DX-68-23-601 & 1st quartile & $2005 / 09 / 01$ & -- & -- & -- & -- & -- & -- & -- & -- & -- & -- \\
\hline 291210099475601 & YP-69-50-506 & 1st quartile & $2004 / 11 / 30$ & $<.5$ & $<.5$ & $<.5$ & $<.5$ & $<2.0$ & $<1.0$ & $<5.0$ & $<1.0$ & $<1.0$ & $<5.0$ \\
\hline
\end{tabular}


Table 13. Wastewater indicator compounds for groundwater samples collected for the study of the transport of anthropogenic and natural contaminants (TANC) to public supply wells in the San Antonio segment of the Edwards aquifer near San Antonio, south-central Texas, 2004-9.-Continued

[By sample category. USGS, U.S. Geological Survey; $\mu \mathrm{g} / \mathrm{L}$, micrograms per liter; <, nondetection less than laboratory method reporting level; --, not measured; V, contaminated]

\begin{tabular}{|c|c|c|c|c|c|c|c|c|c|c|c|c|c|}
\hline $\begin{array}{c}\text { USGS } \\
\text { identification } \\
\text { number }\end{array}$ & $\begin{array}{l}\text { State well } \\
\text { number }\end{array}$ & $\begin{array}{l}\text { Group and } \\
\text { description }\end{array}$ & $\begin{array}{c}\text { Sample } \\
\text { date }\end{array}$ & $\begin{array}{c}\text { 1,4-Di- } \\
\text { chloro- } \\
\text { benzene } \\
(\mu \mathrm{g} / \mathrm{L})\end{array}$ & $\begin{array}{l}\text { 1-Methyl- } \\
\text { naphth- } \\
\text { alene } \\
(\mu \mathrm{g} / \mathrm{L})\end{array}$ & $\begin{array}{c}\text { 2,6-Di- } \\
\text { methyl- } \\
\text { naphth- } \\
\text { alene } \\
\text { ( } \mathrm{gg} / \mathrm{L})\end{array}$ & $\begin{array}{l}\text { 2-Methyl- } \\
\text { naphth- } \\
\text { alene } \\
(\mu \mathrm{g} / \mathrm{L})\end{array}$ & $\begin{array}{l}\text { 3-beta- } \\
\text { Copro- } \\
\text { stanol } \\
(\mu \mathrm{g} / \mathrm{L})\end{array}$ & $\begin{array}{c}\text { 3-Methyl- } \\
\text { 1H-indole } \\
\text { ( } \mu \mathrm{g} / \mathrm{L})\end{array}$ & $\begin{array}{c}\text { 3-tert- } \\
\text { Butyl- } \\
\text { 4-hydroxy- } \\
\text { anisole } \\
\text { ( } \mu \mathrm{g} / \mathrm{L})\end{array}$ & $\begin{array}{c}\text { 4-Cumyl- } \\
\text { phenol } \\
\text { ( } \mu \mathrm{g} / \mathrm{L})\end{array}$ & $\begin{array}{c}\text { 4-n- } \\
\text { Octyl- } \\
\text { phenol } \\
(\mu \mathrm{g} / \mathrm{L})\end{array}$ & $\begin{array}{c}\text { 4-Nonyl- } \\
\text { phenol } \\
\text { (sum of } \\
\text { isomers) } \\
\text { ( } \mu \mathrm{g} / \mathrm{L} \text { ) }\end{array}$ \\
\hline 293111098340901 & AY-68-28-807 & 2d quartile & $2005 / 05 / 26$ & -- & -- & -- & -- & -- & -- & -- & -- & -- & -- \\
\hline 293512098291701 & AY-68-29-109 & 2d quartile & $2005 / 04 / 20$ & $<0.5$ & $<0.5$ & $<0.5$ & $<0.5$ & $<2.0$ & $<1.0$ & $<5.0$ & $<1.0$ & $<1.0$ & $<5.0$ \\
\hline 292424098421501 & AY-68-35-810 & 2d quartile & $2005 / 04 / 21$ & $<.5$ & $<.5$ & $<.5$ & $<.5$ & $<2.0$ & $<1.0$ & $<5.0$ & $<1.0$ & $<1.0$ & V1.10 \\
\hline 292053098365501 & AY-68-44-110 & 2d quartile & $2005 / 05 / 26$ & -- & -- & -- & -- & -- & -- & -- & -- & -- & -- \\
\hline 293807098155301 & DX-68-22-901 & 2d quartile & 2005/05/18 & $<.5$ & $<.5$ & $<.5$ & $<.5$ & $<2.0$ & $<1.0$ & $<5.0$ & $<1.0$ & $<1.0$ & $<5.0$ \\
\hline 292604098563201 & TD-68-33-501 & 2d quartile & 2005/05/16 & $<.5$ & $<.5$ & $<.5$ & $<.5$ & $<2.0$ & $<1.0$ & $<5.0$ & $<1.0$ & $<1.0$ & $<5.0$ \\
\hline 292116099095501 & TD-69-47-305 & 2d quartile & $2005 / 04 / 27$ & $<.5$ & $<.5$ & $<.5$ & $<.5$ & $<2.0$ & $<1.0$ & $<5.0$ & $<1.0$ & $<1.0$ & V.520 \\
\hline 291232099470301 & YP-69-50-339 & 2d quartile & 2005/05/11 & $<.5$ & $<.5$ & $<.5$ & $<.5$ & $<2.0$ & $<1.0$ & $<5.0$ & $<1.0$ & $<1.0$ & $<5.0$ \\
\hline 293128098473101 & AY-68-26-814 & 3d quartile & 2005/04/18 & $<.5$ & $<.5$ & $<.5$ & $<.5$ & $<2.0$ & $<1.0$ & $<5.0$ & $<1.0$ & $<1.0$ & $<5.0$ \\
\hline 293451098313201 & AY-68-28-601 & 3d quartile & $2005 / 05 / 17$ & $<.5$ & $<.5$ & $<.5$ & $<.5$ & $<2.0$ & $<1.0$ & $<5.0$ & $<1.0$ & $<1.0$ & V.980 \\
\hline 294604098060801 & DX-68-16-708 & 3d quartile & $2005 / 04 / 25$ & $<.5$ & $<.5$ & $<.5$ & $<.5$ & $<2.0$ & $<1.0$ & $<5.0$ & $<1.0$ & $<1.0$ & V3.20 \\
\hline 294019098114701 & DX-68-23-504 & 3d quartile & $2005 / 05 / 18$ & $<.5$ & $<.5$ & $<.5$ & $<.5$ & $<2.0$ & $<1.0$ & $<5.0$ & $<1.0$ & $<1.0$ & $<5.0$ \\
\hline 292215098580201 & TD-68-41-103 & 3d quartile & 2005/05/09 & $<.5$ & $<.5$ & $<.5$ & $<.5$ & $<2.0$ & $<1.0$ & $<5.0$ & $<1.0$ & $<1.0$ & $<5.0$ \\
\hline 292119098524901 & TD-68-41-308 & 3d quartile & $2005 / 04 / 27$ & $<.5$ & $<.5$ & $<.5$ & $<.5$ & $<2.0$ & $<1.0$ & $<5.0$ & $<1.0$ & $<1.0$ & V.760 \\
\hline 291943099163301 & TD-69-46-601 & 3d quartile & 2005/05/09 & $<.5$ & $<.5$ & $<.5$ & $<.5$ & $<2.0$ & $<1.0$ & $<5.0$ & $<1.0$ & $<1.0$ & V1.20 \\
\hline 291840099382601 & YP-69-43-606 & 3d quartile & 2005/05/11 & $<.5$ & $<.5$ & $<.5$ & $<.5$ & $<2.0$ & $<1.0$ & $<5.0$ & $<1.0$ & $<1.0$ & $<5.0$ \\
\hline 293518098332601 & AY-68-28-203 & 4th quartile & 2005/04/19 & $<.5$ & $<.5$ & $<.5$ & $<.5$ & $<2.0$ & $<1.0$ & $<5.0$ & $<1.0$ & $<1.0$ & $<5.0$ \\
\hline 293023098355401 & AY-68-28-702 & 4th quartile & $2005 / 04 / 26$ & $<.5$ & $<.5$ & $<.5$ & $<.5$ & $<2.0$ & $<1.0$ & $<5.0$ & $<1.0$ & $<1.0$ & V.990 \\
\hline 293042098305201 & AY-68-28-913 & 4th quartile & 2005/06/30 & $<.5$ & $<.5$ & $<.5$ & $<.5$ & $<2.0$ & $<1.0$ & $<5.0$ & $<1.0$ & $<1.0$ & $<5.0$ \\
\hline 292442098474501 & AY-68-34-803 & 4th quartile & $2005 / 04 / 20$ & $<.5$ & $<.5$ & $<.5$ & $<.5$ & $<2.0$ & $<1.0$ & $<5.0$ & $<1.0$ & $<1.0$ & $<5.0$ \\
\hline 292405098371201 & AY-68-36-704 & 4th quartile & $2005 / 05 / 23$ & $<.5$ & $<.5$ & $<.5$ & $<.5$ & $<2.0$ & $<1.0$ & $<5.0$ & $<1.0$ & $<1.0$ & $<5.0$ \\
\hline 292931098274601 & AY-68-37-124 & 4th quartile & $2005 / 05 / 25$ & $<.5$ & $<.5$ & $<.5$ & $<.5$ & $<2.0$ & $<1.0$ & $<5.0$ & $<1.0$ & $<1.0$ & $<5.0$ \\
\hline 293729098173101 & DX-68-30-215 & 4th quartile & $2005 / 04 / 25$ & $<.5$ & $<.5$ & $<.5$ & $<.5$ & $<2.0$ & $<1.0$ & $<5.0$ & $<1.0$ & $<1.0$ & $<5.0$ \\
\hline 291219099095601 & TD-69-55-604 & 4th quartile & 2005/05/16 & $<.5$ & $<.5$ & $<.5$ & $<.5$ & $<2.0$ & $<1.0$ & $<5.0$ & $<1.0$ & $<1.0$ & V.830 \\
\hline
\end{tabular}


Table 13. Wastewater indicator compounds for groundwater samples collected for the study of the transport of anthropogenic and natural contaminants (TANC) to public supply wells in the San Antonio segment of the Edwards aquifer near San Antonio, south-central Texas, 2004-9._Continued

[By sample category. USGS, U.S. Geological Survey; $\mu \mathrm{g} / \mathrm{L}$, micrograms per liter; <, nondetection less than laboratory method reporting level; --, not measured; V, contaminated]

\begin{tabular}{|c|c|c|c|c|c|c|c|c|c|c|c|c|c|c|c|c|c|}
\hline $\begin{array}{c}\text { USGS } \\
\text { identification } \\
\text { number }\end{array}$ & $\begin{array}{l}\text { 4-Nonyl- } \\
\text { phenol } \\
\text { dieth- } \\
\text { oxylate } \\
\text { (sum of } \\
\text { isomers) } \\
\text { ( } \mu \mathrm{g} / \mathrm{L})\end{array}$ & $\begin{array}{c}\text { 4-tert- } \\
\text { Octyl- } \\
\text { phenol } \\
\text { dieth- } \\
\text { oxylate } \\
\text { ( } \mu \mathrm{g} / \mathrm{L} \text { ) }\end{array}$ & $\begin{array}{c}\text { 4-tert- } \\
\text { Octyl- } \\
\text { phenol } \\
\text { mono- } \\
\text { ethoxylate } \\
\text { ( } \mu \mathrm{g} / \mathrm{L})\end{array}$ & $\begin{array}{c}\text { 4-tert- } \\
\text { Octyl- } \\
\text { phenol } \\
\text { ( } \mathrm{gg} / \mathrm{L} \text { ) }\end{array}$ & $\begin{array}{c}\text { 5-Methyl- } \\
\text { 1H- } \\
\text { benzo- } \\
\text { triazole } \\
\text { ( } \mu \mathrm{g} / \mathrm{L})\end{array}$ & $\begin{array}{c}\text { 9,10- } \\
\text { Anthra- } \\
\text { quinone } \\
\text { ( } \mu \mathrm{g} / \mathrm{L} \text { ) }\end{array}$ & $\begin{array}{l}\text { Aceto- } \\
\text { phe- } \\
\text { none } \\
(\mu \mathrm{g} / \mathrm{L})\end{array}$ & $\begin{array}{c}\text { Acetyl } \\
\text { hexa- } \\
\text { methyl } \\
\text { tetrahydro } \\
\text { naph- } \\
\text { thalene } \\
\text { (AHTN) } \\
\text { ( } \mathrm{gg} / \mathrm{L})\end{array}$ & $\begin{array}{c}\text { Anth- } \\
\text { racene } \\
\text { ( } \mu \mathrm{g} / \mathrm{L})\end{array}$ & $\begin{array}{l}\text { Benzo- } \\
\text { [a]- } \\
\text { pyrene } \\
(\mu \mathrm{g} / \mathrm{L})\end{array}$ & $\begin{array}{c}\text { Benzo- } \\
\text { phe- } \\
\text { none } \\
(\mu \mathrm{g} / \mathrm{L})\end{array}$ & $\begin{array}{l}\text { beta- } \\
\text { Sito- } \\
\text { sterol } \\
(\mu \mathrm{g} / \mathrm{L})\end{array}$ & $\begin{array}{l}\text { beta- } \\
\text { Stigma- } \\
\text { stanol } \\
(\mu \mathrm{g} / \mathrm{L})\end{array}$ & $\begin{array}{c}\text { Brom- } \\
\text { acil } \\
(\mu \mathrm{g} / \mathrm{L})\end{array}$ & $\begin{array}{l}\text { Cam- } \\
\text { phor } \\
(\mu \mathrm{g} / \mathrm{L})\end{array}$ & $\begin{array}{c}\text { Caffeine } \\
(\mu \mathrm{g} / \mathrm{L})\end{array}$ & $\begin{array}{l}\text { Carba- } \\
\text { zole } \\
(\mu \mathrm{g} / \mathrm{L})\end{array}$ \\
\hline \multicolumn{18}{|c|}{ Regional aquifer public-supply wells } \\
\hline 293359098290301 & $<5.0$ & $<1.0$ & $<1.0$ & $<1.0$ & $<2.0$ & $<0.5$ & $<0.5$ & $<0.5$ & $<0.5$ & $<0.5$ & V0.068 & $<2.0$ & $<2.0$ & $<0.018$ & $<0.5$ & $<0.018$ & $<0.5$ \\
\hline 293359098290301 & $<5.0$ & $<1.0$ & $<1.0$ & $<1.0$ & $<2.0$ & $<.5$ & $<.5$ & $<.5$ & $<.5$ & $<.5$ & $<.5$ & $<2.0$ & $<2.0$ & $<.018$ & $<.5$ & $<.018$ & $<.5$ \\
\hline 293358098231101 & $<5.0$ & $<1.0$ & $<1.0$ & $<1.0$ & $<2.0$ & $<.5$ & $<.5$ & $<.5$ & $<.5$ & $<.5$ & $<.5$ & $<2.0$ & $<2.0$ & $<.018$ & $<.5$ & $<.018$ & $<.5$ \\
\hline 293358098231101 & $<5.0$ & $<1.0$ & $<1.0$ & $<1.0$ & $<2.0$ & $<.5$ & $<.5$ & $<.5$ & $<.5$ & $<.5$ & $<.5$ & $<2.0$ & $<2.0$ & $<.018$ & $<.5$ & $<.018$ & $<.5$ \\
\hline 293120098285801 & $<5.0$ & $<1.0$ & $<1.0$ & $<1.0$ & $<2.0$ & $<.5$ & $<.5$ & $<.5$ & $<.5$ & $<.5$ & $<.5$ & $<2.0$ & $<2.0$ & $<.018$ & $<.5$ & V.007 & $<.5$ \\
\hline 293120098285801 & -- & -- & -- & -- & -- & -- & -- & -- & -- & -- & -- & -- & -- & $<.018$ & -- & $<.018$ & -- \\
\hline 293145098224201 & $<5.0$ & $<1.0$ & $<1.0$ & $<1.0$ & $<2.0$ & $<.5$ & $<.5$ & $<.5$ & $<.5$ & $<.5$ & $<.5$ & $<2.0$ & $<2.0$ & $<.018$ & $<.5$ & $<.018$ & $<.5$ \\
\hline 293119098211201 & $<5.0$ & $<1.0$ & $<1.0$ & $<1.0$ & $<2.0$ & $<.5$ & $<.5$ & $<.5$ & $<.5$ & $<.5$ & $<.5$ & $<2.0$ & $<2.0$ & $<.018$ & $<.5$ & $<.018$ & $<.5$ \\
\hline 292843098425101 & $<5.0$ & $<1.0$ & $<1.0$ & $<1.0$ & $<2.0$ & $<.5$ & $<.5$ & $<.5$ & $<.5$ & $<.5$ & $<.5$ & $<2.0$ & $<2.0$ & $<.018$ & $<.5$ & $<.018$ & $<.5$ \\
\hline 292459098382101 & $<5.0$ & $<1.0$ & $<1.0$ & $<1.0$ & $<2.0$ & $<.5$ & $<.5$ & $<.5$ & $<.5$ & $<.5$ & $<.5$ & $<2.0$ & $<2.0$ & $<.018$ & $<.5$ & $<.018$ & $<.5$ \\
\hline 292925098360201 & $<5.0$ & $<1.0$ & $<1.0$ & $<1.0$ & $<2.0$ & $<.5$ & $<.5$ & $<.5$ & $<.5$ & $<.5$ & $<.5$ & $<2.0$ & $<2.0$ & $<.018$ & $<.5$ & V.009 & $<.5$ \\
\hline 292925098360201 & -- & -- & -- & -- & -- & -- & -- & -- & -- & -- & -- & -- & -- & $<.018$ & -- & $<.018$ & -- \\
\hline 292822098325401 & $<5.0$ & $<1.0$ & $<1.0$ & $<1.0$ & $<2.0$ & $<.5$ & $<.5$ & $<.5$ & $<.5$ & $<.5$ & $<.5$ & $<2.0$ & $<2.0$ & $<.018$ & $<.5$ & $<.018$ & $<.5$ \\
\hline 292822098325401 & -- & -- & -- & -- & -- & -- & -- & -- & -- & -- & -- & -- & -- & -- & -- & -- & -- \\
\hline 292944098292301 & $<5.0$ & $<1.0$ & $<1.0$ & $<1.0$ & $<2.0$ & $<.5$ & $<.5$ & $<.5$ & $<.5$ & $<.5$ & $<.5$ & $<2.0$ & $<2.0$ & $<.018$ & $<.5$ & $<.018$ & $<.5$ \\
\hline 292944098292301 & $<5.0$ & $<1.0$ & $<1.0$ & $<1.0$ & $<2.0$ & $<.5$ & $<.5$ & $<.5$ & $<.5$ & $<.5$ & $<.5$ & $<2.0$ & $<2.0$ & $<.5$ & V.004 & $<.5$ & $<.5$ \\
\hline 292522098291901 & $<5.0$ & $<1.0$ & $<1.0$ & $<1.0$ & $<2.0$ & $<.5$ & $<.5$ & $<.5$ & $<.5$ & $<.5$ & $<.5$ & $<2.0$ & $<2.0$ & $<.018$ & $<.5$ & $<.018$ & $<.5$ \\
\hline 292643098241801 & $<5.0$ & $<1.0$ & $<1.0$ & $<1.0$ & $<2.0$ & $<.5$ & $<.5$ & $<.5$ & $<.5$ & $<.5$ & $<.5$ & $<2.0$ & $<2.0$ & $<.018$ & $<.5$ & V.005 & $<.5$ \\
\hline 292643098241801 & -- & -- & -- & -- & -- & -- & -- & -- & -- & -- & -- & -- & -- & $<.018$ & -- & $<.018$ & -- \\
\hline 292328098294601 & $<5.0$ & $<1.0$ & $<1.0$ & $<1.0$ & $<2.0$ & $<.5$ & $<.5$ & $<.5$ & $<.5$ & $<.5$ & $<.5$ & $<2.0$ & $<2.0$ & $<.018$ & $<.5$ & $<.018$ & $<.5$ \\
\hline 294225098080301 & $<5.0$ & $<1.0$ & $<1.0$ & $<1.0$ & $<2.0$ & $<.5$ & $<.5$ & $<.5$ & $<.5$ & $<.5$ & $<.5$ & $<2.0$ & $<2.0$ & $<.018$ & $<.5$ & V.009 & $<.5$ \\
\hline 294225098080301 & -- & -- & -- & -- & -- & -- & -- & -- & -- & -- & -- & -- & -- & -- & -- & -- & -- \\
\hline 291210099475601 & $<5.0$ & $<1.0$ & $<1.0$ & $<1.0$ & $<2.0$ & $<.5$ & $<.5$ & $<.5$ & $<.5$ & $<.5$ & $<.5$ & $<2.0$ & $<2.0$ & $<.018$ & $<.5$ & $<.018$ & $<.5$ \\
\hline
\end{tabular}


Table 13. Wastewater indicator compounds for groundwater samples collected for the study of the transport of anthropogenic and natural contaminants (TANC) to public supply wells in the San Antonio segment of the Edwards aquifer near San Antonio, south-central Texas, 2004-9.-Continued

[By sample category. USGS, U.S. Geological Survey; $\mu \mathrm{g} / \mathrm{L}$, micrograms per liter; <, nondetection less than laboratory method reporting level; --, not measured; V, contaminated]

\begin{tabular}{|c|c|c|c|c|c|c|c|c|c|c|c|c|c|c|c|c|c|}
\hline $\begin{array}{c}\text { USGS } \\
\text { identification } \\
\text { number }\end{array}$ & $\begin{array}{l}\text { 4-Nonyl- } \\
\text { phenol } \\
\text { dieth- } \\
\text { oxylate } \\
\text { (sum of } \\
\text { isomers) } \\
\text { ( } \mu \mathrm{g} / \mathrm{L})\end{array}$ & $\begin{array}{c}\text { 4-tert- } \\
\text { Octyl- } \\
\text { phenol } \\
\text { dieth- } \\
\text { oxylate } \\
\text { ( } \mu \mathrm{g} / \mathrm{L} \text { ) }\end{array}$ & $\begin{array}{c}\text { 4-tert- } \\
\text { Octyl- } \\
\text { phenol } \\
\text { mono- } \\
\text { ethoxylate } \\
(\mu \mathrm{g} / \mathrm{L})\end{array}$ & $\begin{array}{c}\text { 4-tert- } \\
\text { Octyl- } \\
\text { phenol } \\
(\mu \mathrm{g} / \mathrm{L})\end{array}$ & $\begin{array}{c}\text { 5-Methyl- } \\
\text { 1H- } \\
\text { benzo- } \\
\text { triazole } \\
\text { ( } \mu \mathrm{g} / \mathrm{L} \text { ) }\end{array}$ & $\begin{array}{c}\text { 9,10- } \\
\text { Anthra- } \\
\text { quinone } \\
\text { ( } \mu \mathrm{g} / \mathrm{L} \text { ) }\end{array}$ & $\begin{array}{l}\text { Aceto- } \\
\text { phe- } \\
\text { none } \\
(\mu \mathrm{g} / \mathrm{L})\end{array}$ & $\begin{array}{c}\text { Acetyl } \\
\text { hexa- } \\
\text { methyl } \\
\text { tetrahydro } \\
\text { naph- } \\
\text { thalene } \\
\text { (AHTN) } \\
\text { ( } \mu \mathrm{g} / \mathrm{L})\end{array}$ & $\begin{array}{c}\text { Anth- } \\
\text { racene } \\
\text { ( } \mu \mathrm{g} / \mathrm{L})\end{array}$ & $\begin{array}{l}\text { Benzo- } \\
\text { [a]- } \\
\text { pyrene } \\
\text { ( } \mu \mathrm{g} / \mathrm{L})\end{array}$ & $\begin{array}{l}\text { Benzo- } \\
\text { phe- } \\
\text { none } \\
(\mu \mathrm{g} / \mathrm{L})\end{array}$ & $\begin{array}{l}\text { beta- } \\
\text { Sito- } \\
\text { sterol } \\
\text { ( } \mu \mathrm{g} / \mathrm{L})\end{array}$ & $\begin{array}{l}\text { beta- } \\
\text { Stigma- } \\
\text { stanol } \\
(\mu \mathrm{g} / \mathrm{L})\end{array}$ & $\begin{array}{c}\text { Brom- } \\
\text { acil } \\
(\mu \mathrm{g} / \mathrm{L})\end{array}$ & $\begin{array}{l}\text { Cam- } \\
\text { phor } \\
\text { ( } \mu \mathrm{g} / \mathrm{L})\end{array}$ & $\begin{array}{c}\text { Caffeine } \\
\text { ( } \mu \mathrm{g} / \mathrm{L})\end{array}$ & $\begin{array}{c}\text { Carba- } \\
\text { zole } \\
(\mu \mathrm{g} / \mathrm{L})\end{array}$ \\
\hline 293111098340901 & -- & -- & -- & -- & -- & -- & -- & -- & -- & -- & -- & -- & -- & -- & -- & -- & -- \\
\hline 293512098291701 & $<5.0$ & $<1.0$ & $<1.0$ & $<1.0$ & $<2.0$ & $<0.5$ & $<0.5$ & $<0.5$ & $<0.5$ & $<0.5$ & $<0.5$ & $<2.0$ & $<2.0$ & $<0.5$ & $<0.5$ & $<0.5$ & $<0.5$ \\
\hline 292424098421501 & $<5.0$ & $<1.0$ & $<1.0$ & $<1.0$ & $<2.0$ & $<.5$ & $<.5$ & $<.5$ & $<.5$ & $<.5$ & V.048 & $<2.0$ & $<2.0$ & $<.5$ & $<.5$ & $<.5$ & $<.5$ \\
\hline 292053098365501 & -- & -- & -- & -- & -- & -- & -- & -- & -- & -- & -- & -- & -- & -- & -- & -- & -- \\
\hline 293807098155301 & $<5.0$ & $<1.0$ & $<1.0$ & $<1.0$ & $<2.0$ & $<.5$ & $<.5$ & $<.5$ & $<.5$ & $<.5$ & V.066 & $<2.0$ & $<2.0$ & $<.5$ & $<.5$ & $<.5$ & $<.5$ \\
\hline 292604098563201 & $<5.0$ & $<1.0$ & $<1.0$ & $<1.0$ & $<2.0$ & $<.5$ & $<.5$ & $<.5$ & $<.5$ & $<.5$ & $<.5$ & $<2.0$ & $<2.0$ & $<.5$ & $<.5$ & $<.5$ & $<.5$ \\
\hline 292116099095501 & $<5.0$ & $<1.0$ & $<1.0$ & $<1.0$ & $<2.0$ & $<.5$ & $<.5$ & $<.5$ & $<.5$ & $<.5$ & $<.5$ & $<2.0$ & $<2.0$ & $<.5$ & $<.5$ & $<.5$ & $<.5$ \\
\hline 291232099470301 & $<5.0$ & $<1.0$ & $<1.0$ & $<1.0$ & $<2.0$ & $<.5$ & $<.5$ & $<.5$ & $<.5$ & $<.5$ & V.030 & $<2.0$ & $<2.0$ & $<.5$ & $<.5$ & $<.5$ & $<.5$ \\
\hline 293128098473101 & $<5.0$ & $<1.0$ & $<1.0$ & $<1.0$ & $<2.0$ & $<.5$ & $<.5$ & $<.5$ & $<.5$ & $<.5$ & $<.5$ & $<2.0$ & $<2.0$ & $<.5$ & $<.5$ & $<.5$ & $<.5$ \\
\hline 293451098313201 & $<5.0$ & $<1.0$ & $<1.0$ & $<1.0$ & $<2.0$ & $<.5$ & $<.5$ & $<.5$ & $<.5$ & $<.5$ & V.067 & $<2.0$ & $<2.0$ & $<.5$ & $<.5$ & $<.5$ & $<.5$ \\
\hline 294604098060801 & $<5.0$ & $<1.0$ & $<1.0$ & $<1.0$ & $<2.0$ & $<.5$ & $<.5$ & $<.5$ & $<.5$ & $<.5$ & V.220 & $<2.0$ & $<2.0$ & $<.5$ & $<.5$ & $<.5$ & $<.5$ \\
\hline 294019098114701 & $<5.0$ & $<1.0$ & $<1.0$ & $<1.0$ & $<2.0$ & $<.5$ & $<.5$ & $<.5$ & $<.5$ & $<.5$ & $<.5$ & $<2.0$ & $<2.0$ & $<.5$ & $<.5$ & $<.5$ & $<.5$ \\
\hline 292215098580201 & $<5.0$ & $<1.0$ & $<1.0$ & $<1.0$ & $<2.0$ & $<.5$ & $<.5$ & $<.5$ & $<.5$ & $<.5$ & V.027 & $<2.0$ & $<2.0$ & $<.5$ & $<.5$ & $<.5$ & $<.5$ \\
\hline 292119098524901 & $<5.0$ & $<1.0$ & $<1.0$ & $<1.0$ & $<2.0$ & $<.5$ & $<.5$ & $<.5$ & $<.5$ & $<.5$ & $<.5$ & $<2.0$ & $<2.0$ & $<.5$ & $<.5$ & $<.5$ & $<.5$ \\
\hline 291943099163301 & $<5.0$ & $<1.0$ & $<1.0$ & $<1.0$ & $<2.0$ & $<.5$ & $<.5$ & $<.5$ & $<.5$ & $<.5$ & V.013 & $<2.0$ & $<2.0$ & $<.5$ & $<.5$ & $<.5$ & $<.5$ \\
\hline 291840099382601 & $<5.0$ & $<1.0$ & $<1.0$ & $<1.0$ & $<2.0$ & $<.5$ & $<.5$ & $<.5$ & $<.5$ & $<.5$ & V.016 & $<2.0$ & $<2.0$ & $<.5$ & $<.5$ & $<.5$ & $<.5$ \\
\hline 293518098332601 & $<5.0$ & $<1.0$ & $<1.0$ & $<1.0$ & $<2.0$ & $<.5$ & $<.5$ & $<.5$ & $<.5$ & $<.5$ & $<.5$ & $<2.0$ & $<2.0$ & $<.5$ & $<.5$ & $<.5$ & $<.5$ \\
\hline 293023098355401 & $<5.0$ & $<1.0$ & $<1.0$ & $<1.0$ & $<2.0$ & $<.5$ & $<.5$ & $<.5$ & $<.5$ & $<.5$ & V.027 & $<2.0$ & $<2.0$ & $<.5$ & $<.5$ & $<.5$ & $<.5$ \\
\hline 293042098305201 & $<5.0$ & $<1.0$ & $<1.0$ & $<1.0$ & $<2.0$ & $<.5$ & $<.5$ & $<.5$ & $<.5$ & $<.5$ & V.023 & $<2.0$ & $<2.0$ & $<.5$ & V.006 & $<.5$ & $<.5$ \\
\hline 292442098474501 & $<5.0$ & $<1.0$ & $<1.0$ & $<1.0$ & $<2.0$ & $<.5$ & $<.5$ & $<.5$ & $<.5$ & $<.5$ & $<.5$ & $<2.0$ & $<2.0$ & $<.5$ & $<.5$ & $<.5$ & $<.5$ \\
\hline 292405098371201 & $<5.0$ & $<1.0$ & $<1.0$ & $<1.0$ & $<2.0$ & $<.5$ & $<.5$ & $<.5$ & $<.5$ & $<.5$ & $<.5$ & $<2.0$ & $<2.0$ & $<.5$ & $<.5$ & $<.5$ & $<.5$ \\
\hline 292931098274601 & -- & -- & -- & -- & -- & -- & -- & -- & -- & -- & -- & -- & -- & -- & -- & -- & -- \\
\hline 293729098173101 & $<5.0$ & $<1.0$ & $<1.0$ & $<1.0$ & $<2.0$ & $<.5$ & $<.5$ & $<.5$ & $<.5$ & $<.5$ & $<.5$ & $<2.0$ & $<2.0$ & $<.5$ & $<.5$ & $<.5$ & $<.5$ \\
\hline 291219099095601 & $<5.0$ & $<1.0$ & $<1.0$ & $<1.0$ & $<2.0$ & $<.5$ & $<.5$ & $<.5$ & $<.5$ & $<.5$ & V.017 & $<2.0$ & $<2.0$ & $<.5$ & $<.5$ & $<.5$ & $<.5$ \\
\hline
\end{tabular}


Table 13. Wastewater indicator compounds for groundwater samples collected for the study of the transport of anthropogenic and natural contaminants (TANC) to public supply wells in the San Antonio segment of the Edwards aquifer near San Antonio, south-central Texas, 2004-9.-Continued

[By sample category. USGS, U.S. Geological Survey; $\mu \mathrm{g} / \mathrm{L}$, micrograms per liter; <, nondetection less than laboratory method reporting level; --, not measured; V, contaminated]

\begin{tabular}{|c|c|c|c|c|c|c|c|c|c|c|c|c|c|c|}
\hline $\begin{array}{c}\text { USGS } \\
\text { identification } \\
\text { number }\end{array}$ & $\begin{array}{l}\text { Chol- } \\
\text { esterol } \\
\text { ( } \mu \mathrm{g} / \mathrm{L})\end{array}$ & $\begin{array}{c}\text { Cotinine } \\
(\mu \mathrm{g} / \mathrm{L})\end{array}$ & $\begin{array}{c}\mathrm{N}, \mathrm{N}- \\
\text { diethyl- } \\
\text { meta- } \\
\text { tolua- } \\
\text { mide } \\
\text { ( } \mu \mathrm{g} / \mathrm{L})\end{array}$ & $\begin{array}{c}\text { D-Limo- } \\
\text { nene } \\
\text { ( } \mu \mathrm{g} / \mathrm{L})\end{array}$ & $\begin{array}{l}\text { Fluor- } \\
\text { anthene } \\
\text { ( } \mu \mathrm{g} / \mathrm{L})\end{array}$ & $\begin{array}{c}\text { Hexahydro- } \\
\text { hexamethyl } \\
\text { cyclopenta- } \\
\text { benzopyran } \\
\text { (HHCB) } \\
(\mu \mathrm{g} / \mathrm{L})\end{array}$ & $\begin{array}{l}\text { Indole } \\
(\mu \mathrm{g} / \mathrm{L})\end{array}$ & $\begin{array}{c}\text { Iso- } \\
\text { borneol } \\
\text { (pg/L) }\end{array}$ & $\begin{array}{c}\text { Iso- } \\
\text { phorone } \\
\text { ( } \mu \mathrm{g} / \mathrm{L})\end{array}$ & $\begin{array}{c}\text { Iso- } \\
\text { propyl- } \\
\text { benzene } \\
(\mu \mathrm{g} / \mathrm{L})\end{array}$ & $\begin{array}{l}\text { Iso- } \\
\text { quino- } \\
\text { line } \\
(\mu \mathrm{g} / \mathrm{L})\end{array}$ & $\begin{array}{c}\text { Men- } \\
\text { thol } \\
(\mu \mathrm{g} / \mathrm{L})\end{array}$ & $\begin{array}{c}\text { Meta- } \\
\text { laxyl } \\
(\mu \mathrm{g} / \mathrm{L})\end{array}$ & $\begin{array}{c}\text { Methyl } \\
\text { sali- } \\
\text { cylate } \\
\text { ( } \mu \mathrm{g} / \mathrm{L})\end{array}$ \\
\hline \multicolumn{15}{|c|}{ Regional aquifer public-supply wells } \\
\hline 293359098290301 & $<2.0$ & $<1.0$ & $<0.5$ & $<0.5$ & $<0.5$ & $<0.5$ & $<0.5$ & $<0.5$ & $<0.5$ & $<0.5$ & $<0.5$ & $<0.5$ & $<0.012$ & $<0.5$ \\
\hline 293359098290301 & $<2.0$ & $<1.0$ & $<.5$ & $<.5$ & $<.5$ & $<.5$ & $<.5$ & $<.5$ & $<.5$ & V.003 & $<.5$ & $<.5$ & $<.012$ & $<.5$ \\
\hline 293358098231101 & $<2.0$ & $<1.0$ & $<.5$ & $<.5$ & $<.5$ & $<.5$ & $<.5$ & $<.5$ & $<.5$ & $<.5$ & $<.5$ & $<.5$ & $<.012$ & $<.5$ \\
\hline 293358098231101 & $<2.0$ & $<1.0$ & $<.5$ & $<.5$ & $<.5$ & $<.5$ & $<.5$ & $<.5$ & $<.5$ & $<.5$ & $<.5$ & $<.5$ & $<.012$ & $<.5$ \\
\hline 293120098285801 & $<2.0$ & $<1.0$ & $<.5$ & $<.5$ & $<.5$ & $<.5$ & $<.5$ & $<.5$ & $<.5$ & $<.5$ & $<.5$ & $<.5$ & $<.012$ & $<.5$ \\
\hline 293120098285801 & -- & -- & -- & -- & -- & -- & -- & -- & -- & -- & -- & -- & $<.012$ & -- \\
\hline 293145098224201 & $<2.0$ & $<1.0$ & $<.5$ & $<.5$ & $<.5$ & $<.5$ & $<.5$ & $<.5$ & $<.5$ & $<.5$ & $<.5$ & $<.5$ & $<.012$ & $<.5$ \\
\hline 293119098211201 & $<2.0$ & $<1.0$ & $<.5$ & $<.5$ & $<.5$ & $<.5$ & $<.5$ & $<.5$ & $<.5$ & $<.5$ & $<.5$ & $<.5$ & $<.012$ & $<.5$ \\
\hline 292843098425101 & $<2.0$ & $<1.0$ & $<.5$ & $<.5$ & $<.5$ & $<.5$ & $<.5$ & $<.5$ & $<.5$ & $<.5$ & $<.5$ & $<.5$ & $<.012$ & $<.5$ \\
\hline 292459098382101 & $<2.0$ & $<1.0$ & $<.5$ & $<.5$ & $<.5$ & $<.5$ & $<.5$ & $<.5$ & $<.5$ & $<.5$ & $<.5$ & $<.5$ & $<.012$ & $<.5$ \\
\hline 292925098360201 & $<2.0$ & $<1.0$ & $<.5$ & $<.5$ & $<.5$ & $<.5$ & $<.5$ & $<.5$ & $<.5$ & $<.5$ & $<.5$ & $<.5$ & $<.012$ & $<.5$ \\
\hline 292925098360201 & -- & -- & -- & -- & -- & -- & -- & -- & -- & -- & -- & -- & $<.012$ & -- \\
\hline 292822098325401 & $<2.0$ & $<1.0$ & $<.5$ & $<.5$ & $<.5$ & $<.5$ & $<.5$ & $<.5$ & $<.5$ & $<.5$ & $<.5$ & $<.5$ & $<.012$ & $<.5$ \\
\hline 292822098325401 & -- & -- & -- & -- & -- & -- & -- & -- & -- & -- & -- & -- & -- & -- \\
\hline 292944098292301 & $<2.0$ & $<1.0$ & $<.5$ & $<.5$ & $<.5$ & $<.5$ & $<.5$ & $<.5$ & $<.5$ & $<.5$ & $<.5$ & $<.5$ & $<.012$ & $<.5$ \\
\hline 292944098292301 & $<2.0$ & $<1.0$ & $<.5$ & $<.5$ & $<.5$ & $<.5$ & $<.5$ & $<.5$ & $<.5$ & $<.5$ & $<.5$ & $<.5$ & $<.5$ & $<.5$ \\
\hline 292522098291901 & $<2.0$ & $<1.0$ & $<.5$ & $<.5$ & $<.5$ & $<.5$ & $<.5$ & $<.5$ & $<.5$ & $<.5$ & $<.5$ & $<.5$ & $<.012$ & $<.5$ \\
\hline 292643098241801 & $<2.0$ & $<1.0$ & $<.5$ & $<.5$ & $<.5$ & $<.5$ & $<.5$ & $<.5$ & $<.5$ & $<.5$ & $<.5$ & $<.5$ & $<.012$ & $<.5$ \\
\hline 292643098241801 & -- & -- & -- & -- & -- & -- & -- & -- & -- & -- & -- & -- & $<.012$ & -- \\
\hline 292328098294601 & $<2.0$ & $<1.0$ & $<.5$ & $<.5$ & $<.5$ & $<.5$ & $<.5$ & $<.5$ & $<.5$ & $<.5$ & $<.5$ & $<.5$ & $<.012$ & $<.5$ \\
\hline 294225098080301 & $<2.0$ & $<1.0$ & $<.5$ & $<.5$ & $<.5$ & $<.5$ & $<.5$ & $<.5$ & $<.5$ & $<.5$ & $<.5$ & $<.5$ & $<.012$ & $<.5$ \\
\hline 294225098080301 & -- & -- & -- & -- & -- & -- & -- & -- & -- & -- & -- & -- & -- & -- \\
\hline 291210099475601 & $<2.0$ & $<1.0$ & $<.5$ & $<.5$ & $<.5$ & $<.5$ & $<.5$ & $<.5$ & $<.5$ & $<.5$ & $<.5$ & $<.5$ & $<.012$ & $<.5$ \\
\hline
\end{tabular}


Table 13. Wastewater indicator compounds for groundwater samples collected for the study of the transport of anthropogenic and natural contaminants (TANC) to public supply wells in the San Antonio segment of the Edwards aquifer near San Antonio, south-central Texas, 2004-9.-Continued

[By sample category. USGS, U.S. Geological Survey; $\mu \mathrm{g} / \mathrm{L}$, micrograms per liter; <, nondetection less than laboratory method reporting level; --, not measured; V, contaminated]

\begin{tabular}{|c|c|c|c|c|c|c|c|c|c|c|c|c|c|c|}
\hline $\begin{array}{c}\text { USGS } \\
\text { identification } \\
\text { number }\end{array}$ & $\begin{array}{l}\text { Chol- } \\
\text { esterol } \\
(\mu \mathrm{g} / \mathrm{L})\end{array}$ & $\begin{array}{c}\text { Cotinine } \\
\text { ( } \mu \mathrm{g} / \mathrm{L})\end{array}$ & $\begin{array}{c}\text { N,N- } \\
\text { diethyl- } \\
\text { meta- } \\
\text { tolua- } \\
\text { mide } \\
\text { ( } \mu \mathrm{g} / \mathrm{L})\end{array}$ & $\begin{array}{c}\text { D-Limo- } \\
\text { nene } \\
\text { (pg/L) }\end{array}$ & $\begin{array}{c}\text { Fluor- } \\
\text { anthene } \\
\text { ( } \mu \mathrm{g} / \mathrm{L})\end{array}$ & $\begin{array}{c}\text { Hexahydro- } \\
\text { hexamethyl } \\
\text { cyclopenta- } \\
\text { benzopyran } \\
\text { (HHCB) } \\
\text { ( } \mathrm{gg} / \mathrm{L})\end{array}$ & $\begin{array}{c}\text { Indole } \\
\text { ( } \mu \mathrm{g} / \mathrm{L})\end{array}$ & $\begin{array}{c}\text { Iso- } \\
\text { borneol } \\
\text { ( } \mathrm{gg} / \mathrm{L})\end{array}$ & $\begin{array}{c}\text { Iso- } \\
\text { phorone } \\
\text { ( } \mathrm{gg} / \mathrm{L})\end{array}$ & $\begin{array}{c}\text { Iso- } \\
\text { propyl- } \\
\text { benzene } \\
(\mu \mathrm{g} / \mathrm{L})\end{array}$ & $\begin{array}{l}\text { Iso- } \\
\text { quino- } \\
\text { line } \\
(\mu \mathrm{g} / \mathrm{L})\end{array}$ & $\begin{array}{c}\text { Men- } \\
\text { thol } \\
(\mu \mathrm{g} / \mathrm{L})\end{array}$ & $\begin{array}{c}\text { Meta- } \\
\text { laxyl } \\
(\mu \mathrm{g} / \mathrm{L})\end{array}$ & $\begin{array}{c}\text { Methyl } \\
\text { sali- } \\
\text { cylate } \\
\text { ( } \mu \mathrm{g} / \mathrm{L} \text { ) }\end{array}$ \\
\hline 293111098340901 & -- & -- & -- & -- & -- & -- & -- & -- & -- & -- & -- & -- & -- & -- \\
\hline 293512098291701 & $<2.0$ & $<1.0$ & $<0.5$ & $<0.5$ & $<0.5$ & $<0.5$ & $<0.5$ & $<0.5$ & $<0.5$ & $<0.5$ & $<0.5$ & $<0.5$ & $<0.5$ & $<0.5$ \\
\hline 292424098421501 & $<2.0$ & $<1.0$ & $<.5$ & $<.5$ & $<.5$ & $<.5$ & $<.5$ & $<.5$ & $<.5$ & $<.5$ & $<.5$ & $<.5$ & $<.5$ & $<.5$ \\
\hline 292053098365501 & -- & -- & -- & -- & -- & -- & -- & -- & -- & -- & -- & -- & -- & -- \\
\hline 293807098155301 & $<2.0$ & $<1.0$ & $<.5$ & $<.5$ & $<.5$ & $<.5$ & $<.5$ & $<.5$ & $<.5$ & $<.5$ & $<.5$ & $<.5$ & $<.5$ & $<.5$ \\
\hline 292604098563201 & $<2.0$ & $<1.0$ & $<.5$ & $<.5$ & $<.5$ & $<.5$ & $<.5$ & $<.5$ & $<.5$ & $<.5$ & $<.5$ & $<.5$ & $<.5$ & $<.5$ \\
\hline 292116099095501 & $<2.0$ & $<1.0$ & $<.5$ & $<.5$ & $<.5$ & $<.5$ & $<.5$ & $<.5$ & $<.5$ & $<.5$ & $<.5$ & $<.5$ & $<.5$ & $<.5$ \\
\hline 291232099470301 & $<2.0$ & $<1.0$ & $<.5$ & $<.5$ & $<.5$ & $<.5$ & $<.5$ & $<.5$ & $<.5$ & V.023 & $<.5$ & $<.5$ & $<.5$ & $<.5$ \\
\hline 293128098473101 & $<2.0$ & $<1.0$ & $<.5$ & $<.5$ & $<.5$ & $<.5$ & $<.5$ & $<.5$ & $<.5$ & $<.5$ & $<.5$ & $<.5$ & $<.5$ & $<.5$ \\
\hline 293451098313201 & $<2.0$ & $<1.0$ & $<.5$ & $<.5$ & $<.5$ & $<.5$ & $<.5$ & $<.5$ & $<.5$ & $<.5$ & $<.5$ & $<.5$ & $<.5$ & $<.5$ \\
\hline 294604098060801 & $<2.0$ & $<1.0$ & $<.5$ & $<.5$ & $<.5$ & $<.5$ & $<.5$ & $<.5$ & $<.5$ & $<.5$ & $<.5$ & $<.5$ & $<.5$ & $<.5$ \\
\hline 294019098114701 & $<2.0$ & $<1.0$ & $<.5$ & $<.5$ & $<.5$ & $<.5$ & $<.5$ & $<.5$ & $<.5$ & $<.5$ & $<.5$ & $<.5$ & $<.5$ & $<.5$ \\
\hline 292215098580201 & $<2.0$ & $<1.0$ & $<.5$ & $<.5$ & $<.5$ & $<.5$ & $<.5$ & $<.5$ & $<.5$ & $<.5$ & $<.5$ & $<.5$ & $<.5$ & $<.5$ \\
\hline 292119098524901 & $<2.0$ & $<1.0$ & $<.5$ & $<.5$ & $<.5$ & $<.5$ & $<.5$ & $<.5$ & $<.5$ & $<.5$ & $<.5$ & $<.5$ & $<.5$ & $<.5$ \\
\hline 291943099163301 & $<2.0$ & $<1.0$ & $<.5$ & $<.5$ & $<.5$ & $<.5$ & $<.5$ & $<.5$ & $<.5$ & $<.5$ & $<.5$ & $<.5$ & $<.5$ & $<.5$ \\
\hline 291840099382601 & $<2.0$ & $<1.0$ & $<.5$ & $<.5$ & $<.5$ & $<.5$ & $<.5$ & $<.5$ & $<.5$ & $<.5$ & $<.5$ & $<.5$ & $<.5$ & $<.5$ \\
\hline 293518098332601 & $<2.0$ & $<1.0$ & $<.5$ & $<.5$ & $<.5$ & $<.5$ & $<.5$ & $<.5$ & $<.5$ & $<.5$ & $<.5$ & $<.5$ & $<.5$ & $<.5$ \\
\hline 293023098355401 & $<2.0$ & $<1.0$ & $<.5$ & $<.5$ & $<.5$ & $<.5$ & $<.5$ & $<.5$ & $<.5$ & $<.5$ & $<.5$ & $<.5$ & $<.5$ & $<.5$ \\
\hline 293042098305201 & $<2.0$ & $<1.0$ & $<.5$ & $<.5$ & $<.5$ & $<.5$ & $<.5$ & $<.5$ & $<.5$ & $<.5$ & $<.5$ & $<.5$ & $<.5$ & $<.5$ \\
\hline 292442098474501 & $<2.0$ & $<1.0$ & $<.5$ & $<.5$ & $<.5$ & $<.5$ & $<.5$ & $<.5$ & $<.5$ & $<.5$ & $<.5$ & $<.5$ & $<.5$ & $<.5$ \\
\hline 292405098371201 & $<2.0$ & $<1.0$ & $<.5$ & $<.5$ & $<.5$ & $<.5$ & $<.5$ & $<.5$ & $<.5$ & $<.5$ & $<.5$ & $<.5$ & $<.5$ & $<.5$ \\
\hline 292931098274601 & -- & -- & -- & -- & -- & -- & -- & -- & -- & -- & -- & -- & -- & -- \\
\hline 293729098173101 & $<2.0$ & $<1.0$ & $<.5$ & $<.5$ & $<.5$ & $<.5$ & $<.5$ & $<.5$ & $<.5$ & $<.5$ & $<.5$ & $<.5$ & $<.5$ & $<.5$ \\
\hline 291219099095601 & $<2.0$ & $<1.0$ & $<.5$ & $<.5$ & $<.5$ & $<.5$ & $<.5$ & $<.5$ & $<.5$ & $<.5$ & $<.5$ & $<.5$ & $<.5$ & $<.5$ \\
\hline
\end{tabular}


Table 13. Wastewater indicator compounds for groundwater samples collected for the study of the transport of anthropogenic and natural contaminants (TANC) to public supply wells in the San Antonio segment of the Edwards aquifer near San Antonio, south-central Texas, 2004-9._Continued

[By sample category. USGS, U.S. Geological Survey; $\mu \mathrm{g} / \mathrm{L}$, micrograms per liter; <, nondetection less than laboratory method reporting level; --, not measured; V, contaminated]

\begin{tabular}{|c|c|c|c|c|c|c|c|c|c|c|c|c|c|c|}
\hline $\begin{array}{c}\text { USGS } \\
\text { identification } \\
\text { number }\end{array}$ & $\begin{array}{l}\text { Naphth- } \\
\text { alene } \\
(\mu \mathrm{g} / \mathrm{L})\end{array}$ & $\begin{array}{c}\text { p-Cresol } \\
(\mu \mathrm{g} / \mathrm{L})\end{array}$ & $\begin{array}{c}\text { Phen- } \\
\text { anthrene } \\
\text { ( } \mu \mathrm{g} / \mathrm{L})\end{array}$ & $\begin{array}{c}\text { Phenol } \\
\text { ( } \mu \mathrm{g} / \mathrm{L})\end{array}$ & $\begin{array}{c}\text { Pyrene } \\
(\mu \mathrm{g} / \mathrm{L})\end{array}$ & $\begin{array}{c}\text { Tetra- } \\
\text { chloro- } \\
\text { ethene } \\
\text { (PCE) } \\
\text { ( } \mu \mathrm{g} / \mathrm{L})\end{array}$ & $\begin{array}{c}\text { Tribromo- } \\
\text { methane } \\
\text { (bromo- } \\
\text { form) } \\
(\mu \mathrm{g} / \mathrm{L})\end{array}$ & $\begin{array}{l}\text { Tributyl } \\
\text { phos- } \\
\text { phate } \\
\text { ( } \mu \mathrm{g} / \mathrm{L})\end{array}$ & $\begin{array}{c}\text { Tri- } \\
\text { closan } \\
(\mu \mathrm{g} / \mathrm{L})\end{array}$ & $\begin{array}{c}\text { Tri- } \\
\text { ethyl } \\
\text { citrate } \\
(\mu \mathrm{g} / \mathrm{L})\end{array}$ & $\begin{array}{c}\text { Tri- } \\
\text { phenyl } \\
\text { phos- } \\
\text { phate } \\
\text { ( } \mu \mathrm{g} / \mathrm{L} \text { ) }\end{array}$ & $\begin{array}{c}\text { Tris } \\
\text { (2-but- } \\
\text { oxyethyl) } \\
\text { phos- } \\
\text { phate } \\
\text { ( } \mu \mathrm{g} / \mathrm{L})\end{array}$ & $\begin{array}{c}\text { Tris } \\
\text { (2-chloro- } \\
\text { ethyl) } \\
\text { phosphate } \\
\text { (FYROL CEF) } \\
\text { ( } \mu \mathrm{g} / \mathrm{L})\end{array}$ & $\begin{array}{c}\text { Tris } \\
\text { (dichloro- } \\
\text { isopropyl) } \\
\text { phosphate } \\
\text { (FYROL } \\
\text { FR 2) } \\
\text { ( } \mathrm{gg} / \mathrm{L})\end{array}$ \\
\hline \multicolumn{15}{|c|}{ Regional aquifer public-supply wells } \\
\hline 293359098290301 & $<0.5$ & $<1.0$ & $<0.5$ & V0.820 & $<.5$ & V0.280 & $<0.5$ & $<0.5$ & $<1.0$ & $<0.5$ & $<0.5$ & $<0.5$ & $<0.5$ & $<0.5$ \\
\hline 293359098290301 & $<.5$ & $<1.0$ & $<.5$ & $<.5$ & $<.5$ & V.250 & $<.5$ & $<.5$ & $<1.0$ & $<.5$ & $<.5$ & $<.5$ & $<.5$ & $<.5$ \\
\hline 293358098231101 & $<.5$ & $<1.0$ & $<.5$ & V.320 & $<.5$ & V.130 & V.023 & $<.5$ & $<1.0$ & $<.5$ & $<.5$ & $<.5$ & $<.5$ & $<.5$ \\
\hline 293358098231101 & $<.5$ & $<1.0$ & $<.5$ & $<.5$ & $<.5$ & V.093 & $<.5$ & $<.5$ & $<1.0$ & $<.5$ & $<.5$ & $<.5$ & $<.5$ & $<.5$ \\
\hline 293120098285801 & $<.5$ & $<1.0$ & $<.5$ & V.890 & $<.5$ & V.086 & V1.90 & $<.5$ & $<1.0$ & $<.5$ & $<.5$ & $<.5$ & $<.5$ & $<.5$ \\
\hline 293120098285801 & -- & -- & -- & -- & -- & -- & -- & -- & -- & -- & -- & -- & -- & -- \\
\hline 293145098224201 & $<.5$ & $<1.0$ & $<.5$ & V1.50 & $<.5$ & V.037 & $<.5$ & $<.5$ & $<1.0$ & $<.5$ & $<.5$ & $<.5$ & $<.5$ & $<.5$ \\
\hline 293119098211201 & $<.5$ & $<1.0$ & $<.5$ & $<.5$ & $<.5$ & $<.5$ & $<.5$ & $<.5$ & $<1.0$ & $<.5$ & $<.5$ & $<.5$ & $<.5$ & $<.5$ \\
\hline 292843098425101 & $<.5$ & $<1.0$ & $<.5$ & V.210 & $<.5$ & $<.5$ & $<.5$ & $<.5$ & $<1.0$ & $<.5$ & $<.5$ & $<.5$ & $<.5$ & $<.5$ \\
\hline 292459098382101 & $<.5$ & $<1.0$ & $<.5$ & V.480 & $<.5$ & $<.5$ & V.054 & $<.5$ & $<1.0$ & $<.5$ & $<.5$ & $<.5$ & $<.5$ & $<.5$ \\
\hline 292925098360201 & $<.5$ & $<1.0$ & $<.5$ & $<.5$ & $<.5$ & V.055 & V1.10 & $<.5$ & $<1.0$ & $<.5$ & $<.5$ & $<.5$ & $<.5$ & $<.5$ \\
\hline 292925098360201 & -- & -- & -- & -- & -- & -- & -- & -- & -- & -- & -- & -- & -- & -- \\
\hline 292822098325401 & $<.5$ & $<1.0$ & $<.5$ & V.210 & $<.5$ & V.022 & $<.5$ & $<.5$ & $<1.0$ & $<.5$ & $<.5$ & $<.5$ & $<.5$ & $<.5$ \\
\hline 292822098325401 & -- & -- & -- & -- & -- & -- & -- & -- & -- & -- & -- & -- & -- & -- \\
\hline 292944098292301 & $<.5$ & $<1.0$ & $<.5$ & V1.10 & $<.5$ & V.032 & $<.5$ & $<.5$ & $<1.0$ & $<.5$ & $<.5$ & $<.5$ & $<.5$ & $<.5$ \\
\hline 292944098292301 & $<.5$ & $<1.0$ & $<.5$ & $<.5$ & $<.5$ & V.015 & $<.5$ & $<.5$ & $<1.0$ & $<.5$ & $<.5$ & $<.5$ & $<.5$ & $<.5$ \\
\hline 292522098291901 & $<.5$ & $<1.0$ & $<.5$ & V.460 & $<.5$ & $<.5$ & V.024 & $<.5$ & $<1.0$ & $<.5$ & $<.5$ & $<.5$ & $<.5$ & $<.5$ \\
\hline 292643098241801 & $<.5$ & $<1.0$ & $<.5$ & V.690 & $<.5$ & $<.5$ & V.660 & $<.5$ & $<1.0$ & $<.5$ & $<.5$ & $<.5$ & $<.5$ & $<.5$ \\
\hline 292643098241801 & -- & -- & -- & -- & -- & -- & -- & -- & -- & -- & -- & -- & -- & -- \\
\hline 292328098294601 & $<.5$ & $<1.0$ & $<.5$ & V.140 & $<.5$ & V.020 & $<.5$ & $<.5$ & $<1.0$ & $<.5$ & $<.5$ & $<.5$ & $<.5$ & $<.5$ \\
\hline 294225098080301 & $<.5$ & $<1.0$ & $<.5$ & V.400 & $<.5$ & V.072 & $<.5$ & $<.5$ & $<1.0$ & $<.5$ & $<.5$ & $<.5$ & $<.5$ & $<.5$ \\
\hline 294225098080301 & -- & -- & -- & -- & -- & -- & -- & -- & -- & -- & -- & -- & -- & -- \\
\hline 291210099475601 & $<.5$ & $<1.0$ & $<.5$ & $<.5$ & $<.5$ & $<.5$ & $<.5$ & $<.5$ & $<1.0$ & $<.5$ & $<.5$ & $<.5$ & $<.5$ & $<.5$ \\
\hline
\end{tabular}


Table 13. Wastewater indicator compounds for groundwater samples collected for the study of the transport of anthropogenic and natural contaminants (TANC) to public supply wells in the San Antonio segment of the Edwards aquifer near San Antonio, south-central Texas, 2004-9.-Continued

[By sample category. USGS, U.S. Geological Survey; $\mu \mathrm{g} / \mathrm{L}$, micrograms per liter; <, nondetection less than laboratory method reporting level; --, not measured; V, contaminated]

\begin{tabular}{|c|c|c|c|c|c|c|c|c|c|c|c|c|c|c|}
\hline $\begin{array}{c}\text { USGS } \\
\text { identification } \\
\text { number }\end{array}$ & $\begin{array}{c}\text { Naphth- } \\
\text { alene } \\
(\mu \mathrm{g} / \mathrm{L})\end{array}$ & $\begin{array}{c}\text { p-Cresol } \\
(\mu \mathrm{g} / \mathrm{L})\end{array}$ & $\begin{array}{c}\text { Phen- } \\
\text { anthrene } \\
\text { ( } \mu \mathrm{g} / \mathrm{L})\end{array}$ & $\begin{array}{c}\text { Phenol } \\
\text { ( } \mu \mathrm{g} / \mathrm{L})\end{array}$ & $\begin{array}{c}\text { Pyrene } \\
\text { ( } \mu \mathrm{g} / \mathrm{L})\end{array}$ & $\begin{array}{c}\text { Tetra- } \\
\text { chloro- } \\
\text { ethene } \\
\text { (PCE) } \\
\text { ( } \mu \mathrm{g} / \mathrm{L})\end{array}$ & $\begin{array}{c}\text { Tribromo- } \\
\text { methane } \\
\text { (bromo- } \\
\text { form) } \\
(\mu \mathrm{g} / \mathrm{L})\end{array}$ & $\begin{array}{c}\text { Tributyl } \\
\text { phos- } \\
\text { phate } \\
(\mu \mathrm{g} / \mathrm{L})\end{array}$ & $\begin{array}{c}\text { Tri- } \\
\text { closan } \\
(\mu \mathrm{g} / \mathrm{L})\end{array}$ & $\begin{array}{c}\begin{array}{c}\text { Tri- } \\
\text { ethyl } \\
\text { citrate } \\
(\mu \mathrm{g} / \mathrm{L})\end{array}\end{array}$ & $\begin{array}{c}\text { Tri- } \\
\text { phenyl } \\
\text { phos- } \\
\text { phate } \\
\text { ( } \mu \mathrm{g} / \mathrm{L})\end{array}$ & $\begin{array}{c}\text { Tris } \\
\text { (2-but- } \\
\text { oxyethyl) } \\
\text { phos- } \\
\text { phate } \\
\text { ( } \mu \mathrm{g} / \mathrm{L})\end{array}$ & $\begin{array}{c}\text { Tris } \\
\text { (2-chloro- } \\
\text { ethyl) } \\
\text { phosphate } \\
\text { (FYROL CEF) } \\
\text { ( } \mu \mathrm{g} / \mathrm{L})\end{array}$ & $\begin{array}{c}\text { Tris } \\
\text { (dichloro- } \\
\text { isopropyl) } \\
\text { phosphate } \\
\text { (FYROL } \\
\text { FR 2) } \\
\text { ( } \mathrm{gg} / \mathrm{L})\end{array}$ \\
\hline 293111098340901 & -- & -- & -- & -- & -- & -- & -- & -- & -- & -- & -- & -- & -- & -- \\
\hline 293512098291701 & $<0.5$ & $<1.0$ & $<0.5$ & V1.90 & $<0.5$ & $<0.5$ & $<0.5$ & $<0.5$ & $<1.0$ & $<0.5$ & $<0.5$ & $<0.5$ & $<0.5$ & $<0.5$ \\
\hline 292424098421501 & $<.5$ & $<1.0$ & $<.5$ & V1.70 & $<.5$ & $<.5$ & $<.5$ & $<.5$ & $<1.0$ & $<.5$ & $<.5$ & $<.5$ & $<.5$ & $<.5$ \\
\hline 292053098365501 & -- & -- & -- & -- & -- & -- & -- & -- & -- & -- & -- & -- & -- & -- \\
\hline 293807098155301 & $<.5$ & $<1.0$ & $<.5$ & V1.50 & $<.5$ & $<.5$ & V.500 & $<.5$ & $<1.0$ & $<.5$ & $<.5$ & $<.5$ & $<.5$ & $<.5$ \\
\hline 292604098563201 & $<.5$ & $<1.0$ & $<.5$ & V2.20 & $<.5$ & $<.5$ & $<.5$ & $<.5$ & $<1.0$ & $<.5$ & $<.5$ & $<.5$ & $<.5$ & $<.5$ \\
\hline 292116099095501 & $<.5$ & $<1.0$ & $<.5$ & $<.5$ & $<.5$ & $<.5$ & $<.5$ & $<.5$ & $<1.0$ & $<.5$ & $<.5$ & $<.5$ & $<.5$ & $<.5$ \\
\hline 291232099470301 & $<.5$ & $<1.0$ & $<.5$ & V.500 & $<.5$ & V.040 & $<.5$ & $<.5$ & $<1.0$ & $<.5$ & $<.5$ & $<.5$ & $<.5$ & $<.5$ \\
\hline 293128098473101 & $<.5$ & $<1.0$ & $<.5$ & V1.30 & $<.5$ & $<.5$ & $<.5$ & $<.5$ & $<1.0$ & $<.5$ & $<.5$ & $<.5$ & $<.5$ & $<.5$ \\
\hline 293451098313201 & $<.5$ & $<1.0$ & $<.5$ & V1.00 & $<.5$ & $<.5$ & $<.5$ & $<.5$ & $<1.0$ & $<.5$ & $<.5$ & $<.5$ & $<.5$ & $<.5$ \\
\hline 294604098060801 & $<.5$ & $<1.0$ & $<.5$ & V.850 & $<.5$ & $<.5$ & $<.5$ & $<.5$ & $<1.0$ & $<.5$ & $<.5$ & $<.5$ & $<.5$ & $<.5$ \\
\hline 294019098114701 & $<.5$ & $<1.0$ & $<.5$ & $<.5$ & $<.5$ & $<.5$ & $<.5$ & $<.5$ & $<1.0$ & $<.5$ & $<.5$ & $<.5$ & $<.5$ & $<.5$ \\
\hline 292215098580201 & $<.5$ & V.024 & $<.5$ & V4.0 & $<.5$ & $<.5$ & V.078 & $<.5$ & $<1.0$ & $<.5$ & $<.5$ & $<.5$ & $<.5$ & $<.5$ \\
\hline 292119098524901 & $<.5$ & $<1.0$ & $<.5$ & $<.5$ & $<.5$ & $<.5$ & $<.5$ & $<.5$ & $<1.0$ & $<.5$ & $<.5$ & $<.5$ & $<.5$ & $<.5$ \\
\hline 291943099163301 & $<.5$ & $<1.0$ & $<.5$ & V2.40 & $<.5$ & $<.5$ & $<.5$ & $<.5$ & $<1.0$ & $<.5$ & $<.5$ & $<.5$ & $<.5$ & $<.5$ \\
\hline 291840099382601 & $<.5$ & $<1.0$ & $<.5$ & V.280 & $<.5$ & $<.5$ & V.026 & $<.5$ & $<1.0$ & $<.5$ & $<.5$ & $<.5$ & $<.5$ & $<.5$ \\
\hline 293518098332601 & $<.5$ & $<1.0$ & $<.5$ & V1.40 & $<.5$ & V.042 & $<.5$ & $<.5$ & $<1.0$ & $<.5$ & $<.5$ & $<.5$ & $<.5$ & $<.5$ \\
\hline 293023098355401 & $<.5$ & $<1.0$ & $<.5$ & V1.40 & $<.5$ & V.140 & $<.5$ & $<.5$ & $<1.0$ & $<.5$ & $<.5$ & $<.5$ & $<.5$ & $<.5$ \\
\hline 293042098305201 & $<.5$ & $<1.0$ & $<.5$ & V.180 & $<.5$ & V.130 & $<.5$ & $<.5$ & $<1.0$ & $<.5$ & $<.5$ & $<.5$ & $<.5$ & $<.5$ \\
\hline 292442098474501 & $<.5$ & $<1.0$ & $<.5$ & $<.5$ & $<.5$ & $<.5$ & V1.80 & $<.5$ & $<1.0$ & $<.5$ & $<.5$ & $<.5$ & $<.5$ & $<.5$ \\
\hline 292405098371201 & $<.5$ & $<1.0$ & $<.5$ & V.110 & $<.5$ & $<.5$ & $<.5$ & $<.5$ & $<1.0$ & $<.5$ & $<.5$ & $<.5$ & $<.5$ & $<.5$ \\
\hline 292931098274601 & -- & -- & -- & -- & -- & -- & -- & -- & -- & -- & -- & -- & -- & -- \\
\hline 293729098173101 & $<.5$ & $<1.0$ & $<.5$ & V.850 & $<.5$ & $<.5$ & $<.5$ & $<.5$ & $<1.0$ & $<.5$ & $<.5$ & $<.5$ & $<.5$ & $<.5$ \\
\hline 291219099095601 & $<.5$ & $<1.0$ & $<.5$ & V1.90 & $<.5$ & $<.5$ & $<.5$ & $<.5$ & $<1.0$ & $<.5$ & $<.5$ & V.098 & $<.5$ & $<.5$ \\
\hline
\end{tabular}


Table 14. Volatile organic and fuel oxygenate compounds for groundwater samples collected for the study of the transport of anthropogenic and natural contaminants (TANC) to public supply wells in the San Antonio segment of the Edwards aquifer near San Antonio, south-central Texas, 2004-9.

[By sample category. USGS, U.S. Geological Survey; MW, monitoring well; OVB, overburden; $\mu \mathrm{g} / \mathrm{L}$, micrograms per liter; --, not measured or not applicable; E, estimated; <, nondetection less than laboratory method reporting level]

\begin{tabular}{|c|c|c|c|c|c|c|c|c|c|c|c|c|c|}
\hline $\begin{array}{c}\text { USGS } \\
\text { identification } \\
\text { number }\end{array}$ & $\begin{array}{c}\text { State well } \\
\text { number }\end{array}$ & $\begin{array}{l}\text { Group and } \\
\text { description }\end{array}$ & $\begin{array}{c}\text { Sample } \\
\text { date }\end{array}$ & $\begin{array}{c}\text { 1,1,1,2- } \\
\text { Tetra- } \\
\text { chloro- } \\
\text { ethane } \\
\text { ( } \mu \mathrm{g} / \mathrm{L} \text { ) }\end{array}$ & $\begin{array}{l}\text { 1,1,1-Tri- } \\
\text { chloro- } \\
\text { ethane } \\
(\mu \mathrm{g} / \mathrm{L})\end{array}$ & $\begin{array}{c}\text { 1,1,2,2- } \\
\text { Tetra- } \\
\text { chloro- } \\
\text { ethane } \\
\text { ( } \mu \mathrm{g} / \mathrm{L} \text { ) }\end{array}$ & $\begin{array}{c}\text { 1,1,2-Tri- } \\
\text { chloro- } \\
\text { 1,2,2-tri- } \\
\text { fluoro- } \\
\text { ethane } \\
\text { (CFC-113) } \\
\text { ( } \mu \text { g/L) }\end{array}$ & $\begin{array}{l}\text { 1,1,2-Tri- } \\
\text { chloro- } \\
\text { ethane } \\
(\mu \mathrm{g} / \mathrm{L})\end{array}$ & $\begin{array}{l}\text { 1,1-Di- } \\
\text { chloro- } \\
\text { ethane } \\
(\mu \mathrm{g} / \mathrm{L})\end{array}$ & $\begin{array}{l}\text { 1,1-Di- } \\
\text { chloro- } \\
\text { ethene } \\
(\mu \mathrm{g} / \mathrm{L})\end{array}$ & $\begin{array}{c}\text { 1,1-Di- } \\
\text { chloro- } \\
\text { propene } \\
(\mu \mathrm{g} / \mathrm{L})\end{array}$ & $\begin{array}{c}\text { 1,2,3,4- } \\
\text { Tetra- } \\
\text { methyl- } \\
\text { benzene } \\
\text { (prehni- } \\
\text { tene) } \\
\text { ( } \mathrm{g} / \mathrm{L} \text { ) }\end{array}$ & $\begin{array}{c}\text { 1,2,3,5- } \\
\text { Tetra- } \\
\text { methyl- } \\
\text { benzene } \\
\text { (iso- } \\
\text { durene) } \\
\text { ( } \mu \mathrm{g} / \mathrm{L} \text { ) }\end{array}$ \\
\hline \multicolumn{14}{|c|}{ Regional aquifer public-supply wells } \\
\hline 293359098290301 & AY-68-29-414 & 1st (highest) quartile & 2004/12/06 & $<0.03$ & $<0.032$ & $<0.08$ & E0.038 & $<0.04$ & $<0.035$ & $<0.024$ & $<0.026$ & $<0.14$ & $<0.14$ \\
\hline 293359098290301 & AY-68-29-414 & 1st quartile & 2005/09/01 & $<.03$ & $<.032$ & $<.08$ & $<.038$ & $<.04$ & $<.035$ & $<.024$ & $<.026$ & $<.14$ & $<.14$ \\
\hline 293358098231101 & AY-68-29-610 & 1st quartile & $2004 / 12 / 15$ & $<.03$ & $<.032$ & $<.08$ & $<.038$ & $<.04$ & $<.035$ & $<.024$ & $<.026$ & $<.14$ & $<.14$ \\
\hline 293358098231101 & AY-68-29-610 & 1st quartile & $2005 / 08 / 29$ & $<.03$ & $<.032$ & $<.08$ & $<.038$ & $<.04$ & $<.035$ & $<.024$ & $<.026$ & $<.14$ & $<.14$ \\
\hline 293120098285801 & AY-68-29-714 & 1st quartile & $2004 / 12 / 14$ & $<.03$ & $<.032$ & $<.08$ & $<.038$ & $<.04$ & $<.035$ & $<.024$ & $<.026$ & $<.14$ & $<.14$ \\
\hline 293120098285801 & AY-68-29-714 & 1st quartile & $2005 / 08 / 30$ & $<.03$ & $<.032$ & $<.08$ & $<.038$ & $<.04$ & $<.035$ & $<.024$ & $<.026$ & $<.14$ & $<.14$ \\
\hline 293145098224201 & AY-68-29-929 & 1st quartile & $2004 / 12 / 15$ & $<.03$ & $<.032$ & $<.08$ & $<.038$ & $<.04$ & $<.035$ & $<.024$ & $<.026$ & $<.14$ & $<.14$ \\
\hline 293119098211201 & AY-68-30-718 & 1st quartile & $2004 / 12 / 16$ & $<.03$ & $<.032$ & $<.08$ & $<.038$ & $<.04$ & $<.035$ & $<.024$ & $<.026$ & $<.14$ & $<.14$ \\
\hline 292843098425101 & AY-68-35-106 & 1st quartile & $2004 / 12 / 13$ & $<.03$ & $<.032$ & $<.08$ & $<.038$ & $<.04$ & $<.035$ & $<.024$ & $<.026$ & $<.14$ & $<.14$ \\
\hline 292459098382101 & AY-68-35-913 & 1st quartile & $2004 / 12 / 13$ & $<.03$ & $<.032$ & $<.08$ & $<.038$ & $<.04$ & $<.035$ & $<.024$ & $<.026$ & $<.14$ & $<.14$ \\
\hline 292925098360201 & AY-68-36-104 & 1st quartile & $2004 / 12 / 13$ & $<.03$ & $<.032$ & $<.08$ & $<.038$ & $<.04$ & $<.035$ & $<.024$ & $<.026$ & $<.14$ & $<.14$ \\
\hline 292925098360201 & AY-68-36-104 & 1st quartile & $2005 / 08 / 31$ & $<.03$ & $<.032$ & $<.08$ & $<.038$ & $<.04$ & $<.035$ & $<.024$ & $<.026$ & $<.14$ & $<.14$ \\
\hline 292822098325401 & AY-68-36-206 & 1st quartile & $2004 / 12 / 13$ & $<.03$ & $<.032$ & $<.08$ & $<.038$ & $<.04$ & $<.035$ & $<.024$ & $<.026$ & $<.14$ & $<.14$ \\
\hline 292822098325401 & AY-68-36-206 & 1st quartile & 2005/08/31 & $<.03$ & $<.032$ & $<.08$ & $<.038$ & $<.04$ & $<.035$ & $<.024$ & $<.026$ & $<.14$ & $<.14$ \\
\hline 292944098292301 & AY-68-37-105 & 1st quartile & $2004 / 12 / 14$ & $<.03$ & $<.032$ & $<.08$ & $<.038$ & $<.04$ & $<.035$ & $<.024$ & $<.026$ & $<.14$ & $<.14$ \\
\hline 292944098292301 & AY-68-37-105 & 1st quartile & 2005/08/31 & -- & -- & -- & -- & -- & -- & -- & -- & -- & -- \\
\hline 292522098291901 & AY-68-37-426 & 1st quartile & $2004 / 12 / 14$ & $<.03$ & $<.032$ & $<.08$ & $<.038$ & $<.04$ & $<.035$ & $<.024$ & $<.026$ & $<.14$ & $<.14$ \\
\hline 292643098241801 & AY-68-37-601 & 1st quartile & 2004/12/15 & $<.03$ & $<.032$ & $<.08$ & $<.038$ & $<.04$ & $<.035$ & $<.024$ & $<.026$ & $<.14$ & $<.14$ \\
\hline 292643098241801 & AY-68-37-601 & 1st quartile & $2005 / 08 / 30$ & $<.03$ & $<.032$ & $<.08$ & $<.038$ & $<.04$ & $<.035$ & $<.024$ & $<.026$ & $<.14$ & $<.14$ \\
\hline 292328098294601 & AY-68-37-705 & 1st quartile & $2004 / 12 / 14$ & $<.03$ & $<.032$ & $<.08$ & $<.038$ & $<.04$ & $<.035$ & $<.024$ & $<.026$ & $<.14$ & $<.14$ \\
\hline 294225098080301 & DX-68-23-601 & 1st quartile & 2004/12/08 & $<.03$ & $<.032$ & $<.08$ & $<.038$ & $<.04$ & $<.035$ & $<.024$ & $<.026$ & $<.14$ & $<.14$ \\
\hline 294225098080301 & DX-68-23-601 & 1st quartile & 2005/09/01 & $<.03$ & $<.032$ & $<.08$ & $<.038$ & $<.04$ & $<.035$ & $<.024$ & $<.026$ & $<.14$ & $<.14$ \\
\hline 291210099475601 & YP-69-50-506 & 1st quartile & $2004 / 11 / 30$ & $<.03$ & $<.032$ & $<.08$ & $<.038$ & $<.04$ & $<.035$ & $<.024$ & $<.026$ & $<.14$ & $<.14$ \\
\hline 293111098340901 & AY-68-28-807 & 2d quartile & $2005 / 05 / 26$ & $<.03$ & $<.032$ & $<.08$ & $<.038$ & $<.04$ & $<.035$ & $<.024$ & $<.026$ & $<.14$ & $<.14$ \\
\hline 293512098291701 & AY-68-29-109 & 2d quartile & $2005 / 04 / 20$ & $<.03$ & $<.032$ & $<.08$ & $<.038$ & $<.04$ & $<.035$ & $<.024$ & $<.026$ & $<.14$ & $<.14$ \\
\hline 292424098421501 & AY-68-35-810 & 2d quartile & $2005 / 04 / 21$ & $<.03$ & $<.032$ & $<.08$ & $<.038$ & $<.04$ & $<.035$ & $<.024$ & $<.026$ & $<.14$ & $<.14$ \\
\hline
\end{tabular}


Table 14. Volatile organic and fuel oxygenate compounds for groundwater samples collected for the study of the transport of anthropogenic and natural contaminants (TANC) to public supply wells in the San Antonio segment of the Edwards aquifer near San Antonio, south-central Texas, 2004-9.-Continued

[By sample category. USGS, U.S. Geological Survey; MW, monitoring well; OVB, overburden; $\mu \mathrm{g} / \mathrm{L}$, micrograms per liter; --, not measured or not applicable; E, estimated; <, nondetection less than laboratory method reporting level]

\begin{tabular}{|c|c|c|c|c|c|c|c|c|c|c|c|c|c|}
\hline $\begin{array}{c}\text { USGS } \\
\text { identification } \\
\text { number }\end{array}$ & $\begin{array}{l}\text { State well } \\
\text { number }\end{array}$ & $\begin{array}{l}\text { Group and } \\
\text { description }\end{array}$ & $\begin{array}{c}\text { Sample } \\
\text { date }\end{array}$ & $\begin{array}{c}\text { 1,1,1,2- } \\
\text { Tetra- } \\
\text { chloro- } \\
\text { ethane } \\
\text { ( } \mu \mathrm{g} / \mathrm{L} \text { ) }\end{array}$ & $\begin{array}{c}\text { 1,1,1-Tri- } \\
\text { chloro- } \\
\text { ethane } \\
(\mu \mathrm{g} / \mathrm{L})\end{array}$ & $\begin{array}{c}\text { 1,1,2,2- } \\
\text { Tetra- } \\
\text { chloro- } \\
\text { ethane } \\
\text { ( } \mu \mathrm{g} / \mathrm{L} \text { ) }\end{array}$ & $\begin{array}{c}\text { 1,1,2-Tri- } \\
\text { chloro- } \\
\text { 1,2,2-tri- } \\
\text { fluoro- } \\
\text { ethane } \\
\text { (CFC-113) } \\
\text { ( } \mu \mathrm{g} / \mathrm{L})\end{array}$ & $\begin{array}{l}\text { 1,1,2-Tri- } \\
\text { chloro- } \\
\text { ethane } \\
(\mu \mathrm{g} / \mathrm{L})\end{array}$ & $\begin{array}{l}\text { 1,1-Di- } \\
\text { chloro- } \\
\text { ethane } \\
(\mu \mathrm{g} / \mathrm{L})\end{array}$ & $\begin{array}{l}\text { 1,1-Di- } \\
\text { chloro- } \\
\text { ethene } \\
(\mu \mathrm{g} / \mathrm{L})\end{array}$ & $\begin{array}{c}\text { 1,1-Di- } \\
\text { chloro- } \\
\text { propene } \\
(\mu \mathrm{g} / \mathrm{L})\end{array}$ & $\begin{array}{c}\text { 1,2,3,4- } \\
\text { Tetra- } \\
\text { methyl- } \\
\text { benzene } \\
\text { (prehni- } \\
\text { tene) } \\
(\mu \mathrm{g} / \mathrm{L})\end{array}$ & $\begin{array}{c}\text { 1,2,3,5- } \\
\text { Tetra- } \\
\text { methyl- } \\
\text { benzene } \\
\text { (iso- } \\
\text { durene) } \\
\text { ( } \mu \mathrm{g} / \mathrm{L} \text { ) }\end{array}$ \\
\hline 292053098365501 & AY-68-44-110 & 2d quartile & $2005 / 05 / 26$ & $<0.03$ & $<0.032$ & $<0.08$ & $<0.038$ & $<0.04$ & $<0.035$ & $<0.024$ & $<0.026$ & $<0.14$ & $<0.14$ \\
\hline 293807098155301 & DX-68-22-901 & 2d quartile & $2005 / 05 / 18$ & $<.03$ & $<.032$ & $<.08$ & $<.038$ & $<.04$ & $<.035$ & $<.024$ & $<.026$ & $<.14$ & $<.14$ \\
\hline 292604098563201 & TD-68-33-501 & 2d quartile & $2005 / 05 / 16$ & $<.03$ & $<.032$ & $<.08$ & $<.038$ & $<.04$ & $<.035$ & $<.024$ & $<.026$ & $<.14$ & $<.14$ \\
\hline 292116099095501 & TD-69-47-305 & 2d quartile & $2005 / 04 / 27$ & $<.03$ & $<.032$ & $<.08$ & $<.038$ & $<.04$ & $<.035$ & $<.024$ & $<.026$ & $<.14$ & $<.14$ \\
\hline 291232099470301 & YP-69-50-339 & 2d quartile & $2005 / 05 / 11$ & $<.03$ & $<.032$ & $<.08$ & $<.038$ & $<.04$ & $<.035$ & $<.024$ & $<.026$ & $<.14$ & $<.14$ \\
\hline 293128098473101 & AY-68-26-814 & 3d quartile & $2005 / 04 / 18$ & $<.03$ & $<.032$ & $<.08$ & $<.038$ & $<.04$ & $<.035$ & $<.024$ & $<.026$ & $<.14$ & $<.14$ \\
\hline 293451098313201 & AY-68-28-601 & 3d quartile & $2005 / 05 / 17$ & $<.03$ & $<.032$ & $<.08$ & $<.038$ & $<.04$ & $<.035$ & $<.024$ & $<.026$ & $<.14$ & $<.14$ \\
\hline 294604098060801 & DX-68-16-708 & 3d quartile & $2005 / 04 / 25$ & $<.03$ & $<.032$ & $<.08$ & $<.038$ & $<.04$ & $<.035$ & $<.024$ & $<.026$ & $<.14$ & $<.14$ \\
\hline 294019098114701 & DX-68-23-504 & 3d quartile & $2005 / 05 / 18$ & $<.03$ & $<.032$ & $<.08$ & $<.038$ & $<.04$ & $<.035$ & $<.024$ & $<.026$ & $<.14$ & $<.14$ \\
\hline 292215098580201 & TD-68-41-103 & 3d quartile & $2005 / 05 / 09$ & $<.03$ & $<.032$ & $<.08$ & $<.038$ & $<.04$ & $<.035$ & $<.024$ & $<.026$ & $<.14$ & $<.14$ \\
\hline 292119098524901 & TD-68-41-308 & 3d quartile & $2005 / 04 / 27$ & $<.03$ & $<.032$ & $<.08$ & $<.038$ & $<.04$ & $<.035$ & $<.024$ & $<.026$ & $<.14$ & $<.14$ \\
\hline 291943099163301 & TD-69-46-601 & 3d quartile & 2005/05/09 & $<.03$ & $<.032$ & $<.08$ & $<.038$ & $<.04$ & $<.035$ & $<.024$ & $<.026$ & $<.14$ & $<.14$ \\
\hline 291840099382601 & YP-69-43-606 & 3d quartile & 2005/05/11 & $<.03$ & $<.032$ & $<.08$ & $<.038$ & $<.04$ & $<.035$ & $<.024$ & $<.026$ & $<.14$ & $<.14$ \\
\hline 293518098332601 & AY-68-28-203 & 4th quartile & $2005 / 04 / 19$ & $<.03$ & $<.032$ & $<.08$ & $<.038$ & $<.04$ & $<.035$ & $<.024$ & $<.026$ & $<.14$ & $<.14$ \\
\hline 293023098355401 & AY-68-28-702 & 4th quartile & $2005 / 04 / 26$ & $<.03$ & $<.032$ & $<.08$ & $<.038$ & $<.04$ & $<.035$ & $<.024$ & $<.026$ & $<.14$ & $<.14$ \\
\hline 293042098305201 & AY-68-28-913 & 4th quartile & $2005 / 06 / 30$ & $<.03$ & $<.032$ & $<.08$ & $<.038$ & $<.04$ & $<.035$ & $<.024$ & $<.026$ & $<.14$ & $<.14$ \\
\hline 292442098474501 & AY-68-34-803 & 4th quartile & $2005 / 04 / 20$ & $<.03$ & $<.032$ & $<.08$ & $<.038$ & $<.04$ & $<.035$ & $<.024$ & $<.026$ & $<.14$ & $<.14$ \\
\hline 292405098371201 & AY-68-36-704 & 4th quartile & $2005 / 05 / 23$ & $<.03$ & $<.032$ & $<.08$ & $<.038$ & $<.04$ & $<.035$ & $<.024$ & $<.026$ & $<.14$ & $<.14$ \\
\hline 292931098274601 & AY-68-37-124 & 4th quartile & $2005 / 05 / 25$ & $<.03$ & $<.032$ & $<.08$ & $<.038$ & $<.04$ & $<.035$ & $<.024$ & $<.026$ & $<.14$ & $<.14$ \\
\hline 293729098173101 & DX-68-30-215 & 4th quartile & $2005 / 04 / 25$ & $<.03$ & $<.032$ & $<.08$ & $<.038$ & $<.04$ & $<.035$ & $<.024$ & $<.026$ & $<.14$ & $<.14$ \\
\hline 291219099095601 & TD-69-55-604 & 4th quartile & $2005 / 05 / 16$ & $<.03$ & $<.032$ & $<.08$ & $<.038$ & $<.04$ & $<.035$ & $<.024$ & $<.026$ & $<.14$ & $<.14$ \\
\hline \multicolumn{14}{|c|}{ Monitoring wells } \\
\hline 292943098354401 & AY-68-36-135 & TANC MW OVB & $2007 / 10 / 30$ & $<.04$ & $<.02$ & $<.1$ & $<.04$ & $<.06$ & $<.04$ & $<.02$ & $<.04$ & $<.14$ & $<.12$ \\
\hline 292943098354402 & AY-68-36-133 & TANC MW & $2007 / 10 / 31$ & $<.04$ & $<.02$ & $<.1$ & $<.04$ & $<.06$ & $<.04$ & $<.02$ & $<.04$ & $<.14$ & $<.12$ \\
\hline 292943098354403 & AY-68-36-134 & TANC MW & $2007 / 10 / 30$ & $<.04$ & $<.02$ & $<.1$ & $<.04$ & $<.06$ & $<.04$ & $<.02$ & $<.04$ & $<.14$ & $<.12$ \\
\hline 292943098354404 & AY-68-36-132 & TANC MW & 2007/11/01 & $<.04$ & $<.02$ & $<.1$ & $<.04$ & $<.06$ & $<.04$ & $<.02$ & $<.04$ & $<.14$ & $<.12$ \\
\hline
\end{tabular}


Table 14. Volatile organic and fuel oxygenate compounds for groundwater samples collected for the study of the transport of anthropogenic and natural contaminants (TANC) to public supply wells in the San Antonio segment of the Edwards aquifer near San Antonio, south-central Texas, 2004-9.-Continued

[By sample category. USGS, U.S. Geological Survey; MW, monitoring well; OVB, overburden; $\mu \mathrm{g} / \mathrm{L}$, micrograms per liter; --, not measured or not applicable; E, estimated; <, nondetection less than laboratory method reporting level]

\begin{tabular}{|c|c|c|c|c|c|c|c|c|c|c|c|c|c|}
\hline $\begin{array}{c}\text { USGS } \\
\text { identification } \\
\text { number }\end{array}$ & $\begin{array}{l}\text { State well } \\
\text { number }\end{array}$ & $\begin{array}{l}\text { Group and } \\
\text { description }\end{array}$ & $\begin{array}{c}\text { Sample } \\
\text { date }\end{array}$ & $\begin{array}{c}\text { 1,1,1,2- } \\
\text { Tetra- } \\
\text { chloro- } \\
\text { ethane } \\
\text { ( } \mu \mathrm{g} / \mathrm{L} \text { ) }\end{array}$ & $\begin{array}{c}\text { 1,1,1-Tri- } \\
\text { chloro- } \\
\text { ethane } \\
(\mu \mathrm{g} / \mathrm{L})\end{array}$ & $\begin{array}{c}\text { 1,1,2,2- } \\
\text { Tetra- } \\
\text { chloro- } \\
\text { ethane } \\
\text { ( } \mu \mathrm{g} / \mathrm{L} \text { ) }\end{array}$ & $\begin{array}{c}\text { 1,1,2-Tri- } \\
\text { chloro- } \\
\text { 1,2,2-tri- } \\
\text { fluoro- } \\
\text { ethane } \\
\text { (CFC-113) } \\
\text { ( } \mu \mathrm{g} / \mathrm{L} \text { ) }\end{array}$ & $\begin{array}{c}\text { 1,1,2-Tri- } \\
\text { chloro- } \\
\text { ethane } \\
(\mu \mathrm{g} / \mathrm{L})\end{array}$ & $\begin{array}{l}\text { 1,1-Di- } \\
\text { chloro- } \\
\text { ethane } \\
(\mu \mathrm{g} / \mathrm{L})\end{array}$ & $\begin{array}{l}\text { 1,1-Di- } \\
\text { chloro- } \\
\text { ethene } \\
(\mu \mathrm{g} / \mathrm{L})\end{array}$ & $\begin{array}{c}\text { 1,1-Di- } \\
\text { chloro- } \\
\text { propene } \\
(\mu \mathrm{g} / \mathrm{L})\end{array}$ & $\begin{array}{c}\text { 1,2,3,4- } \\
\text { Tetra- } \\
\text { methyl- } \\
\text { benzene } \\
\text { (prehni- } \\
\text { tene) } \\
\text { ( } \mu \mathrm{g} / \mathrm{L})\end{array}$ & $\begin{array}{c}\text { 1,2,3,5- } \\
\text { Tetra- } \\
\text { methyl- } \\
\text { benzene } \\
\text { (iso- } \\
\text { durene) } \\
\text { ( } \mu \mathrm{g} / \mathrm{L} \text { ) }\end{array}$ \\
\hline 292851098374401 & AY-68-35-315 & TANC MW & $2008 / 05 / 06$ & $<0.04$ & $<0.02$ & $<0.1$ & $<0.04$ & $<0.06$ & $<0.04$ & $<0.02$ & $<0.04$ & $<0.14$ & $<0.12$ \\
\hline 292851098374402 & AY-68-35-314 & TANC MW & $2008 / 05 / 07$ & $<.04$ & $<.02$ & $<.1$ & $<.04$ & $<.06$ & $<.04$ & $<.02$ & $<.04$ & $<.14$ & $<.12$ \\
\hline \multicolumn{14}{|c|}{ Well-field depth-dependent sampling (W4) } \\
\hline 292916098360701 & AY-68-36-105 & $\begin{array}{l}\text { W4-shallow (380), } \\
\text { normal }\end{array}$ & $2007 / 11 / 16$ & $<.04$ & $<.02$ & $<.1$ & $<.04$ & $<.06$ & $<.04$ & $<.02$ & $<.04$ & $<.14$ & $<.12$ \\
\hline 292916098360701 & AY-68-36-105 & $\begin{array}{c}\text { W4-intermediate } \\
\text { (430), normal }\end{array}$ & $2007 / 11 / 15$ & $<.04$ & $<.02$ & $<.1$ & $<.04$ & $<.06$ & $<.04$ & $<.02$ & $<.04$ & $<.14$ & $<.12$ \\
\hline 292916098360701 & AY-68-36-105 & $\begin{array}{l}\text { W4-deep (540), } \\
\text { normal }\end{array}$ & 2007/11/15 & $<.04$ & $<.02$ & $<.1$ & $<.04$ & $<.06$ & $<.04$ & $<.02$ & $<.04$ & $<.14$ & $<.12$ \\
\hline 292916098360701 & AY-68-36-105 & $\begin{array}{l}\text { W4-shallow (380), } \\
\text { ambient }\end{array}$ & 2007/11/16 & $<.04$ & $<.02$ & $<.1$ & $<.04$ & $<.06$ & $<.04$ & $<.02$ & $<.04$ & $<.14$ & $<.12$ \\
\hline 292916098360701 & AY-68-36-105 & $\begin{array}{l}\text { W4-intermediate } \\
\text { (430), ambient }\end{array}$ & 2007/11/14 & $<.04$ & $<.02$ & $<.1$ & $<.04$ & $<.06$ & $<.04$ & $<.02$ & $<.04$ & $<.14$ & $<.12$ \\
\hline 292916098360701 & AY-68-36-105 & $\begin{array}{l}\text { W4-deep (540), } \\
\text { ambient }\end{array}$ & 2007/11/15 & $<.04$ & $<.02$ & $<.1$ & $<.04$ & $<.06$ & $<.04$ & $<.02$ & $<.04$ & $<.14$ & $<.12$ \\
\hline 292916098360701 & AY-68-36-105 & $\begin{array}{l}\text { W4-shallow (380), } \\
\text { moderate }\end{array}$ & 2007/11/16 & $<.04$ & $<.02$ & $<.1$ & $<.04$ & $<.06$ & $<.04$ & $<.02$ & $<.04$ & $<.14$ & $<.12$ \\
\hline 292916098360701 & AY-68-36-105 & $\begin{array}{l}\text { W4-intermediate } \\
\text { (430), moderate }\end{array}$ & 2007/11/14 & $<.04$ & $<.02$ & $<.1$ & $<.04$ & $<.06$ & $<.04$ & $<.02$ & $<.04$ & $<.14$ & $<.12$ \\
\hline 292916098360701 & AY-68-36-105 & $\begin{array}{l}\text { W4-deep (540), } \\
\text { moderate }\end{array}$ & 2007/11/15 & $<.04$ & $<.02$ & $<.1$ & $<.04$ & $<.06$ & $<.04$ & $<.02$ & $<.04$ & $<.14$ & $<.12$ \\
\hline \multicolumn{14}{|c|}{ Well-field wells (wellhead sampling) } \\
\hline 292919098360501 & AY-68-36-103 & wellhead & $2007 / 11 / 29$ & $<.04$ & $<.02$ & $<.1$ & $<.04$ & $<.06$ & $<.04$ & $<.02$ & $<.04$ & $<.14$ & $<.12$ \\
\hline 292925098360201 & AY-68-36-104 & wellhead & $2007 / 11 / 28$ & $<.04$ & $<.02$ & $<.1$ & $<.04$ & $<.06$ & $<.04$ & $<.02$ & $<.04$ & $<.14$ & $<.12$ \\
\hline 292916098360701 & AY-68-36-105 & *wellhead & 2007/11/16 & $<.04$ & $<.02$ & $<.1$ & $<.04$ & $<.06$ & $<.04$ & $<.02$ & $<.04$ & $<.14$ & $<.12$ \\
\hline 292920098360601 & AY-68-36-130 & wellhead & $2007 / 11 / 29$ & $<.04$ & $<.02$ & $<.1$ & $<.04$ & $<.06$ & $<.04$ & $<.02$ & $<.04$ & $<.14$ & $<.12$ \\
\hline 292923098360301 & AY-68-36-131 & wellhead & $2007 / 11 / 28$ & $<.04$ & $<.02$ & $<.1$ & $<.04$ & $<.06$ & $<.04$ & $<.02$ & $<.04$ & $<.14$ & $<.12$ \\
\hline \multicolumn{14}{|c|}{ Temporal sampling } \\
\hline 292923098360301 & AY-68-36-131 & $\begin{array}{l}\text { TANC PSW pre- } \\
\text { storm }\end{array}$ & 2009/04/09 & $<.04$ & $<.02$ & $<.1$ & $<.04$ & $<.06$ & $<.04$ & $<.02$ & $<.04$ & $<.08$ & $<.08$ \\
\hline 292923098360301 & AY-68-36-131 & TANC PSW storm 1 & 2009/10/06 & $<.04$ & $<.03$ & $<.14$ & $<.034$ & $<.046$ & $<.044$ & $<.022$ & $<.03$ & $<.08$ & $<.08$ \\
\hline
\end{tabular}

292923098360301 AY-68-36-131 TANC PSW storm 1 2009/10/06 
Table 14. Volatile organic and fuel oxygenate compounds for groundwater samples collected for the study of the transport of anthropogenic and natural contaminants (TANC) to public supply wells in the San Antonio segment of the Edwards aquifer near San Antonio, south-central Texas, 2004-9.-Continued

[By sample category. USGS, U.S. Geological Survey; MW, monitoring well; OVB, overburden; $\mu \mathrm{g} / \mathrm{L}$, micrograms per liter; --, not measured or not applicable; E, estimated; <, nondetection less than laboratory method reporting level]

\begin{tabular}{|c|c|c|c|c|c|c|c|c|c|c|c|c|c|}
\hline $\begin{array}{c}\text { USGS } \\
\text { identification } \\
\text { number }\end{array}$ & $\begin{array}{l}\text { State well } \\
\text { number }\end{array}$ & $\begin{array}{l}\text { Group and } \\
\text { description }\end{array}$ & $\begin{array}{c}\text { Sample } \\
\text { date }\end{array}$ & $\begin{array}{c}1,1,1,2- \\
\text { Tetra- } \\
\text { chloro- } \\
\text { ethane } \\
(\mu \mathrm{g} / \mathrm{L})\end{array}$ & $\begin{array}{c}\text { 1,1,1-Tri- } \\
\text { chloro- } \\
\text { ethane } \\
(\mu \mathrm{g} / \mathrm{L})\end{array}$ & $\begin{array}{c}\text { 1,1,2,2- } \\
\text { Tetra- } \\
\text { chloro- } \\
\text { ethane } \\
\text { ( } \mu \mathrm{g} / \mathrm{L} \text { ) }\end{array}$ & $\begin{array}{c}\text { 1,1,2-Tri- } \\
\text { chloro- } \\
\text { 1,2,2-tri- } \\
\text { fluoro- } \\
\text { ethane } \\
\text { (CFC-113) } \\
\text { ( } \mu \mathrm{g} / \mathrm{L})\end{array}$ & $\begin{array}{c}\text { 1,1,2-Tri- } \\
\text { chloro- } \\
\text { ethane } \\
(\mu \mathrm{g} / \mathrm{L})\end{array}$ & $\begin{array}{l}\text { 1,1-Di- } \\
\text { chloro- } \\
\text { ethane } \\
(\mu \mathrm{g} / \mathrm{L})\end{array}$ & $\begin{array}{c}\text { 1,1-Di- } \\
\text { chloro- } \\
\text { ethene } \\
(\mu \mathrm{g} / \mathrm{L})\end{array}$ & $\begin{array}{c}\text { 1,1-Di- } \\
\text { chloro- } \\
\text { propene } \\
(\mu \mathrm{g} / \mathrm{L})\end{array}$ & $\begin{array}{c}\text { 1,2,3,4- } \\
\text { Tetra- } \\
\text { methyl- } \\
\text { benzene } \\
\text { (prehni- } \\
\text { tene) } \\
(\mu \mathrm{g} / \mathrm{L})\end{array}$ & $\begin{array}{c}1,2,3,5- \\
\text { Tetra- } \\
\text { methyl- } \\
\text { benzene } \\
\text { (iso- } \\
\text { durene) } \\
\text { ( } \mu \mathrm{g} / \mathrm{L} \text { ) }\end{array}$ \\
\hline 292923098360301 & AY-68-36-131 & TANC PSW storm 2 & 2009/10/09 & $<0.04$ & $<0.03$ & $<0.14$ & $<0.034$ & $<0.046$ & $<0.044$ & $<0.022$ & $<0.03$ & $<0.08$ & $<0.08$ \\
\hline 292923098360301 & AY-68-36-131 & TANC PSW storm 3 & 2009/10/19 & $<.04$ & $<.03$ & $<.14$ & $<.034$ & $<.046$ & $<.044$ & $<.022$ & $<.03$ & $<.08$ & $<.08$ \\
\hline 292923098360301 & AY-68-36-131 & TANC PSW storm 4 & $2009 / 10 / 30$ & $<.04$ & $<.03$ & $<.14$ & $<.034$ & $<.046$ & $<.044$ & $<.022$ & $<.03$ & $<.08$ & $<.08$ \\
\hline 292923098360301 & AY-68-36-131 & TANC PSW storm 5 & 2009/11/19 & $<.04$ & $<.03$ & $<.14$ & $<.034$ & $<.046$ & $<.044$ & $<.022$ & $<.03$ & $<.08$ & $<.08$ \\
\hline 292943098354402 & AY-68-36-133 & $\begin{array}{l}\text { TANC MW pre- } \\
\text { storm }\end{array}$ & $2009 / 04 / 08$ & $<.04$ & $<.02$ & $<.1$ & $<.04$ & $<.06$ & $<.04$ & $<.02$ & $<.04$ & $<.08$ & $<.08$ \\
\hline 292943098354402 & AY-68-36-133 & TANC MW storm 1 & 2009/10/05 & $<.04$ & $<.03$ & $<.14$ & $<.034$ & $<.046$ & $<.044$ & $<.022$ & $<.03$ & $<.08$ & $<.08$ \\
\hline 292943098354402 & AY-68-36-133 & TANC MW storm 2 & 2009/10/07 & $<.04$ & $<.03$ & $<.14$ & $<.034$ & $<.046$ & $<.044$ & $<.022$ & $<.03$ & $<.08$ & $<.08$ \\
\hline 292943098354402 & AY-68-36-133 & TANC MW storm 3 & 2009/10/17 & $<.04$ & $<.03$ & $<.14$ & $<.034$ & $<.046$ & $<.044$ & $<.022$ & $<.03$ & $<.08$ & $<.08$ \\
\hline 292943098354402 & AY-68-36-133 & TANC MW storm 4 & $2009 / 10 / 28$ & $<.04$ & $<.03$ & $<.14$ & $<.034$ & $<.046$ & $<.044$ & $<.022$ & $<.03$ & $<.08$ & $<.08$ \\
\hline 292943098354402 & AY-68-36-133 & TANC MW storm 5 & 2009/11/18 & $<.04$ & $<.03$ & $<.14$ & $<.034$ & $<.046$ & $<.044$ & $<.022$ & $<.03$ & $<.08$ & $<.08$ \\
\hline 292943098354403 & AY-68-36-134 & $\begin{array}{l}\text { TANC MW pre- } \\
\text { storm }\end{array}$ & 2009/04/09 & $<.04$ & $<.02$ & $<.1$ & $<.04$ & $<.06$ & $<.04$ & $<.02$ & $<.04$ & $<.08$ & $<.08$ \\
\hline 292943098354403 & AY-68-36-134 & TANC MW storm 1 & $2009 / 10 / 05$ & $<.04$ & $<.03$ & $<.14$ & $<.034$ & $<.046$ & $<.044$ & $<.022$ & $<.03$ & $<.08$ & $<.08$ \\
\hline 292943098354403 & AY-68-36-134 & TANC MW storm 2 & 2009/10/08 & $<.04$ & $<.03$ & $<.14$ & $<.034$ & $<.046$ & $<.044$ & $<.022$ & $<.03$ & $<.08$ & $<.08$ \\
\hline 292943098354403 & AY-68-36-134 & TANC MW storm 3 & $2009 / 10 / 18$ & $<.04$ & $<.03$ & $<.14$ & $<.034$ & $<.046$ & $<.044$ & $<.022$ & $<.03$ & $<.08$ & $<.08$ \\
\hline 292943098354403 & AY-68-36-134 & TANC MW storm 4 & $2009 / 10 / 29$ & $<.04$ & $<.03$ & $<.14$ & $<.034$ & $<.046$ & $<.044$ & $<.022$ & $<.03$ & $<.08$ & $<.08$ \\
\hline 292943098354403 & AY-68-36-134 & TANC MW storm 5 & 2009/11/18 & $<.04$ & $<.03$ & $<.14$ & $<.034$ & $<.046$ & $<.044$ & $<.022$ & $<.03$ & $<.08$ & $<.08$ \\
\hline 292943098354404 & AY-68-36-132 & $\begin{array}{l}\text { TANC MW pre- } \\
\text { storm }\end{array}$ & 2009/04/09 & $<.04$ & $<.02$ & $<.1$ & $<.04$ & $<.06$ & $<.04$ & $<.02$ & $<.04$ & $<.08$ & $<.08$ \\
\hline 292943098354404 & AY-68-36-132 & TANC MW storm 1 & $2009 / 10 / 05$ & $<.04$ & $<.03$ & $<.14$ & $<.034$ & $<.046$ & $<.044$ & $<.022$ & $<.03$ & $<.08$ & $<.08$ \\
\hline 292943098354404 & AY-68-36-132 & TANC MW storm 2 & 2009/10/08 & $<.04$ & $<.03$ & $<.14$ & $<.034$ & $<.046$ & $<.044$ & $<.022$ & $<.03$ & $<.08$ & $<.08$ \\
\hline 292943098354404 & AY-68-36-132 & TANC MW storm 3 & 2009/10/18 & $<.04$ & $<.03$ & $<.14$ & $<.034$ & $<.046$ & $<.044$ & $<.022$ & $<.03$ & $<.08$ & $<.08$ \\
\hline 292943098354404 & AY-68-36-132 & TANC MW storm 4 & $2009 / 10 / 29$ & $<.04$ & $<.03$ & $<.14$ & $<.034$ & $<.046$ & $<.044$ & $<.022$ & $<.03$ & $<.08$ & $<.08$ \\
\hline 292943098354404 & AY-68-36-132 & TANC MW storm 5 & 2009/11/18 & $<.04$ & $<.03$ & $<.14$ & $<.034$ & $<.046$ & $<.044$ & $<.022$ & $<.03$ & $<.08$ & $<.08$ \\
\hline 293252098380801 & AY-68-27-610 & $\begin{array}{l}\text { TANC MW pre- } \\
\text { storm }\end{array}$ & $2009 / 04 / 14$ & $<.04$ & $<.02$ & $<.1$ & $<.04$ & $<.06$ & $<.04$ & $<.02$ & $<.04$ & $<.08$ & $<.08$ \\
\hline 293252098380801 & AY-68-27-610 & TANC MW storm 1 & 2009/10/04 & $<.04$ & $<.03$ & $<.14$ & $<.034$ & $<.046$ & $<.044$ & $<.022$ & $<.03$ & $<.08$ & $<.08$ \\
\hline 293252098380801 & AY-68-27-610 & TANC MW storm 2 & 2009/10/07 & $<.04$ & $<.03$ & $<.14$ & $<.034$ & $<.046$ & $<.044$ & $<.022$ & $<.03$ & $<.08$ & $<.08$ \\
\hline 293252098380801 & AY-68-27-610 & TANC MW storm 3 & 2009/10/17 & $<.04$ & $<.03$ & $<.14$ & $<.034$ & $<.046$ & $<.044$ & $<.022$ & $<.03$ & $<.08$ & $<.08$ \\
\hline 293252098380801 & AY-68-27-610 & TANC MW storm 4 & $2009 / 10 / 28$ & $<.04$ & $<.03$ & $<.14$ & $<.034$ & $<.046$ & $<.044$ & $<.022$ & $<.03$ & $<.08$ & $<.08$ \\
\hline 293252098380801 & AY-68-27-610 & TANC MW storm 5 & 2009/11/17 & $<.04$ & $<.03$ & $<.14$ & $<.034$ & $<.046$ & $<.044$ & $<.022$ & $<.03$ & $<.08$ & $<.08$ \\
\hline
\end{tabular}


Table 14. Volatile organic and fuel oxygenate compounds for groundwater samples collected for the study of the transport of anthropogenic and natural contaminants (TANC) to public supply wells in the San Antonio segment of the Edwards aquifer near San Antonio, south-central Texas, 2004-9.-Continued

[By sample category. USGS, U.S. Geological Survey; MW, monitoring well; OVB, overburden; $\mu \mathrm{g} / \mathrm{L}$, micrograms per liter; --, not measured or not applicable; E, estimated; <, nondetection less than laboratory method reporting level]

\begin{tabular}{|c|c|c|c|c|c|c|c|c|c|c|c|c|c|c|}
\hline $\begin{array}{c}\text { USGS } \\
\text { identification } \\
\text { number }\end{array}$ & $\begin{array}{c}\text { 1,2,3-Tri- } \\
\text { chloro- } \\
\text { benzene } \\
(\mu \mathrm{g} / \mathrm{L})\end{array}$ & $\begin{array}{c}\text { 1,2,3-Tri- } \\
\text { chloro- } \\
\text { propane } \\
(\mu \mathrm{g} / \mathrm{L})\end{array}$ & $\begin{array}{c}\text { 1,2,3-Tri- } \\
\text { methyl- } \\
\text { benzene } \\
(\mu \mathrm{g} / \mathrm{L})\end{array}$ & $\begin{array}{c}\text { 1,2,4-Tri- } \\
\text { chloro- } \\
\text { benzene } \\
(\mu \mathrm{g} / \mathrm{L})\end{array}$ & $\begin{array}{c}\text { 1,2,4-Tri- } \\
\text { methyl- } \\
\text { benzene } \\
(\mu \mathrm{g} / \mathrm{L})\end{array}$ & $\begin{array}{c}\text { 1,2-Di- } \\
\text { bromo- } \\
\text { 3-chloro- } \\
\text { propane } \\
\text { ( } \mathrm{gg} / \mathrm{L})\end{array}$ & $\begin{array}{c}\text { 1,2-Di- } \\
\text { bromo- } \\
\text { ethane } \\
(\mu \mathrm{g} / \mathrm{L})\end{array}$ & $\begin{array}{c}\text { 1,2-Di- } \\
\text { chloro- } \\
\text { benzene } \\
(\mu \mathrm{g} / \mathrm{L})\end{array}$ & $\begin{array}{c}\text { 1,2-Di- } \\
\text { chloro- } \\
\text { ethane } \\
(\mu \mathrm{g} / \mathrm{L})\end{array}$ & $\begin{array}{c}\text { 1,2-Di- } \\
\text { chloro- } \\
\text { propane } \\
(\mu \mathrm{g} / \mathrm{L})\end{array}$ & $\begin{array}{c}\text { 1,3,5-Tri- } \\
\text { methyl- } \\
\text { benzene } \\
(\mu \mathrm{g} / \mathrm{L})\end{array}$ & $\begin{array}{c}\text { 1,3-Di- } \\
\text { chloro- } \\
\text { benzene } \\
(\mu \mathrm{g} / \mathrm{L})\end{array}$ & $\begin{array}{c}\text { 1,3-Di- } \\
\text { chloro- } \\
\text { propane } \\
(\mu \mathrm{g} / \mathrm{L})\end{array}$ & $\begin{array}{c}\text { 1,4-Di- } \\
\text { chloro- } \\
\text { benzene } \\
(\mu \mathrm{g} / \mathrm{L})\end{array}$ \\
\hline \multicolumn{15}{|c|}{ Regional aquifer public-supply wells } \\
\hline 293359098290301 & $<0.18$ & $<0.18$ & $<0.06$ & $<0.12$ & $<0.056$ & $<0.51$ & $<0.036$ & $<0.048$ & $<0.13$ & $<0.029$ & $<0.044$ & $<0.03$ & $<0.06$ & $<0.034$ \\
\hline 293359098290301 & $<.18$ & $<.18$ & $<.06$ & $<.12$ & $<.056$ & $<.51$ & $<.036$ & $<.048$ & $<.13$ & $<.029$ & $<.044$ & $<.03$ & $<.06$ & $<.034$ \\
\hline 293358098231101 & $<.18$ & $<.18$ & $<.06$ & $<.12$ & $<.056$ & $<.51$ & $<.036$ & $<.048$ & $<.13$ & $<.029$ & $<.044$ & $<.03$ & $<.06$ & $<.034$ \\
\hline 293358098231101 & $<.18$ & $<.18$ & $<.06$ & $<.12$ & $<.056$ & $<.51$ & $<.036$ & $<.048$ & $<.13$ & $<.029$ & $<.044$ & $<.03$ & $<.06$ & $<.034$ \\
\hline 293120098285801 & $<.18$ & $<.18$ & $<.06$ & $<.12$ & $<.056$ & $<.51$ & $<.036$ & $<.048$ & $<.13$ & $<.029$ & $<.044$ & $<.03$ & $<.06$ & $<.034$ \\
\hline 293120098285801 & $<.18$ & $<.18$ & $<.06$ & $<.12$ & $<.056$ & $<.51$ & $<.036$ & $<.048$ & $<.13$ & $<.029$ & $<.044$ & $<.03$ & $<.06$ & $<.034$ \\
\hline 293145098224201 & $<.18$ & $<.18$ & $<.06$ & $<.12$ & $<.056$ & $<.51$ & $<.036$ & $<.048$ & $<.13$ & $<.029$ & $<.044$ & $<.03$ & $<.06$ & $<.034$ \\
\hline 293119098211201 & $<.18$ & $<.18$ & $<.06$ & $<.12$ & $<.056$ & $<.51$ & $<.036$ & $<.048$ & $<.13$ & $<.029$ & $<.044$ & $<.03$ & $<.06$ & $<.034$ \\
\hline 292843098425101 & $<.18$ & $<.18$ & $<.06$ & $<.12$ & $<.056$ & $<.51$ & $<.036$ & $<.048$ & $<.13$ & $<.029$ & $<.044$ & $<.03$ & $<.06$ & $<.034$ \\
\hline 292459098382101 & $<.18$ & $<.18$ & $<.06$ & $<.12$ & $<.056$ & $<.51$ & $<.036$ & $<.048$ & $<.13$ & $<.029$ & $<.044$ & $<.03$ & $<.06$ & $<.034$ \\
\hline 292925098360201 & $<.18$ & $<.18$ & $<.06$ & $<.12$ & $<.056$ & $<.51$ & $<.036$ & $<.048$ & $<.13$ & $<.029$ & $<.044$ & $<.03$ & $<.06$ & $<.034$ \\
\hline 292925098360201 & $<.18$ & $<.18$ & $<.06$ & $<.12$ & $<.056$ & $<.51$ & $<.036$ & $<.048$ & $<.13$ & $<.029$ & $<.044$ & $<.03$ & $<.06$ & $<.034$ \\
\hline 292822098325401 & $<.18$ & $<.18$ & $<.06$ & $<.12$ & $<.056$ & $<.51$ & $<.036$ & $<.048$ & $<.13$ & $<.029$ & $<.044$ & $<.03$ & $<.06$ & $<.034$ \\
\hline 292822098325401 & $<.18$ & $<.18$ & $<.06$ & $<.12$ & $<.056$ & $<.51$ & $<.036$ & $<.048$ & $<.13$ & $<.029$ & $<.044$ & $<.03$ & $<.06$ & $<.034$ \\
\hline 292944098292301 & $<.18$ & $<.18$ & $<.06$ & $<.12$ & $<.056$ & $<.51$ & $<.036$ & $<.048$ & $<.13$ & $<.029$ & $<.044$ & $<.03$ & $<.06$ & $<.034$ \\
\hline 292944098292301 & -- & -- & -- & -- & -- & -- & -- & -- & -- & -- & -- & -- & -- & -- \\
\hline 292522098291901 & $<.18$ & $<.18$ & $<.06$ & $<.12$ & $<.056$ & $<.51$ & $<.036$ & $<.048$ & $<.13$ & $<.029$ & $<.044$ & $<.03$ & $<.06$ & $<.034$ \\
\hline 292643098241801 & $<.18$ & $<.18$ & $<.06$ & $<.12$ & $<.056$ & $<.51$ & $<.036$ & $<.048$ & $<.13$ & $<.029$ & $<.044$ & $<.03$ & $<.06$ & $<.034$ \\
\hline 292643098241801 & $<.18$ & $<.18$ & $<.06$ & $<.12$ & $<.056$ & $<.51$ & $<.036$ & $<.048$ & $<.13$ & $<.029$ & $<.044$ & $<.03$ & $<.06$ & $<.034$ \\
\hline 292328098294601 & $<.18$ & $<.18$ & $<.06$ & $<.12$ & $<.056$ & $<.51$ & $<.036$ & $<.048$ & $<.13$ & $<.029$ & $<.044$ & $<.03$ & $<.06$ & $<.034$ \\
\hline 294225098080301 & $<.18$ & $<.18$ & $<.06$ & $<.12$ & $<.056$ & $<.51$ & $<.036$ & $<.048$ & $<.13$ & $<.029$ & $<.044$ & $<.03$ & $<.06$ & $<.034$ \\
\hline 294225098080301 & $<.18$ & $<.18$ & $<.06$ & $<.12$ & $<.056$ & $<.51$ & $<.036$ & $<.048$ & $<.13$ & $<.029$ & $<.044$ & $<.03$ & $<.06$ & $<.034$ \\
\hline 291210099475601 & $<.18$ & $<.18$ & $<.06$ & $<.12$ & $<.056$ & $<.51$ & $<.036$ & $<.048$ & $<.13$ & $<.029$ & $<.044$ & $<.03$ & $<.06$ & $<.034$ \\
\hline 293111098340901 & $<.18$ & $<.18$ & $<.06$ & $<.12$ & $<.056$ & $<.51$ & $<.036$ & $<.048$ & $<.13$ & $<.029$ & $<.044$ & $<.03$ & $<.06$ & $<.034$ \\
\hline 293512098291701 & $<.18$ & $<.18$ & $<.06$ & $<.12$ & $<.056$ & $<.51$ & $<.036$ & $<.048$ & $<.13$ & $<.029$ & $<.044$ & $<.03$ & $<.06$ & $<.034$ \\
\hline 292424098421501 & $<.18$ & $<.18$ & $<.06$ & $<.12$ & $<.056$ & $<.51$ & $<.036$ & $<.048$ & $<.13$ & $<.029$ & $<.044$ & $<.03$ & $<.06$ & $<.034$ \\
\hline
\end{tabular}


Table 14. Volatile organic and fuel oxygenate compounds for groundwater samples collected for the study of the transport of anthropogenic and natural contaminants (TANC) to public supply wells in the San Antonio segment of the Edwards aquifer near San Antonio, south-central Texas, 2004-9.-Continued

[By sample category. USGS, U.S. Geological Survey; MW, monitoring well; OVB, overburden; $\mu \mathrm{g} / \mathrm{L}$, micrograms per liter; --, not measured or not applicable; E, estimated; <, nondetection less than laboratory method reporting level]

\begin{tabular}{|c|c|c|c|c|c|c|c|c|c|c|c|c|c|c|}
\hline $\begin{array}{c}\text { USGS } \\
\text { identification } \\
\text { number }\end{array}$ & $\begin{array}{c}\text { 1,2,3-Tri- } \\
\text { chloro- } \\
\text { benzene } \\
(\mu \mathrm{g} / \mathrm{L})\end{array}$ & $\begin{array}{c}\text { 1,2,3-Tri- } \\
\text { chloro- } \\
\text { propane } \\
(\mu \mathrm{g} / \mathrm{L})\end{array}$ & $\begin{array}{c}\text { 1,2,3-Tri- } \\
\text { methyl- } \\
\text { benzene } \\
(\mu \mathrm{g} / \mathrm{L})\end{array}$ & $\begin{array}{c}\text { 1,2,4-Tri- } \\
\text { chloro- } \\
\text { benzene } \\
(\mu \mathrm{g} / \mathrm{L})\end{array}$ & $\begin{array}{c}\text { 1,2,4-Tri- } \\
\text { methyl- } \\
\text { benzene } \\
(\mu \mathrm{g} / \mathrm{L})\end{array}$ & $\begin{array}{l}\text { 1,2-Di- } \\
\text { bromo- } \\
\text { 3-chloro- } \\
\text { propane } \\
\text { ( } \mu \mathrm{g} / \mathrm{L})\end{array}$ & $\begin{array}{l}\text { 1,2-Di- } \\
\text { bromo- } \\
\text { ethane } \\
(\mu \mathrm{g} / \mathrm{L})\end{array}$ & $\begin{array}{c}\text { 1,2-Di- } \\
\text { chloro- } \\
\text { benzene } \\
(\mu \mathrm{g} / \mathrm{L})\end{array}$ & $\begin{array}{l}\text { 1,2-Di- } \\
\text { chloro- } \\
\text { ethane } \\
(\mu \mathrm{g} / \mathrm{L})\end{array}$ & $\begin{array}{c}\text { 1,2-Di- } \\
\text { chloro- } \\
\text { propane } \\
\text { ( } \mu \mathrm{g} / \mathrm{L})\end{array}$ & $\begin{array}{c}\text { 1,3,5-Tri- } \\
\text { methyl- } \\
\text { benzene } \\
(\mu \mathrm{g} / \mathrm{L})\end{array}$ & $\begin{array}{c}\text { 1,3-Di- } \\
\text { chloro- } \\
\text { benzene } \\
(\mu \mathrm{g} / \mathrm{L})\end{array}$ & $\begin{array}{l}\text { 1,3-Di- } \\
\text { chloro- } \\
\text { propane } \\
(\mu \mathrm{g} / \mathrm{L})\end{array}$ & $\begin{array}{c}\text { 1,4-Di- } \\
\text { chloro- } \\
\text { benzene } \\
(\mu \mathrm{g} / \mathrm{L})\end{array}$ \\
\hline 292053098365501 & $<0.18$ & $<0.18$ & $<0.06$ & $<0.12$ & $<0.056$ & $<0.51$ & $<0.036$ & $<0.048$ & $<0.13$ & $<0.029$ & $<0.044$ & $<0.03$ & $<0.06$ & $<0.034$ \\
\hline 293807098155301 & $<.18$ & $<.18$ & $<.06$ & $<.12$ & $<.056$ & $<.51$ & $<.036$ & $<.048$ & $<.13$ & $<.029$ & $<.044$ & $<.03$ & $<.06$ & $<.034$ \\
\hline 292604098563201 & $<.18$ & $<.18$ & $<.06$ & $<.12$ & $<.056$ & $<.51$ & $<.036$ & $<.048$ & $<.13$ & $<.029$ & $<.044$ & $<.03$ & $<.06$ & $<.034$ \\
\hline 292116099095501 & $<.18$ & $<.18$ & $<.06$ & $<.12$ & $<.056$ & $<.51$ & $<.036$ & $<.048$ & $<.13$ & $<.029$ & $<.044$ & $<.03$ & $<.06$ & $<.034$ \\
\hline 291232099470301 & $<.18$ & $<.18$ & $<.06$ & $<.12$ & $<.056$ & $<.51$ & $<.036$ & $<.048$ & $<.13$ & $<.029$ & $<.044$ & $<.03$ & $<.06$ & $<.034$ \\
\hline 293128098473101 & $<.18$ & $<.18$ & $<.06$ & $<.12$ & $<.056$ & $<.51$ & $<.036$ & $<.048$ & $<.13$ & $<.029$ & $<.044$ & $<.03$ & $<.06$ & $<.034$ \\
\hline 293451098313201 & $<.18$ & $<.18$ & $<.06$ & $<.12$ & $<.056$ & $<.51$ & $<.036$ & $<.048$ & $<.13$ & $<.029$ & $<.044$ & $<.03$ & $<.06$ & $<.034$ \\
\hline 294604098060801 & $<.18$ & $<.18$ & $<.06$ & $<.12$ & $<.056$ & $<.51$ & $<.036$ & $<.048$ & $<.13$ & $<.029$ & $<.044$ & $<.03$ & $<.06$ & $<.034$ \\
\hline 294019098114701 & $<.18$ & $<.18$ & $<.06$ & $<.12$ & $<.056$ & $<.51$ & $<.036$ & $<.048$ & $<.13$ & $<.029$ & $<.044$ & $<.03$ & $<.06$ & $<.034$ \\
\hline 292215098580201 & $<.18$ & $<.18$ & $<.06$ & $<.12$ & $<.056$ & $<.51$ & $<.036$ & $<.048$ & $<.13$ & $<.029$ & $<.044$ & $<.03$ & $<.06$ & $<.034$ \\
\hline 292119098524901 & $<.18$ & $<.18$ & $<.06$ & $<.12$ & $<.056$ & $<.51$ & $<.036$ & $<.048$ & $<.13$ & $<.029$ & $<.044$ & $<.03$ & $<.06$ & $<.034$ \\
\hline 291943099163301 & $<.18$ & $<.18$ & $<.06$ & $<.12$ & $<.056$ & $<.51$ & $<.036$ & $<.048$ & $<.13$ & $<.029$ & $<.044$ & $<.03$ & $<.06$ & $<.034$ \\
\hline 291840099382601 & $<.18$ & $<.18$ & $<.06$ & $<.12$ & $<.056$ & $<.51$ & $<.036$ & $<.048$ & $<.13$ & $<.029$ & $<.044$ & $<.03$ & $<.06$ & $<.034$ \\
\hline 293518098332601 & $<.18$ & $<.18$ & $<.06$ & $<.12$ & $<.056$ & $<.51$ & $<.036$ & $<.048$ & $<.13$ & $<.029$ & $<.044$ & $<.03$ & $<.06$ & $<.034$ \\
\hline 293023098355401 & $<.18$ & $<.18$ & $<.06$ & $<.12$ & $<.056$ & $<.51$ & $<.036$ & $<.048$ & $<.13$ & $<.029$ & $<.044$ & $<.03$ & $<.06$ & $<.034$ \\
\hline 293042098305201 & $<.18$ & $<.18$ & $<.06$ & $<.12$ & $<.056$ & $<.51$ & $<.036$ & $<.048$ & $<.13$ & $<.029$ & $<.044$ & $<.03$ & $<.06$ & $<.034$ \\
\hline 292442098474501 & $<.18$ & $<.18$ & $<.06$ & $<.12$ & $<.056$ & $<.51$ & $<.036$ & $<.048$ & $<.13$ & $<.029$ & $<.044$ & $<.03$ & $<.06$ & $<.034$ \\
\hline 292405098371201 & $<.18$ & $<.18$ & $<.06$ & $<.12$ & $<.056$ & $<.51$ & $<.036$ & $<.048$ & $<.13$ & $<.029$ & $<.044$ & $<.03$ & $<.06$ & $<.034$ \\
\hline 292931098274601 & $<.18$ & $<.18$ & $<.06$ & $<.12$ & $<.056$ & $<.51$ & $<.036$ & $<.048$ & $<.13$ & $<.029$ & $<.044$ & $<.03$ & $<.06$ & $<.034$ \\
\hline 293729098173101 & $<.18$ & $<.18$ & $<.06$ & $<.12$ & $<.056$ & $<.51$ & $<.036$ & $<.048$ & $<.13$ & $<.029$ & $<.044$ & $<.03$ & $<.06$ & $<.034$ \\
\hline 291219099095601 & $<.18$ & $<.18$ & $<.06$ & $<.12$ & $<.056$ & $<.51$ & $<.036$ & $<.048$ & $<.13$ & $<.029$ & $<.044$ & $<.03$ & $<.06$ & $<.034$ \\
\hline \multicolumn{15}{|c|}{ Monitoring wells } \\
\hline 292943098354401 & $<.08$ & $<.12$ & $<.08$ & $<.08$ & $<.04$ & $<.5$ & $<.04$ & $<.02$ & $<.06$ & $<.02$ & $<.04$ & $<.04$ & $<.06$ & $<.02$ \\
\hline 292943098354402 & $<.08$ & $<.12$ & $<.08$ & $<.08$ & $<.04$ & $<.5$ & $<.04$ & $<.02$ & $<.06$ & $<.02$ & $<.04$ & $<.04$ & $<.06$ & $<.02$ \\
\hline 292943098354403 & $<.08$ & $<.12$ & $<.08$ & $<.08$ & $<.04$ & $<.5$ & $<.04$ & $<.02$ & $<.06$ & $<.02$ & $<.04$ & $<.04$ & $<.06$ & $<.02$ \\
\hline 292943098354404 & $<.08$ & $<.12$ & $<.08$ & $<.08$ & $<.04$ & $<.5$ & $<.04$ & $<.02$ & $<.06$ & $<.02$ & $<.04$ & $<.04$ & $<.06$ & $<.02$ \\
\hline
\end{tabular}


Table 14. Volatile organic and fuel oxygenate compounds for groundwater samples collected for the study of the transport of anthropogenic and natural contaminants (TANC) to public supply wells in the San Antonio segment of the Edwards aquifer near San Antonio, south-central Texas, 2004-9.-Continued

[By sample category. USGS, U.S. Geological Survey; MW, monitoring well; OVB, overburden; $\mu \mathrm{g} / \mathrm{L}$, micrograms per liter; --, not measured or not applicable; E, estimated; <, nondetection less than laboratory method reporting level]

\begin{tabular}{|c|c|c|c|c|c|c|c|c|c|c|c|c|c|c|}
\hline $\begin{array}{c}\text { USGS } \\
\text { identification } \\
\text { number }\end{array}$ & $\begin{array}{c}1,2,3-\text { Tri- } \\
\text { chloro- } \\
\text { benzene } \\
(\mu \mathrm{g} / \mathrm{L})\end{array}$ & $\begin{array}{c}\text { 1,2,3-Tri- } \\
\text { chloro- } \\
\text { propane } \\
(\mu \mathrm{g} / \mathrm{L})\end{array}$ & $\begin{array}{c}\text { 1,2,3-Tri- } \\
\text { methyl- } \\
\text { benzene } \\
(\mu \mathrm{g} / \mathrm{L})\end{array}$ & $\begin{array}{c}\text { 1,2,4-Tri- } \\
\text { chloro- } \\
\text { benzene } \\
(\mu \mathrm{g} / \mathrm{L})\end{array}$ & $\begin{array}{c}\text { 1,2,4-Tri- } \\
\text { methyl- } \\
\text { benzene } \\
(\mu \mathrm{g} / \mathrm{L})\end{array}$ & $\begin{array}{c}\text { 1,2-Di- } \\
\text { bromo- } \\
\text { 3-chloro- } \\
\text { propane } \\
\text { ( } \mathrm{gg} / \mathrm{L} \text { ) }\end{array}$ & $\begin{array}{c}\text { 1,2-Di- } \\
\text { bromo- } \\
\text { ethane } \\
(\mu \mathrm{g} / \mathrm{L})\end{array}$ & $\begin{array}{c}\text { 1,2-Di- } \\
\text { chloro- } \\
\text { benzene } \\
(\mu \mathrm{g} / \mathrm{L})\end{array}$ & $\begin{array}{l}\text { 1,2-Di- } \\
\text { chloro- } \\
\text { ethane } \\
(\mu \mathrm{g} / \mathrm{L})\end{array}$ & $\begin{array}{c}\text { 1,2-Di- } \\
\text { chloro- } \\
\text { propane } \\
(\mu \mathrm{g} / \mathrm{L})\end{array}$ & $\begin{array}{c}\text { 1,3,5-Tri- } \\
\text { methyl- } \\
\text { benzene } \\
(\mu \mathrm{g} / \mathrm{L})\end{array}$ & $\begin{array}{c}\text { 1,3-Di- } \\
\text { chloro- } \\
\text { benzene } \\
(\mu \mathrm{g} / \mathrm{L})\end{array}$ & $\begin{array}{c}\text { 1,3-Di- } \\
\text { chloro- } \\
\text { propane } \\
(\mu \mathrm{g} / \mathrm{L})\end{array}$ & $\begin{array}{c}\text { 1,4-Di- } \\
\text { chloro- } \\
\text { benzene } \\
(\mu \mathrm{g} / \mathrm{L})\end{array}$ \\
\hline 292851098374401 & $<0.08$ & $<0.12$ & $<0.08$ & $<0.08$ & $<0.04$ & $<0.5$ & $<0.04$ & $<0.02$ & $<0.06$ & $<0.02$ & $<0.04$ & $<0.04$ & $<0.06$ & $<0.02$ \\
\hline 292851098374402 & $<.08$ & $<.12$ & $<.08$ & $<.08$ & $<.04$ & $<.5$ & $<.04$ & $<.02$ & $<.06$ & $<.02$ & $<.04$ & $<.04$ & $<.06$ & $<.02$ \\
\hline \multicolumn{15}{|c|}{ Well-field depth-dependent sampling (W4) } \\
\hline 292916098360701 & $<.08$ & $<.12$ & $<.08$ & $<.08$ & E.040 & $<.5$ & $<.04$ & $<.02$ & $<.06$ & $<.02$ & $<.04$ & $<.04$ & $<.06$ & $<.02$ \\
\hline 292916098360701 & $<.08$ & $<.12$ & $<.08$ & $<.08$ & E.046 & $<.5$ & $<.04$ & $<.02$ & $<.06$ & $<.02$ & $<.04$ & $<.04$ & $<.06$ & $<.02$ \\
\hline 292916098360701 & $<.08$ & $<.12$ & $<.08$ & $<.08$ & $<.04$ & $<.5$ & $<.04$ & $<.02$ & $<.06$ & $<.02$ & $<.04$ & $<.04$ & $<.06$ & $<.02$ \\
\hline 292916098360701 & $<.08$ & $<.12$ & $<.08$ & $<.08$ & E.026 & $<.5$ & $<.04$ & $<.02$ & $<.06$ & $<.02$ & $<.04$ & $<.04$ & $<.06$ & $<.02$ \\
\hline 292916098360701 & $<.08$ & $<.12$ & $<.08$ & $<.08$ & $<.04$ & $<.5$ & $<.04$ & $<.02$ & $<.06$ & $<.02$ & $<.04$ & $<.04$ & $<.06$ & $<.02$ \\
\hline 292916098360701 & $<.08$ & $<.12$ & $<.08$ & $<.08$ & $<.04$ & $<.5$ & $<.04$ & $<.02$ & $<.06$ & $<.02$ & $<.04$ & $<.04$ & $<.06$ & $<.02$ \\
\hline 292916098360701 & $<.08$ & $<.12$ & $<.08$ & $<.08$ & $<.04$ & $<.5$ & $<.04$ & $<.02$ & $<.06$ & $<.02$ & $<.04$ & $<.04$ & $<.06$ & $<.02$ \\
\hline 292916098360701 & $<.08$ & $<.12$ & $<.08$ & $<.08$ & $<.04$ & $<.5$ & $<.04$ & $<.02$ & $<.06$ & $<.02$ & $<.04$ & $<.04$ & $<.06$ & $<.02$ \\
\hline 292916098360701 & $<.08$ & $<.12$ & $<.08$ & $<.08$ & $<.04$ & $<.5$ & $<.04$ & $<.02$ & $<.06$ & $<.02$ & $<.04$ & $<.04$ & $<.06$ & $<.02$ \\
\hline \multicolumn{15}{|c|}{ Well-field wells (wellhead sampling) } \\
\hline 292919098360501 & $<.08$ & $<.12$ & $<.08$ & $<.08$ & $<.04$ & $<.5$ & $<.04$ & $<.02$ & $<.06$ & $<.02$ & $<.04$ & $<.04$ & $<.06$ & $<.02$ \\
\hline 292925098360201 & $<.08$ & $<.12$ & $<.08$ & $<.08$ & $<.04$ & $<.5$ & $<.04$ & $<.02$ & $<.06$ & $<.02$ & $<.04$ & $<.04$ & $<.06$ & $<.02$ \\
\hline 292916098360701 & $<.08$ & $<.12$ & $<.08$ & $<.08$ & $<.04$ & $<.5$ & $<.04$ & $<.02$ & $<.06$ & $<.02$ & $<.04$ & $<.04$ & $<.06$ & $<.02$ \\
\hline 292920098360601 & $<.08$ & $<.12$ & $<.08$ & $<.08$ & $<.04$ & $<.5$ & $<.04$ & $<.02$ & $<.06$ & $<.02$ & $<.04$ & $<.04$ & $<.06$ & $<.02$ \\
\hline 292923098360301 & $<.08$ & $<.12$ & $<.08$ & $<.08$ & $<.04$ & $<.5$ & $<.04$ & $<.02$ & $<.06$ & $<.02$ & $<.04$ & $<.04$ & $<.06$ & $<.02$ \\
\hline \multicolumn{15}{|c|}{ Temporal sampling } \\
\hline 292923098360301 & $<.06$ & $<.12$ & $<.08$ & $<.04$ & $<.04$ & $<1$ & $<.04$ & $<.02$ & $<.06$ & $<.02$ & $<.04$ & $<.02$ & $<.06$ & $<.02$ \\
\hline 292923098360301 & $<.06$ & $<.12$ & $<.06$ & $<.08$ & $<.032$ & $<.34$ & $<.05$ & $<.028$ & $<.08$ & $<.026$ & $<.032$ & $<.024$ & $<.06$ & $<.026$ \\
\hline
\end{tabular}


Table 14. Volatile organic and fuel oxygenate compounds for groundwater samples collected for the study of the transport of anthropogenic and natural contaminants (TANC) to public supply wells in the San Antonio segment of the Edwards aquifer near San Antonio, south-central Texas, 2004-9.-Continued

[By sample category. USGS, U.S. Geological Survey; MW, monitoring well; OVB, overburden; $\mu \mathrm{g} / \mathrm{L}$, micrograms per liter; --, not measured or not applicable; E, estimated; <, nondetection less than laboratory method reporting level]

\begin{tabular}{|c|c|c|c|c|c|c|c|c|c|c|c|c|c|c|}
\hline $\begin{array}{c}\text { USGS } \\
\text { identification } \\
\text { number }\end{array}$ & $\begin{array}{c}\text { 1,2,3-Tri- } \\
\text { chloro- } \\
\text { benzene } \\
(\mu \mathrm{g} / \mathrm{L})\end{array}$ & $\begin{array}{c}\text { 1,2,3-Tri- } \\
\text { chloro- } \\
\text { propane } \\
(\mu \mathrm{g} / \mathrm{L})\end{array}$ & $\begin{array}{c}\text { 1,2,3-Tri- } \\
\text { methyl- } \\
\text { benzene } \\
(\mu \mathrm{g} / \mathrm{L})\end{array}$ & $\begin{array}{c}\text { 1,2,4-Tri- } \\
\text { chloro- } \\
\text { benzene } \\
(\mu \mathrm{g} / \mathrm{L})\end{array}$ & $\begin{array}{c}\text { 1,2,4-Tri- } \\
\text { methyl- } \\
\text { benzene } \\
(\mu \mathrm{g} / \mathrm{L})\end{array}$ & $\begin{array}{l}\text { 1,2-Di- } \\
\text { bromo- } \\
\text { 3-chloro- } \\
\text { propane } \\
\text { ( } \mu \mathrm{g} / \mathrm{L})\end{array}$ & $\begin{array}{l}\text { 1,2-Di- } \\
\text { bromo- } \\
\text { ethane } \\
(\mu \mathrm{g} / \mathrm{L})\end{array}$ & $\begin{array}{c}\text { 1,2-Di- } \\
\text { chloro- } \\
\text { benzene } \\
(\mu \mathrm{g} / \mathrm{L})\end{array}$ & $\begin{array}{l}\text { 1,2-Di- } \\
\text { chloro- } \\
\text { ethane } \\
(\mu \mathrm{g} / \mathrm{L})\end{array}$ & $\begin{array}{c}\text { 1,2-Di- } \\
\text { chloro- } \\
\text { propane } \\
(\mu \mathrm{g} / \mathrm{L})\end{array}$ & $\begin{array}{c}\text { 1,3,5-Tri- } \\
\text { methyl- } \\
\text { benzene } \\
(\mu \mathrm{g} / \mathrm{L})\end{array}$ & $\begin{array}{c}\text { 1,3-Di- } \\
\text { chloro- } \\
\text { benzene } \\
(\mu \mathrm{g} / \mathrm{L})\end{array}$ & $\begin{array}{c}\text { 1,3-Di- } \\
\text { chloro- } \\
\text { propane } \\
(\mu \mathrm{g} / \mathrm{L})\end{array}$ & $\begin{array}{c}\text { 1,4-Di- } \\
\text { chloro- } \\
\text { benzene } \\
(\mu \mathrm{g} / \mathrm{L})\end{array}$ \\
\hline 292923098360301 & $<0.06$ & $<0.12$ & $<0.06$ & $<0.08$ & $<0.032$ & $<0.34$ & $<0.05$ & $<0.028$ & $<0.08$ & $<0.026$ & $<0.032$ & $<0.024$ & $<0.06$ & $<0.026$ \\
\hline 292923098360301 & $<.06$ & $<.12$ & $<.06$ & $<.08$ & $<.032$ & $<.34$ & $<.05$ & $<.028$ & $<.08$ & $<.026$ & $<.032$ & $<.024$ & $<.06$ & $<.026$ \\
\hline 292923098360301 & $<.06$ & $<.12$ & $<.06$ & $<.08$ & $<.032$ & $<.34$ & $<.05$ & $<.028$ & $<.08$ & $<.026$ & $<.032$ & $<.024$ & $<.06$ & $<.026$ \\
\hline 292923098360301 & $<.06$ & $<.12$ & $<.06$ & $<.08$ & $<.032$ & $<.34$ & $<.05$ & $<.028$ & $<.08$ & $<.026$ & $<.032$ & $<.024$ & $<.06$ & $<.026$ \\
\hline 292943098354402 & $<.06$ & $<.12$ & $<.08$ & $<.04$ & $<.04$ & $<1$ & $<.04$ & $<.02$ & $<.06$ & $<.02$ & $<.04$ & $<.02$ & $<.06$ & $<.02$ \\
\hline 292943098354402 & $<.06$ & $<.12$ & $<.06$ & $<.08$ & $<.032$ & $<.34$ & $<.05$ & $<.028$ & $<.08$ & $<.026$ & $<.032$ & $<.024$ & $<.06$ & $<.026$ \\
\hline 292943098354402 & $<.06$ & $<.12$ & $<.06$ & $<.08$ & $<.032$ & $<.34$ & $<.05$ & $<.028$ & $<.08$ & $<.026$ & $<.032$ & $<.024$ & $<.06$ & $<.026$ \\
\hline 292943098354402 & $<.06$ & $<.12$ & $<.06$ & $<.08$ & $<.032$ & $<.34$ & $<.05$ & $<.028$ & $<.08$ & $<.026$ & $<.032$ & $<.024$ & $<.06$ & $<.026$ \\
\hline 292943098354402 & $<.06$ & $<.12$ & $<.06$ & $<.08$ & $<.032$ & $<.34$ & $<.05$ & $<.028$ & $<.08$ & $<.026$ & $<.032$ & $<.024$ & $<.06$ & $<.026$ \\
\hline 292943098354402 & $<.06$ & $<.12$ & $<.06$ & $<.08$ & $<.032$ & $<.34$ & $<.05$ & $<.028$ & $<.08$ & $<.026$ & $<.032$ & $<.024$ & $<.06$ & $<.026$ \\
\hline 292943098354403 & $<.06$ & $<.12$ & $<.08$ & $<.04$ & $<.04$ & $<1$ & $<.04$ & $<.02$ & $<.06$ & $<.02$ & $<.04$ & $<.02$ & $<.06$ & $<.02$ \\
\hline 292943098354403 & $<.06$ & $<.12$ & $<.06$ & $<.08$ & $<.032$ & $<.34$ & $<.05$ & $<.028$ & $<.08$ & $<.026$ & $<.032$ & $<.024$ & $<.06$ & $<.026$ \\
\hline 292943098354403 & $<.06$ & $<.12$ & $<.06$ & $<.08$ & $<.032$ & $<.34$ & $<.05$ & $<.028$ & $<.08$ & $<.026$ & $<.032$ & $<.024$ & $<.06$ & $<.026$ \\
\hline 292943098354403 & $<.06$ & $<.12$ & $<.06$ & $<.08$ & $<.032$ & $<.34$ & $<.05$ & $<.028$ & $<.08$ & $<.026$ & $<.032$ & $<.024$ & $<.06$ & $<.026$ \\
\hline 292943098354403 & $<.06$ & $<.12$ & $<.06$ & $<.08$ & $<.032$ & $<.34$ & $<.05$ & $<.028$ & $<.08$ & $<.026$ & $<.032$ & $<.024$ & $<.06$ & $<.026$ \\
\hline 292943098354403 & $<.06$ & $<.12$ & $<.06$ & $<.08$ & $<.032$ & $<.34$ & $<.05$ & $<.028$ & $<.08$ & $<.026$ & $<.032$ & $<.024$ & $<.06$ & $<.026$ \\
\hline 292943098354404 & $<.06$ & $<.12$ & $<.08$ & $<.04$ & $<.04$ & $<1$ & $<.04$ & $<.02$ & $<.06$ & $<.02$ & $<.04$ & $<.02$ & $<.06$ & $<.02$ \\
\hline 292943098354404 & $<.06$ & $<.12$ & $<.06$ & $<.08$ & $<.032$ & $<.34$ & $<.05$ & $<.028$ & $<.08$ & $<.026$ & $<.032$ & $<.024$ & $<.06$ & $<.026$ \\
\hline 292943098354404 & $<.06$ & $<.12$ & $<.06$ & $<.08$ & $<.032$ & $<.34$ & $<.05$ & $<.028$ & $<.08$ & $<.026$ & $<.032$ & $<.024$ & $<.06$ & $<.026$ \\
\hline 292943098354404 & $<.06$ & $<.12$ & $<.06$ & $<.08$ & $<.032$ & $<.34$ & $<.05$ & $<.028$ & $<.08$ & $<.026$ & $<.032$ & $<.024$ & $<.06$ & $<.026$ \\
\hline 292943098354404 & $<.06$ & $<.12$ & $<.06$ & $<.08$ & $<.032$ & $<.34$ & $<.05$ & $<.028$ & $<.08$ & $<.026$ & $<.032$ & $<.024$ & $<.06$ & $<.026$ \\
\hline 292943098354404 & $<.06$ & $<.12$ & $<.06$ & $<.08$ & $<.032$ & $<.34$ & $<.05$ & $<.028$ & $<.08$ & $<.026$ & $<.032$ & $<.024$ & $<.06$ & $<.026$ \\
\hline 293252098380801 & $<.06$ & $<.12$ & $<.08$ & $<.04$ & $<.04$ & $<1$ & $<.04$ & $<.02$ & $<.06$ & $<.02$ & $<.04$ & $<.02$ & $<.06$ & $<.02$ \\
\hline 293252098380801 & $<.06$ & $<.12$ & $<.06$ & $<.08$ & $<.032$ & $<.34$ & $<.05$ & $<.028$ & $<.08$ & $<.026$ & $<.032$ & $<.024$ & $<.06$ & $<.026$ \\
\hline 293252098380801 & $<.06$ & $<.12$ & $<.06$ & $<.08$ & $<.032$ & $<.34$ & $<.05$ & $<.028$ & $<.08$ & $<.026$ & $<.032$ & $<.024$ & $<.06$ & $<.026$ \\
\hline 293252098380801 & $<.06$ & $<.12$ & $<.06$ & $<.08$ & $<.032$ & $<.34$ & $<.05$ & $<.028$ & $<.08$ & $<.026$ & $<.032$ & $<.024$ & $<.06$ & $<.026$ \\
\hline 293252098380801 & $<.06$ & $<.12$ & $<.06$ & $<.08$ & $<.032$ & $<.34$ & $<.05$ & $<.028$ & $<.08$ & $<.026$ & $<.032$ & $<.024$ & $<.06$ & $<.026$ \\
\hline 293252098380801 & $<.06$ & $<.12$ & $<.06$ & $<.08$ & $<.032$ & $<.34$ & $<.05$ & $<.028$ & $<.08$ & $<.026$ & $<.032$ & $<.024$ & $<.06$ & $<.026$ \\
\hline
\end{tabular}


Table 14. Volatile organic and fuel oxygenate compounds for groundwater samples collected for the study of the transport of anthropogenic and natural contaminants (TANC) to public supply wells in the San Antonio segment of the Edwards aquifer near San Antonio, south-central Texas, 2004-9.-Continued

[By sample category. USGS, U.S. Geological Survey; MW, monitoring well; OVB, overburden; $\mu \mathrm{g} / \mathrm{L}$, micrograms per liter; --, not measured or not applicable; E, estimated; <, nondetection less than laboratory method reporting level]

\begin{tabular}{|c|c|c|c|c|c|c|c|c|c|c|c|c|c|c|c|}
\hline $\begin{array}{c}\text { USGS } \\
\text { identification } \\
\text { number }\end{array}$ & $\begin{array}{c}\text { 2,2-Di- } \\
\text { chloro- } \\
\text { propane } \\
(\mu \mathrm{g} / \mathrm{L})\end{array}$ & $\begin{array}{c}2- \\
\text { Chloro- } \\
\text { toluene } \\
(\mu \mathrm{g} / \mathrm{L})\end{array}$ & $\begin{array}{c}\text { 2-Ethyl- } \\
\text { toluene } \\
\text { ( } \mu \mathrm{g} / \mathrm{L})\end{array}$ & $\begin{array}{c}\text { 3-Chloro- } \\
\text { propene } \\
\text { ( } \mathrm{gg} / \mathrm{L})\end{array}$ & $\begin{array}{c}\text { 4-Chloro- } \\
\text { toluene } \\
(\mu \mathrm{g} / \mathrm{L})\end{array}$ & $\begin{array}{c}\text { 4-Iso- } \\
\text { propyl- } \\
\text { toluene } \\
(\mu \mathrm{g} / \mathrm{L})\end{array}$ & $\begin{array}{c}\text { Acetone } \\
\text { ( } \mu \mathrm{g} / \mathrm{L})\end{array}$ & $\begin{array}{c}\text { Acrylo- } \\
\text { nitrile } \\
\text { ( } \mu \mathrm{g} / \mathrm{L})\end{array}$ & $\begin{array}{c}\text { Benzene } \\
(\mu \mathrm{g} / \mathrm{L})\end{array}$ & $\begin{array}{c}\text { Bromo- } \\
\text { benzene } \\
(\mu \mathrm{g} / \mathrm{L})\end{array}$ & $\begin{array}{c}\text { Bromo- } \\
\text { chloro- } \\
\text { methane } \\
(\mu \mathrm{g} / \mathrm{L})\end{array}$ & $\begin{array}{c}\text { Bromo- } \\
\text { dichloro- } \\
\text { methane } \\
(\mu \mathrm{g} / \mathrm{L})\end{array}$ & $\begin{array}{c}\text { Bromo- } \\
\text { ethene } \\
\text { ( } \mu \mathrm{g} / \mathrm{L} \text { ) }\end{array}$ & $\begin{array}{c}\text { Bromo- } \\
\text { meth- } \\
\text { ane } \\
(\mu \mathrm{g} / \mathrm{L})\end{array}$ & $\begin{array}{c}\text { Carbon } \\
\text { di- } \\
\text { sulfide } \\
\text { ( } \mu \mathrm{g} / \mathrm{L} \text { ) } \\
\end{array}$ \\
\hline \multicolumn{16}{|c|}{ Regional aquifer public-supply wells } \\
\hline 293359098290301 & $<0.05$ & $<0.04$ & $<0.06$ & $<0.5$ & $<0.05$ & $<0.08$ & $<6$ & $<0.8$ & $<0.021$ & $<0.028$ & $<0.12$ & $<0.028$ & $<0.1$ & $<0.26$ & $<0.038$ \\
\hline 293359098290301 & $<.05$ & $<.04$ & $<.06$ & $<.5$ & $<.05$ & $<.08$ & $<6$ & $<.8$ & $<.021$ & $<.028$ & $<.12$ & $<.028$ & $<.1$ & $<.26$ & $<.038$ \\
\hline 293358098231101 & $<.05$ & $<.04$ & $<.06$ & $<.5$ & $<.05$ & $<.08$ & $<6$ & $<.8$ & $<.021$ & $<.028$ & $<.12$ & $<.028$ & $<.1$ & $<.26$ & $<.038$ \\
\hline 293358098231101 & $<.05$ & $<.04$ & $<.06$ & $<.5$ & $<.05$ & $<.08$ & $<6$ & $<.8$ & $<.021$ & $<.028$ & $<.12$ & $<.028$ & $<.1$ & $<.26$ & $<.038$ \\
\hline 293120098285801 & $<.05$ & $<.04$ & $<.06$ & $<.5$ & $<.05$ & $<.08$ & $<6$ & $<.8$ & $<.021$ & $<.028$ & $<.12$ & .163 & $<.1$ & $<.26$ & $<.038$ \\
\hline 293120098285801 & $<.05$ & $<.04$ & $<.06$ & $<.5$ & $<.05$ & $<.08$ & $<6$ & $<.8$ & $<.021$ & $<.028$ & $<.12$ & E.035 & $<.1$ & $<.26$ & $<.038$ \\
\hline 293145098224201 & $<.05$ & $<.04$ & $<.06$ & $<.5$ & $<.05$ & $<.08$ & $<6$ & $<.8$ & $<.021$ & $<.028$ & $<.12$ & $<.028$ & $<.1$ & $<.26$ & $<.038$ \\
\hline 293119098211201 & $<.05$ & $<.04$ & $<.06$ & $<.5$ & $<.05$ & $<.08$ & $<6$ & $<.8$ & $<.021$ & $<.028$ & $<.12$ & $<.028$ & $<.1$ & $<.26$ & $<.038$ \\
\hline 292843098425101 & $<.05$ & $<.04$ & $<.06$ & $<.5$ & $<.05$ & $<.08$ & $<6$ & $<.8$ & $<.021$ & $<.028$ & $<.12$ & $<.028$ & $<.1$ & $<.26$ & $<.038$ \\
\hline 292459098382101 & $<.05$ & $<.04$ & $<.06$ & $<.5$ & $<.05$ & $<.08$ & $<6$ & $<.8$ & $<.021$ & $<.028$ & $<.12$ & $<.028$ & $<.1$ & $<.26$ & $<.038$ \\
\hline 292925098360201 & $<.05$ & $<.04$ & $<.06$ & $<.5$ & $<.05$ & $<.08$ & $<6$ & $<.8$ & $<.021$ & $<.028$ & $<.12$ & $<.028$ & $<.1$ & $<.26$ & $<.038$ \\
\hline 292925098360201 & $<.05$ & $<.04$ & $<.06$ & $<.5$ & $<.05$ & $<.08$ & $<6$ & $<.8$ & $<.021$ & $<.028$ & $<.12$ & $<.028$ & $<.1$ & $<.26$ & $<.038$ \\
\hline 292822098325401 & $<.05$ & $<.04$ & $<.06$ & $<.5$ & $<.05$ & $<.08$ & $<6$ & $<.8$ & $<.021$ & $<.028$ & $<.12$ & $<.028$ & $<.1$ & $<.26$ & $<.038$ \\
\hline 292822098325401 & $<.05$ & $<.04$ & $<.06$ & $<.5$ & $<.05$ & $<.08$ & $<6$ & $<.8$ & $<.021$ & $<.028$ & $<.12$ & $<.028$ & $<.1$ & $<.26$ & $<.038$ \\
\hline 292944098292301 & $<.05$ & $<.04$ & $<.06$ & $<.5$ & $<.05$ & $<.08$ & $<6$ & $<.8$ & $<.021$ & $<.028$ & $<.12$ & $<.028$ & $<.1$ & $<.26$ & $<.038$ \\
\hline 292944098292301 & -- & -- & -- & -- & -- & -- & -- & -- & -- & -- & -- & -- & -- & -- & -- \\
\hline 292522098291901 & $<.05$ & $<.04$ & $<.06$ & $<.5$ & $<.05$ & $<.08$ & $<6$ & $<.8$ & $<.021$ & $<.028$ & $<.12$ & $<.028$ & $<.1$ & $<.26$ & $<.038$ \\
\hline 292643098241801 & $<.05$ & $<.04$ & $<.06$ & $<.5$ & $<.05$ & $<.08$ & $<6$ & $<.8$ & $<.021$ & $<.028$ & $<.12$ & .788 & $<.1$ & $<.26$ & $<.038$ \\
\hline 292643098241801 & $<.05$ & $<.04$ & $<.06$ & $<.5$ & $<.05$ & $<.08$ & $<6$ & $<.8$ & $<.021$ & $<.028$ & $<.12$ & $<.028$ & $<.1$ & $<.26$ & $<.038$ \\
\hline 292328098294601 & $<.05$ & $<.04$ & $<.06$ & $<.5$ & $<.05$ & $<.08$ & $<6$ & $<.8$ & $<.021$ & $<.028$ & $<.12$ & $<.028$ & $<.1$ & $<.26$ & $<.038$ \\
\hline 294225098080301 & $<.05$ & $<.04$ & $<.06$ & $<.5$ & $<.05$ & $<.08$ & $<6$ & $<.8$ & $<.021$ & $<.028$ & $<.12$ & $<.028$ & $<.1$ & $<.26$ & $<.038$ \\
\hline 294225098080301 & $<.05$ & $<.04$ & $<.06$ & $<.5$ & $<.05$ & $<.08$ & $<6$ & $<.8$ & $<.021$ & $<.028$ & $<.12$ & $<.028$ & $<.1$ & $<.26$ & $<.038$ \\
\hline 291210099475601 & $<.05$ & $<.04$ & $<.06$ & $<.5$ & $<.05$ & $<.08$ & $<6$ & $<.8$ & $<.021$ & $<.028$ & $<.12$ & $<.028$ & $<.1$ & $<.26$ & $<.038$ \\
\hline 293111098340901 & $<.05$ & $<.04$ & $<.06$ & $<.5$ & $<.05$ & $<.08$ & $<6$ & $<.8$ & $<.021$ & $<.028$ & $<.12$ & $<.028$ & $<.1$ & $<.26$ & $<.038$ \\
\hline 293512098291701 & $<.05$ & $<.04$ & $<.06$ & $<.5$ & $<.05$ & $<.08$ & $<6$ & $<.8$ & $<.021$ & $<.028$ & $<.12$ & E.027 & $<.1$ & $<.26$ & $<.038$ \\
\hline 292424098421501 & $<.05$ & $<.04$ & $<.06$ & $<.5$ & $<.05$ & $<.08$ & $<6$ & $<.8$ & $<.021$ & $<.028$ & $<.12$ & $<.028$ & $<.1$ & $<.26$ & $<.038$ \\
\hline
\end{tabular}


Table 14. Volatile organic and fuel oxygenate compounds for groundwater samples collected for the study of the transport of anthropogenic and natural contaminants (TANC) to public supply wells in the San Antonio segment of the Edwards aquifer near San Antonio, south-central Texas, 2004-9.-Continued

[By sample category. USGS, U.S. Geological Survey; MW, monitoring well; OVB, overburden; $\mu \mathrm{g} / \mathrm{L}$, micrograms per liter; --, not measured or not applicable; E, estimated; <, nondetection less than laboratory method reporting level]

\begin{tabular}{|c|c|c|c|c|c|c|c|c|c|c|c|c|c|c|c|}
\hline $\begin{array}{c}\text { USGS } \\
\text { identification } \\
\text { number }\end{array}$ & $\begin{array}{c}\text { 2,2-Di- } \\
\text { chloro- } \\
\text { propane } \\
(\mu \mathrm{g} / \mathrm{L})\end{array}$ & $\begin{array}{c}2- \\
\text { Chloro- } \\
\text { toluene } \\
(\mu \mathrm{g} / \mathrm{L})\end{array}$ & $\begin{array}{c}\text { 2-Ethyl- } \\
\text { toluene } \\
\text { ( } \mu \mathrm{g} / \mathrm{L})\end{array}$ & $\begin{array}{c}\text { 3-Chloro- } \\
\text { propene } \\
\text { ( } \mathrm{gg} / \mathrm{L})\end{array}$ & $\begin{array}{c}\text { 4-Chloro- } \\
\text { toluene } \\
\text { ( } \mathrm{\mu g} / \mathrm{L})\end{array}$ & $\begin{array}{c}\text { 4-Iso- } \\
\text { propyl- } \\
\text { toluene } \\
(\mu \mathrm{g} / \mathrm{L})\end{array}$ & $\begin{array}{c}\text { Acetone } \\
\text { ( } \mu \mathrm{g} / \mathrm{L})\end{array}$ & $\begin{array}{c}\text { Acrylo- } \\
\text { nitrile } \\
\text { ( } \mu \mathrm{g} / \mathrm{L})\end{array}$ & $\begin{array}{c}\text { Benzene } \\
(\mu \mathrm{g} / \mathrm{L})\end{array}$ & $\begin{array}{c}\text { Bromo- } \\
\text { benzene } \\
(\mu \mathrm{g} / \mathrm{L})\end{array}$ & $\begin{array}{c}\text { Bromo- } \\
\text { chloro- } \\
\text { methane } \\
(\mu \mathrm{g} / \mathrm{L})\end{array}$ & $\begin{array}{l}\text { Bromo- } \\
\text { dichloro- } \\
\text { methane } \\
(\mu \mathrm{g} / \mathrm{L})\end{array}$ & $\begin{array}{c}\text { Bromo- } \\
\text { ethene } \\
(\mu \mathrm{g} / \mathrm{L})\end{array}$ & $\begin{array}{c}\text { Bromo- } \\
\text { meth- } \\
\text { ane } \\
(\mu \mathrm{g} / \mathrm{L})\end{array}$ & $\begin{array}{c}\text { Carbon } \\
\text { di- } \\
\text { sulfide } \\
(\mu \mathrm{g} / \mathrm{L})\end{array}$ \\
\hline 292053098365501 & $<0.05$ & $<0.04$ & $<0.06$ & $<0.5$ & $<0.05$ & $<0.08$ & $<6$ & $<0.8$ & $<0.021$ & $<0.028$ & $<0.12$ & E0.046 & $<0.1$ & $<0.26$ & $<0.038$ \\
\hline 293807098155301 & $<.05$ & $<.04$ & $<.06$ & $<.5$ & $<.05$ & $<.08$ & $<6$ & $<.8$ & $<.021$ & $<.028$ & $<.12$ & E.056 & $<.1$ & $<.26$ & $<.038$ \\
\hline 292604098563201 & $<.05$ & $<.04$ & $<.06$ & $<.5$ & $<.05$ & $<.08$ & $<6$ & $<.8$ & $<.021$ & $<.028$ & $<.12$ & $<.028$ & $<.1$ & $<.26$ & $<.038$ \\
\hline 292116099095501 & $<.05$ & $<.04$ & $<.06$ & $<.5$ & $<.05$ & $<.08$ & $<6$ & $<.8$ & $<.021$ & $<.028$ & $<.12$ & $<.028$ & $<.1$ & $<.26$ & $<.038$ \\
\hline 291232099470301 & $<.05$ & $<.04$ & $<.06$ & $<.5$ & $<.05$ & $<.08$ & $<6$ & $<.8$ & $<.021$ & $<.028$ & $<.12$ & $<.028$ & $<.1$ & $<.26$ & $<.038$ \\
\hline 293128098473101 & $<.05$ & $<.04$ & $<.06$ & $<.5$ & $<.05$ & $<.08$ & $<6$ & $<.8$ & $<.021$ & $<.028$ & $<.12$ & $<.028$ & $<.1$ & $<.26$ & $<.038$ \\
\hline 293451098313201 & $<.05$ & $<.04$ & $<.06$ & $<.5$ & $<.05$ & $<.08$ & $<6$ & $<.8$ & $<.021$ & $<.028$ & $<.12$ & E.029 & $<.1$ & $<.26$ & $<.038$ \\
\hline 294604098060801 & $<.05$ & $<.04$ & $<.06$ & $<.5$ & $<.05$ & $<.08$ & $<6$ & $<.8$ & $<.021$ & $<.028$ & $<.12$ & $<.028$ & $<.1$ & $<.26$ & $<.038$ \\
\hline 294019098114701 & $<.05$ & $<.04$ & $<.06$ & $<.5$ & $<.05$ & $<.08$ & $<6$ & $<.8$ & $<.021$ & $<.028$ & $<.12$ & $<.028$ & $<.1$ & $<.26$ & $<.038$ \\
\hline 292215098580201 & $<.05$ & $<.04$ & $<.06$ & $<.5$ & $<.05$ & $<.08$ & $<6$ & $<.8$ & $<.021$ & $<.028$ & $<.12$ & $<.028$ & $<.1$ & $<.26$ & $<.038$ \\
\hline 292119098524901 & $<.05$ & $<.04$ & $<.06$ & $<.5$ & $<.05$ & $<.08$ & $<6$ & $<.8$ & $<.021$ & $<.028$ & $<.12$ & $<.028$ & $<.1$ & $<.26$ & $<.038$ \\
\hline 291943099163301 & $<.05$ & $<.04$ & $<.06$ & $<.5$ & $<.05$ & $<.08$ & $<6$ & $<.8$ & $<.021$ & $<.028$ & $<.12$ & $<.028$ & $<.1$ & $<.26$ & $<.038$ \\
\hline 291840099382601 & $<.05$ & $<.04$ & $<.06$ & $<.5$ & $<.05$ & $<.08$ & $<6$ & $<.8$ & $<.021$ & $<.028$ & $<.12$ & $<.028$ & $<.1$ & $<.26$ & $<.038$ \\
\hline 293518098332601 & $<.05$ & $<.04$ & $<.06$ & $<.5$ & $<.05$ & $<.08$ & $<6$ & $<.8$ & $<.021$ & $<.028$ & $<.12$ & $<.028$ & $<.1$ & $<.26$ & $<.038$ \\
\hline 293023098355401 & $<.05$ & $<.04$ & $<.06$ & $<.5$ & $<.05$ & $<.08$ & $<6$ & $<.8$ & $<.021$ & $<.028$ & $<.12$ & $<.028$ & $<.1$ & $<.26$ & $<.038$ \\
\hline 293042098305201 & $<.05$ & $<.04$ & $<.06$ & $<.5$ & $<.05$ & $<.08$ & $<6$ & $<.8$ & $<.021$ & $<.028$ & $<.12$ & $<.028$ & $<.1$ & $<.26$ & $<.038$ \\
\hline 292442098474501 & $<.05$ & $<.04$ & $<.06$ & $<.5$ & $<.05$ & $<.08$ & $<6$ & $<.8$ & $<.021$ & $<.028$ & $<.12$ & .123 & $<.1$ & $<.26$ & $<.038$ \\
\hline 292405098371201 & $<.05$ & $<.04$ & $<.06$ & $<.5$ & $<.05$ & $<.08$ & $<6$ & $<.8$ & $<.021$ & $<.028$ & $<.12$ & $<.028$ & $<.1$ & $<.26$ & $<.038$ \\
\hline 292931098274601 & $<.05$ & $<.04$ & $<.06$ & $<.5$ & $<.05$ & $<.08$ & $<6$ & $<.8$ & $<.021$ & $<.028$ & $<.12$ & $<.028$ & $<.1$ & $<.26$ & $<.038$ \\
\hline 293729098173101 & $<.05$ & $<.04$ & $<.06$ & $<.5$ & $<.05$ & $<.08$ & $<6$ & $<.8$ & $<.021$ & $<.028$ & $<.12$ & $<.028$ & $<.1$ & $<.26$ & $<.038$ \\
\hline 291219099095601 & $<.05$ & $<.04$ & $<.06$ & $<.5$ & $<.05$ & $<.08$ & $<6$ & $<.8$ & $<.021$ & $<.028$ & $<.12$ & $<.028$ & $<.1$ & $<.26$ & $<.038$ \\
\hline \multicolumn{16}{|c|}{ Monitoring wells } \\
\hline 292943098354401 & $<.06$ & $<.04$ & $<.04$ & $<.08$ & $<.04$ & $<.08$ & $<4$ & $<.4$ & $<.02$ & $<.02$ & $<.06$ & $<.04$ & $<.12$ & $<.4$ & E.026 \\
\hline 292943098354402 & $<.06$ & $<.04$ & $<.04$ & $<.08$ & $<.04$ & $<.08$ & $<4$ & $<.4$ & $<.02$ & $<.02$ & $<.06$ & $<.04$ & $<.12$ & $<.4$ & E.074 \\
\hline 292943098354403 & $<.06$ & $<.04$ & $<.04$ & $<.08$ & $<.04$ & $<.08$ & $<4$ & $<.4$ & $<.02$ & $<.02$ & $<.06$ & $<.04$ & $<.12$ & $<.4$ & $<.06$ \\
\hline 292943098354404 & $<.06$ & $<.04$ & $<.04$ & $<.08$ & $<.04$ & $<.08$ & $<4$ & $<.4$ & $<.02$ & $<.02$ & $<.06$ & $<.04$ & $<.12$ & $<.4$ & $<.06$ \\
\hline
\end{tabular}


Table 14. Volatile organic and fuel oxygenate compounds for groundwater samples collected for the study of the transport of anthropogenic and natural contaminants (TANC) to public supply wells in the San Antonio segment of the Edwards aquifer near San Antonio, south-central Texas, 2004-9.-Continued

[By sample category. USGS, U.S. Geological Survey; MW, monitoring well; OVB, overburden; $\mu \mathrm{g} / \mathrm{L}$, micrograms per liter; --, not measured or not applicable; E, estimated; <, nondetection less than laboratory method reporting level]

\begin{tabular}{|c|c|c|c|c|c|c|c|c|c|c|c|c|c|c|c|}
\hline $\begin{array}{c}\text { USGS } \\
\text { identification } \\
\text { number }\end{array}$ & $\begin{array}{c}\text { 2,2-Di- } \\
\text { chloro- } \\
\text { propane } \\
(\mu \mathrm{g} / \mathrm{L})\end{array}$ & $\begin{array}{c}2- \\
\text { Chloro- } \\
\text { toluene } \\
(\mu \mathrm{g} / \mathrm{L})\end{array}$ & $\begin{array}{c}\text { 2-Ethyl- } \\
\text { toluene } \\
\text { ( } \mu \mathrm{g} / \mathrm{L})\end{array}$ & $\begin{array}{c}\text { 3-Chloro- } \\
\text { propene } \\
\text { ( } \mathrm{gg} / \mathrm{L})\end{array}$ & $\begin{array}{c}\text { 4-Chloro- } \\
\text { toluene } \\
\text { ( } \mu \mathrm{g} / \mathrm{L})\end{array}$ & $\begin{array}{c}\text { 4-lso- } \\
\text { propyl- } \\
\text { toluene } \\
(\mu \mathrm{g} / \mathrm{L})\end{array}$ & $\begin{array}{c}\text { Acetone } \\
\text { ( } \mu \mathrm{g} / \mathrm{L})\end{array}$ & $\begin{array}{c}\text { Acrylo- } \\
\text { nitrile } \\
\text { ( } \mu \mathrm{g} / \mathrm{L})\end{array}$ & $\begin{array}{c}\text { Benzene } \\
(\mu \mathrm{g} / \mathrm{L})\end{array}$ & $\begin{array}{c}\text { Bromo- } \\
\text { benzene } \\
\text { ( } \mu \mathrm{g} / \mathrm{L})\end{array}$ & $\begin{array}{c}\text { Bromo- } \\
\text { chloro- } \\
\text { methane } \\
(\mu \mathrm{g} / \mathrm{L})\end{array}$ & $\begin{array}{c}\text { Bromo- } \\
\text { dichloro- } \\
\text { methane } \\
(\mu \mathrm{g} / \mathrm{L})\end{array}$ & $\begin{array}{l}\text { Bromo- } \\
\text { ethene } \\
\text { ( } \mu \mathrm{g} / \mathrm{L})\end{array}$ & $\begin{array}{c}\text { Bromo- } \\
\text { meth- } \\
\text { ane } \\
(\mu \mathrm{g} / \mathrm{L})\end{array}$ & $\begin{array}{c}\text { Carbon } \\
\text { di- } \\
\text { sulfide } \\
(\mu \mathrm{g} / \mathrm{L}) \\
\end{array}$ \\
\hline 292851098374401 & $<0.06$ & $<0.04$ & $<0.04$ & $<0.08$ & $<0.04$ & $<0.08$ & $<4$ & $<0.4$ & $<0.02$ & $<0.02$ & $<0.06$ & $<0.04$ & $<0.12$ & $<0.4$ & $<0.06$ \\
\hline 292851098374402 & $<.06$ & $<.04$ & $<.04$ & $<.08$ & $<.04$ & $<.08$ & $<4$ & $<.4$ & $<.02$ & $<.02$ & $<.06$ & $<.04$ & $<.12$ & $<.4$ & $<.06$ \\
\hline \multicolumn{16}{|c|}{ Well-field depth-dependent sampling (W4) } \\
\hline 292916098360701 & $<.06$ & $<.04$ & $<.04$ & $<.08$ & $<.04$ & $<.08$ & $<4$ & $<.4$ & $<.02$ & $<.02$ & $<.06$ & $<.04$ & $<.12$ & $<.4$ & $<.06$ \\
\hline 292916098360701 & $<.06$ & $<.04$ & $<.04$ & $<.08$ & $<.04$ & $<.08$ & $<4$ & $<.4$ & $<.02$ & $<.02$ & $<.06$ & $<.04$ & $<.12$ & $<.4$ & $<.06$ \\
\hline 292916098360701 & $<.06$ & $<.04$ & $<.04$ & $<.08$ & $<.04$ & $<.08$ & $<4$ & $<.4$ & $<.02$ & $<.02$ & $<.06$ & $<.04$ & $<.12$ & $<.4$ & $<.06$ \\
\hline 292916098360701 & $<.06$ & $<.04$ & $<.04$ & $<.08$ & $<.04$ & $<.08$ & $<4$ & $<.4$ & $<.02$ & $<.02$ & $<.06$ & $<.04$ & $<.12$ & $<.4$ & $<.06$ \\
\hline 292916098360701 & $<.06$ & $<.04$ & $<.04$ & $<.08$ & $<.04$ & $<.08$ & $<4$ & $<.4$ & $<.02$ & $<.02$ & $<.06$ & $<.04$ & $<.12$ & $<.4$ & $<.06$ \\
\hline 292916098360701 & $<.06$ & $<.04$ & $<.04$ & $<.08$ & $<.04$ & $<.08$ & $<4$ & $<.4$ & $<.02$ & $<.02$ & $<.06$ & $<.04$ & $<.12$ & $<.4$ & $<.06$ \\
\hline 292916098360701 & $<.06$ & $<.04$ & $<.04$ & $<.08$ & $<.04$ & $<.08$ & $<4$ & $<.4$ & $<.02$ & $<.02$ & $<.06$ & $<.04$ & $<.12$ & $<.4$ & $<.06$ \\
\hline 292916098360701 & $<.06$ & $<.04$ & $<.04$ & $<.08$ & $<.04$ & $<.08$ & $<4$ & $<.4$ & $<.02$ & $<.02$ & $<.06$ & $<.04$ & $<.12$ & $<.4$ & $<.06$ \\
\hline 292916098360701 & $<.06$ & $<.04$ & $<.04$ & $<.08$ & $<.04$ & $<.08$ & $<4$ & $<.4$ & $<.02$ & $<.02$ & $<.06$ & $<.04$ & $<.12$ & $<.4$ & $<.06$ \\
\hline \multicolumn{16}{|c|}{ Well-field wells (wellhead sampling) } \\
\hline 292919098360501 & $<.06$ & $<.04$ & $<.04$ & $<.08$ & $<.04$ & $<.08$ & $<4$ & $<.4$ & $<.02$ & $<.02$ & $<.06$ & $<.04$ & $<.12$ & $<.4$ & $<.06$ \\
\hline 292925098360201 & $<.06$ & $<.04$ & $<.04$ & $<.08$ & $<.04$ & $<.08$ & $<4$ & $<.4$ & $<.02$ & $<.02$ & $<.06$ & E.071 & $<.12$ & $<.4$ & $<.06$ \\
\hline 292916098360701 & $<.06$ & $<.04$ & $<.04$ & $<.08$ & $<.04$ & $<.08$ & $<4$ & $<.4$ & $<.02$ & $<.02$ & $<.06$ & $<.04$ & $<.12$ & $<.4$ & $<.06$ \\
\hline 292920098360601 & $<.06$ & $<.04$ & $<.04$ & $<.08$ & $<.04$ & $<.08$ & $<4$ & $<.4$ & $<.02$ & $<.02$ & $<.06$ & E.032 & $<.12$ & $<.4$ & $<.06$ \\
\hline 292923098360301 & $<.06$ & $<.04$ & $<.04$ & $<.08$ & $<.04$ & $<.08$ & $<4$ & $<.4$ & $<.02$ & $<.02$ & $<.06$ & E.037 & $<.12$ & $<.4$ & $<.06$ \\
\hline \multicolumn{16}{|c|}{ Temporal sampling } \\
\hline 292923098360301 & $<.06$ & $<.02$ & $<.02$ & $<.08$ & $<.02$ & $<.06$ & $<4$ & $<.4$ & $<.016$ & $<.02$ & $<.06$ & $<.04$ & $<.12$ & $<.4$ & $<.04$ \\
\hline 292923098360301 & $<.06$ & $<.028$ & $<.032$ & $<.08$ & $<.042$ & $<.06$ & $<3.4$ & $<.8$ & $<.026$ & $<.022$ & $<.06$ & E.032 & $<.12$ & $<.2$ & $<.04$ \\
\hline
\end{tabular}

(2) 
Table 14. Volatile organic and fuel oxygenate compounds for groundwater samples collected for the study of the transport of anthropogenic and natural contaminants (TANC) to public supply wells in the San Antonio segment of the Edwards aquifer near San Antonio, south-central Texas, 2004-9.-Continued

[By sample category. USGS, U.S. Geological Survey; MW, monitoring well; OVB, overburden; $\mu \mathrm{g} / \mathrm{L}$, micrograms per liter; --, not measured or not applicable; E, estimated; <, nondetection less than laboratory method reporting level]

\begin{tabular}{|c|c|c|c|c|c|c|c|c|c|c|c|c|c|c|c|}
\hline $\begin{array}{c}\text { USGS } \\
\text { identification } \\
\text { number }\end{array}$ & $\begin{array}{c}\text { 2,2-Di- } \\
\text { chloro- } \\
\text { propane } \\
(\mu \mathrm{g} / \mathrm{L})\end{array}$ & $\begin{array}{c}2- \\
\text { Chloro- } \\
\text { toluene } \\
\text { ( } \mu \mathrm{g} / \mathrm{L})\end{array}$ & $\begin{array}{l}\text { 2-Ethyl- } \\
\text { toluene } \\
\text { ( } \mu \mathrm{g} / \mathrm{L})\end{array}$ & $\begin{array}{l}\text { 3-Chloro- } \\
\text { propene } \\
\text { ( } \mu \mathrm{g} / \mathrm{L})\end{array}$ & $\begin{array}{c}\text { 4-Chloro- } \\
\text { toluene } \\
\text { ( } \mu \mathrm{g} / \mathrm{L})\end{array}$ & $\begin{array}{c}\text { 4-Iso- } \\
\text { propyl- } \\
\text { toluene } \\
(\mu \mathrm{g} / \mathrm{L})\end{array}$ & $\begin{array}{c}\text { Acetone } \\
(\mu \mathrm{g} / \mathrm{L})\end{array}$ & $\begin{array}{c}\text { Acrylo- } \\
\text { nitrile } \\
\text { ( } \mu \mathrm{g} / \mathrm{L})\end{array}$ & $\begin{array}{c}\text { Benzene } \\
(\mu \mathrm{g} / \mathrm{L})\end{array}$ & $\begin{array}{c}\text { Bromo- } \\
\text { benzene } \\
\text { ( } \mu \mathrm{g} / \mathrm{L})\end{array}$ & $\begin{array}{c}\text { Bromo- } \\
\text { chloro- } \\
\text { methane } \\
(\mu \mathrm{g} / \mathrm{L})\end{array}$ & $\begin{array}{l}\text { Bromo- } \\
\text { dichloro- } \\
\text { methane } \\
(\mu \mathrm{g} / \mathrm{L})\end{array}$ & $\begin{array}{c}\text { Bromo- } \\
\text { ethene } \\
\text { ( } \mu \mathrm{g} / \mathrm{L} \text { ) }\end{array}$ & $\begin{array}{c}\text { Bromo- } \\
\text { meth- } \\
\text { ane } \\
(\mu \mathrm{g} / \mathrm{L})\end{array}$ & $\begin{array}{c}\text { Carbon } \\
\text { di- } \\
\text { sulfide } \\
\text { ( } \mu \mathrm{g} / \mathrm{L} \text { ) }\end{array}$ \\
\hline 292923098360301 & $<0.06$ & $<0.028$ & $<0.032$ & $<0.08$ & $<0.042$ & $<0.06$ & $<3.4$ & $<0.8$ & $<0.026$ & $<0.022$ & $<0.06$ & $<0.034$ & $<0.12$ & $<0.2$ & $<0.04$ \\
\hline 292923098360301 & $<.06$ & $<.028$ & $<.032$ & $<.08$ & $<.042$ & $<.06$ & $<3.4$ & $<.8$ & $<.026$ & $<.022$ & $<.06$ & E.096 & $<.12$ & $<.2$ & $<.04$ \\
\hline 292923098360301 & $<.06$ & $<.028$ & $<.032$ & $<.08$ & $<.042$ & $<.06$ & $<3.4$ & $<.8$ & $<.026$ & $<.022$ & $<.06$ & E.066 & $<.12$ & $<.2$ & $<.04$ \\
\hline 292923098360301 & $<.06$ & $<.028$ & $<.032$ & $<.08$ & $<.042$ & $<.06$ & $<3.4$ & $<.8$ & $<.026$ & $<.022$ & $<.06$ & $<.034$ & $<.12$ & $<.2$ & $<.04$ \\
\hline 292943098354402 & $<.06$ & $<.02$ & $<.02$ & $<.08$ & $<.02$ & $<.06$ & $<4$ & $<.4$ & $<.016$ & $<.02$ & $<.06$ & $<.04$ & $<.12$ & $<.4$ & $<.04$ \\
\hline 292943098354402 & $<.06$ & $<.028$ & $<.032$ & $<.08$ & $<.042$ & $<.06$ & $<3.4$ & $<.8$ & $<.026$ & $<.022$ & $<.06$ & $<.034$ & $<.12$ & $<.2$ & $<.04$ \\
\hline 292943098354402 & $<.06$ & $<.028$ & $<.032$ & $<.08$ & $<.042$ & $<.06$ & $<3.4$ & $<.8$ & $<.026$ & $<.022$ & $<.06$ & $<.034$ & $<.12$ & $<.2$ & $<.04$ \\
\hline 292943098354402 & $<.06$ & $<.028$ & $<.032$ & $<.08$ & $<.042$ & $<.06$ & $<3.4$ & $<.8$ & $<.026$ & $<.022$ & $<.06$ & $<.034$ & $<.12$ & $<.2$ & $<.04$ \\
\hline 292943098354402 & $<.06$ & $<.028$ & $<.032$ & $<.08$ & $<.042$ & $<.06$ & $<3.4$ & $<.8$ & $<.026$ & $<.022$ & $<.06$ & $<.034$ & $<.12$ & $<.2$ & $<.04$ \\
\hline 292943098354402 & $<.06$ & $<.028$ & $<.032$ & $<.08$ & $<.042$ & $<.06$ & $<3.4$ & $<.8$ & $<.026$ & $<.022$ & $<.06$ & $<.034$ & $<.12$ & $<.2$ & $<.04$ \\
\hline 292943098354403 & $<.06$ & $<.02$ & $<.02$ & $<.08$ & $<.02$ & $<.06$ & $<4$ & $<.4$ & $<.016$ & $<.02$ & $<.06$ & $<.04$ & $<.12$ & $<.4$ & $<.04$ \\
\hline 292943098354403 & $<.06$ & $<.028$ & $<.032$ & $<.08$ & $<.042$ & $<.06$ & $<3.4$ & $<.8$ & $<.026$ & $<.022$ & $<.06$ & $<.034$ & $<.12$ & $<.2$ & $<.04$ \\
\hline 292943098354403 & $<.06$ & $<.028$ & $<.032$ & $<.08$ & $<.042$ & $<.06$ & $<3.4$ & $<.8$ & $<.026$ & $<.022$ & $<.06$ & $<.034$ & $<.12$ & $<.2$ & $<.04$ \\
\hline 292943098354403 & $<.06$ & $<.028$ & $<.032$ & $<.08$ & $<.042$ & $<.06$ & $<3.4$ & $<.8$ & $<.026$ & $<.022$ & $<.06$ & $<.034$ & $<.12$ & $<.2$ & $<.04$ \\
\hline 292943098354403 & $<.06$ & $<.028$ & $<.032$ & $<.08$ & $<.042$ & $<.06$ & $<3.4$ & $<.8$ & $<.026$ & $<.022$ & $<.06$ & $<.034$ & $<.12$ & $<.2$ & $<.04$ \\
\hline 292943098354403 & $<.06$ & $<.028$ & $<.032$ & $<.08$ & $<.042$ & $<.06$ & $<3.4$ & $<.8$ & $<.026$ & $<.022$ & $<.06$ & $<.034$ & $<.12$ & $<.2$ & $<.04$ \\
\hline 292943098354404 & $<.06$ & $<.02$ & $<.02$ & $<.08$ & $<.02$ & $<.06$ & $<4$ & $<.4$ & $<.016$ & $<.02$ & $<.06$ & $<.04$ & $<.12$ & $<.4$ & $<.04$ \\
\hline 292943098354404 & $<.06$ & $<.028$ & $<.032$ & $<.08$ & $<.042$ & $<.06$ & $<3.4$ & $<.8$ & $<.026$ & $<.022$ & $<.06$ & $<.034$ & $<.12$ & $<.2$ & $<.04$ \\
\hline 292943098354404 & $<.06$ & $<.028$ & $<.032$ & $<.08$ & $<.042$ & $<.06$ & $<3.4$ & $<.8$ & $<.026$ & $<.022$ & $<.06$ & $<.034$ & $<.12$ & $<.2$ & $<.04$ \\
\hline 292943098354404 & $<.06$ & $<.028$ & $<.032$ & $<.08$ & $<.042$ & $<.06$ & $<3.4$ & $<.8$ & $<.026$ & $<.022$ & $<.06$ & $<.034$ & $<.12$ & $<.2$ & $<.04$ \\
\hline 292943098354404 & $<.06$ & $<.028$ & $<.032$ & $<.08$ & $<.042$ & $<.06$ & $<3.4$ & $<.8$ & $<.026$ & $<.022$ & $<.06$ & $<.034$ & $<.12$ & $<.2$ & $<.04$ \\
\hline 292943098354404 & $<.06$ & $<.028$ & $<.032$ & $<.08$ & $<.042$ & $<.06$ & $<3.4$ & $<.8$ & $<.026$ & $<.022$ & $<.06$ & $<.034$ & $<.12$ & $<.2$ & $<.04$ \\
\hline 293252098380801 & $<.06$ & $<.02$ & $<.02$ & $<.08$ & $<.02$ & $<.06$ & $<4$ & $<.4$ & $<.016$ & $<.02$ & $<.06$ & $<.04$ & $<.12$ & $<.4$ & $<.04$ \\
\hline 293252098380801 & $<.06$ & $<.028$ & $<.032$ & $<.08$ & $<.042$ & $<.06$ & $<3.4$ & $<.8$ & $<.026$ & $<.022$ & $<.06$ & E.053 & $<.12$ & $<.2$ & $<.04$ \\
\hline 293252098380801 & $<.06$ & $<.028$ & $<.032$ & $<.08$ & $<.042$ & $<.06$ & $<3.4$ & $<.8$ & $<.026$ & $<.022$ & $<.06$ & $<.034$ & $<.12$ & $<.2$ & $<.04$ \\
\hline 293252098380801 & $<.06$ & $<.028$ & $<.032$ & $<.08$ & $<.042$ & $<.06$ & $<3.4$ & $<.8$ & $<.026$ & $<.022$ & $<.06$ & E.077 & $<.12$ & $<.2$ & $<.04$ \\
\hline 293252098380801 & $<.06$ & $<.028$ & $<.032$ & $<.08$ & $<.042$ & $<.06$ & $<3.4$ & $<.8$ & $<.026$ & $<.022$ & $<.06$ & E.071 & $<.12$ & $<.2$ & $<.04$ \\
\hline 293252098380801 & $<.06$ & $<.028$ & $<.032$ & $<.08$ & $<.042$ & $<.06$ & $<3.4$ & $<.8$ & $<.026$ & $<.022$ & $<.06$ & .155 & $<.12$ & $<.2$ & $<.04$ \\
\hline
\end{tabular}


Table 14. Volatile organic and fuel oxygenate compounds for groundwater samples collected for the study of the transport of anthropogenic and natural contaminants (TANC) to public supply wells in the San Antonio segment of the Edwards aquifer near San Antonio, south-central Texas, 2004-9.-Continued

[By sample category. USGS, U.S. Geological Survey; MW, monitoring well; OVB, overburden; $\mu \mathrm{g} / \mathrm{L}$, micrograms per liter; --, not measured or not applicable; E, estimated; <, nondetection less than laboratory method reporting level]

\begin{tabular}{|c|c|c|c|c|c|c|c|c|c|c|c|c|c|c|c|c|}
\hline $\begin{array}{c}\text { USGS } \\
\text { identification } \\
\text { number }\end{array}$ & $\begin{array}{c}\text { Chloro- } \\
\text { benzene } \\
\text { ( } \mu \mathrm{g} / \mathrm{L})\end{array}$ & $\begin{array}{c}\text { Chloro- } \\
\text { ethane } \\
\text { ( } \mu \mathrm{g} / \mathrm{L} \text { ) }\end{array}$ & $\begin{array}{l}\text { Chloro- } \\
\text { methane } \\
(\mu \mathrm{g} / \mathrm{L})\end{array}$ & $\begin{array}{c}\text { cis-1,2- } \\
\text { Di- } \\
\text { chloro- } \\
\text { ethene } \\
\text { ( } \mu \mathrm{g} / \mathrm{L})\end{array}$ & $\begin{array}{c}\text { cis-1,3- } \\
\text { Di- } \\
\text { chloro- } \\
\text { propene } \\
\text { ( } \mu \mathrm{g} / \mathrm{L} \text { ) }\end{array}$ & $\begin{array}{c}\text { Di- } \\
\text { bromo- } \\
\text { chloro- } \\
\text { methane } \\
\text { ( } \mu \mathrm{g} / \mathrm{L})\end{array}$ & $\begin{array}{c}\text { Di- } \\
\text { bromo- } \\
\text { methane } \\
(\mu \mathrm{g} / \mathrm{L})\end{array}$ & $\begin{array}{c}\text { Dichloro- } \\
\text { difluoro- } \\
\text { methane } \\
\text { (CFC-12) } \\
\text { ( } \mu \mathrm{g} / \mathrm{L})\end{array}$ & $\begin{array}{c}\text { Di- } \\
\text { chloro- } \\
\text { meth- } \\
\text { ane } \\
(\mu \mathrm{g} / \mathrm{L})\end{array}$ & $\begin{array}{l}\text { Di- } \\
\text { ethyl } \\
\text { ether } \\
(\mu \mathrm{g} / \mathrm{L})\end{array}$ & $\begin{array}{c}\text { Di- } \\
\text { iso- } \\
\text { propyl } \\
\text { ether } \\
(\mu \mathrm{g} / \mathrm{L})\end{array}$ & $\begin{array}{c}\text { Ethyl } \\
\text { meth- } \\
\text { acrylate } \\
(\mu \mathrm{g} / \mathrm{L})\end{array}$ & $\begin{array}{c}\text { Ethyl } \\
\text { methyl } \\
\text { ketone } \\
(\mu \mathrm{g} / \mathrm{L})\end{array}$ & $\begin{array}{l}\text { Ethyl- } \\
\text { ben- } \\
\text { zene } \\
(\mu \mathrm{g} / \mathrm{L})\end{array}$ & $\begin{array}{c}\text { Hexa- } \\
\text { chloro- } \\
\text { buta- } \\
\text { diene } \\
\text { ( } \mu \mathrm{g} / \mathrm{L})\end{array}$ & $\begin{array}{l}\text { Hexa- } \\
\text { chloro- } \\
\text { ethane } \\
(\mu \mathrm{g} / \mathrm{L})\end{array}$ \\
\hline \multicolumn{17}{|c|}{ Regional aquifer public-supply wells } \\
\hline 293359098290301 & $<0.028$ & $<0.12$ & $<0.17$ & $<0.024$ & $<0.05$ & $<0.1$ & $<0.05$ & $<0.18$ & $<0.06$ & $<0.08$ & $<0.1$ & $<0.18$ & $<2$ & $<0.03$ & $<0.14$ & $<0.14$ \\
\hline 293359098290301 & $<.028$ & $<.12$ & $<.17$ & $<.024$ & $<.05$ & $<.1$ & $<.05$ & $<.18$ & $<.06$ & $<.08$ & $<.1$ & $<.18$ & $<2$ & $<.03$ & $<.14$ & $<.14$ \\
\hline 293358098231101 & $<.028$ & $<.12$ & $<.17$ & $<.024$ & $<.05$ & $<.1$ & $<.05$ & $<.18$ & $<.06$ & $<.08$ & $<.1$ & $<.18$ & $<2$ & $<.03$ & $<.14$ & $<.14$ \\
\hline 293358098231101 & $<.028$ & $<.12$ & $<.17$ & $<.024$ & $<.05$ & $<.1$ & $<.05$ & $<.18$ & $<.06$ & $<.08$ & $<.1$ & $<.18$ & $<2$ & $<.03$ & $<.14$ & $<.14$ \\
\hline 293120098285801 & $<.028$ & $<.12$ & $<.17$ & $<.024$ & $<.05$ & .519 & $<.05$ & $<.18$ & $<.06$ & $<.08$ & $<.1$ & $<.18$ & $<2$ & $<.03$ & $<.14$ & $<.14$ \\
\hline 293120098285801 & $<.028$ & $<.12$ & $<.17$ & $<.024$ & $<.05$ & E.099 & $<.05$ & $<.18$ & $<.06$ & $<.08$ & $<.1$ & $<.18$ & $<2$ & $<.03$ & $<.14$ & $<.14$ \\
\hline 293145098224201 & $<.028$ & $<.12$ & $<.17$ & $<.024$ & $<.05$ & $<.1$ & $<.05$ & $<.18$ & $<.06$ & $<.08$ & $<.1$ & $<.18$ & $<2$ & $<.03$ & $<.14$ & $<.14$ \\
\hline 293119098211201 & $<.028$ & $<.12$ & $<.17$ & $<.024$ & $<.05$ & $<.1$ & $<.05$ & $<.18$ & $<.06$ & $<.08$ & $<.1$ & $<.18$ & $<2$ & $<.03$ & $<.14$ & $<.14$ \\
\hline 292843098425101 & $<.028$ & $<.12$ & $<.17$ & $<.024$ & $<.05$ & $<.1$ & $<.05$ & $<.18$ & $<.06$ & $<.08$ & $<.1$ & $<.18$ & $<2$ & $<.03$ & $<.14$ & $<.14$ \\
\hline 292459098382101 & $<.028$ & $<.12$ & $<.17$ & $<.024$ & $<.05$ & $<.1$ & $<.05$ & $<.18$ & $<.06$ & $<.08$ & $<.1$ & $<.18$ & $<2$ & $<.03$ & $<.14$ & $<.14$ \\
\hline 292925098360201 & $<.028$ & $<.12$ & $<.17$ & $<.024$ & $<.05$ & .154 & $<.05$ & $<.18$ & $<.06$ & $<.08$ & $<.1$ & $<.18$ & $<2$ & $<.03$ & $<.14$ & $<.14$ \\
\hline 292925098360201 & $<.028$ & $<.12$ & $<.17$ & $<.024$ & $<.05$ & E.057 & $<.05$ & $<.18$ & $<.06$ & $<.08$ & $<.1$ & $<.18$ & $<2$ & $<.03$ & $<.14$ & $<.14$ \\
\hline 292822098325401 & $<.028$ & $<.12$ & $<.17$ & $<.024$ & $<.05$ & $<.1$ & $<.05$ & $<.18$ & $<.06$ & $<.08$ & $<.1$ & $<.18$ & $<2$ & $<.03$ & $<.14$ & $<.14$ \\
\hline 292822098325401 & $<.028$ & $<.12$ & $<.17$ & $<.024$ & $<.05$ & $<.1$ & $<.05$ & $<.18$ & $<.06$ & $<.08$ & $<.1$ & $<.18$ & $<2$ & $<.03$ & $<.14$ & $<.14$ \\
\hline 292944098292301 & $<.028$ & $<.12$ & $<.17$ & $<.024$ & $<.05$ & $<.1$ & $<.05$ & $<.18$ & $<.06$ & $<.08$ & $<.1$ & $<.18$ & $<2$ & $<.03$ & $<.14$ & $<.14$ \\
\hline 292944098292301 & -- & -- & -- & -- & -- & -- & -- & -- & -- & -- & -- & -- & -- & -- & -- & -- \\
\hline 292522098291901 & $<.028$ & $<.12$ & $<.17$ & $<.024$ & $<.05$ & $<.1$ & $<.05$ & $<.18$ & $<.06$ & $<.08$ & $<.1$ & $<.18$ & $<2$ & $<.03$ & $<.14$ & $<.14$ \\
\hline 292643098241801 & $<.028$ & $<.12$ & $<.17$ & $<.024$ & $<.05$ & 1.01 & $<.05$ & $<.18$ & $<.06$ & $<.08$ & $<.1$ & $<.18$ & $<2$ & $<.03$ & $<.14$ & $<.14$ \\
\hline 292643098241801 & $<.028$ & $<.12$ & $<.17$ & $<.024$ & $<.05$ & $<.1$ & $<.05$ & $<.18$ & $<.06$ & $<.08$ & $<.1$ & $<.18$ & $<2$ & $<.03$ & $<.14$ & $<.14$ \\
\hline 292328098294601 & $<.028$ & $<.12$ & $<.17$ & $<.024$ & $<.05$ & $<.1$ & $<.05$ & $<.18$ & $<.06$ & $<.08$ & $<.1$ & $<.18$ & $<2$ & $<.03$ & $<.14$ & $<.14$ \\
\hline 294225098080301 & $<.028$ & $<.12$ & $<.17$ & $<.024$ & $<.05$ & $<.1$ & $<.05$ & $<.18$ & $<.06$ & $<.08$ & $<.1$ & $<.18$ & $<2$ & $<.03$ & $<.14$ & $<.14$ \\
\hline 294225098080301 & $<.028$ & $<.12$ & $<.17$ & $<.024$ & $<.05$ & $<.1$ & $<.05$ & $<.18$ & $<.06$ & $<.08$ & $<.1$ & $<.18$ & $<2$ & $<.03$ & $<.14$ & $<.14$ \\
\hline 291210099475601 & $<.028$ & $<.12$ & $<.17$ & $<.024$ & $<.05$ & $<.1$ & $<.05$ & $<.18$ & $<.06$ & $<.08$ & $<.1$ & $<.18$ & $<2$ & $<.03$ & $<.14$ & $<.14$ \\
\hline 293111098340901 & $<.028$ & $<.12$ & $<.17$ & $<.024$ & $<.05$ & $<.1$ & $<.05$ & $<.18$ & $<.06$ & $<.08$ & $<.1$ & $<.18$ & $<2$ & $<.03$ & $<.14$ & $<.14$ \\
\hline 293512098291701 & $<.028$ & $<.12$ & $<.17$ & $<.024$ & $<.05$ & $<.1$ & $<.05$ & $<.18$ & $<.06$ & $<.08$ & $<.1$ & $<.18$ & $<2$ & $<.03$ & $<.14$ & $<.14$ \\
\hline 292424098421501 & $<.028$ & $<.12$ & $<.17$ & $<.024$ & $<.05$ & $<.1$ & $<.05$ & $<.18$ & $<.06$ & $<.08$ & $<.1$ & $<.18$ & $<2$ & $<.03$ & $<.14$ & $<.14$ \\
\hline
\end{tabular}


Table 14. Volatile organic and fuel oxygenate compounds for groundwater samples collected for the study of the transport of anthropogenic and natural contaminants (TANC) to public supply wells in the San Antonio segment of the Edwards aquifer near San Antonio, south-central Texas, 2004-9.-Continued

[By sample category. USGS, U.S. Geological Survey; MW, monitoring well; OVB, overburden; $\mu \mathrm{g} / \mathrm{L}$, micrograms per liter; --, not measured or not applicable; E, estimated; <, nondetection less than laboratory method reporting level]

\begin{tabular}{|c|c|c|c|c|c|c|c|c|c|c|c|c|c|c|c|c|}
\hline $\begin{array}{c}\text { USGS } \\
\text { identification } \\
\text { number }\end{array}$ & $\begin{array}{c}\text { Chloro- } \\
\text { benzene } \\
\text { ( } \mu \mathrm{g} / \mathrm{L})\end{array}$ & $\begin{array}{c}\text { Chloro- } \\
\text { ethane } \\
\text { ( } \mu \mathrm{g} / \mathrm{L} \text { ) }\end{array}$ & $\begin{array}{c}\text { Chloro- } \\
\text { methane } \\
(\mu \mathrm{g} / \mathrm{L})\end{array}$ & $\begin{array}{c}\text { cis-1,2- } \\
\text { Di- } \\
\text { chloro- } \\
\text { ethene } \\
\text { ( } \mu \mathrm{g} / \mathrm{L})\end{array}$ & $\begin{array}{c}\text { cis-1,3- } \\
\text { Di- } \\
\text { chloro- } \\
\text { propene } \\
\text { ( } \mu \mathrm{g} / \mathrm{L} \text { ) }\end{array}$ & $\begin{array}{c}\text { Di- } \\
\text { bromo- } \\
\text { chloro- } \\
\text { methane } \\
\text { ( } \mu \mathrm{g} / \mathrm{L})\end{array}$ & $\begin{array}{c}\text { Di- } \\
\text { bromo- } \\
\text { methane } \\
(\mu \mathrm{g} / \mathrm{L})\end{array}$ & $\begin{array}{c}\text { Dichloro- } \\
\text { difluoro- } \\
\text { methane } \\
\text { (CFC-12) } \\
\text { ( } \mu \mathrm{g} / \mathrm{L})\end{array}$ & $\begin{array}{c}\text { Di- } \\
\text { chloro- } \\
\text { meth- } \\
\text { ane } \\
\text { ( } \mu \mathrm{g} / \mathrm{L})\end{array}$ & $\begin{array}{l}\text { Di- } \\
\text { ethyl } \\
\text { ether } \\
(\mu \mathrm{g} / \mathrm{L})\end{array}$ & $\begin{array}{c}\text { Di- } \\
\text { iso- } \\
\text { propyl } \\
\text { ether } \\
(\mu \mathrm{g} / \mathrm{L})\end{array}$ & $\begin{array}{c}\text { Ethyl } \\
\text { meth- } \\
\text { acrylate } \\
\text { ( } \mu \mathrm{g} / \mathrm{L})\end{array}$ & $\begin{array}{l}\text { Ethyl } \\
\text { methyl } \\
\text { ketone } \\
(\mu \mathrm{g} / \mathrm{L})\end{array}$ & $\begin{array}{l}\text { Ethyl- } \\
\text { ben- } \\
\text { zene } \\
(\mu \mathrm{g} / \mathrm{L})\end{array}$ & $\begin{array}{c}\text { Hexa- } \\
\text { chloro- } \\
\text { buta- } \\
\text { diene } \\
\text { ( } \mu \mathrm{g} / \mathrm{L} \text { ) }\end{array}$ & $\begin{array}{l}\text { Hexa- } \\
\text { chloro- } \\
\text { ethane } \\
(\mu \mathrm{g} / \mathrm{L})\end{array}$ \\
\hline 292053098365501 & $<0.028$ & $<0.12$ & $<0.17$ & $<0.024$ & $<0.05$ & E0.081 & $<0.05$ & $<0.18$ & $<0.06$ & $<0.08$ & $<0.1$ & $<0.18$ & $<2$ & $<0.03$ & $<0.14$ & $<0.14$ \\
\hline 293807098155301 & $<.028$ & $<.12$ & $<.17$ & $<.024$ & $<.05$ & .166 & $<.05$ & $<.18$ & $<.06$ & $<.08$ & $<.1$ & $<.18$ & $<2$ & E.019 & $<.14$ & $<.14$ \\
\hline 292604098563201 & $<.028$ & $<.12$ & $<.17$ & $<.024$ & $<.05$ & $<.1$ & $<.05$ & $<.18$ & $<.06$ & $<.08$ & $<.1$ & $<.18$ & $<2$ & $<.03$ & $<.14$ & $<.14$ \\
\hline 292116099095501 & $<.028$ & $<.12$ & $<.17$ & $<.024$ & $<.05$ & $<.1$ & $<.05$ & $<.18$ & $<.06$ & $<.08$ & $<.1$ & $<.18$ & $<2$ & $<.03$ & $<.14$ & $<.14$ \\
\hline 291232099470301 & $<.028$ & $<.12$ & $<.17$ & $<.024$ & $<.05$ & $<.1$ & $<.05$ & $<.18$ & $<.06$ & $<.08$ & $<.1$ & $<.18$ & $<2$ & $<.03$ & $<.14$ & $<.14$ \\
\hline 293128098473101 & $<.028$ & $<.12$ & $<.17$ & $<.024$ & $<.05$ & $<.1$ & $<.05$ & $<.18$ & $<.06$ & $<.08$ & $<.1$ & $<.18$ & $<2$ & $<.03$ & $<.14$ & $<.14$ \\
\hline 293451098313201 & $<.028$ & $<.12$ & $<.17$ & $<.024$ & $<.05$ & $<.1$ & $<.05$ & $<.18$ & $<.06$ & $<.08$ & $<.1$ & $<.18$ & $<2$ & $<.03$ & $<.14$ & $<.14$ \\
\hline 294604098060801 & $<.028$ & $<.12$ & $<.17$ & $<.024$ & $<.05$ & $<.1$ & $<.05$ & $<.18$ & $<.06$ & $<.08$ & $<.1$ & $<.18$ & $<2$ & $<.03$ & $<.14$ & $<.14$ \\
\hline 294019098114701 & $<.028$ & $<.12$ & $<.17$ & $<.024$ & $<.05$ & $<.1$ & $<.05$ & $<.18$ & $<.06$ & $<.08$ & $<.1$ & $<.18$ & $<2$ & $<.03$ & $<.14$ & $<.14$ \\
\hline 292215098580201 & $<.028$ & $<.12$ & $<.17$ & $<.024$ & $<.05$ & $<.1$ & $<.05$ & $<.18$ & $<.06$ & $<.08$ & $<.1$ & $<.18$ & $<2$ & $<.03$ & $<.14$ & $<.14$ \\
\hline 292119098524901 & $<.028$ & $<.12$ & $<.17$ & $<.024$ & $<.05$ & $<.1$ & $<.05$ & $<.18$ & $<.06$ & $<.08$ & $<.1$ & $<.18$ & $<2$ & $<.03$ & $<.14$ & $<.14$ \\
\hline 291943099163301 & $<.028$ & $<.12$ & $<.17$ & $<.024$ & $<.05$ & $<.1$ & $<.05$ & $<.18$ & $<.06$ & $<.08$ & $<.1$ & $<.18$ & $<2$ & $<.03$ & $<.14$ & $<.14$ \\
\hline 291840099382601 & $<.028$ & $<.12$ & $<.17$ & $<.024$ & $<.05$ & $<.1$ & $<.05$ & $<.18$ & $<.06$ & $<.08$ & $<.1$ & $<.18$ & $<2$ & $<.03$ & $<.14$ & $<.14$ \\
\hline 293518098332601 & $<.028$ & $<.12$ & $<.17$ & $<.024$ & $<.05$ & $<.1$ & $<.05$ & $<.18$ & $<.06$ & $<.08$ & $<.1$ & $<.18$ & $<2$ & $<.03$ & $<.14$ & $<.14$ \\
\hline 293023098355401 & $<.028$ & $<.12$ & $<.17$ & $<.024$ & $<.05$ & $<.1$ & $<.05$ & $<.18$ & $<.06$ & $<.08$ & $<.1$ & $<.18$ & $<2$ & $<.03$ & $<.14$ & $<.14$ \\
\hline 293042098305201 & $<.028$ & $<.12$ & $<.17$ & $<.024$ & $<.05$ & $<.1$ & $<.05$ & $<.18$ & $<.06$ & $<.08$ & $<.1$ & $<.18$ & $<2$ & $<.03$ & $<.14$ & $<.14$ \\
\hline 292442098474501 & $<.028$ & $<.12$ & $<.17$ & $<.024$ & $<.05$ & .263 & $<.05$ & $<.18$ & $<.06$ & $<.08$ & $<.1$ & $<.18$ & $<2$ & $<.03$ & $<.14$ & $<.14$ \\
\hline 292405098371201 & $<.028$ & $<.12$ & $<.17$ & $<.024$ & $<.05$ & $<.1$ & $<.05$ & $<.18$ & $<.06$ & $<.08$ & $<.1$ & $<.18$ & $<2$ & $<.03$ & $<.14$ & $<.14$ \\
\hline 292931098274601 & $<.028$ & $<.12$ & $<.17$ & $<.024$ & $<.05$ & $<.1$ & $<.05$ & $<.18$ & $<.06$ & $<.08$ & $<.1$ & $<.18$ & $<2$ & $<.03$ & $<.14$ & $<.14$ \\
\hline 293729098173101 & $<.028$ & $<.12$ & $<.17$ & $<.024$ & $<.05$ & $<.1$ & $<.05$ & $<.18$ & $<.06$ & $<.08$ & $<.1$ & $<.18$ & $<2$ & $<.03$ & $<.14$ & $<.14$ \\
\hline 291219099095601 & $<.028$ & $<.12$ & $<.17$ & $<.024$ & $<.05$ & $<.1$ & $<.05$ & $<.18$ & $<.06$ & $<.08$ & $<.1$ & $<.18$ & $<2$ & $<.03$ & $<.14$ & $<.14$ \\
\hline \multicolumn{17}{|c|}{ Monitoring wells } \\
\hline 292943098354401 & $<.02$ & $<.1$ & $<.1$ & $<.02$ & $<.1$ & $<.12$ & $<.04$ & $<.14$ & $<.04$ & $<.12$ & $<.06$ & $<.14$ & $<1.6$ & $<.04$ & $<.06$ & $<.14$ \\
\hline 292943098354402 & $<.02$ & $<.1$ & $<.1$ & $<.02$ & $<.1$ & $<.12$ & $<.04$ & $<.14$ & $<.04$ & $<.12$ & $<.06$ & $<.14$ & $<1.6$ & $<.04$ & $<.06$ & $<.14$ \\
\hline 292943098354403 & $<.02$ & $<.1$ & $<.1$ & $<.02$ & $<.1$ & $<.12$ & $<.04$ & $<.14$ & $<.04$ & $<.12$ & $<.06$ & $<.14$ & $<1.6$ & $<.04$ & $<.06$ & $<.14$ \\
\hline 292943098354404 & $<.02$ & $<.1$ & $<.1$ & $<.02$ & $<.1$ & $<.12$ & $<.04$ & $<.14$ & $<.04$ & $<.12$ & $<.06$ & $<.14$ & $<1.6$ & $<.04$ & $<.06$ & $<.14$ \\
\hline
\end{tabular}


Table 14. Volatile organic and fuel oxygenate compounds for groundwater samples collected for the study of the transport of anthropogenic and natural contaminants (TANC) to public supply wells in the San Antonio segment of the Edwards aquifer near San Antonio, south-central Texas, 2004-9.-Continued

[By sample category. USGS, U.S. Geological Survey; MW, monitoring well; OVB, overburden; $\mu \mathrm{g} / \mathrm{L}$, micrograms per liter; --, not measured or not applicable; E, estimated; <, nondetection less than laboratory method reporting level]

\begin{tabular}{|c|c|c|c|c|c|c|c|c|c|c|c|c|c|c|c|c|}
\hline $\begin{array}{c}\text { USGS } \\
\text { identification } \\
\text { number }\end{array}$ & $\begin{array}{c}\text { Chloro- } \\
\text { benzene } \\
(\mu \mathrm{g} / \mathrm{L})\end{array}$ & $\begin{array}{c}\text { Chloro- } \\
\text { ethane } \\
\text { ( } \mu \mathrm{g} / \mathrm{L} \text { ) }\end{array}$ & $\begin{array}{c}\text { Chloro- } \\
\text { methane } \\
(\mu \mathrm{g} / \mathrm{L})\end{array}$ & $\begin{array}{c}\text { cis-1,2- } \\
\text { Di- } \\
\text { chloro- } \\
\text { ethene } \\
\text { ( } \mu \mathrm{g} / \mathrm{L})\end{array}$ & $\begin{array}{c}\text { cis-1,3- } \\
\text { Di- } \\
\text { chloro- } \\
\text { propene } \\
\text { ( } \mu \mathrm{g} / \mathrm{L} \text { ) }\end{array}$ & $\begin{array}{c}\text { Di- } \\
\text { bromo- } \\
\text { chloro- } \\
\text { methane } \\
\text { ( } \mu \mathrm{g} / \mathrm{L})\end{array}$ & $\begin{array}{c}\text { Di- } \\
\text { bromo- } \\
\text { methane } \\
(\mu \mathrm{g} / \mathrm{L})\end{array}$ & $\begin{array}{c}\text { Dichloro- } \\
\text { difluoro- } \\
\text { methane } \\
\text { (CFC-12) } \\
\text { ( } \mu \mathrm{g} / \mathrm{L})\end{array}$ & $\begin{array}{c}\text { Di- } \\
\text { chloro- } \\
\text { meth- } \\
\text { ane } \\
\text { ( } \mu \mathrm{g} / \mathrm{L})\end{array}$ & $\begin{array}{l}\text { Di- } \\
\text { ethyl } \\
\text { ether } \\
\text { ( } \mu \mathrm{g} / \mathrm{L})\end{array}$ & $\begin{array}{l}\text { Di- } \\
\text { iso- } \\
\text { propyl } \\
\text { ether } \\
(\mu \mathrm{g} / \mathrm{L})\end{array}$ & $\begin{array}{c}\text { Ethyl } \\
\text { meth- } \\
\text { acrylate } \\
(\mu \mathrm{g} / \mathrm{L})\end{array}$ & $\begin{array}{c}\text { Ethyl } \\
\text { methyl } \\
\text { ketone } \\
(\mu \mathrm{g} / \mathrm{L})\end{array}$ & $\begin{array}{l}\text { Ethyl- } \\
\text { ben- } \\
\text { zene } \\
\text { ( } \mu \mathrm{g} / \mathrm{L})\end{array}$ & $\begin{array}{c}\text { Hexa- } \\
\text { chloro- } \\
\text { buta- } \\
\text { diene } \\
\text { ( } \mu \mathrm{g} / \mathrm{L} \text { ) }\end{array}$ & $\begin{array}{l}\text { Hexa- } \\
\text { chloro- } \\
\text { ethane } \\
(\mu \mathrm{g} / \mathrm{L})\end{array}$ \\
\hline 292851098374401 & $<0.02$ & $<0.1$ & $<0.1$ & $<0.02$ & $<0.1$ & $<0.12$ & $<0.004$ & $<0.14$ & $<0.04$ & $<0.12$ & $<0.06$ & $<0.14$ & $<1.6$ & $<0.04$ & $<0.06$ & $<0.14$ \\
\hline 292851098374402 & $<.02$ & $<.1$ & $<.1$ & $<.02$ & $<.1$ & $<.12$ & $<.04$ & $<.14$ & $<.04$ & $<.12$ & $<.06$ & $<.14$ & $<1.6$ & $<.04$ & $<.06$ & $<.14$ \\
\hline \multicolumn{17}{|c|}{ Well-field depth-dependent sampling (W4) } \\
\hline 292916098360701 & $<.02$ & $<.1$ & $<.1$ & $<.02$ & $<.1$ & $<.12$ & $<.04$ & $<.14$ & $<.04$ & $<.12$ & $<.06$ & $<.14$ & $<1.6$ & $<.04$ & $<.06$ & $<.14$ \\
\hline 292916098360701 & $<.02$ & $<.1$ & $<.1$ & $<.02$ & $<.1$ & $<.12$ & $<.04$ & $<.14$ & $<.04$ & $<.12$ & $<.06$ & $<.14$ & $<1.6$ & $<.04$ & $<.06$ & $<.14$ \\
\hline 292916098360701 & $<.02$ & $<.1$ & $<.1$ & $<.02$ & $<.1$ & $<.12$ & $<.04$ & $<.14$ & $<.04$ & $<.12$ & $<.06$ & $<.14$ & $<1.6$ & $<.04$ & $<.06$ & $<.14$ \\
\hline 292916098360701 & $<.02$ & $<.1$ & $<.1$ & $<.02$ & $<.1$ & $<.12$ & $<.04$ & $<.14$ & $<.04$ & $<.12$ & $<.06$ & $<.14$ & $<1.6$ & $<.04$ & $<.06$ & $<.14$ \\
\hline 292916098360701 & $<.02$ & $<.1$ & $<.1$ & $<.02$ & $<.1$ & $<.12$ & $<.04$ & $<.14$ & $<.04$ & $<.12$ & $<.06$ & $<.14$ & $<1.6$ & $<.04$ & $<.06$ & $<.14$ \\
\hline 292916098360701 & $<.02$ & $<.1$ & $<.1$ & $<.02$ & $<.1$ & $<.12$ & $<.04$ & $<.14$ & $<.04$ & $<.12$ & $<.06$ & $<.14$ & $<1.6$ & $<.04$ & $<.06$ & $<.14$ \\
\hline 292916098360701 & $<.02$ & $<.1$ & $<.1$ & $<.02$ & $<.1$ & $<.12$ & $<.04$ & $<.14$ & $<.04$ & $<.12$ & $<.06$ & $<.14$ & $<1.6$ & $<.04$ & $<.06$ & $<.14$ \\
\hline 292916098360701 & $<.02$ & $<.1$ & $<.1$ & $<.02$ & $<.1$ & $<.12$ & $<.04$ & $<.14$ & $<.04$ & $<.12$ & $<.06$ & $<.14$ & $<1.6$ & $<.04$ & $<.06$ & $<.14$ \\
\hline 292916098360701 & $<.02$ & $<.1$ & $<.1$ & $<.02$ & $<.1$ & $<.12$ & $<.04$ & $<.14$ & $<.04$ & $<.12$ & $<.06$ & $<.14$ & $<1.6$ & $<.04$ & $<.06$ & $<.14$ \\
\hline \multicolumn{17}{|c|}{ Well-field wells (wellhead sampling) } \\
\hline 292919098360501 & $<.02$ & $<.1$ & $<.1$ & $<.02$ & $<.1$ & $<.12$ & $<.04$ & $<.14$ & $<.04$ & $<.12$ & $<.06$ & $<.14$ & $<1.6$ & $<.04$ & $<.06$ & $<.14$ \\
\hline 292925098360201 & $<.02$ & $<.1$ & $<.1$ & $<.02$ & $<.1$ & .299 & $<.04$ & $<.14$ & $<.04$ & $<.12$ & $<.06$ & $<.14$ & $<1.6$ & $<.04$ & $<.06$ & $<.14$ \\
\hline 292916098360701 & $<.02$ & $<.1$ & $<.1$ & $<.02$ & $<.1$ & $<.12$ & $<.04$ & $<.14$ & $<.04$ & $<.12$ & $<.06$ & $<.14$ & $<1.6$ & $<.04$ & $<.06$ & $<.14$ \\
\hline 292920098360601 & $<.02$ & $<.1$ & $<.1$ & $<.02$ & $<.1$ & .123 & $<.04$ & $<.14$ & $<.04$ & $<.12$ & $<.06$ & $<.14$ & $<1.6$ & $<.04$ & $<.06$ & $<.14$ \\
\hline 292923098360301 & $<.02$ & $<.1$ & $<.1$ & $<.02$ & $<.1$ & .203 & $<.04$ & $<.14$ & $<.04$ & $<.12$ & $<.06$ & $<.14$ & $<1.6$ & $<.04$ & $<.06$ & $<.14$ \\
\hline \multicolumn{17}{|c|}{ Temporal sampling } \\
\hline 292923098360301 & $<.02$ & $<.1$ & $<.14$ & $<.02$ & $<.1$ & $<.12$ & $<.04$ & $<.1$ & $<.04$ & $<.12$ & $<.06$ & $<.14$ & $<1.6$ & $<.04$ & $<.06$ & $<.14$ \\
\hline 292923098360301 & $<.016$ & $<.06$ & $<.14$ & $<.022$ & $<.1$ & E.114 & $<.05$ & $<.1$ & $<.038$ & $<.08$ & $<.06$ & $<.14$ & $<1.6$ & $<.036$ & $<.06$ & $<.14$ \\
\hline
\end{tabular}


Table 14. Volatile organic and fuel oxygenate compounds for groundwater samples collected for the study of the transport of anthropogenic and natural contaminants (TANC) to public supply wells in the San Antonio segment of the Edwards aquifer near San Antonio, south-central Texas, 2004-9.-Continued

[By sample category. USGS, U.S. Geological Survey; MW, monitoring well; OVB, overburden; $\mu \mathrm{g} / \mathrm{L}$, micrograms per liter; --, not measured or not applicable; E, estimated; <, nondetection less than laboratory method reporting level]

\begin{tabular}{|c|c|c|c|c|c|c|c|c|c|c|c|c|c|c|c|c|}
\hline $\begin{array}{c}\text { USGS } \\
\text { identification } \\
\text { number }\end{array}$ & $\begin{array}{c}\text { Chloro- } \\
\text { benzene } \\
\text { ( } \mu \mathrm{g} / \mathrm{L})\end{array}$ & $\begin{array}{l}\text { Chloro- } \\
\text { ethane } \\
\text { ( } \mu \mathrm{g} / \mathrm{L})\end{array}$ & $\begin{array}{l}\text { Chloro- } \\
\text { methane } \\
\text { ( } \mu \mathrm{g} / \mathrm{L})\end{array}$ & $\begin{array}{l}\text { cis-1,2- } \\
\text { Di- } \\
\text { chloro- } \\
\text { ethene } \\
\text { ( } \mu \mathrm{g} / \mathrm{L})\end{array}$ & $\begin{array}{c}\text { cis-1,3- } \\
\text { Di- } \\
\text { chloro- } \\
\text { propene } \\
\text { ( } \mu \mathrm{g} / \mathrm{L} \text { ) }\end{array}$ & 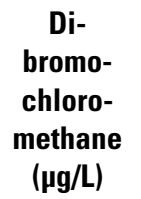 & $\begin{array}{c}\text { Di- } \\
\text { bromo- } \\
\text { methane } \\
(\mu \mathrm{g} / \mathrm{L})\end{array}$ & 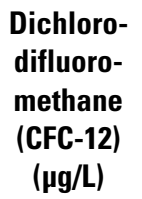 & $\begin{array}{c}\text { Di- } \\
\text { chloro- } \\
\text { meth- } \\
\text { ane } \\
(\mu \mathrm{g} / \mathrm{L})\end{array}$ & $\begin{array}{l}\text { Di- } \\
\text { ethyl } \\
\text { ether } \\
\text { ( } \mu \mathrm{g} / \mathrm{L})\end{array}$ & $\begin{array}{l}\text { Di- } \\
\text { iso- } \\
\text { propyl } \\
\text { ether } \\
\text { ( } \mu \mathrm{g} / \mathrm{L})\end{array}$ & $\begin{array}{l}\text { Ethyl } \\
\text { meth- } \\
\text { acrylate } \\
(\mu \mathrm{g} / \mathrm{L})\end{array}$ & $\begin{array}{l}\text { Ethyl } \\
\text { methyl } \\
\text { ketone } \\
(\mu \mathrm{g} / \mathrm{L})\end{array}$ & $\begin{array}{l}\text { Ethyl- } \\
\text { ben- } \\
\text { zene } \\
\text { ( } \mu \mathrm{g} / \mathrm{L})\end{array}$ & $\begin{array}{l}\text { Hexa- } \\
\text { chloro- } \\
\text { buta- } \\
\text { diene } \\
\text { ( } \mu \mathrm{g} / \mathrm{L} \text { ) }\end{array}$ & $\begin{array}{l}\text { Hexa- } \\
\text { chloro- } \\
\text { ethane } \\
(\mu \mathrm{g} / \mathrm{L})\end{array}$ \\
\hline 292923098360301 & $<0.016$ & $<0.06$ & $<0.14$ & $<0.022$ & $<0.1$ & $<0.12$ & $<0.05$ & $<0.1$ & $<0.038$ & $<0.08$ & $<0.06$ & $<0.14$ & $<1.6$ & $<0.036$ & $<.06$ & $<0.14$ \\
\hline 292923098360301 & $<.016$ & $<.06$ & $<.14$ & $<.022$ & $<.1$ & .310 & $<.05$ & $<.1$ & $<.038$ & $<.08$ & $<.06$ & $<.14$ & $<1.6$ & $<.036$ & $<.06$ & $<.14$ \\
\hline 292923098360301 & $<.016$ & $<.06$ & $<.14$ & $<.022$ & $<.1$ & .225 & $<.05$ & $<.1$ & $<.038$ & $<.08$ & $<.06$ & $<.14$ & $<1.6$ & $<.036$ & $<.06$ & $<.14$ \\
\hline 292923098360301 & $<.016$ & $<.06$ & $<.14$ & $<.022$ & $<.1$ & E.115 & $<.05$ & $<.1$ & $<.038$ & $<.08$ & $<.06$ & $<.14$ & $<1.6$ & $<.036$ & $<.06$ & $<.14$ \\
\hline 292943098354402 & $<.02$ & $<.1$ & $<.14$ & $<.02$ & $<.1$ & $<.12$ & $<.04$ & $<.1$ & $<.04$ & $<.12$ & $<.06$ & $<.14$ & $<1.6$ & $<.04$ & $<.06$ & $<.14$ \\
\hline 292943098354402 & $<.016$ & $<.06$ & $<.14$ & $<.022$ & $<.1$ & $<.12$ & $<.05$ & $<.1$ & $<.038$ & $<.08$ & $<.06$ & $<.14$ & $<1.6$ & $<.036$ & $<.06$ & $<.14$ \\
\hline 292943098354402 & $<.016$ & $<.06$ & $<.14$ & $<.022$ & $<.1$ & $<.12$ & $<.05$ & $<.1$ & $<.038$ & $<.08$ & $<.06$ & $<.14$ & $<1.6$ & $<.036$ & $<.06$ & $<.14$ \\
\hline 292943098354402 & $<.016$ & $<.06$ & $<.14$ & $<.022$ & $<.1$ & $<.12$ & $<.05$ & $<.1$ & $<.038$ & $<.08$ & $<.06$ & $<.14$ & $<1.6$ & $<.036$ & $<.06$ & $<.14$ \\
\hline 292943098354402 & $<.016$ & $<.06$ & $<.14$ & $<.022$ & $<.1$ & $<.12$ & $<.05$ & $<.1$ & $<.038$ & $<.08$ & $<.06$ & $<.14$ & $<1.6$ & $<.036$ & $<.06$ & $<.14$ \\
\hline 292943098354402 & $<.016$ & $<.06$ & $<.14$ & $<.022$ & $<.1$ & $<.12$ & $<.05$ & $<.1$ & $<.038$ & $<.08$ & $<.06$ & $<.14$ & $<1.6$ & $<.036$ & $<.06$ & $<.14$ \\
\hline 292943098354403 & $<.02$ & $<.1$ & $<.14$ & $<.02$ & $<.1$ & $<.12$ & $<.04$ & $<.1$ & $<.04$ & $<.12$ & $<.06$ & $<.14$ & $<1.6$ & $<.04$ & $<.06$ & $<.14$ \\
\hline 292943098354403 & $<.016$ & $<.06$ & $<.14$ & $<.022$ & $<.1$ & $<.12$ & $<.05$ & $<.1$ & $<.038$ & $<.08$ & $<.06$ & $<.14$ & $<1.6$ & $<.036$ & $<.06$ & $<.14$ \\
\hline 292943098354403 & $<.016$ & $<.06$ & $<.14$ & $<.022$ & $<.1$ & $<.12$ & $<.05$ & $<.1$ & $<.038$ & $<.08$ & $<.06$ & $<.14$ & $<1.6$ & $<.036$ & $<.06$ & $<.14$ \\
\hline 292943098354403 & $<.016$ & $<.06$ & $<.14$ & $<.022$ & $<.1$ & $<.12$ & $<.05$ & $<.1$ & $<.038$ & $<.08$ & $<.06$ & $<.14$ & $<1.6$ & $<.036$ & $<.06$ & $<.14$ \\
\hline 292943098354403 & $<.016$ & $<.06$ & $<.14$ & $<.022$ & $<.1$ & $<.12$ & $<.05$ & $<.1$ & $<.038$ & $<.08$ & $<.06$ & $<.14$ & $<1.6$ & $<.036$ & $<.06$ & $<.14$ \\
\hline 292943098354403 & $<.016$ & $<.06$ & $<.14$ & $<.022$ & $<.1$ & $<.12$ & $<.05$ & $<.1$ & $<.038$ & $<.08$ & $<.06$ & $<.14$ & $<1.6$ & $<.036$ & $<.06$ & $<.14$ \\
\hline 292943098354404 & $<.02$ & $<.1$ & $<.14$ & $<.02$ & $<.1$ & $<.12$ & $<.04$ & $<.1$ & $<.04$ & $<.12$ & $<.06$ & $<.14$ & $<1.6$ & $<.04$ & $<.06$ & $<.14$ \\
\hline 292943098354404 & $<.016$ & $<.06$ & $<.14$ & $<.022$ & $<.1$ & $<.12$ & $<.05$ & $<.1$ & $<.038$ & $<.08$ & $<.06$ & $<.14$ & $<1.6$ & $<.036$ & $<.06$ & $<.14$ \\
\hline 292943098354404 & $<.016$ & $<.06$ & $<.14$ & $<.022$ & $<.1$ & $<.12$ & $<.05$ & $<.1$ & $<.038$ & $<.08$ & $<.06$ & $<.14$ & $<1.6$ & $<.036$ & $<.06$ & $<.14$ \\
\hline 292943098354404 & $<.016$ & $<.06$ & $<.14$ & $<.022$ & $<.1$ & $<.12$ & $<.05$ & $<.1$ & $<.038$ & $<.08$ & $<.06$ & $<.14$ & $<1.6$ & $<.036$ & $<.06$ & $<.14$ \\
\hline 292943098354404 & $<.016$ & $<.06$ & $<.14$ & $<.022$ & $<.1$ & $<.12$ & $<.05$ & $<.1$ & $<.038$ & $<.08$ & $<.06$ & $<.14$ & $<1.6$ & $<.036$ & $<.06$ & $<.14$ \\
\hline 292943098354404 & $<.016$ & $<.06$ & $<.14$ & $<.022$ & $<.1$ & $<.12$ & $<.05$ & $<.1$ & $<.038$ & $<.08$ & $<.06$ & $<.14$ & $<1.6$ & $<.036$ & $<.06$ & $<.14$ \\
\hline 293252098380801 & $<.02$ & $<.1$ & $<.14$ & $<.02$ & $<.1$ & $<.12$ & $<.04$ & $<.1$ & $<.04$ & $<.12$ & $<.06$ & $<.14$ & $<1.6$ & $<.04$ & $<.06$ & $<.14$ \\
\hline 293252098380801 & $<.016$ & $<.06$ & $<.14$ & $<.022$ & $<.1$ & $<.12$ & $<.05$ & $<.1$ & $<.038$ & $<.08$ & $<.06$ & $<.14$ & $<1.6$ & $<.036$ & $<.06$ & $<.14$ \\
\hline 293252098380801 & $<.016$ & $<.06$ & $<.14$ & $<.022$ & $<.1$ & $<.12$ & $<.05$ & $<.1$ & $<.038$ & $<.08$ & $<.06$ & $<.14$ & $<1.6$ & $<.036$ & $<.06$ & $<.14$ \\
\hline 293252098380801 & $<.016$ & $<.06$ & $<.14$ & $<.022$ & $<.1$ & $<.12$ & $<.05$ & $<.1$ & $<.038$ & $<.08$ & $<.06$ & $<.14$ & $<1.6$ & $<.036$ & $<.06$ & $<.14$ \\
\hline 293252098380801 & $<.016$ & $<.06$ & $<.14$ & $<.022$ & $<.1$ & $<.12$ & $<.05$ & $<.1$ & $<.038$ & $<.08$ & $<.06$ & $<.14$ & $<1.6$ & $<.036$ & $<.06$ & $<.14$ \\
\hline 293252098380801 & $<.016$ & $<.06$ & $<.14$ & $<.022$ & $<.1$ & E.048 & $<.05$ & $<.1$ & $<.038$ & $<.08$ & $<.06$ & $<.14$ & $<1.6$ & $<.036$ & $<.06$ & $<.14$ \\
\hline
\end{tabular}


Table 14. Volatile organic and fuel oxygenate compounds for groundwater samples collected for the study of the transport of anthropogenic and natural contaminants (TANC) to public supply wells in the San Antonio segment of the Edwards aquifer near San Antonio, south-central Texas, 2004-9.-Continued

[By sample category. USGS, U.S. Geological Survey; MW, monitoring well; OVB, overburden; $\mu \mathrm{g} / \mathrm{L}$, micrograms per liter; --, not measured or not applicable; E, estimated; <, nondetection less than laboratory method reporting level]

\begin{tabular}{|c|c|c|c|c|c|c|c|c|c|c|c|c|c|c|c|c|}
\hline $\begin{array}{c}\text { USGS } \\
\text { identification } \\
\text { number }\end{array}$ & $\begin{array}{c}\text { lodo- } \\
\text { methane } \\
(\mu \mathrm{g} / \mathrm{L})\end{array}$ & $\begin{array}{c}\text { Iso- } \\
\text { butyl } \\
\text { methyl } \\
\text { ketone } \\
\text { ( } \mu \mathrm{g} / \mathrm{L} \text { ) }\end{array}$ & $\begin{array}{c}\text { Iso- } \\
\text { propyl- } \\
\text { ben- } \\
\text { zene } \\
\text { ( } \mathrm{gg} / \mathrm{L} \text { ) }\end{array}$ & $\begin{array}{l}\text { Methyl } \\
\text { arylo- } \\
\text { nitrile } \\
(\mu \mathrm{g} / \mathrm{L})\end{array}$ & $\begin{array}{c}\text { Methyl } \\
\text { acrylate } \\
\text { ( } \mu \mathrm{g} / \mathrm{L})\end{array}$ & $\begin{array}{l}\text { Methyl } \\
\text { meth- } \\
\text { acrylate } \\
\text { ( } \mu \mathrm{g} / \mathrm{L})\end{array}$ & $\begin{array}{c}\text { Methyl } \\
\text { tert- } \\
\text { pentyl } \\
\text { ether } \\
\text { ( } \mu \mathrm{g} / \mathrm{L} \text { ) }\end{array}$ & $\begin{array}{c}\text { m- } \\
\text { plus } \\
\text { p- } \\
\text { Xylene } \\
\text { (pg/L) }\end{array}$ & $\begin{array}{l}\text { Naphth- } \\
\text { alene } \\
\text { (pg/L) }\end{array}$ & $\begin{array}{c}\text { n-Butyl } \\
\text { methyl } \\
\text { ketone } \\
\text { ( } \mu \text { g/L) }\end{array}$ & $\begin{array}{c}\text { n-Butyl- } \\
\text { ben- } \\
\text { zene } \\
(\mu \mathrm{g} / \mathrm{L})\end{array}$ & $\begin{array}{c}n- \\
\text { Propyl- } \\
\text { benzene } \\
(\mu \mathrm{g} / \mathrm{L})\end{array}$ & $\begin{array}{c}\text { o- } \\
\text { Xylene } \\
\text { (pg/L) }\end{array}$ & $\begin{array}{c}\text { sec- } \\
\text { Butyl- } \\
\text { benzene } \\
\text { ( } \mu \mathrm{g} / \mathrm{L})\end{array}$ & $\begin{array}{c}\text { Styrene } \\
\text { ( } \mu \mathrm{g} / \mathrm{L})\end{array}$ & $\begin{array}{c}\text { tert- } \\
\text { Amyl } \\
\text { alcohol } \\
(\mu \mathrm{g} / \mathrm{L})\end{array}$ \\
\hline \multicolumn{17}{|c|}{ Regional aquifer public-supply wells } \\
\hline 293359098290301 & $<0.5$ & $<0.37$ & $<0.038$ & $<0.4$ & $<1$ & $<0.2$ & $<0.04$ & $<0.06$ & $<0.52$ & $<0.4$ & $<0.12$ & $<0.042$ & $<0.038$ & $<0.06$ & $<0.042$ & $<1$ \\
\hline 293359098290301 & $<.5$ & $<.37$ & $<.038$ & $<.4$ & $<1$ & $<.2$ & $<.04$ & $<.06$ & $<.52$ & $<.4$ & $<.12$ & $<.042$ & $<.038$ & $<.06$ & $<.042$ & -- \\
\hline 293358098231101 & $<.5$ & $<.37$ & $<.038$ & $<.4$ & $<1$ & $<.2$ & $<.04$ & $<.06$ & $<.52$ & $<.4$ & $<.12$ & $<.042$ & $<.038$ & $<.06$ & $<.042$ & $<1$ \\
\hline 293358098231101 & $<.5$ & $<.37$ & $<.038$ & $<.4$ & $<1$ & $<.2$ & $<.04$ & $<.06$ & $<.52$ & $<.4$ & $<.12$ & $<.042$ & $<.038$ & $<.06$ & $<.042$ & -- \\
\hline 293120098285801 & $<.5$ & $<.37$ & $<.038$ & $<.4$ & $<1$ & $<.2$ & $<.04$ & $<.06$ & $<.52$ & $<.4$ & $<.12$ & $<.042$ & $<.038$ & $<.06$ & $<.042$ & $<1$ \\
\hline 293120098285801 & $<.5$ & $<.37$ & $<.038$ & $<.4$ & $<1$ & $<.2$ & $<.04$ & $<.06$ & $<.52$ & $<.4$ & $<.12$ & $<.042$ & $<.038$ & $<.06$ & $<.042$ & -- \\
\hline 293145098224201 & $<.5$ & $<.37$ & $<.038$ & $<.4$ & $<1$ & $<.2$ & $<.04$ & $<.06$ & $<.52$ & $<.4$ & $<.12$ & $<.042$ & $<.038$ & $<.06$ & $<.042$ & $<1$ \\
\hline 293119098211201 & $<.5$ & $<.37$ & $<.038$ & $<.4$ & $<1$ & $<.2$ & $<.04$ & $<.06$ & $<.52$ & $<.4$ & $<.12$ & $<.042$ & $<.038$ & $<.06$ & $<.042$ & $<1$ \\
\hline 292843098425101 & $<.5$ & $<.37$ & $<.038$ & $<.4$ & $<1$ & $<.2$ & $<.04$ & $<.06$ & $<.52$ & $<.4$ & $<.12$ & $<.042$ & $<.038$ & $<.06$ & $<.042$ & $<1$ \\
\hline 292459098382101 & $<.5$ & $<.37$ & $<.038$ & $<.4$ & $<1$ & $<.2$ & $<.04$ & $<.06$ & $<.52$ & $<.4$ & $<.12$ & $<.042$ & $<.038$ & $<.06$ & $<.042$ & $<1$ \\
\hline 292925098360201 & $<.5$ & $<.37$ & $<.038$ & $<.4$ & $<1$ & $<.2$ & $<.04$ & $<.06$ & $<.52$ & $<.4$ & $<.12$ & $<.042$ & $<.038$ & $<.06$ & $<.042$ & $<1$ \\
\hline 292925098360201 & $<.5$ & $<.37$ & $<.038$ & $<.4$ & $<1$ & $<.2$ & $<.04$ & $<.06$ & $<.52$ & $<.4$ & $<.12$ & $<.042$ & $<.038$ & $<.06$ & $<.042$ & -- \\
\hline 292822098325401 & $<.5$ & $<.37$ & $<.038$ & $<.4$ & $<1$ & $<.2$ & $<.04$ & $<.06$ & $<.52$ & $<.4$ & $<.12$ & $<.042$ & $<.038$ & $<.06$ & $<.042$ & $<1$ \\
\hline 292822098325401 & $<.5$ & $<.37$ & $<.038$ & $<.4$ & $<1$ & $<.2$ & $<.04$ & $<.06$ & $<.52$ & $<.4$ & $<.12$ & $<.042$ & $<.038$ & $<.06$ & $<.042$ & -- \\
\hline 292944098292301 & $<.5$ & $<.37$ & $<.038$ & $<.4$ & $<1$ & $<.2$ & $<.04$ & $<.06$ & $<.52$ & $<.4$ & $<.12$ & $<.042$ & $<.038$ & $<.06$ & $<.042$ & $<1$ \\
\hline 292944098292301 & -- & -- & -- & -- & -- & -- & -- & -- & -- & -- & -- & -- & -- & -- & -- & -- \\
\hline 292522098291901 & $<.5$ & $<.37$ & $<.038$ & $<.4$ & $<1$ & $<.2$ & $<.04$ & $<.06$ & $<.52$ & $<.4$ & $<.12$ & $<.042$ & $<.038$ & $<.06$ & $<.042$ & $<1$ \\
\hline 292643098241801 & $<.5$ & $<.37$ & $<.038$ & $<.4$ & $<1$ & $<.2$ & $<.04$ & E.021 & $<.52$ & $<.4$ & $<.12$ & $<.042$ & $<.038$ & $<.06$ & $<.042$ & $<1$ \\
\hline 292643098241801 & $<.5$ & $<.37$ & $<.038$ & $<.4$ & $<1$ & $<.2$ & $<.04$ & $<.06$ & $<.52$ & $<.4$ & $<.12$ & $<.042$ & $<.038$ & $<.06$ & $<.042$ & -- \\
\hline 292328098294601 & $<.5$ & $<.37$ & $<.038$ & $<.4$ & $<1$ & $<.2$ & $<.04$ & $<.06$ & $<.52$ & $<.4$ & $<.12$ & $<.042$ & $<.038$ & $<.06$ & $<.042$ & $<1$ \\
\hline 294225098080301 & $<.5$ & $<.37$ & $<.038$ & $<.4$ & $<1$ & $<.2$ & $<.04$ & $<.06$ & $<.52$ & $<.4$ & $<.12$ & $<.042$ & $<.038$ & $<.06$ & $<.042$ & $<1$ \\
\hline 294225098080301 & $<.5$ & $<.37$ & $<.038$ & $<.4$ & $<1$ & $<.2$ & $<.04$ & $<.06$ & $<.52$ & $<.4$ & $<.12$ & $<.042$ & $<.038$ & $<.06$ & $<.042$ & -- \\
\hline 291210099475601 & $<.5$ & $<.37$ & $<.038$ & $<.4$ & $<1$ & $<.2$ & $<.04$ & $<.06$ & $<.52$ & $<.4$ & $<.12$ & $<.042$ & $<.038$ & $<.06$ & $<.042$ & $<1$ \\
\hline 293111098340901 & $<.5$ & $<.37$ & $<.038$ & $<.4$ & $<1$ & $<.2$ & $<.04$ & $<.06$ & $<.52$ & $<.4$ & $<.12$ & $<.042$ & $<.038$ & $<.06$ & $<.042$ & $<1$ \\
\hline 293512098291701 & $<.5$ & $<.37$ & $<.038$ & $<.4$ & $<1$ & $<.2$ & $<.04$ & $<.06$ & $<.52$ & $<.4$ & $<.12$ & $<.042$ & $<.038$ & $<.06$ & $<.042$ & $<1$ \\
\hline 292424098421501 & $<.5$ & $<.37$ & $<.038$ & $<.4$ & $<1$ & $<.2$ & $<.04$ & $<.06$ & $<.52$ & $<.4$ & $<.12$ & $<.042$ & $<.038$ & $<.06$ & $<.042$ & $<1$ \\
\hline
\end{tabular}


Table 14. Volatile organic and fuel oxygenate compounds for groundwater samples collected for the study of the transport of anthropogenic and natural contaminants (TANC) to public supply wells in the San Antonio segment of the Edwards aquifer near San Antonio, south-central Texas, 2004-9.-Continued

[By sample category. USGS, U.S. Geological Survey; MW, monitoring well; OVB, overburden; $\mu \mathrm{g} / \mathrm{L}$, micrograms per liter; --, not measured or not applicable; E, estimated; <, nondetection less than laboratory method reporting level]

\begin{tabular}{|c|c|c|c|c|c|c|c|c|c|c|c|c|c|c|c|c|}
\hline $\begin{array}{c}\text { USGS } \\
\text { identification } \\
\text { number }\end{array}$ & $\begin{array}{c}\text { lodo- } \\
\text { methane } \\
(\mu \mathrm{g} / \mathrm{L})\end{array}$ & $\begin{array}{c}\text { Iso- } \\
\text { butyl } \\
\text { methyl } \\
\text { ketone } \\
\text { (pg/L) }\end{array}$ & $\begin{array}{c}\text { Iso- } \\
\text { propyl- } \\
\text { ben- } \\
\text { zene } \\
\text { (pg/L) }\end{array}$ & $\begin{array}{l}\text { Methyl } \\
\text { arylo- } \\
\text { nitrile } \\
(\mu \mathrm{g} / \mathrm{L})\end{array}$ & $\begin{array}{c}\text { Methyl } \\
\text { acrylate } \\
\text { ( } \mathrm{gg} / \mathrm{L})\end{array}$ & $\begin{array}{c}\text { Methyl } \\
\text { meth- } \\
\text { acrylate } \\
(\mu \mathrm{g} / \mathrm{L})\end{array}$ & $\begin{array}{c}\text { Methyl } \\
\text { tert- } \\
\text { pentyl } \\
\text { ether } \\
(\mu \mathrm{g} / \mathrm{L})\end{array}$ & $\begin{array}{c}\text { m- } \\
\text { plus } \\
\text { p- } \\
\text { Xylene } \\
(\mu \mathrm{g} / \mathrm{L})\end{array}$ & $\begin{array}{c}\text { Naphth- } \\
\text { alene } \\
\text { ( } \mu \mathrm{g} / \mathrm{L})\end{array}$ & $\begin{array}{c}\text { n-Butyl } \\
\text { methyl } \\
\text { ketone } \\
(\mu \mathrm{g} / \mathrm{L})\end{array}$ & $\begin{array}{l}\text { n-Butyl- } \\
\text { ben- } \\
\text { zene } \\
\text { ( } \mu \mathrm{g} / \mathrm{L})\end{array}$ & $\begin{array}{c}n- \\
\text { Propyl- } \\
\text { benzene } \\
(\mu \mathrm{g} / \mathrm{L})\end{array}$ & $\begin{array}{c}\text { o- } \\
\text { Xylene } \\
\text { ( } \mu \mathrm{g} / \mathrm{L})\end{array}$ & $\begin{array}{c}\text { sec- } \\
\text { Butyl- } \\
\text { benzene } \\
(\mu \mathrm{g} / \mathrm{L})\end{array}$ & $\begin{array}{c}\text { Styrene } \\
(\mu \mathrm{g} / \mathrm{L})\end{array}$ & $\begin{array}{c}\text { tert- } \\
\text { Amyl } \\
\text { alcohol } \\
(\mu \mathrm{g} / \mathrm{L})\end{array}$ \\
\hline 292053098365501 & $<0.5$ & $<0.37$ & $<0.038$ & $<0.4$ & $<1$ & $<0.2$ & $<0.04$ & $<0.06$ & $<0.52$ & $<0.4$ & $<0.12$ & $<0.042$ & $<0.038$ & $<0.06$ & $<0.042$ & $<1$ \\
\hline 293807098155301 & $<.5$ & $<.37$ & $<.038$ & $<.4$ & $<1$ & $<.2$ & $<.04$ & $<.06$ & $<.52$ & $<.4$ & $<.12$ & $<.042$ & $<.038$ & $<.06$ & $<.042$ & $<1$ \\
\hline 292604098563201 & $<.5$ & $<.37$ & $<.038$ & $<.4$ & $<1$ & $<.2$ & $<.04$ & $<.06$ & $<.52$ & $<.4$ & $<.12$ & $<.042$ & $<.038$ & $<.06$ & $<.042$ & $<1$ \\
\hline 292116099095501 & $<.5$ & $<.37$ & $<.038$ & $<.4$ & $<1$ & $<.2$ & $<.04$ & $<.06$ & $<.52$ & $<.4$ & $<.12$ & $<.042$ & $<.038$ & $<.06$ & $<.042$ & $<1$ \\
\hline 291232099470301 & $<.5$ & $<.37$ & $<.038$ & $<.4$ & $<1$ & $<.2$ & $<.04$ & $<.06$ & $<.52$ & $<.4$ & $<.12$ & $<.042$ & $<.038$ & $<.06$ & $<.042$ & $<1$ \\
\hline 293128098473101 & $<.5$ & $<.37$ & $<.038$ & $<.4$ & $<1$ & $<.2$ & $<.04$ & $<.06$ & $<.52$ & $<.4$ & $<.12$ & $<.042$ & $<.038$ & $<.06$ & $<.042$ & $<1$ \\
\hline 293451098313201 & $<.5$ & $<.37$ & $<.038$ & $<.4$ & $<1$ & $<.2$ & $<.04$ & $<.06$ & $<.52$ & $<.4$ & $<.12$ & $<.042$ & $<.038$ & $<.06$ & $<.042$ & $<1$ \\
\hline 294604098060801 & $<.5$ & $<.37$ & $<.038$ & $<.4$ & $<1$ & $<.2$ & $<.04$ & $<.06$ & $<.52$ & $<.4$ & $<.12$ & $<.042$ & $<.038$ & $<.06$ & $<.042$ & $<1$ \\
\hline 294019098114701 & $<.5$ & $<.37$ & $<.038$ & $<.4$ & $<1$ & $<.2$ & $<.04$ & $<.06$ & $<.52$ & $<.4$ & $<.12$ & $<.042$ & $<.038$ & $<.06$ & $<.042$ & $<1$ \\
\hline 292215098580201 & $<.5$ & $<.37$ & $<.038$ & $<.4$ & $<1$ & $<.2$ & $<.04$ & $<.06$ & $<.52$ & $<.4$ & $<.12$ & $<.042$ & $<.038$ & $<.06$ & $<.042$ & $<1$ \\
\hline 292119098524901 & $<.5$ & $<.37$ & $<.038$ & $<.4$ & $<1$ & $<.2$ & $<.04$ & $<.06$ & $<.52$ & $<.4$ & $<.12$ & $<.042$ & $<.038$ & $<.06$ & $<.042$ & $<1$ \\
\hline 291943099163301 & $<.5$ & $<.37$ & $<.038$ & $<.4$ & $<1$ & $<.2$ & $<.04$ & $<.06$ & $<.52$ & $<.4$ & $<.12$ & $<.042$ & $<.038$ & $<.06$ & $<.042$ & $<1$ \\
\hline 291840099382601 & $<.5$ & $<.37$ & $<.038$ & $<.4$ & $<1$ & $<.2$ & $<.04$ & $<.06$ & $<.52$ & $<.4$ & $<.12$ & $<.042$ & $<.038$ & $<.06$ & $<.042$ & $<1$ \\
\hline 293518098332601 & $<.5$ & $<.37$ & $<.038$ & $<.4$ & $<1$ & $<.2$ & $<.04$ & $<.06$ & $<.52$ & $<.4$ & $<.12$ & $<.042$ & $<.038$ & $<.06$ & $<.042$ & $<1$ \\
\hline 293023098355401 & $<.5$ & $<.37$ & $<.038$ & $<.4$ & $<1$ & $<.2$ & $<.04$ & $<.06$ & $<.52$ & $<.4$ & $<.12$ & $<.042$ & $<.038$ & $<.06$ & $<.042$ & $<1$ \\
\hline 293042098305201 & $<.5$ & $<.37$ & $<.038$ & $<.4$ & $<1$ & $<.2$ & $<.04$ & $<.06$ & $<.52$ & $<.4$ & $<.12$ & $<.042$ & $<.038$ & $<.06$ & $<.042$ & $<1$ \\
\hline 292442098474501 & $<.5$ & $<.37$ & $<.038$ & $<.4$ & $<1$ & $<.2$ & $<.04$ & $<.06$ & $<.52$ & $<.4$ & $<.12$ & $<.042$ & $<.038$ & $<.06$ & $<.042$ & $<1$ \\
\hline 292405098371201 & $<.5$ & $<.37$ & $<.038$ & $<.4$ & $<1$ & $<.2$ & $<.04$ & $<.06$ & $<.52$ & $<.4$ & $<.12$ & $<.042$ & $<.038$ & $<.06$ & $<.042$ & $<1$ \\
\hline 292931098274601 & $<.5$ & $<.37$ & $<.038$ & $<.4$ & $<1$ & $<.2$ & $<.04$ & $<.06$ & $<.52$ & $<.4$ & $<.12$ & $<.042$ & $<.038$ & $<.06$ & $<.042$ & $<1$ \\
\hline 293729098173101 & $<.5$ & $<.37$ & $<.038$ & $<.4$ & $<1$ & $<.2$ & $<.04$ & $<.06$ & $<.52$ & $<.4$ & $<.12$ & $<.042$ & $<.038$ & $<.06$ & $<.042$ & $<1$ \\
\hline 291219099095601 & $<.5$ & $<.37$ & $<.038$ & $<.4$ & $<1$ & $<.2$ & $<.04$ & $<.06$ & $<.52$ & $<.4$ & $<.12$ & $<.042$ & $<.038$ & $<.06$ & $<.042$ & $<1$ \\
\hline \multicolumn{17}{|c|}{ Monitoring wells } \\
\hline 292943098354401 & $<.4$ & $<.4$ & $<.04$ & $<.2$ & $<.6$ & $<.2$ & $<.06$ & $<.08$ & $<.2$ & $<.6$ & $<.14$ & $<.04$ & $<.04$ & $<.04$ & $<.04$ & -- \\
\hline 292943098354402 & $<.4$ & $<.4$ & $<.04$ & $<.2$ & $<.6$ & $<.2$ & $<.06$ & $<.08$ & $<.2$ & $<.6$ & $<.14$ & $<.04$ & $<.04$ & $<.04$ & $<.04$ & -- \\
\hline 292943098354403 & $<.4$ & $<.4$ & $<.04$ & $<.2$ & $<.6$ & $<.2$ & $<.06$ & $<.08$ & $<.2$ & $<.6$ & $<.14$ & $<.04$ & $<.04$ & $<.04$ & $<.04$ & -- \\
\hline 292943098354404 & $<.4$ & $<.4$ & $<.04$ & $<.2$ & $<.6$ & $<.2$ & $<.06$ & $<.08$ & $<.2$ & $<.6$ & $<.14$ & $<.04$ & $<.04$ & $<.04$ & $<.04$ & -- \\
\hline
\end{tabular}


Table 14. Volatile organic and fuel oxygenate compounds for groundwater samples collected for the study of the transport of anthropogenic and natural contaminants (TANC) to public supply wells in the San Antonio segment of the Edwards aquifer near San Antonio, south-central Texas, 2004-9.-Continued

[By sample category. USGS, U.S. Geological Survey; MW, monitoring well; OVB, overburden; $\mu \mathrm{g} / \mathrm{L}$, micrograms per liter; --, not measured or not applicable; E, estimated; <, nondetection less than laboratory method reporting level]

\begin{tabular}{|c|c|c|c|c|c|c|c|c|c|c|c|c|c|c|c|c|}
\hline $\begin{array}{c}\text { USGS } \\
\text { identification } \\
\text { number }\end{array}$ & $\begin{array}{l}\text { lodo- } \\
\text { methane } \\
(\mu \mathrm{g} / \mathrm{L})\end{array}$ & $\begin{array}{c}\text { Iso- } \\
\text { butyl } \\
\text { methyl } \\
\text { ketone } \\
\text { ( } \mathrm{gg} / \mathrm{L} \text { ) }\end{array}$ & $\begin{array}{c}\text { Iso- } \\
\text { propyl- } \\
\text { ben- } \\
\text { zene } \\
\text { ( } \mathrm{gg} / \mathrm{L})\end{array}$ & $\begin{array}{l}\text { Methyl } \\
\text { arylo- } \\
\text { nitrile } \\
(\mu \mathrm{g} / \mathrm{L})\end{array}$ & $\begin{array}{c}\text { Methyl } \\
\text { acrylate } \\
\text { ( } \mu \mathrm{g} / \mathrm{L})\end{array}$ & $\begin{array}{l}\text { Methyl } \\
\text { meth- } \\
\text { acrylate } \\
(\mu \mathrm{g} / \mathrm{L})\end{array}$ & $\begin{array}{l}\text { Methyl } \\
\text { tert- } \\
\text { pentyl } \\
\text { ether } \\
(\mu \mathrm{g} / \mathrm{L})\end{array}$ & $\begin{array}{c}\text { m- } \\
\text { plus } \\
\text { p- } \\
\text { Xylene } \\
\text { (pg/L) }\end{array}$ & $\begin{array}{c}\text { Naphth- } \\
\text { alene } \\
\text { ( } \mu \mathrm{g} / \mathrm{L})\end{array}$ & $\begin{array}{c}\text { n-Butyl } \\
\text { methyl } \\
\text { ketone } \\
\text { ( } \mu \mathrm{g} / \mathrm{L})\end{array}$ & $\begin{array}{l}\text { n-Butyl- } \\
\text { ben- } \\
\text { zene } \\
\text { ( } \mu \mathrm{g} / \mathrm{L} \text { ) }\end{array}$ & $\begin{array}{c}n- \\
\text { Propyl- } \\
\text { benzene } \\
(\mu \mathrm{g} / \mathrm{L})\end{array}$ & $\begin{array}{c}0- \\
\text { Xylene } \\
(\mu \mathrm{g} / \mathrm{L})\end{array}$ & $\begin{array}{c}\text { sec- } \\
\text { Butyl- } \\
\text { benzene } \\
\text { ( } \mu \mathrm{g} / \mathrm{L})\end{array}$ & $\begin{array}{c}\text { Styrene } \\
\text { ( } \mu \mathrm{g} / \mathrm{L})\end{array}$ & $\begin{array}{c}\text { tert- } \\
\text { Amyl } \\
\text { alcohol } \\
(\mu \mathrm{g} / \mathrm{L})\end{array}$ \\
\hline 292851098374401 & $<0.4$ & $<0.4$ & $<0.04$ & $<0.2$ & $<0.6$ & $<0.2$ & $<0.06$ & $<0.08$ & $<0.2$ & $<0.6$ & $<0.14$ & $<0.04$ & $<0.04$ & $<0.04$ & $<0.04$ & -- \\
\hline 292851098374402 & $<.4$ & $<.4$ & $<.04$ & $<.2$ & $<.6$ & $<.2$ & $<.06$ & $<.08$ & $<.2$ & $<.6$ & $<.14$ & $<.04$ & $<.04$ & $<.04$ & $<.04$ & -- \\
\hline \multicolumn{17}{|c|}{ Well-field depth-dependent sampling (W4) } \\
\hline 292916098360701 & $<.4$ & $<.4$ & $<.04$ & $<.2$ & $<.6$ & $<.2$ & $<.06$ & $<.08$ & $<.2$ & $<.6$ & $<.14$ & $<.04$ & $<.04$ & $<.04$ & $<.04$ & -- \\
\hline 292916098360701 & $<.4$ & $<.4$ & $<.04$ & $<.2$ & $<.6$ & $<.2$ & $<.06$ & $<.08$ & $<.2$ & $<.6$ & $<.14$ & $<.04$ & $<.04$ & $<.04$ & $<.04$ & -- \\
\hline 292916098360701 & $<.4$ & $<.4$ & $<.04$ & $<.2$ & $<.6$ & $<.2$ & $<.06$ & $<.08$ & $<.2$ & $<.6$ & $<.14$ & $<.04$ & $<.04$ & $<.04$ & $<.04$ & -- \\
\hline 292916098360701 & $<.4$ & $<.4$ & $<.04$ & $<.2$ & $<.6$ & $<.2$ & $<.06$ & $<.08$ & $<.2$ & $<.6$ & $<.14$ & $<.04$ & $<.04$ & $<.04$ & $<.04$ & -- \\
\hline 292916098360701 & $<.4$ & $<.4$ & $<.04$ & $<.2$ & $<.6$ & $<.2$ & $<.06$ & $<.08$ & $<.2$ & $<.6$ & $<.14$ & $<.04$ & $<.04$ & $<.04$ & $<.04$ & -- \\
\hline 292916098360701 & $<.4$ & $<.4$ & $<.04$ & $<.2$ & $<.6$ & $<.2$ & $<.06$ & $<.08$ & $<.2$ & $<.6$ & $<.14$ & $<.04$ & $<.04$ & $<.04$ & $<.04$ & -- \\
\hline 292916098360701 & $<.4$ & $<.4$ & $<.04$ & $<.2$ & $<.6$ & $<.2$ & $<.06$ & $<.08$ & $<.2$ & $<.6$ & $<.14$ & $<.04$ & $<.04$ & $<.04$ & $<.04$ & -- \\
\hline 292916098360701 & $<.4$ & $<.4$ & $<.04$ & $<.2$ & $<.6$ & $<.2$ & $<.06$ & $<.08$ & $<.2$ & $<.6$ & $<.14$ & $<.04$ & $<.04$ & $<.04$ & $<.04$ & -- \\
\hline 292916098360701 & $<.4$ & $<.4$ & $<.04$ & $<.2$ & $<.6$ & $<.2$ & $<.06$ & $<.08$ & $<.2$ & $<.6$ & $<.14$ & $<.04$ & $<.04$ & $<.04$ & $<.04$ & -- \\
\hline \multicolumn{17}{|c|}{ Well-field wells (wellhead sampling) } \\
\hline 292919098360501 & $<.4$ & $<.4$ & $<.04$ & $<.2$ & $<.6$ & $<.2$ & $<.06$ & $<.08$ & $<.2$ & $<.6$ & $<.14$ & $<.04$ & $<.04$ & $<.04$ & $<.04$ & -- \\
\hline 292925098360201 & $<.4$ & $<.4$ & $<.04$ & $<.2$ & $<.6$ & $<.2$ & $<.06$ & $<.08$ & $<.2$ & $<.6$ & $<.14$ & $<.04$ & $<.04$ & $<.04$ & $<.04$ & -- \\
\hline 292916098360701 & $<.4$ & $<.4$ & $<.04$ & $<.2$ & $<.6$ & $<.2$ & $<.06$ & $<.08$ & $<.2$ & $<.6$ & $<.14$ & $<.04$ & $<.04$ & $<.04$ & $<.04$ & -- \\
\hline 292920098360601 & $<.4$ & $<.4$ & $<.04$ & $<.2$ & $<.6$ & $<.2$ & $<.06$ & $<.08$ & $<.2$ & $<.6$ & $<.14$ & $<.04$ & $<.04$ & $<.04$ & $<.04$ & -- \\
\hline 292923098360301 & $<.4$ & $<.4$ & $<.04$ & $<.2$ & $<.6$ & $<.2$ & $<.06$ & $<.08$ & $<.2$ & $<.6$ & $<.14$ & $<.04$ & $<.04$ & $<.04$ & $<.04$ & -- \\
\hline \multicolumn{17}{|c|}{ Temporal sampling } \\
\hline 292923098360301 & $<.8$ & $<.4$ & $<.04$ & $<.2$ & $<.6$ & $<.2$ & $<.06$ & $<.08$ & $<.2$ & $<.6$ & $<.08$ & $<.04$ & $<.04$ & $<.02$ & $<.04$ & -- \\
\hline 292923098360301 & $<.26$ & $<.32$ & $<.042$ & $<.26$ & $<.56$ & $<.22$ & $<.06$ & $<.08$ & $<.18$ & $<.46$ & $<.08$ & $<.036$ & $<.032$ & $<.034$ & $<.03$ & -- \\
\hline
\end{tabular}


Table 14. Volatile organic and fuel oxygenate compounds for groundwater samples collected for the study of the transport of anthropogenic and natural contaminants (TANC) to public supply wells in the San Antonio segment of the Edwards aquifer near San Antonio, south-central Texas, 2004-9.-Continued

[By sample category. USGS, U.S. Geological Survey; MW, monitoring well; OVB, overburden; $\mu \mathrm{g} / \mathrm{L}$, micrograms per liter; --, not measured or not applicable; E, estimated; <, nondetection less than laboratory method reporting level]

\begin{tabular}{|c|c|c|c|c|c|c|c|c|c|c|c|c|c|c|c|c|}
\hline $\begin{array}{c}\text { USGS } \\
\text { identification } \\
\text { number }\end{array}$ & $\begin{array}{l}\text { lodo- } \\
\text { methane } \\
(\mu \mathrm{g} / \mathrm{L})\end{array}$ & $\begin{array}{l}\text { Iso- } \\
\text { butyl } \\
\text { methyl } \\
\text { ketone } \\
\text { ( } \mu \mathrm{g} / \mathrm{L} \text { ) }\end{array}$ & $\begin{array}{c}\text { Iso- } \\
\text { propyl- } \\
\text { ben- } \\
\text { zene } \\
\text { (pg/L) }\end{array}$ & $\begin{array}{l}\text { Methyl } \\
\text { arylo- } \\
\text { nitrile } \\
(\mu \mathrm{g} / \mathrm{L})\end{array}$ & $\begin{array}{c}\text { Methyl } \\
\text { acrylate } \\
\text { (pg/L) }\end{array}$ & $\begin{array}{l}\text { Methyl } \\
\text { meth- } \\
\text { acrylate } \\
(\mu \mathrm{g} / \mathrm{L})\end{array}$ & $\begin{array}{c}\text { Methyl } \\
\text { tert- } \\
\text { pentyl } \\
\text { ether } \\
\text { ( } \mathrm{gg} / \mathrm{L})\end{array}$ & $\begin{array}{c}\text { m- } \\
\text { plus } \\
\text { p- } \\
\text { Xylene } \\
\text { ( } \mathrm{gg} / \mathrm{L} \text { ) }\end{array}$ & $\begin{array}{c}\text { Naphth- } \\
\text { alene } \\
\text { ( } \mu \mathrm{g} / \mathrm{L})\end{array}$ & $\begin{array}{c}\text { n-Butyl } \\
\text { methyl } \\
\text { ketone } \\
(\mu \mathrm{g} / \mathrm{L})\end{array}$ & $\begin{array}{l}\text { n-Butyl- } \\
\text { ben- } \\
\text { zene } \\
\text { ( } \mu \mathrm{g} / \mathrm{L})\end{array}$ & $\begin{array}{c}n- \\
\text { Propyl- } \\
\text { benzene } \\
(\mu \mathrm{g} / \mathrm{L})\end{array}$ & $\begin{array}{c}\text { o- } \\
\text { Xylene } \\
\text { (pg/L) }\end{array}$ & $\begin{array}{c}\text { sec- } \\
\text { Butyl- } \\
\text { benzene } \\
(\mu \mathrm{g} / \mathrm{L})\end{array}$ & $\begin{array}{c}\text { Styrene } \\
\text { ( } \mu \mathrm{g} / \mathrm{L})\end{array}$ & $\begin{array}{c}\text { tert- } \\
\text { Amyl } \\
\text { alcohol } \\
(\mu \mathrm{g} / \mathrm{L})\end{array}$ \\
\hline 292923098360301 & $<0.26$ & $<0.32$ & $<0.042$ & $<0.26$ & $<0.56$ & $<0.22$ & $<0.06$ & $<0.08$ & $<0.18$ & $<0.46$ & $<0.08$ & $<0.036$ & $<0.032$ & $<0.034$ & $<0.03$ & -- \\
\hline 292923098360301 & $<.26$ & $<.32$ & $<.042$ & $<.26$ & $<.56$ & $<.22$ & $<.06$ & $<.08$ & $<.18$ & $<.46$ & $<.08$ & $<.036$ & $<.032$ & $<.034$ & $<.03$ & -- \\
\hline 292923098360301 & $<.26$ & $<.32$ & $<.042$ & $<.26$ & $<.56$ & $<.22$ & $<.06$ & $<.08$ & $<.18$ & $<.46$ & $<.08$ & $<.036$ & $<.032$ & $<.034$ & $<.03$ & -- \\
\hline 292923098360301 & $<.26$ & $<.32$ & $<.042$ & $<.26$ & $<.56$ & $<.22$ & $<.06$ & $<.08$ & $<.18$ & $<.46$ & $<.08$ & $<.036$ & $<.032$ & $<.034$ & $<.03$ & -- \\
\hline 292943098354402 & $<.8$ & $<.4$ & $<.04$ & $<.2$ & $<.6$ & $<.2$ & $<.06$ & $<.08$ & $<.2$ & $<.6$ & $<.08$ & $<.04$ & $<.04$ & $<.02$ & $<.04$ & -- \\
\hline 292943098354402 & $<.26$ & $<.32$ & $<.042$ & $<.26$ & $<.56$ & $<.22$ & $<.06$ & $<.08$ & $<.18$ & $<.46$ & $<.08$ & $<.036$ & $<.032$ & $<.034$ & $<.03$ & -- \\
\hline 292943098354402 & $<.26$ & $<.32$ & $<.042$ & $<.26$ & $<.56$ & $<.22$ & $<.06$ & $<.08$ & $<.18$ & $<.46$ & $<.08$ & $<.036$ & $<.032$ & $<.034$ & $<.03$ & -- \\
\hline 292943098354402 & $<.26$ & $<.32$ & $<.042$ & $<.26$ & $<.56$ & $<.22$ & $<.06$ & $<.08$ & $<.18$ & $<.46$ & $<.08$ & $<.036$ & $<.032$ & $<.034$ & $<.03$ & -- \\
\hline 292943098354402 & $<.26$ & $<.32$ & $<.042$ & $<.26$ & $<.56$ & $<.22$ & $<.06$ & $<.08$ & $<.18$ & $<.46$ & $<.08$ & $<.036$ & $<.032$ & $<.034$ & $<.03$ & -- \\
\hline 292943098354402 & $<.26$ & $<.32$ & $<.042$ & $<.26$ & $<.56$ & $<.22$ & $<.06$ & $<.08$ & $<.18$ & $<.46$ & $<.08$ & $<.036$ & $<.032$ & $<.034$ & $<.03$ & -- \\
\hline 292943098354403 & $<.8$ & $<.4$ & $<.04$ & $<.2$ & $<.6$ & $<.2$ & $<.06$ & $<.08$ & $<.2$ & $<.6$ & $<.08$ & $<.04$ & $<.04$ & $<.02$ & $<.04$ & -- \\
\hline 292943098354403 & $<.26$ & $<.32$ & $<.042$ & $<.26$ & $<.56$ & $<.22$ & $<.06$ & $<.08$ & $<.18$ & $<.46$ & $<.08$ & $<.036$ & $<.032$ & $<.034$ & $<.03$ & -- \\
\hline 292943098354403 & $<.26$ & $<.32$ & $<.042$ & $<.26$ & $<.56$ & $<.22$ & $<.06$ & $<.08$ & $<.18$ & $<.46$ & $<.08$ & $<.036$ & $<.032$ & $<.034$ & $<.03$ & -- \\
\hline 292943098354403 & $<.26$ & $<.32$ & $<.042$ & $<.26$ & $<.56$ & $<.22$ & $<.06$ & $<.08$ & $<.18$ & $<.46$ & $<.08$ & $<.036$ & $<.032$ & $<.034$ & $<.03$ & -- \\
\hline 292943098354403 & $<.26$ & $<.32$ & $<.042$ & $<.26$ & $<.56$ & $<.22$ & $<.06$ & $<.08$ & $<.18$ & $<.46$ & $<.08$ & $<.036$ & $<.032$ & $<.034$ & $<.03$ & -- \\
\hline 292943098354403 & $<.26$ & $<.32$ & $<.042$ & $<.26$ & $<.56$ & $<.22$ & $<.06$ & $<.08$ & $<.18$ & $<.46$ & $<.08$ & $<.036$ & $<.032$ & $<.034$ & $<.03$ & -- \\
\hline 292943098354404 & $<.8$ & $<.4$ & $<.04$ & $<.2$ & $<.6$ & $<.2$ & $<.06$ & $<.08$ & $<.2$ & $<.6$ & $<.08$ & $<.04$ & $<.04$ & $<.02$ & $<.04$ & -- \\
\hline 292943098354404 & $<.26$ & $<.32$ & $<.042$ & $<.26$ & $<.56$ & $<.22$ & $<.06$ & $<.08$ & $<.18$ & $<.46$ & $<.08$ & $<.036$ & $<.032$ & $<.034$ & $<.03$ & -- \\
\hline 292943098354404 & $<.26$ & $<.32$ & $<.042$ & $<.26$ & $<.56$ & $<.22$ & $<.06$ & $<.08$ & $<.18$ & $<.46$ & $<.08$ & $<.036$ & $<.032$ & $<.034$ & $<.03$ & -- \\
\hline 292943098354404 & $<.26$ & $<.32$ & $<.042$ & $<.26$ & $<.56$ & $<.22$ & $<.06$ & $<.08$ & $<.18$ & $<.46$ & $<.08$ & $<.036$ & $<.032$ & $<.034$ & $<.03$ & -- \\
\hline 292943098354404 & $<.26$ & $<.32$ & $<.042$ & $<.26$ & $<.56$ & $<.22$ & $<.06$ & $<.08$ & $<.18$ & $<.46$ & $<.08$ & $<.036$ & $<.032$ & $<.034$ & $<.03$ & -- \\
\hline 292943098354404 & $<.26$ & $<.32$ & $<.042$ & $<.26$ & $<.56$ & $<.22$ & $<.06$ & $<.08$ & $<.18$ & $<.46$ & $<.08$ & $<.036$ & $<.032$ & $<.034$ & $<.03$ & -- \\
\hline 293252098380801 & $<.8$ & $<.4$ & $<.04$ & $<.2$ & $<.6$ & $<.2$ & $<.06$ & $<.08$ & $<.2$ & $<.6$ & $<.08$ & $<.04$ & $<.04$ & $<.02$ & $<.04$ & -- \\
\hline 293252098380801 & $<.26$ & $<.32$ & $<.042$ & $<.26$ & $<.56$ & $<.22$ & $<.06$ & $<.08$ & $<.18$ & $<.46$ & $<.08$ & $<.036$ & $<.032$ & $<.034$ & $<.03$ & -- \\
\hline 293252098380801 & $<.26$ & $<.32$ & $<.042$ & $<.26$ & $<.56$ & $<.22$ & $<.06$ & $<.08$ & $<.18$ & $<.46$ & $<.08$ & $<.036$ & $<.032$ & $<.034$ & $<.03$ & -- \\
\hline 293252098380801 & $<.26$ & $<.32$ & $<.042$ & $<.26$ & $<.56$ & $<.22$ & $<.06$ & $<.08$ & $<.18$ & $<.46$ & $<.08$ & $<.036$ & $<.032$ & $<.034$ & $<.03$ & -- \\
\hline 293252098380801 & $<.26$ & $<.32$ & $<.042$ & $<.26$ & $<.56$ & $<.22$ & $<.06$ & $<.08$ & $<.18$ & $<.46$ & $<.08$ & $<.036$ & $<.032$ & $<.034$ & $<.03$ & -- \\
\hline 293252098380801 & $<.26$ & $<.32$ & $<.042$ & $<.26$ & $<.56$ & $<.22$ & $<.06$ & $<.08$ & $<.18$ & $<.46$ & $<.08$ & $<.036$ & $<.032$ & $<.034$ & $<.03$ & -- \\
\hline
\end{tabular}


Table 14. Volatile organic and fuel oxygenate compounds for groundwater samples collected for the study of the transport of anthropogenic and natural contaminants (TANC) to public supply wells in the San Antonio segment of the Edwards aquifer near San Antonio, south-central Texas, 2004-9.-Continued

[By sample category. USGS, U.S. Geological Survey; MW, monitoring well; OVB, overburden; $\mu \mathrm{g} / \mathrm{L}$, micrograms per liter; --, not measured or not applicable; E, estimated; <, nondetection less than laboratory method reporting level]

\begin{tabular}{|c|c|c|c|c|c|c|c|c|c|c|c|c|c|c|c|c|}
\hline $\begin{array}{c}\text { USGS } \\
\text { identification } \\
\text { number }\end{array}$ & $\begin{array}{l}\text { tert- } \\
\text { Butyl } \\
\text { alcohol } \\
(\mu \mathrm{g} / \mathrm{L})\end{array}$ & $\begin{array}{l}\text { tert- } \\
\text { Butyl } \\
\text { ethyl } \\
\text { ether } \\
\text { ( } \mu \mathrm{g} / \mathrm{L} \text { ) }\end{array}$ & $\begin{array}{c}\text { Methyl } \\
\text { tert-butyl } \\
\text { ether } \\
\text { (MTBE) } \\
\text { ( } \mathrm{\mu g} / \mathrm{L})\end{array}$ & $\begin{array}{c}\text { tert- } \\
\text { Butyl- } \\
\text { benzene } \\
\text { ( } \mu \mathrm{g} / \mathrm{L})\end{array}$ & $\begin{array}{c}\text { Tetra- } \\
\text { chloro- } \\
\text { ethene } \\
\text { (PCE) } \\
\text { ( } \mu \mathrm{g} / \mathrm{L})\end{array}$ & $\begin{array}{l}\text { Tetra- } \\
\text { chloro- } \\
\text { methane } \\
(\mu \mathrm{g} / \mathrm{L})\end{array}$ & $\begin{array}{l}\text { Tetra- } \\
\text { hydro- } \\
\text { furan } \\
\text { ( } \mu \mathrm{g} / \mathrm{L} \text { ) }\end{array}$ & $\begin{array}{c}\text { Toluene } \\
\text { ( } \mu \mathrm{g} / \mathrm{L})\end{array}$ & $\begin{array}{l}\text { trans- } \\
\text { 1,2-Di- } \\
\text { chloro- } \\
\text { ethene } \\
\text { ( } \mu \mathrm{g} / \mathrm{L} \text { ) }\end{array}$ & $\begin{array}{c}\text { trans- } \\
\text { 1,3-Di- } \\
\text { chloro- } \\
\text { propene } \\
\text { ( } \mu \mathrm{g} / \mathrm{L})\end{array}$ & $\begin{array}{c}\text { trans- } \\
\text { 1,4-Di- } \\
\text { chloro- } \\
\text { 2-butene } \\
\text { ( } \mu \mathrm{g} / \mathrm{L})\end{array}$ & 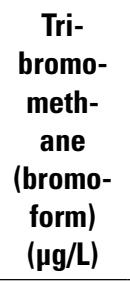 & $\begin{array}{c}\text { Tri- } \\
\text { chloro- } \\
\text { ethene } \\
\text { (TCE) } \\
(\mu \mathrm{g} / \mathrm{L})\end{array}$ & $\begin{array}{c}\text { Tri- } \\
\text { chloro- } \\
\text { fluoro- } \\
\text { methane } \\
\text { (CFC-11) } \\
\text { ( } \mu \mathrm{g} / \mathrm{L})\end{array}$ & $\begin{array}{c}\text { Tri- } \\
\text { chloro- } \\
\text { methane } \\
\text { (chloro- } \\
\text { form) } \\
\text { ( } \mu \mathrm{g} / \mathrm{L} \text { ) }\end{array}$ & $\begin{array}{l}\text { Vinyl } \\
\text { chlo- } \\
\text { ride } \\
(\mu \mathrm{g} / \mathrm{L})\end{array}$ \\
\hline \multicolumn{17}{|c|}{ Regional aquifer public-supply wells } \\
\hline 293359098290301 & $<2$ & $<0.03$ & $<0.1$ & $<0.06$ & 0.549 & $<0.06$ & $<1$ & $<0.02$ & $<0.032$ & $<0.09$ & $<0.7$ & 0.1 & 0.038 & 0.275 & 0.094 & 0.08 \\
\hline 293359098290301 & -- & $<.03$ & $<.1$ & $<.06$ & .830 & $<.06$ & $<1$ & $<.02$ & $<.032$ & $<.09$ & $<.7$ & $<.1$ & $<.038$ & .109 & E.085 & $<.08$ \\
\hline 293358098231101 & $<2$ & $<.03$ & $<.1$ & $<.06$ & .158 & $<.06$ & $<1$ & $<.02$ & $<.032$ & $<.09$ & $<.7$ & $<.1$ & E.016 & $<.08$ & E.035 & $<.08$ \\
\hline 293358098231101 & -- & $<.03$ & $<.1$ & $<.06$ & .183 & $<.06$ & $<1$ & $<.02$ & $<.032$ & $<.09$ & $<.7$ & $<.1$ & $<.038$ & $<.08$ & E.035 & $<.08$ \\
\hline 293120098285801 & $<2$ & $<.03$ & $<.1$ & $<.06$ & .130 & $<.06$ & $<1$ & $<.02$ & $<.032$ & $<.09$ & $<.7$ & 1.90 & E.023 & $<.08$ & E.089 & $<.08$ \\
\hline 293120098285801 & -- & $<.03$ & $<.1$ & $<.06$ & .244 & $<.06$ & $<1$ & $<.02$ & $<.032$ & $<.09$ & $<.7$ & .386 & E.021 & $<.08$ & E.056 & $<.08$ \\
\hline 293145098224201 & $<2$ & $<.03$ & $<.1$ & $<.06$ & E.046 & $<.06$ & $<1$ & $<.02$ & $<.032$ & $<.09$ & $<.7$ & $<.1$ & $<.038$ & $<.08$ & E.021 & $<.08$ \\
\hline 293119098211201 & $<2$ & $<.03$ & $<.1$ & $<.06$ & $<.03$ & $<.06$ & $<1$ & $<.02$ & $<.032$ & $<.09$ & $<.7$ & $<.1$ & $<.038$ & $<.08$ & $<.024$ & $<.08$ \\
\hline 292843098425101 & $<2$ & $<.03$ & $<.1$ & $<.06$ & $<.03$ & $<.06$ & $<1$ & $<.02$ & $<.032$ & $<.09$ & $<.7$ & $<.1$ & $<.038$ & $<.08$ & $<.024$ & $<.08$ \\
\hline 292459098382101 & $<2$ & $<.03$ & $<.1$ & $<.06$ & $<.03$ & $<.06$ & $<1$ & $<.02$ & $<.032$ & $<.09$ & $<.7$ & $<.1$ & $<.038$ & $<.08$ & $<.024$ & $<.08$ \\
\hline 292925098360201 & $<2$ & $<.03$ & $<.1$ & $<.06$ & .107 & $<.06$ & $<1$ & $<.02$ & $<.032$ & $<.09$ & $<.7$ & .477 & $<.038$ & $<.08$ & E.020 & $<.08$ \\
\hline 292925098360201 & -- & $<.03$ & $<.1$ & $<.06$ & .140 & $<.06$ & $<1$ & $<.02$ & $<.032$ & $<.09$ & $<.7$ & .352 & $<.038$ & $<.08$ & E.025 & $<.08$ \\
\hline 292822098325401 & $<2$ & $<.03$ & $<.1$ & $<.06$ & E.017 & $<.06$ & $<1$ & $<.02$ & $<.032$ & $<.09$ & $<.7$ & $<.1$ & $<.038$ & $<.08$ & E.022 & $<.08$ \\
\hline 292822098325401 & -- & $<.03$ & $<.1$ & $<.06$ & E.019 & $<.06$ & $<1$ & $<.02$ & $<.032$ & $<.09$ & $<.7$ & $<.1$ & $<.038$ & $<.08$ & E.030 & $<.08$ \\
\hline 292944098292301 & $<2$ & $<.03$ & $<.1$ & $<.06$ & E.030 & $<.06$ & $<1$ & $<.02$ & $<.032$ & $<.09$ & $<.7$ & $<.1$ & $<.038$ & $<.08$ & $<.024$ & $<.08$ \\
\hline 292944098292301 & -- & -- & -- & -- & -- & -- & -- & -- & -- & -- & -- & -- & -- & -- & -- & -- \\
\hline 292522098291901 & $<2$ & $<.03$ & $<.1$ & $<.06$ & $<.03$ & $<.06$ & $<1$ & $<.02$ & $<.032$ & $<.09$ & $<.7$ & $<.1$ & $<.038$ & $<.08$ & $<.024$ & $<.08$ \\
\hline 292643098241801 & $<2$ & $<.03$ & $<.1$ & $<.06$ & $<.03$ & $<.06$ & $<1$ & $<.02$ & $<.032$ & $<.09$ & $<.7$ & 1.02 & $<.038$ & $<.08$ & .360 & $<.08$ \\
\hline 292643098241801 & -- & $<.03$ & $<.1$ & $<.06$ & $<.03$ & $<.06$ & $<1$ & $<.02$ & $<.032$ & $<.09$ & $<.7$ & $<.1$ & $<.038$ & $<.08$ & E.017 & $<.08$ \\
\hline 292328098294601 & $<2$ & $<.03$ & $<.1$ & $<.06$ & $<.03$ & $<.06$ & $<1$ & $<.02$ & $<.032$ & $<.09$ & $<.7$ & $<.1$ & $<.038$ & $<.08$ & $<.024$ & $<.08$ \\
\hline 294225098080301 & $<2$ & $<.03$ & $<.1$ & $<.06$ & .110 & $<.06$ & $<1$ & E.011 & $<.032$ & $<.09$ & $<.7$ & $<.1$ & $<.038$ & $<.08$ & E.026 & $<.08$ \\
\hline 294225098080301 & -- & $<.03$ & $<.1$ & $<.06$ & E.087 & $<.06$ & $<1$ & $<.02$ & $<.032$ & $<.09$ & $<.7$ & $<.1$ & $<.038$ & $<.08$ & E.024 & $<.08$ \\
\hline 291210099475601 & $<2$ & $<.03$ & $<.1$ & $<.06$ & $<.03$ & $<.06$ & $<1$ & $<.02$ & $<.032$ & $<.09$ & $<.7$ & $<.1$ & $<.038$ & $<.08$ & E.010 & $<.08$ \\
\hline 293111098340901 & $<2$ & $<.03$ & $<.1$ & $<.06$ & E.046 & $<.06$ & $<1$ & $<.02$ & $<.032$ & $<.09$ & $<.7$ & $<.1$ & $<.038$ & $<.08$ & E.040 & $<.08$ \\
\hline 293512098291701 & $<2$ & $<.03$ & $<.1$ & $<.06$ & E.037 & $<.06$ & $<1$ & E.009 & $<.032$ & $<.09$ & $<.7$ & E.057 & $<.038$ & $<.08$ & E.077 & $<.08$ \\
\hline 292424098421501 & $<2$ & $<.03$ & $<.1$ & $<.06$ & $<.03$ & $<.06$ & $<1$ & $<.02$ & $<.032$ & $<.09$ & $<.7$ & $<.1$ & $<.038$ & $<.08$ & $<.024$ & $<.08$ \\
\hline
\end{tabular}


Table 14. Volatile organic and fuel oxygenate compounds for groundwater samples collected for the study of the transport of anthropogenic and natural contaminants (TANC) to public supply wells in the San Antonio segment of the Edwards aquifer near San Antonio, south-central Texas, 2004-9.-Continued

[By sample category. USGS, U.S. Geological Survey; MW, monitoring well; OVB, overburden; $\mu \mathrm{g} / \mathrm{L}$, micrograms per liter; --, not measured or not applicable; E, estimated; <, nondetection less than laboratory method reporting level]

\begin{tabular}{|c|c|c|c|c|c|c|c|c|c|c|c|c|c|c|c|c|}
\hline $\begin{array}{c}\text { USGS } \\
\text { identification } \\
\text { number }\end{array}$ & $\begin{array}{c}\text { tert- } \\
\text { Butyl } \\
\text { alcohol } \\
\text { ( } \mu \mathrm{g} / \mathrm{L})\end{array}$ & $\begin{array}{l}\text { tert- } \\
\text { Butyl } \\
\text { ethyl } \\
\text { ether } \\
\text { ( } \mu \mathrm{g} / \mathrm{L})\end{array}$ & $\begin{array}{c}\text { Methyl } \\
\text { tert-butyl } \\
\text { ether } \\
\text { (MTBE) } \\
\text { ( } \mathrm{gg} / \mathrm{L})\end{array}$ & $\begin{array}{c}\text { tert- } \\
\text { Butyl- } \\
\text { benzene } \\
(\mu \mathrm{g} / \mathrm{L})\end{array}$ & $\begin{array}{c}\text { Tetra- } \\
\text { chloro- } \\
\text { ethene } \\
\text { (PCE) } \\
\text { ( } \mu \mathrm{g} / \mathrm{L})\end{array}$ & $\begin{array}{c}\text { Tetra- } \\
\text { chloro- } \\
\text { methane } \\
(\mu \mathrm{g} / \mathrm{L})\end{array}$ & $\begin{array}{l}\text { Tetra- } \\
\text { hydro- } \\
\text { furan } \\
(\mu \mathrm{g} / \mathrm{L})\end{array}$ & $\begin{array}{c}\text { Toluene } \\
\text { ( } \mu \mathrm{g} / \mathrm{L})\end{array}$ & $\begin{array}{l}\text { trans- } \\
\text { 1,2-Di- } \\
\text { chloro- } \\
\text { ethene } \\
\text { ( } \mu \mathrm{g} / \mathrm{L} \text { ) }\end{array}$ & $\begin{array}{c}\text { trans- } \\
\text { 1,3-Di- } \\
\text { chloro- } \\
\text { propene } \\
\text { ( } \mu \mathrm{g} / \mathrm{L})\end{array}$ & $\begin{array}{c}\text { trans- } \\
\text { 1,4-Di- } \\
\text { chloro- } \\
\text { 2-butene } \\
\text { ( } \mu \mathrm{g} / \mathrm{L})\end{array}$ & $\begin{array}{c}\text { Tri- } \\
\text { bromo- } \\
\text { meth- } \\
\text { ane } \\
\text { (bromo- } \\
\text { form) } \\
\text { ( } \mu \mathrm{g} / \mathrm{L} \text { ) }\end{array}$ & $\begin{array}{c}\text { Tri- } \\
\text { chloro- } \\
\text { ethene } \\
\text { (TCE) } \\
\text { ( } \mu \mathrm{g} / \mathrm{L})\end{array}$ & $\begin{array}{c}\text { Tri- } \\
\text { chloro- } \\
\text { fluoro- } \\
\text { methane } \\
\text { (CFC-11) } \\
\text { ( } \mu \mathrm{g} / \mathrm{L})\end{array}$ & $\begin{array}{c}\text { Tri- } \\
\text { chloro- } \\
\text { methane } \\
\text { (chloro- } \\
\text { form) } \\
\text { ( } \mu \mathrm{g} / \mathrm{L} \text { ) }\end{array}$ & $\begin{array}{l}\text { Vinyl } \\
\text { chlo- } \\
\text { ride } \\
(\mu \mathrm{g} / \mathrm{L})\end{array}$ \\
\hline 292053098365501 & $<2$ & $<0.03$ & $<0.1$ & $<0.06$ & $<0.03$ & $<0.06$ & $<1$ & $<0.02$ & $<0.032$ & $<0.09$ & $<0.7$ & 0.347 & $<0.038$ & $<0.08$ & E0.025 & $<0.08$ \\
\hline 293807098155301 & $<2$ & $<.03$ & $<.1$ & $<.06$ & $<.03$ & $<.06$ & $<1$ & $<.02$ & $<.032$ & $<.09$ & $<.7$ & .494 & $<.038$ & $<.08$ & E.019 & $<.08$ \\
\hline 292604098563201 & $<2$ & $<.03$ & $<.1$ & $<.06$ & $<.03$ & $<.06$ & $<1$ & $<.02$ & $<.032$ & $<.09$ & $<.7$ & $<.1$ & $<.038$ & $<.08$ & $<.024$ & $<.08$ \\
\hline 292116099095501 & $<2$ & $<.03$ & $<.1$ & $<.06$ & $<.03$ & $<.06$ & $<1$ & $<.02$ & $<.032$ & $<.09$ & $<.7$ & $<.1$ & $<.038$ & $<.08$ & $<.024$ & $<.08$ \\
\hline 291232099470301 & $<2$ & $<.03$ & $<.1$ & $<.06$ & E.069 & $<.06$ & $<1$ & $<.02$ & $<.032$ & $<.09$ & $<.7$ & $<.1$ & $<.038$ & $<.08$ & E.015 & $<.08$ \\
\hline 293128098473101 & $<2$ & $<.03$ & $<.1$ & $<.06$ & $<.03$ & $<.06$ & $<1$ & $<.02$ & $<.032$ & $<.09$ & $<.7$ & $<.1$ & $<.038$ & $<.08$ & $<.024$ & $<.08$ \\
\hline 293451098313201 & $<2$ & $<.03$ & $<.1$ & $<.06$ & E.026 & $<.06$ & $<1$ & $<.02$ & $<.032$ & $<.09$ & $<.7$ & $<.1$ & E.01502 & $<.08$ & .101 & $<.08$ \\
\hline 294604098060801 & $<2$ & $<.03$ & $<.1$ & $<.06$ & $<.03$ & $<.06$ & $<1$ & $<.02$ & $<.032$ & $<.09$ & $<.7$ & $<.1$ & $<.038$ & $<.08$ & $<.024$ & $<.08$ \\
\hline 294019098114701 & $<2$ & $<.03$ & $<.1$ & $<.06$ & .120 & $<.06$ & $<1$ & $<.02$ & $<.032$ & $<.09$ & $<.7$ & E.099 & $<.038$ & $<.08$ & E.021 & $<.08$ \\
\hline 292215098580201 & $<2$ & $<.03$ & $<.1$ & $<.06$ & $<.03$ & $<.06$ & $<1$ & $<.02$ & $<.032$ & $<.09$ & $<.7$ & .101 & $<.038$ & $<.08$ & E.014 & $<.08$ \\
\hline 292119098524901 & $<2$ & $<.03$ & $<.1$ & $<.06$ & $<.03$ & $<.06$ & $<1$ & $<.02$ & $<.032$ & $<.09$ & $<.7$ & $<.1$ & $<.038$ & $<.08$ & E.011 & $<.08$ \\
\hline 291943099163301 & $<2$ & $<.03$ & $<.1$ & $<.06$ & $<.03$ & $<.06$ & $<1$ & $<.02$ & $<.032$ & $<.09$ & $<.7$ & $<.1$ & $<.038$ & $<.08$ & E.011 & $<.08$ \\
\hline 291840099382601 & $<2$ & $<.03$ & $<.1$ & $<.06$ & $<.03$ & $<.06$ & $<1$ & $<.02$ & $<.032$ & $<.09$ & $<.7$ & $<.1$ & $<.038$ & $<.08$ & E.015 & $<.08$ \\
\hline 293518098332601 & $<2$ & $<.03$ & $<.1$ & $<.06$ & E.059 & $<.06$ & $<1$ & $<.02$ & $<.032$ & $<.09$ & $<.7$ & $<.1$ & $<.038$ & $<.08$ & .100 & $<.08$ \\
\hline 293023098355401 & $<2$ & $<.03$ & $<.1$ & $<.06$ & .223 & $<.06$ & $<1$ & $<.02$ & $<.032$ & $<.09$ & $<.7$ & $<.1$ & $<.038$ & $<.08$ & E.016 & $<.08$ \\
\hline 293042098305201 & $<2$ & $<.03$ & $<.1$ & $<.06$ & .197 & $<.06$ & $<1$ & $<.02$ & $<.032$ & $<.09$ & $<.7$ & $<.1$ & $<.038$ & $<.08$ & E.044 & $<.08$ \\
\hline 292442098474501 & $<2$ & $<.03$ & $<.1$ & $<.06$ & $<.03$ & $<.06$ & $<1$ & $<.02$ & $<.032$ & $<.09$ & $<.7$ & .345 & $<.038$ & $<.08$ & E.056 & $<.08$ \\
\hline 292405098371201 & $<2$ & $<.03$ & $<.1$ & $<.06$ & $<.03$ & $<.06$ & $<1$ & $<.02$ & $<.032$ & $<.09$ & $<.7$ & $<.1$ & $<.038$ & $<.08$ & $<.024$ & $<.08$ \\
\hline 292931098274601 & $<2$ & $<.03$ & $<.1$ & $<.06$ & $<.03$ & $<.06$ & $<1$ & $<.02$ & $<.032$ & $<.09$ & $<.7$ & .172 & $<.038$ & $<.08$ & E.020 & $<.08$ \\
\hline 291219099095601 & $<2$ & $<.03$ & $<.1$ & $<.06$ & $<.03$ & $<.06$ & $<1$ & $<.02$ & $<.032$ & $<.09$ & $<.7$ & $<.1$ & $<.038$ & $<.08$ & $<.024$ & $<.08$ \\
\hline 293729098173101 & $<2$ & $<.03$ & $<.1$ & $<.06$ & E.016 & $<.06$ & $<1$ & $<.02$ & $<.032$ & $<.09$ & $<.7$ & $<.1$ & $<.038$ & $<.08$ & E.019 & $<.08$ \\
\hline \multicolumn{17}{|c|}{ Monitoring wells } \\
\hline 292943098354401 & -- & $<.04$ & $<.1$ & $<.06$ & .372 & $<.08$ & $<1.4$ & $<.02$ & $<.02$ & $<.1$ & $<.6$ & $<.08$ & $<.02$ & $<.08$ & .218 & $<.08$ \\
\hline 292943098354402 & -- & $<.04$ & $<.1$ & $<.06$ & .365 & $<.08$ & $<1.4$ & $<.02$ & $<.02$ & $<.1$ & $<.6$ & $<.08$ & $<.02$ & $<.08$ & .131 & $<.08$ \\
\hline 292943098354403 & -- & $<.04$ & $<.1$ & $<.06$ & .479 & $<.08$ & $<1.4$ & $<.02$ & $<.02$ & $<.1$ & $<.6$ & $<.08$ & $<.02$ & $<.08$ & E.037 & $<.08$ \\
\hline 292943098354404 & -- & $<.04$ & $<.1$ & $<.06$ & .174 & $<.08$ & $<1.4$ & $<.02$ & $<.02$ & $<.1$ & $<.6$ & $<.08$ & $<.02$ & $<.08$ & E.015 & $<.08$ \\
\hline
\end{tabular}


Table 14. Volatile organic and fuel oxygenate compounds for groundwater samples collected for the study of the transport of anthropogenic and natural contaminants (TANC) to public supply wells in the San Antonio segment of the Edwards aquifer near San Antonio, south-central Texas, 2004-9.-Continued

[By sample category. USGS, U.S. Geological Survey; MW, monitoring well; OVB, overburden; $\mu \mathrm{g} / \mathrm{L}$, micrograms per liter; --, not measured or not applicable; E, estimated; <, nondetection less than laboratory method reporting level]

\begin{tabular}{|c|c|c|c|c|c|c|c|c|c|c|c|c|c|c|c|c|}
\hline $\begin{array}{c}\text { USGS } \\
\text { identification } \\
\text { number }\end{array}$ & $\begin{array}{c}\text { tert- } \\
\text { Butyl } \\
\text { alcohol } \\
(\mu \mathrm{g} / \mathrm{L})\end{array}$ & $\begin{array}{l}\text { tert- } \\
\text { Butyl } \\
\text { ethyl } \\
\text { ether } \\
\text { ( } \mu \mathrm{g} / \mathrm{L} \text { ) }\end{array}$ & $\begin{array}{c}\text { Methyl } \\
\text { tert-butyl } \\
\text { ether } \\
\text { (MTBE) } \\
\text { ( } \mu \mathrm{g} / \mathrm{L})\end{array}$ & $\begin{array}{c}\text { tert- } \\
\text { Butyl- } \\
\text { benzene } \\
\text { ( } \mu \mathrm{g} / \mathrm{L})\end{array}$ & $\begin{array}{c}\text { Tetra- } \\
\text { chloro- } \\
\text { ethene } \\
\text { (PCE) } \\
\text { ( } \mu \mathrm{g} / \mathrm{L})\end{array}$ & $\begin{array}{l}\text { Tetra- } \\
\text { chloro- } \\
\text { methane } \\
(\mu \mathrm{g} / \mathrm{L})\end{array}$ & $\begin{array}{l}\text { Tetra- } \\
\text { hydro- } \\
\text { furan } \\
\text { ( } \mu \mathrm{g} / \mathrm{L} \text { ) }\end{array}$ & $\begin{array}{c}\text { Toluene } \\
\text { ( } \mu \mathrm{g} / \mathrm{L} \text { ) }\end{array}$ & $\begin{array}{c}\text { trans- } \\
\text { 1,2-Di- } \\
\text { chloro- } \\
\text { ethene } \\
\text { ( } \mu \mathrm{g} / \mathrm{L} \text { ) }\end{array}$ & $\begin{array}{c}\text { trans- } \\
\text { 1,3-Di- } \\
\text { chloro- } \\
\text { propene } \\
\text { ( } \mu \mathrm{g} / \mathrm{L} \text { ) }\end{array}$ & $\begin{array}{c}\text { trans- } \\
\text { 1,4-Di- } \\
\text { chloro- } \\
\text { 2-butene } \\
\text { ( } \mathrm{gg} / \mathrm{L})\end{array}$ & $\begin{array}{c}\text { Tri- } \\
\text { bromo- } \\
\text { meth- } \\
\text { ane } \\
\text { (bromo- } \\
\text { form) } \\
\text { ( } \mu \mathrm{g} / \mathrm{L} \text { ) }\end{array}$ & $\begin{array}{c}\text { Tri- } \\
\text { chloro- } \\
\text { ethene } \\
\text { (TCE) } \\
\text { ( } \mathrm{\mu g} / \mathrm{L})\end{array}$ & $\begin{array}{c}\text { Tri- } \\
\text { chloro- } \\
\text { fluoro- } \\
\text { methane } \\
\text { (CFC-11) } \\
\text { ( } \mu \mathrm{g} / \mathrm{L})\end{array}$ & 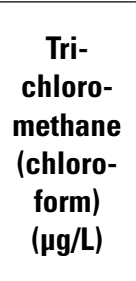 & $\begin{array}{c}\text { Vinyl } \\
\text { chlo- } \\
\text { ride } \\
(\mu \mathrm{g} / \mathrm{L})\end{array}$ \\
\hline 292851098374401 & -- & $<0.04$ & $<0.1$ & $<0.06$ & E0.060 & $<0.08$ & $<1.4$ & $<0.02$ & $<0.02$ & $<0.1$ & $<0.6$ & $<0.08$ & $<0.02$ & $<0.08$ & $<0.02$ & $<0.08$ \\
\hline 292851098374402 & -- & $<.04$ & $<.1$ & $<.06$ & .164 & $<.08$ & $<1.4$ & $<.02$ & $<.02$ & $<.1$ & $<.6$ & $<.08$ & E.066 & E.032 & E.028 & $<.08$ \\
\hline \multicolumn{17}{|c|}{ Well-field depth-dependent sampling (W4) } \\
\hline 292916098360701 & -- & $<.04$ & $<.1$ & $<.06$ & E.055 & $<.08$ & $<1.4$ & $<.02$ & $<.02$ & $<.1$ & $<.6$ & $<.08$ & $<.02$ & $<.08$ & E.028 & $<.08$ \\
\hline 292916098360701 & -- & $<.04$ & $<.1$ & $<.06$ & E.055 & $<.08$ & $<1.4$ & $<.02$ & $<.02$ & $<.1$ & $<.6$ & $<.08$ & $<.02$ & $<.08$ & E.021 & $<.08$ \\
\hline 292916098360701 & -- & $<.04$ & $<.1$ & $<.06$ & .127 & $<.08$ & $<1.4$ & $<.02$ & $<.02$ & $<.1$ & $<.6$ & $<.08$ & $<.02$ & $<.08$ & E.034 & $<.08$ \\
\hline 292916098360701 & -- & $<.04$ & $<.1$ & $<.06$ & E.057 & $<.08$ & $<1.4$ & $<.02$ & $<.02$ & $<.1$ & $<.6$ & $<.08$ & $<.02$ & $<.08$ & E.024 & $<.08$ \\
\hline 292916098360701 & -- & $<.04$ & $<.1$ & $<.06$ & E.078 & $<.08$ & $<1.4$ & $<.02$ & $<.02$ & $<.1$ & $<.6$ & $<.08$ & $<.02$ & $<.08$ & E.028 & $<.08$ \\
\hline 292916098360701 & -- & $<.04$ & $<.1$ & $<.06$ & .102 & $<.08$ & $<1.4$ & $<.02$ & $<.02$ & $<.1$ & $<.6$ & $<.08$ & $<.02$ & $<.08$ & E.033 & $<.08$ \\
\hline 292916098360701 & -- & $<.04$ & $<.1$ & $<.06$ & .137 & $<.08$ & $<1.4$ & $<.02$ & $<.02$ & $<.1$ & $<.6$ & $<.08$ & $<.02$ & $<.08$ & E.030 & $<.08$ \\
\hline 292916098360701 & -- & $<.04$ & $<.1$ & $<.06$ & E.086 & $<.08$ & $<1.4$ & $<.02$ & $<.02$ & $<.1$ & $<.6$ & $<.08$ & $<.02$ & $<.08$ & E.031 & $<.08$ \\
\hline 292916098360701 & -- & $<.04$ & $<.1$ & $<.06$ & E.049 & $<.08$ & $<1.4$ & $<.02$ & $<.02$ & $<.1$ & $<.6$ & $<.08$ & $<.02$ & $<.08$ & E.026 & $<.08$ \\
\hline \multicolumn{17}{|c|}{ Well-field wells (wellhead sampling) } \\
\hline 292919098360501 & -- & $<.04$ & $<.1$ & $<.06$ & .176 & $<.08$ & $<1.4$ & $<.02$ & $<.02$ & $<.1$ & $<.6$ & .327 & $<.02$ & $<.08$ & E.038 & $<.08$ \\
\hline 292925098360201 & -- & $<.04$ & $<.1$ & $<.06$ & .115 & $<.08$ & $<1.4$ & $<.02$ & $<.02$ & $<.1$ & $<.6$ & 2.01 & $<.02$ & $<.08$ & E.029 & $<.08$ \\
\hline 292916098360701 & -- & $<.04$ & $<.1$ & $<.06$ & .126 & $<.08$ & $<1.4$ & $<.02$ & $<.02$ & $<.1$ & $<.6$ & $<.08$ & $<.02$ & $<.08$ & E.029 & $<.08$ \\
\hline 292920098360601 & -- & $<.04$ & $<.1$ & $<.06$ & .223 & $<.08$ & $<1.4$ & $<.02$ & $<.02$ & $<.1$ & $<.6$ & .756 & $<.02$ & $<.08$ & E.032 & $<.08$ \\
\hline 292923098360301 & -- & $<.04$ & $<.1$ & $<.06$ & .210 & $<.08$ & $<1.4$ & $<.02$ & $<.02$ & $<.1$ & $<.6$ & 1.15 & $<.02$ & $<.08$ & E.037 & $<.08$ \\
\hline \multicolumn{17}{|c|}{ Temporal sampling } \\
\hline 292923098360301 & -- & $<.04$ & $<.1$ & $<.06$ & .208 & $<.06$ & $<1.4$ & $<.018$ & $<.018$ & $<.1$ & $<.4$ & .260 & $<.02$ & $<.08$ & E.040 & $<.08$ \\
\hline 292923098360301 & -- & $<.032$ & $<.1$ & $<.06$ & .292 & $<.052$ & $<1.4$ & $<.018$ & $<.018$ & $<.14$ & $<.36$ & .561 & $<.022$ & $<.08$ & E.031 & $<.06$ \\
\hline
\end{tabular}




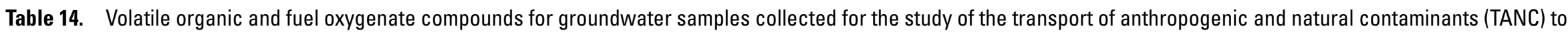
public supply wells in the San Antonio segment of the Edwards aquifer near San Antonio, south-central Texas, 2004-9.-Continued

[By sample category. USGS, U.S. Geological Survey; MW, monitoring well; OVB, overburden; $\mu \mathrm{g} / \mathrm{L}$, micrograms per liter; --, not measured or not applicable; E, estimated; <, nondetection less than laboratory method reporting level]

\begin{tabular}{|c|c|c|c|c|c|c|c|c|c|c|c|c|c|c|c|c|}
\hline $\begin{array}{c}\text { USGS } \\
\text { identification } \\
\text { number }\end{array}$ & $\begin{array}{c}\text { tert- } \\
\text { Butyl } \\
\text { alcohol } \\
(\mu \mathrm{g} / \mathrm{L})\end{array}$ & $\begin{array}{l}\text { tert- } \\
\text { Butyl } \\
\text { ethyl } \\
\text { ether } \\
\text { ( } \mu \mathrm{g} / \mathrm{L})\end{array}$ & $\begin{array}{c}\text { Methyl } \\
\text { tert-butyl } \\
\text { ether } \\
\text { (MTBE) } \\
\text { ( } \mathrm{gg} / \mathrm{L})\end{array}$ & $\begin{array}{c}\text { tert- } \\
\text { Butyl- } \\
\text { benzene } \\
(\mu \mathrm{g} / \mathrm{L})\end{array}$ & $\begin{array}{c}\text { Tetra- } \\
\text { chloro- } \\
\text { ethene } \\
\text { (PCE) } \\
\text { ( } \mu \mathrm{g} / \mathrm{L})\end{array}$ & $\begin{array}{l}\text { Tetra- } \\
\text { chloro- } \\
\text { methane } \\
(\mu \mathrm{g} / \mathrm{L})\end{array}$ & $\begin{array}{l}\text { Tetra- } \\
\text { hydro- } \\
\text { furan } \\
\text { ( } \mu \mathrm{g} / \mathrm{L} \text { ) }\end{array}$ & $\begin{array}{c}\text { Toluene } \\
\text { ( } \mu \mathrm{g} / \mathrm{L})\end{array}$ & $\begin{array}{l}\text { trans- } \\
\text { 1,2-Di- } \\
\text { chloro- } \\
\text { ethene } \\
\text { ( } \mu \mathrm{g} / \mathrm{L} \text { ) }\end{array}$ & $\begin{array}{c}\text { trans- } \\
\text { 1,3-Di- } \\
\text { chloro- } \\
\text { propene } \\
\text { ( } \mu \mathrm{g} / \mathrm{L} \text { ) }\end{array}$ & $\begin{array}{c}\text { trans- } \\
\text { 1,4-Di- } \\
\text { chloro- } \\
\text { 2-butene } \\
\text { ( } \mu \mathrm{g} / \mathrm{L})\end{array}$ & $\begin{array}{c}\text { Tri- } \\
\text { bromo- } \\
\text { meth- } \\
\text { ane } \\
\text { (bromo- } \\
\text { form) } \\
(\mu \mathrm{g} / \mathrm{L})\end{array}$ & $\begin{array}{c}\text { Tri- } \\
\text { chloro- } \\
\text { ethene } \\
(\mathrm{TCE}) \\
(\mu \mathrm{g} / \mathrm{L})\end{array}$ & $\begin{array}{c}\text { Tri- } \\
\text { chloro- } \\
\text { fluoro- } \\
\text { methane } \\
\text { (CFC-11) } \\
\text { ( } \mu \mathrm{g} / \mathrm{L})\end{array}$ & $\begin{array}{c}\text { Tri- } \\
\text { chloro- } \\
\text { methane } \\
\text { (chloro- } \\
\text { form) } \\
\text { ( } \mu \mathrm{g} / \mathrm{L} \text { ) }\end{array}$ & $\begin{array}{l}\text { Vinyl } \\
\text { chlo- } \\
\text { ride } \\
(\mu \mathrm{g} / \mathrm{L})\end{array}$ \\
\hline 292923098360301 & -- & $<0.032$ & $<0.1$ & $<0.06$ & 0.290 & $<0.052$ & $<1.4$ & $<0.018$ & $<0.018$ & $<0.14$ & $<0.36$ & 0.475 & $<0.022$ & $<0.08$ & E0.032 & $<0.06$ \\
\hline 292923098360301 & -- & $<.032$ & $<.1$ & $<.06$ & .408 & $<.052$ & $<1.4$ & $<.018$ & $<.018$ & $<.14$ & $<.36$ & 1.00 & $<.022$ & $<.08$ & E.044 & $<.06$ \\
\hline 292923098360301 & -- & $<.032$ & $<.1$ & $<.06$ & .295 & $<.052$ & $<1.4$ & $<.018$ & $<.018$ & $<.14$ & $<.36$ & .943 & $<.022$ & $<.08$ & E.038 & $<.06$ \\
\hline 292923098360301 & -- & $<.032$ & $<.1$ & $<.06$ & .247 & $<.052$ & $<1.4$ & $<.018$ & $<.018$ & $<.14$ & $<.36$ & .644 & $<.022$ & $<.08$ & E.039 & $<.06$ \\
\hline 292943098354402 & -- & $<.04$ & $<.1$ & $<.06$ & .383 & $<.06$ & $<1.4$ & $<.018$ & $<.018$ & $<.1$ & $<.4$ & $<.1$ & $<.02$ & $<.08$ & $<.04$ & $<.08$ \\
\hline 292943098354402 & -- & $<.032$ & $<.1$ & $<.06$ & .634 & $<.052$ & $<1.4$ & $<.018$ & $<.018$ & $<.14$ & $<.36$ & $<.1$ & $<.022$ & E.011 & E.023 & $<.06$ \\
\hline 292943098354402 & -- & $<.032$ & $<.1$ & $<.06$ & .680 & $<.052$ & $<1.4$ & $<.018$ & $<.018$ & $<.14$ & $<.36$ & $<.1$ & $<.022$ & $<.08$ & E.023 & $<.06$ \\
\hline 292943098354402 & -- & $<.032$ & $<.1$ & $<.06$ & .681 & $<.052$ & $<1.4$ & $<.018$ & $<.018$ & $<.14$ & $<.36$ & $<.1$ & $<.022$ & $<.08$ & E.024 & $<.06$ \\
\hline 292943098354402 & -- & $<.032$ & $<.1$ & $<.06$ & .706 & $<.052$ & $<1.4$ & $<.018$ & $<.018$ & $<.14$ & $<.36$ & $<.1$ & $<.022$ & $<.08$ & E.024 & $<.06$ \\
\hline 292943098354402 & -- & $<.032$ & $<.1$ & $<.06$ & .574 & $<.052$ & $<1.4$ & $<.018$ & $<.018$ & $<.14$ & $<.36$ & $<.1$ & $<.022$ & $<.08$ & E.026 & $<.06$ \\
\hline 292943098354403 & -- & $<.04$ & $<.1$ & $<.06$ & .587 & $<.06$ & $<1.4$ & $<.018$ & $<.018$ & $<.1$ & $<.4$ & $<.1$ & $<.02$ & $<.08$ & $<.04$ & $<.08$ \\
\hline 292943098354403 & -- & $<.032$ & $<.1$ & $<.06$ & .727 & $<.052$ & $<1.4$ & $<.018$ & $<.018$ & $<.14$ & $<.36$ & $<.1$ & $<.022$ & $<.08$ & E.021 & $<.06$ \\
\hline 292943098354403 & -- & $<.032$ & $<.1$ & $<.06$ & .810 & $<.052$ & $<1.4$ & $<.018$ & $<.018$ & $<.14$ & $<.36$ & $<.1$ & $<.022$ & $<.08$ & E.024 & $<.06$ \\
\hline 292943098354403 & -- & $<.032$ & $<.1$ & $<.06$ & .814 & $<.052$ & $<1.4$ & $<.018$ & $<.018$ & $<.14$ & $<.36$ & $<.1$ & $<.022$ & $<.08$ & E.020 & $<.06$ \\
\hline 292943098354403 & -- & $<.032$ & $<.1$ & $<.06$ & .733 & $<.052$ & $<1.4$ & $<.018$ & $<.018$ & $<.14$ & $<.36$ & $<.1$ & $<.022$ & $<.08$ & E.031 & $<.06$ \\
\hline 292943098354403 & -- & $<.032$ & $<.1$ & $<.06$ & .733 & $<.052$ & $<1.4$ & $<.018$ & $<.018$ & $<.14$ & $<.36$ & $<.1$ & $<.022$ & $<.08$ & E.028 & $<.06$ \\
\hline 292943098354404 & -- & $<.04$ & $<.1$ & $<.06$ & .257 & $<.06$ & $<1.4$ & $<.018$ & $<.018$ & $<.1$ & $<.4$ & $<.1$ & $<.02$ & $<.08$ & $<.04$ & $<.08$ \\
\hline 292943098354404 & -- & $<.032$ & $<.1$ & $<.06$ & .277 & $<.052$ & $<1.4$ & $<.018$ & $<.018$ & $<.14$ & $<.36$ & $<.1$ & $<.022$ & $<.08$ & E.018 & $<.06$ \\
\hline 292943098354404 & -- & $<.032$ & $<.1$ & $<.06$ & .306 & $<.052$ & $<1.4$ & $<.018$ & $<.018$ & $<.14$ & $<.36$ & $<.1$ & $<.022$ & $<.08$ & E.020 & $<.06$ \\
\hline 292943098354404 & -- & $<.032$ & $<.1$ & $<.06$ & .288 & $<.052$ & $<1.4$ & $<.018$ & $<.018$ & $<.14$ & $<.36$ & $<.1$ & $<.022$ & $<.08$ & $<.03$ & $<.06$ \\
\hline 292943098354404 & -- & $<.032$ & $<.1$ & $<.06$ & .307 & $<.052$ & $<1.4$ & $<.018$ & $<.018$ & $<.14$ & $<.36$ & $<.1$ & $<.022$ & $<.08$ & E.016 & $<.06$ \\
\hline 292943098354404 & -- & $<.032$ & $<.1$ & $<.06$ & .265 & $<.052$ & $<1.4$ & $<.018$ & $<.018$ & $<.14$ & $<.36$ & $<.1$ & $<.022$ & $<.08$ & E.021 & $<.06$ \\
\hline 293252098380801 & -- & $<.04$ & $<.1$ & $<.06$ & E.037 & $<.06$ & $<1.4$ & $<.018$ & $<.018$ & $<.1$ & $<.4$ & $<.1$ & $<.02$ & $<.08$ & E.066 & $<.08$ \\
\hline 293252098380801 & -- & $<.032$ & $<.1$ & $<.06$ & E.025 & $<.052$ & $<1.4$ & $<.018$ & $<.018$ & $<.14$ & $<.36$ & $<.1$ & $<.022$ & $<.08$ & E.087 & $<.06$ \\
\hline 293252098380801 & -- & $<.032$ & $<.1$ & $<.06$ & E.024 & $<.052$ & $<1.4$ & $<.018$ & $<.018$ & $<.14$ & $<.36$ & $<.1$ & $<.022$ & $<.08$ & .132 & $<.06$ \\
\hline 293252098380801 & -- & $<.032$ & $<.1$ & $<.06$ & $<.026$ & $<.052$ & $<1.4$ & $<.018$ & $<.018$ & $<.14$ & $<.36$ & $<.1$ & $<.022$ & $<.08$ & .104 & $<.06$ \\
\hline 293252098380801 & -- & $<.032$ & $<.1$ & $<.06$ & E.018 & $<.052$ & $<1.4$ & $<.018$ & $<.018$ & $<.14$ & $<.36$ & $<.1$ & $<.022$ & $<.08$ & .129 & $<.06$ \\
\hline 293252098380801 & -- & $<.032$ & $<.1$ & $<.06$ & E.020 & $<.052$ & $<1.4$ & $<.018$ & $<.018$ & $<.14$ & $<.36$ & $<.1$ & $<.022$ & $<.08$ & .192 & $<.06$ \\
\hline
\end{tabular}


Table 15. Soluble pesticide compounds for groundwater samples collected for the study of the transport of anthropogenic and natural contaminants (TANC) to public supply wells in the San Antonio segment of the Edwards aquifer near San Antonio, south-central Texas, 2004-9.

[By sample category. USGS, U.S. Geological Survey; MW, monitoring well; OVB, overburden; $\mu \mathrm{g} / \mathrm{L}$, micrograms per liter; --, not measured; E, estimated; u, unable to determine; <, nondetection less than laboratory method reporting level]

\begin{tabular}{|c|c|c|c|c|c|c|c|c|c|c|c|c|c|}
\hline $\begin{array}{c}\text { USGS } \\
\text { identification } \\
\text { number }\end{array}$ & $\begin{array}{c}\text { State well } \\
\text { number }\end{array}$ & $\begin{array}{l}\text { Group and } \\
\text { description }\end{array}$ & $\begin{array}{c}\text { Sample } \\
\text { date }\end{array}$ & $\begin{array}{c}\text { 1-Naph- } \\
\text { thol } \\
\text { ( } \mathrm{gg} / \mathrm{L})\end{array}$ & $\begin{array}{c}\text { 2,6-Di- } \\
\text { ethyl- } \\
\text { aniline } \\
(\mu \mathrm{g} / \mathrm{L})\end{array}$ & $\begin{array}{l}\text { 2-Chloro- } \\
\text { 4-isopropyl- } \\
\text { amino-6- } \\
\text { amino-s- } \\
\text { triazine } \\
\text { (CIAT) } \\
\text { ( } \mu \mathrm{g} / \mathrm{L})\end{array}$ & $\begin{array}{l}\text { 2-Chloro- } \\
\mathrm{N}-(2,6-\mathrm{di}- \\
\text { ethylphenyl)- } \\
\text { acetamide } \\
\text { (alachlor } \\
\text { 2nd amide) } \\
\text { ( } \mu \mathrm{g} / \mathrm{L})\end{array}$ & $\begin{array}{c}\text { 2-Ethyl- } \\
\text { 6-methyl- } \\
\text { aniline } \\
\text { ( } \mu \mathrm{g} / \mathrm{L})\end{array}$ & $\begin{array}{c}\text { 3,4-Di- } \\
\text { chloro- } \\
\text { aniline } \\
(\mu \mathrm{g} / \mathrm{L})\end{array}$ & $\begin{array}{c}\text { 3,5-Di- } \\
\text { chloro- } \\
\text { aniline } \\
(\mu \mathrm{g} / \mathrm{L})\end{array}$ & $\begin{array}{c}\text { 4-Chloro- } \\
\text { 2-methyl- } \\
\text { phenol } \\
\text { ( } \mu \mathrm{g} / \mathrm{L})\end{array}$ & $\begin{array}{l}\text { Aceto- } \\
\text { chlor } \\
(\mu \mathrm{g} / \mathrm{L})\end{array}$ & $\begin{array}{l}\text { Ala- } \\
\text { chlor } \\
\text { ( } \mu \mathrm{g} / \mathrm{L})\end{array}$ \\
\hline \multicolumn{14}{|c|}{ Regional aquifer public-supply wells } \\
\hline 293359098290301 & AY-68-29-414 & 1st (highest) quartile & $2004 / 12 / 06$ & $<0.088$ & $<0.006$ & E0.011 & $<0.005$ & $<0.005$ & $<0.005$ & -- & $<0.006$ & $<0.006$ & $<0.005$ \\
\hline 293359098290301 & AY-68-29-414 & 1st quartile & 2005/09/01 & $<.088$ & $<.006$ & E.010 & $<.005$ & $<.005$ & $<.005$ & $<0.004$ & $<.006$ & $<.006$ & $<.005$ \\
\hline 293358098231101 & AY-68-29-610 & 1st quartile & $2004 / 12 / 15$ & $<.088$ & $<.006$ & E.012 & $<.005$ & $<.005$ & $<.005$ & -- & $<.006$ & $<.006$ & $<.005$ \\
\hline 293358098231101 & AY-68-29-610 & 1st quartile & $2005 / 08 / 29$ & $<.088$ & $<.006$ & E.013 & $<.005$ & $<.005$ & $<.005$ & $<.004$ & $<.006$ & $<.006$ & $<.005$ \\
\hline 293120098285801 & AY-68-29-714 & 1st quartile & $2004 / 12 / 14$ & $<.088$ & $<.006$ & E.011 & $<.005$ & $<.005$ & $<.005$ & -- & $<.006$ & $<.006$ & $<.005$ \\
\hline 293120098285801 & AY-68-29-714 & 1st quartile & $2005 / 08 / 30$ & -- & -- & E.012 & -- & -- & -- & -- & -- & -- & -- \\
\hline 293145098224201 & AY-68-29-929 & 1st quartile & $2004 / 12 / 15$ & $<.088$ & $<.006$ & $<.01$ & $<.005$ & $<.005$ & $<.005$ & -- & $<.006$ & $<.006$ & $<.005$ \\
\hline 293119098211201 & AY-68-30-718 & 1st quartile & $2004 / 12 / 16$ & $<.088$ & $<.006$ & $<.006$ & $<.005$ & $<.005$ & $<.005$ & -- & $<.006$ & $<.006$ & $<.005$ \\
\hline 292843098425101 & AY-68-35-106 & 1st quartile & $2004 / 12 / 13$ & $<.088$ & $<.006$ & $<.006$ & $<.005$ & $<.005$ & $<.005$ & -- & $<.006$ & $<.006$ & $<.005$ \\
\hline 292459098382101 & AY-68-35-913 & 1st quartile & $2004 / 12 / 13$ & $<.088$ & $<.006$ & $<.006$ & $<.005$ & $<.005$ & $<.005$ & -- & $<.006$ & $<.006$ & $<.005$ \\
\hline 292925098360201 & AY-68-36-104 & 1st quartile & $2004 / 12 / 13$ & $<.088$ & $<.006$ & E.009 & $<.005$ & $<.005$ & $<.005$ & -- & $<.006$ & $<.006$ & $<.005$ \\
\hline 292925098360201 & AY-68-36-104 & 1st quartile & $2005 / 08 / 31$ & $<.088$ & $<.006$ & E.008 & $<.005$ & $<.005$ & $<.005$ & $<.004$ & $<.006$ & $<.006$ & $<.005$ \\
\hline 292822098325401 & AY-68-36-206 & 1st quartile & $2004 / 12 / 13$ & $<.088$ & $<.006$ & E.009 & $<.005$ & $<.005$ & $<.005$ & -- & $<.006$ & $<.006$ & $<.005$ \\
\hline 292822098325401 & AY-68-36-206 & 1st quartile & $2005 / 08 / 31$ & $<.088$ & $<.006$ & E.012 & $<.005$ & $<.005$ & $<.005$ & $<.004$ & $<.006$ & $<.006$ & $<.005$ \\
\hline 292944098292301 & AY-68-37-105 & 1st quartile & $2004 / 12 / 14$ & $<.088$ & $<.006$ & E.010 & $<.005$ & $<.005$ & $<.005$ & -- & $<.006$ & $<.006$ & $<.005$ \\
\hline 292944098292301 & AY-68-37-105 & 1st quartile & $2005 / 08 / 31$ & $<.088$ & $<.006$ & E.011 & $<.005$ & $<.005$ & $<.005$ & $<.004$ & $<.006$ & $<.006$ & $<.005$ \\
\hline 292522098291901 & AY-68-37-426 & 1st quartile & $2004 / 12 / 14$ & $<.088$ & $<.006$ & $<.006$ & $<.005$ & $<.005$ & $<.005$ & -- & $<.006$ & $<.006$ & $<.005$ \\
\hline 292643098241801 & AY-68-37-601 & 1st quartile & $2004 / 12 / 15$ & $<.088$ & $<.006$ & $<.006$ & $<.005$ & $<.005$ & $<.005$ & -- & $<.006$ & $<.006$ & $<.005$ \\
\hline 292643098241801 & AY-68-37-601 & 1st quartile & $2005 / 08 / 30$ & -- & -- & $<.028$ & -- & -- & -- & -- & -- & -- & -- \\
\hline 292328098294601 & AY-68-37-705 & 1st quartile & $2004 / 12 / 14$ & $<.088$ & $<.006$ & $<.006$ & $<.005$ & $<.005$ & $<.005$ & -- & $<.006$ & $<.006$ & $<.005$ \\
\hline 294225098080301 & DX-68-23-601 & 1st quartile & $2004 / 12 / 08$ & $<.088$ & $<.006$ & E.010 & $<.005$ & $<.005$ & $<.005$ & -- & $<.006$ & $<.006$ & $<.005$ \\
\hline 294225098080301 & DX-68-23-601 & 1st quartile & 2005/09/01 & $<.088$ & $<.006$ & E.008 & $<.005$ & $<.005$ & $<.005$ & $<.004$ & $<.006$ & $<.006$ & $<.005$ \\
\hline 291210099475601 & YP-69-50-506 & 1st quartile & $2004 / 11 / 30$ & $<.088$ & $<.006$ & E.006 & $<.005$ & $<.005$ & $<.005$ & -- & $<.006$ & $<.006$ & $<.005$ \\
\hline 293111098340901 & AY-68-28-807 & 2d quartile & $2005 / 05 / 26$ & $<.088$ & $<.006$ & E.007 & $<.005$ & $<.005$ & $<.005$ & -- & $<.006$ & $<.006$ & $<.005$ \\
\hline 293512098291701 & AY-68-29-109 & 2d quartile & $2005 / 04 / 20$ & $<.088$ & $<.006$ & E.010 & $<.005$ & $<.005$ & $<.005$ & -- & $<.006$ & $<.006$ & $<.005$ \\
\hline 292424098421501 & AY-68-35-810 & 2d quartile & $2005 / 04 / 21$ & $<.088$ & $<.006$ & E.008 & $<.005$ & $<.005$ & $<.005$ & -- & $<.006$ & $<.006$ & $<.005$ \\
\hline
\end{tabular}


Table 15. Soluble pesticide compounds for groundwater samples collected for the study of the transport of anthropogenic and natural contaminants (TANC) to public supply wells in the San Antonio segment of the Edwards aquifer near San Antonio, south-central Texas, 2004-9.-Continued

[By sample category. USGS, U.S. Geological Survey; MW, monitoring well; OVB, overburden; $\mu g / L$, micrograms per liter; --, not measured; E, estimated; u, unable to determine; <, nondetection less than laboratory method reporting level]

\begin{tabular}{|c|c|c|c|c|c|c|c|c|c|c|c|c|c|}
\hline $\begin{array}{c}\text { USGS } \\
\text { identification } \\
\text { number }\end{array}$ & $\begin{array}{c}\text { State well } \\
\text { number }\end{array}$ & $\begin{array}{l}\text { Group and } \\
\text { description }\end{array}$ & $\begin{array}{c}\text { Sample } \\
\text { date }\end{array}$ & $\begin{array}{c}\text { 1-Naph- } \\
\text { thol } \\
\text { ( } \mu \mathrm{g} / \mathrm{L})\end{array}$ & $\begin{array}{c}2,6-\mathrm{Di}- \\
\text { ethyl- } \\
\text { aniline } \\
(\mu \mathrm{g} / \mathrm{L})\end{array}$ & $\begin{array}{l}\text { 2-Chloro- } \\
\text { 4-isopropyl- } \\
\text { amino-6- } \\
\text { amino-s- } \\
\text { triazine } \\
\text { (CIAT) } \\
(\mu \mathrm{g} / \mathrm{L})\end{array}$ & $\begin{array}{c}\text { 2-Chloro- } \\
\mathrm{N} \text {-(2,6-di- } \\
\text { ethylphenyl)- } \\
\text { acetamide } \\
\text { (alachlor } \\
\text { 2nd amide) } \\
(\mu \mathrm{g} / \mathrm{L})\end{array}$ & $\begin{array}{l}\text { 2-Ethyl- } \\
\text { 6-methyl- } \\
\text { aniline } \\
\text { ( } \mu \mathrm{g} / \mathrm{L})\end{array}$ & $\begin{array}{l}\text { 3,4-Di- } \\
\text { chloro- } \\
\text { aniline } \\
(\mu \mathrm{g} / \mathrm{L})\end{array}$ & $\begin{array}{c}\text { 3,5-Di- } \\
\text { chloro- } \\
\text { aniline } \\
(\mu \mathrm{g} / \mathrm{L})\end{array}$ & $\begin{array}{l}\text { 4-Chloro- } \\
\text { 2-methyl- } \\
\text { phenol } \\
\text { ( } \mu \mathrm{g} / \mathrm{L})\end{array}$ & $\begin{array}{c}\text { Aceto- } \\
\text { chlor } \\
\text { (pg/L) }\end{array}$ & $\begin{array}{l}\text { Ala- } \\
\text { chlor } \\
\text { ( } \mu \mathrm{g} / \mathrm{L})\end{array}$ \\
\hline 292053098365501 & AY-68-44-110 & 2d quartile & $2005 / 05 / 26$ & $<0.088$ & $<0.006$ & E0.004 & $<0.005$ & $<0.005$ & $<0.005$ & -- & $<0.006$ & $<0.006$ & $<0.005$ \\
\hline 293807098155301 & DX-68-22-901 & 2d quartile & $2005 / 05 / 18$ & $<.088$ & $<.006$ & E.005 & $<.005$ & $<.005$ & $<.005$ & -- & $<.006$ & $<.006$ & $<.005$ \\
\hline 292604098563201 & TD-68-33-501 & 2d quartile & $2005 / 05 / 16$ & $<.088$ & $<.006$ & $<.006$ & $<.005$ & $<.005$ & $<.005$ & -- & $<.006$ & $<.006$ & $<.005$ \\
\hline 292116099095501 & TD-69-47-305 & 2d quartile & $2005 / 04 / 27$ & $<.088$ & $<.006$ & E.006 & $<.005$ & $<.005$ & $<.005$ & -- & $<.006$ & $<.006$ & $<.005$ \\
\hline 291232099470301 & YP-69-50-339 & 2d quartile & $2005 / 05 / 11$ & $<.088$ & $<.006$ & E.005 & $<.005$ & $<.005$ & -- & $\begin{array}{l}-- \\
--\end{array}$ & $<.006$ & $<.006$ & $<.005$ \\
\hline 293128098473101 & AY-68-26-814 & 3d quartile & $2005 / 04 / 18$ & $<.088$ & $<.006$ & $<.006$ & $<.005$ & $<.005$ & $<.005$ & -- & $<.006$ & $<.006$ & $<.005$ \\
\hline 293451098313201 & AY-68-28-601 & 3d quartile & $2005 / 05 / 17$ & $<.088$ & $<.006$ & E.015 & $<.005$ & $<.005$ & E.003 & -- & $<.006$ & $<.006$ & $<.005$ \\
\hline 294604098060801 & DX-68-16-708 & 3d quartile & $2005 / 04 / 25$ & $<.088$ & $<.006$ & $<.006$ & $<.005$ & $<.005$ & $<.005$ & -- & $<.006$ & $<.006$ & $<.005$ \\
\hline 294019098114701 & DX-68-23-504 & 3d quartile & $2005 / 05 / 18$ & $<.088$ & $<.006$ & E.007 & $<.005$ & $<.005$ & $<.005$ & -- & $<.006$ & $<.006$ & $<.005$ \\
\hline 292215098580201 & TD-68-41-103 & 3d quartile & $2005 / 05 / 09$ & $<.088$ & $<.006$ & E.006 & $<.005$ & $<.005$ & -- & -- & $<.006$ & $<.006$ & $<.005$ \\
\hline 292119098524901 & TD-68-41-308 & 3d quartile & $2005 / 04 / 27$ & $<.088$ & $<.006$ & E.005 & $<.005$ & $<.005$ & $<.005$ & -- & $<.006$ & $<.006$ & $<.005$ \\
\hline 291943099163301 & TD-69-46-601 & 3d quartile & $2005 / 05 / 09$ & $<.088$ & $<.006$ & $<.006$ & $<.005$ & $<.005$ & -- & -- & $<.006$ & $<.006$ & $<.005$ \\
\hline 291840099382601 & YP-69-43-606 & 3d quartile & 2005/05/11 & $<.088$ & $<.006$ & E.006 & $<.005$ & $<.005$ & -- & -- & $<.006$ & $<.006$ & $<.005$ \\
\hline 293518098332601 & AY-68-28-203 & 4th quartile & 2005/04/19 & $<.088$ & $<.006$ & E.005 & $<.005$ & $<.005$ & $<.005$ & -- & $<.006$ & $<.006$ & $<.005$ \\
\hline 293023098355401 & AY-68-28-702 & 4th quartile & $2005 / 04 / 26$ & $<.088$ & $<.006$ & E.011 & $<.005$ & $<.005$ & $<.005$ & -- & $<.006$ & $<.006$ & $<.005$ \\
\hline 293042098305201 & AY-68-28-913 & 4th quartile & $2005 / 06 / 30$ & $<.088$ & $<.006$ & E.010 & $<.005$ & $<.005$ & $<.005$ & $<.004$ & $<.006$ & $<.006$ & $<.005$ \\
\hline 292442098474501 & AY-68-34-803 & 4th quartile & $2005 / 04 / 20$ & $<.088$ & $<.006$ & E.013 & $<.005$ & $<.005$ & $<.005$ & -- & $<.006$ & $<.006$ & $<.005$ \\
\hline 292405098371201 & AY-68-36-704 & 4th quartile & $2005 / 05 / 23$ & $<.088$ & $<.006$ & E.006 & $<.005$ & $<.005$ & $<.005$ & -- & $<.006$ & $<.006$ & $<.005$ \\
\hline 292931098274601 & AY-68-37-124 & 4th quartile & $2005 / 05 / 25$ & $<.088$ & $<.006$ & E.009 & $<.005$ & $<.005$ & $<.005$ & -- & $<.006$ & $<.006$ & $<.005$ \\
\hline 293729098173101 & DX-68-30-215 & 4th quartile & $2005 / 04 / 25$ & $<.088$ & $<.006$ & E.006 & $<.005$ & $<.005$ & $<.005$ & -- & $<.006$ & $<.006$ & $<.005$ \\
\hline 291219099095601 & TD-69-55-604 & 4th quartile & $2005 / 05 / 16$ & $<.088$ & $<.006$ & E.006 & $<.005$ & $<.005$ & $<.005$ & -- & $<.006$ & $<.006$ & $<.005$ \\
\hline \multicolumn{14}{|c|}{ Monitoring wells } \\
\hline 292943098354401 & AY-68-36-135 & MW OVB & 2007/10/30 & $<.04$ & $<.006$ & E.010 & $<.01$ & $<.010$ & $<.006$ & $<.008$ & $<.005$ & $<.006$ & $<.006$ \\
\hline 292943098354402 & AY-68-36-133 & TANC MW & 2007/10/31 & $<.04$ & $<.006$ & E.011 & $<.01$ & $<.010$ & $<.006$ & $<.008$ & $<.005$ & $<.0100$ & $<.006$ \\
\hline 292943098354403 & AY-68-36-134 & TANC MW & 2007/10/30 & $<.04$ & $<.006$ & E.013 & $<.01$ & $<.010$ & $<.006$ & $<.008$ & $<.005$ & $<.006$ & $<.006$ \\
\hline 292943098354404 & AY-68-36-132 & TANC MW & 2007/11/01 & $<.04$ & $<.006$ & E.012 & $<.01$ & $<.010$ & $<.006$ & $<.008$ & $<.005$ & $<.006$ & $<.006$ \\
\hline
\end{tabular}


Table 15. Soluble pesticide compounds for groundwater samples collected for the study of the transport of anthropogenic and natural contaminants (TANC) to public supply wells in the San Antonio segment of the Edwards aquifer near San Antonio, south-central Texas, 2004-9.-Continued

[By sample category. USGS, U.S. Geological Survey; MW, monitoring well; OVB, overburden; $\mu \mathrm{g} / \mathrm{L}$, micrograms per liter; --, not measured; E, estimated; u, unable to determine; <, nondetection less than laboratory method reporting level]

\begin{tabular}{|c|c|c|c|c|c|c|c|c|c|c|c|c|c|}
\hline $\begin{array}{c}\text { USGS } \\
\text { identification } \\
\text { number }\end{array}$ & $\begin{array}{l}\text { State well } \\
\text { number }\end{array}$ & $\begin{array}{l}\text { Group and } \\
\text { description }\end{array}$ & $\begin{array}{l}\text { Sample } \\
\text { date }\end{array}$ & $\begin{array}{c}\text { 1-Naph- } \\
\text { thol } \\
(\mu \mathrm{g} / \mathrm{L})\end{array}$ & $\begin{array}{c}2,6-\mathrm{Di}- \\
\text { ethyl- } \\
\text { aniline } \\
(\mu \mathrm{g} / \mathrm{L})\end{array}$ & $\begin{array}{c}\text { 2-Chloro- } \\
\text { 4-isopropyl- } \\
\text { amino-6- } \\
\text { amino-s- } \\
\text { triazine } \\
\text { (CIAT) } \\
\text { ( } \mu \mathrm{g} / \mathrm{L})\end{array}$ & $\begin{array}{c}\text { 2-Chloro- } \\
\text { N-(2,6-di- } \\
\text { ethylphenyl)- } \\
\text { acetamide } \\
\text { (alachlor } \\
\text { 2nd amide) } \\
\text { ( } \mu \mathrm{g} / \mathrm{L})\end{array}$ & $\begin{array}{l}\text { 2-Ethyl- } \\
\text { 6-methyl- } \\
\text { aniline } \\
\text { ( } \mu \mathrm{g} / \mathrm{L})\end{array}$ & $\begin{array}{c}\text { 3,4-Di- } \\
\text { chloro- } \\
\text { aniline } \\
(\mu \mathrm{g} / \mathrm{L})\end{array}$ & $\begin{array}{c}\text { 3,5-Di- } \\
\text { chloro- } \\
\text { aniline } \\
(\mu \mathrm{g} / \mathrm{L})\end{array}$ & $\begin{array}{c}\text { 4-Chloro- } \\
\text { 2-methyl- } \\
\text { phenol } \\
\text { ( } \mu \mathrm{g} / \mathrm{L})\end{array}$ & $\begin{array}{c}\text { Aceto- } \\
\text { chlor } \\
\text { ( } \mu \mathrm{g} / \mathrm{L})\end{array}$ & $\begin{array}{l}\text { Ala- } \\
\text { chlor } \\
\text { ( } \mu \mathrm{g} / \mathrm{L})\end{array}$ \\
\hline 292851098374401 & AY-68-35-315 & TANC MW & $2008 / 05 / 06$ & $<0.04$ & $<0.006$ & E0.013 & $<0.01$ & $<0.010$ & $<0.006$ & $<0.008$ & $<0.005$ & $<0.006$ & $<0.006$ \\
\hline 292851098374402 & AY-68-35-314 & TANC MW & $2008 / 05 / 07$ & $<.04$ & $<.006$ & E.021 & $<.01$ & $<.010$ & $<.006$ & $<.008$ & $<.005$ & $<.006$ & $<.006$ \\
\hline \multicolumn{14}{|c|}{ Well-field depth-dependent sampling (W4) } \\
\hline 292916098360701 & AY-68-36-105 & $\begin{array}{l}\text { W4-shallow (380), } \\
\text { normal }\end{array}$ & $2007 / 11 / 16$ & $<.04$ & $<.006$ & E.011 & $<.01$ & $<.010$ & $<.006$ & $<.008$ & $<.005$ & $<.006$ & $<.006$ \\
\hline 292916098360701 & AY-68-36-105 & $\begin{array}{l}\text { W4-intermediate (430), } \\
\text { normal }\end{array}$ & 2007/11/15 & $<.04$ & $<.006$ & E.011 & $<.01$ & $<.010$ & $<.006$ & $<.008$ & $<.005$ & $<.006$ & $<.006$ \\
\hline 292916098360701 & AY-68-36-105 & W4-deep (540), normal & $2007 / 11 / 15$ & $<.04$ & $<.006$ & E.013 & $<.01$ & $<.010$ & $<.006$ & $<.008$ & $<.005$ & $<.006$ & $<.006$ \\
\hline 292916098360701 & AY-68-36-105 & $\begin{array}{l}\text { W4-shallow (380), ambi- } \\
\text { ent }\end{array}$ & $2007 / 11 / 16$ & $<.04$ & $<.006$ & E.011 & $<.01$ & $<.010$ & $<.006$ & $<.008$ & $<.005$ & $<.006$ & $<.006$ \\
\hline 292916098360701 & AY-68-36-105 & $\begin{array}{l}\text { W4-intermediate (430), } \\
\text { ambient }\end{array}$ & $2007 / 11 / 14$ & $<.04$ & $<.006$ & E.012 & $<.01$ & $<.010$ & $<.006$ & $<.008$ & $<.005$ & $<.006$ & $<.006$ \\
\hline 292916098360701 & AY-68-36-105 & W4-deep (540), ambient & 2007/11/15 & $<.04$ & $<.006$ & E.013 & $<.01$ & $<.010$ & $<.006$ & $<.008$ & $<.005$ & $<.006$ & $<.006$ \\
\hline 292916098360701 & AY-68-36-105 & $\begin{array}{l}\text { W4-shallow (380), } \\
\text { moderate }\end{array}$ & $2007 / 11 / 16$ & $<.04$ & $<.006$ & E.014 & $<.01$ & $<.010$ & $<.006$ & $<.008$ & $<.005$ & $<.006$ & $<.006$ \\
\hline 292916098360701 & AY-68-36-105 & $\begin{array}{l}\text { W4-intermediate (430), } \\
\text { moderate }\end{array}$ & $2007 / 11 / 14$ & $<.04$ & $<.006$ & E.013 & $<.01$ & $<.010$ & $<.006$ & $<.008$ & $<.005$ & $<.006$ & $<.006$ \\
\hline 292916098360701 & AY-68-36-105 & W4-deep (540), moderate & $2007 / 11 / 15$ & $<.04$ & $<.006$ & E.011 & $<.01$ & $<.010$ & $<.006$ & $<.008$ & $<.005$ & $<.006$ & $<.006$ \\
\hline \multicolumn{14}{|c|}{ Well-field wells (wellhead sampling) } \\
\hline 292919098360501 & AY-68-36-103 & wellhead & $2007 / 11 / 29$ & $<.04$ & $<.006$ & E.015 & $<.01$ & $<.010$ & $<.006$ & $<.008$ & $<.005$ & $<.006$ & $<.006$ \\
\hline 292925098360201 & AY-68-36-104 & wellhead & $2007 / 11 / 28$ & $<.04$ & $<.006$ & E.010 & $<.01$ & $<.010$ & $<.006$ & $<.008$ & $<.005$ & $<.006$ & $<.006$ \\
\hline 292916098360701 & AY-68-36-105 & *wellhead & $2007 / 11 / 16$ & $<.04$ & $<.006$ & E.015 & $<.01$ & $<.010$ & $<.006$ & $<.008$ & $<.005$ & $<.006$ & $<.006$ \\
\hline 292920098360601 & AY-68-36-130 & wellhead & $2007 / 11 / 29$ & $<.04$ & $<.006$ & E.015 & $<.01$ & $<.010$ & $<.006$ & $<.008$ & $<.005$ & $<.006$ & $<.006$ \\
\hline 292923098360301 & AY-68-36-131 & wellhead & $2007 / 11 / 28$ & $<.04$ & $<.006$ & E.012 & $<.01$ & $<.010$ & $<.006$ & $<.008$ & $<.005$ & $<.006$ & $<.006$ \\
\hline \multicolumn{14}{|c|}{ Temporal sampling } \\
\hline 292923098360301 & AY-68-36-131 & TANC PSW pre-storm & $2009 / 04 / 09$ & -- & -- & -- & -- & -- & -- & -- & -- & -- & -- \\
\hline 292923098360301 & AY-68-36-131 & TANC PSW storm 1 & 2009/10/06 & -- & -- & -- & -- & -- & -- & -- & -- & -- & -- \\
\hline 292923098360301 & AY-68-36-131 & TANC PSW storm 2 & 2009/10/09 & -- & -- & -- & -- & -- & -- & -- & -- & -- & -- \\
\hline
\end{tabular}


Table 15. Soluble pesticide compounds for groundwater samples collected for the study of the transport of anthropogenic and natural contaminants (TANC) to public supply wells in the San Antonio segment of the Edwards aquifer near San Antonio, south-central Texas, 2004-9. - Continued

[By sample category. USGS, U.S. Geological Survey; MW, monitoring well; OVB, overburden; $\mu g / L$, micrograms per liter; --, not measured; E, estimated; u, unable to determine; <, nondetection less than laboratory method reporting level]

\begin{tabular}{|c|c|c|c|c|c|c|c|c|c|c|c|c|c|}
\hline $\begin{array}{c}\text { USGS } \\
\text { identification } \\
\text { number }\end{array}$ & $\begin{array}{l}\text { State well } \\
\text { number }\end{array}$ & $\begin{array}{l}\text { Group and } \\
\text { description }\end{array}$ & $\begin{array}{c}\text { Sample } \\
\text { date }\end{array}$ & $\begin{array}{c}\text { 1-Naph- } \\
\text { thol } \\
\text { ( } \mu \mathrm{g} / \mathrm{L})\end{array}$ & $\begin{array}{c}2,6-\mathrm{Di}- \\
\text { ethyl- } \\
\text { aniline } \\
(\mu \mathrm{g} / \mathrm{L})\end{array}$ & $\begin{array}{l}\text { 2-Chloro- } \\
\text { 4-isopropyl- } \\
\text { amino-6- } \\
\text { amino-s- } \\
\text { triazine } \\
\text { (CIAT) } \\
\text { ( } \mu \mathrm{g} / \mathrm{L})\end{array}$ & $\begin{array}{c}\text { 2-Chloro- } \\
\mathrm{N} \text {-(2,6-di- } \\
\text { ethylphenyl)- } \\
\text { acetamide } \\
\text { (alachlor } \\
\text { 2nd amide) } \\
\text { ( } \mu \mathrm{g} / \mathrm{L})\end{array}$ & $\begin{array}{l}\text { 2-Ethyl- } \\
\text { 6-methyl- } \\
\text { aniline } \\
(\mu \mathrm{g} / \mathrm{L})\end{array}$ & $\begin{array}{c}\text { 3,4-Di- } \\
\text { chloro- } \\
\text { aniline } \\
(\mu \mathrm{g} / \mathrm{L})\end{array}$ & $\begin{array}{c}\text { 3,5-Di- } \\
\text { chloro- } \\
\text { aniline } \\
(\mu \mathrm{g} / \mathrm{L})\end{array}$ & $\begin{array}{l}\text { 4-Chloro- } \\
\text { 2-methyl- } \\
\text { phenol } \\
(\mu \mathrm{g} / \mathrm{L})\end{array}$ & $\begin{array}{c}\text { Aceto- } \\
\text { chlor } \\
\text { ( } \mu \mathrm{g} / \mathrm{L})\end{array}$ & $\begin{array}{l}\text { Ala- } \\
\text { chlor } \\
\text { ( } \mu \mathrm{g} / \mathrm{L})\end{array}$ \\
\hline 292923098360301 & AY-68-36-131 & TANC PSW storm 3 & 2009/10/19 & $<0.036$ & $<0.006$ & E0.015 & $<0.010$ & $<0.010$ & $<0.004$ & $<0.003$ & $<0.003$ & $<0.010$ & $<0.008$ \\
\hline 292923098360301 & AY-68-36-131 & TANC PSW storm 4 & 2009/10/30 & $<.036$ & $<.006$ & E.016 & $<.010$ & $<.010$ & $<.004$ & $<.003$ & $<.003$ & $<.010$ & $<.008$ \\
\hline 292923098360301 & AY-68-36-131 & TANC PSW storm 5 & 2009/11/19 & $<.036$ & $<.006$ & E.015 & $<.010$ & $<.010$ & $<.004$ & $<.003$ & $<.003$ & $<.010$ & $<.008$ \\
\hline 292943098354402 & AY-68-36-133 & TANC MW pre-storm & 2009/04/08 & -- & -- & -- & -- & -- & -- & -- & -- & -- & -- \\
\hline 292943098354402 & AY-68-36-133 & TANC MW storm 1 & 2009/10/05 & -- & -- & -- & -- & -- & -- & -- & -- & -- & -- \\
\hline 292943098354402 & AY-68-36-133 & TANC MW storm 2 & 2009/10/07 & -- & -- & -- & -- & -- & -- & -- & -- & -- & -- \\
\hline 292943098354402 & AY-68-36-133 & TANC MW storm 3 & 2009/10/17 & $<.036$ & $<.006$ & E.015 & $<.010$ & $<.010$ & $<.004$ & $<.003$ & $<.003$ & $<.010$ & $<.008$ \\
\hline 292943098354402 & AY-68-36-133 & TANC MW storm 4 & 2009/10/28 & $<.036$ & $<.006$ & E.015 & $<.010$ & $<.010$ & $<.004$ & $<.003$ & $<.003$ & $<.010$ & $<.008$ \\
\hline 292943098354402 & AY-68-36-133 & TANC MW storm 5 & 2009/11/18 & $<.036$ & $<.006$ & E.015 & $<.010$ & $<.010$ & $<.004$ & $<.003$ & $<.003$ & $<.010$ & $<.008$ \\
\hline 292943098354403 & AY-68-36-134 & TANC MW pre-storm & 2009/04/09 & -- & -- & -- & -- & -- & -- & -- & -- & -- & -- \\
\hline 292943098354403 & AY-68-36-134 & TANC MW storm 1 & 2009/10/05 & -- & -- & -- & -- & -- & -- & -- & -- & -- & -- \\
\hline 292943098354403 & AY-68-36-134 & TANC MW storm 2 & 2009/10/08 & -- & -- & -- & -- & -- & -- & -- & -- & -- & -- \\
\hline 292943098354403 & AY-68-36-134 & TANC MW storm 3 & 2009/10/18 & $<.036$ & $<.006$ & E.016 & $<.010$ & $<.010$ & $<.004$ & $<.003$ & $<.003$ & $<.010$ & $<.008$ \\
\hline 292943098354403 & AY-68-36-134 & TANC MW storm 4 & 2009/10/29 & $<.036$ & $<.006$ & E.019 & $<.010$ & $<.010$ & $<.004$ & $<.003$ & $<.003$ & $<.010$ & $<.008$ \\
\hline 292943098354403 & AY-68-36-134 & TANC MW storm 5 & 2009/11/18 & $<.036$ & $<.006$ & E.016 & $<.010$ & $<.010$ & $<.004$ & $<.003$ & $<.003$ & $<.010$ & $<.008$ \\
\hline 292943098354404 & AY-68-36-132 & TANC MW pre-storm & 2009/04/09 & -- & -- & -- & -- & -- & -- & -- & -- & -- & -- \\
\hline 292943098354404 & AY-68-36-132 & TANC MW storm 1 & 2009/10/05 & -- & -- & -- & -- & -- & -- & -- & -- & -- & -- \\
\hline 292943098354404 & AY-68-36-132 & TANC MW storm 2 & 2009/10/08 & -- & -- & -- & -- & -- & -- & -- & -- & -- & -- \\
\hline 292943098354404 & AY-68-36-132 & TANC MW storm 3 & 2009/10/18 & $<.036$ & $<.006$ & E.017 & $<.010$ & $<.010$ & $<.004$ & $<.003$ & $<.003$ & $<.010$ & $<.008$ \\
\hline 292943098354404 & AY-68-36-132 & TANC MW storm 4 & 2009/10/29 & $<.036$ & $<.006$ & E.018 & $<.010$ & $<.010$ & $<.004$ & $<.003$ & $<.003$ & $<.010$ & $<.008$ \\
\hline 292943098354404 & AY-68-36-132 & TANC MW storm 5 & 2009/11/18 & $<.036$ & $<.006$ & E.020 & $<.010$ & $<.010$ & $<.004$ & $<.003$ & $<.003$ & $<.010$ & $<.008$ \\
\hline 293252098380801 & AY-68-27-610 & TANC MW pre-storm & $2009 / 04 / 14$ & -- & -- & -- & -- & -- & -- & -- & -- & -- & -- \\
\hline 293252098380801 & AY-68-27-610 & TANC MW storm 1 & 2009/10/04 & -- & -- & -- & -- & -- & -- & -- & -- & -- & -- \\
\hline 293252098380801 & AY-68-27-610 & TANC MW storm 2 & 2009/10/07 & -- & -- & -- & -- & -- & -- & -- & -- & -- & -- \\
\hline 293252098380801 & AY-68-27-610 & TANC MW storm 3 & 2009/10/17 & $<.036$ & $<.006$ & E.028 & $<.010$ & $<.010$ & $<.004$ & $<.003$ & $<.003$ & $<.010$ & $<.008$ \\
\hline 293252098380801 & AY-68-27-610 & TANC MW storm 4 & 2009/10/28 & $<.036$ & $<.006$ & E.032 & $<.010$ & $<.010$ & $<.004$ & $<.003$ & $<.003$ & $<.010$ & $<.008$ \\
\hline 293252098380801 & AY-68-27-610 & TANC MW storm 5 & 2009/11/17 & $<.036$ & $<.006$ & E.036 & $<.010$ & $<.010$ & $<.004$ & $<.003$ & $<.003$ & $<.010$ & $<.008$ \\
\hline
\end{tabular}


Table 15. Soluble pesticide compounds for groundwater samples collected for the study of the transport of anthropogenic and natural contaminants (TANC) to public supply wells in the San Antonio segment of the Edwards aquifer near San Antonio, south-central Texas, 2004-9.-Continued

[By sample category. USGS, U.S. Geological Survey; MW, monitoring well; OVB, overburden; $\mu \mathrm{g} / \mathrm{L}$, micrograms per liter; --, not measured; E, estimated; u, unable to determine; <, nondetection less than laboratory method reporting level]

\begin{tabular}{|c|c|c|c|c|c|c|c|c|c|c|c|c|c|c|c|c|c|}
\hline $\begin{array}{c}\text { USGS } \\
\text { identification } \\
\text { number }\end{array}$ & $\begin{array}{l}\text { alpha- } \\
\text { Endo- } \\
\text { sulfan } \\
(\mu \mathrm{g} / \mathrm{L})\end{array}$ & $\begin{array}{l}\text { Atra- } \\
\text { zine } \\
(\mu \mathrm{g} / \mathrm{L})\end{array}$ & $\begin{array}{c}\text { Azin- } \\
\text { phos- } \\
\text { methyl } \\
\text { oxygen } \\
\text { analog } \\
\text { ( } \mu \mathrm{g} / \mathrm{L})\end{array}$ & $\begin{array}{c}\text { Azin- } \\
\text { phos- } \\
\text { methyl } \\
(\mu \mathrm{g} / \mathrm{L})\end{array}$ & $\begin{array}{c}\text { Ben- } \\
\text { fluralin } \\
\text { ( } \mu \mathrm{g} / \mathrm{L})\end{array}$ & $\begin{array}{c}\text { Carb- } \\
\text { aryl } \\
(\mu \mathrm{g} / \mathrm{L})\end{array}$ & $\begin{array}{l}\text { Carbo- } \\
\text { furan } \\
(\mu \mathrm{g} / \mathrm{L})\end{array}$ & $\begin{array}{c}\text { Chlor- } \\
\text { pyrifos } \\
\text { ( } 1 \mathrm{~g} / \mathrm{L} \text { ) }\end{array}$ & $\begin{array}{l}\text { cis- } \\
\text { Perm- } \\
\text { ethrin } \\
(\mu \mathrm{g} / \mathrm{L})\end{array}$ & $\begin{array}{l}\text { cis- } \\
\text { Pro- } \\
\text { picon- } \\
\text { azole } \\
\text { ( } \mu \mathrm{g} / \mathrm{L})\end{array}$ & $\begin{array}{l}\text { Cyana- } \\
\text { zine } \\
\text { ( } \mu \mathrm{g} / \mathrm{L})\end{array}$ & $\begin{array}{l}\text { Cyflu- } \\
\text { thrin } \\
(\mu g / L)\end{array}$ & $\begin{array}{l}\text { lambda- } \\
\text { Cyhalo- } \\
\text { thrin } \\
(\mu \mathrm{g} / \mathrm{L})\end{array}$ & $\begin{array}{l}\text { Cy- } \\
\text { perm- } \\
\text { ethrin } \\
\text { ( } \mu \mathrm{g} / \mathrm{L})\end{array}$ & $\begin{array}{c}\text { Dacthal } \\
\text { (DCPA) } \\
\text { ( } \mu \mathrm{g} / \mathrm{L})\end{array}$ & 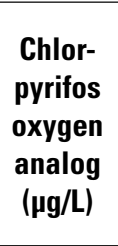 & $\begin{array}{c}\text { Desulf- } \\
\text { inyl- } \\
\text { fipronil } \\
\text { amide } \\
(\mu \mathrm{g} / \mathrm{L})\end{array}$ \\
\hline \multicolumn{18}{|c|}{ Regional aquifer public-supply wells } \\
\hline 293359098290301 & -- & 0.01 & $<0.070$ & $<0.05$ & $<0.010$ & $<0.041$ & -- & $<0.005$ & $<0.006$ & -- & -- & $<0.008$ & -- & $<0.009$ & $<0.003$ & $<0.056$ & $<0.029$ \\
\hline 293359098290301 & $<0.005$ & .008 & $<.070$ & $<.05$ & $<.01$ & $<.041$ & $<0.02$ & $<.005$ & $<.006$ & $<0.008$ & $<0.018$ & $<.027$ & $<0.009$ & $<.009$ & $<.003$ & $<.056$ & $<.029$ \\
\hline 293358098231101 & -- & .014 & $<.070$ & $<.05$ & $<.010$ & $<.041$ & -- & $<.005$ & $<.006$ & -- & -- & $<.008$ & -- & $<.009$ & $<.003$ & $<.056$ & $<.029$ \\
\hline 293358098231101 & $<.005$ & .011 & $<.070$ & $<.05$ & $<.01$ & $<.041$ & $<.02$ & $<.005$ & $<.006$ & $<.008$ & $<.018$ & $<.027$ & $<.009$ & $<.009$ & $<.003$ & $<.056$ & $<.029$ \\
\hline 293120098285801 & -- & $<.01$ & $<.070$ & $<.05$ & $<.010$ & $<.041$ & -- & $<.005$ & $<.006$ & -- & -- & $<.008$ & -- & $<.009$ & $<.003$ & $<.056$ & $<.029$ \\
\hline 293120098285801 & -- & E.005 & -- & -- & -- & -- & -- & -- & -- & -- & -- & -- & -- & -- & -- & -- & -- \\
\hline 293145098224201 & -- & $<.007$ & $<.070$ & $<.05$ & $<.010$ & $<.041$ & -- & $<.005$ & $<.006$ & -- & -- & $<.008$ & -- & $<.009$ & $<.003$ & $<.056$ & $<.029$ \\
\hline 293119098211201 & -- & $<.007$ & $<.070$ & $<.05$ & $<.010$ & $<.041$ & -- & $<.005$ & $<.006$ & -- & -- & $<.008$ & -- & $<.009$ & $<.003$ & $<.056$ & $<.029$ \\
\hline 292843098425101 & -- & $<.007$ & $<.070$ & $<.05$ & $<.010$ & $<.041$ & -- & $<.005$ & $<.006$ & -- & -- & $<.008$ & -- & $<.009$ & $<.003$ & $<.056$ & $<.029$ \\
\hline 292459098382101 & -- & $<.007$ & $<.070$ & $<.05$ & $<.010$ & $<.041$ & -- & $<.005$ & $<.006$ & -- & -- & $<.008$ & -- & $<.009$ & $<.003$ & $<.056$ & $<.029$ \\
\hline 292925098360201 & -- & .008 & $<.070$ & $<.05$ & $<.010$ & $<.041$ & -- & $<.005$ & $<.006$ & -- & -- & $<.008$ & -- & $<.009$ & $<.003$ & $<.056$ & $<.029$ \\
\hline 292925098360201 & $<.005$ & E.007 & $<.070$ & $<.05$ & $<.01$ & $<.041$ & $<.02$ & $<.005$ & $<.006$ & $<.008$ & $<.018$ & $<.027$ & $<.009$ & $<.009$ & $<.003$ & $<.056$ & $<.029$ \\
\hline 292822098325401 & -- & .007 & $<.070$ & $<.05$ & $<.010$ & $<.041$ & -- & $<.005$ & $<.006$ & -- & -- & $<.008$ & -- & $<.009$ & $<.003$ & $<.056$ & $<.029$ \\
\hline 292822098325401 & $<.005$ & E.007 & $<.070$ & $<.05$ & $<.01$ & $<.041$ & $<.02$ & $<.005$ & $<.006$ & $<.008$ & $<.018$ & $<.027$ & $<.009$ & $<.009$ & $<.003$ & $<.056$ & $<.029$ \\
\hline 292944098292301 & -- & .008 & $<.070$ & $<.05$ & $<.010$ & $<.041$ & -- & $<.005$ & $<.006$ & -- & -- & $<.008$ & -- & $<.009$ & $<.003$ & $<.056$ & $<.029$ \\
\hline 292944098292301 & $<.005$ & E.007 & $<.070$ & $<.05$ & $<.01$ & $<.041$ & $<.02$ & $<.005$ & $<.006$ & $<.008$ & $<.018$ & $<.027$ & $<.009$ & $<.009$ & $<.003$ & $<.056$ & $<.029$ \\
\hline 292522098291901 & -- & $<.007$ & $<.070$ & $<.05$ & $<.010$ & $<.041$ & -- & $<.005$ & $<.006$ & -- & -- & $<.008$ & -- & $<.009$ & $<.003$ & $<.056$ & $<.029$ \\
\hline 292643098241801 & -- & $<.007$ & $<.070$ & $<.05$ & $<.010$ & $<.041$ & -- & $<.005$ & $<.006$ & -- & -- & $<.008$ & -- & $<.009$ & $<.003$ & $<.056$ & $<.029$ \\
\hline 292643098241801 & -- & $<.008$ & -- & -- & -- & -- & -- & -- & -- & -- & -- & -- & -- & -- & -- & -- & -- \\
\hline 292328098294601 & -- & $<.007$ & $<.070$ & $<.05$ & $<.010$ & $<.041$ & -- & $<.005$ & $<.006$ & -- & -- & $<.008$ & -- & $<.009$ & $<.003$ & $<.056$ & $<.029$ \\
\hline 294225098080301 & -- & .008 & $<.070$ & $<.05$ & $<.010$ & $<.041$ & -- & $<.005$ & $<.006$ & -- & -- & $<.008$ & -- & $<.009$ & $<.003$ & $<.056$ & $<.029$ \\
\hline 294225098080301 & $<.005$ & E.006 & $<.070$ & $<.05$ & $<.01$ & $<.041$ & $<.02$ & $<.005$ & $<.006$ & $<.008$ & $<.018$ & $<.027$ & $<.009$ & $<.009$ & $<.003$ & $<.056$ & $<.029$ \\
\hline 291210099475601 & -- & E.004 & $<.070$ & $<.05$ & $<.010$ & $<.041$ & -- & $<.005$ & $<.006$ & -- & -- & $<.008$ & -- & $<.009$ & $<.003$ & $<.056$ & $<.029$ \\
\hline 293111098340901 & -- & .007 & $<.070$ & $<.05$ & $<.010$ & $<.041$ & -- & $<.005$ & $<.006$ & -- & -- & $<.027$ & -- & $<.009$ & $<.003$ & $<.056$ & $<.029$ \\
\hline 293512098291701 & -- & .009 & $<.070$ & $<.05$ & $<.010$ & $<.041$ & -- & $<.005$ & $<.006$ & -- & -- & $<.027$ & -- & $<.009$ & $<.003$ & $<.056$ & $<.029$ \\
\hline 292424098421501 & -- & .007 & $<.070$ & $<.05$ & $<.010$ & $<.041$ & -- & $<.005$ & $<.006$ & -- & -- & $<.027$ & -- & $<.009$ & $<.003$ & $<.056$ & $<.029$ \\
\hline
\end{tabular}


Table 15. Soluble pesticide compounds for groundwater samples collected for the study of the transport of anthropogenic and natural contaminants (TANC) to public supply wells in the San Antonio segment of the Edwards aquifer near San Antonio, south-central Texas, 2004-9.-Continued

[By sample category. USGS, U.S. Geological Survey; MW, monitoring well; OVB, overburden; $\mu g / L$, micrograms per liter; --, not measured; E, estimated; u, unable to determine; <, nondetection less than laboratory method reporting level]

\begin{tabular}{|c|c|c|c|c|c|c|c|c|c|c|c|c|c|c|c|c|c|}
\hline $\begin{array}{c}\text { USGS } \\
\text { identification } \\
\text { number }\end{array}$ & $\begin{array}{l}\text { alpha- } \\
\text { Endo- } \\
\text { sulfan } \\
(\mu \mathrm{g} / \mathrm{L})\end{array}$ & $\begin{array}{l}\text { Atra- } \\
\text { zine } \\
(\mu g / L)\end{array}$ & 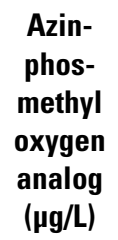 & $\begin{array}{c}\text { Azin- } \\
\text { phos- } \\
\text { methyl } \\
(\mu \mathrm{g} / \mathrm{L})\end{array}$ & $\begin{array}{c}\text { Ben- } \\
\text { fluralin } \\
\text { ( } \mu \mathrm{g} / \mathrm{L})\end{array}$ & $\begin{array}{c}\text { Carb- } \\
\text { aryl } \\
(\mu \mathrm{g} / \mathrm{L})\end{array}$ & $\begin{array}{l}\text { Carbo- } \\
\text { furan } \\
\text { ( } \mu \mathrm{g} / \mathrm{L} \text { ) }\end{array}$ & $\begin{array}{c}\text { Chlor- } \\
\text { pyrifos } \\
\text { ( } \mu \mathrm{g} / \mathrm{L})\end{array}$ & $\begin{array}{l}\text { cis- } \\
\text { Perm- } \\
\text { ethrin } \\
(\mu \mathrm{g} / \mathrm{L})\end{array}$ & $\begin{array}{l}\text { cis- } \\
\text { Pro- } \\
\text { picon- } \\
\text { azole } \\
\text { ( } \mu \mathrm{g} / \mathrm{L})\end{array}$ & $\begin{array}{l}\text { Cyana- } \\
\text { zine } \\
(\mu \mathrm{g} / \mathrm{L})\end{array}$ & $\begin{array}{l}\text { Cyflu- } \\
\text { thrin } \\
\text { ( } \mu \mathrm{g} / \mathrm{L})\end{array}$ & $\begin{array}{l}\text { lambda- } \\
\text { Cyhalo- } \\
\text { thrin } \\
(\mu \mathrm{g} / \mathrm{L})\end{array}$ & $\begin{array}{l}\text { Cy- } \\
\text { perm- } \\
\text { ethrin } \\
(\mu \mathrm{g} / \mathrm{L})\end{array}$ & $\begin{array}{c}\text { Dacthal } \\
\text { (DCPA) } \\
\text { ( } \mu \mathrm{g} / \mathrm{L})\end{array}$ & $\begin{array}{l}\text { Chlor- } \\
\text { pyrifos } \\
\text { oxygen } \\
\text { analog } \\
\text { ( } \mu \mathrm{g} / \mathrm{L} \text { ) }\end{array}$ & $\begin{array}{l}\text { Desulf- } \\
\text { inyl- } \\
\text { fipronil } \\
\text { amide } \\
\text { ( } \mu \mathrm{g} / \mathrm{L})\end{array}$ \\
\hline 292053098365501 & -- & $<0.007$ & $<0.070$ & $<0.05$ & $<0.010$ & $<0.041$ & -- & $<0.005$ & $<0.006$ & -- & -- & $<0.027$ & -- & $<0.009$ & $<0.003$ & $<0.056$ & $<0.029$ \\
\hline 293807098155301 & -- & E.004 & $<.070$ & $<.05$ & $<.010$ & $<.041$ & -- & $<.005$ & $<.006$ & -- & -- & $<.027$ & -- & $<.009$ & $<.003$ & $<.056$ & $<.029$ \\
\hline 292604098563201 & -- & $<.007$ & $<.070$ & $<.05$ & $<.010$ & $<.041$ & -- & $<.005$ & $<.006$ & -- & -- & $<.027$ & -- & $<.009$ & $<.003$ & $<.056$ & $<.029$ \\
\hline 292116099095501 & -- & $<.007$ & $<.070$ & $<.05$ & $<.010$ & $<.041$ & -- & $<.005$ & $<.006$ & -- & -- & $<.027$ & -- & $<.009$ & $<.003$ & $<.056$ & $<.029$ \\
\hline 291232099470301 & -- & E.004 & $<.070$ & $<.05$ & $<.010$ & $<.041$ & -- & $<.005$ & $<.006$ & -- & -- & $<.027$ & -- & $<.009$ & $<.003$ & $<.056$ & $<.029$ \\
\hline & -- & & & & & & -- & & & & & & & & & & \\
\hline 293128098473101 & -- & $<.007$ & $<.070$ & $<.05$ & $<.010$ & $<.041$ & -- & $<.005$ & $<.006$ & -- & -- & $<.027$ & -- & $<.009$ & $<.003$ & $<.056$ & $<.029$ \\
\hline 293451098313201 & -- & .018 & $<.070$ & $<.05$ & $<.010$ & $<.041$ & -- & $<.005$ & $<.006$ & -- & -- & $<.027$ & -- & $<.009$ & $<.003$ & $<.056$ & $<.029$ \\
\hline 294604098060801 & -- & $<.007$ & $<.070$ & $<.05$ & $<.010$ & $<.041$ & -- & $<.005$ & $<.006$ & -- & -- & $<.027$ & -- & $<.009$ & $<.003$ & $<.056$ & $<.029$ \\
\hline 294019098114701 & -- & E.005 & $<.070$ & $<.05$ & $<.010$ & $<.041$ & -- & $<.005$ & $<.006$ & -- & -- & $<.027$ & -- & $<.009$ & $<.003$ & $<.056$ & $<.029$ \\
\hline 292215098580201 & -- & $<.007$ & $<.070$ & $<.05$ & $<.010$ & $<.041$ & -- & $<.005$ & $<.006$ & -- & -- & $<.027$ & -- & $<.009$ & $<.003$ & $<.056$ & $<.029$ \\
\hline 292119098524901 & -- & $<.007$ & $<.070$ & $<.05$ & $<.010$ & $<.041$ & -- & $<.005$ & $<.006$ & -- & -- & $<.027$ & -- & $<.009$ & $<.003$ & $<.056$ & $<.029$ \\
\hline 291943099163301 & -- & $<.007$ & $<.070$ & $<.05$ & $<.010$ & $<.041$ & -- & $<.005$ & $<.006$ & -- & -- & $<.027$ & -- & $<.009$ & $<.003$ & $<.056$ & $<.029$ \\
\hline 291840099382601 & -- & E.004 & $<.070$ & $<.05$ & $<.010$ & $<.041$ & -- & $<.005$ & $<.006$ & -- & -- & $<.027$ & -- & $<.009$ & $<.003$ & $<.056$ & $<.029$ \\
\hline 293518098332601 & -- & E.006 & $<.070$ & $<.05$ & $<.010$ & $<.041$ & -- & $<.005$ & $<.006$ & -- & -- & $<.027$ & -- & $<.009$ & $<.003$ & $<.056$ & $<.029$ \\
\hline 293023098355401 & -- & .012 & $<.070$ & $<.05$ & $<.010$ & $<.041$ & -- & $<.005$ & $<.006$ & -- & -- & $<.027$ & -- & $<.009$ & $<.003$ & $<.056$ & $<.029$ \\
\hline 293042098305201 & $<0.005$ & E.007 & $<.070$ & $<.05$ & $<.01$ & $<.041$ & $<0.02$ & $<.005$ & $<.006$ & $<0.008$ & $<0.018$ & $<.027$ & $<0.009$ & $<.009$ & $<.003$ & $<.056$ & $<.029$ \\
\hline 292442098474501 & -- & E.005 & $<.070$ & $<.05$ & $<.010$ & $<.041$ & -- & $<.005$ & $<.006$ & -- & -- & $<.027$ & -- & $<.009$ & $<.003$ & $<.056$ & $<.029$ \\
\hline 292405098371201 & -- & $<.007$ & $<.070$ & $<.05$ & $<.010$ & $<.041$ & -- & $<.005$ & $<.006$ & -- & -- & $<.027$ & -- & $<.009$ & $<.003$ & $<.056$ & $<.029$ \\
\hline 292931098274601 & -- & .007 & $<.070$ & $<.05$ & $<.010$ & $<.041$ & -- & $<.005$ & $<.006$ & -- & -- & $<.027$ & -- & $<.009$ & $<.003$ & $<.056$ & $<.029$ \\
\hline 293729098173101 & -- & E.005 & $<.070$ & $<.05$ & $<.010$ & $<.041$ & -- & $<.005$ & $<.006$ & -- & -- & $<.027$ & -- & $<.009$ & $<.003$ & $<.056$ & $<.029$ \\
\hline 291219099095601 & -- & $<.007$ & $<.070$ & $<.05$ & $<.010$ & $<.041$ & -- & $<.005$ & $<.006$ & -- & -- & $<.027$ & -- & $<.009$ & $<.003$ & $<.056$ & $<.029$ \\
\hline \multicolumn{18}{|c|}{ Monitoring wells } \\
\hline 292943098354401 & $<.006$ & .009 & $<.042$ & $<.12$ & $<.0059$ & $<.06$ & $<.02$ & $<.005$ & $<.01$ & $<.006$ & $<.02$ & $<.016$ & $<.004$ & $<.014$ & $<.003$ & $<.056$ & $<.029$ \\
\hline 292943098354402 & $<.006$ & .009 & $<.042$ & $<.12$ & $<.004$ & $<.06$ & $<.02$ & $<.005$ & $<.01$ & $<.006$ & $<.02$ & $<.016$ & $<.004$ & $<.014$ & $<.003$ & $<.056$ & $<.029$ \\
\hline 292943098354403 & $<.006$ & .012 & $<.042$ & $<.12$ & $<.004$ & $<.06$ & $<.02$ & $<.005$ & $<.01$ & $<.006$ & $<.02$ & $<.016$ & $<.004$ & $<.014$ & $<.003$ & $<.056$ & $<.029$ \\
\hline 292943098354404 & $<.006$ & $<.008$ & $<.042$ & $<.12$ & $<.004$ & $<.06$ & $<.02$ & $<.005$ & $<.01$ & $<.006$ & $<.02$ & $<.016$ & $<.004$ & $<.014$ & $<.003$ & $<.056$ & $<.029$ \\
\hline 292851098374401 & $<0.006$ & 0.008 & $<0.06$ & $<0.12$ & $<0.01$ & $<0.06$ & $<0.02$ & $<0.005$ & $<0.01$ & $<0.006$ & $<0.02$ & $<0.016$ & $<0.004$ & $<0.014$ & $<0.003$ & $<0.056$ & $<0.029$ \\
\hline
\end{tabular}


Table 15. Soluble pesticide compounds for groundwater samples collected for the study of the transport of anthropogenic and natural contaminants (TANC) to public supply wells in the San Antonio segment of the Edwards aquifer near San Antonio, south-central Texas, 2004-9._Continued

[By sample category. USGS, U.S. Geological Survey; MW, monitoring well; OVB, overburden; $\mathrm{ng} / \mathrm{L}$, micrograms per liter; --, not measured; E, estimated; u, unable to determine; <, nondetection less than laboratory method reporting level]

\begin{tabular}{|c|c|c|c|c|c|c|c|c|c|c|c|c|c|c|c|c|c|}
\hline $\begin{array}{c}\text { USGS } \\
\text { identification } \\
\text { number }\end{array}$ & $\begin{array}{l}\text { alpha- } \\
\text { Endo- } \\
\text { sulfan } \\
(\mu \mathrm{g} / \mathrm{L})\end{array}$ & $\begin{array}{c}\text { Atra- } \\
\text { zine } \\
(\mu \mathrm{g} / \mathrm{L})\end{array}$ & $\begin{array}{l}\text { Azin- } \\
\text { phos- } \\
\text { methyl } \\
\text { oxygen } \\
\text { analog } \\
\text { ( } \mu \mathrm{g} / \mathrm{L})\end{array}$ & $\begin{array}{c}\text { Azin- } \\
\text { phos- } \\
\text { methyl } \\
(\mu \mathrm{g} / \mathrm{L})\end{array}$ & $\begin{array}{c}\text { Ben- } \\
\text { fluralin } \\
\text { ( } \mu \mathrm{g} / \mathrm{L})\end{array}$ & $\begin{array}{c}\text { Carb- } \\
\text { aryl } \\
(\mu \mathrm{g} / \mathrm{L})\end{array}$ & $\begin{array}{c}\text { Carbo- } \\
\text { furan } \\
(\mu \mathrm{g} / \mathrm{L})\end{array}$ & $\begin{array}{c}\text { Chlor- } \\
\text { pyrifos } \\
\text { ( } \mu \mathrm{g} / \mathrm{L})\end{array}$ & $\begin{array}{l}\text { cis- } \\
\text { Perm- } \\
\text { ethrin } \\
(\mu \mathrm{g} / \mathrm{L})\end{array}$ & $\begin{array}{l}\text { cis- } \\
\text { Pro- } \\
\text { picon- } \\
\text { azole } \\
\text { ( } \mu \mathrm{g} / \mathrm{L})\end{array}$ & $\begin{array}{l}\text { Cyana- } \\
\text { zine } \\
(\mu \mathrm{g} / \mathrm{L})\end{array}$ & $\begin{array}{c}\text { Cyflu- } \\
\text { thrin } \\
(\mu \mathrm{g} / \mathrm{L})\end{array}$ & $\begin{array}{c}\text { lambda- } \\
\text { Cyhalo- } \\
\text { thrin } \\
(\mu \mathrm{g} / \mathrm{L})\end{array}$ & $\begin{array}{l}\text { Cy- } \\
\text { perm- } \\
\text { ethrin } \\
(\mu \mathrm{g} / \mathrm{L})\end{array}$ & $\begin{array}{c}\text { Dacthal } \\
\text { (DCPA) } \\
\text { ( } \mu \mathrm{g} / \mathrm{L})\end{array}$ & $\begin{array}{c}\text { Chlor- } \\
\text { pyrifos } \\
\text { oxygen } \\
\text { analog } \\
\text { ( } \mu \mathrm{g} / \mathrm{L})\end{array}$ & $\begin{array}{c}\text { Desulf- } \\
\text { inyl- } \\
\text { fipronil } \\
\text { amide } \\
(\mu \mathrm{g} / \mathrm{L})\end{array}$ \\
\hline 292851098374402 & $<.006$ & E.014 & $<.042$ & $<.12$ & $<.01$ & $<.06$ & $<.02$ & $<.005$ & $<.01$ & $<.006$ & $<.02$ & $<.016$ & $<.004$ & $<.014$ & $<.003$ & $<.056$ & $<.029$ \\
\hline \multicolumn{18}{|c|}{ Well-field depth-dependent sampling (W4) } \\
\hline 292916098360701 & $<.006$ & E.008 & $<.042$ & $<.12$ & $<.004$ & $<.06$ & $<.02$ & $<.005$ & $<.01$ & $<.006$ & $<.02$ & $<.016$ & $<.004$ & $<.014$ & $<.003$ & $<.056$ & $<.029$ \\
\hline 292916098360701 & $<.006$ & .011 & $<.042$ & $<.12$ & $<.004$ & $<.06$ & $<.02$ & $<.005$ & $<.01$ & $<.006$ & $<.02$ & $<.016$ & $<.004$ & $<.014$ & $<.003$ & $<.056$ & $<.029$ \\
\hline 292916098360701 & $<.006$ & $\mathrm{u}$ & $<.042$ & $<.12$ & $<.004$ & $<.06$ & $<.02$ & $<.005$ & $<.01$ & $<.006$ & $<.02$ & $<.016$ & $<.004$ & $<.014$ & $<.003$ & $<.056$ & $<.029$ \\
\hline 292916098360701 & $<.006$ & .009 & $<.042$ & $<.12$ & $<.004$ & $<.06$ & $<.02$ & $<.005$ & $<.01$ & $<.006$ & $<.02$ & $<.016$ & $<.004$ & $<.014$ & $<.003$ & $<.056$ & $<.029$ \\
\hline 292916098360701 & $<.006$ & E.011 & $<.042$ & $<.12$ & $<.004$ & $<.06$ & $<.02$ & $<.005$ & $<.01$ & $<.006$ & $<.02$ & $<.016$ & $<.004$ & $<.014$ & $<.003$ & $<.056$ & $<.029$ \\
\hline 292916098360701 & $<.006$ & .015 & $<.042$ & $<.12$ & $<.004$ & $<.06$ & $<.02$ & $<.005$ & $<.01$ & $<.006$ & $<.02$ & $<.016$ & $<.004$ & $<.014$ & $<.003$ & $<.056$ & $<.029$ \\
\hline 292916098360701 & $<.006$ & .016 & $<.042$ & $<.12$ & $<.004$ & $<.06$ & $<.02$ & $<.005$ & $<.01$ & $<.006$ & $<.02$ & $<.016$ & $<.004$ & $<.014$ & $<.003$ & $<.056$ & $<.029$ \\
\hline 292916098360701 & $<.006$ & .012 & $<.042$ & $<.12$ & $<.004$ & $<.06$ & $<.02$ & $<.005$ & $<.01$ & $<.006$ & $<.02$ & $<.016$ & $<.004$ & $<.014$ & $<.003$ & $<.056$ & $<.029$ \\
\hline 292916098360701 & $<.006$ & .011 & $<.042$ & $<.12$ & $<.004$ & $<.06$ & $<.02$ & $<.005$ & $<.01$ & $<.006$ & $<.02$ & $<.016$ & $<.004$ & $<.014$ & $<.003$ & $<.056$ & $<.029$ \\
\hline \multicolumn{18}{|c|}{ Well-field wells (wellhead sampling) } \\
\hline 292919098360501 & $<.006$ & .017 & $<.042$ & $<.12$ & $<.004$ & $<.06$ & $<.02$ & $<.005$ & $<.01$ & $<.006$ & $<.02$ & $<.016$ & $<.004$ & $<.014$ & $<.003$ & $<.056$ & $<.029$ \\
\hline 292925098360201 & $<.006$ & .009 & $<.042$ & $<.12$ & $<.004$ & $<.06$ & $<.02$ & $<.005$ & $<.01$ & $<.006$ & $<.02$ & $<.016$ & $<.004$ & $<.014$ & $<.003$ & $<.056$ & $<.029$ \\
\hline 292916098360701 & $<.006$ & .017 & $<.042$ & $<.12$ & $<.004$ & $<.06$ & $<.02$ & $<.005$ & $<.01$ & $<.006$ & $<.02$ & $<.016$ & $<.004$ & $<.014$ & $<.003$ & $<.056$ & $<.029$ \\
\hline 292920098360601 & $<.006$ & .015 & $<.042$ & $<.12$ & $<.004$ & $<.06$ & $<.02$ & $<.005$ & $<.01$ & $<.006$ & $<.02$ & $<.016$ & $<.004$ & $<.014$ & $<.003$ & $<.056$ & $<.029$ \\
\hline 292923098360301 & $<.006$ & .015 & $<.042$ & $<.12$ & $<.0058$ & $<.06$ & $<.02$ & $<.005$ & $<.01$ & $<.006$ & $<.02$ & $<.016$ & $<.004$ & $<.014$ & $<.003$ & $<.056$ & $<.029$ \\
\hline \multicolumn{18}{|c|}{ Temporal sampling } \\
\hline 292923098360301 & -- & -- & -- & -- & -- & -- & -- & -- & -- & -- & -- & -- & -- & -- & -- & -- & -- \\
\hline 292923098360301 & -- & -- & -- & -- & -- & -- & -- & -- & -- & -- & -- & -- & -- & -- & -- & -- & -- \\
\hline 292923098360301 & -- & -- & -- & -- & -- & -- & -- & -- & -- & -- & -- & -- & -- & -- & -- & -- & -- \\
\hline 292923098360301 & $<0.006$ & 0.008 & $<0.042$ & $<0.12$ & $<0.014$ & $<0.06$ & $<0.060$ & $<0.010$ & $<0.014$ & $<0.006$ & $<0.022$ & $<0.016$ & $<0.010$ & $<0.020$ & $<0.008$ & $<0.05$ & $<0.029$ \\
\hline 292923098360301 & $<.006$ & E.006 & $<.042$ & $<.12$ & $<.014$ & $<.06$ & $<.060$ & $<.010$ & $<.014$ & $<.006$ & $<.022$ & $<.016$ & $<.010$ & $<.020$ & $<.008$ & $<.05$ & $<.029$ \\
\hline
\end{tabular}


Table 15. Soluble pesticide compounds for groundwater samples collected for the study of the transport of anthropogenic and natural contaminants (TANC) to public supply wells in the San Antonio segment of the Edwards aquifer near San Antonio, south-central Texas, 2004-9.-Continued

[By sample category. USGS, U.S. Geological Survey; MW, monitoring well; OVB, overburden; $\mu$ g/L, micrograms per liter; --, not measured; E, estimated; u, unable to determine; <, nondetection less than laboratory method reporting level]

\begin{tabular}{|c|c|c|c|c|c|c|c|c|c|c|c|c|c|c|c|c|c|}
\hline $\begin{array}{c}\text { USGS } \\
\text { identification } \\
\text { number }\end{array}$ & $\begin{array}{l}\text { alpha- } \\
\text { Endo- } \\
\text { sulfan } \\
(\mu \mathrm{g} / \mathrm{L})\end{array}$ & $\begin{array}{c}\text { Atra- } \\
\text { zine } \\
(\mu \mathrm{g} / \mathrm{L})\end{array}$ & 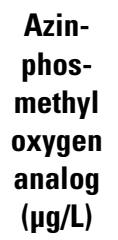 & $\begin{array}{l}\text { Azin- } \\
\text { phos- } \\
\text { methyl } \\
(\mu \mathrm{g} / \mathrm{L})\end{array}$ & $\begin{array}{c}\text { Ben- } \\
\text { fluralin } \\
\text { ( } \mu \mathrm{g} / \mathrm{L})\end{array}$ & $\begin{array}{c}\text { Carb- } \\
\text { aryl } \\
(\mu \mathrm{g} / \mathrm{L})\end{array}$ & $\begin{array}{l}\text { Carbo- } \\
\text { furan } \\
(\mu \mathrm{g} / \mathrm{L})\end{array}$ & $\begin{array}{l}\text { Chlor- } \\
\text { pyrifos } \\
(\mu \mathrm{g} / \mathrm{L})\end{array}$ & $\begin{array}{l}\text { cis- } \\
\text { Perm- } \\
\text { ethrin } \\
(\mu \mathrm{g} / \mathrm{L})\end{array}$ & $\begin{array}{c}\text { cis- } \\
\text { Pro- } \\
\text { picon- } \\
\text { azole } \\
\text { ( } \mu \mathrm{g} / \mathrm{L})\end{array}$ & $\begin{array}{l}\text { Cyana- } \\
\text { zine } \\
(\mu \mathrm{g} / \mathrm{L})\end{array}$ & $\begin{array}{c}\text { Cyflu- } \\
\text { thrin } \\
(\mu \mathrm{g} / \mathrm{L})\end{array}$ & $\begin{array}{l}\text { lambda- } \\
\text { Cyhalo- } \\
\text { thrin } \\
(\mu \mathrm{g} / \mathrm{L})\end{array}$ & $\begin{array}{l}\text { Cy- } \\
\text { perm- } \\
\text { ethrin } \\
(\mu \mathrm{g} / \mathrm{L})\end{array}$ & $\begin{array}{c}\text { Dacthal } \\
\text { (DCPA) } \\
\text { ( } \mu \mathrm{g} / \mathrm{L})\end{array}$ & $\begin{array}{l}\text { Chlor- } \\
\text { pyrifos } \\
\text { oxygen } \\
\text { analog } \\
\text { ( } \mu \mathrm{g} / \mathrm{L})\end{array}$ & $\begin{array}{c}\text { Desulf- } \\
\text { inyl- } \\
\text { fipronil } \\
\text { amide } \\
\text { ( } \mu \mathrm{g} / \mathrm{L} \text { ) }\end{array}$ \\
\hline 292923098360301 & $<.006$ & E.008 & $<.042$ & $<.12$ & $<.014$ & $<.06$ & $<.060$ & $<.010$ & $<.014$ & $<.006$ & $<.022$ & $<.016$ & $<.010$ & $<.020$ & $<.008$ & $\mathrm{u}$ & $<.029$ \\
\hline 292943098354402 & -- & -- & -- & -- & -- & -- & -- & -- & -- & -- & -- & -- & -- & -- & -- & -- & -- \\
\hline 292943098354402 & -- & -- & -- & -- & -- & -- & -- & -- & -- & -- & -- & -- & -- & -- & -- & -- & -- \\
\hline 292943098354402 & -- & -- & -- & -- & -- & -- & -- & -- & -- & -- & -- & -- & -- & -- & -- & -- & -- \\
\hline 292943098354402 & $<.006$ & .009 & $<.042$ & $<.12$ & $<.014$ & $<.06$ & $<.060$ & $<.010$ & $<.014$ & $<.006$ & $<.022$ & $<.016$ & $<.010$ & $<.020$ & $<.008$ & $<.05$ & $<.029$ \\
\hline 292943098354402 & $<.006$ & .009 & $<.042$ & $<.12$ & $<.014$ & $<.06$ & $<.060$ & $<.010$ & $<.014$ & $<.006$ & $<.022$ & $<.016$ & $<.010$ & $<.020$ & $<.008$ & $<.05$ & $<.029$ \\
\hline 292943098354402 & $<.006$ & .008 & $<.042$ & $<.12$ & $<.014$ & $<.06$ & $<.060$ & $<.010$ & $<.014$ & $<.006$ & $<.022$ & $<.016$ & $<.010$ & $<.020$ & $<.008$ & $<.05$ & $<.029$ \\
\hline 292943098354403 & -- & -- & -- & -- & -- & -- & -- & -- & -- & -- & -- & -- & -- & -- & -- & -- & -- \\
\hline 292943098354403 & -- & -- & -- & -- & -- & -- & -- & -- & -- & -- & -- & -- & -- & -- & -- & -- & -- \\
\hline 292943098354403 & -- & -- & -- & -- & -- & -- & -- & -- & -- & -- & -- & -- & -- & -- & -- & -- & -- \\
\hline 292943098354403 & $<.006$ & .009 & $<.042$ & $<.12$ & $<.014$ & $<.06$ & $<.060$ & $<.010$ & $<.014$ & $<.006$ & $<.022$ & $<.016$ & $<.010$ & $<.020$ & $<.008$ & $<.05$ & $<.029$ \\
\hline 292943098354403 & $<.006$ & .009 & $<.042$ & $<.12$ & $<.014$ & $<.06$ & $<.060$ & $<.010$ & $<.014$ & $<.006$ & $<.022$ & $<.016$ & $<.010$ & $<.020$ & $<.008$ & $<.05$ & $<.029$ \\
\hline 292943098354403 & $<.006$ & .008 & $<.042$ & $<.12$ & $<.014$ & $<.06$ & $<.060$ & $<.010$ & $<.014$ & $<.006$ & $<.022$ & $<.016$ & $<.010$ & $<.020$ & $<.008$ & $\mathrm{u}$ & $<.029$ \\
\hline 292943098354404 & -- & -- & -- & -- & -- & -- & -- & -- & -- & -- & -- & -- & -- & -- & -- & -- & -- \\
\hline 292943098354404 & -- & -- & -- & -- & -- & -- & -- & -- & -- & -- & -- & -- & -- & -- & -- & -- & -- \\
\hline 292943098354404 & -- & -- & -- & -- & -- & -- & -- & -- & -- & -- & -- & -- & -- & -- & -- & -- & -- \\
\hline 292943098354404 & $<.006$ & .009 & $<.042$ & $<.12$ & $<.014$ & $<.06$ & $<.060$ & $<.010$ & $<.014$ & $<.006$ & $<.022$ & $<.016$ & $<.010$ & $<.020$ & $<.008$ & $<.05$ & $<.029$ \\
\hline 292943098354404 & $<.006$ & .009 & $<.042$ & $<.12$ & $<.014$ & $<.06$ & $<.060$ & $<.010$ & $<.014$ & $<.006$ & $<.022$ & $<.016$ & $<.010$ & $<.020$ & $<.008$ & $\mathrm{u}$ & $<.029$ \\
\hline 292943098354404 & $<.006$ & .009 & $<.042$ & $<.12$ & $<.014$ & $<.06$ & $<.060$ & $<.010$ & $<.014$ & $<.006$ & $<.022$ & $<.016$ & $<.010$ & $<.020$ & $<.008$ & $\mathrm{u}$ & $<.029$ \\
\hline 293252098380801 & -- & -- & -- & -- & -- & -- & -- & -- & -- & -- & -- & -- & -- & -- & -- & -- & -- \\
\hline 293252098380801 & -- & -- & -- & -- & -- & -- & -- & -- & -- & -- & -- & -- & -- & -- & -- & -- & -- \\
\hline 293252098380801 & -- & -- & -- & -- & -- & -- & -- & -- & -- & -- & -- & -- & -- & -- & -- & -- & -- \\
\hline 293252098380801 & $<.006$ & .017 & $<.042$ & $<.12$ & $<.014$ & $<.06$ & $<.060$ & $<.010$ & $<.014$ & $<.006$ & $<.022$ & $<.016$ & $<.010$ & $<.020$ & $<.008$ & $<.05$ & $<.029$ \\
\hline 293252098380801 & $<.006$ & .015 & $<.042$ & $<.12$ & $<.014$ & $<.06$ & $<.060$ & $<.010$ & $<.014$ & $<.006$ & $<.022$ & $<.016$ & $<.010$ & $<.020$ & $<.008$ & $\mathrm{u}$ & $<.029$ \\
\hline 293252098380801 & $<.006$ & .017 & $<.042$ & $<.12$ & $<.014$ & $<.06$ & $<.060$ & $<.010$ & $<.014$ & $<.006$ & $<.022$ & $<.016$ & $<.010$ & $<.020$ & $<.008$ & $<.05$ & $<.029$ \\
\hline
\end{tabular}


Table 15. Soluble pesticide compounds for groundwater samples collected for the study of the transport of anthropogenic and natural contaminants (TANC) to public supply wells in the San Antonio segment of the Edwards aquifer near San Antonio, south-central Texas, 2004-9.-Continued

[By sample category. USGS, U.S. Geological Survey; MW, monitoring well; OVB, overburden; rg/L, micrograms per liter; --, not measured; E, estimated; u, unable to determine; <, nondetection less than laboratory method reporting level]

\begin{tabular}{|c|c|c|c|c|c|c|c|c|c|c|c|c|c|c|c|c|c|}
\hline $\begin{array}{c}\text { USGS } \\
\text { identification } \\
\text { number }\end{array}$ & $\begin{array}{c}\text { Diaz- } \\
\text { inon } \\
(\mu \mathrm{g} / \mathrm{L})\end{array}$ & $\begin{array}{l}\text { Diaz- } \\
\text { oxon } \\
(\mu \mathrm{g} / \mathrm{L})\end{array}$ & $\begin{array}{c}\text { Di- } \\
\text { chlor- } \\
\text { vos } \\
(\mu \mathrm{g} / \mathrm{L})\end{array}$ & $\begin{array}{l}\text { Di- } \\
\text { croto- } \\
\text { phos } \\
(\mu \mathrm{g} / \mathrm{L})\end{array}$ & $\begin{array}{c}\text { Diel- } \\
\text { drin } \\
(\mu \mathrm{g} / \mathrm{L})\end{array}$ & $\begin{array}{c}\text { Di- } \\
\text { meth- } \\
\text { oate } \\
(\mu \mathrm{g} / \mathrm{L})\end{array}$ & $\begin{array}{c}\text { Di- } \\
\text { sulf- } \\
\text { oton } \\
\text { sulfone } \\
\text { ( } \mu \mathrm{g} / \mathrm{L} \text { ) }\end{array}$ & $\begin{array}{c}\text { Di- } \\
\text { sulf- } \\
\text { oton } \\
\text { ( } \mu \mathrm{g} / \mathrm{L})\end{array}$ & $\begin{array}{c}\text { Endo- } \\
\text { sulfan } \\
\text { sulfate } \\
(\mu \mathrm{g} / \mathrm{L})\end{array}$ & $\begin{array}{l}\text { EPTC } \\
(\mu \mathrm{g} / \mathrm{L})\end{array}$ & $\begin{array}{c}\text { Ethion } \\
\text { mon- } \\
\text { oxon } \\
(\mu \mathrm{g} / \mathrm{L})\end{array}$ & $\begin{array}{l}\text { Ethion } \\
\text { ( } \mu \mathrm{g} / \mathrm{L})\end{array}$ & $\begin{array}{l}\text { Etho- } \\
\text { prop } \\
\text { ( } \mu \mathrm{g} / \mathrm{L})\end{array}$ & $\begin{array}{c}\text { Fen- } \\
\text { amiphos } \\
\text { sulfone } \\
(\mu \mathrm{g} / \mathrm{L})\end{array}$ & $\begin{array}{l}\text { Fen- } \\
\text { ami- } \\
\text { phos } \\
\text { sulf- } \\
\text { oxide } \\
\text { ( } \mu \mathrm{g} / \mathrm{L} \text { ) }\end{array}$ & $\begin{array}{l}\text { Fen- } \\
\text { ami- } \\
\text { phos } \\
(\mu \mathrm{g} / \mathrm{L})\end{array}$ & $\begin{array}{c}\text { Desulf- } \\
\text { inyl- } \\
\text { fipronil } \\
(\mu \mathrm{g} / \mathrm{L})\end{array}$ \\
\hline \multicolumn{18}{|c|}{ Regional aquifer public-supply wells } \\
\hline 293359098290301 & $<0.005$ & $<0.006$ & $<0.012$ & $<0.084$ & $<0.009$ & $<0.006$ & -- & -- & -- & -- & $<0.002$ & $<0.004$ & -- & $<0.049$ & $<0.039$ & $<0.029$ & $<0.012$ \\
\hline 293359098290301 & $<.005$ & $<.006$ & $<.012$ & $<.084$ & $<.009$ & $<.006$ & $<0.006$ & $<0.021$ & $<0.014$ & $<0.004$ & $<.002$ & $<.004$ & $<0.005$ & $<.049$ & $<.039$ & $<.029$ & $<.012$ \\
\hline 293358098231101 & $<.005$ & $<.006$ & $<.012$ & $<.084$ & $<.009$ & $<.006$ & -- & -- & -- & -- & $<.002$ & $<.004$ & -- & $<.049$ & $\mathrm{u}$ & $<.029$ & $<.012$ \\
\hline 293358098231101 & $<.005$ & $<.006$ & $<.012$ & $<.084$ & $<.009$ & $<.006$ & $<.006$ & $<.021$ & $<.014$ & $<.004$ & $<.002$ & $<.004$ & $<.005$ & $<.049$ & $<.039$ & $<.029$ & $<.012$ \\
\hline 293120098285801 & $<.005$ & $<.006$ & $<.012$ & $<.084$ & $<.009$ & $<.006$ & -- & -- & -- & -- & $<.002$ & $<.004$ & -- & $<.049$ & $\mathrm{u}$ & $<.029$ & $<.012$ \\
\hline 293120098285801 & -- & -- & -- & -- & -- & -- & -- & -- & -- & -- & -- & -- & -- & -- & -- & -- & -- \\
\hline 293145098224201 & $<.005$ & $<.006$ & $<.012$ & $<.084$ & $<.009$ & $<.006$ & -- & -- & -- & -- & $<.002$ & $<.004$ & -- & $<.049$ & $\mathrm{u}$ & $<.029$ & $<.012$ \\
\hline 293119098211201 & $<.005$ & $<.006$ & $<.012$ & $<.084$ & $<.009$ & $<.006$ & -- & -- & -- & -- & $<.002$ & $<.004$ & -- & $<.049$ & $\mathrm{u}$ & $<.029$ & $<.012$ \\
\hline 292843098425101 & $<.005$ & $<.006$ & $<.012$ & $<.084$ & $<.009$ & $<.006$ & -- & -- & -- & -- & $<.002$ & $<.004$ & -- & $<.049$ & $<.039$ & $<.029$ & $<.012$ \\
\hline 292459098382101 & $<.005$ & $<.006$ & $<.012$ & $<.084$ & $<.009$ & $<.006$ & -- & -- & -- & -- & $<.002$ & $<.004$ & -- & $<.049$ & $\mathrm{u}$ & $<.029$ & $<.012$ \\
\hline 292925098360201 & $<.005$ & $<.006$ & $<.012$ & $<.084$ & $<.009$ & $<.006$ & -- & -- & -- & -- & $<.002$ & $<.004$ & -- & $<.049$ & $<.039$ & $<.029$ & $<.012$ \\
\hline 292925098360201 & $<.005$ & $<.006$ & $<.012$ & $<.084$ & $<.009$ & $<.006$ & $<.006$ & $<.021$ & $<.014$ & $<.004$ & $<.002$ & $<.004$ & $<.005$ & $<.049$ & $<.039$ & $<.029$ & $<.012$ \\
\hline 292822098325401 & $<.005$ & $<.006$ & $<.012$ & $<.084$ & $<.009$ & $<.006$ & -- & -- & -- & -- & $<.002$ & $<.004$ & -- & $<.049$ & $<.039$ & $<.029$ & $<.012$ \\
\hline 292822098325401 & $<.005$ & $<.006$ & $<.012$ & $<.084$ & $<.009$ & $<.006$ & $<.006$ & $<.021$ & $<.014$ & $<.004$ & $<.002$ & $<.004$ & $<.005$ & $<.049$ & $<.039$ & $<.029$ & $<.012$ \\
\hline 292944098292301 & $<.005$ & $<.006$ & $<.012$ & $<.084$ & $<.009$ & $<.006$ & -- & -- & -- & -- & $<.002$ & $<.004$ & -- & $<.049$ & $\mathrm{u}$ & $<.029$ & $<.012$ \\
\hline 292944098292301 & $<.005$ & $<.006$ & $<.012$ & $<.084$ & $<.009$ & $<.006$ & $<.006$ & $<.021$ & $<.014$ & $<.004$ & $<.002$ & $<.004$ & $<.005$ & $<.049$ & $<.039$ & $<.029$ & $<.012$ \\
\hline 292522098291901 & $<.005$ & $<.006$ & $<.012$ & $<.084$ & $<.009$ & $<.006$ & -- & -- & -- & -- & $<.002$ & $<.004$ & -- & $<.049$ & $\mathrm{u}$ & $<.029$ & $<.012$ \\
\hline 292643098241801 & $<.005$ & $<.006$ & $<.012$ & $<.084$ & $<.009$ & $<.006$ & -- & -- & -- & -- & $<.002$ & $<.004$ & -- & $<.049$ & $\mathrm{u}$ & $<.029$ & $<.012$ \\
\hline 292643098241801 & -- & -- & -- & -- & -- & -- & -- & -- & -- & -- & -- & -- & -- & -- & -- & -- & -- \\
\hline 292328098294601 & $<.005$ & $<.006$ & $<.012$ & $<.084$ & $<.009$ & $<.006$ & -- & -- & -- & -- & $<.002$ & $<.004$ & -- & $<.049$ & $\mathrm{u}$ & $<.029$ & $<.012$ \\
\hline 294225098080301 & $<.005$ & $<.006$ & $<.012$ & $<.084$ & $<.009$ & $<.006$ & -- & -- & -- & -- & $<.002$ & $<.004$ & -- & $<.049$ & $<.039$ & $<.029$ & $<.012$ \\
\hline 294225098080301 & $<.005$ & $<.006$ & $<.012$ & $<.084$ & $<.009$ & $<.006$ & $<.006$ & $<.021$ & $<.014$ & $<.004$ & $<.002$ & $<.004$ & $<.005$ & $<.049$ & $<.039$ & $<.029$ & $<.012$ \\
\hline 291210099475601 & $<.005$ & $<.006$ & $<.012$ & $<.084$ & $<.009$ & $<.006$ & -- & -- & -- & -- & $<.002$ & $<.004$ & -- & $<.049$ & $<.039$ & $<.029$ & $<.012$ \\
\hline 293111098340901 & $<.005$ & $<.006$ & $<.012$ & $<.084$ & $<.009$ & $<.006$ & -- & -- & -- & -- & $<.002$ & $<.004$ & -- & $<.049$ & $<.039$ & $<.029$ & $<.012$ \\
\hline 293512098291701 & $<.005$ & $<.006$ & $<.012$ & $<.084$ & $<.009$ & $<.006$ & -- & -- & -- & -- & $<.002$ & $<.004$ & -- & $<.049$ & $<.039$ & $<.029$ & $<.012$ \\
\hline 292424098421501 & $<.005$ & $<.006$ & $<.012$ & $<.084$ & $<.009$ & $<.006$ & -- & -- & -- & -- & $<.002$ & $<.004$ & -- & $<.049$ & $<.039$ & $<.029$ & $<.012$ \\
\hline
\end{tabular}


Table 15. Soluble pesticide compounds for groundwater samples collected for the study of the transport of anthropogenic and natural contaminants (TANC) to public supply wells in the San Antonio segment of the Edwards aquifer near San Antonio, south-central Texas, 2004-9._Continued

[By sample category. USGS, U.S. Geological Survey; MW, monitoring well; OVB, overburden; $\mu$ g/L, micrograms per liter; --, not measured; E, estimated; u, unable to determine; <, nondetection less than laboratory method reporting level]

\begin{tabular}{|c|c|c|c|c|c|c|c|c|c|c|c|c|c|c|c|c|c|}
\hline $\begin{array}{c}\text { USGS } \\
\text { identification } \\
\text { number }\end{array}$ & $\begin{array}{c}\text { Diaz- } \\
\text { inon } \\
(\mu \mathrm{g} / \mathrm{L})\end{array}$ & $\begin{array}{l}\text { Diaz- } \\
\text { oxon } \\
(\mu \mathrm{g} / \mathrm{L})\end{array}$ & $\begin{array}{c}\text { Di- } \\
\text { chlor- } \\
\text { vos } \\
(\mu \mathrm{g} / \mathrm{L})\end{array}$ & $\begin{array}{l}\text { Di- } \\
\text { croto- } \\
\text { phos } \\
(\mu \mathrm{g} / \mathrm{L})\end{array}$ & $\begin{array}{l}\text { Diel- } \\
\text { drin } \\
(\mu \mathrm{g} / \mathrm{L})\end{array}$ & $\begin{array}{c}\text { Di- } \\
\text { meth- } \\
\text { oate } \\
(\mu \mathrm{g} / \mathrm{L})\end{array}$ & $\begin{array}{c}\text { Di- } \\
\text { sulf- } \\
\text { oton } \\
\text { sulfone } \\
\text { ( } \mu \mathrm{g} / \mathrm{L})\end{array}$ & $\begin{array}{l}\text { Di- } \\
\text { sulf- } \\
\text { oton } \\
(\mu \mathrm{g} / \mathrm{L})\end{array}$ & $\begin{array}{c}\text { Endo- } \\
\text { sulfan } \\
\text { sulfate } \\
\text { ( } \mu \mathrm{g} / \mathrm{L} \text { ) }\end{array}$ & $\begin{array}{l}\text { EPTC } \\
(\mu \mathrm{g} / \mathrm{L})\end{array}$ & $\begin{array}{c}\text { Ethion } \\
\text { mon- } \\
\text { oxon } \\
\text { ( } \mu \mathrm{g} / \mathrm{L})\end{array}$ & $\begin{array}{l}\text { Ethion } \\
\text { ( } \mu \mathrm{g} / \mathrm{L})\end{array}$ & $\begin{array}{l}\text { Etho- } \\
\text { prop } \\
\text { ( } \mu \mathrm{g} / \mathrm{L})\end{array}$ & $\begin{array}{c}\text { Fen- } \\
\text { amiphos } \\
\text { sulfone } \\
\text { ( } \mu \mathrm{g} / \mathrm{L})\end{array}$ & $\begin{array}{l}\text { Fen- } \\
\text { ami- } \\
\text { phos } \\
\text { sulf- } \\
\text { oxide } \\
\text { ( } \mathrm{pg} / \mathrm{L} \text { ) }\end{array}$ & $\begin{array}{l}\text { Fen- } \\
\text { ami- } \\
\text { phos } \\
\text { ( } \mu \mathrm{g} / \mathrm{L})\end{array}$ & $\begin{array}{l}\text { Desulf- } \\
\text { inyl- } \\
\text { fipronil } \\
(\mu \mathrm{g} / \mathrm{L})\end{array}$ \\
\hline 292053098365501 & $<0.005$ & $<0.006$ & $<0.012$ & $<0.084$ & $<0.009$ & $<0.006$ & -- & -- & -- & -- & $<0.002$ & $<0.004$ & -- & $<0.049$ & $<0.039$ & $<0.029$ & $<0.012$ \\
\hline 293807098155301 & $<.005$ & $<.006$ & $<.012$ & $<.084$ & $<.009$ & $<.006$ & -- & -- & -- & -- & $<.002$ & $<.004$ & -- & $<.049$ & $<.039$ & $<.029$ & $<.012$ \\
\hline 292604098563201 & $<.005$ & $<.006$ & $<.012$ & $<.084$ & $<.009$ & $<.006$ & -- & -- & -- & -- & $<.002$ & $<.004$ & -- & $<.049$ & $<.039$ & $<.029$ & $<.012$ \\
\hline 292116099095501 & $<.005$ & $<.006$ & $<.012$ & $<.084$ & $<.009$ & $<.006$ & -- & -- & -- & -- & $<.002$ & $<.004$ & -- & $<.049$ & $<.039$ & $<.029$ & $<.012$ \\
\hline 291232099470301 & $<.005$ & $<.006$ & $<.012$ & $<.084$ & $<.009$ & $<.006$ & -- & -- & -- & -- & $<.002$ & $<.004$ & -- & $<.049$ & $<.039$ & $<.029$ & $<.012$ \\
\hline 293128098473101 & $<.005$ & $<.006$ & $<.012$ & $<.084$ & $<.009$ & $<.006$ & -- & -- & -- & -- & $<.002$ & $<.004$ & -- & $<.049$ & $<.039$ & $<.029$ & $<.012$ \\
\hline 293451098313201 & $<.005$ & $<.006$ & $<.012$ & $<.084$ & $<.009$ & $<.006$ & -- & -- & -- & -- & $<.002$ & $<.004$ & -- & $<.049$ & $<.039$ & $<.029$ & $<.012$ \\
\hline 294604098060801 & $<.005$ & $<.006$ & $<.012$ & $<.084$ & $<.009$ & $<.006$ & -- & -- & -- & -- & $<.002$ & $<.004$ & -- & $<.049$ & $<.039$ & $<.029$ & $<.012$ \\
\hline 294019098114701 & $<.005$ & $<.006$ & $<.012$ & $<.084$ & $<.009$ & $<.006$ & -- & -- & -- & -- & $<.002$ & $<.004$ & -- & $<.049$ & $<.039$ & $<.029$ & $<.012$ \\
\hline 292215098580201 & $<.005$ & $<.006$ & $<.012$ & $<.084$ & $<.009$ & $<.006$ & -- & -- & -- & -- & $<.002$ & $<.004$ & -- & $<.049$ & $<.039$ & $<.029$ & $<.012$ \\
\hline 292119098524901 & $<.005$ & $<.006$ & $<.012$ & $<.084$ & $<.009$ & $<.006$ & -- & -- & -- & -- & $<.002$ & $<.004$ & -- & $<.049$ & $<.039$ & $<.029$ & $<.012$ \\
\hline 291943099163301 & $<.005$ & $<.006$ & $<.012$ & $<.084$ & $<.009$ & $<.006$ & -- & -- & -- & -- & $<.002$ & $<.004$ & -- & $<.049$ & $<.039$ & $<.029$ & $<.012$ \\
\hline 291840099382601 & $<.005$ & $<.006$ & $<.012$ & $<.084$ & $<.009$ & $<.006$ & -- & -- & -- & -- & $<.002$ & $<.004$ & -- & $<.049$ & $<.039$ & $<.029$ & $<.012$ \\
\hline 293518098332601 & $<.005$ & $<.006$ & $<.012$ & $<.084$ & $<.009$ & $<.006$ & -- & -- & -- & -- & $<.002$ & $<.004$ & -- & $<.049$ & $<.039$ & $<.029$ & $<.012$ \\
\hline 293023098355401 & $<.005$ & $<.006$ & $<.012$ & $<.084$ & $<.009$ & $<.006$ & -- & -- & -- & -- & $<.002$ & $<.004$ & -- & $<.049$ & $<.039$ & $<.029$ & $<.012$ \\
\hline 293042098305201 & $<.005$ & $<.006$ & $<.012$ & $<.084$ & $<.009$ & $<.006$ & $<0.006$ & $<0.021$ & $<0.014$ & $<0.004$ & $<.002$ & $<.004$ & $<0.005$ & $<.049$ & $<.039$ & $<.029$ & $<.012$ \\
\hline 292442098474501 & $<.005$ & $<.006$ & $<.012$ & $<.084$ & E.003 & $<.006$ & -- & -- & -- & -- & $<.002$ & $<.004$ & -- & $<.049$ & $<.039$ & $<.029$ & $<.012$ \\
\hline 292405098371201 & $<.005$ & $<.006$ & $<.012$ & $<.084$ & $<.009$ & $<.006$ & -- & -- & -- & -- & $<.002$ & $<.004$ & -- & $<.049$ & $<.039$ & $<.029$ & $<.012$ \\
\hline 292931098274601 & $<.005$ & $<.006$ & $<.012$ & $<.084$ & $<.009$ & $<.006$ & -- & -- & -- & -- & $<.002$ & $<.004$ & -- & $<.049$ & $<.039$ & $<.029$ & $<.012$ \\
\hline 293729098173101 & $<.005$ & $<.006$ & $<.012$ & $<.084$ & $<.009$ & $<.006$ & -- & -- & -- & -- & $<.002$ & $<.004$ & -- & $<.049$ & $<.039$ & $<.029$ & $<.012$ \\
\hline 291219099095601 & $<.005$ & $<.006$ & $<.012$ & $<.084$ & $<.009$ & $<.006$ & -- & -- & -- & -- & $<.002$ & $<.004$ & -- & $<.049$ & $<.039$ & $<.029$ & $<.012$ \\
\hline \multicolumn{18}{|c|}{ Monitoring wells } \\
\hline 292943098354401 & $<.005$ & $<.006$ & $<.013$ & $<.084$ & $<.009$ & $<.006$ & $<.014$ & $<.04$ & $<.022$ & $<.002$ & $<.021$ & $<.006$ & $<.012$ & $<.053$ & $<.06$ & $<.029$ & $<.012$ \\
\hline 292943098354402 & $<.005$ & $<.006$ & $<.013$ & $<.084$ & $<.009$ & $<.006$ & $<.014$ & $<.060$ & $<.022$ & $<.002$ & $<.021$ & $<.006$ & $<.012$ & $<.053$ & $<.040$ & $<.029$ & $<.012$ \\
\hline 292943098354403 & $<.005$ & $<.006$ & $<.013$ & $<.084$ & $<.009$ & $<.006$ & $<.014$ & $<.04$ & $<.022$ & $<.002$ & $<.021$ & $<.006$ & $<.012$ & $<.053$ & $<.06$ & $<.029$ & $<.012$ \\
\hline 292943098354404 & $<.005$ & $<.006$ & $<.013$ & $<.084$ & $<.009$ & $<.006$ & $<.014$ & $<.04$ & $<.022$ & $<.002$ & $<.021$ & $<.006$ & $<.012$ & $<.053$ & $<.040$ & $<.029$ & $<.012$ \\
\hline 292851098374401 & $<0.005$ & $<0.006$ & $<0.013$ & $<0.084$ & $<0.009$ & $<0.006$ & $<0.014$ & $<0.04$ & $<0.022$ & $<0.002$ & $<0.021$ & $<0.006$ & $<0.012$ & $<0.053$ & $<0.2$ & $<0.029$ & $<0.012$ \\
\hline
\end{tabular}


Table 15. Soluble pesticide compounds for groundwater samples collected for the study of the transport of anthropogenic and natural contaminants (TANC) to public supply wells in the San Antonio segment of the Edwards aquifer near San Antonio, south-central Texas, 2004-9._Continued

[By sample category. USGS, U.S. Geological Survey; MW, monitoring well; OVB, overburden; $\mathrm{ng} / \mathrm{L}$, micrograms per liter; --, not measured; E, estimated; u, unable to determine; <, nondetection less than laboratory method reporting level]

\begin{tabular}{|c|c|c|c|c|c|c|c|c|c|c|c|c|c|c|c|c|c|}
\hline $\begin{array}{c}\text { USGS } \\
\text { identification } \\
\text { number }\end{array}$ & $\begin{array}{c}\text { Diaz- } \\
\text { inon } \\
(\mu \mathrm{g} / \mathrm{L})\end{array}$ & $\begin{array}{l}\text { Diaz- } \\
\text { oxon } \\
(\mu \mathrm{g} / \mathrm{L})\end{array}$ & $\begin{array}{l}\text { Di- } \\
\text { chlor- } \\
\text { vos } \\
(\mu \mathrm{g} / \mathrm{L})\end{array}$ & $\begin{array}{c}\text { Di- } \\
\text { croto- } \\
\text { phos } \\
(\mu \mathrm{g} / \mathrm{L})\end{array}$ & $\begin{array}{c}\text { Diel- } \\
\text { drin } \\
(\mu \mathrm{g} / \mathrm{L})\end{array}$ & $\begin{array}{c}\text { Di- } \\
\text { meth- } \\
\text { oate } \\
(\mu \mathrm{g} / \mathrm{L})\end{array}$ & $\begin{array}{c}\text { Di- } \\
\text { sulf- } \\
\text { oton } \\
\text { sulfone } \\
(\mu \mathrm{g} / \mathrm{L})\end{array}$ & $\begin{array}{c}\text { Di- } \\
\text { sulf- } \\
\text { oton } \\
(\mu \mathrm{g} / \mathrm{L})\end{array}$ & $\begin{array}{l}\text { Endo- } \\
\text { sulfan } \\
\text { sulfate } \\
(\mu \mathrm{g} / \mathrm{L})\end{array}$ & $\begin{array}{c}\text { EPTC } \\
\text { ( } \mu \mathrm{g} / \mathrm{L})\end{array}$ & $\begin{array}{l}\text { Ethion } \\
\text { mon- } \\
\text { oxon } \\
(\mu \mathrm{g} / \mathrm{L})\end{array}$ & $\begin{array}{l}\text { Ethion } \\
\text { ( } \mu \mathrm{g} / \mathrm{L})\end{array}$ & $\begin{array}{l}\text { Etho- } \\
\text { prop } \\
(\mu \mathrm{g} / \mathrm{L})\end{array}$ & $\begin{array}{c}\text { Fen- } \\
\text { amiphos } \\
\text { sulfone } \\
(\mu \mathrm{g} / \mathrm{L})\end{array}$ & $\begin{array}{l}\text { Fen- } \\
\text { ami- } \\
\text { phos } \\
\text { sulf- } \\
\text { oxide } \\
\text { ( } \mu \mathrm{g} / \mathrm{L} \text { ) }\end{array}$ & $\begin{array}{l}\text { Fen- } \\
\text { ami- } \\
\text { phos } \\
(\mu \mathrm{g} / \mathrm{L})\end{array}$ & $\begin{array}{c}\text { Desulf- } \\
\text { inyl- } \\
\text { fipronil } \\
(\mu \mathrm{g} / \mathrm{L})\end{array}$ \\
\hline 292851098374402 & $<.005$ & $<.006$ & $<.013$ & $<.084$ & $<.009$ & $<.006$ & $<.014$ & $<.04$ & $<.022$ & $<.002$ & $<.021$ & $<.006$ & $<.012$ & $<.053$ & $<.2$ & $<.029$ & $<.012$ \\
\hline \multicolumn{18}{|c|}{ Well-field depth-dependent sampling (W4) } \\
\hline 292916098360701 & $<.005$ & $<.006$ & $<.013$ & $<.084$ & $<.009$ & $<.006$ & $<.014$ & $<.04$ & $<.022$ & $<.002$ & $<.021$ & $<.006$ & $<.012$ & $<.053$ & $<.040$ & $<.029$ & $<.012$ \\
\hline 292916098360701 & $<.005$ & $<.006$ & $<.013$ & $<.084$ & $<.009$ & $<.006$ & $<.014$ & $<.04$ & $<.022$ & $<.002$ & $<.021$ & $<.006$ & $<.012$ & $<.053$ & $<.040$ & $<.029$ & $<.012$ \\
\hline 292916098360701 & $<.005$ & $<.006$ & $<.013$ & $<.084$ & $<.009$ & $<.006$ & $<.014$ & $<.04$ & $<.022$ & $<.002$ & $<.021$ & $<.006$ & $<.012$ & $<.053$ & $<.040$ & $<.029$ & $<.012$ \\
\hline 292916098360701 & $<.005$ & $<.006$ & $<.013$ & $<.084$ & $<.009$ & $<.006$ & $<.014$ & $<.04$ & $<.022$ & $<.002$ & $<.021$ & $<.006$ & $<.012$ & $<.053$ & $<.040$ & $<.029$ & $<.012$ \\
\hline 292916098360701 & $<.005$ & $<.006$ & $<.013$ & $<.084$ & $<.009$ & $<.006$ & $<.014$ & $<.04$ & $<.022$ & $<.002$ & $<.021$ & $<.006$ & $<.012$ & $<.053$ & $<.040$ & $<.029$ & $<.012$ \\
\hline 292916098360701 & $<.005$ & $<.006$ & $<.013$ & $<.084$ & $<.009$ & $<.006$ & $<.014$ & $<.04$ & $<.022$ & $<.002$ & $<.021$ & $<.006$ & $<.012$ & $<.053$ & $<.040$ & $<.029$ & $<.012$ \\
\hline 292916098360701 & $<.005$ & $<.006$ & $<.013$ & $<.084$ & $<.009$ & $<.006$ & $<.014$ & $<.04$ & $<.022$ & $<.002$ & $<.021$ & $<.006$ & $<.012$ & $<.053$ & $<.06$ & $<.029$ & $<.012$ \\
\hline 292916098360701 & $<.005$ & $<.006$ & $<.013$ & $<.084$ & $<.009$ & $<.006$ & $<.014$ & $<.04$ & $<.022$ & $<.002$ & $<.021$ & $<.006$ & $<.012$ & $<.053$ & $<.040$ & $<.029$ & $<.012$ \\
\hline 292916098360701 & $<.005$ & $<.006$ & $<.013$ & $<.084$ & $<.009$ & $<.006$ & $<.014$ & $<.04$ & $<.022$ & $<.002$ & $<.021$ & $<.006$ & $<.012$ & $<.053$ & $<.040$ & $<.029$ & $<.012$ \\
\hline \multicolumn{18}{|c|}{ Well-field wells (wellhead sampling) } \\
\hline 292919098360501 & $<.005$ & $<.006$ & $<.013$ & $<.084$ & $<.009$ & $<.006$ & $<.014$ & $<.04$ & $<.022$ & $<.002$ & $<.021$ & $<.006$ & $<.012$ & $<.053$ & $<.040$ & $<.029$ & $<.012$ \\
\hline 292925098360201 & $<.005$ & $<.006$ & $<.013$ & $<.084$ & $<.009$ & $<.006$ & $<.014$ & $<.04$ & $<.022$ & $<.002$ & $<.021$ & $<.006$ & $<.012$ & $<.053$ & $<.040$ & $<.029$ & $<.012$ \\
\hline 292916098360701 & $<.005$ & $<.006$ & $<.013$ & $<.084$ & $<.009$ & $<.006$ & $<.014$ & $<.04$ & $<.022$ & $<.002$ & $<.021$ & $<.006$ & $<.012$ & $<.053$ & $<.040$ & $<.029$ & $<.012$ \\
\hline 292920098360601 & $<.005$ & $<.006$ & $<.013$ & $<.084$ & $<.009$ & $<.006$ & $<.014$ & $<.04$ & $<.022$ & $<.002$ & $<.021$ & $<.006$ & $<.012$ & $<.053$ & $<.040$ & $<.029$ & $<.012$ \\
\hline 292923098360301 & $<.005$ & $<.006$ & $<.013$ & $<.084$ & $<.009$ & $<.006$ & $<.014$ & $<.04$ & $<.022$ & $<.002$ & $<.021$ & $<.006$ & $<.012$ & $<.053$ & $<.06$ & $<.029$ & $<.012$ \\
\hline \multicolumn{18}{|c|}{ Temporal sampling } \\
\hline 292923098360301 & -- & -- & -- & -- & -- & -- & -- & -- & -- & -- & -- & -- & -- & -- & -- & -- & -- \\
\hline 292923098360301 & -- & -- & -- & -- & -- & -- & -- & -- & -- & -- & -- & -- & -- & -- & -- & -- & -- \\
\hline 292923098360301 & -- & -- & -- & -- & -- & -- & -- & -- & -- & -- & -- & -- & -- & -- & -- & -- & -- \\
\hline 292923098360301 & $<0.005$ & -- & $<0.02$ & $<0.08$ & $<0.009$ & $<0.006$ & $<0.014$ & $<0.04$ & $<0.014$ & $<0.002$ & $<0.021$ & $<0.008$ & $<0.016$ & $<0.053$ & $<0.08$ & $<0.030$ & $<0.012$ \\
\hline
\end{tabular}


Table 15. Soluble pesticide compounds for groundwater samples collected for the study of the transport of anthropogenic and natural contaminants (TANC) to public supply wells in the San Antonio segment of the Edwards aquifer near San Antonio, south-central Texas, 2004-9.-Continued

[By sample category. USGS, U.S. Geological Survey; MW, monitoring well; OVB, overburden; $\mu g / L$, micrograms per liter; --, not measured; E, estimated; u, unable to determine; <, nondetection less than laboratory method reporting level]

\begin{tabular}{|c|c|c|c|c|c|c|c|c|c|c|c|c|c|c|c|c|c|}
\hline $\begin{array}{c}\text { USGS } \\
\text { identification } \\
\text { number }\end{array}$ & $\begin{array}{l}\text { Diaz- } \\
\text { inon } \\
(\mu \mathrm{g} / \mathrm{L})\end{array}$ & $\begin{array}{l}\text { Diaz- } \\
\text { oxon } \\
(\mu \mathrm{g} / \mathrm{L})\end{array}$ & $\begin{array}{c}\text { Di- } \\
\text { chlor- } \\
\text { vos } \\
(\mu \mathrm{g} / \mathrm{L})\end{array}$ & $\begin{array}{c}\text { Di- } \\
\text { croto- } \\
\text { phos } \\
(\mu \mathrm{g} / \mathrm{L})\end{array}$ & $\begin{array}{l}\text { Diel- } \\
\text { drin } \\
(\mu \mathrm{g} / \mathrm{L})\end{array}$ & $\begin{array}{c}\text { Di- } \\
\text { meth- } \\
\text { oate } \\
(\mu \mathrm{g} / \mathrm{L})\end{array}$ & $\begin{array}{c}\text { Di- } \\
\text { sulf- } \\
\text { oton } \\
\text { sulfone } \\
\text { ( } \mu \mathrm{g} / \mathrm{L})\end{array}$ & $\begin{array}{l}\text { Di- } \\
\text { sulf- } \\
\text { oton } \\
(\mu \mathrm{g} / \mathrm{L})\end{array}$ & $\begin{array}{l}\text { Endo- } \\
\text { sulfan } \\
\text { sulfate } \\
(\mu \mathrm{g} / \mathrm{L})\end{array}$ & $\begin{array}{l}\text { EPTC } \\
(\mu \mathrm{g} / \mathrm{L})\end{array}$ & $\begin{array}{c}\text { Ethion } \\
\text { mon- } \\
\text { oxon } \\
\text { ( } \mu \mathrm{g} / \mathrm{L})\end{array}$ & $\begin{array}{l}\text { Ethion } \\
\text { ( } \mu \mathrm{g} / \mathrm{L})\end{array}$ & $\begin{array}{l}\text { Etho- } \\
\text { prop } \\
(\mu \mathrm{g} / \mathrm{L})\end{array}$ & $\begin{array}{c}\text { Fen- } \\
\text { amiphos } \\
\text { sulfone } \\
\text { ( } \mu \mathrm{g} / \mathrm{L})\end{array}$ & $\begin{array}{l}\text { Fen- } \\
\text { ami- } \\
\text { phos } \\
\text { sulf- } \\
\text { oxide } \\
\text { ( } \mathrm{pg} / \mathrm{L} \text { ) }\end{array}$ & $\begin{array}{l}\text { Fen- } \\
\text { ami- } \\
\text { phos } \\
\text { ( } \mu \mathrm{g} / \mathrm{L})\end{array}$ & $\begin{array}{l}\text { Desulf- } \\
\text { inyl- } \\
\text { fipronil } \\
(\mu \mathrm{g} / \mathrm{L})\end{array}$ \\
\hline 292923098360301 & $<.005$ & -- & $<.02$ & $<.08$ & $<.009$ & $<.006$ & $<.014$ & $<.04$ & $<.014$ & $<.002$ & $<.021$ & $<.008$ & $<.016$ & $<.053$ & $<.08$ & $<.030$ & $<.012$ \\
\hline 292923098360301 & $<.005$ & -- & $<.02$ & $<.08$ & $<.009$ & $<.006$ & $<.014$ & $<.04$ & $<.014$ & $<.002$ & $<.021$ & $<.008$ & $<.016$ & $<.053$ & $<.08$ & $<.030$ & $<.012$ \\
\hline 292943098354402 & -- & -- & -- & -- & -- & -- & -- & -- & -- & -- & -- & -- & -- & -- & -- & -- & -- \\
\hline 292943098354402 & -- & -- & -- & -- & -- & -- & -- & -- & -- & -- & -- & -- & -- & -- & -- & -- & -- \\
\hline 292943098354402 & -- & -- & -- & -- & -- & -- & -- & -- & -- & -- & -- & -- & -- & -- & -- & -- & -- \\
\hline 292943098354402 & $<.005$ & -- & $<.02$ & $<.08$ & $<.009$ & $<.006$ & $<.014$ & $<.04$ & $<.014$ & $<.002$ & $<.021$ & $<.008$ & $<.016$ & $<.053$ & $<.08$ & $<.030$ & $<.012$ \\
\hline 292943098354402 & $<.005$ & -- & $<.02$ & $<.08$ & $<.009$ & $<.006$ & $<.014$ & $<.04$ & $<.014$ & $<.002$ & $<.021$ & $<.008$ & $<.016$ & $<.053$ & $<.08$ & $<.030$ & $<.012$ \\
\hline 292943098354402 & $<.005$ & -- & $<.02$ & $<.08$ & $<.009$ & $<.006$ & $<.014$ & $<.04$ & $<.014$ & $<.002$ & $<.021$ & $<.008$ & $<.016$ & $<.053$ & $<.08$ & $<.030$ & $<.012$ \\
\hline 292943098354403 & -- & -- & -- & -- & -- & -- & -- & -- & -- & -- & -- & -- & -- & -- & -- & -- & -- \\
\hline 292943098354403 & -- & -- & -- & -- & -- & -- & -- & -- & -- & -- & -- & -- & -- & -- & -- & -- & -- \\
\hline 292943098354403 & -- & -- & -- & -- & -- & -- & -- & -- & -- & -- & -- & -- & -- & -- & -- & -- & -- \\
\hline 292943098354403 & $<.005$ & -- & $<.02$ & $<.08$ & $<.009$ & $<.006$ & $<.014$ & $<.04$ & $<.014$ & $<.002$ & $<.021$ & $<.008$ & $<.016$ & $<.053$ & $<.08$ & $<.030$ & $<.012$ \\
\hline 292943098354403 & $<.005$ & -- & $<.02$ & $<.08$ & $<.009$ & $<.006$ & $<.014$ & $<.04$ & $<.014$ & $<.002$ & $<.021$ & $<.008$ & $<.016$ & $<.053$ & $<.08$ & $<.030$ & $<.012$ \\
\hline 292943098354403 & $<.005$ & -- & $<.02$ & $<.08$ & $<.009$ & $<.006$ & $<.014$ & $<.04$ & $<.014$ & $<.002$ & $<.021$ & $<.008$ & $<.016$ & $<.053$ & $<.08$ & $<.030$ & $<.012$ \\
\hline 292943098354404 & -- & -- & -- & -- & -- & -- & -- & -- & -- & -- & -- & -- & -- & -- & -- & -- & -- \\
\hline 292943098354404 & -- & -- & -- & -- & -- & -- & -- & -- & -- & -- & -- & -- & -- & -- & -- & -- & -- \\
\hline 292943098354404 & -- & -- & -- & -- & -- & -- & -- & -- & -- & -- & -- & -- & -- & -- & -- & -- & -- \\
\hline 292943098354404 & $<.005$ & -- & $<.02$ & $<.08$ & $<.009$ & $<.006$ & $<.014$ & $<.04$ & $<.014$ & $<.002$ & $<.021$ & $<.008$ & $<.016$ & $<.053$ & $<.08$ & $<.030$ & $<.012$ \\
\hline 292943098354404 & $<.005$ & -- & $<.02$ & $<.08$ & $<.009$ & $<.006$ & $<.014$ & $<.04$ & $<.014$ & $<.002$ & $<.021$ & $<.008$ & $<.016$ & $<.053$ & $<.08$ & $<.030$ & $<.012$ \\
\hline 292943098354404 & $<.005$ & -- & $<.02$ & $<.08$ & $<.009$ & $<.006$ & $<.014$ & $<.04$ & $<.014$ & $<.002$ & $<.021$ & $<.008$ & $<.016$ & $<.053$ & $<.08$ & $<.030$ & $<.012$ \\
\hline 293252098380801 & -- & -- & -- & -- & -- & -- & -- & -- & -- & -- & -- & -- & -- & -- & -- & -- & -- \\
\hline 293252098380801 & -- & -- & -- & -- & -- & -- & -- & -- & -- & -- & -- & -- & -- & -- & -- & -- & -- \\
\hline 293252098380801 & -- & -- & -- & -- & -- & -- & -- & -- & -- & -- & -- & -- & -- & -- & -- & -- & -- \\
\hline 293252098380801 & $<.005$ & -- & $<.02$ & $<.08$ & $<.009$ & $<.006$ & $<.014$ & $<.04$ & $<.014$ & $<.002$ & $<.021$ & $<.008$ & $<.016$ & $<.053$ & $<.08$ & $<.030$ & $<.012$ \\
\hline 293252098380801 & $<.005$ & -- & $<.02$ & $<.08$ & $<.009$ & $<.006$ & $<.014$ & $<.04$ & $<.014$ & $<.002$ & $<.021$ & $<.008$ & $<.016$ & $<.053$ & $<.08$ & $<.030$ & $<.012$ \\
\hline 293252098380801 & $<.005$ & -- & $<.02$ & $<.08$ & $<.009$ & $<.006$ & $<.014$ & $<.04$ & $<.014$ & $<.002$ & $<.021$ & $<.008$ & $<.016$ & $<.053$ & $<.08$ & $<.030$ & $<.012$ \\
\hline
\end{tabular}


Table 15. Soluble pesticide compounds for groundwater samples collected for the study of the transport of anthropogenic and natural contaminants (TANC) to public supply wells in the San Antonio segment of the Edwards aquifer near San Antonio, south-central Texas, 2004-9.-Continued

[By sample category. USGS, U.S. Geological Survey; MW, monitoring well; OVB, overburden; $\mu$ g/L, micrograms per liter; --, not measured; E, estimated; u, unable to determine; <, nondetection less than laboratory method reporting level]

\begin{tabular}{|c|c|c|c|c|c|c|c|c|c|c|c|c|c|c|c|c|c|c|}
\hline $\begin{array}{c}\text { USGS } \\
\text { identification } \\
\text { number }\end{array}$ & $\begin{array}{c}\text { Fip- } \\
\text { ronil } \\
\text { sulfide } \\
(\mu \mathrm{g} / \mathrm{L}) \\
\end{array}$ & $\begin{array}{c}\text { Fip- } \\
\text { ronil } \\
\text { sulfone } \\
(\mu \mathrm{g} / \mathrm{L}) \\
\end{array}$ & $\begin{array}{l}\text { Fip- } \\
\text { ronil } \\
(\mu \mathrm{g} / \mathrm{L})\end{array}$ & $\begin{array}{c}\text { Fonofos } \\
\text { oxygen } \\
\text { analog } \\
(\mu \mathrm{g} / \mathrm{L}) \\
\end{array}$ & $\begin{array}{l}\text { Fon- } \\
\text { ofos } \\
(\mu \mathrm{g} / \mathrm{L})\end{array}$ & $\begin{array}{c}\text { Hexa- } \\
\text { zinone } \\
\text { ( } \mathrm{gg} / \mathrm{L})\end{array}$ & $\begin{array}{l}\text { Ipro- } \\
\text { dione } \\
\text { ( } \mu \mathrm{g} / \mathrm{L})\end{array}$ & $\begin{array}{c}\text { Isofen- } \\
\text { phos } \\
\text { ( } \mu \mathrm{g} / \mathrm{L})\end{array}$ & $\begin{array}{c}\text { Mala- } \\
\text { oxon } \\
(\mu \mathrm{g} / \mathrm{L})\end{array}$ & $\begin{array}{l}\text { Mala- } \\
\text { thion } \\
(\mu \mathrm{g} / \mathrm{L})\end{array}$ & $\begin{array}{l}\text { Meta- } \\
\text { laxyl } \\
(\mu \mathrm{g} / \mathrm{L})\end{array}$ & $\begin{array}{l}\text { Meth- } \\
\text { ida- } \\
\text { thion } \\
(\mu \mathrm{g} / \mathrm{L})\end{array}$ & $\begin{array}{c}\text { Methyl } \\
\text { para- } \\
\text { oxon } \\
(\mu \mathrm{g} / \mathrm{L}) \\
\end{array}$ & $\begin{array}{c}\text { Methyl } \\
\text { para- } \\
\text { thion } \\
(\mu \mathrm{g} / \mathrm{L}) \\
\end{array}$ & $\begin{array}{l}\text { Meto- } \\
\text { la- } \\
\text { chlor } \\
(\mu \mathrm{g} / \mathrm{L})\end{array}$ & $\begin{array}{l}\text { Metri- } \\
\text { buzin } \\
(\mu \mathrm{g} / \mathrm{L})\end{array}$ & $\begin{array}{l}\text { Mol- } \\
\text { inate } \\
(\mu \mathrm{g} / \mathrm{L})\end{array}$ & $\begin{array}{l}\text { Myclo- } \\
\text { but- } \\
\text { anil } \\
\text { ( } \mu \mathrm{g} / \mathrm{L})\end{array}$ \\
\hline \multicolumn{19}{|c|}{ Regional aquifer public-supply wells } \\
\hline 293359098290301 & $<0.013$ & $<0.024$ & $<0.016$ & $<0.003$ & $<0.003$ & $<0.013$ & $<0.387$ & $<0.003$ & $<0.030$ & $<0.027$ & $<0.005$ & $<0.006$ & $<0.030$ & $<0.015$ & $<0.006$ & $<0.006$ & -- & $<0.008$ \\
\hline 293359098290301 & $<.013$ & $<.024$ & $<.016$ & -- & $<.003$ & $<.013$ & $<.538$ & $<.003$ & $<.030$ & $<.027$ & $<.005$ & $<.006$ & $<.030$ & $<.015$ & $<.006$ & $<.006$ & $<0.003$ & $<.008$ \\
\hline 293358098231101 & $<.013$ & $<.024$ & $<.016$ & $<.003$ & $<.003$ & $<.013$ & $<.387$ & $<.003$ & $<.030$ & $<.027$ & $<.005$ & $<.006$ & $<.030$ & $<.015$ & $<.006$ & $<.006$ & -- & $<.008$ \\
\hline 293358098231101 & $<.013$ & $<.024$ & $<.016$ & -- & $<.003$ & $<.013$ & $<.538$ & $<.003$ & $<.030$ & $<.027$ & $<.005$ & $<.006$ & $<.030$ & $<.015$ & $<.006$ & $<.006$ & $<.003$ & $<.008$ \\
\hline 293120098285801 & $<.013$ & $<.024$ & $<.016$ & $<.003$ & $<.003$ & $<.013$ & $<.387$ & $<.003$ & $<.030$ & $<.027$ & $<.005$ & $<.006$ & $<.030$ & $<.015$ & $<.006$ & $<.006$ & -- & $<.008$ \\
\hline 293120098285801 & -- & -- & -- & -- & -- & -- & -- & -- & -- & -- & -- & -- & -- & -- & -- & -- & -- & -- \\
\hline 293145098224201 & $<.013$ & $<.024$ & $<.016$ & $<.003$ & $<.003$ & $<.013$ & $<.387$ & $<.003$ & $<.030$ & $<.027$ & $<.005$ & $<.006$ & $<.030$ & $<.015$ & $<.006$ & $<.006$ & -- & $<.008$ \\
\hline 293119098211201 & $<.013$ & $<.024$ & $<.016$ & $<.003$ & $<.003$ & $<.013$ & $<.387$ & $<.003$ & $<.030$ & $<.027$ & $<.005$ & $<.006$ & $<.030$ & $<.015$ & $<.006$ & $<.006$ & -- & $<.008$ \\
\hline 292843098425101 & $<.013$ & $<.024$ & $<.016$ & $<.003$ & $<.003$ & $<.013$ & $<.387$ & $<.003$ & $<.030$ & $<.027$ & $<.005$ & $<.006$ & $<.030$ & $<.015$ & $<.006$ & $<.006$ & -- & $<.008$ \\
\hline 292459098382101 & $<.013$ & $<.024$ & $<.016$ & $<.003$ & $<.003$ & $<.013$ & $<.387$ & $<.003$ & $<.030$ & $<.027$ & $<.005$ & $<.006$ & $<.030$ & $<.015$ & $<.006$ & $<.006$ & -- & $<.008$ \\
\hline 292925098360201 & $<.013$ & $<.024$ & $<.016$ & $<.003$ & $<.003$ & $<.013$ & $<.387$ & $<.003$ & $<.030$ & $<.027$ & $<.005$ & $<.006$ & $<.030$ & $<.015$ & $<.006$ & $<.006$ & -- & $<.008$ \\
\hline 292925098360201 & $<.013$ & $<.024$ & $<.016$ & -- & $<.003$ & $<.013$ & $<.538$ & $<.003$ & $<.030$ & $<.027$ & $<.005$ & $<.006$ & $<.030$ & $<.015$ & $<.006$ & $<.006$ & $<.003$ & $<.008$ \\
\hline 292822098325401 & $<.013$ & $<.024$ & $<.016$ & $<.003$ & $<.003$ & $<.013$ & $<.387$ & $<.003$ & $<.030$ & $<.027$ & $<.005$ & $<.006$ & $<.030$ & $<.015$ & $<.006$ & $<.006$ & -- & $<.008$ \\
\hline 292822098325401 & $<.013$ & $<.024$ & $<.016$ & -- & $<.003$ & $<.013$ & $<.538$ & $<.003$ & $<.030$ & $<.027$ & $<.005$ & $<.006$ & $<.030$ & $<.015$ & $<.006$ & $<.006$ & $<.003$ & $<.008$ \\
\hline 292944098292301 & $<.013$ & $<.024$ & $<.016$ & $<.003$ & $<.003$ & $<.013$ & $<.387$ & $<.003$ & $<.030$ & $<.027$ & $<.005$ & $<.006$ & $<.030$ & $<.015$ & $<.006$ & $<.006$ & -- & $<.008$ \\
\hline 292944098292301 & $<.013$ & $<.024$ & $<.016$ & -- & $<.003$ & $<.013$ & $<.538$ & $<.003$ & $<.030$ & $<.027$ & $<.005$ & $<.006$ & $<.030$ & $<.015$ & $<.006$ & $<.006$ & $<.003$ & $<.008$ \\
\hline 292522098291901 & $<.013$ & $<.024$ & $<.016$ & $<.003$ & $<.003$ & $<.013$ & $<.387$ & $<.003$ & $<.030$ & $<.027$ & $<.005$ & $<.006$ & $<.030$ & $<.015$ & $<.006$ & $<.006$ & -- & $<.008$ \\
\hline 292643098241801 & $<.013$ & $<.024$ & $<.016$ & $<.003$ & $<.003$ & $<.013$ & $<.387$ & $<.003$ & $<.030$ & $<.027$ & $<.005$ & $<.006$ & $<.030$ & $<.015$ & $<.006$ & $<.006$ & -- & $<.008$ \\
\hline 292643098241801 & -- & -- & -- & -- & -- & -- & -- & -- & -- & -- & -- & -- & -- & -- & -- & -- & -- & -- \\
\hline 292328098294601 & $<.013$ & $<.024$ & $<.016$ & $<.003$ & $<.003$ & $<.013$ & $<.387$ & $<.003$ & $<.030$ & $<.027$ & $<.005$ & $<.006$ & $<.030$ & $<.015$ & $<.006$ & $<.006$ & -- & $<.008$ \\
\hline 294225098080301 & $<.013$ & $<.024$ & $<.016$ & $<.003$ & $<.003$ & $<.013$ & $<.387$ & $<.003$ & $<.030$ & $<.027$ & $<.005$ & $<.006$ & $<.030$ & $<.015$ & $<.006$ & $<.006$ & -- & $<.008$ \\
\hline 294225098080301 & $<.013$ & $<.024$ & $<.016$ & -- & $<.003$ & $<.013$ & $<.538$ & $<.003$ & $<.030$ & $<.027$ & $<.005$ & $<.006$ & $<.030$ & $<.015$ & $<.006$ & $<.006$ & $<.003$ & $<.008$ \\
\hline 291210099475601 & $<.013$ & $<.024$ & $<.016$ & $<.003$ & $<.003$ & $<.013$ & $<.387$ & $<.003$ & $<.030$ & $<.027$ & $<.005$ & $<.006$ & $<.030$ & $<.015$ & E.003 & $<.006$ & -- & $<.008$ \\
\hline 293111098340901 & $<.013$ & $<.024$ & $<.016$ & -- & $<.003$ & $<.013$ & $<.538$ & $<.003$ & $<.030$ & $<.027$ & $<.005$ & $<.006$ & $<.030$ & $<.015$ & $<.006$ & $<.006$ & -- & $<.008$ \\
\hline 293512098291701 & $<.013$ & $<.024$ & $<.016$ & -- & $<.003$ & $<.013$ & $<.538$ & $<.003$ & $<.030$ & $<.027$ & $<.005$ & $<.006$ & $<.030$ & $<.015$ & $<.006$ & $<.006$ & -- & $<.008$ \\
\hline 292424098421501 & $<.013$ & $<.024$ & $<.016$ & -- & $<.003$ & $<.013$ & $<.538$ & $<.003$ & $<.030$ & $<.027$ & $<.005$ & $<.006$ & $<.030$ & $<.015$ & $<.006$ & $<.006$ & -- & $<.008$ \\
\hline
\end{tabular}


Table 15. Soluble pesticide compounds for groundwater samples collected for the study of the transport of anthropogenic and natural contaminants (TANC) to public supply wells in the San Antonio segment of the Edwards aquifer near San Antonio, south-central Texas, 2004-9._Continued

[By sample category. USGS, U.S. Geological Survey; MW, monitoring well; OVB, overburden; $\mu g / L$, micrograms per liter; --, not measured; E, estimated; u, unable to determine; <, nondetection less than laboratory method reporting level]

\begin{tabular}{|c|c|c|c|c|c|c|c|c|c|c|c|c|c|c|c|c|c|c|}
\hline $\begin{array}{c}\text { USGS } \\
\text { identification } \\
\text { number }\end{array}$ & $\begin{array}{c}\text { Fip- } \\
\text { ronil } \\
\text { sulfide } \\
(\mu \mathrm{g} / \mathrm{L}) \\
\end{array}$ & $\begin{array}{c}\text { Fip- } \\
\text { ronil } \\
\text { sulfone } \\
(\mu \mathrm{g} / \mathrm{L}) \\
\end{array}$ & $\begin{array}{l}\text { Fip- } \\
\text { ronil } \\
(\mu \mathrm{g} / \mathrm{L})\end{array}$ & $\begin{array}{c}\text { Fonofos } \\
\text { oxygen } \\
\text { analog } \\
(\mu \mathrm{g} / \mathrm{L}) \\
\end{array}$ & $\begin{array}{l}\text { Fon- } \\
\text { ofos } \\
(\mu \mathrm{g} / \mathrm{L})\end{array}$ & $\begin{array}{l}\text { Hexa- } \\
\text { zinone } \\
(\mu \mathrm{g} / \mathrm{L})\end{array}$ & $\begin{array}{l}\text { Ipro- } \\
\text { dione } \\
\text { ( } \mu \mathrm{g} / \mathrm{L} \text { ) }\end{array}$ & $\begin{array}{c}\text { Isofen- } \\
\text { phos } \\
\text { (pg/L) }\end{array}$ & $\begin{array}{c}\text { Mala- } \\
\text { oxon } \\
(\mu \mathrm{g} / \mathrm{L})\end{array}$ & $\begin{array}{l}\text { Mala- } \\
\text { thion } \\
\text { ( } \mathrm{gg} / \mathrm{L})\end{array}$ & $\begin{array}{l}\text { Meta- } \\
\text { laxyl } \\
(\mu \mathrm{g} / \mathrm{L})\end{array}$ & $\begin{array}{l}\text { Meth- } \\
\text { ida- } \\
\text { thion } \\
\text { ( } \mu \mathrm{g} / \mathrm{L}) \\
\end{array}$ & $\begin{array}{c}\text { Methyl } \\
\text { para- } \\
\text { oxon } \\
(\mu \mathrm{g} / \mathrm{L}) \\
\end{array}$ & $\begin{array}{l}\text { Methyl } \\
\text { para- } \\
\text { thion } \\
(\mu \mathrm{g} / \mathrm{L})\end{array}$ & $\begin{array}{c}\text { Meto- } \\
\text { la- } \\
\text { chlor } \\
\text { ( } \mu \mathrm{g} / \mathrm{L})\end{array}$ & $\begin{array}{l}\text { Metri- } \\
\text { buzin } \\
(\mu \mathrm{g} / \mathrm{L})\end{array}$ & $\begin{array}{l}\text { Mol- } \\
\text { inate } \\
(\mu \mathrm{g} / \mathrm{L})\end{array}$ & $\begin{array}{l}\text { Myclo- } \\
\text { but- } \\
\text { anil } \\
(\mu \mathrm{g} / \mathrm{L})\end{array}$ \\
\hline 292053098365501 & $<0.013$ & $<0.024$ & $<0.016$ & -- & $<0.003$ & $<0.013$ & $<0.538$ & $<0.003$ & $<0.030$ & $<0.027$ & $<0.005$ & $<0.006$ & $<0.030$ & $<0.015$ & $<0.006$ & $<0.006$ & -- & $<0.008$ \\
\hline 293807098155301 & $<.013$ & $<.024$ & $<.016$ & -- & $<.003$ & $<.013$ & $<.538$ & $<.003$ & $<.030$ & $<.027$ & $<.005$ & $<.006$ & $<.030$ & $<.015$ & $<.006$ & $<.006$ & -- & $<.008$ \\
\hline 292604098563201 & $<.013$ & $<.024$ & $<.016$ & -- & $<.003$ & $<.013$ & $<.538$ & $<.003$ & $<.030$ & $<.027$ & $<.005$ & $<.006$ & $<.030$ & $<.015$ & $<.006$ & $<.006$ & -- & $<.008$ \\
\hline 292116099095501 & $<.013$ & $<.024$ & $<.016$ & -- & $<.003$ & $<.013$ & $<.538$ & $<.003$ & $<.030$ & $<.027$ & $<.005$ & $<.006$ & $<.030$ & $<.015$ & $<.006$ & $<.006$ & -- & $<.008$ \\
\hline 291232099470301 & $<.013$ & $<.024$ & $<.016$ & -- & $<.003$ & $<.013$ & $<.538$ & $<.003$ & $<.030$ & $<.027$ & $<.005$ & $<.006$ & $<.030$ & $<.015$ & $<.006$ & $<.006$ & -- & $<.008$ \\
\hline 293128098473101 & $<.013$ & $<.024$ & $<.016$ & -- & $<.003$ & $<.013$ & $<.538$ & $<.00$ & $<.030$ & $<.027$ & $<.005$ & $<.006$ & $<.030$ & $<$. & $<.006$ & $<.006$ & -- & $<.008$ \\
\hline 293451098313201 & $<.013$ & $<.024$ & $<.016$ & -- & $<.003$ & $<.013$ & $<.538$ & $<.003$ & $<.030$ & $<.027$ & $<.005$ & $<.006$ & $<.030$ & $<.015$ & $<.006$ & $<.006$ & -- & $<.008$ \\
\hline 294604098060801 & $<.013$ & $<.024$ & $<.016$ & -- & $<.003$ & $<.013$ & $<.538$ & $<.003$ & $<.030$ & $<.027$ & $<.005$ & $<.006$ & $<.030$ & $<.015$ & $<.006$ & $<.006$ & -- & $<.008$ \\
\hline 294019098114701 & $<.013$ & $<.024$ & $<.016$ & -- & $<.003$ & $<.013$ & $<.538$ & $<.003$ & $<.030$ & $<.027$ & $<.005$ & $<.006$ & $<.030$ & $<.01$ & $<.006$ & $<.006$ & -- & $<.008$ \\
\hline 292215098580201 & $<.013$ & $<.024$ & $<.016$ & -- & $<.003$ & $<.013$ & $<.538$ & $<.003$ & $<.030$ & $<.027$ & $<.005$ & $<.006$ & $<.030$ & $<.015$ & $<.006$ & $<.006$ & -- & $<.008$ \\
\hline 292119098524901 & $<.013$ & $<.024$ & $<.016$ & -- & $<.003$ & $<.013$ & $<.538$ & $<.003$ & $<.030$ & $<.027$ & $<.005$ & $<.006$ & $<.030$ & $<.015$ & $<.006$ & $<.006$ & -- & $<.008$ \\
\hline 291943099163301 & $<.013$ & $<.024$ & $<.016$ & -- & $<.003$ & $<.013$ & $<.538$ & $<.003$ & $<.030$ & $<.027$ & $<.005$ & $<.006$ & $<.030$ & $<.015$ & $<.006$ & $<.006$ & -- & $<.008$ \\
\hline 291840099382601 & $<.013$ & $<.024$ & $<.016$ & -- & $<.003$ & $<.013$ & $<.538$ & $<.003$ & $<.030$ & $<.027$ & $<.005$ & $<.006$ & $<.030$ & $<.015$ & $<.006$ & $<.006$ & -- & $<.008$ \\
\hline 293518098332601 & $<.013$ & $<.024$ & $<.016$ & -- & $<.003$ & $<.013$ & $<.538$ & $<.003$ & $<.030$ & $<.027$ & $<.005$ & $<.006$ & $<.030$ & $<.015$ & $<.006$ & $<.006$ & -- & $<.008$ \\
\hline 293023098355401 & $<.013$ & $<.024$ & $<.016$ & -- & $<.003$ & $<.013$ & $<.538$ & $<.003$ & $<.030$ & $<.027$ & $<.005$ & $<.006$ & $<.030$ & $<.015$ & $<.006$ & $<.006$ & -- & $<.008$ \\
\hline 293042098305201 & $<.013$ & $<.024$ & $<.016$ & -- & $<.003$ & $<.013$ & $<.538$ & $<.003$ & $<.030$ & $<.027$ & $<.005$ & $<.006$ & $<.030$ & $<.015$ & $<.006$ & $<.006$ & $<0.003$ & $<.008$ \\
\hline 292442098474501 & Е.008 & E.009 & E.008 & -- & $<.003$ & $<.013$ & $<.538$ & $<.003$ & $<.030$ & $<.027$ & $<.005$ & $<.006$ & $<.030$ & $<.015$ & $<.006$ & $<.006$ & -- & $<.008$ \\
\hline 292405098371201 & $<.013$ & $<.024$ & $<.016$ & -- & $<.003$ & $<.013$ & $<.538$ & $<.003$ & $<.030$ & $<.027$ & $<.005$ & $<.006$ & $<.030$ & $<.015$ & $<.006$ & $<.006$ & -- & $<.008$ \\
\hline 292931098274601 & $<.013$ & $<.024$ & $<.016$ & -- & $<.003$ & $<.013$ & $<.538$ & $<.003$ & $<.030$ & $<.027$ & $<.005$ & $<.006$ & $<.030$ & $<.015$ & $<.006$ & $<.006$ & -- & $<.008$ \\
\hline 293729098173101 & $<.013$ & $<.024$ & $<.016$ & -- & $<.003$ & $<.013$ & $<.538$ & $<.003$ & $<.030$ & $<.027$ & $<.005$ & $<.006$ & $<.030$ & $<.015$ & $<.006$ & $<.006$ & -- & $<.008$ \\
\hline 291219099095601 & $<.013$ & $<.024$ & $<.016$ & -- & $<.003$ & $<.013$ & $<.538$ & $<.003$ & $<.030$ & $<.027$ & $<.005$ & $<.006$ & $<.030$ & $<.015$ & $<.006$ & $<.006$ & -- & $<.008$ \\
\hline \multicolumn{19}{|c|}{ onitoring wells } \\
\hline 292943098354401 & $<.013$ & $<.024$ & $<.02$ & -- & $<.01$ & $<.008$ & $<.01$ & $<.006$ & $<.02$ & $<.016$ & $<.007$ & $<.004$ & $<.01$ & $<.008$ & $<.010$ & $<.012$ & $<.003$ & $<.01$ \\
\hline 292943098354402 & $<.013$ & $<.024$ & $<.02$ & -- & $<.01$ & $<.008$ & $<.01$ & $<.006$ & $<.02$ & $<.016$ & $<.007$ & $<.004$ & $<.01$ & $<.008$ & $<.010$ & $<.012$ & $<.003$ & $<.01$ \\
\hline 292943098354403 & $<.013$ & $<.024$ & $<.02$ & -- & $<.01$ & $<.008$ & $<.01$ & $<.006$ & $<.02$ & $<.016$ & $<.007$ & $<.004$ & $<.01$ & $<.008$ & $<.010$ & $<.012$ & $<.003$ & $<.01$ \\
\hline 292943098354404 & $<.013$ & $<.024$ & $<.02$ & -- & $<.01$ & $<.008$ & $<.01$ & $<.006$ & $<.02$ & $<.016$ & $<.007$ & $<.004$ & $<.01$ & $<.008$ & $<.010$ & $<.012$ & $<.003$ & $<.01$ \\
\hline
\end{tabular}


Table 15. Soluble pesticide compounds for groundwater samples collected for the study of the transport of anthropogenic and natural contaminants (TANC) to public supply wells in the San Antonio segment of the Edwards aquifer near San Antonio, south-central Texas, 2004-9.-Continued

[By sample category. USGS, U.S. Geological Survey; MW, monitoring well; OVB, overburden; rg/L, micrograms per liter; --, not measured; E, estimated; u, unable to determine; <, nondetection less than laboratory method reporting level]

\begin{tabular}{|c|c|c|c|c|c|c|c|c|c|c|c|c|c|c|c|c|c|c|}
\hline $\begin{array}{c}\text { USGS } \\
\text { identification } \\
\text { number }\end{array}$ & $\begin{array}{c}\text { Fip- } \\
\text { ronil } \\
\text { sulfide } \\
(\mu \mathrm{g} / \mathrm{L}) \\
\end{array}$ & $\begin{array}{c}\text { Fip- } \\
\text { ronil } \\
\text { sulfone } \\
(\mu \mathrm{g} / \mathrm{L})\end{array}$ & $\begin{array}{l}\text { Fip- } \\
\text { ronil } \\
(\mu \mathrm{g} / \mathrm{L})\end{array}$ & $\begin{array}{c}\text { Fonofos } \\
\text { oxygen } \\
\text { analog } \\
(\mu \mathrm{g} / \mathrm{L})\end{array}$ & $\begin{array}{l}\text { Fon- } \\
\text { ofos } \\
(\mu \mathrm{g} / \mathrm{L})\end{array}$ & $\begin{array}{c}\text { Hexa- } \\
\text { zinone } \\
(\mu \mathrm{g} / \mathrm{L})\end{array}$ & $\begin{array}{l}\text { Ipro- } \\
\text { dione } \\
\text { ( } \mu \mathrm{g} / \mathrm{L})\end{array}$ & $\begin{array}{c}\text { Isofen- } \\
\text { phos } \\
\text { ( } \mu \mathrm{g} / \mathrm{L})\end{array}$ & $\begin{array}{c}\text { Mala- } \\
\text { oxon } \\
\text { ( } \mu \mathrm{g} / \mathrm{L})\end{array}$ & $\begin{array}{l}\text { Mala- } \\
\text { thion } \\
(\mu \mathrm{g} / \mathrm{L})\end{array}$ & $\begin{array}{l}\text { Meta- } \\
\text { laxyl } \\
\text { (pg/L) }\end{array}$ & $\begin{array}{l}\text { Meth- } \\
\text { ida- } \\
\text { thion } \\
(\mu \mathrm{g} / \mathrm{L})\end{array}$ & $\begin{array}{c}\text { Methyl } \\
\text { para- } \\
\text { oxon } \\
(\mu \mathrm{g} / \mathrm{L})\end{array}$ & $\begin{array}{l}\text { Methyl } \\
\text { para- } \\
\text { thion } \\
(\mu \mathrm{g} / \mathrm{L})\end{array}$ & $\begin{array}{l}\text { Meto- } \\
\text { la- } \\
\text { chlor } \\
\text { ( } \mu \mathrm{g} / \mathrm{L})\end{array}$ & $\begin{array}{c}\text { Metri- } \\
\text { buzin } \\
\text { ( } \mu \mathrm{g} / \mathrm{L})\end{array}$ & $\begin{array}{l}\text { Mol- } \\
\text { inate } \\
(\mu \mathrm{g} / \mathrm{L})\end{array}$ & $\begin{array}{l}\text { Myclo- } \\
\text { but- } \\
\text { anil } \\
\text { ( } \mu \mathrm{g} / \mathrm{L})\end{array}$ \\
\hline 292851098374401 & $<0.013$ & $<0.024$ & $<0.02$ & -- & $<0.01$ & $<0.008$ & $<0.01$ & $<0.006$ & $<0.02$ & $<0.016$ & $<0.007$ & $<0.004$ & $<0.01$ & $<0.008$ & $<0.010$ & $<0.012$ & $<0.003$ & $<0.01$ \\
\hline 292851098374402 & $<.013$ & $<.024$ & $<.02$ & -- & $<.01$ & $<.008$ & $<.01$ & $<.006$ & $<.02$ & $<.016$ & $<.007$ & $<.004$ & $<.01$ & $<.008$ & $<.010$ & $<.012$ & $<.003$ & $<.01$ \\
\hline \multicolumn{19}{|c|}{ Well-field depth-dependent sampling (W4) } \\
\hline 292916098360701 & $<.013$ & $<.024$ & $<.02$ & -- & $<.01$ & $<.008$ & $<.01$ & $<.006$ & $<.02$ & $<.016$ & $<.007$ & $<.004$ & $<.01$ & $<.008$ & $<.010$ & $<.012$ & $<.003$ & $<.01$ \\
\hline 292916098360701 & $<.013$ & $<.024$ & $<.02$ & -- & $<.01$ & $<.008$ & $<.01$ & $<.006$ & $<.02$ & $<.016$ & $<.007$ & $<.004$ & $<.01$ & $<.008$ & $<.010$ & $<.012$ & $<.030$ & $<.01$ \\
\hline 292916098360701 & $<.013$ & $<.024$ & $<.02$ & -- & $<.01$ & $<.008$ & $<.01$ & $<.006$ & $<.02$ & $<.016$ & $<.007$ & $<.004$ & $<.01$ & $<.008$ & $<.010$ & $<.012$ & $<.029$ & $<.01$ \\
\hline 292916098360701 & $<.013$ & $<.024$ & $<.02$ & -- & $<.01$ & $<.008$ & $<.01$ & $<.006$ & $<.02$ & $<.016$ & $<.007$ & $<.004$ & $<.01$ & $<.008$ & $<.010$ & $<.012$ & $<.003$ & $<.01$ \\
\hline 292916098360701 & $<.013$ & $<.024$ & $<.02$ & -- & $<.01$ & $<.008$ & $<.01$ & $<.006$ & $<.02$ & $<.016$ & $<.007$ & $<.004$ & $<.01$ & $<.008$ & $<.010$ & $<.012$ & $<.028$ & $<.01$ \\
\hline 292916098360701 & $<.013$ & $<.024$ & $<.02$ & -- & $<.01$ & $<.008$ & $<.01$ & $<.006$ & $<.02$ & $<.016$ & $<.007$ & $<.004$ & $<.01$ & $<.008$ & $<.010$ & $<.012$ & $<.047$ & $<.01$ \\
\hline 292916098360701 & $<.013$ & $<.024$ & $<.02$ & -- & $<.01$ & $<.008$ & $<.01$ & $<.006$ & $<.02$ & $<.016$ & $<.007$ & $<.004$ & $<.01$ & $<.008$ & $<.010$ & $<.012$ & $<.003$ & $<.01$ \\
\hline 292916098360701 & $<.013$ & $<.024$ & $<.02$ & -- & $<.01$ & $<.008$ & $<.01$ & $<.006$ & $<.02$ & $<.016$ & $<.007$ & $<.004$ & $<.01$ & $<.008$ & $<.010$ & $<.012$ & $<.026$ & $<.01$ \\
\hline 292916098360701 & $<.013$ & $<.024$ & $<.02$ & -- & $<.01$ & $<.008$ & $<.01$ & $<.006$ & $<.02$ & $<.016$ & $<.007$ & $<.004$ & $<.01$ & $<.008$ & $<.010$ & $<.012$ & $<.022$ & $<.01$ \\
\hline \multicolumn{19}{|c|}{ Well-field wells (wellhead sampling) } \\
\hline 292919098360501 & $<.013$ & $<.024$ & $<.02$ & -- & $<.01$ & $<.008$ & $<.01$ & $<.006$ & $<.02$ & $<.016$ & $<.007$ & $<.004$ & $<.01$ & $<.008$ & $<.010$ & $<.012$ & $<.003$ & $<.01$ \\
\hline 292925098360201 & $<.013$ & $<.024$ & $<.02$ & -- & $<.01$ & $<.008$ & $<.01$ & $<.006$ & $<.02$ & $<.016$ & $<.007$ & $<.004$ & $<.01$ & $<.008$ & $<.010$ & $<.012$ & $<.003$ & $<.01$ \\
\hline 292916098360701 & $<.013$ & $<.024$ & $<.02$ & -- & $<.01$ & $<.008$ & $<.01$ & $<.006$ & $<.02$ & $<.016$ & $<.007$ & $<.004$ & $<.01$ & $<.008$ & $<.010$ & $<.012$ & $<.003$ & $<.01$ \\
\hline 292920098360601 & $<.013$ & $<.024$ & $<.02$ & -- & $<.01$ & $<.008$ & $<.01$ & $<.006$ & $<.02$ & $<.016$ & $<.007$ & $<.004$ & $<.01$ & $<.008$ & $<.010$ & $<.012$ & $<.003$ & $<.01$ \\
\hline 292923098360301 & $<.013$ & $<.024$ & $<.02$ & -- & $<.01$ & $<.008$ & $<.01$ & $<.006$ & $<.02$ & $<.016$ & $<.007$ & $<.004$ & $<.01$ & $<.008$ & $<.010$ & $<.012$ & $<.003$ & $<.01$ \\
\hline \multicolumn{19}{|c|}{ Temporal sampling } \\
\hline 292923098360301 & -- & -- & -- & -- & -- & -- & -- & -- & -- & -- & -- & -- & -- & -- & -- & -- & -- & -- \\
\hline 292923098360301 & -- & -- & -- & -- & -- & -- & -- & -- & -- & -- & -- & -- & -- & -- & -- & -- & -- & -- \\
\hline 292923098360301 & -- & -- & -- & -- & -- & -- & -- & -- & -- & -- & -- & -- & -- & -- & -- & -- & -- & -- \\
\hline
\end{tabular}


Table 15. Soluble pesticide compounds for groundwater samples collected for the study of the transport of anthropogenic and natural contaminants (TANC) to public supply wells in the San Antonio segment of the Edwards aquifer near San Antonio, south-central Texas, 2004-9._Continued

[By sample category. USGS, U.S. Geological Survey; MW, monitoring well; OVB, overburden; $\mu$ g/L, micrograms per liter; --, not measured; E, estimated; u, unable to determine; <, nondetection less than laboratory method reporting level]

\begin{tabular}{|c|c|c|c|c|c|c|c|c|c|c|c|c|c|c|c|c|c|c|}
\hline $\begin{array}{c}\text { USGS } \\
\text { identification } \\
\text { number }\end{array}$ & $\begin{array}{c}\text { Fip- } \\
\text { ronil } \\
\text { sulfide } \\
(\mu \mathrm{g} / \mathrm{L})\end{array}$ & $\begin{array}{l}\text { Fip- } \\
\text { ronil } \\
\text { sulfone } \\
(\mu \mathrm{g} / \mathrm{L})\end{array}$ & $\begin{array}{l}\text { Fip- } \\
\text { ronil } \\
(\mu \mathrm{g} / \mathrm{L})\end{array}$ & $\begin{array}{c}\text { Fonofos } \\
\text { oxygen } \\
\text { analog } \\
(\mu \mathrm{g} / \mathrm{L})\end{array}$ & $\begin{array}{l}\text { Fon- } \\
\text { ofos } \\
(\mu \mathrm{g} / \mathrm{L})\end{array}$ & $\begin{array}{l}\text { Hexa- } \\
\text { zinone } \\
\text { ( } \mu \mathrm{g} / \mathrm{L})\end{array}$ & $\begin{array}{l}\text { Ipro- } \\
\text { dione } \\
(\mu \mathrm{g} / \mathrm{L})\end{array}$ & $\begin{array}{l}\text { Isofen- } \\
\text { phos } \\
(\mu \mathrm{g} / \mathrm{L})\end{array}$ & $\begin{array}{c}\text { Mala- } \\
\text { oxon } \\
(\mu \mathrm{g} / \mathrm{L})\end{array}$ & $\begin{array}{l}\text { Mala- } \\
\text { thion } \\
(\mu \mathrm{g} / \mathrm{L})\end{array}$ & $\begin{array}{c}\text { Meta- } \\
\text { laxyl } \\
\text { (pg/L) }\end{array}$ & $\begin{array}{l}\text { Meth- } \\
\text { ida- } \\
\text { thion } \\
(\mu \mathrm{g} / \mathrm{L})\end{array}$ & $\begin{array}{c}\text { Methyl } \\
\text { para- } \\
\text { oxon } \\
(\mu \mathrm{g} / \mathrm{L})\end{array}$ & $\begin{array}{l}\text { Methyl } \\
\text { para- } \\
\text { thion } \\
(\mu \mathrm{g} / \mathrm{L})\end{array}$ & $\begin{array}{l}\text { Meto- } \\
\text { la- } \\
\text { chlor } \\
\text { ( } \mu \mathrm{g} / \mathrm{L})\end{array}$ & $\begin{array}{l}\text { Metri- } \\
\text { buzin } \\
(\mu \mathrm{g} / \mathrm{L})\end{array}$ & $\begin{array}{l}\text { Mol- } \\
\text { inate } \\
(\mu \mathrm{g} / \mathrm{L})\end{array}$ & $\begin{array}{l}\text { Myclo- } \\
\text { but- } \\
\text { anil } \\
\text { ( } \mu \mathrm{g} / \mathrm{L})\end{array}$ \\
\hline 292923098360301 & $<0.013$ & $<0.024$ & $<0.018$ & -- & $<0.004$ & $<0.008$ & $<0.014$ & $<0.006$ & $<0.08$ & $<0.016$ & $<0.007$ & $<0.006$ & $<0.010$ & $<0.008$ & $<0.014$ & $<0.012$ & $<0.003$ & $<0.010$ \\
\hline 292923098360301 & $<.013$ & $<.024$ & $<.018$ & -- & $<.004$ & $<.008$ & $<.014$ & $<.006$ & $<.08$ & $<.016$ & $<.007$ & $<.006$ & $<.010$ & $<.008$ & $<.014$ & $<.012$ & $<.003$ & $<.010$ \\
\hline 292923098360301 & $<.013$ & $<.024$ & $<.018$ & -- & $<.004$ & $<.008$ & $<.014$ & $<.006$ & $<.08$ & $<.016$ & $<.007$ & $<.006$ & $<.010$ & $<.008$ & $<.014$ & $<.012$ & $<.003$ & $<.010$ \\
\hline 292943098354402 & -- & -- & -- & -- & -- & -- & -- & -- & -- & -- & -- & -- & -- & -- & -- & -- & -- & -- \\
\hline 292943098354402 & -- & -- & -- & -- & -- & -- & -- & -- & -- & -- & -- & -- & -- & -- & -- & -- & -- & -- \\
\hline 292943098354402 & -- & -- & -- & -- & -- & -- & -- & -- & -- & -- & -- & -- & -- & -- & -- & -- & -- & -- \\
\hline 292943098354402 & $<.013$ & $<.024$ & $<.018$ & -- & $<.004$ & $<.008$ & $<.014$ & $<.006$ & $<.08$ & $<.016$ & $<.007$ & $<.006$ & $<.010$ & $<.008$ & $<.014$ & $<.012$ & $<.003$ & $<.010$ \\
\hline 292943098354402 & $<.013$ & $<.024$ & $<.018$ & -- & $<.004$ & $<.008$ & $<.014$ & $<.006$ & $<.08$ & $<.016$ & $<.007$ & $<.006$ & $<.010$ & $<.008$ & $<.014$ & $<.012$ & $<.003$ & $<.010$ \\
\hline 292943098354402 & $<.013$ & $<.024$ & $<.018$ & -- & $<.004$ & $<.008$ & $<.014$ & $<.006$ & $<.08$ & $<.016$ & $<.007$ & $<.006$ & $<.010$ & $<.008$ & $<.014$ & $<.012$ & $<.003$ & $<.010$ \\
\hline 292943098354403 & -- & -- & -- & -- & -- & -- & -- & -- & -- & -- & -- & -- & -- & -- & -- & -- & -- & -- \\
\hline 292943098354403 & -- & -- & -- & -- & -- & -- & -- & -- & -- & -- & -- & -- & -- & -- & -- & -- & -- & -- \\
\hline 292943098354403 & -- & -- & -- & -- & -- & -- & -- & -- & -- & -- & -- & -- & -- & -- & -- & -- & -- & -- \\
\hline 292943098354403 & $<.013$ & $<.024$ & $<.018$ & -- & $<.004$ & $<.008$ & $<.014$ & $<.006$ & $<.08$ & $<.016$ & $<.007$ & $<.006$ & $<.010$ & $<.008$ & $<.014$ & $<.012$ & $<.003$ & $<.010$ \\
\hline 292943098354403 & $<.013$ & $<.024$ & $<.018$ & -- & $<.004$ & $<.008$ & $<.014$ & $<.006$ & $<.08$ & $<.016$ & $<.007$ & $<.006$ & $<.010$ & $<.008$ & $<.014$ & $<.012$ & $<.003$ & $<.010$ \\
\hline 292943098354403 & $<.013$ & $<.024$ & $<.018$ & -- & $<.004$ & $<.008$ & $<.014$ & $<.006$ & $<.08$ & $<.016$ & $<.007$ & $<.006$ & $<.010$ & $<.008$ & $<.014$ & $<.012$ & $<.003$ & $<.010$ \\
\hline 292943098354404 & -- & -- & -- & -- & -- & -- & -- & -- & -- & -- & -- & -- & -- & -- & -- & -- & -- & -- \\
\hline 292943098354404 & -- & -- & -- & -- & -- & -- & -- & -- & -- & -- & -- & -- & -- & -- & -- & -- & -- & -- \\
\hline 292943098354404 & -- & -- & -- & -- & -- & -- & -- & -- & -- & -- & -- & -- & -- & -- & -- & -- & -- & -- \\
\hline 292943098354404 & $<.013$ & $<.024$ & $<.018$ & -- & $<.004$ & $<.008$ & $<.014$ & $<.006$ & $<.08$ & $<.016$ & $<.007$ & $<.006$ & $<.010$ & $<.008$ & $<.014$ & $<.012$ & $<.003$ & $<.010$ \\
\hline 292943098354404 & $<.013$ & $<.024$ & $<.018$ & -- & $<.004$ & $<.008$ & $<.014$ & $<.006$ & $<.08$ & $<.016$ & $<.007$ & $<.006$ & $<.010$ & $<.008$ & $<.014$ & $<.012$ & $<.003$ & $<.010$ \\
\hline 292943098354404 & $<.013$ & $<.024$ & $<.018$ & -- & $<.004$ & $<.008$ & $<.014$ & $<.006$ & $<.08$ & $<.016$ & $<.007$ & $<.006$ & $<.010$ & $<.008$ & $<.014$ & $<.012$ & $<.003$ & $<.010$ \\
\hline 293252098380801 & -- & -- & -- & -- & -- & -- & -- & -- & -- & -- & -- & -- & -- & -- & -- & -- & -- & -- \\
\hline 293252098380801 & -- & -- & -- & -- & -- & -- & -- & -- & -- & -- & -- & -- & -- & -- & -- & -- & -- & -- \\
\hline 293252098380801 & -- & -- & -- & -- & -- & -- & -- & -- & -- & -- & -- & -- & -- & -- & -- & -- & -- & -- \\
\hline 293252098380801 & $<.013$ & $<.024$ & $<.018$ & -- & $<.004$ & $<.008$ & $<.014$ & $<.006$ & $<.08$ & $<.016$ & $<.007$ & $<.006$ & $<.010$ & $<.008$ & $<.014$ & $<.012$ & $<.003$ & $<.010$ \\
\hline 293252098380801 & $<.013$ & $<.024$ & $<.018$ & -- & $<.004$ & $<.008$ & $<.014$ & $<.006$ & $<.08$ & $<.016$ & $<.007$ & $<.006$ & $<.010$ & $<.008$ & $<.014$ & $<.012$ & $<.003$ & $<.010$ \\
\hline 293252098380801 & $<.013$ & $<.024$ & $<.018$ & -- & $<.004$ & $<.008$ & $<.014$ & $<.006$ & $<.08$ & $<.016$ & $<.007$ & $<.006$ & $<.010$ & $<.008$ & $<.014$ & $<.012$ & $<.003$ & $<.010$ \\
\hline
\end{tabular}


Table 15. Soluble pesticide compounds for groundwater samples collected for the study of the transport of anthropogenic and natural contaminants (TANC) to public supply wells in the San Antonio segment of the Edwards aquifer near San Antonio, south-central Texas, 2004-9.-Continued

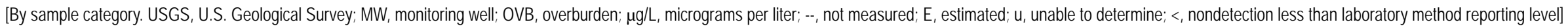

\begin{tabular}{|c|c|c|c|c|c|c|c|c|c|c|c|c|c|c|c|c|c|c|c|c|c|c|}
\hline $\begin{array}{c}\text { USGS } \\
\text { identification } \\
\text { number }\end{array}$ & $\begin{array}{c}\text { Oxy- } \\
\text { fluor- } \\
\text { fen } \\
(\mu \mathrm{g} / \mathrm{L})\end{array}$ & $\begin{array}{l}\text { Pendi- } \\
\text { meth- } \\
\text { alin } \\
(\mu \mathrm{g} / \mathrm{L})\end{array}$ & $\begin{array}{l}\text { Phor- } \\
\text { ate } \\
\text { oxy- } \\
\text { gen } \\
\text { analog } \\
\text { ( } \mu \mathrm{g} / \mathrm{L})\end{array}$ & $\begin{array}{l}\text { Phor- } \\
\text { ate } \\
(\mu \mathrm{g} / \mathrm{L})\end{array}$ & 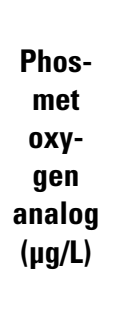 & $\begin{array}{c}\text { Phos- } \\
\text { met } \\
(\mu \mathrm{g} / \mathrm{L})\end{array}$ & $\begin{array}{l}\text { Pro- } \\
\text { meton } \\
(\mu \mathrm{g} / \mathrm{L})\end{array}$ & $\begin{array}{c}\text { Pro- } \\
\text { metryn } \\
\text { ( } \mu \mathrm{g} / \mathrm{L})\end{array}$ & $\begin{array}{l}\text { Pro- } \\
\text { pyz- } \\
\text { amide } \\
(\mu \mathrm{g} / \mathrm{L})\end{array}$ & $\begin{array}{l}\text { Prop- } \\
\text { anil } \\
(\mu g / L)\end{array}$ & $\begin{array}{l}\text { Prop- } \\
\text { argite } \\
\text { ( } \mu \mathrm{g} / \mathrm{L})\end{array}$ & $\begin{array}{l}\text { Sim- } \\
\text { azine } \\
\text { ( } \mu \mathrm{g} / \mathrm{L})\end{array}$ & $\begin{array}{l}\text { Tebu- } \\
\text { con- } \\
\text { azole } \\
\text { ( } \mu \mathrm{g} / \mathrm{L} \text { ) }\end{array}$ & $\begin{array}{c}\text { Tebu- } \\
\text { thi- } \\
\text { uron } \\
(\mu \mathrm{g} / \mathrm{L})\end{array}$ & $\begin{array}{l}\text { Teflu- } \\
\text { thrin } \\
(\mu \mathrm{g} / \mathrm{L})\end{array}$ & $\begin{array}{c}\text { Terb- } \\
\text { ufos } \\
\text { oxy- } \\
\text { gen } \\
\text { analog } \\
\text { sul- } \\
\text { fone } \\
\text { ( } \mu \mathrm{g} / \mathrm{L} \text { ) }\end{array}$ & $\begin{array}{c}\text { Terb } \\
\text { ufos } \\
(\mu \mathrm{g} / \mathrm{l}\end{array}$ & $\begin{array}{c}\begin{array}{c}\text { Ter- } \\
\text { buthyl- }\end{array} \\
\text { azine } \\
\text { ( } \mu \mathrm{g} / \mathrm{L})\end{array}$ & $\begin{array}{l}\text { Thio } \\
\text { ben- } \\
\text { carb } \\
(\mu \mathrm{g} / \mathrm{L}\end{array}$ & $\begin{array}{c}\text { trans- } \\
\text { Propi- } \\
\text { con- } \\
\text { azole } \\
\text { ( } \mu \mathrm{g} / \mathrm{L})\end{array}$ & $\begin{array}{l}\text { Tri- } \\
\text { bu- } \\
\text { phos } \\
\text { ( } \mu \mathrm{g} / \mathrm{L})\end{array}$ & $\begin{array}{l}\text { Tri- } \\
\text { flur- } \\
\text { alin } \\
\text { ( } \mu \mathrm{g} / \mathrm{L})\end{array}$ \\
\hline
\end{tabular}

Regional aquifer public-supply wells

\begin{tabular}{|c|c|c|c|c|c|c|c|c|c|c|c|c|c|c|c|c|c|c|c|c|c|c|}
\hline 301 & -- & $<$ & $<0$ & $<$ & $<0$ & 008 & 013 & $<0.0$ & 4 & -- & -- & 0.008 & -- & 6 & -- & 3 & 7 & 0 & - & - & - & 0.00 \\
\hline $293359098290301<$ & $<0.007$ & $<.022$ & 105 & $<.011$ & $<.051$ & $<.008$ & .011 & 005 & 4 & & 3 & 09 & 4 & $<.016$ & 8 & 8 & $<$ & $10<$ & & & & 99 \\
\hline 8231101 & -- & $<.022$ & 105 & .011 & 051 & 8 & 9 & 5 & 4 & - & -- & $<$ & -- & 16 & -- & 8 & 17 & 0 & -- & -- & -- & .009 \\
\hline Э3358098231101 & $<.007$ & K.022 & 105 & $<.011$ & 051 & 008 & 008 & $<.005$ & 004 & 1 & $<.023$ & E.007 & 014 & 016 & $<.008$ & 68 & $<.017$ & $<.010$ & .010 & $<.0$ & 4 & $<.009$ \\
\hline 35801 & -- & $<.022$ & 105 & $<.011$ & 051 & 08 & 010 & .005 & 04 & - & -- & 005 & - & $<.016$ & 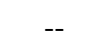 & $<.068$ & $<.017$ & $<.010$ & -- & - & - & .009 \\
\hline 801 & -- & -- & -- & -- & -- & -- & -- & 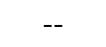 & -- & 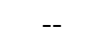 & 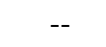 & 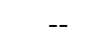 & -- & $<.026$ & 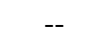 & 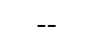 & 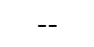 & -- & 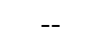 & 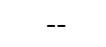 & 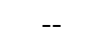 & -- \\
\hline 201 & -- & $<.022$ & .105 & $<.011$ & .051 & 008 & 010 & .005 & .004 & -1 & -- & 05 & -- & $<.016$ & -- & $<.0$ & $<.017$ & $<.010$ & 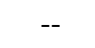 & -- & -- & .009 \\
\hline 01 & -- & .022 & 105 & $<.011$ & 051 & 08 & .010 & <.005 & 04 & -- & - & $-1+2$ & -1 & 16 & -- & & $<.017$ & $<.010$ & -- & -- & -- & .009 \\
\hline 1 & -- & $<.022$ & 105 & $<.011$ & .051 & 08 & .010 & $<.005$ & 04 & -- & -- & & -- & 16 & 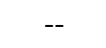 & & $<$. & $<$. & 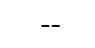 & -- & 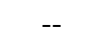 & $<.009$ \\
\hline & -- & 022 & 3 & $<.011$ & 1 & 0 & 0 & 5 & & - & -- & & -- & & -- & & 7 & 0 & & -- & - & 09 \\
\hline & -- & 22 & 105 & $<.011$ & .051 & 008 & 10 & $<.005$ & & - & 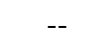 & & - & & - & & & 10 & & - & 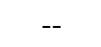 & $<.009$ \\
\hline 201 & $<.007$ & $<.022$ & 105 & $<.011$ & $\mathrm{u}$ & $\mathrm{u}$ & E.004 & $<.005$ & 04 & $<.011$ & $<.023$ & E & .014 & 16 & $<.008$ & & $<$ & 10 & $<.010$ & $<.013$ & & $<.009$ \\
\hline 401 & -- & $<.022$ & 105 & $<.011$ & 051 & 008 & $<.010$ & $<.005$ & 4 & -- & 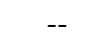 & $<$ & 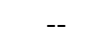 & 16 & - & & $<$ & $<.010$ & 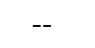 & 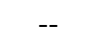 & 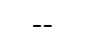 & .009 \\
\hline 01 & $<.016$ & .022 & 105 & $<.011$ & 051 & 008 & $<.010$ & 5 & & .011 & $<.023$ & & 4 & & .010 & & & 10 & $<.010$ & & & $<.009$ \\
\hline 01 & -- & 2 & 105 & $<.011$ & $<.051$ & 000 & 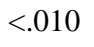 & 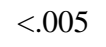 & & -- & 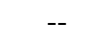 & & ( & & - & & & $<$ & -- & -- & -- & $<.009$ \\
\hline 01 & $<.007$ & $<.022$ & 5 & $<.011$ & 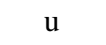 & . & 4 & $<.0$ & & $<.011$ & & & $<.014$ & & $<.008$ & & & & $<.010$ & $<.013$ & $<.004$ & $<.009$ \\
\hline 1 & -- & $<.022$ & $10 \Gamma$ & $<.011$ & & & $<010$ & & & - & -- & & -- & & -- & & & & -- & -- & -- & $<.009$ \\
\hline 301 & -- & $<.022$ & .105 & $<.011$ & $<.051$ & 008 & $<.010$ & $<.005$ & . & -- & -- & . & -- & & -- & & $<.017$ & $<.010$ & 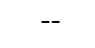 & -- & -- & $<.009$ \\
\hline 801 & -- & -- & -- & -- & -- & -- & -- & -- & -- & -- & -- & -- & -- & $<.026$ & -- & - & -- & 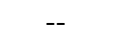 & -- & -- & -- & -- \\
\hline 098294601 & -- & $<.022$ & $<.105$ & $<.011$ & $<.051$ & .008 & $<.010$ & $<.005$ & $<.004$ & -- & -- & $<.005$ & -- & $<.016$ & -- & & $<.017$ & $<.010$ & & -- & -- & $<.009$ \\
\hline 301 & -- & $<.022$ & .105 & $<.011$ & $<.051$ & .008 & $<.010$ & $<.005$ & $<.004$ & -- & -- & .00 & -- & $<.016$ & -- & & $<.017$ & $<.010$ & & -- & -- & $<.009$ \\
\hline 80301 & $<.007$ & $<.022$ & .105 & $<.011$ & $<.051$ & .008 & E.007 & $<.005$ & $<.004$ & $<.011$ & $<.023$ & .008 & .014 & $<.016$ & $<.008$ & & $<.017$ & $<.010$ & $<.010$ & $<.013$ & $<.004$ & $<.009$ \\
\hline 291210099475601 & -- & $<.022$ & $<.105$ & $<.011$ & $<.051$ & K.008 & $<.010$ & $<.005$ & $<.004$ & -- & -- & $<.005$ & -- & $<.016$ & -- & $<.068$ & $<.017$ & $<.010$ & -- & -- & -- & $<.009$ \\
\hline & -- & .022 & -.100 & .011 & 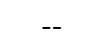 & $\mathrm{u}$ & ᄃ.000 & -.003 & .001 & - & - & & - & .010 & 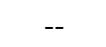 & & $<.017$ & $<.0102$ & - & 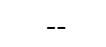 & 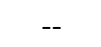 & $<.009$ \\
\hline 098291701 & -- & $<.022$ & $<.105$ & $<.011$ & $<.051$ & $<.008$ & 0.010 & $<.005$ & $<.004$ & -- & -- & .010 & -- & $<.016$ & -- & $<.068$ & $<.017$ & $<.010$ & -- & -- & -- & $<.00 s$ \\
\hline 92424098421501 & -- & $<.022$ & $<.105$ & $<.011$ & $<.051$ & $<.008$ & $<.010$ & $<.005$ & $<.004$ & -- & -- & $<.005$ & -- & $<.016$ & -- & $<.068$ & $<.017$ & $<.010$ & -- & -- & -- & $<.00$ \\
\hline
\end{tabular}


Table 15. Soluble pesticide compounds for groundwater samples collected for the study of the transport of anthropogenic and natural contaminants (TANC) to public supply wells in the San Antonio segment of the Edwards aquifer near San Antonio, south-central Texas, 2004-9. - Continued

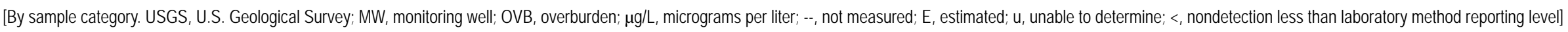

\begin{tabular}{|c|c|c|c|c|c|c|c|c|c|c|c|c|c|c|c|c|c|c|c|c|c|c|}
\hline $\begin{array}{c}\text { USGS } \\
\text { identification } \\
\text { number }\end{array}$ & $\begin{array}{c}\text { Oxy- } \\
\text { fluor- } \\
\text { fen } \\
(\mu g / L)\end{array}$ & $\begin{array}{l}\text { Pendi- } \\
\text { meth- } \\
\text { alin } \\
(\mu \mathrm{g} / \mathrm{L})\end{array}$ & $\begin{array}{c}\text { Phor- } \\
\text { ate } \\
\text { oxy- } \\
\text { gen } \\
\text { analog } \\
\text { ( } \mu \mathrm{g} / \mathrm{L})\end{array}$ & $\begin{array}{c}\text { Phor- } \\
\text { ate } \\
(\mu \mathrm{g} / \mathrm{L})\end{array}$ & 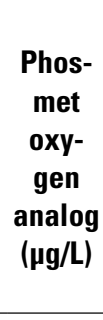 & $\begin{array}{c}\text { Phos- } \\
\text { met } \\
\text { ( } \mathrm{gg} / \mathrm{L})\end{array}$ & $\begin{array}{l}\text { Pro- } \\
\text { meton } \\
\text { ( } \mu \mathrm{g} / \mathrm{L})\end{array}$ & $\begin{array}{c}\text { Pro- } \\
\text { metryn } \\
\text { ( } \mathrm{gg} / \mathrm{L})\end{array}$ & $\begin{array}{l}\text { Pro- } \\
\text { pyz- } \\
\text { amide } \\
\text { ( } \mu \mathrm{g} / \mathrm{L})\end{array}$ & $\begin{array}{c}\text { Prop- } \\
\text { anil } \\
(\mu \mathrm{g} / \mathrm{L})\end{array}$ & $\begin{array}{l}\text { Prop- } \\
\text { argite } \\
(\mu \mathrm{g} / \mathrm{L})\end{array}$ & $\begin{array}{l}\text { Sim- } \\
\text { azine } \\
\text { ( } \mu \text { g/L) }\end{array}$ & $\begin{array}{l}\text { Tebu- } \\
\text { con- } \\
\text { azole } \\
(\mu \mathrm{g} / \mathrm{L})\end{array}$ & $\begin{array}{c}\text { Tebu- } \\
\text { thi- } \\
\text { uron } \\
(\mu \mathrm{g} / \mathrm{L})\end{array}$ & $\begin{array}{l}\text { Teflu- } \\
\text { thrin } \\
(\mu \mathrm{g} / \mathrm{L})\end{array}$ & $\begin{array}{c}\text { Terb- } \\
\text { ufos } \\
\text { oxy- } \\
\text { gen } \\
\text { analog } \\
\text { sul- } \\
\text { fone } \\
\text { ( } \mu \mathrm{g} / \mathrm{L}) \\
\end{array}$ & $\begin{array}{c}\text { Terb- } \\
\text { ufos } \\
(\mu \mathrm{g} / \mathrm{L})\end{array}$ & $\begin{array}{c}\text { Ter- } \\
\text { buthyl- } \\
\text { azine } \\
\text { ( } \mu \mathrm{g} / \mathrm{L} \text { ) }\end{array}$ & $\begin{array}{l}\text { Thio- } \\
\text { ben- } \\
\text { carb } \\
\text { ( } \mu \mathrm{g} / \mathrm{L})\end{array}$ & $\begin{array}{l}\text { trans- } \\
\text { Propi- } \\
\text { con- } \\
\text { azole } \\
\text { ( } \mu \text { g/L) }\end{array}$ & $\begin{array}{l}\text { Tri- } \\
\text { bu- } \\
\text { phos } \\
(\mu \mathrm{g} / \mathrm{L})\end{array}$ & $\begin{array}{l}\text { Tri- } \\
\text { flur- } \\
\text { alin } \\
(\mu g / L)\end{array}$ \\
\hline 01 & -- & $<0.022$ & $2<0.1$ & $<0.011$ & $\mathrm{u}$ & $\mathrm{u}$ & $<0.010$ & $<0.005$ & $<0.004$ & - & -- & $<0.005$ & - & $<0.016$ & -- & $<0.068$ & $<0.017$ & 10 & -- & -- & -- & $<0.009$ \\
\hline 301 & -- & $<.022$ & $<.105$ & $<.011$ & $<.051$ & $<.008$ & 10 & 05 & $<.004$ & -- & -- & 66 & -- & & -- & $<.068$ & $<.017$ & 10 & -- & -- & -- & .009 \\
\hline 26040985 & -- & $<.022$ & 5 & $<.011$ & $<.051$ & $<.008$ & 010 & 005 & & -- & -- & & -- & 10 & -- & .068 & $<.017$ & $<.010$ & - & -- & -- & .003 \\
\hline 2116099095501 & -- & $<.022$ & 105 & $<.011$ & $\mathrm{u}$ & $<.008$ & 010 & .005 & $<.004$ & -- & -- & $<.005$ & -- & .016 & -- & $<.068$ & $<.017$ & $<.010$ & -- & -- & -- & $<.009$ \\
\hline 91232099470301 & -- & $<.022$ & $<.105$ & $<.011$ & .051 & $<.008$ & Е.005 & .005 & $<.004$ & -- & -- & $<.005$ & -- & .016 & -- & $<.068$ & $<.017$ & $<.010$ & -- & -- & -- & $<.009$ \\
\hline 3128 & -- & $<.022$ & $<.105$ & $<.011$ & $<.051$ & $<.008$ & 10 & 05 & $<$ & -- & -- & 5 & -- & & -- & 68 & $<.017$ & & - & -- & -- & $<.009$ \\
\hline 34510 & -- & $<.022$ & $<.105$ & $<.011$ & $<.051$ & $<.008$ & 7 & & $<$. & -- & 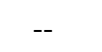 & & -- & & _- & & & & 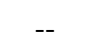 & -- & -- & $<.009$ \\
\hline 460 & -- & $<.022$ & 5 & $<.011$ & 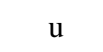 & $<.0$ & & 5 & 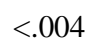 & -- & -- & 5 & -- & & -- & 8 & $<$ & $<$ & -- & -- & -- & $<.009$ \\
\hline 701 & -- & $<.022$ & 105 & $<.011$ & $<.051$ & $<.008$ & 005 & 05 & $<.004$ & -- & -- & .006 & -- & 16 & -- & .068 & $<.017$ & $<.010$ & -- & -- & -- & $<.009$ \\
\hline 922150 & -- & $<.022$ & $<.105$ & $<.011$ & $<.051$ & $<.008$ & 010 & .005 & $<.004$ & -- & -- & $<.005$ & -- & 16 & -- & .068 & $<.017$ & $<.010$ & -- & -- & -- & $<.009$ \\
\hline 4901 & -- & $<.022$ & 105 & $<.011$ & 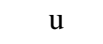 & $<.008$ & 010 & .005 & $<.004$ & -- & -- & .005 & -- & 16 & -- & 68 & $<.017$ & 10 & -- & -- & -- & $<.009$ \\
\hline 9194 & -- & $<.022$ & 105 & $<.011$ & $<.051$ & $<.008$ & 10 & $<.005$ & $<$ & -- & -- & $<$ & -- & 16 & -- & 68 & $<.017$ & 10 & -- & -- & -- & $<.009$ \\
\hline 91840099382601 & -- & $<.022$ & 5 & $<.011$ & $<.051$ & $<.008$ & & 5 & $<.1$ & -- & 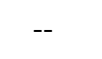 & $<.005$ & -- & 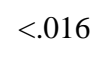 & -- & $<.068$ & $<.017$ & $<$. & -- & 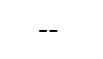 & -- & $<.009$ \\
\hline 3518 & -- & $.0 \angle 2$ & 100 & .011 & $<.051$ & .000 & & .005 & & 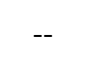 & 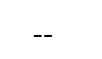 & & 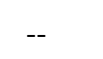 & & 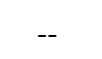 & 68 & & & 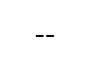 & 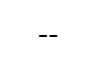 & -- & $<.009$ \\
\hline 293023098355401 & -- & $<.022$ & $<.105$ & $<.011$ & $\mathrm{u}$ & $<.008$ & $<.010$ & 005 & $<.004$ & -- & -- & $<.005$ & -- & 016 & -- & $<.068$ & $<.017$ & $<.010$ & -- & -- & -- & $<.009$ \\
\hline 93042098305201 & $<.007$ & $<.022$ & $<.105$ & $<.011$ & $<.051$ & $<.008$ & E.005 & $<.005$ & $<.004$ & $<0.011$ & $<0.023$ & E.007 & $<.014$ & $<.016$ & $<0.008$ & $<.068$ & $<.017$ & $<.010$ & $<0.010$ & $<0.013$ & $<0.004$ & $<.009$ \\
\hline 2442098474501 & -- & $<.022$ & 105 & $<.011$ & $<.051$ & $<.008$ & & .005 & $<.004$ & -- & -- & $<.005$ & -- & $<.016$ & -- & $<.068$ & $<.017$ & $<.010$ & 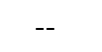 & -- & -- & $<.009$ \\
\hline 2405 & -- & $<$ & 5 & 11 & $<.051$ & $<.008$ & & & & -- & -- & & -- & & -- & & & & -- & -- & -- & $<.009$ \\
\hline 4601 & -- & $<.022$ & & $<.0$ & $\mathrm{u}$ & $\mathrm{u}$ & & 05 & & -- & -- & & -- & & -- & & & & -- & -- & -- & $<.009$ \\
\hline 3101 & -- & $<.022$ & $<.105$ & $<.011$ & 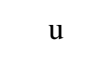 & $<.008$ & E.008 & $<.005$ & $<.004$ & -- & -- & .007 & -- & $<.016$ & -- & $<.068$ & $<.017$ & $<.010$ & -- & -- & -- & $<.009$ \\
\hline 99095601 & -- & $<.022$ & $<.105$ & $<.011$ & .051 & $<.008$ & $<.010$ & .005 & $<.004$ & -- & -- & $<.005$ & -- & 16 & -- & $<.068$ & $<.017$ & $<.010$ & -- & 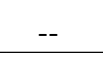 & -- & $<.009$ \\
\hline \multicolumn{23}{|c|}{ Monitoring wells } \\
\hline & & & & & & & & & & & & & & & & & & & & & & $<.006$ \\
\hline 354402 & $<.006$ & $<.012$ & .027 & $<.04$ & $<.051$ & $<.008$ & $<.0$ & $<.006$ & $<.004$ & .006 & $<.04$ & E.005 & $<.018$ & $<.016$ & $<.003$ & $<.045$ & $<.018$ & .008 & $<.010$ & $<.02$ & $<.035$ & $<.006$ \\
\hline 2943098354403 & $<.006$ & $<.012$ & $<.027$ & $<.04$ & $\mathrm{u}$ & $<.008$ & $<.01$ & 006 & $<.004$ & .006 & $<.04$ & $<.006$ & $<.018$ & $<.016$ & $<.003$ & $<.045$ & $<.018$ & .008 & $<.010$ & $<.02$ & $<.035$ & $<.006$ \\
\hline 2943098354404 & $<.006$ & $<.012$ & $<.027$ & $<.04$ & $<.051$ & $<.008$ & $<.01$ & $<.006$ & $<.004$ & $<.006$ & $<.04$ & $<.006$ & $<.018$ & $<.016$ & $<.003$ & $<.045$ & $<.018$ & $<.008$ & $<.010$ & $<.02$ & $<.035$ & .006 \\
\hline
\end{tabular}


Table 15. Soluble pesticide compounds for groundwater samples collected for the study of the transport of anthropogenic and natural contaminants (TANC) to public supply wells in the San Antonio segment of the Edwards aquifer near San Antonio, south-central Texas, 2004-9.-Continued

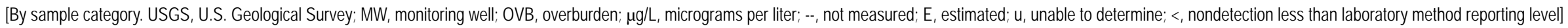

\begin{tabular}{|c|c|c|c|c|c|c|c|c|c|c|c|c|c|c|c|c|c|c|c|c|c|c|}
\hline $\begin{array}{c}\text { USGS } \\
\text { identification } \\
\text { number }\end{array}$ & $\begin{array}{c}\text { Oxy- } \\
\text { fluor- } \\
\text { fen } \\
(\mu \mathrm{g} / \mathrm{L})\end{array}$ & $\begin{array}{l}\text { Pendi- } \\
\text { meth- } \\
\text { alin } \\
(\mu \mathrm{g} / \mathrm{L})\end{array}$ & $\begin{array}{l}\text { Phor- } \\
\text { ate } \\
\text { oxy- } \\
\text { gen } \\
\text { analog } \\
\text { ( } \mu \mathrm{g} / \mathrm{L})\end{array}$ & $\begin{array}{l}\text { Phor- } \\
\text { ate } \\
(\mu \mathrm{g} / \mathrm{L})\end{array}$ & $\begin{array}{c}\text { Phos- } \\
\text { met } \\
\text { oxy- } \\
\text { gen } \\
\text { analog } \\
\text { ( } \mu \mathrm{g} / \mathrm{L})\end{array}$ & $\begin{array}{c}\text { Phos- } \\
\text { met } \\
(\mu \mathrm{g} / \mathrm{L})\end{array}$ & $\begin{array}{l}\text { Pro- } \\
\text { meton } \\
(\mu \mathrm{g} / \mathrm{L})\end{array}$ & $\begin{array}{c}\text { Pro- } \\
\text { metryn } \\
(\mu \mathrm{g} / \mathrm{L})\end{array}$ & $\begin{array}{l}\text { Pro- } \\
\text { pyz- } \\
\text { amide } \\
\text { ( } \mu \mathrm{g} / \mathrm{L})\end{array}$ & $\begin{array}{l}\text { Prop- } \\
\text { anil } \\
(\mu \mathrm{g} / \mathrm{L})\end{array}$ & $\begin{array}{l}\text { Prop- } \\
\text { argite } \\
\text { ( } \mu \mathrm{g} / \mathrm{L} \text { ) }\end{array}$ & $\begin{array}{l}\text { Sim- } \\
\text { azine } \\
(\mu \mathrm{g} / \mathrm{L})\end{array}$ & $\begin{array}{l}\text { Tebu- } \\
\text { con- } \\
\text { azole } \\
\text { ( } \mu \mathrm{g} / \mathrm{L})\end{array}$ & $\begin{array}{l}\text { Tebu- } \\
\text { thi- } \\
\text { uron } \\
\text { ( } \mu \mathrm{g} / \mathrm{L})\end{array}$ & $\begin{array}{l}\text { Teflu- } \\
\text { thrin } \\
(\mu \mathrm{g} / \mathrm{L})\end{array}$ & $\begin{array}{c}\text { Terb- } \\
\text { ufos } \\
\text { oxy- } \\
\text { gen } \\
\text { analog } \\
\text { sul- } \\
\text { fone } \\
\text { ( } \mu \mathrm{g} / \mathrm{L} \text { ) }\end{array}$ & $\begin{array}{c}\text { Terb- } \\
\text { ufos } \\
(\mu \mathrm{g} / \mathrm{L})\end{array}$ & $\begin{array}{c}\text { Ter- } \\
\text { buthyl- } \\
\text { azine } \\
\text { ( } \mu \mathrm{g} / \mathrm{L})\end{array}$ & $\begin{array}{l}\text { Thio- } \\
\text { ben- } \\
\text { carb } \\
(\mu \mathrm{g} / \mathrm{L})\end{array}$ & $\begin{array}{c}\text { trans- } \\
\text { Propi- } \\
\text { con- } \\
\text { azole } \\
(\mu \mathrm{g} / \mathrm{L})\end{array}$ & $\begin{array}{c}\text { Tri- } \\
\text { bu- } \\
\text { phos } \\
\text { ( } \mu \mathrm{g} / \mathrm{L})\end{array}$ & $\begin{array}{l}\text { Tri- } \\
\text { flur- } \\
\text { alin } \\
(\mu \mathrm{g} / \mathrm{L})\end{array}$ \\
\hline 292851098374401 & $<0.006$ & $<0.012$ & $<0.027$ & $<0.04$ & $<0.051$ & $<0.008$ & $<0.01$ & $<0.006$ & $<0.004$ & $<0.006$ & $<0.04$ & 0.006 & $<0.018$ & $<0.016$ & $<0.003$ & $<0.045$ & $<0.018$ & $<0.008$ & $<0.010$ & $<0.02$ & $<0.035$ & $<0.009$ \\
\hline 292851098374402 & $<.006$ & $<.012$ & $<.027$ & $<.04$ & $<.051$ & $<.008$ & $<.01$ & $<.006$ & $<.004$ & $<.006$ & $<.04$ & E.006 & $<.018$ & $<.016$ & $<.003$ & $<.045$ & $<.018$ & $<.008$ & $<.010$ & $<.02$ & $<.035$ & $<.009$ \\
\hline \multicolumn{23}{|c|}{ Well-field depth-dependent s } \\
\hline 292916098 & $<.006$ & $<.012$ & $<.027$ & $<.04$ & $<.051$ & $<.008$ & $<.01$ & $<.006$ & $<.004$ & $<.006$ & $<.04$ & $<.006$ & $<.018$ & $<.016$ & $<.003$ & $<.045$ & $<.018$ & $<.008$ & $<.010$ & $<.02$ & $<.035$ & $<.006$ \\
\hline 292916098360701 & $<.006$ & $<.012$ & $<.027$ & $<.04$ & $<.051$ & $<.008$ & $<.01$ & $<.006$ & $<.004$ & $<.006$ & $<.04$ & .008 & $<.018$ & $<.016$ & $<.003$ & $<.045$ & $<.018$ & $<.008$ & $<.010$ & $<.02$ & $<.035$ & $<.006$ \\
\hline 292916098360701 & $<.006$ & $<.012$ & $<.027$ & $<.04$ & $<.051$ & $<.008$ & .01 & $<.006$ & $\mathrm{u}$ & 06 & $<$ & $<.006$ & 18 & $<.016$ & $<.003$ & $<.045$ & $<.018$ & , & $<.010$ & $<.02$ & $<.035$ & $<.006$ \\
\hline 292916098360701 & $<.006$ & $<.012$ & $<.027$ & $<.04$ & $<.051$ & $<.008$ & $<.01$ & $<.006$ & $<.004$ & $<.006$ & $<.04$ & E.005 & $<.018$ & $<.016$ & $<.003$ & $<.045$ & $<.018$ & $<.008$ & $<.010$ & $<.02$ & $<.035$ & $<.006$ \\
\hline 292916098360701 & $<.006$ & $<.012$ & $<.027$ & $<.04$ & $<.051$ & $<.008$ & $<.01$ & $<.006$ & $<.004$ & $<.006$ & $<.04$ & $<.006$ & $<.018$ & $<.016$ & $<.003$ & $<.045$ & $<.018$ & $\mathrm{u}$ & $<.010$ & $<.02$ & $<.035$ & $<.006$ \\
\hline 292916098360701 & $<.006$ & $<.012$ & $<.027$ & $<.04$ & $<.051$ & $<.008$ & $<.01$ & $<.006$ & $<.004$ & $<.006$ & $<.0$ & .009 & $<.018$ & $<.016$ & $<.003$ & $<.045$ & $<.018$ & E.007 & $<.010$ & $<.02$ & $<.035$ & $<.006$ \\
\hline 292916098360701 & $<.006$ & $<.012$ & $<.027$ & $<.04$ & $<.051$ & $<.008$ & $<.01$ & $<.006$ & $<.004$ & $<.006$ & $<.04$ & E.006 & $<.018$ & $<.016$ & $<.003$ & $<.045$ & $<.018$ & $<.008$ & $<.010$ & $<.02$ & $<.035$ & $<.006$ \\
\hline 292916098360701 & $<.006$ & $<.012$ & $<.027$ & $<.04$ & $<.051$ & $<.008$ & $<.01$ & $<.006$ & $<.004$ & $<.006$ & $<.04$ & .009 & $<.018$ & $<.016$ & $<.003$ & $<.045$ & $<.018$ & $<.008$ & $<.010$ & $<.02$ & $<.035$ & $<.006$ \\
\hline 292916098360701 & $<.006$ & $<.012$ & $<.027$ & $<.04$ & $<.051$ & $<.008$ & $<.01$ & $<.006$ & $<.004$ & $<.006$ & $<.04$ & .008 & $<.018$ & $<.016$ & $<.003$ & $<.045$ & $<.018$ & $<.008$ & $<.010$ & $<.02$ & $<.035$ & $<.006$ \\
\hline
\end{tabular}

\begin{tabular}{|c|c|c|c|c|c|c|c|c|c|c|c|c|c|c|c|c|c|c|c|c|c|c|}
\hline \multicolumn{23}{|c|}{ Well-field wells (wellhead sampling) } \\
\hline 292919098360501 & $<.006$ & $<.012$ & $<.027$ & $<.04$ & $<.051$ & $<.008$ & $<.01$ & $<.006$ & $<.004$ & $<.006$ & $<.04$ & E.005 & $<.018$ & $<.016$ & $<.003$ & $<.045$ & $<.018$ & $<.008$ & $<.010$ & $<.02$ & $<.035$ & $<.006$ \\
\hline 292925098360201 & $<.006$ & $<.012$ & $<.027$ & $<.04$ & $<.051$ & $<.008$ & $<.01$ & $<.006$ & $<.004$ & $<.006$ & $<.04$ & $<.006$ & $<.018$ & $<.016$ & $<.003$ & $<.045$ & $<.018$ & $<.008$ & $<.010$ & $<.02$ & $<.035$ & $<.006$ \\
\hline 292916098360701 & $<.006$ & $<.012$ & $<.027$ & $<.04$ & $<.051$ & $<.008$ & $<.01$ & $<.006$ & $<.004$ & $<.006$ & $<.04$ & E.005 & $<.018$ & $<.016$ & $<.003$ & $<.045$ & $<.018$ & $<.008$ & $<.010$ & $<.02$ & $<.035$ & $<.006$ \\
\hline 292920098360601 & $<.006$ & $<.012$ & $<.027$ & $<.04$ & $<.051$ & $<.008$ & $<.01$ & $<.006$ & $<.004$ & $<.006$ & $<.04$ & E.005 & $<.018$ & $<.016$ & $<.003$ & $<.045$ & $<.018$ & $<.008$ & $<.010$ & $<.02$ & $<.035$ & $<.006$ \\
\hline 292923098360301 & $<.006$ & $<.012$ & $<.027$ & $<.04$ & $\mathrm{u}$ & $<.008$ & $<.01$ & $<.006$ & $<.004$ & $<.006$ & $<.04$ & $<.006$ & $<.018$ & $<.016$ & $<.003$ & $<.045$ & $<.018$ & $<.008$ & $<.010$ & $<.02$ & $<.035$ & $<.006$ \\
\hline \multicolumn{23}{|c|}{ Temporal sampling } \\
\hline 292923098360301 & -- & -- & -- & -- & -- & -- & -- & -- & -- & -- & -- & -- & -- & -- & -- & -- & -- & -- & -- & -- & -- & -- \\
\hline 292923098360301 & -- & -- & -- & -- & -- & -- & -- & -- & -- & -- & -- & -- & -- & -- & -- & -- & -- & -- & -- & -- & -- & -- \\
\hline 292923098360301 & -- & -- & -- & -- & -- & -- & -- & -- & -- & -- & -- & -- & -- & -- & -- & -- & -- & -- & -- & -- & -- & -- \\
\hline
\end{tabular}


Table 15. Soluble pesticide compounds for groundwater samples collected for the study of the transport of anthropogenic and natural contaminants (TANC) to public supply wells in the San Antonio segment of the Edwards aquifer near San Antonio, south-central Texas, 2004-9. - Continued

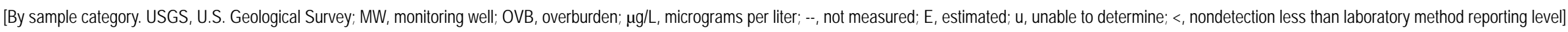

\begin{tabular}{|c|c|c|c|c|c|c|c|c|c|c|c|c|c|c|c|c|c|c|c|c|c|c|}
\hline $\begin{array}{c}\text { USGS } \\
\text { identification } \\
\text { number }\end{array}$ & $\begin{array}{c}\text { Oxy- } \\
\text { fluor- } \\
\text { fen } \\
(\mu g / L)\end{array}$ & $\begin{array}{c}\text { Pendi- } \\
\text { meth- } \\
\text { alin } \\
(\mu \mathrm{g} / \mathrm{L})\end{array}$ & $\begin{array}{c}\text { Phor- } \\
\text { ate } \\
\text { oxy- } \\
\text { gen } \\
\text { analog } \\
(\mu \mathrm{g} / \mathrm{L})\end{array}$ & $\begin{array}{l}\text { Phor- } \\
\text { ate } \\
(\mu \mathrm{g} / \mathrm{L})\end{array}$ & $\begin{array}{c}\text { Phos- } \\
\text { met } \\
\text { oxy- } \\
\text { gen } \\
\text { analog } \\
\text { ( } \mu \mathrm{g} / \mathrm{L})\end{array}$ & $\begin{array}{c}\text { Phos- } \\
\text { met } \\
\text { ( } \mu \mathrm{g} / \mathrm{L})\end{array}$ & $\begin{array}{l}\text { Pro- } \\
\text { meton } \\
(\mu g / L)\end{array}$ & $\begin{array}{c}\text { Pro- } \\
\text { metryn } \\
(\mu \mathrm{g} / \mathrm{L})\end{array}$ & $\begin{array}{c}\text { Pro- } \\
\text { pyz- } \\
\text { amide } \\
\text { ( } \mu \mathrm{g} / \mathrm{L})\end{array}$ & $\begin{array}{c}\text { Prop- } \\
\text { anil } \\
(\mu \mathrm{g} / \mathrm{L})\end{array}$ & $\begin{array}{l}\text { Prop- } \\
\text { argite } \\
(\mu \mathrm{g} / \mathrm{L})\end{array}$ & $\begin{array}{l}\text { Sim- } \\
\text { azine } \\
\text { ( } \mathrm{gg} / \mathrm{L})\end{array}$ & $\begin{array}{l}\text { Tebu- } \\
\text { con- } \\
\text { azole } \\
\text { ( } \mu \mathrm{g} / \mathrm{L})\end{array}$ & $\begin{array}{c}\text { Tebu- } \\
\text { thi- } \\
\text { uron } \\
(\mu \mathrm{g} / \mathrm{L})\end{array}$ & $\begin{array}{l}\text { Teflu- } \\
\text { thrin } \\
(\mu \mathrm{g} / \mathrm{L})\end{array}$ & $\begin{array}{c}\text { Terb- } \\
\text { ufos } \\
\text { oxy- } \\
\text { gen } \\
\text { analog } \\
\text { sul- } \\
\text { fone } \\
(\mu \mathrm{g} / \mathrm{L})\end{array}$ & $\begin{array}{l}\text { Terb- } \\
\text { ufos } \\
(\mu \mathrm{g} / \mathrm{L})\end{array}$ & $\begin{array}{c}\text { Ter- } \\
\text { buthyl- } \\
\text { azine } \\
\text { ( } \mu \mathrm{g} / \mathrm{L} \text { ) }\end{array}$ & $\begin{array}{l}\text { Thio- } \\
\text { ben- } \\
\text { carb } \\
\text { ( } \mu \mathrm{g} / \mathrm{L})\end{array}$ & $\begin{array}{l}\text { trans- } \\
\text { Propi- } \\
\text { con- } \\
\text { azole } \\
(\mu \mathrm{g} / \mathrm{L})\end{array}$ & $\begin{array}{c}\text { Tri- } \\
\text { bu- } \\
\text { phos } \\
(\mu \mathrm{g} / \mathrm{L})\end{array}$ & $\begin{array}{c}\text { Tri- } \\
\text { flur- } \\
\text { alin } \\
(\mu \mathrm{g} / \mathrm{L})\end{array}$ \\
\hline 2923098360301 & $<0.010$ & $<0.012$ & $<0$. & $<0.02$ & $<0.051$ & $<0.034$ & E0.008 & $<0.006$ & $<0.004$ & $<0.010$ & $<0.020$ & $<0.006$ & -- & $<0.028$ & $<0.010$ & $<0.045$ & $<0.018$ & $<0.006$ & $<0.016$ & $<0.02$ & $<0.018$ & $<0.018$ \\
\hline 2923098360301 & $<.010$ & $<.012$ & $<.027$ & $<.02$ & $<.051$ & $<.034$ & $<.012$ & $<.006$ & $<.004$ & $<.010$ & $<.020$ & $<.006$ & -- & $<.028$ & $<.010$ & $<.045$ & $<.018$ & $<.006$ & $<.016$ & $<.02$ & $<.018$ & $<.018$ \\
\hline 2923098360301 & $<.010$ & $<.012$ & $<.027$ & $<.02$ & u & $<.034$ & $<.012$ & $<.006$ & $<.004$ & $<.010$ & $<.020$ & E.006 & -- & $<.028$ & $<.010$ & $<.040$ & $<.018$ & $<.006$ & $<.016$ & $<.02$ & $<.018$ & $<.018$ \\
\hline 2943098354402 & -- & -- & -- & -- & -- & -- & -- & -- & -- & -- & -- & -- & -- & -- & -- & -- & -- & -- & -- & -- & -- & -- \\
\hline 92943098354402 & -- & -- & -- & -- & -- & -- & -- & -- & -- & -- & -- & -- & -- & -- & -- & -- & -- & -- & -- & -- & -- & -- \\
\hline 2943098354402 & -- & -- & -- & -- & -- & -- & -- & -- & -- & -- & -- & -- & -- & -- & -- & -- & -- & -- & -- & -- & -- & -- \\
\hline 2943098354402 & $<.010$ & $<.012$ & $<.027$ & $<.02$ & $<.051$ & $<.034$ & $<.012$ & $<.006$ & $<.007$ & $<.010$ & $<.020$ & .008 & -- & $<.028$ & $<.010$ & $<.045$ & $<.018$ & $<.006$ & $<.016$ & $<.02$ & $<.018$ & $<.018$ \\
\hline 92943098354402 & $<.010$ & $<.012$ & $<.027$ & $<.02$ & $<.051$ & $<.034$ & $<.012$ & $<.006$ & $\mathrm{u}$ & $<.010$ & $<.020$ & $<.006$ & -- & $<.028$ & $<.010$ & $<.045$ & $<.018$ & $<.011$ & $<.016$ & $<.02$ & $<.018$ & $<.018$ \\
\hline 92943098354402 & $<.010$ & $<.012$ & $<.027$ & $<.02$ & $<.051$ & $<.034$ & $<.012$ & $<.006$ & $<.004$ & $<.010$ & $<.020$ & E.007 & -- & $<.028$ & $<.010$ & $<.045$ & $<.018$ & $<.007$ & $<.016$ & $<.02$ & $<.018$ & $<.018$ \\
\hline 294309 & -- & -- & -- & -- & -- & -- & -- & -- & -- & -- & -- & -- & -- & -- & -- & -- & -- & -- & -- & -- & -- & -- \\
\hline 92943098354403 & -- & -- & -- & -- & -- & -- & -- & -- & -- & -- & -- & -- & -- & -- & -- & -- & -- & -- & -- & -- & -- & -- \\
\hline 92943098 & -- & -- & -- & -- & -- & -- & -- & -- & -- & -- & -- & -- & -- & -- & -- & -- & -- & -- & -- & -- & -- & -- \\
\hline 92943098354403 & $<.010$ & K.012 & $<.027$ & $<.02$ & $<.051$ & $<.034$ & $<.012$ & $<.006$ & - & $<.010$ & $<.020$ & $<.008$ & -- & $<.028$ & $<.010$ & $<.045$ & $<.018$ & $<.006$ & $<.016$ & $<.02$ & $<.018$ & $<.018$ \\
\hline 92943098354403 & $<.010$ & $<.012$ & $<.027$ & $<.02$ & $<.051$ & $<.034$ & $<.012$ & $<.006$ & $<.004$ & $<.010$ & $<.020$ & E.003 & -- & $<.028$ & $<.010$ & $<.045$ & $<.018$ & $<.006$ & $<.016$ & $<.02$ & $<.018$ & $<.018$ \\
\hline 92943098354403 & $<.010$ & $<.012$ & $<.027$ & $<.02$ & u & $<.034$ & $<.012$ & $<.006$ & u & $<.010$ & $<.020$ & E.003 & -- & $<.028$ & $<.010$ & $<.045$ & $<.018$ & $<.006$ & $<.016$ & $<.02$ & $<.018$ & $<.018$ \\
\hline 92943098354404 & -- & -- & -- & -- & -- & -- & -- & -- & -- & -- & -- & -- & -- & -- & -- & -- & -- & -- & -- & -- & -- & -- \\
\hline 92943098354404 & -- & -- & -- & -- & -- & -- & -- & -- & -- & -- & -- & -- & -- & -- & -- & -- & -- & -- & -- & -- & -- & -- \\
\hline 92943098354404 & 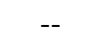 & -- & -- & -- & -- & -- & -- & -- & 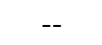 & -- & -- & -- & -- & -- & -- & -- & -- & -- & -- & -- & -- & -- \\
\hline 92943098354404 & $<.010$ & .012 & $<.027$ & $<.02$ & $<.051$ & $<.034$ & $<.012$ & $<.006$ & $<.009$ & $<.010$ & $<.020$ & $<.008$ & -- & $<.028$ & $<.010$ & $<.045$ & $<.018$ & $<.006$ & $<.016$ & $<.02$ & $<.018$ & $<.018$ \\
\hline 92943098354404 & $<.010$ & $<.012$ & $<.027$ & $<.02$ & $<.051$ & $<.034$ & $<.012$ & $<.006$ & $<.004$ & $<.010$ & $<.020$ & $<.007$ & -- & $<.028$ & $<.010$ & $<.045$ & $<.018$ & $<.006$ & $<.016$ & $<.02$ & $<.018$ & $<.018$ \\
\hline 92943098354404 & $<.010$ & $<.012$ & $<.027$ & $<.02$ & $<.051$ & $<.034$ & $<.012$ & $<.006$ & $<.004$ & $<.010$ & $<.020$ & $<.007$ & -- & $<.028$ & $<.010$ & $<.045$ & $<.018$ & $<.006$ & $<.016$ & $<.02$ & $<.018$ & $<.018$ \\
\hline 80801 & -- & -- & -- & -- & -- & -- & -- & -- & -- & -- & -- & -- & -- & -- & -- & -- & -- & -- & -- & -- & -- & -- \\
\hline 93252098380801 & -- & -- & -- & -- & -- & -- & -- & -- & -- & -- & -- & -- & -- & -- & -- & -- & -- & -- & -- & -- & -- & -- \\
\hline 93252098380801 & -- & -- & -- & -- & -- & -- & -- & -- & -- & -- & -- & -- & -- & -- & -- & -- & -- & -- & -- & -- & -- & -- \\
\hline 293252098380801 & $<.010$ & $<.012$ & $<.027$ & $<.02$ & $<.051$ & $<.034$ & $<.012$ & $<.006$ & $\mathrm{u}$ & $<.010$ & $<.020$ & .008 & -- & $<.028$ & $<.010$ & $<.045$ & $<.018$ & $<.006$ & $<.016$ & $<.02$ & $<.018$ & $<.018$ \\
\hline 80801 & $<.010$ & $<.012$ & $<.027$ & $<.02$ & $<.051$ & $<.034$ & E.004 & $<.006$ & $<.004$ & $<.010$ & $<.020$ & Е.007 & -- & $<.028$ & $<.010$ & $<.045$ & $<.018$ & $<.006$ & $<.016$ & $<.02$ & $<.018$ & $<.018$ \\
\hline 880801 & $<.010$ & $<.012$ & 027 & 02 & $<.051$ & $<.034$ & $<.012$ & $<.006$ & $<.004$ & $<.010$ & $<.020$ & E.007 & -- & $<.028$ & $<.010$ & $<.045$ & $<.018$ & $<.006$ & $<.016$ & $<.02$ & $<.018$ & $<.018$ \\
\hline
\end{tabular}


Table 16. Polar pesticide compounds for groundwater samples collected for the study of the transport of anthropogenic and natural contaminants (TANC) to public supply wells in the San Antonio segment of the Edwards aquifer near San Antonio, south-central Texas, 2004-9.

[By sample category. USGS, U.S. Geological Survey; $\mu \mathrm{g} / \mathrm{L}$, micrograms per liter; E, estimated; u, unable to determine; <, nondetection less than laboratory method reporting level; --, not measured]

\begin{tabular}{|c|c|c|c|c|c|c|c|c|c|c|c|c|c|c|c|}
\hline $\begin{array}{c}\text { USGS } \\
\text { identification } \\
\text { number }\end{array}$ & $\begin{array}{l}\text { State well } \\
\text { number }\end{array}$ & $\begin{array}{l}\text { Group and } \\
\text { description }\end{array}$ & $\begin{array}{c}\text { Sample } \\
\text { date }\end{array}$ & $\begin{array}{c}\text { 2,4-D } \\
\text { methyl } \\
\text { ester } \\
(\mu \mathrm{g} / \mathrm{L})\end{array}$ & $\begin{array}{l}2,4-D \\
(\mu \mathrm{g} / \mathrm{L})\end{array}$ & $\begin{array}{c}2,4-D B \\
(\mu \mathrm{g} / \mathrm{L})\end{array}$ & $\begin{array}{c}\text { 2-Chloro- } \\
\text { 6-ethyl- } \\
\text { amino- } \\
\text { 4-amino- } \\
\text { s-triazine } \\
\text { (CEAT) } \\
\text { ( } \mu \mathrm{g} / \mathrm{L})\end{array}$ & $\begin{array}{c}\text { 2-Hydroxy- } \\
\text { 4-isopropyl- } \\
\text { amino- } \\
\text { 6-ethyl- } \\
\text { amino-s- } \\
\text { triazine } \\
\text { (OIET) } \\
\text { ( } \mu \mathrm{g} / \mathrm{L})\end{array}$ & $\begin{array}{c}\text { 3-Ke- } \\
\text { to- } \\
\text { carbo- } \\
\text { furan } \\
(\mu \mathrm{g} / \mathrm{L})\end{array}$ & $\begin{array}{c}\text { 3-Hy- } \\
\text { droxy } \\
\text { carbo- } \\
\text { furan } \\
(\mu \mathrm{g} / \mathrm{L})\end{array}$ & $\begin{array}{c}\text { Acifluor- } \\
\text { fen } \\
(\mu g / L)\end{array}$ & $\begin{array}{l}\text { Aldi- } \\
\text { carb } \\
\text { sulf- } \\
\text { one } \\
\text { ( } \mu \mathrm{g} / \mathrm{L})\end{array}$ & $\begin{array}{l}\text { Aldi- } \\
\text { carb } \\
\text { sulf- } \\
\text { oxide } \\
\text { ( } \mu \mathrm{g} / \mathrm{L} \text { ) }\end{array}$ & $\begin{array}{c}\text { Aldi- } \\
\text { carb } \\
(\mu \mathrm{g} / \mathrm{L})\end{array}$ & $\begin{array}{c}\text { Bendio- } \\
\text { carb } \\
\text { ( } \mu \mathrm{g} / \mathrm{L})\end{array}$ \\
\hline \multicolumn{16}{|c|}{ Regional aquifer public-supply wells } \\
\hline 293359098290301 & AY-68-29-414 & 1st (highest) quartile & $2004 / 12 / 06$ & $<0.016$ & $<0.038$ & $<0.02$ & E0.006 & $<0.032$ & $<0.02$ & $<0.008$ & $<0.028$ & $<0.018$ & $<0.022$ & $<0.04$ & $<0.02$ \\
\hline 293359098290301 & AY-68-29-414 & 1st quartile & $2005 / 09 / 01$ & $<.016$ & $<.038$ & $<.02$ & $<.08$ & $<.032$ & $<.02$ & $<.008$ & $<.028$ & $<.018$ & $<.022$ & $<.04$ & $<.02$ \\
\hline 293358098231101 & AY-68-29-610 & 1st quartile & $2004 / 12 / 15$ & $<.016$ & $<.038$ & $<.02$ & E.005 & E.007 & $<.02$ & $<.008$ & $<.028$ & $<.018$ & $<.022$ & $<.04$ & $<.02$ \\
\hline 293358098231101 & AY-68-29-610 & 1st quartile & $2005 / 08 / 29$ & $<.016$ & $<.038$ & $<.020$ & E.009 & $<.032$ & $<.02$ & $<.008$ & $<.028$ & $<.018$ & $<.022$ & $<.04$ & $<.020$ \\
\hline 293120098285801 & AY-68-29-714 & 1st quartile & $2004 / 12 / 14$ & $<.016$ & $<.038$ & $<.02$ & E.005 & E.004 & $<.02$ & $<.008$ & $<.028$ & $<.018$ & $<.022$ & $<.04$ & $<.02$ \\
\hline 293120098285801 & AY-68-29-714 & 1st quartile & $2005 / 08 / 30$ & $<.016$ & $<.038$ & $<.020$ & $<.08$ & $<.032$ & $<.02$ & $<.008$ & $<.028$ & $<.018$ & $<.022$ & $<.04$ & $<.020$ \\
\hline 293145098224201 & AY-68-29-929 & 1st quartile & $2004 / 12 / 15$ & $<.016$ & $<.038$ & $<.02$ & $<.08$ & $<.032$ & $<.02$ & $<.008$ & $<.028$ & $<.018$ & $<.022$ & $<.04$ & $<.02$ \\
\hline 293119098211201 & AY-68-30-718 & 1st quartile & $2004 / 12 / 16$ & $<.016$ & $<.038$ & $<.02$ & $<.08$ & $<.032$ & $<.02$ & $<.008$ & $<.028$ & $<.018$ & $<.022$ & $<.04$ & $<.02$ \\
\hline 292843098425101 & AY-68-35-106 & 1st quartile & $2004 / 12 / 13$ & $<.016$ & $<.038$ & $<.02$ & $<.08$ & $<.032$ & $<.02$ & $<.008$ & $<.028$ & $<.018$ & $<.022$ & $<.04$ & $<.02$ \\
\hline 292459098382101 & AY-68-35-913 & 1st quartile & $2004 / 12 / 13$ & $<.016$ & $<.038$ & $<.02$ & $<.08$ & $<.032$ & $<.02$ & $<.008$ & $<.028$ & $<.018$ & $<.022$ & $<.04$ & $<.02$ \\
\hline 292925098360201 & AY-68-36-104 & 1st quartile & $2004 / 12 / 13$ & $<.016$ & $<.038$ & $<.02$ & E.005 & E.003 & $<.02$ & $<.008$ & $<.028$ & $<.018$ & $<.022$ & $<.04$ & $<.02$ \\
\hline 292925098360201 & AY-68-36-104 & 1st quartile & $2005 / 08 / 31$ & $<.016$ & $<.038$ & $<.020$ & $<.08$ & $<.032$ & $<.02$ & $<.008$ & $<.028$ & $<.018$ & $<.022$ & $<.04$ & $<.020$ \\
\hline 292822098325401 & AY-68-36-206 & 1st quartile & $2004 / 12 / 13$ & $<.016$ & $<.038$ & $<.02$ & E.003 & $<.032$ & $<.02$ & $<.008$ & $<.028$ & $<.018$ & $<.022$ & $<.04$ & $<.02$ \\
\hline 292822098325401 & AY-68-36-206 & 1st quartile & $2005 / 08 / 31$ & -- & -- & -- & -- & -- & -- & -- & -- & -- & -- & -- & -- \\
\hline 292944098292301 & AY-68-37-105 & 1st quartile & $2004 / 12 / 14$ & $<.016$ & $<.038$ & $<.02$ & $<.08$ & $<.032$ & $<.02$ & $<.008$ & $<.028$ & $<.018$ & $<.022$ & $<.04$ & $<.02$ \\
\hline 292944098292301 & AY-68-37-105 & 1st quartile & $2005 / 08 / 31$ & -- & -- & -- & -- & -- & -- & -- & -- & -- & -- & -- & -- \\
\hline 292522098291901 & AY-68-37-426 & 1st quartile & $2004 / 12 / 14$ & $<.016$ & $<.038$ & $<.02$ & $<.08$ & $<.032$ & $<.02$ & $<.008$ & $<.028$ & $<.018$ & $<.022$ & $<.04$ & $<.02$ \\
\hline 292643098241801 & AY-68-37-601 & 1st quartile & $2004 / 12 / 15$ & $<.016$ & Е.009 & $<.02$ & $<.08$ & $<.032$ & $<.02$ & $<.008$ & $<.028$ & $<.018$ & $<.022$ & $<.04$ & $<.02$ \\
\hline 292643098241801 & AY-68-37-601 & 1st quartile & $2005 / 08 / 30$ & $<.016$ & $<.038$ & $<.020$ & $<.08$ & $<.032$ & $<.02$ & $<.008$ & $<.028$ & $<.018$ & $<.022$ & $<.04$ & $<.020$ \\
\hline 292328098294601 & AY-68-37-705 & 1st quartile & $2004 / 12 / 14$ & $<.016$ & $<.038$ & $<.02$ & $<.08$ & $<.032$ & $<.02$ & $<.008$ & $<.028$ & $<.018$ & $<.022$ & $<.04$ & $<.02$ \\
\hline 294225098080301 & DX-68-23-601 & 1st quartile & $2004 / 12 / 08$ & $<.016$ & $<.038$ & $<.02$ & $<.08$ & $<.032$ & $<.02$ & $<.008$ & $<.028$ & $<.018$ & $<.022$ & $<.04$ & $<.02$ \\
\hline 294225098080301 & DX-68-23-601 & 1st quartile & $2005 / 09 / 01$ & -- & -- & -- & -- & -- & -- & -- & -- & -- & -- & -- & -- \\
\hline 291210099475601 & YP-69-50-506 & 1st quartile & $2004 / 11 / 30$ & $<.016$ & $<.038$ & $<.02$ & $<.08$ & $<.032$ & $<.02$ & $<.008$ & $<.028$ & $<.018$ & $<.022$ & $<.04$ & $<.02$ \\
\hline
\end{tabular}


Table 16. Polar pesticide compounds for groundwater samples collected for the study of the transport of anthropogenic and natural contaminants (TANC) to public supply wells in the San Antonio segment of the Edwards aquifer near San Antonio, south-central Texas, 2004-9.-Continued

[By sample category. USGS, U.S. Geological Survey; $\mu \mathrm{g} / \mathrm{L}$, micrograms per liter; E, estimated; u, unable to determine; <, nondetection less than laboratory method reporting level; --, not measured]

\begin{tabular}{|c|c|c|c|c|c|c|c|c|c|c|c|c|c|c|c|}
\hline $\begin{array}{c}\text { USGS } \\
\text { identification } \\
\text { number }\end{array}$ & $\begin{array}{c}\text { State well } \\
\text { number }\end{array}$ & $\begin{array}{l}\text { Group and } \\
\text { description }\end{array}$ & $\begin{array}{c}\text { Sample } \\
\text { date }\end{array}$ & $\begin{array}{c}2,4-D \\
\text { methyl } \\
\text { ester } \\
\text { ( } \mathrm{gg} / \mathrm{L})\end{array}$ & $\begin{array}{l}2,4-D \\
(\mu \mathrm{g} / \mathrm{L})\end{array}$ & $\begin{array}{r}2,4-D B \\
\text { ( } \mathrm{gg} / \mathrm{L})\end{array}$ & $\begin{array}{l}\text { 2-Chloro- } \\
\text { 6-ethyl- } \\
\text { amino- } \\
\text { 4-amino- } \\
\text { s-triazine } \\
\text { (CEAT) } \\
\text { ( } \mathrm{g} / \mathrm{L})\end{array}$ & $\begin{array}{c}\text { 2-Hydroxy- } \\
\text { 4-isopropyl- } \\
\text { amino- } \\
\text { 6-ethyl- } \\
\text { amino-s- } \\
\text { triazine } \\
\text { (OIET) } \\
\text { ( } \mu \mathrm{g} / \mathrm{L})\end{array}$ & $\begin{array}{c}\text { 3-Ke- } \\
\text { to- } \\
\text { carbo- } \\
\text { furan } \\
\text { ( } \mu \mathrm{g} / \mathrm{L})\end{array}$ & $\begin{array}{l}\text { 3-Hy- } \\
\text { droxy } \\
\text { carbo- } \\
\text { furan } \\
(\mu \mathrm{g} / \mathrm{L})\end{array}$ & $\begin{array}{l}\text { Acifluor- } \\
\text { fen } \\
(\mu \mathrm{g} / \mathrm{L})\end{array}$ & $\begin{array}{l}\text { Aldi- } \\
\text { carb } \\
\text { sulf- } \\
\text { one } \\
(\mu \mathrm{g} / \mathrm{L})\end{array}$ & $\begin{array}{l}\text { Aldi- } \\
\text { carb } \\
\text { sulf- } \\
\text { oxide } \\
\text { ( } \mu \mathrm{g} / \mathrm{L})\end{array}$ & $\begin{array}{l}\text { Aldi- } \\
\text { carb } \\
(\mu g / L)\end{array}$ & $\begin{array}{l}\text { Bendio- } \\
\text { carb } \\
(\mu \mathrm{g} / \mathrm{L})\end{array}$ \\
\hline 293111098340901 & AY-68-28-807 & 2d quartile & $2005 / 05 / 26$ & -- & -- & -- & - & -- & -- & -- & -- & -- & -- & -- & -- \\
\hline 293512098291701 & AY-68-29-109 & 2d quartile & $2005 / 04 / 20$ & -- & -- & -- & -- & -- & -- & -- & -- & -- & -- & -- & -- \\
\hline 292424098421501 & AY-68-35-810 & 2d quartile & $2005 / 04 / 21$ & -- & -- & -- & -- & -- & -- & -- & -- & -- & -- & -- & -- \\
\hline 292053098365501 & AY-68-44-110 & 2d quartile & $2005 / 05 / 26$ & -- & -- & -- & -- & -- & -- & -- & -- & -- & -- & -- & -- \\
\hline 293807098155301 & DX-68-22-901 & 2d quartile & 2005/05/18 & -- & -- & -- & -- & -- & -- & -- & -- & -- & -- & -- & -- \\
\hline 292604098563201 & TD-68-33-501 & 2d quartile & 2005/05/16 & -- & -- & -- & -- & -- & -- & -- & -- & -- & -- & -- & -- \\
\hline 292116099095501 & TD-69-47-305 & 2d quartile & $2005 / 04 / 27$ & -- & -- & -- & -- & -- & -- & -- & -- & -- & -- & -- & -- \\
\hline 291232099470301 & YP-69-50-339 & 2d quartile & 2005/05/11 & -- & -- & -- & -- & -- & -- & -- & -- & -- & -- & -- & -- \\
\hline 293128098473101 & AY-68-26-814 & 3d quartile & 2005/04/18 & -- & -- & -- & -- & -- & -- & -- & -- & -- & -- & -- & -- \\
\hline 293451098313201 & AY-68-28-601 & 3d quartile & 2005/05/17 & -- & -- & -- & -- & -- & -- & -- & -- & -- & -- & -- & -- \\
\hline 294604098060801 & DX-68-16-708 & 3d quartile & 2005/04/25 & -- & -- & -- & -- & -- & -- & -- & -- & -- & -- & -- & -- \\
\hline 294019098114701 & DX-68-23-504 & 3d quartile & 2005/05/18 & -- & -- & -- & -- & -- & -- & -- & -- & -- & -- & -- & -- \\
\hline 292215098580201 & TD-68-41-103 & 3d quartile & 2005/05/09 & -- & -- & -- & -- & -- & -- & -- & -- & -- & -- & -- & -- \\
\hline 292119098524901 & TD-68-41-308 & 3d quartile & 2005/04/27 & -- & -- & -- & -- & -- & -- & -- & -- & -- & -- & -- & -- \\
\hline 291943099163301 & TD-69-46-601 & 3d quartile & 2005/05/09 & -- & -- & -- & -- & -- & -- & -- & -- & -- & -- & -- & -- \\
\hline 291840099382601 & YP-69-43-606 & 3d quartile & 2005/05/11 & -- & -- & -- & -- & -- & -- & -- & -- & -- & -- & -- & -- \\
\hline 293518098332601 & AY-68-28-203 & 4th quartile & 2005/04/19 & -- & -- & -- & -- & -- & -- & -- & -- & -- & -- & -- & -- \\
\hline 293023098355401 & AY-68-28-702 & 4th quartile & $2005 / 04 / 26$ & -- & -- & -- & -- & -- & -- & -- & -- & -- & -- & -- & -- \\
\hline 293042098305201 & AY-68-28-913 & 4th quartile & 2005/06/30 & -- & -- & -- & -- & -- & -- & -- & -- & -- & -- & -- & -- \\
\hline 292442098474501 & AY-68-34-803 & 4th quartile & $2005 / 04 / 20$ & -- & -- & -- & -- & -- & -- & -- & -- & -- & -- & -- & -- \\
\hline 292405098371201 & AY-68-36-704 & 4th quartile & $2005 / 05 / 23$ & -- & -- & -- & -- & -- & -- & -- & -- & -- & -- & -- & -- \\
\hline 292931098274601 & AY-68-37-124 & 4th quartile & 2005/05/25 & -- & -- & -- & -- & -- & -- & -- & -- & -- & -- & -- & -- \\
\hline 293729098173101 & DX-68-30-215 & 4th quartile & 2005/04/25 & -- & -- & -- & -- & -- & -- & -- & -- & -- & -- & -- & -- \\
\hline 291219099095601 & TD-69-55-604 & 4th quartile & 2005/05/16 & -- & -- & -- & -- & -- & -- & -- & -- & -- & -- & -- & -- \\
\hline
\end{tabular}


Table 16. Polar pesticide compounds for groundwater samples collected for the study of the transport of anthropogenic and natural contaminants (TANC) to public supply wells in the San Antonio segment of the Edwards aquifer near San Antonio, south-central Texas, 2004-9.-Continued

[By sample category. USGS, U.S. Geological Survey; $\mu \mathrm{g} / \mathrm{L}$, micrograms per liter; E, estimated; u, unable to determine; <, nondetection less than laboratory method reporting level; --, not measured]

\begin{tabular}{|c|c|c|c|c|c|c|c|c|c|c|c|c|c|c|c|c|c|}
\hline $\begin{array}{c}\text { USGS } \\
\text { identification } \\
\text { number }\end{array}$ & $\begin{array}{l}\text { Ben- } \\
\text { omyl } \\
(\mu g / L)\end{array}$ & $\begin{array}{c}\text { Bensulf- } \\
\text { uron- } \\
\text { methyl } \\
(\mu \mathrm{g} / \mathrm{L})\end{array}$ & $\begin{array}{c}\text { Bentazon } \\
\text { ( } \mu \mathrm{g} / \mathrm{L})\end{array}$ & $\begin{array}{l}\text { Brom- } \\
\text { oxynil } \\
\text { ( } \mu \mathrm{g} / \mathrm{L} \text { ) }\end{array}$ & $\begin{array}{l}\text { Carb- } \\
\text { aryl } \\
(\mu \mathrm{g} / \mathrm{L})\end{array}$ & $\begin{array}{l}\text { Carbo- } \\
\text { furan } \\
\text { ( } \mu \mathrm{g} / \mathrm{L})\end{array}$ & $\begin{array}{c}\text { Chlor- } \\
\text { amben } \\
\text { methyl } \\
\text { ester } \\
\text { ( } \mu \mathrm{g} / \mathrm{L})\end{array}$ & $\begin{array}{l}\text { Chlor- } \\
\text { im- } \\
\text { uron- } \\
\text { ethyl } \\
\text { ( } \mu \mathrm{g} / \mathrm{L})\end{array}$ & $\begin{array}{c}\text { Chloro- } \\
\text { diamino- } \\
\text { s-triazine } \\
\text { (CAAT) } \\
\text { ( } \mathrm{gg} / \mathrm{L})\end{array}$ & $\begin{array}{c}\text { Chloro- } \\
\text { thal- } \\
\text { onil } \\
(\mu \mathrm{g} / \mathrm{L})\end{array}$ & $\begin{array}{l}\text { Clopyr- } \\
\text { alid } \\
(\mu \mathrm{g} / \mathrm{L})\end{array}$ & $\begin{array}{l}\text { Cyclo- } \\
\text { ate } \\
(\mu \mathrm{g} / \mathrm{L})\end{array}$ & $\begin{array}{c}\text { Dacthal- } \\
\text { mono- } \\
\text { acid } \\
(\mu \mathrm{g} / \mathrm{L})\end{array}$ & $\begin{array}{c}\text { Di- } \\
\text { camba } \\
(\mu \mathrm{g} / \mathrm{L})\end{array}$ & $\begin{array}{l}\text { Di- } \\
\text { chlor- } \\
\text { prop } \\
(\mu \mathrm{g} / \mathrm{L})\end{array}$ & $\begin{array}{c}\text { Dino- } \\
\text { seb } \\
(\mu g / L)\end{array}$ & $\begin{array}{l}\text { Di- } \\
\text { phen- } \\
\text { amid } \\
(\mu \mathrm{g} / \mathrm{L})\end{array}$ \\
\hline \multicolumn{18}{|c|}{ Regional aquifer public-supply wells } \\
\hline 293359098290301 & $<0.022$ & $<0.018$ & $<0.012$ & $<0.028$ & $<0.018$ & $<0.016$ & $<0.024$ & $<0.032$ & $<0.04$ & $<0.035$ & $<0.024$ & $<0.014$ & $<0.028$ & $<0.036$ & $<0.028$ & $<0.038$ & $<0.01$ \\
\hline 293359098290301 & $<.022$ & $<.018$ & $<.012$ & $<.028$ & $<.018$ & $<.016$ & $<.024$ & $<.032$ & $<.04$ & $<.035$ & $<.024$ & $<.014$ & $<.028$ & $<.036$ & $<.028$ & $<.038$ & $<.01$ \\
\hline 293358098231101 & $<.022$ & $<.018$ & $<.012$ & $<.028$ & $<.018$ & $<.016$ & $<.024$ & $<.032$ & $<.04$ & $<.035$ & $<.024$ & $<.014$ & $<.028$ & $<.036$ & $<.028$ & $<.038$ & $<.01$ \\
\hline 293358098231101 & $<.022$ & $<.018$ & $<.012$ & $<.028$ & $<.018$ & $<.016$ & $<.024$ & $<.032$ & $<.04$ & $<.035$ & $<.024$ & $<.014$ & $<.028$ & $<.036$ & $<.028$ & $<.038$ & $<.010$ \\
\hline 293120098285801 & $<.022$ & $<.018$ & $<.012$ & $<.028$ & $<.018$ & $<.016$ & $<.024$ & $<.032$ & $<.04$ & $<.035$ & $<.024$ & $<.014$ & $<.028$ & $<.036$ & $<.028$ & $<.038$ & $<.01$ \\
\hline 293120098285801 & $<.022$ & $<.018$ & $<.012$ & $<.028$ & $<.018$ & $<.016$ & $<.024$ & $<.032$ & $<.04$ & $<.035$ & $<.024$ & $<.014$ & $<.028$ & $<.036$ & $<.028$ & $<.038$ & $<.010$ \\
\hline 293145098224201 & $<.022$ & $<.018$ & $<.012$ & $<.028$ & $<.018$ & $<.016$ & $<.024$ & $<.032$ & $<.04$ & $<.035$ & $<.024$ & $<.014$ & $<.028$ & $<.036$ & $<.028$ & $<.038$ & $<.01$ \\
\hline 293119098211201 & $<.022$ & $<.018$ & $<.012$ & $<.028$ & $<.018$ & $<.016$ & $<.024$ & $<.032$ & $<.04$ & $<.035$ & $<.024$ & $<.014$ & $<.028$ & $<.036$ & $<.028$ & $<.038$ & $<.01$ \\
\hline 292843098425101 & $<.022$ & $<.018$ & $<.012$ & $<.028$ & $<.018$ & $<.016$ & $<.024$ & $<.032$ & $<.04$ & $<.035$ & $<.024$ & $<.014$ & $<.028$ & $<.036$ & $<.028$ & $<.038$ & $<.01$ \\
\hline 292459098382101 & $<.022$ & $<.018$ & $<.012$ & $<.028$ & $<.018$ & $<.016$ & $<.024$ & $<.032$ & $<.04$ & $<.035$ & $<.024$ & $<.014$ & $<.028$ & $<.036$ & $<.028$ & $<.038$ & $<.01$ \\
\hline 292925098360201 & $<.022$ & $<.018$ & $<.012$ & $<.028$ & $<.018$ & $<.016$ & $<.024$ & $<.032$ & $<.04$ & $<.035$ & $<.024$ & $<.014$ & $<.028$ & $<.036$ & $<.028$ & $<.038$ & $<.01$ \\
\hline 292925098360201 & $<.022$ & $<.018$ & $<.012$ & $<.028$ & $<.018$ & $<.016$ & $<.024$ & $<.032$ & $<.04$ & $<.035$ & $<.024$ & $<.014$ & $<.028$ & $<.036$ & $<.028$ & $<.038$ & $<.010$ \\
\hline 292822098325401 & $<.022$ & $<.018$ & $<.012$ & $<.028$ & $<.018$ & $<.016$ & $<.024$ & $<.032$ & $<.04$ & $<.035$ & $<.024$ & $<.014$ & $<.028$ & $<.036$ & $<.028$ & $<.038$ & $<.01$ \\
\hline 292822098325401 & -- & -- & -- & -- & -- & -- & -- & -- & -- & -- & -- & -- & -- & -- & -- & -- & -- \\
\hline 292944098292301 & $<.022$ & $<.018$ & $<.012$ & $<.028$ & $<.018$ & $<.016$ & $<.024$ & $<.032$ & $<.04$ & $<.035$ & $<.024$ & $<.014$ & $<.028$ & $<.036$ & $<.028$ & $<.038$ & $<.01$ \\
\hline 292944098292301 & -- & -- & -- & -- & -- & -- & -- & -- & -- & -- & -- & -- & -- & -- & -- & -- & -- \\
\hline 292522098291901 & $<.022$ & $<.018$ & $<.012$ & $<.028$ & $<.018$ & $<.016$ & $<.024$ & $<.032$ & $<.04$ & $<.035$ & $<.024$ & $<.014$ & $<.028$ & $<.036$ & $<.028$ & $<.038$ & $<.01$ \\
\hline 292643098241801 & $<.022$ & $<.018$ & $<.012$ & $<.028$ & $<.018$ & $<.016$ & $<.024$ & $<.032$ & $<.04$ & $<.035$ & $<.024$ & $<.014$ & $<.028$ & $<.036$ & $<.028$ & $<.038$ & $<.01$ \\
\hline 292643098241801 & $<.022$ & $<.018$ & $<.012$ & $<.028$ & $<.018$ & $<.016$ & $<.024$ & $<.032$ & $<.04$ & $<.035$ & $<.024$ & $<.014$ & $<.028$ & $<.036$ & $<.028$ & $<.038$ & $<.010$ \\
\hline 292328098294601 & $<.022$ & $<.018$ & $<.012$ & $<.028$ & $<.018$ & $<.016$ & $<.024$ & $<.032$ & $<.04$ & $<.035$ & $<.024$ & $<.014$ & $<.028$ & $<.036$ & $<.028$ & $<.038$ & $<.01$ \\
\hline 294225098080301 & $<.022$ & $<.018$ & $<.012$ & $<.028$ & $<.018$ & $<.016$ & $<.024$ & $<.032$ & $<.04$ & $<.035$ & $<.024$ & $<.014$ & $<.028$ & $<.036$ & $<.028$ & $<.038$ & $<.01$ \\
\hline 294225098080301 & -- & -- & -- & -- & -- & -- & -- & -- & -- & -- & -- & -- & -- & -- & -- & -- & -- \\
\hline 291210099475601 & $<.022$ & $<.018$ & $<.012$ & $<.028$ & $<.018$ & $<.016$ & $<.024$ & $<.032$ & $<.04$ & $<.035$ & $<.024$ & $<.014$ & $<.028$ & $<.036$ & $<.028$ & $<.038$ & $<.01$ \\
\hline
\end{tabular}




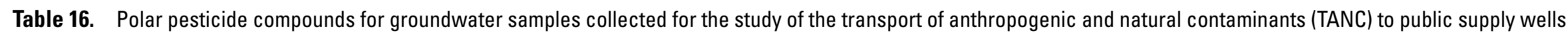
in the San Antonio segment of the Edwards aquifer near San Antonio, south-central Texas, 2004-9._Continued

[By sample category. USGS, U.S. Geological Survey; $\mu \mathrm{g} / \mathrm{L}$, micrograms per liter; E, estimated; u, unable to determine; <, nondetection less than laboratory method reporting level; --, not measured]

\begin{tabular}{|c|c|c|c|c|c|c|c|c|c|c|c|c|c|c|c|c|c|}
\hline $\begin{array}{c}\text { USGS } \\
\text { identification } \\
\text { number }\end{array}$ & $\begin{array}{l}\text { Ben- } \\
\text { omyl } \\
\text { ( } \mu \mathrm{g} / \mathrm{L})\end{array}$ & $\begin{array}{c}\text { Bensulf- } \\
\text { uron- } \\
\text { methyl } \\
(\mu \mathrm{g} / \mathrm{L})\end{array}$ & $\begin{array}{c}\text { Bentazon } \\
(\mu \mathrm{g} / \mathrm{L})\end{array}$ & $\begin{array}{l}\text { Brom- } \\
\text { oxynil } \\
\text { ( } \mu \mathrm{g} / \mathrm{L})\end{array}$ & $\begin{array}{l}\text { Carb- } \\
\text { aryl } \\
(\mu \mathrm{g} / \mathrm{L})\end{array}$ & $\begin{array}{c}\text { Carbo- } \\
\text { furan } \\
(\mu \mathrm{g} / \mathrm{L})\end{array}$ & $\begin{array}{c}\text { Chlor- } \\
\text { amben } \\
\text { methyl } \\
\text { ester } \\
\text { ( } \mu \mathrm{g} / \mathrm{L})\end{array}$ & $\begin{array}{c}\text { Chlor- } \\
\text { im- } \\
\text { uron- } \\
\text { ethyl } \\
\text { ( } \mu \mathrm{g} / \mathrm{L})\end{array}$ & $\begin{array}{c}\text { Chloro- } \\
\text { diamino- } \\
\text { s-triazine } \\
\text { (CAAT) } \\
\text { ( } \mu \mathrm{g} / \mathrm{L})\end{array}$ & $\begin{array}{c}\text { Chloro- } \\
\text { thal- } \\
\text { onil } \\
(\mu \mathrm{g} / \mathrm{L})\end{array}$ & $\begin{array}{l}\text { Clopyr- } \\
\text { alid } \\
\text { ( } \mu \mathrm{g} / \mathrm{L})\end{array}$ & $\begin{array}{l}\text { Cyclo- } \\
\text { ate } \\
(\mu \mathrm{g} / \mathrm{L})\end{array}$ & $\begin{array}{c}\text { Dacthal- } \\
\text { mono- } \\
\text { acid } \\
(\mu \mathrm{g} / \mathrm{L})\end{array}$ & $\begin{array}{c}\text { Di- } \\
\text { camba } \\
(\mu \mathrm{g} / \mathrm{L})\end{array}$ & $\begin{array}{c}\text { Di- } \\
\text { chlor- } \\
\text { prop } \\
(\mu \mathrm{g} / \mathrm{L})\end{array}$ & $\begin{array}{c}\text { Dino- } \\
\text { seb } \\
(\mu \mathrm{g} / \mathrm{L})\end{array}$ & $\begin{array}{l}\text { Di- } \\
\text { phen- } \\
\text { amid } \\
\text { ( } \mu \mathrm{g} / \mathrm{L})\end{array}$ \\
\hline 293111098340901 & -- & -- & -- & -- & -- & -- & -- & -- & -- & -- & -- & -- & -- & -- & -- & -- & -- \\
\hline 293512098291701 & -- & -- & -- & -- & -- & -- & -- & -- & -- & -- & -- & -- & -- & -- & -- & -- & -- \\
\hline 292424098421501 & -- & -- & -- & -- & -- & -- & -- & -- & -- & -- & -- & -- & -- & -- & -- & -- & -- \\
\hline 292053098365501 & -- & -- & -- & -- & -- & -- & -- & -- & -- & -- & -- & -- & -- & -- & -- & -- & -- \\
\hline 293807098155301 & -- & -- & -- & -- & -- & -- & -- & -- & -- & -- & -- & -- & -- & -- & -- & -- & -- \\
\hline 292604098563201 & -- & -- & -- & -- & -- & -- & -- & -- & -- & -- & -- & -- & -- & -- & -- & -- & -- \\
\hline 292116099095501 & -- & -- & -- & -- & -- & -- & -- & -- & -- & -- & -- & -- & -- & -- & -- & -- & -- \\
\hline 291232099470301 & -- & -- & -- & -- & -- & -- & -- & -- & -- & -- & -- & -- & -- & -- & -- & -- & -- \\
\hline 293128098473101 & -- & -- & -- & -- & -- & -- & -- & -- & -- & -- & -- & -- & -- & -- & -- & -- & -- \\
\hline 293451098313201 & -- & -- & -- & -- & -- & -- & -- & -- & -- & -- & -- & -- & -- & -- & -- & -- & -- \\
\hline 294604098060801 & -- & -- & -- & -- & -- & -- & -- & -- & -- & -- & -- & -- & -- & -- & -- & -- & -- \\
\hline 294019098114701 & -- & -- & -- & -- & -- & -- & -- & -- & -- & -- & -- & -- & -- & -- & -- & -- & -- \\
\hline 292215098580201 & -- & -- & -- & -- & -- & -- & -- & -- & -- & -- & -- & -- & -- & -- & -- & -- & -- \\
\hline 292119098524901 & -- & -- & -- & -- & -- & -- & -- & -- & -- & -- & -- & -- & -- & -- & -- & -- & -- \\
\hline 291943099163301 & -- & -- & -- & -- & -- & -- & -- & -- & -- & -- & -- & -- & -- & -- & -- & -- & -- \\
\hline 291840099382601 & -- & -- & -- & -- & -- & -- & -- & -- & -- & -- & -- & -- & -- & -- & -- & -- & -- \\
\hline 293518098332601 & -- & -- & -- & -- & -- & -- & -- & -- & -- & -- & -- & -- & -- & -- & -- & -- & -- \\
\hline 293023098355401 & -- & -- & -- & -- & -- & -- & -- & -- & -- & -- & -- & -- & -- & -- & -- & -- & -- \\
\hline 293042098305201 & -- & -- & -- & -- & -- & -- & -- & -- & -- & -- & -- & -- & -- & -- & -- & -- & -- \\
\hline 292442098474501 & -- & -- & -- & -- & -- & -- & -- & -- & -- & -- & -- & -- & -- & -- & -- & -- & -- \\
\hline 292405098371201 & -- & -- & -- & -- & -- & -- & -- & -- & -- & -- & -- & -- & -- & -- & -- & -- & -- \\
\hline 292931098274601 & -- & -- & -- & -- & -- & -- & -- & -- & -- & -- & -- & -- & -- & -- & -- & -- & -- \\
\hline 293729098173101 & -- & -- & -- & -- & -- & -- & -- & -- & -- & -- & -- & -- & -- & -- & -- & -- & -- \\
\hline 291219099095601 & -- & -- & -- & -- & -- & -- & -- & -- & -- & -- & -- & -- & -- & -- & -- & -- & -- \\
\hline
\end{tabular}


Table 16. Polar pesticide compounds for groundwater samples collected for the study of the transport of anthropogenic and natural contaminants (TANC) to public supply wells in the San Antonio segment of the Edwards aquifer near San Antonio, south-central Texas, 2004-9.-Continued

[By sample category. USGS, U.S. Geological Survey; $\mu \mathrm{g} / \mathrm{L}$, micrograms per liter; E, estimated; u, unable to determine; <, nondetection less than laboratory method reporting level; --, not measured]

\begin{tabular}{|c|c|c|c|c|c|c|c|c|c|c|c|c|c|c|}
\hline $\begin{array}{c}\text { USGS } \\
\text { identification } \\
\text { number }\end{array}$ & $\begin{array}{c}\text { Diuron } \\
\text { ( } \mu \mathrm{g} / \mathrm{L})\end{array}$ & $\begin{array}{c}\text { Fenuron } \\
(\mu \mathrm{g} / \mathrm{L})\end{array}$ & $\begin{array}{l}\text { Flumet- } \\
\text { sulam } \\
\text { ( } \mu \mathrm{g} / \mathrm{L})\end{array}$ & $\begin{array}{c}\text { Fluo- } \\
\text { meturon } \\
\text { ( } \mu \mathrm{g} / \mathrm{L})\end{array}$ & $\begin{array}{l}\text { Imaz- } \\
\text { aquin } \\
(\mu \mathrm{g} / \mathrm{L})\end{array}$ & $\begin{array}{l}\text { Imaz- } \\
\text { etha- } \\
\mathrm{pyr} \\
(\mu \mathrm{g} / \mathrm{L})\end{array}$ & $\begin{array}{l}\text { Imida- } \\
\text { cloprid } \\
\text { ( } \mu \mathrm{g} / \mathrm{L} \text { ) }\end{array}$ & $\begin{array}{c}\text { Linuron } \\
\text { ( } \mu \mathrm{g} / \mathrm{L} \text { ) }\end{array}$ & $\begin{array}{c}\text { MCPA } \\
(\mu \mathrm{g} / \mathrm{L})\end{array}$ & $\begin{array}{c}\text { MCPB } \\
\text { ( } \mu \mathrm{g} / \mathrm{L})\end{array}$ & $\begin{array}{c}\text { Methio- } \\
\text { carb } \\
\text { ( } \mu \mathrm{g} / \mathrm{L})\end{array}$ & $\begin{array}{c}\text { Meth- } \\
\text { omyl } \\
(\mu \mathrm{g} / \mathrm{L})\end{array}$ & $\begin{array}{c}\text { Met- } \\
\text { sulfuron } \\
\text { ( } \mu \mathrm{g} / \mathrm{L})\end{array}$ & $\begin{array}{c}\text { N-(4-chloro- } \\
\text { phenyl)-N'- } \\
\text { methyl-urea } \\
(\mu \mathrm{g} / \mathrm{L})\end{array}$ \\
\hline \multicolumn{15}{|c|}{ Regional aquifer public-supply wells } \\
\hline 293359098290301 & $<0.015$ & $<0.019$ & $<0.04$ & $<0.016$ & $<0.036$ & $<0.038$ & $<0.02$ & $<0.014$ & $<0.03$ & $<0.01$ & $<0.02$ & $<0.025$ & $<0.036$ & $<0.012$ \\
\hline 293359098290301 & $<.015$ & $<.019$ & $<.04$ & $<.016$ & $<.036$ & $<.038$ & $<.02$ & $<.014$ & $<.03$ & $<.01$ & $<.01$ & $<.02$ & $<.025$ & $<.036$ \\
\hline 293358098231101 & $<.015$ & $<.019$ & $<.04$ & $<.016$ & $<.036$ & $<.038$ & $<.02$ & $<.014$ & $\mathrm{u}$ & $<.01$ & $<.01$ & $<.02$ & $<.025$ & $<.036$ \\
\hline 293358098231101 & $<.015$ & $<.019$ & $<.040$ & $<.016$ & $<.036$ & $<.038$ & $<.020$ & $<.014$ & $<.030$ & $<.010$ & $<.010$ & $<.020$ & $<.025$ & $<.036$ \\
\hline 293120098285801 & $<.015$ & $<.019$ & $<.04$ & $<.016$ & $<.036$ & $<.038$ & $<.02$ & $<.014$ & $\mathrm{u}$ & $<.01$ & $<.01$ & $<.02$ & $<.025$ & $<.036$ \\
\hline 293120098285801 & $<.015$ & $<.019$ & $<.040$ & $<.016$ & $<.036$ & $<.038$ & $<.020$ & $<.014$ & $<.030$ & $<.010$ & $<.010$ & $<.020$ & $<.025$ & $<.036$ \\
\hline 293145098224201 & $<.015$ & $<.019$ & $<.04$ & $<.016$ & $<.036$ & $<.038$ & $<.02$ & $<.014$ & $\mathrm{u}$ & $<.01$ & $<.01$ & $<.02$ & $<.025$ & $<.036$ \\
\hline 293119098211201 & $<.015$ & $<.019$ & $<.04$ & $<.016$ & $<.036$ & $<.038$ & $<.02$ & $<.014$ & $\mathrm{u}$ & $<.01$ & $<.01$ & $<.02$ & $<.025$ & $<.036$ \\
\hline 292843098425101 & $<.015$ & $<.019$ & $<.04$ & $<.016$ & $<.036$ & $<.038$ & $<.02$ & $<.014$ & $<.03$ & $<.01$ & $<.01$ & $<.02$ & $<.025$ & $<.036$ \\
\hline 292459098382101 & $<.015$ & $<.019$ & $<.04$ & $<.016$ & $<.036$ & $<.038$ & $<.02$ & $<.014$ & $<.03$ & $<.01$ & $<.01$ & $<.02$ & E.035 & $<.036$ \\
\hline 292925098360201 & $<.015$ & $<.019$ & $<.04$ & $<.016$ & $<.036$ & $<.038$ & $<.02$ & $<.014$ & $<.03$ & $<.01$ & $<.01$ & $<.02$ & $<.025$ & $<.036$ \\
\hline 292925098360201 & $<.015$ & $<.019$ & $<.040$ & $<.016$ & $<.036$ & $<.038$ & $<.020$ & $<.014$ & $<.030$ & $<.010$ & $<.010$ & $<.020$ & $<.025$ & $<.036$ \\
\hline 292822098325401 & $<.015$ & $<.019$ & $<.04$ & $<.016$ & $<.036$ & $<.038$ & $<.02$ & $<.014$ & $<.03$ & $<.01$ & $<.01$ & $<.02$ & $<.025$ & $<.036$ \\
\hline 292822098325401 & -- & -- & -- & -- & -- & -- & -- & -- & -- & -- & -- & -- & -- & -- \\
\hline 292944098292301 & $<.015$ & $<.019$ & $<.04$ & $<.016$ & $<.036$ & $<.038$ & $<.02$ & $<.014$ & $\mathrm{u}$ & $<.01$ & $<.01$ & $<.02$ & $<.025$ & $<.036$ \\
\hline 292944098292301 & -- & -- & -- & -- & -- & -- & -- & -- & -- & -- & -- & -- & -- & -- \\
\hline 292522098291901 & $<.015$ & $<.019$ & $<.04$ & $<.016$ & $<.036$ & $<.038$ & $<.02$ & $<.014$ & $\mathrm{u}$ & $<.01$ & $<.01$ & $<.02$ & $<.025$ & $<.036$ \\
\hline 292643098241801 & $<.015$ & $<.019$ & $<.04$ & $<.016$ & $<.036$ & $<.038$ & $<.02$ & $<.014$ & $\mathrm{u}$ & $<.01$ & $<.01$ & $<.02$ & $<.025$ & $<.036$ \\
\hline 292643098241801 & $<.015$ & $<.019$ & $<.040$ & $<.016$ & $<.036$ & $<.038$ & $<.020$ & $<.014$ & $<.030$ & $<.010$ & $<.010$ & $<.020$ & $<.025$ & $<.036$ \\
\hline 292328098294601 & $<.015$ & $<.019$ & $<.04$ & $<.016$ & $<.036$ & $<.038$ & $<.02$ & $<.014$ & $\mathrm{u}$ & $<.01$ & $<.01$ & $<.02$ & $<.025$ & $<.036$ \\
\hline 294225098080301 & $<.015$ & $<.019$ & $<.04$ & $<.016$ & $<.036$ & $<.038$ & $<.02$ & $<.014$ & $<.03$ & $<.01$ & $<.01$ & $<.02$ & $<.025$ & $<.036$ \\
\hline 294225098080301 & -- & -- & -- & -- & -- & -- & -- & -- & -- & -- & -- & -- & -- & -- \\
\hline 291210099475601 & $<.015$ & $<.019$ & $<.04$ & $<.016$ & $<.036$ & $<.038$ & $<.02$ & $<.014$ & $<.03$ & $<.01$ & $<.01$ & $<.02$ & $<.025$ & $<.036$ \\
\hline
\end{tabular}


Table 16. Polar pesticide compounds for groundwater samples collected for the study of the transport of anthropogenic and natural contaminants (TANC) to public supply wells in the San Antonio segment of the Edwards aquifer near San Antonio, south-central Texas, 2004-9.-Continued

[By sample category. USGS, U.S. Geological Survey; $\mu \mathrm{g} / \mathrm{L}$, micrograms per liter; E, estimated; u, unable to determine; <, nondetection less than laboratory method reporting level; --, not measured]

\begin{tabular}{|c|c|c|c|c|c|c|c|c|c|c|c|c|c|c|}
\hline $\begin{array}{c}\text { USGS } \\
\text { identification } \\
\text { number }\end{array}$ & $\begin{array}{l}\text { Diuron } \\
(\mu \mathrm{g} / \mathrm{L})\end{array}$ & $\begin{array}{c}\text { Fenuron } \\
(\mu \mathrm{g} / \mathrm{L})\end{array}$ & $\begin{array}{l}\text { Flumet- } \\
\text { sulam } \\
\text { ( } \mu \mathrm{g} / \mathrm{L})\end{array}$ & $\begin{array}{c}\text { Fluo- } \\
\text { meturon } \\
(\mu \mathrm{g} / \mathrm{L})\end{array}$ & $\begin{array}{l}\text { Imaz- } \\
\text { aquin } \\
(\mu \mathrm{g} / \mathrm{L})\end{array}$ & $\begin{array}{l}\text { Imaz- } \\
\text { etha- } \\
\text { pyr } \\
(\mu \mathrm{g} / \mathrm{L})\end{array}$ & $\begin{array}{l}\text { Imida- } \\
\text { cloprid } \\
\text { ( } \mu \mathrm{g} / \mathrm{L})\end{array}$ & $\begin{array}{c}\text { Linuron } \\
(\mu \mathrm{g} / \mathrm{L})\end{array}$ & $\begin{array}{l}\text { MCPA } \\
(\mu \mathrm{g} / \mathrm{L})\end{array}$ & $\begin{array}{l}\text { MCPB } \\
(\mu \mathrm{g} / \mathrm{L})\end{array}$ & $\begin{array}{l}\text { Methio- } \\
\text { carb } \\
(\mu \mathrm{g} / \mathrm{L})\end{array}$ & $\begin{array}{l}\text { Meth- } \\
\text { omyl } \\
\text { ( } \mu \mathrm{g} / \mathrm{L})\end{array}$ & $\begin{array}{c}\text { Met- } \\
\text { sulfuron } \\
\text { ( } \mu \mathrm{g} / \mathrm{L})\end{array}$ & $\begin{array}{c}\text { N-(4-chloro- } \\
\text { phenyl)-N'- } \\
\text { methyl-urea } \\
(\mu \mathrm{g} / \mathrm{L})\end{array}$ \\
\hline 293111098340901 & -- & -- & -- & -- & -- & -- & -- & -- & -- & -- & -- & -- & -- & -- \\
\hline 293512098291701 & -- & -- & -- & -- & -- & -- & -- & -- & -- & -- & -- & -- & -- & -- \\
\hline 292424098421501 & -- & -- & -- & -- & -- & -- & -- & -- & -- & -- & -- & -- & -- & -- \\
\hline 292053098365501 & -- & -- & -- & -- & -- & -- & -- & -- & -- & -- & -- & -- & -- & -- \\
\hline 293807098155301 & -- & -- & -- & -- & -- & -- & -- & -- & -- & -- & -- & -- & -- & -- \\
\hline 292604098563201 & -- & -- & -- & -- & -- & -- & -- & -- & -- & -- & -- & -- & -- & -- \\
\hline 292116099095501 & -- & -- & -- & -- & -- & -- & -- & -- & -- & -- & -- & -- & -- & -- \\
\hline 291232099470301 & -- & -- & -- & -- & -- & -- & -- & -- & -- & -- & -- & -- & -- & -- \\
\hline 293128098473101 & -- & -- & -- & -- & -- & -- & -- & -- & -- & -- & -- & -- & -- & -- \\
\hline 293451098313201 & -- & -- & -- & -- & -- & -- & -- & -- & -- & -- & -- & -- & -- & -- \\
\hline 294604098060801 & -- & -- & -- & -- & -- & -- & -- & -- & -- & -- & -- & -- & -- & -- \\
\hline 294019098114701 & -- & -- & -- & -- & -- & -- & -- & -- & -- & -- & -- & -- & -- & -- \\
\hline 292215098580201 & -- & -- & -- & -- & -- & -- & -- & -- & -- & -- & -- & -- & -- & -- \\
\hline 292119098524901 & -- & -- & -- & -- & -- & -- & -- & -- & -- & -- & -- & -- & -- & -- \\
\hline 291943099163301 & -- & -- & -- & -- & -- & -- & -- & -- & -- & -- & -- & -- & -- & -- \\
\hline 291840099382601 & -- & -- & -- & -- & -- & -- & -- & -- & -- & -- & -- & -- & -- & -- \\
\hline 293518098332601 & -- & -- & -- & -- & -- & -- & -- & -- & -- & -- & -- & -- & -- & -- \\
\hline 293023098355401 & -- & -- & -- & -- & -- & -- & -- & -- & -- & -- & -- & -- & -- & -- \\
\hline 293042098305201 & -- & -- & -- & -- & -- & -- & -- & -- & -- & -- & -- & -- & -- & -- \\
\hline 292442098474501 & -- & -- & -- & -- & -- & -- & -- & -- & -- & -- & -- & -- & -- & -- \\
\hline 292405098371201 & -- & -- & -- & -- & -- & -- & -- & -- & -- & -- & -- & -- & -- & -- \\
\hline 292931098274601 & -- & -- & -- & -- & -- & -- & -- & -- & -- & -- & -- & -- & -- & -- \\
\hline 293729098173101 & -- & -- & -- & -- & -- & -- & -- & -- & -- & -- & -- & -- & -- & -- \\
\hline 291219099095601 & -- & -- & -- & -- & -- & -- & -- & -- & -- & -- & -- & -- & -- & -- \\
\hline
\end{tabular}


Table 16. Polar pesticide compounds for groundwater samples collected for the study of the transport of anthropogenic and natural contaminants (TANC) to public supply wells in the San Antonio segment of the Edwards aquifer near San Antonio, south-central Texas, 2004-9.-Continued

[By sample category. USGS, U.S. Geological Survey; $\mu \mathrm{g} / \mathrm{L}$, micrograms per liter; E, estimated; u, unable to determine; <, nondetection less than laboratory method reporting level; --, not measured]

\begin{tabular}{|c|c|c|c|c|c|c|c|c|c|c|c|c|c|c|}
\hline $\begin{array}{c}\text { USGS } \\
\text { identification } \\
\text { number }\end{array}$ & $\begin{array}{c}\text { Neburon } \\
\text { ( } \mu \mathrm{g} / \mathrm{L})\end{array}$ & $\begin{array}{l}\text { Nico- } \\
\text { sulfuron } \\
\text { ( } \mu \mathrm{g} / \mathrm{L})\end{array}$ & $\begin{array}{c}\text { Nor- } \\
\text { flurazon } \\
\text { ( } \mu \mathrm{g} / \mathrm{L})\end{array}$ & $\begin{array}{c}\text { Oryz- } \\
\text { alin } \\
(\mu \mathrm{g} / \mathrm{L})\end{array}$ & 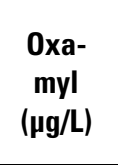 & $\begin{array}{l}\text { Pic- } \\
\text { loram } \\
(\mu \mathrm{g} / \mathrm{L})\end{array}$ & $\begin{array}{l}\text { Prop- } \\
\text { ham } \\
(\mu \mathrm{g} / \mathrm{L})\end{array}$ & $\begin{array}{l}\text { Propi- } \\
\text { con- } \\
\text { azole } \\
(\mu \mathrm{g} / \mathrm{L})\end{array}$ & $\begin{array}{c}\text { Prop- } \\
\text { oxur } \\
(\mu \mathrm{g} / \mathrm{L})\end{array}$ & $\begin{array}{c}\text { Siduron } \\
\text { ( } \mu \mathrm{g} / \mathrm{L})\end{array}$ & $\begin{array}{l}\text { Sulfo- } \\
\text { meturon } \\
(\mu \mathrm{g} / \mathrm{L})\end{array}$ & $\begin{array}{c}\text { Terbacil } \\
\text { ( } \mu \mathrm{g} / \mathrm{L})\end{array}$ & $\begin{array}{c}\text { Triben- } \\
\text { uron- } \\
\text { methyl } \\
(\mu \mathrm{g} / \mathrm{L})\end{array}$ & $\begin{array}{c}\text { Triclopyr } \\
\text { ( } \mu \mathrm{g} / \mathrm{L})\end{array}$ \\
\hline \multicolumn{15}{|c|}{ Regional aquifer public-supply wells } \\
\hline 293359098290301 & $<0.04$ & $<0.02$ & $<0.012$ & $<0.03$ & $<0.032$ & $<0.03$ & $<0.01$ & $<0.008$ & $<0.02$ & $<0.038$ & $<0.016$ & $\mathrm{u}$ & $<0.026$ & $<0.026$ \\
\hline 293359098290301 & $<.012$ & $<.04$ & $<.02$ & $<.012$ & $<.03$ & $<.032$ & $<.03$ & $<.01$ & $<.008$ & $<.02$ & $<.038$ & $<0.016$ & -- & $<.026$ \\
\hline 293358098231101 & $<.012$ & $<.04$ & $<.02$ & $<.012$ & $<.03$ & $<.032$ & $<.03$ & $<.01$ & $<.008$ & $<.02$ & $<.038$ & $<.016$ & $\mathrm{u}$ & $<.026$ \\
\hline 293358098231101 & $<.012$ & $<.04$ & $<.020$ & $<.012$ & $<.030$ & $<.032$ & $<.030$ & $<.010$ & $<.008$ & $<.020$ & $<.038$ & $<.016$ & -- & $<.026$ \\
\hline 293120098285801 & $<.012$ & $<.04$ & $<.02$ & $<.012$ & $<.03$ & $<.032$ & $<.03$ & $<.01$ & $<.008$ & $<.02$ & $<.038$ & $<.016$ & $\mathrm{u}$ & $<.026$ \\
\hline 293120098285801 & $<.012$ & $<.04$ & $<.020$ & $<.012$ & $<.030$ & $<.032$ & $<.030$ & $<.010$ & $<.008$ & $<.020$ & $<.038$ & $<.016$ & -- & $<.026$ \\
\hline 293145098224201 & $<.012$ & $<.04$ & $<.02$ & $<.012$ & $<.03$ & $<.032$ & $<.03$ & $<.01$ & $<.008$ & $<.02$ & $<.038$ & $<.016$ & $\mathrm{u}$ & $<.026$ \\
\hline 293119098211201 & $<.012$ & $<.04$ & $<.02$ & $<.012$ & $<.03$ & $<.032$ & $<.03$ & $<.01$ & $<.008$ & $<.02$ & $<.038$ & $<.016$ & $\mathrm{u}$ & $<.026$ \\
\hline 292843098425101 & $<.012$ & $<.04$ & $<.02$ & $<.012$ & $<.03$ & $<.032$ & $<.03$ & $<.01$ & $<.008$ & $<.02$ & $<.038$ & $<.016$ & $\mathrm{u}$ & $<.026$ \\
\hline 292459098382101 & $<.012$ & $<.04$ & $<.02$ & $<.012$ & $<.03$ & $<.032$ & $<.03$ & $<.01$ & $<.008$ & $<.02$ & $<.038$ & $<.016$ & $\mathrm{u}$ & $<.026$ \\
\hline 292925098360201 & $<.012$ & $<.04$ & $<.02$ & $<.012$ & $<.03$ & $<.032$ & $<.03$ & $<.01$ & $<.008$ & $<.02$ & $<.038$ & $<.016$ & $\mathrm{u}$ & $<.026$ \\
\hline 292925098360201 & $<.012$ & $<.04$ & $<.020$ & $<.012$ & $<.030$ & $<.032$ & $<.030$ & $<.010$ & $<.008$ & $<.020$ & $<.038$ & $<.016$ & -- & $<.026$ \\
\hline 292822098325401 & $<.012$ & $<.04$ & $<.02$ & $<.012$ & $<.03$ & $<.032$ & $<.03$ & $<.01$ & $<.008$ & $<.02$ & $<.038$ & $<.016$ & $\mathrm{u}$ & $<.026$ \\
\hline 292822098325401 & -- & -- & -- & -- & -- & -- & -- & -- & -- & -- & -- & -- & -- & -- \\
\hline 292944098292301 & $<.012$ & $<.04$ & $<.02$ & $<.012$ & $<.03$ & $<.032$ & $<.03$ & $<.01$ & $<.008$ & $<.02$ & $<.038$ & $<.016$ & $\mathrm{u}$ & $<.026$ \\
\hline 292944098292301 & -- & -- & -- & -- & -- & -- & -- & -- & -- & -- & -- & -- & -- & -- \\
\hline 292522098291901 & $<.012$ & $<.04$ & $<.02$ & $<.012$ & $<.03$ & $<.032$ & $<.03$ & $<.01$ & $<.008$ & $<.02$ & $<.038$ & $<.016$ & $\mathrm{u}$ & $<.026$ \\
\hline 292643098241801 & $<.012$ & $<.04$ & $<.02$ & $<.012$ & $<.03$ & $<.032$ & $<.03$ & $<.01$ & $<.008$ & $<.02$ & $<.038$ & $<.016$ & $\mathrm{u}$ & $<.026$ \\
\hline 292643098241801 & $<.012$ & $<.04$ & $<.020$ & $<.012$ & $<.030$ & $<.032$ & $<.030$ & $<.010$ & $<.008$ & $<.020$ & $<.038$ & $<.016$ & -- & $<.026$ \\
\hline 292328098294601 & $<.012$ & $<.04$ & $<.02$ & $<.012$ & $<.03$ & $<.032$ & $<.03$ & $<.01$ & $<.008$ & $<.02$ & $<.038$ & $<.016$ & $\mathrm{u}$ & $<.026$ \\
\hline 294225098080301 & $<.012$ & $<.04$ & $<.02$ & $<.012$ & $<.03$ & $<.032$ & $<.03$ & $<.01$ & $<.008$ & $<.02$ & $<.038$ & $<.016$ & $\mathrm{u}$ & $<.026$ \\
\hline 294225098080301 & -- & -- & -- & -- & -- & -- & -- & -- & -- & -- & -- & -- & -- & -- \\
\hline 291210099475601 & $<.012$ & $<.04$ & $<.02$ & $<.012$ & $<.03$ & $<.032$ & $<.03$ & $<.01$ & $<.008$ & $<.02$ & $<.038$ & $<.016$ & $\mathrm{u}$ & $<.026$ \\
\hline
\end{tabular}


Table 16. Polar pesticide compounds for groundwater samples collected for the study of the transport of anthropogenic and natural contaminants (TANC) to public supply wells in the San Antonio segment of the Edwards aquifer near San Antonio, south-central Texas, 2004-9.-Continued

[By sample category. USGS, U.S. Geological Survey; $\mu \mathrm{g} / \mathrm{L}$, micrograms per liter; E, estimated; u, unable to determine; <, nondetection less than laboratory method reporting level; --, not measured]

\begin{tabular}{|c|c|c|c|c|c|c|c|c|c|c|c|c|c|c|}
\hline $\begin{array}{c}\text { USGS } \\
\text { identification } \\
\text { number }\end{array}$ & $\begin{array}{c}\text { Neburon } \\
\text { ( } \mu \mathrm{g} / \mathrm{L})\end{array}$ & $\begin{array}{l}\text { Nico- } \\
\text { sulfuron } \\
\text { ( } \mu \mathrm{g} / \mathrm{L} \text { ) }\end{array}$ & $\begin{array}{c}\text { Nor- } \\
\text { flurazon } \\
\text { ( } \mathrm{\mu g} / \mathrm{L})\end{array}$ & $\begin{array}{l}\text { Oryz- } \\
\text { alin } \\
(\mu \mathrm{g} / \mathrm{L})\end{array}$ & $\begin{array}{c}\text { Oxa- } \\
\text { myl } \\
(\mu g / L)\end{array}$ & $\begin{array}{l}\text { Pic- } \\
\text { loram } \\
\text { ( } \mu \mathrm{g} / \mathrm{L})\end{array}$ & $\begin{array}{l}\text { Prop- } \\
\text { ham } \\
(\mu \mathrm{g} / \mathrm{L})\end{array}$ & $\begin{array}{l}\text { Propi- } \\
\text { con- } \\
\text { azole } \\
(\mu \mathrm{g} / \mathrm{L})\end{array}$ & $\begin{array}{c}\text { Prop- } \\
\text { oxur } \\
(\mu \mathrm{g} / \mathrm{L})\end{array}$ & $\begin{array}{c}\text { Siduron } \\
(\mu \mathrm{g} / \mathrm{L})\end{array}$ & $\begin{array}{c}\text { Sulfo- } \\
\text { meturon } \\
(\mu \mathrm{g} / \mathrm{L})\end{array}$ & $\begin{array}{c}\text { Terbacil } \\
\text { ( } \mu \mathrm{g} / \mathrm{L})\end{array}$ & $\begin{array}{l}\text { Triben- } \\
\text { uron- } \\
\text { methyl } \\
(\mu \mathrm{g} / \mathrm{L})\end{array}$ & $\begin{array}{c}\text { Triclopy } \\
\text { ( } \mu \mathrm{g} / \mathrm{L})\end{array}$ \\
\hline 293111098340901 & -- & -- & -- & -- & -- & -- & -- & -- & -- & -- & -- & -- & -- & -- \\
\hline 293512098291701 & -- & -- & -- & -- & -- & -- & -- & -- & -- & -- & -- & -- & -- & -- \\
\hline 292424098421501 & -- & -- & -- & -- & -- & -- & -- & -- & -- & -- & -- & -- & -- & -- \\
\hline 292053098365501 & -- & -- & -- & -- & -- & -- & -- & -- & -- & -- & -- & -- & -- & -- \\
\hline 293807098155301 & -- & -- & -- & -- & -- & -- & -- & -- & -- & -- & -- & -- & -- & -- \\
\hline 292604098563201 & -- & -- & -- & -- & -- & -- & -- & -- & -- & -- & -- & -- & -- & -- \\
\hline 292116099095501 & -- & -- & -- & -- & -- & -- & -- & -- & -- & -- & -- & -- & -- & -- \\
\hline 291232099470301 & -- & -- & -- & -- & -- & -- & -- & -- & -- & -- & -- & -- & -- & -- \\
\hline 293128098473101 & -- & -- & -- & -- & -- & -- & -- & -- & -- & -- & -- & -- & -- & -- \\
\hline 293451098313201 & -- & -- & -- & -- & -- & -- & -- & -- & -- & -- & -- & -- & -- & -- \\
\hline 294604098060801 & -- & -- & -- & -- & -- & -- & -- & -- & -- & -- & -- & -- & -- & -- \\
\hline 294019098114701 & -- & -- & -- & -- & -- & -- & -- & -- & -- & -- & -- & -- & -- & -- \\
\hline 292215098580201 & -- & -- & -- & -- & -- & -- & -- & -- & -- & -- & -- & -- & -- & -- \\
\hline 292119098524901 & -- & -- & -- & -- & -- & -- & -- & -- & -- & -- & -- & -- & -- & -- \\
\hline 291943099163301 & -- & -- & -- & -- & -- & -- & -- & -- & -- & -- & -- & -- & -- & -- \\
\hline 291840099382601 & -- & -- & -- & -- & -- & -- & -- & -- & -- & -- & -- & -- & -- & -- \\
\hline 293518098332601 & -- & -- & -- & -- & -- & -- & -- & -- & -- & -- & -- & -- & -- & -- \\
\hline 293023098355401 & -- & -- & -- & -- & -- & -- & -- & -- & -- & -- & -- & -- & -- & -- \\
\hline 293042098305201 & -- & -- & -- & -- & -- & -- & -- & -- & -- & -- & -- & -- & -- & -- \\
\hline 292442098474501 & -- & -- & -- & -- & -- & -- & -- & -- & -- & -- & -- & -- & -- & -- \\
\hline 292405098371201 & -- & -- & -- & -- & -- & -- & -- & -- & -- & -- & -- & -- & -- & -- \\
\hline 292931098274601 & -- & -- & -- & -- & -- & -- & -- & -- & -- & -- & -- & -- & -- & -- \\
\hline 293729098173101 & -- & -- & -- & -- & -- & -- & -- & -- & -- & -- & -- & -- & -- & -- \\
\hline 291219099095601 & -- & -- & -- & -- & -- & -- & -- & -- & -- & -- & -- & -- & -- & -- \\
\hline
\end{tabular}


Table 17. Acetamide pesticide compounds for groundwater samples collected for the study of the transport of anthropogenic and natural contaminants (TANC) to public supply wells in the San Antonio segment of the Edwards aquifer near San Antonio, south-central Texas, 2004-9.

[By sample category. USGS, U.S. Geological Survey; $\mu \mathrm{g} / \mathrm{L}$, micrograms per liter; --, not measured; <, nondetection less than laboratory method reporting level]

\begin{tabular}{|c|c|c|c|c|c|c|c|c|c|c|c|c|c|c|}
\hline $\begin{array}{c}\text { USGS } \\
\text { identification } \\
\text { number }\end{array}$ & $\begin{array}{c}\text { State well } \\
\text { number }\end{array}$ & $\begin{array}{c}\text { Sample } \\
\text { date }\end{array}$ & $\begin{array}{l}\text { Group and } \\
\text { description }\end{array}$ & $\begin{array}{c}\text { 2-[(2-Ethyl- } \\
\text { 6-methyl- } \\
\text { phenyl) } \\
\text { amino]- } \\
\text { 2-oxo- } \\
\text { ethane- } \\
\text { sulfonic } \\
\text { acid (N-(eth- } \\
\text { methphen) } \\
\text { ox ESA) } \\
\text { ( } \mu \mathrm{g} / \mathrm{L})\end{array}$ & $\begin{array}{l}\text { Ala- } \\
\text { chlor } \\
\text { 2nd } \\
\text { amide, } \\
\text { ( } \mu \mathrm{g} / \mathrm{L})\end{array}$ & $\begin{array}{c}\text { 2-Chloro- } \\
\text { N-(2-ethyl- } \\
\text { 6-methyl- } \\
\text { phenyl)- } \\
\text { acetamid } \\
\text { (aceto- } \\
\text { chlor 2nd } \\
\text { amide) } \\
\text { ( } \mu \mathrm{g} / \mathrm{L})\end{array}$ & $\begin{array}{c}\text { Aceto- } \\
\text { chlor } \\
\text { ethane- } \\
\text { sulf- } \\
\text { onic } \\
\text { acid } \\
\text { (aceto- } \\
\text { chlor } \\
\text { ESA) } \\
\text { ( } \mu \mathrm{g} / \mathrm{L} \text { ) }\end{array}$ & $\begin{array}{c}\text { Aceto- } \\
\text { chlor } \\
\text { oxa- } \\
\text { nilic } \\
\text { acid } \\
\text { (aceto- } \\
\text { chlor } \\
\text { OA) } \\
\text { ( } \mu \mathrm{g} / \mathrm{L})\end{array}$ & $\begin{array}{l}\text { Aceto- } \\
\text { chlor } \\
\text { sulf- } \\
\text { ynil- } \\
\text { acetic } \\
\text { acid } \\
\text { (aceto- } \\
\text { chlor } \\
\text { SAA) } \\
\text { ( } \mu \mathrm{g} / \mathrm{L} \text { ) }\end{array}$ & $\begin{array}{c}\text { Alachlor } \\
\text { ethane- } \\
\text { sulfonic } \\
\text { acid } \\
\text { sec- } \\
\text { ondary } \\
\text { amide } \\
\text { (ala- } \\
\text { chlor } \\
\text { ESA SA) } \\
\text { ( } \mu \mathrm{g} / \mathrm{L} \text { ) }\end{array}$ & 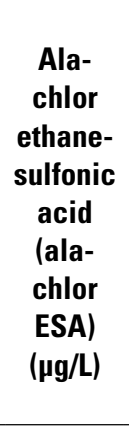 & $\begin{array}{c}\text { Ala- } \\
\text { chlor } \\
\text { oxanilic } \\
\text { acid } \\
\text { (ala- } \\
\text { chlor } \\
\text { OA) } \\
\text { ( } \mu \mathrm{g} / \mathrm{L})\end{array}$ & $\begin{array}{c}\text { Alachlor } \\
\text { sulfynil- } \\
\text { acetic } \\
\text { acid } \\
\text { (ala- } \\
\text { chlor } \\
\text { SAA) } \\
\text { ( } \mu \mathrm{g} / \mathrm{L} \text { ) }\end{array}$ & $\begin{array}{c}\text { De- } \\
\text { chloro- } \\
\text { aceto- } \\
\text { chlor } \\
\text { ( } \mu \mathrm{g} / \mathrm{L})\end{array}$ \\
\hline \multicolumn{15}{|c|}{ Regional aquifer public-supply wells } \\
\hline 293359098290301 & AY-68-29-414 & $2004 / 12 / 06$ & $\begin{array}{c}\text { 1st (highest) } \\
\text { quartile }\end{array}$ & -- & -- & -- & -- & -- & -- & -- & -- & -- & -- & -- \\
\hline 293359098290301 & AY-68-29-414 & 2005/09/01 & 1st quartile & -- & -- & -- & -- & -- & -- & -- & -- & -- & -- & -- \\
\hline 293358098231101 & AY-68-29-610 & $2004 / 12 / 15$ & 1st quartile & -- & -- & -- & -- & -- & -- & -- & -- & -- & -- & -- \\
\hline 293358098231101 & AY-68-29-610 & $2005 / 08 / 29$ & 1st quartile & -- & -- & -- & -- & -- & -- & -- & -- & -- & -- & -- \\
\hline 293120098285801 & AY-68-29-714 & $2004 / 12 / 14$ & 1st quartile & -- & -- & -- & -- & -- & -- & -- & -- & -- & -- & -- \\
\hline 293120098285801 & AY-68-29-714 & 2005/08/30 & 1st quartile & -- & -- & -- & -- & -- & -- & -- & -- & -- & -- & -- \\
\hline 293145098224201 & AY-68-29-929 & 2004/12/15 & 1st quartile & -- & -- & -- & -- & -- & -- & -- & -- & -- & -- & -- \\
\hline 293119098211201 & AY-68-30-718 & $2004 / 12 / 16$ & 1st quartile & -- & -- & -- & -- & -- & -- & -- & -- & -- & -- & -- \\
\hline 292843098425101 & AY-68-35-106 & $2004 / 12 / 13$ & 1st quartile & -- & -- & -- & -- & -- & -- & -- & -- & -- & -- & -- \\
\hline 292459098382101 & AY-68-35-913 & $2004 / 12 / 13$ & 1st quartile & -- & -- & -- & -- & -- & -- & -- & -- & -- & -- & -- \\
\hline 292925098360201 & AY-68-36-104 & 2004/12/13 & 1st quartile & -- & -- & -- & -- & -- & -- & -- & -- & -- & -- & -- \\
\hline 292925098360201 & AY-68-36-104 & 2005/08/31 & 1st quartile & -- & -- & -- & -- & -- & -- & -- & -- & -- & -- & -- \\
\hline 292822098325401 & AY-68-36-206 & 2004/12/13 & 1st quartile & -- & -- & -- & -- & -- & -- & -- & -- & -- & -- & -- \\
\hline 292822098325401 & AY-68-36-206 & $2005 / 08 / 31$ & 1st quartile & -- & -- & -- & -- & -- & -- & -- & -- & -- & -- & -- \\
\hline 292944098292301 & AY-68-37-105 & $2004 / 12 / 14$ & 1st quartile & -- & -- & -- & -- & -- & -- & -- & -- & -- & -- & -- \\
\hline 292944098292301 & AY-68-37-105 & 2005/08/31 & 1st quartile & -- & -- & -- & -- & -- & -- & -- & -- & -- & -- & -- \\
\hline 292522098291901 & AY-68-37-426 & $2004 / 12 / 14$ & 1st quartile & -- & -- & -- & -- & -- & -- & -- & -- & -- & -- & -- \\
\hline 292643098241801 & AY-68-37-601 & 2004/12/15 & 1st quartile & -- & -- & -- & -- & -- & -- & -- & -- & -- & -- & -- \\
\hline 292643098241801 & AY-68-37-601 & 2005/08/30 & 1st quartile & -- & -- & -- & -- & -- & -- & -- & -- & -- & -- & -- \\
\hline 292328098294601 & AY-68-37-705 & $2004 / 12 / 14$ & 1st quartile & -- & -- & -- & -- & -- & -- & -- & -- & -- & -- & -- \\
\hline 294225098080301 & DX-68-23-601 & 2004/12/08 & 1st quartile & -- & -- & -- & -- & -- & -- & -- & -- & -- & -- & -- \\
\hline 294225098080301 & DX-68-23-601 & 2005/09/01 & 1st quartile & -- & -- & -- & -- & -- & -- & -- & -- & -- & -- & -- \\
\hline 291210099475601 & YP-69-50-506 & 2004/11/30 & 1st quartile & -- & -- & -- & -- & -- & -- & -- & -- & -- & -- & -- \\
\hline
\end{tabular}


Table 17. Acetamide pesticide compounds for groundwater samples collected for the study of the transport of anthropogenic and natural contaminants (TANC) to public supply wells in the San Antonio segment of the Edwards aquifer near San Antonio, south-central Texas, 2004-9.

[By sample category. USGS, U.S. Geological Survey; $\mu \mathrm{g} / \mathrm{L}$, micrograms per liter; --, not measured; <, nondetection less than laboratory method reporting level]

\begin{tabular}{|c|c|c|c|c|c|c|c|c|c|c|c|c|c|c|}
\hline $\begin{array}{c}\text { USGS } \\
\text { identification } \\
\text { number }\end{array}$ & $\begin{array}{l}\text { State well } \\
\text { number }\end{array}$ & $\begin{array}{c}\text { Sample } \\
\text { date }\end{array}$ & $\begin{array}{l}\text { Group and } \\
\text { description }\end{array}$ & $\begin{array}{c}\text { 2-[(2-Ethyl- } \\
\text { 6-methyl- } \\
\text { phenyl) } \\
\text { amino]- } \\
\text { 2-oxo- } \\
\text { ethane- } \\
\text { sulfonic } \\
\text { acid (N-(eth- } \\
\text { methphen) } \\
\text { ox ESA) } \\
\text { ( } \mu \mathrm{g} / \mathrm{L})\end{array}$ & $\begin{array}{l}\text { Ala- } \\
\text { chlor } \\
\text { 2nd } \\
\text { amide, } \\
\text { ( } \mu \mathrm{g} / \mathrm{L} \text { ) }\end{array}$ & $\begin{array}{c}\text { 2-Chloro- } \\
\text { N-(2-ethyl- } \\
\text { 6-methyl- } \\
\text { phenyl)- } \\
\text { acetamid } \\
\text { (aceto- } \\
\text { chlor 2nd } \\
\text { amide) } \\
\text { ( } \mu \mathrm{g} / \mathrm{L})\end{array}$ & $\begin{array}{c}\text { Aceto- } \\
\text { chlor } \\
\text { ethane- } \\
\text { sulf- } \\
\text { onic } \\
\text { acid } \\
\text { (aceto- } \\
\text { chlor } \\
\text { ESA) } \\
\text { ( } \mu \mathrm{g} / \mathrm{L} \text { ) }\end{array}$ & $\begin{array}{c}\text { Aceto- } \\
\text { chlor } \\
\text { oxa- } \\
\text { nilic } \\
\text { acid } \\
\text { (aceto- } \\
\text { chlor } \\
\text { OA) } \\
\text { ( } \mu \mathrm{g} / \mathrm{L} \text { ) }\end{array}$ & 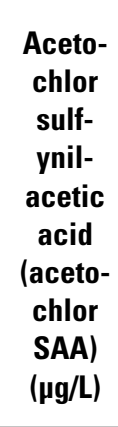 & $\begin{array}{l}\text { Alachlor } \\
\text { ethane- } \\
\text { sulfonic } \\
\text { acid } \\
\text { sec- } \\
\text { ondary } \\
\text { amide } \\
\text { (ala- } \\
\text { chlor } \\
\text { ESA SA) } \\
\text { ( } \mu \mathrm{g} / \mathrm{L} \text { ) }\end{array}$ & 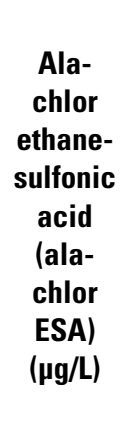 & $\begin{array}{c}\text { Ala- } \\
\text { chlor } \\
\text { oxanilic } \\
\text { acid } \\
\text { (ala- } \\
\text { chlor } \\
\text { OA) } \\
\text { ( } \mu \mathrm{g} / \mathrm{L} \text { ) }\end{array}$ & $\begin{array}{c}\text { Alachlor } \\
\text { sulfynil- } \\
\text { acetic } \\
\text { acid } \\
\text { (ala- } \\
\text { chlor } \\
\text { SAA) } \\
\text { ( } \mu \mathrm{g} / \mathrm{L} \text { ) }\end{array}$ & $\begin{array}{c}\text { De- } \\
\text { chloro- } \\
\text { aceto- } \\
\text { chlor } \\
\text { ( } \mu \mathrm{g} / \mathrm{L})\end{array}$ \\
\hline 293111098340901 & AY-68-28-807 & $2005 / 05 / 26$ & 2d quartile & $<0.02$ & $<0.02$ & $<0.02$ & $<0.02$ & $<0.02$ & $<0.02$ & $<0.02$ & 0.02 & $<0.02$ & $<0.02$ & $<0.02$ \\
\hline 293512098291701 & AY-68-29-109 & $2005 / 04 / 20$ & 2d quartile & $<.02$ & $<.02$ & $<.02$ & $<.02$ & $<.02$ & $<.02$ & $<.02$ & $<.02$ & $<.02$ & $<.02$ & $<.02$ \\
\hline 292424098421501 & AY-68-35-810 & $2005 / 04 / 21$ & 2d quartile & $<.02$ & $<.02$ & $<.02$ & $<.02$ & $<.02$ & $<.02$ & $<.02$ & $<.02$ & $<.02$ & $<.02$ & $<.02$ \\
\hline 292053098365501 & AY-68-44-110 & $2005 / 05 / 26$ & 2d quartile & $<.02$ & $<.02$ & $<.02$ & $<.02$ & $<.02$ & $<.02$ & $<.02$ & $<.02$ & $<.02$ & $<.02$ & $<.02$ \\
\hline 293807098155301 & DX-68-22-901 & $2005 / 05 / 18$ & 2d quartile & $<.02$ & $<.02$ & $<.02$ & $<.02$ & $<.02$ & $<.02$ & $<.02$ & $<.02$ & $<.02$ & $<.02$ & $<.02$ \\
\hline 292604098563201 & TD-68-33-501 & $2005 / 05 / 16$ & 2d quartile & $<.02$ & $<.02$ & $<.02$ & $<.02$ & $<.02$ & $<.02$ & $<.02$ & $<.02$ & $<.02$ & $<.02$ & $<.02$ \\
\hline 292116099095501 & TD-69-47-305 & $2005 / 04 / 27$ & 2d quartile & $<.02$ & $<.02$ & $<.02$ & $<.02$ & $<.02$ & $<.02$ & $<.02$ & $<.02$ & $<.02$ & $<.02$ & $<.02$ \\
\hline 291232099470301 & YP-69-50-339 & $2005 / 05 / 11$ & 2d quartile & $<.02$ & $<.02$ & $<.02$ & $<.02$ & $<.02$ & $<.02$ & $<.02$ & $<.02$ & $<.02$ & $<.02$ & $<.02$ \\
\hline 293128098473101 & AY-68-26-814 & $2005 / 04 / 18$ & 3d quartile & $<.02$ & $<.02$ & $<.02$ & $<.02$ & $<.02$ & $<.02$ & $<.02$ & $<.02$ & $<.02$ & $<.02$ & $<.02$ \\
\hline 293451098313201 & AY-68-28-601 & $2005 / 05 / 17$ & 3d quartile & $<.02$ & $<.02$ & $<.02$ & $<.02$ & $<.02$ & $<.02$ & $<.02$ & $<.02$ & $<.02$ & $<.02$ & $<.02$ \\
\hline 294604098060801 & DX-68-16-708 & $2005 / 04 / 25$ & 3d quartile & $<.02$ & $<.02$ & $<.02$ & $<.02$ & $<.02$ & $<.02$ & $<.02$ & $<.02$ & $<.02$ & $<.02$ & $<.02$ \\
\hline 294019098114701 & DX-68-23-504 & $2005 / 05 / 18$ & 3d quartile & $<.02$ & $<.02$ & $<.02$ & $<.02$ & $<.02$ & $<.02$ & $<.02$ & $<.02$ & $<.02$ & $<.02$ & $<.02$ \\
\hline 292215098580201 & TD-68-41-103 & 2005/05/09 & 3d quartile & $<.02$ & $<.02$ & $<.02$ & $<.02$ & $<.02$ & $<.02$ & $<.02$ & $<.02$ & $<.02$ & $<.02$ & $<.02$ \\
\hline 292119098524901 & TD-68-41-308 & $2005 / 04 / 27$ & 3d quartile & $<.02$ & $<.02$ & $<.02$ & $<.02$ & $<.02$ & $<.02$ & $<.02$ & $<.02$ & $<.02$ & $<.02$ & $<.02$ \\
\hline 291943099163301 & TD-69-46-601 & $2005 / 05 / 09$ & 3d quartile & $<.02$ & $<.02$ & $<.02$ & $<.02$ & $<.02$ & $<.02$ & $<.02$ & $<.02$ & $<.02$ & $<.02$ & $<.02$ \\
\hline 291840099382601 & YP-69-43-606 & $2005 / 05 / 11$ & 3d quartile & $<.02$ & $<.02$ & $<.02$ & $<.02$ & $<.02$ & $<.02$ & $<.02$ & $<.02$ & $<.02$ & $<.02$ & $<.02$ \\
\hline 293518098332601 & AY-68-28-203 & $2005 / 04 / 19$ & 4th quartile & $<.02$ & $<.02$ & $<.02$ & $<.02$ & $<.02$ & $<.02$ & $<.02$ & $<.02$ & $<.02$ & $<.02$ & $<.02$ \\
\hline 293023098355401 & AY-68-28-702 & $2005 / 04 / 26$ & 4th quartile & $<.02$ & $<.02$ & $<.02$ & $<.02$ & $<.02$ & $<.02$ & $<.02$ & $<.02$ & $<.02$ & $<.02$ & $<.02$ \\
\hline 293042098305201 & AY-68-28-913 & $2005 / 06 / 30$ & 4th quartile & $<.02$ & $<.02$ & $<.02$ & $<.02$ & $<.02$ & $<.02$ & $<.02$ & $<.02$ & $<.02$ & $<.02$ & $<.02$ \\
\hline 292442098474501 & AY-68-34-803 & $2005 / 04 / 20$ & 4th quartile & $<.02$ & $<.02$ & $<.02$ & $<.02$ & $<.02$ & $<.02$ & $<.02$ & $<.02$ & $<.02$ & $<.02$ & $<.02$ \\
\hline 292405098371201 & AY-68-36-704 & $2005 / 05 / 23$ & 4th quartile & $<.02$ & $<.02$ & $<.02$ & $<.02$ & $<.02$ & $<.02$ & $<.02$ & $<.02$ & $<.02$ & $<.02$ & $<.02$ \\
\hline 292931098274601 & AY-68-37-124 & $2005 / 05 / 25$ & 4th quartile & $<.02$ & $<.02$ & $<.02$ & $<.02$ & $<.02$ & $<.02$ & $<.02$ & 0.02 & $<.02$ & $<.02$ & $<.02$ \\
\hline 293729098173101 & DX-68-30-215 & $2005 / 04 / 25$ & 4th quartile & $<.02$ & $<.02$ & $<.02$ & $<.02$ & $<.02$ & $<.02$ & $<.02$ & $<.02$ & $<.02$ & $<.02$ & $<.02$ \\
\hline 291219099095601 & TD-69-55-604 & $2005 / 05 / 16$ & 4th quartile & $<.02$ & $<.02$ & $<.02$ & $<.02$ & $<.02$ & $<.02$ & $<.02$ & $<.02$ & $<.02$ & $<.02$ & $<.02$ \\
\hline
\end{tabular}


Table 17. Acetamide pesticide compounds for groundwater samples collected for the study of the transport of anthropogenic and natural contaminants (TANC) to public supply wells in the San Antonio segment of the Edwards aquifer near San Antonio, south-central Texas, 2004-9._Continued

[By sample category. USGS, U.S. Geological Survey; $\mu \mathrm{g} / \mathrm{L}$, micrograms per liter; --, not measured; <, nondetection less than laboratory method reporting level]

\begin{tabular}{|c|c|c|c|c|c|c|c|c|c|c|c|c|c|c|c|c|c|}
\hline $\begin{array}{c}\text { USGS } \\
\text { identification } \\
\text { number }\end{array}$ & $\begin{array}{c}\text { De- } \\
\text { chloro- } \\
\text { ala- } \\
\text { chlor } \\
\text { ( } \mathrm{\mu g} / \mathrm{L})\end{array}$ & $\begin{array}{c}\text { De- } \\
\text { chloro- } \\
\text { di- } \\
\text { methen- } \\
\text { amid } \\
\text { ( } \mu \mathrm{g} / \mathrm{L})\end{array}$ & $\begin{array}{c}\text { De- } \\
\text { chloro- } \\
\text { metola- } \\
\text { chlor } \\
(\mu \mathrm{g} / \mathrm{L})\end{array}$ & $\begin{array}{c}\text { Di- } \\
\text { methen- } \\
\text { amid } \\
\text { ethane- } \\
\text { sulfonic } \\
\text { acid } \\
(\mu \mathrm{g} / \mathrm{L})\end{array}$ & $\begin{array}{c}\text { Di- } \\
\text { methen- } \\
\text { amid } \\
\text { oxa- } \\
\text { nilic } \\
\text { acid } \\
(\mu \mathrm{g} / \mathrm{L}) \\
\end{array}$ & $\begin{array}{c}\text { Di- } \\
\text { methen- } \\
\text { amid } \\
(\mu \mathrm{g} / \mathrm{L})\end{array}$ & $\begin{array}{l}\text { Flufen- } \\
\text { acet } \\
\text { ethane- } \\
\text { sulfonic } \\
\text { acid } \\
\text { ( } \mu \mathrm{g} / \mathrm{L} \text { ) }\end{array}$ & $\begin{array}{l}\text { Flufen- } \\
\text { acet } \\
\text { oxa- } \\
\text { nilic } \\
\text { acid } \\
\text { ( } \mu \mathrm{g} / \mathrm{L})\end{array}$ & $\begin{array}{c}\text { Flufen- } \\
\text { acet } \\
\text { ( } \mu \mathrm{g} / \mathrm{L})\end{array}$ & $\begin{array}{l}\text { Hy- } \\
\text { droxy- } \\
\text { aceto- } \\
\text { chlor } \\
(\mu \mathrm{g} / \mathrm{L})\end{array}$ & $\begin{array}{c}\text { Hy- } \\
\text { droxy- } \\
\text { ala- } \\
\text { chlor } \\
\text { ( } \mu \mathrm{g} / \mathrm{L})\end{array}$ & $\begin{array}{c}\text { Hy- } \\
\text { droxy- } \\
\text { di- } \\
\text { methen- } \\
\text { amid } \\
\text { ( } \mu \mathrm{g} / \mathrm{L} \text { ) }\end{array}$ & $\begin{array}{c}\text { Hy- } \\
\text { droxy- } \\
\text { metola- } \\
\text { chlor } \\
\text { ( } \mathrm{gg} / \mathrm{L} \text { ) }\end{array}$ & $\begin{array}{c}\text { Metola- } \\
\text { chlor } \\
\text { ethane- } \\
\text { sulf- } \\
\text { onic } \\
\text { acid } \\
(\mu \mathrm{g} / \mathrm{L}) \\
\end{array}$ & $\begin{array}{c}\text { Metola- } \\
\text { chlor } \\
\text { oxa- } \\
\text { nilic } \\
\text { acid } \\
\text { ( } \mu \mathrm{g} / \mathrm{L})\end{array}$ & $\begin{array}{l}\text { Prop- } \\
\text { achlor } \\
\text { ethane- } \\
\text { sulf- } \\
\text { onic } \\
\text { acid } \\
(\mu \mathrm{g} / \mathrm{L}) \\
\end{array}$ & $\begin{array}{c}\text { Prop- } \\
\text { achlor } \\
\text { oxa- } \\
\text { nilic acid } \\
\text { ( } \mu \mathrm{g} / \mathrm{L} \text { ) }\end{array}$ \\
\hline \multicolumn{18}{|c|}{ Regional aquifer public-supply wells } \\
\hline 293359098290301 & -- & -- & -- & -- & -- & -- & -- & -- & -- & -- & -- & -- & -- & -- & -- & -- & -- \\
\hline 293359098290301 & -- & -- & -- & -- & -- & -- & -- & -- & -- & -- & -- & -- & -- & -- & -- & -- & -- \\
\hline 293358098231101 & -- & -- & -- & -- & -- & -- & -- & -- & -- & -- & -- & -- & -- & -- & -- & -- & -- \\
\hline 293358098231101 & -- & -- & -- & -- & -- & -- & -- & -- & -- & -- & -- & -- & -- & -- & -- & -- & -- \\
\hline 293120098285801 & -- & -- & -- & -- & -- & -- & -- & -- & -- & -- & -- & -- & -- & -- & -- & -- & -- \\
\hline 293120098285801 & -- & -- & -- & -- & -- & -- & -- & -- & -- & -- & -- & -- & -- & -- & -- & -- & -- \\
\hline 293145098224201 & -- & -- & -- & -- & -- & -- & -- & -- & -- & -- & -- & -- & -- & -- & -- & -- & -- \\
\hline 293119098211201 & -- & -- & -- & -- & -- & -- & -- & -- & -- & -- & -- & -- & -- & -- & -- & -- & -- \\
\hline 292843098425101 & -- & -- & -- & -- & -- & -- & -- & -- & -- & -- & -- & -- & -- & -- & -- & -- & -- \\
\hline 292459098382101 & -- & -- & -- & -- & -- & -- & -- & -- & -- & -- & -- & -- & -- & -- & -- & -- & -- \\
\hline 292925098360201 & -- & -- & -- & -- & -- & -- & -- & -- & -- & -- & -- & -- & -- & -- & -- & -- & -- \\
\hline 292925098360201 & -- & -- & -- & -- & -- & -- & -- & -- & -- & -- & -- & -- & -- & -- & -- & -- & -- \\
\hline 292822098325401 & -- & -- & -- & -- & -- & -- & -- & -- & -- & -- & -- & -- & -- & -- & -- & -- & -- \\
\hline 292822098325401 & -- & -- & -- & -- & -- & -- & -- & -- & -- & -- & -- & -- & -- & -- & -- & -- & -- \\
\hline 292944098292301 & -- & -- & -- & -- & -- & -- & -- & -- & -- & -- & -- & -- & -- & -- & -- & -- & -- \\
\hline 292944098292301 & -- & -- & -- & -- & -- & -- & -- & -- & -- & -- & -- & -- & -- & -- & -- & -- & -- \\
\hline 292522098291901 & -- & -- & -- & -- & -- & -- & -- & -- & -- & -- & -- & -- & -- & -- & -- & -- & -- \\
\hline 292643098241801 & -- & -- & -- & -- & -- & -- & -- & -- & -- & -- & -- & -- & -- & -- & -- & -- & -- \\
\hline 292643098241801 & -- & -- & -- & -- & -- & -- & -- & -- & -- & -- & -- & -- & -- & -- & -- & -- & -- \\
\hline 292328098294601 & -- & -- & -- & -- & -- & -- & -- & -- & -- & -- & -- & -- & -- & -- & -- & -- & -- \\
\hline 294225098080301 & -- & -- & -- & -- & -- & -- & -- & -- & -- & -- & -- & -- & -- & -- & -- & -- & -- \\
\hline 294225098080301 & -- & -- & -- & -- & -- & -- & -- & -- & -- & -- & -- & -- & -- & -- & -- & -- & -- \\
\hline 291210099475601 & -- & -- & -- & -- & -- & -- & -- & -- & -- & -- & -- & -- & -- & -- & -- & -- & -- \\
\hline
\end{tabular}


Table 17. Acetamide pesticide compounds for groundwater samples collected for the study of the transport of anthropogenic and natural contaminants (TANC) to public supply wells in the San Antonio segment of the Edwards aquifer near San Antonio, south-central Texas, 2004-9.-Continued

[By sample category. USGS, U.S. Geological Survey; $\mu \mathrm{g} / \mathrm{L}$, micrograms per liter; --, not measured; <, nondetection less than laboratory method reporting level]

\begin{tabular}{|c|c|c|c|c|c|c|c|c|c|c|c|c|c|c|c|c|c|}
\hline $\begin{array}{c}\text { USGS } \\
\text { identification } \\
\text { number }\end{array}$ & $\begin{array}{c}\text { De- } \\
\text { chloro- } \\
\text { ala- } \\
\text { chlor } \\
\text { ( } \mu \mathrm{g} / \mathrm{L})\end{array}$ & $\begin{array}{l}\text { De- } \\
\text { chloro- } \\
\text { di- } \\
\text { methen- } \\
\text { amid } \\
\text { ( } \mu \mathrm{g} / \mathrm{L})\end{array}$ & $\begin{array}{c}\text { De- } \\
\text { chloro- } \\
\text { metola- } \\
\text { chlor } \\
\text { ( } \mathrm{\mu g} / \mathrm{L})\end{array}$ & $\begin{array}{c}\text { Di- } \\
\text { methen- } \\
\text { amid } \\
\text { ethane- } \\
\text { sulfonic } \\
\text { acid } \\
(\mu \mathrm{g} / \mathrm{L})\end{array}$ & $\begin{array}{c}\text { Di- } \\
\text { methen- } \\
\text { amid } \\
\text { oxa- } \\
\text { nilic } \\
\text { acid } \\
\text { ( } \mu \mathrm{g} / \mathrm{L})\end{array}$ & $\begin{array}{c}\text { Di- } \\
\text { methen- } \\
\text { amid } \\
(\mu \mathrm{g} / \mathrm{L})\end{array}$ & $\begin{array}{c}\text { Flufen- } \\
\text { acet } \\
\text { ethane- } \\
\text { sulfonic } \\
\text { acid } \\
\text { ( } \mathrm{rg} / \mathrm{L} \text { ) }\end{array}$ & $\begin{array}{l}\text { Flufen- } \\
\text { acet } \\
\text { oxa- } \\
\text { nilic } \\
\text { acid } \\
\text { ( } \mu \mathrm{g} / \mathrm{L} \text { ) }\end{array}$ & $\begin{array}{c}\text { Flufen- } \\
\text { acet } \\
(\mu \mathrm{g} / \mathrm{L})\end{array}$ & $\begin{array}{c}\text { Hy- } \\
\text { droxy- } \\
\text { aceto- } \\
\text { chlor } \\
\text { ( } \mu \mathrm{g} / \mathrm{L})\end{array}$ & $\begin{array}{l}\text { Hy- } \\
\text { droxy- } \\
\text { ala- } \\
\text { chlor } \\
\text { ( } \mu \mathrm{g} / \mathrm{L})\end{array}$ & $\begin{array}{c}\text { Hy- } \\
\text { droxy- } \\
\text { di- } \\
\text { methen- } \\
\text { amid } \\
\text { ( } \mu \mathrm{g} / \mathrm{L} \text { ) }\end{array}$ & $\begin{array}{c}\text { Hy- } \\
\text { droxy- } \\
\text { metola- } \\
\text { chlor } \\
\text { ( } \mathrm{\mu g} / \mathrm{L})\end{array}$ & $\begin{array}{c}\text { Metola- } \\
\text { chlor } \\
\text { ethane- } \\
\text { sulf- } \\
\text { onic } \\
\text { acid } \\
(\mu \mathrm{g} / \mathrm{L}) \\
\end{array}$ & $\begin{array}{l}\text { Metola- } \\
\text { chlor } \\
\text { oxa- } \\
\text { nilic } \\
\text { acid } \\
\text { ( } \mathrm{gg} / \mathrm{L} \text { ) }\end{array}$ & $\begin{array}{l}\text { Prop- } \\
\text { achlor } \\
\text { ethane- } \\
\text { sulf- } \\
\text { onic } \\
\text { acid } \\
(\mu \mathrm{g} / \mathrm{L})\end{array}$ & $\begin{array}{c}\text { Prop- } \\
\text { achlor } \\
\text { oxa- } \\
\text { nilic acid } \\
\text { ( } \mu \mathrm{g} / \mathrm{L})\end{array}$ \\
\hline 293111098340901 & $<0.02$ & $<0.02$ & $<0.02$ & $<0.02$ & $<0.02$ & $<0.02$ & $<0.02$ & $<0.02$ & $<0.02$ & $<0.02$ & $<0.02$ & $<0.02$ & $<0.02$ & $<0.02$ & $<0.02$ & $<0.05$ & $<0.02$ \\
\hline 293512098291701 & $<.02$ & $<.02$ & $<.02$ & $<.02$ & $<.02$ & $<.02$ & $<.02$ & $<.02$ & $<.02$ & $<.02$ & $<.02$ & $<.02$ & $<.02$ & $<.02$ & $<.02$ & $<.05$ & $<.02$ \\
\hline 292424098421501 & $<.02$ & $<.02$ & $<.02$ & $<.02$ & $<.02$ & $<.02$ & $<.02$ & $<.02$ & $<.02$ & $<.02$ & $<.02$ & $<.02$ & $<.02$ & $<.02$ & $<.02$ & $<.05$ & $<.02$ \\
\hline 292053098365501 & $<.02$ & $<.02$ & $<.02$ & $<.02$ & $<.02$ & $<.02$ & $<.02$ & $<.02$ & $<.02$ & $<.02$ & $<.02$ & $<.02$ & $<.02$ & $<.02$ & $<.02$ & $<.05$ & $<.02$ \\
\hline 293807098155301 & $<.02$ & $<.02$ & $<.02$ & $<.02$ & $<.02$ & $<.02$ & $<.02$ & $<.02$ & $<.02$ & $<.02$ & $<.02$ & $<.02$ & $<.02$ & $<.02$ & $<.02$ & $<.05$ & $<.02$ \\
\hline 292604098563201 & $<.02$ & $<.02$ & $<.02$ & $<.02$ & $<.02$ & $<.02$ & $<.02$ & $<.02$ & $<.02$ & $<.02$ & $<.02$ & $<.02$ & $<.02$ & $<.02$ & $<.02$ & $<.05$ & $<.02$ \\
\hline 292116099095501 & $<.02$ & $<.02$ & $<.02$ & $<.02$ & $<.02$ & $<.02$ & $<.02$ & $<.02$ & $<.02$ & $<.02$ & $<.02$ & $<.02$ & $<.02$ & $<.02$ & $<.02$ & $<.05$ & $<.02$ \\
\hline 291232099470301 & $<.02$ & $<.02$ & $<.02$ & $<.02$ & $<.02$ & $<.02$ & $<.02$ & $<.02$ & $<.02$ & $<.02$ & $<.02$ & $<.02$ & $<.02$ & $<.02$ & $<.02$ & $<.05$ & $<.02$ \\
\hline 293128098473101 & $<.02$ & $<.02$ & $<.02$ & $<.02$ & $<.02$ & $<.02$ & $<.02$ & $<.02$ & $<.02$ & $<.02$ & $<.02$ & $<.02$ & $<.02$ & $<.02$ & $<.02$ & $<.05$ & $<.02$ \\
\hline 293451098313201 & $<.02$ & $<.02$ & $<.02$ & $<.02$ & $<.02$ & $<.02$ & $<.02$ & $<.02$ & $<.02$ & $<.02$ & $<.02$ & $<.02$ & $<.02$ & $<.02$ & $<.02$ & $<.05$ & $<.02$ \\
\hline 294604098060801 & $<.02$ & $<.02$ & $<.02$ & $<.02$ & $<.02$ & $<.02$ & $<.02$ & $<.02$ & $<.02$ & $<.02$ & $<.02$ & $<.02$ & $<.02$ & $<.02$ & $<.02$ & $<.05$ & $<.02$ \\
\hline 294019098114701 & $<.02$ & $<.02$ & $<.02$ & $<.02$ & $<.02$ & $<.02$ & $<.02$ & $<.02$ & $<.02$ & $<.02$ & $<.02$ & $<.02$ & $<.02$ & $<.02$ & $<.02$ & $<.05$ & $<.02$ \\
\hline 292215098580201 & $<.02$ & $<.02$ & $<.02$ & $<.02$ & $<.02$ & $<.02$ & $<.02$ & $<.02$ & $<.02$ & $<.02$ & $<.02$ & $<.02$ & $<.02$ & $<.02$ & $<.02$ & $<.05$ & $<.02$ \\
\hline 292119098524901 & $<.02$ & $<.02$ & $<.02$ & $<.02$ & $<.02$ & $<.02$ & $<.02$ & $<.02$ & $<.02$ & $<.02$ & $<.02$ & $<.02$ & $<.02$ & $<.02$ & $<.02$ & $<.05$ & $<.02$ \\
\hline 291943099163301 & $<.02$ & $<.02$ & $<.02$ & $<.02$ & $<.02$ & $<.02$ & $<.02$ & $<.02$ & $<.02$ & $<.02$ & $<.02$ & $<.02$ & $<.02$ & $<.02$ & $<.02$ & $<.05$ & $<.02$ \\
\hline 291840099382601 & $<.02$ & $<.02$ & $<.02$ & $<.02$ & $<.02$ & $<.02$ & $<.02$ & $<.02$ & $<.02$ & $<.02$ & $<.02$ & $<.02$ & $<.02$ & $<.02$ & $<.02$ & $<.05$ & $<.02$ \\
\hline 293518098332601 & $<.02$ & $<.02$ & $<.02$ & $<.02$ & $<.02$ & $<.02$ & $<.02$ & $<.02$ & $<.02$ & $<.02$ & $<.02$ & $<.02$ & $<.02$ & $<.02$ & $<.02$ & $<.05$ & $<.02$ \\
\hline 293023098355401 & $<.02$ & $<.02$ & $<.02$ & $<.02$ & $<.02$ & $<.02$ & $<.02$ & $<.02$ & $<.02$ & $<.02$ & $<.02$ & $<.02$ & $<.02$ & $<.02$ & $<.02$ & $<.05$ & $<.02$ \\
\hline 293042098305201 & $<.02$ & $<.02$ & $<.02$ & $<.02$ & $<.02$ & $<.02$ & $<.02$ & $<.02$ & $<.02$ & $<.02$ & $<.02$ & $<.02$ & $<.02$ & $<.02$ & $<.02$ & $<.05$ & $<.02$ \\
\hline 292442098474501 & $<.02$ & $<.02$ & $<.02$ & $<.02$ & $<.02$ & $<.02$ & $<.02$ & $<.02$ & $<.02$ & $<.02$ & $<.02$ & $<.02$ & $<.02$ & $<.02$ & $<.02$ & $<.05$ & $<.02$ \\
\hline 292405098371201 & $<.02$ & $<.02$ & $<.02$ & $<.02$ & $<.02$ & $<.02$ & $<.02$ & $<.02$ & $<.02$ & $<.02$ & $<.02$ & $<.02$ & $<.02$ & $<.02$ & $<.02$ & $<.05$ & $<.02$ \\
\hline 292931098274601 & $<.02$ & $<.02$ & $<.02$ & $<.02$ & $<.02$ & $<.02$ & $<.02$ & $<.02$ & $<.02$ & $<.02$ & $<.02$ & $<.02$ & $<.02$ & $<.02$ & $<.02$ & $<.05$ & $<.02$ \\
\hline 293729098173101 & $<.02$ & $<.02$ & $<.02$ & $<.02$ & $<.02$ & $<.02$ & $<.02$ & $<.02$ & $<.02$ & $<.02$ & $<.02$ & $<.02$ & $<.02$ & $<.02$ & $<.02$ & $<.05$ & $<.02$ \\
\hline 291219099095601 & $<.02$ & $<.02$ & $<.02$ & $<.02$ & $<.02$ & $<.02$ & $<.02$ & $<.02$ & $<.02$ & $<.02$ & $<.02$ & $<.02$ & $<.02$ & $<.02$ & $<.02$ & $<.05$ & $<.02$ \\
\hline
\end{tabular}


Table 18. Summary of sulfur hexafluoride and chlorofluorocarbon age-tracer data and piston-flow model results for groundwater samples collected for the study of the transport of anthropogenic and natural contaminants (TANC) to public supply wells in the San Antonio segment of the Edwards aquifer near San Antonio, south-central Texas, 2004-9.

[By sample category. $\mathrm{SF}_{6}$, sulfur hexafluoride; $\mathrm{CFC}$, chlorofluorocarbon; ${ }^{\circ} \mathrm{C}$, degrees Celsius; $\mathrm{m}$, meter; pptv, parts per trillion by volume; $\mathrm{C}$, contaminated]

\begin{tabular}{|c|c|c|c|c|c|c|c|c|c|c|c|c|c|}
\hline $\begin{array}{c}\text { USGS } \\
\text { identification } \\
\text { number }\end{array}$ & $\begin{array}{c}\text { State well } \\
\text { number }\end{array}$ & $\begin{array}{c}\text { Local } \\
\text { identifier } \\
\text { and } \\
\text { description }\end{array}$ & $\begin{array}{c}\text { Sample } \\
\text { date }\end{array}$ & $\begin{array}{l}\text { Recharge } \\
\text { tempera- } \\
\text { ture } \\
\left({ }^{\circ} \mathrm{C}\right)\end{array}$ & $\begin{array}{c}\text { Recharge } \\
\text { elevation } \\
\text { (m) }\end{array}$ & $\begin{array}{c}\mathbf{S F}_{6^{\prime}} \text { atmo- } \\
\text { spheric } \\
\text { mixing } \\
\text { ratio } \\
\text { (pptv)* }\end{array}$ & $\begin{array}{c}S^{S F_{6^{\prime}}} \\
\text { appar- } \\
\text { ent age, } \\
\text { (years)** }\end{array}$ & $\begin{array}{c}\text { CFC-11, at- } \\
\text { mospheric } \\
\text { mixing } \\
\text { ratio } \\
\text { (pptv)* }\end{array}$ & $\begin{array}{c}\text { CFC-12, at- } \\
\text { mospheric } \\
\text { mixing } \\
\text { ratio } \\
\text { (pptv)* }\end{array}$ & $\begin{array}{c}\text { CFC-113, } \\
\text { atmospher- } \\
\text { ic mixing } \\
\text { ratio } \\
\text { (pptv)* }\end{array}$ & $\begin{array}{l}\text { CFC-11 } \\
\text { piston- } \\
\text { flow } \\
\text { apparent } \\
\text { age } \\
\text { (years) }^{* *}\end{array}$ & $\begin{array}{l}\text { CFC-12 } \\
\text { piston- } \\
\text { flow } \\
\text { apparent } \\
\text { age } \\
\text { (years)** }^{*}\end{array}$ & $\begin{array}{l}\text { CFC-113 } \\
\text { piston- } \\
\text { flow } \\
\text { apparent } \\
\text { age } \\
\text { (years)** }^{*}\end{array}$ \\
\hline \multicolumn{14}{|c|}{ Monitoring wells } \\
\hline 292943098354401 & AY-68-36-135 & Z-OVB & $10 / 30 / 2007$ & 28.3 & 258.5 & $\begin{array}{l}56.13, \\
57.32\end{array}$ & $\mathrm{C}$ & $\begin{array}{l}4515.5, \\
4607.1\end{array}$ & $\begin{array}{l}1972.9, \\
1930.3\end{array}$ & $\begin{array}{l}\text { 4040.7, } \\
3852.0\end{array}$ & $\mathrm{C}$ & $\mathrm{C}$ & $\mathrm{C}$ \\
\hline 292943098354402 & AY-68-36-133 & Z-SED & $10 / 31 / 2007$ & 27.1 & 258.5 & $\begin{array}{l}20.92, \\
39.23\end{array}$ & $\mathrm{C}$ & $\begin{array}{c}4541.5 \\
4402.1\end{array}$ & $\begin{array}{l}\text { 1487.8, } \\
1449.3\end{array}$ & $\begin{array}{c}295.4 \\
285.8\end{array}$ & $\mathrm{C}$ & $\mathrm{C}$ & $\mathrm{C}$ \\
\hline 292943098354403 & AY-68-36-134 & Z-IED & $10 / 30 / 2007$ & 25.1 & 258.5 & $\begin{array}{l}17.89 \\
18.78\end{array}$ & $\mathrm{C}$ & $\begin{array}{c}\text { 1615.9, } \\
4949.0 \\
4488.3\end{array}$ & $\begin{array}{c}1519.1, \\
1628.3, \\
1403.0\end{array}$ & $\begin{array}{l}244.2 \\
281.7 \\
281.3\end{array}$ & $\mathrm{C}$ & $\mathrm{C}$ & $\mathrm{C}$ \\
\hline 292943098354404 & AY-68-36-132 & Z-DED & $11 / 1 / 2007$ & 26.8 & 258.5 & $\begin{array}{c}12.77, \\
8.58\end{array}$ & C & $\begin{array}{l}3563.5, \\
3021.7\end{array}$ & $\begin{array}{l}\text { 1375.4, } \\
1332.1\end{array}$ & $\begin{array}{l}238.9 \\
242.1\end{array}$ & $\mathrm{C}$ & $\mathrm{C}$ & $\mathrm{C}$ \\
\hline 292851098374401 & AY-68-35-315 & T-IED & $5 / 6 / 2008$ & 16.7 & 242.3 & 7.37, 7.11 & $\mathrm{C}$ & $\begin{array}{c}\text { 5588.6, } \\
5511.1\end{array}$ & $\begin{array}{l}\text { 24893.7, } \\
\text { 23877.0 }\end{array}$ & $\begin{array}{l}493.4 \\
493.4\end{array}$ & $\mathrm{C}$ & $\mathrm{C}$ & $\mathrm{C}$ \\
\hline 292851098374402 & AY-68-35-314 & T-DED & $5 / 7 / 2008$ & 15.8 & 242.3 & $\begin{array}{l}11.84 \\
11.59\end{array}$ & $\mathrm{C}$ & $\begin{array}{l}2385.8, \\
2482.6, \\
2524.1\end{array}$ & $\begin{array}{l}1279.6, \\
1366.7, \\
1385.5\end{array}$ & $\begin{array}{l}456.9, \\
485.9, \\
493.5 \\
\end{array}$ & $\mathrm{C}$ & $\mathrm{C}$ & $\mathrm{C}$ \\
\hline \multicolumn{14}{|c|}{ Well-field wells (wellhead sampling) } \\
\hline 292919098360501 & AY-68-36-103 & W2 & $11 / 29 / 2007$ & 22.0 & 276.5 & $\begin{array}{l}15.76, \\
15.70\end{array}$ & $\mathrm{C}$ & $\begin{array}{c}4548.4, \\
4676.9\end{array}$ & $\begin{array}{l}2566.0, \\
2758.6\end{array}$ & $\begin{array}{l}345.0, \\
361.5\end{array}$ & $\mathrm{C}$ & $\mathrm{C}$ & $\mathrm{C}$ \\
\hline 292925098360201 & AY-68-36-104 & W3 & $11 / 28 / 2007$ & 20.8 & 269.8 & $\begin{array}{l}11.44, \\
16.94\end{array}$ & $\mathrm{C}$ & $\begin{array}{c}4952.2, \\
4967.3, \\
4479.9\end{array}$ & $\begin{array}{l}2033.1, \\
2074.9, \\
2210.3\end{array}$ & $\begin{array}{l}563.8, \\
485.7 \\
526.7\end{array}$ & $\mathrm{C}$ & $\mathrm{C}$ & $\mathrm{C}$ \\
\hline 292916098360701 & AY-68-36-105 & W4 & $11 / 16 / 2007$ & 24.1 & 270.4 & $\begin{array}{l}27.33 \\
18.54\end{array}$ & $\mathrm{C}$ & $\begin{array}{c}4952.2, \\
4967.3 \\
4479.9\end{array}$ & $\begin{array}{c}4497.9, \\
3999.8, \\
3337.9\end{array}$ & $\begin{array}{l}258.6, \\
449.6, \\
449.6\end{array}$ & $\mathrm{C}$ & $\mathrm{C}$ & $\mathrm{C}$ \\
\hline 292920098360601 & AY-68-36-130 & W5 & $11 / 29 / 2007$ & 21.9 & 275.2 & $\begin{array}{l}17.54, \\
24.67\end{array}$ & $\mathrm{C}$ & $\begin{array}{l}\text { 5229.2, } \\
5592.4\end{array}$ & $\begin{array}{l}3141.1, \\
3072.6\end{array}$ & $\begin{array}{l}441.0 \\
404.9\end{array}$ & $\mathrm{C}$ & $\mathrm{C}$ & $\mathrm{C}$ \\
\hline 292920098360601 & AY-68-36-130 & W5 replicate & & & & & & $\begin{array}{l}58.4 \\
47.8\end{array}$ & $\begin{array}{l}248.8 \\
229.7\end{array}$ & $\begin{array}{l}28.0 \\
24.0\end{array}$ & $\begin{array}{l}38.4 \\
39.4\end{array}$ & $\begin{array}{l}31.9, \\
32.9\end{array}$ & $\begin{array}{l}26.4, \\
27.9\end{array}$ \\
\hline 292920098360601 & AY-68-36-130 & W5 replicate & & & & & & $\begin{array}{l}53.3 \\
49.1 \\
63.1\end{array}$ & $\begin{array}{l}223.7 \\
204.6 \\
406.1\end{array}$ & $\begin{array}{l}47.3 \\
21.7 \\
26.1\end{array}$ & $\begin{array}{l}38.9 \\
39.4, \\
37.4\end{array}$ & $\begin{array}{l}33.4 \\
33.9 \\
22.4\end{array}$ & $\begin{array}{l}22.4, \\
28.4, \\
26.9\end{array}$ \\
\hline 292923098360301 & AY-68-36-131 & W6 & $11 / 28 / 2007$ & 21.9 & 276.2 & $\begin{array}{l}\text { 16.11, } \\
21.46\end{array}$ & $\mathrm{C}$ & $\begin{array}{c}4160.1, \\
3616.1, \\
4925.8\end{array}$ & $\begin{array}{c}13871.5, \\
16355.0 \\
5380.3\end{array}$ & $\begin{array}{l}455.5, \\
373.5, \\
404.6\end{array}$ & $\mathrm{C}$ & $\mathrm{C}$ & $\mathrm{C}$ \\
\hline 292923098360301 & AY-68-36-131 & W6 replicate & & & & & & $\begin{array}{c}4166.9, \\
1400.9, \\
5039.2\end{array}$ & $\begin{array}{c}4762.2 \\
5377.8 \\
2641.0\end{array}$ & $\begin{array}{l}383.4, \\
332.8, \\
371.7\end{array}$ & $\mathrm{C}$ & $\mathrm{C}$ & $\mathrm{C}$ \\
\hline
\end{tabular}


Table 18. Summary of sulfur hexafluoride and chlorofluorocarbon age-tracer data and piston-flow model results for groundwater samples collected for the study of the transport of anthropogenic and natural contaminants (TANC) to public supply wells in the San Antonio segment of the Edwards aquifer near San Antonio, south-central Texas, 2004-9.-Continued

[By sample category. $\mathrm{SF}_{6}$, sulfur hexafluoride; $\mathrm{CFC}$, chlorofluorocarbon; ${ }^{\circ} \mathrm{C}$, degrees Celsius; $\mathrm{m}$, meter; pptv, parts per trillion by volume; $\mathrm{C}$, contaminated]

\begin{tabular}{|c|c|c|c|c|c|c|c|c|c|c|c|c|c|}
\hline $\begin{array}{c}\text { USGS } \\
\text { identification } \\
\text { number }\end{array}$ & $\begin{array}{c}\text { State well } \\
\text { number }\end{array}$ & $\begin{array}{c}\text { Local } \\
\text { identifier } \\
\text { and } \\
\text { description }\end{array}$ & $\begin{array}{c}\text { Sample } \\
\text { date }\end{array}$ & $\begin{array}{c}\text { Recharge } \\
\text { tempera- } \\
\text { ture } \\
\left({ }^{\circ} \mathrm{C}\right)\end{array}$ & $\begin{array}{l}\text { Recharge } \\
\text { elevation } \\
\text { (m) }\end{array}$ & $\begin{array}{c}\mathrm{SF}_{6^{\prime}} \text { atmo- } \\
\text { spheric } \\
\text { mixing } \\
\text { ratio } \\
(p p t v)^{*}\end{array}$ & $\begin{array}{c}S_{6^{\prime}} \\
\text { appar- } \\
\text { ent age, } \\
\text { (years)** }\end{array}$ & $\begin{array}{c}\text { CFC-11, at- } \\
\text { mospheric } \\
\text { mixing } \\
\text { ratio } \\
(p p t v)^{*}\end{array}$ & $\begin{array}{c}\text { CFC-12, at- } \\
\text { mospheric } \\
\text { mixing } \\
\text { ratio } \\
\text { (pptv)* }\end{array}$ & $\begin{array}{c}\text { CFC-113, } \\
\text { atmospher- } \\
\text { ic mixing } \\
\text { ratio } \\
(p p t v)^{*}\end{array}$ & $\begin{array}{l}\text { CFC-11 } \\
\text { piston- } \\
\text { flow } \\
\text { apparent } \\
\text { age } \\
\text { (years)** }^{* *}\end{array}$ & $\begin{array}{l}\text { CFC-12 } \\
\text { piston- } \\
\text { flow } \\
\text { apparent } \\
\text { age } \\
\text { (years)** }^{*}\end{array}$ & $\begin{array}{l}\text { CFC-113 } \\
\text { piston- } \\
\text { flow } \\
\text { apparent } \\
\text { age } \\
\text { (years)** }\end{array}$ \\
\hline \multicolumn{14}{|c|}{ Well-field depth-dependent sampling (W4) } \\
\hline 292916098360701 & AY-68-36-105 & $\begin{array}{c}\text { W4-shallow } \\
\text { (380), } \\
\text { ambient }\end{array}$ & $11 / 16 / 2007$ & 24.3 & 270.4 & $\begin{array}{l}39.62, \\
40.24\end{array}$ & $\mathrm{C}$ & $\begin{array}{l}3778.9, \\
3757.7\end{array}$ & $\begin{array}{l}3596.5, \\
6780.4\end{array}$ & $\begin{array}{l}549.3, \\
542.1\end{array}$ & $\mathrm{C}$ & $\mathrm{C}$ & $\mathrm{C}$ \\
\hline 292916098360701 & AY-68-36-105 & $\begin{array}{l}\text { W4-interme- } \\
\text { diate (430), } \\
\text { ambient }\end{array}$ & $11 / 14 / 2007$ & 25.6 & 270.4 & $\begin{array}{c}12.86 \\
9.52\end{array}$ & $\mathrm{C}$ & $\begin{array}{l}3047.8, \\
2311.2, \\
1879.9 \\
3080.8\end{array}$ & $\begin{array}{l}3508.5, \\
2477.3 \\
2076.0 \\
2626.5\end{array}$ & $\begin{array}{l}527.0 \\
517.6 \\
444.0 \\
585.0\end{array}$ & $\mathrm{C}$ & $\mathrm{C}$ & $\mathrm{C}$ \\
\hline 292916098360701 & AY-68-36-105 & $\begin{array}{l}\text { W4-deep } \\
\text { (540), } \\
\text { ambient }\end{array}$ & $11 / 15 / 2007$ & 23.9 & 270.4 & $\begin{array}{l}24.60 \\
32.54\end{array}$ & $\mathrm{C}$ & $\begin{array}{l}4272.3, \\
2249.2, \\
3794.6\end{array}$ & $\begin{array}{c}3045.7, \\
2169.3, \\
3277.3\end{array}$ & $\begin{array}{l}464.7 \\
342.5 \\
497.4\end{array}$ & $\mathrm{C}$ & $\mathrm{C}$ & $\mathrm{C}$ \\
\hline 292916098360701 & AY-68-36-105 & $\begin{array}{c}\text { W4-shallow } \\
\text { (380), } \\
\text { moderate }\end{array}$ & $11 / 16 / 2007$ & 24.7 & 270.4 & $\begin{array}{l}13.60 \\
12.38\end{array}$ & $\mathrm{C}$ & $\begin{array}{l}4497.8, \\
4170.3, \\
4498.5\end{array}$ & $\begin{array}{l}3687.3, \\
3110.6, \\
4210.5\end{array}$ & $\begin{array}{l}420.3 \\
457.8 \\
420.2\end{array}$ & $\mathrm{C}$ & $\mathrm{C}$ & $\mathrm{C}$ \\
\hline 292916098360701 & AY-68-36-105 & $\begin{array}{c}\text { W4-interme- } \\
\text { diate (430), } \\
\text { moderate }\end{array}$ & $11 / 14 / 2007$ & 24.4 & 270.4 & $\begin{array}{l}41.21 \\
30.57\end{array}$ & $\mathrm{C}$ & $\begin{array}{c}3049.0 \\
2437.7 \\
1257.2\end{array}$ & $\begin{array}{l}2656.7, \\
2647.3, \\
2445.3\end{array}$ & $\begin{array}{l}569.8, \\
263.6, \\
437.8\end{array}$ & $\mathrm{C}$ & $\mathrm{C}$ & $\mathrm{C}$ \\
\hline 292916098360701 & AY-68-36-105 & $\begin{array}{l}\text { W4-deep } \\
(540), \\
\text { moderate }\end{array}$ & $11 / 15 / 2007$ & 24.1 & 270.4 & $\begin{array}{c}15.73 \\
11.08\end{array}$ & $\mathrm{C}$ & $\begin{array}{l}3205.6, \\
3399.0, \\
3236.0\end{array}$ & $\begin{array}{c}2480.6, \\
2558.7, \\
4272.7\end{array}$ & $\begin{array}{l}595.1 \\
554.2 \\
537.4\end{array}$ & $\mathrm{C}$ & $\mathrm{C}$ & $\mathrm{C}$ \\
\hline 292916098360701 & AY-68-36-105 & $\begin{array}{c}\text { W4-shallow } \\
\text { (380), } \\
\text { normal }\end{array}$ & $11 / 16 / 2007$ & 25.1 & 270.4 & $\begin{array}{l}23.62, \\
15.13\end{array}$ & $\mathrm{C}$ & $\begin{array}{l}3394.5, \\
3032.0 \\
2284.9\end{array}$ & $\begin{array}{l}3919.6, \\
3640.5, \\
3251.3\end{array}$ & $\begin{array}{l}566.4, \\
553.3 \\
506.2\end{array}$ & $\mathrm{C}$ & $\mathrm{C}$ & $\mathrm{C}$ \\
\hline 292916098360701 & AY-68-36-105 & $\begin{array}{c}\text { W4-interme- } \\
\text { diate (430), } \\
\text { normal }\end{array}$ & $11 / 15 / 2007$ & 23.6 & 270.4 & $\begin{array}{l}14.81 \\
46.17\end{array}$ & $\mathrm{C}$ & $\begin{array}{l}3031.0, \\
3176.5, \\
2919.2\end{array}$ & $\begin{array}{l}3043.9, \\
2766.6, \\
2319.1\end{array}$ & $\begin{array}{l}541.8, \\
551.4 \\
577.6\end{array}$ & $\mathrm{C}$ & $\mathrm{C}$ & $\mathrm{C}$ \\
\hline 292916098360701 & AY-68-36-105 & $\begin{array}{c}\text { W4-deep } \\
\text { (540), } \\
\text { normal } \\
\end{array}$ & $11 / 15 / 2007$ & 23.9 & 270.4 & $\begin{array}{l}25.91 \\
47.14\end{array}$ & $\mathrm{C}$ & $\begin{array}{l}4341.1 \\
4033.8\end{array}$ & $\begin{array}{l}3512.0 \\
3430.5\end{array}$ & $\begin{array}{l}260.6 \\
261.8\end{array}$ & $\mathrm{C}$ & $\mathrm{C}$ & $\mathrm{C}$ \\
\hline
\end{tabular}

* Corrected for excess air and recharge temperature.

** C, contaminated, age not resolvable (tracer concentration greater than would result from atmospheric sources, indicating contamination for the purposes of apparent-age determination). 
Table 19. Summary of tritium/helium-3 age-tracer data and piston-flow model results for groundwater samples collected for the study of the transport of anthropogenic and natural contaminants (TANC) to public supply wells in the San Antonio segment of the Edwards aquifer near San Antonio, south-central Texas, 2004-9.

[By sample category. ${ }^{\circ} \mathrm{C}$, degrees Celsius; m, meter; ${ }^{3} \mathrm{H}$, tritium; ${ }^{3} \mathrm{H}_{0}$, tritium naught; ${ }^{3} \mathrm{He}$, helium-3; ${ }^{3} \mathrm{He}$ trit , helium derived from tritium decay; ${ }^{4} \mathrm{He}$, helium-4; ${ }^{4} \mathrm{He} \mathrm{terr}$, helium derived from terrigenic sources; $\mathrm{cm}^{3} \mathrm{STP} / \mathrm{g} \mathrm{H}_{2} \mathrm{O}$, cubic centimeters per gram at standard temperature $\left(20^{\circ} \mathrm{C}\right)$ and pressure $(1$ atmosphere $) ;--$, not determined]

\begin{tabular}{|c|c|c|c|c|c|c|c|c|c|c|c|}
\hline $\begin{array}{c}\text { USGS } \\
\text { identification } \\
\text { number }\end{array}$ & $\begin{array}{l}\text { Local identifier } \\
\text { and description }\end{array}$ & $\begin{array}{c}\text { Sample } \\
\text { date }\end{array}$ & $\begin{array}{c}\text { Re- } \\
\text { charge } \\
\text { temper- } \\
\text { ature } \\
\left({ }^{\circ} \mathrm{C}\right)\end{array}$ & $\begin{array}{c}\text { Re- } \\
\text { charge } \\
\text { eleva- } \\
\text { tion } \\
\text { (m) }\end{array}$ & $\begin{array}{c}{ }^{3} \mathbf{H} \\
\text { (tritium } \\
\text { units) }\end{array}$ & $\begin{array}{c}{ }^{3} \mathrm{H} \text { error } \\
\text { (tritium } \\
\text { units) }\end{array}$ & $\begin{array}{c}\text { Delta }{ }^{3} \mathrm{He} \\
\left(\Delta^{3} \mathrm{He}\right), \\
\text { measured } \\
\text { (uncor- } \\
\text { rected) } \\
\text { (percent) }\end{array}$ & $\begin{array}{c}\Delta^{3} \mathrm{He} \\
\text { error } \\
\text { (1 sigma) } \\
\text { (percent) }\end{array}$ & $\begin{array}{c}\text { Helium-4 } \\
\left({ }^{4} \mathrm{He}\right) \\
\text { measured } \\
\left(\mathrm{cm}^{3} \mathrm{STP} / \mathrm{g}\right. \\
\left.\mathrm{H}_{2} \mathrm{O}\right)\end{array}$ & $\begin{array}{c}{ }^{4} \mathrm{He} \text { error } \\
\left(\mathrm{cm}^{3} \mathrm{STP} / \mathrm{g}\right. \\
\left.\mathrm{H}_{2} \mathrm{O}\right)\end{array}$ & $\begin{array}{c}\text { Excess } \\
{ }^{4} \mathrm{He} \\
\left(\Delta^{4} \mathrm{He}\right) \\
\text { (percent) }\end{array}$ \\
\hline \multicolumn{12}{|c|}{ Monitoring wells } \\
\hline 292943098354401 AY-68-36-135 & Z-OVB & $10 / 30 / 2007$ & 28.3 & 258.5 & 1.30 & 0.048 & -8.94 & 0.23 & $8.34937 \mathrm{E}^{-08}$ & $1.57 \mathrm{E}^{-10}$ & 96.8 \\
\hline 292943098354402 AY-68-36-133 & Z-SED & $10 / 31 / 2007$ & 27.1 & 258.5 & 2.17 & .061 & -.44 & .18 & $1.06614 \mathrm{E}^{-07}$ & $3.58 \mathrm{E}^{-10}$ & 151 \\
\hline 292943098354403 AY-68-36-134 & Z-IED & $10 / 30 / 2007$ & 25.1 & 258.5 & 2.08 & .056 & -.21 & .23 & $8.78542 \mathrm{E}^{-08}$ & $1.67 \mathrm{E}^{-10}$ & 105 \\
\hline 292943098354404 AY-68-36-132 & Z-DED & $11 / 1 / 2007$ & 26.8 & 258.5 & 2.13 & .065 & -1.88 & .30 & $8.18674 \mathrm{E}^{-08}$ & $2.01 \mathrm{E}^{-10}$ & 92.3 \\
\hline 292851098374401 AY-68-35-315 & T-IED & $5 / 6 / 2008$ & 16.7 & 242.3 & 1.77 & .185 & .66 & .17 & $1.39 \mathrm{E}^{-07}$ & $2.50 \mathrm{E}^{-10}$ & 217 \\
\hline 292851098374402 AY-68-35-314 & T-DED & $5 / 7 / 2008$ & 15.8 & 242.3 & 1.72 & .185 & -1.85 & .23 & $9.49 \mathrm{E}^{-08}$ & $1.00 \mathrm{E}^{-10}$ & 115 \\
\hline \multicolumn{12}{|c|}{ Well-field wells (wellhead samples) } \\
\hline 292919098360501 AY-68-36-103 & W2 & $11 / 29 / 2007$ & 22 & 276.5 & 2.08 & .060 & -.04 & .23 & $8.01809 \mathrm{E}^{-08}$ & $1.52 \mathrm{E}^{-10}$ & 86.3 \\
\hline 292925098360201 AY-68-36-104 & W3 & $11 / 28 / 2007$ & 20.8 & 269.8 & 2.05 & .057 & -3.02 & .23 & $8.19502 \mathrm{E}^{-08}$ & $1.54 \mathrm{E}^{-10}$ & 89.5 \\
\hline 292916098360701 AY-68-36-105 & W4 & $11 / 16 / 2007$ & 24.1 & 270.4 & 1.88 & .075 & .09 & .29 & $7.8893 \mathrm{E}^{-08}$ & $1.87 \mathrm{E}^{-10}$ & 84.2 \\
\hline 292920098360601 AY-68-36-130 & W5 & $11 / 29 / 2007$ & 21.9 & 275.2 & 2.18 & .070 & 3.87 & .25 & $4.37746 \mathrm{E}^{-08}$ & $8.10 \mathrm{E}^{-11}$ & 1.60 \\
\hline 292923098360301 AY-68-36-131 & W6 & $11 / 28 / 2007$ & 21.9 & 276.2 & 1.91 & .058 & -1.03 & .19 & $8.25234 \mathrm{E}^{-08}$ & $2.72 \mathrm{E}^{-10}$ & 91.6 \\
\hline \multicolumn{12}{|c|}{ Well-field depth-dependent sampling (W4) } \\
\hline 292916098360701 AY-68-36-105 & W4-shallow (380), ambient & $11 / 16 / 2007$ & 24.3 & 270.4 & $<1$ & -- & -.40 & .30 & $7.99629 \mathrm{E}^{-08}$ & $1.97 \mathrm{E}^{-10}$ & 86.8 \\
\hline 292916098360701 AY-68-36-105 & W4-intermediate (430), ambient & $11 / 14 / 2007$ & 25.6 & 270.4 & 2.20 & .074 & -1.30 & .19 & $7.96141 \mathrm{E}^{-08}$ & $2.61 \mathrm{E}^{-10}$ & 86.7 \\
\hline 292916098360701 AY-68-36-105 & W4-deep (540), ambient & $11 / 15 / 2007$ & 23.9 & 270.4 & 1.97 & .046 & -.17 & .30 & $8.04951 \mathrm{E}^{-08}$ & $1.99 \mathrm{E}^{-10}$ & 87.9 \\
\hline 292916098360701 AY-68-36-105 & W4-shallow (380), moderate & $11 / 16 / 2007$ & 24.7 & 270.4 & 1.82 & .066 & -.93 & .19 & $7.81165 \mathrm{E}^{-08}$ & $2.62 \mathrm{E}^{-10}$ & 82.7 \\
\hline 292916098360701 AY-68-36-105 & W4-intermediate (430), moderate & $11 / 14 / 2007$ & 24.4 & 270.4 & 1.98 & .161 & -.06 & .19 & $8.28429 \mathrm{E}^{-08}$ & $2.81 \mathrm{E}^{-10}$ & 93.6 \\
\hline 292916098360701 AY-68-36-105 & W4-deep (540), moderate & $11 / 15 / 2007$ & 24.1 & 270.4 & 1.63 & .073 & -.77 & .19 & $8.34208 \mathrm{E}^{-08}$ & $2.80 \mathrm{E}^{-10}$ & 94.8 \\
\hline 292916098360701 AY-68-36-105 & W4-shallow (380), normal & $11 / 16 / 2007$ & 25.1 & 270.4 & 2.23 & .071 & -.54 & .29 & $8.14245 \mathrm{E}^{-08}$ & $1.94 \mathrm{E}^{-10}$ & 90.7 \\
\hline 292916098360701 AY-68-36-105 & W4-intermediate (430), normal & $11 / 15 / 2007$ & 23.6 & 270.4 & 1.78 & .053 & 67.81 & 1.49 & $5.61 \mathrm{E}^{-11}$ & $7.57 \mathrm{E}^{-12}$ & -99.9 \\
\hline 292916098360701 AY-68-36-105 & W4-deep (540), normal & $11 / 15 / 2007$ & 23.9 & 270.4 & 1.90 & .058 & 3.58 & .21 & $4.58499 \mathrm{E}^{-08}$ & $1.53 \mathrm{E}^{-10}$ & 7.00 \\
\hline
\end{tabular}


Table 19. Summary of tritium/helium-3 age-tracer data and piston-flow model results for groundwater samples collected for the study of the transport of anthropogenic and natural contaminants (TANC) to public supply wells in the San Antonio segment of the Edwards aquifer near San Antonio, south-central Texas, 2004-9.—Continued

[By sample category. ${ }^{\circ} \mathrm{C}$, degrees Celsius; m, meter; ${ }^{3} \mathrm{H}$, tritium; ${ }^{3} \mathrm{H}_{0}$, tritium naught; ${ }^{3} \mathrm{He}$, helium-3; ${ }^{3} \mathrm{He}_{\text {trit }}$, helium derived from tritium decay; ${ }^{4} \mathrm{He}$, helium-4; ${ }^{4} \mathrm{He}{ }_{\text {tern }}$, helium derived from terrigenic sources; $\mathrm{cm}^{3} \mathrm{STP} / \mathrm{g} \mathrm{H}_{2} \mathrm{O}$, cubic centimeters per gram at standard temperature $\left(20^{\circ} \mathrm{C}\right)$ and pressure (1 atmosphere); --, not determined]

\begin{tabular}{|c|c|c|c|c|c|c|c|c|c|c|}
\hline $\begin{array}{c}\text { USGS } \\
\text { identification } \\
\text { number }\end{array}$ & $\begin{array}{c}\text { Excess } \\
\text { Neon } \\
(\Delta \mathrm{Ne}) \\
\text { (per- } \\
\text { cent) }\end{array}$ & $\begin{array}{c}\text { Tritio- } \\
\text { genic } \\
{ }^{3} \mathrm{He} \\
\left({ }^{3} \mathrm{He}_{\text {trit }}\right) \\
\text { (tritium } \\
\text { units) }\end{array}$ & $\begin{array}{c}{ }^{3} \mathrm{He}_{\text {trit' }} \\
\text { error } \\
\text { (tritium } \\
\text { units) }\end{array}$ & $\begin{array}{c}\text { Terrigenic } \\
\text { helium-4 } \\
\left({ }^{4} \mathrm{He}_{\text {terr }}\right) \\
\left(\mathrm{cm}^{3} \mathrm{STP} / \mathrm{g}\right. \\
\left.\mathrm{H}_{2} \mathrm{O}\right)\end{array}$ & $\begin{array}{c}{ }^{4} \mathrm{He}_{\text {terr }} \\
\left(\Delta^{4} \mathrm{He}_{\text {terr }}\right) \\
\text { percent of } \\
\text { measured } \\
\text { helium }\end{array}$ & $\begin{array}{c}\text { “Tritium } \\
\text { naught" } \\
\left({ }^{3} \mathrm{H}_{0}\right) \\
\left({ }^{3} \mathrm{H}^{3}{ }^{3} \mathrm{He}_{\text {trit }}\right) \\
\text { (tritium } \\
\text { units) }\end{array}$ & ${ }^{3} \mathrm{H} /{ }^{3} \mathbf{H}_{0}$ & $\begin{array}{c}{ }^{3} \mathrm{H} /{ }^{3} \mathrm{He} \\
\text { apparent } \\
\text { age, years } \\
\text { (piston- } \\
\text { flow } \\
\text { model) }\end{array}$ & $\begin{array}{c}{ }^{3} \mathrm{H} /{ }^{3} \mathrm{He} \\
\text { appar- } \\
\text { ent- } \\
\text { age } \\
\text { error } \\
\text { (years) }\end{array}$ & Comment \\
\hline \multicolumn{11}{|c|}{ Monitoring wells } \\
\hline 292943098354401 & 79.0 & $-2.38 * *$ & 0.16 & $2.5942 \mathrm{E}^{-09}$ & 3.11 & -- & -- & -- & -- & Age not resolvable because of low ${ }^{3} \mathrm{H}$ \\
\hline 292943098354402 & 101 & 8.03 & .24 & $1.4519 \mathrm{E}^{-08}$ & 13.6 & 10.2 & 0.21 & 27.5 & 0.6 & \\
\hline 292943098354403 & 84.5 & 1.90 & .18 & $3.009 \mathrm{E}^{-09}$ & 3.43 & 3.97 & .52 & 11.5 & .8 & \\
\hline 292943098354404 & 77.4 & 0.16 & .64 & $1.222 \mathrm{E}^{-09}$ & 1.49 & 2.28 & .93 & 1.3 & 5.0 & \\
\hline 292851098374401 & 126 & 16.3 & 1.22 & $2.822 \mathrm{E}^{-08}$ & 20.3 & 18.1 & .10 & 41.3 & 2.1 & \\
\hline 292851098374402 & 63.9 & 8.43 & .61 & $1.656 \mathrm{E}^{-08}$ & 17.5 & 10.1 & .17 & 31.6 & 1.9 & \\
\hline \multicolumn{11}{|c|}{ Well-field wells (wellhead samples) } \\
\hline 292919098360501 & 61.1 & 3.71 & .16 & $6.1193 \mathrm{E}^{-09}$ & 7.63 & 5.79 & .36 & 18.2 & .6 & \\
\hline 292925098360201 & 58.6 & 3.73 & .16 & $8.6435 \mathrm{E}^{-09}$ & 10.5 & 5.79 & .35 & 18.4 & .6 & \\
\hline 292916098360701 & 73.1 & .12 & .64 & $-5.1124 \mathrm{E}^{-10}$ & $-.65^{* *}$ & 2.00 & .94 & $3.4^{*}$ & $1.0^{*}$ & $\begin{array}{l}\text { Age calculation uncorrected for } \Delta^{4} \mathrm{He}_{\text {terr }} \text { because of negative } \\
\Delta^{4} \mathrm{He}_{\text {terr }} \text { value }\end{array}$ \\
\hline 292920098360601 & -26.3 & 9.04 & .10 & $1.4099 \mathrm{E}^{-08}$ & 32.2 & 11.2 & .19 & -- & -- & Age not resolvable because of negative $\Delta \mathrm{Ne}$ value \\
\hline 292923098360301 & 66.7 & 2.95 & .18 & $5.5689 \mathrm{E}^{-09}$ & 6.75 & 4.86 & .39 & 16.6 & .8 & \\
\hline \multicolumn{11}{|c|}{ Well-field depth-dependent sampling (W4) } \\
\hline 292916098360701 & 70.6 & 1.23 & .63 & $1.8748 \mathrm{E}^{-09}$ & 2.34 & -- & -- & -- & -- & Age not resolvable because of low ${ }^{3} \mathrm{H}$ \\
\hline 292916098360701 & 65.2 & 2.33 & .18 & $4.6682 \mathrm{E}^{-09}$ & 5.86 & 4.53 & .48 & 12.9 & .8 & \\
\hline 292916098360701 & 68.1 & 2.24 & .62 & $3.5324 \mathrm{E}^{-09}$ & 4.39 & 4.21 & .47 & 13.5 & 2.6 & \\
\hline 292916098360701 & 65.0 & 1.58 & .17 & $2.9632 \mathrm{E}^{-09}$ & 3.79 & 3.40 & .53 & 11.1 & 1.0 & \\
\hline 292916098360701 & 64.1 & 4.73 & .19 & $8.0402 \mathrm{E}^{-09}$ & 9.71 & 6.72 & .30 & 21.7 & 1.1 & \\
\hline 292916098360701 & 68.9 & 3.36 & .19 & $6.1269 \mathrm{E}^{-09}$ & 7.34 & 4.99 & .33 & 19.9 & .9 & \\
\hline 292916098360701 & 80.5 & $-.61 * *$ & .67 & $-1.3155 \mathrm{E}^{-09}$ & $-1.62 * *$ & 2.23 & 1.00 & $.8 *$ & $1.0^{*}$ & $\begin{array}{l}\text { Age calculation uncorrected for }{ }^{4} \mathrm{He}_{\text {terr }} \text { because of negative }{ }^{4} \mathrm{He}_{\text {terr }} \\
\text { value }\end{array}$ \\
\hline 292916098360701 & -- & 4.44 & .03 & $7.4103 \mathrm{E}^{-09}$ & 13,212 & 6.23 & .29 & -- & -- & $\begin{array}{l}\text { Age not resolvable because of negative } \Delta^{4} \mathrm{He} \text { value and because of } \\
\Delta \mathrm{Ne} \text { value }\end{array}$ \\
\hline 292916098360701 & -21.1 & 8.70 & .12 & $1.3561 \mathrm{E}^{-08}$ & 29.6 & 10.6 & .18 & -- & -- & $\begin{array}{l}\text { Age not resolvable because of negative } \Delta^{4} \mathrm{He} \text { value and because of } \\
\text { low } \Delta \mathrm{Ne} \text { value }\end{array}$ \\
\hline
\end{tabular}

* Age calculation not corrected for ${ }^{4} \mathrm{He}_{\text {terr }}$ because of negative ${ }^{4} \mathrm{He}_{\text {terr }}$ value.

** Negative values result from errors associated with measurements values near 0 . 
Table 20. Results of forecasting analysis for the study of the transport of anthropogenic and natural contaminants (TANC) to public supply wells in the San Antonio segment of the Edwards aquifer near San Antonio, south-central Texas, 2004-9.

\begin{tabular}{lcccc}
\hline Forecast model scenario & $\begin{array}{c}\text { Peak } \\
\text { concentration } \\
\text { (or lag time, in } \\
\text { years) relative } \\
\text { to time zero } \\
\text { (start of input) }\end{array}$ & $\begin{array}{c}\text { Dilution at peak } \\
\text { concentration } \\
\text { (concentration } \\
\text { at peak/concentration } \\
\text { of input at time zero (1)) }\end{array}$ & $\begin{array}{c}\text { Arrival of } \\
\mathbf{1} \text { percent } \\
\text { of total } \\
\text { mass } \\
\text { (years) }\end{array}$ & $\begin{array}{c}\text { Flush of } \mathbf{9 9} \\
\text { percent } \\
\text { of total } \\
\text { mass (years) } \\
\text { relative to } \\
\text { year of } \\
\text { end of input }\end{array}$ \\
\hline $\begin{array}{l}\text { Uniform input across area contributing recharge to well, no degra- } \\
\text { dation }\end{array}$ & 30 & 0.98 & 1 & 32 \\
$\begin{array}{l}\text { Uniform input across area contributing recharge to well, first- } \\
\text { order reaction kinetics degradation rate constant }=0.1 \text { year }\end{array}$ & 30 & .73 & 1 & 12 \\
\hline
\end{tabular}

Publishing support provided by

Lafayette Publishing Service Center

Information regarding water resources in Texas is available at

http://tx.usgs.gov/ 

